Qhe $66^{\circ}$

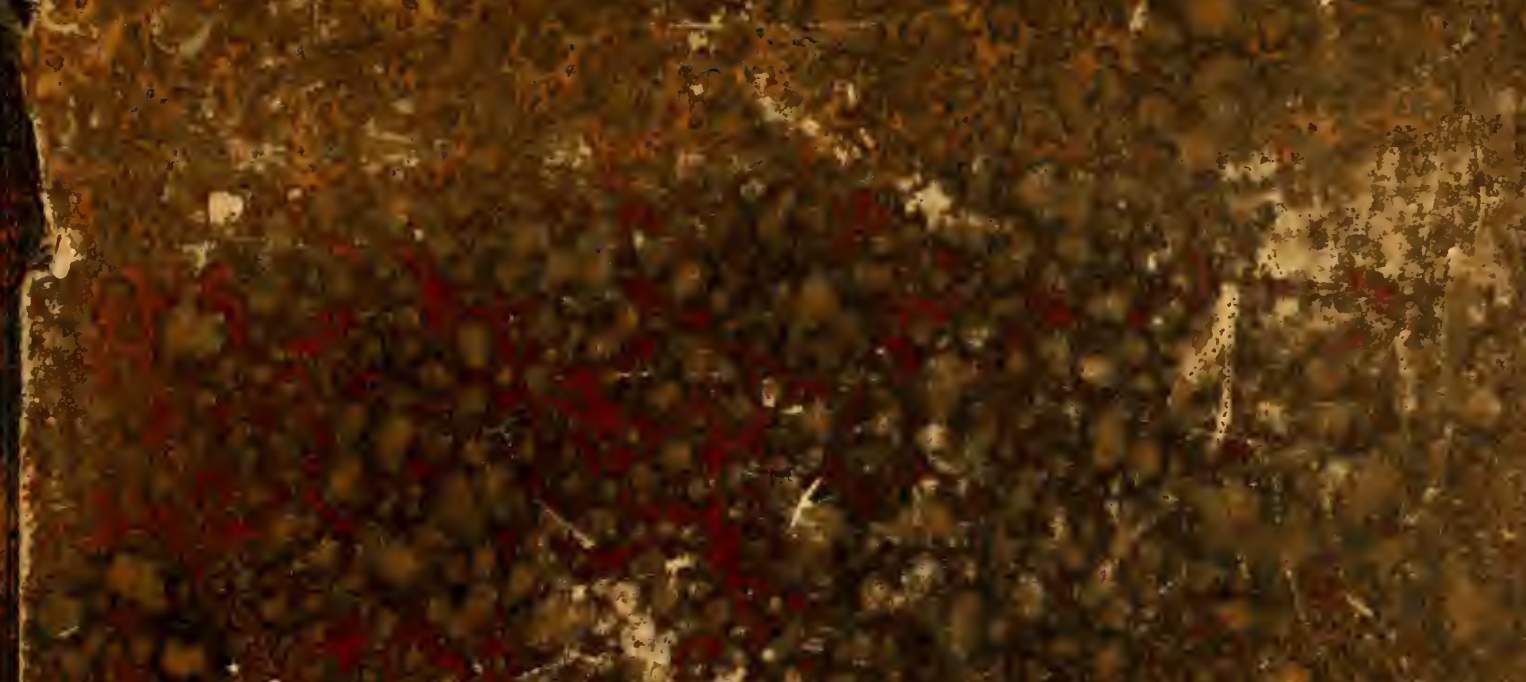

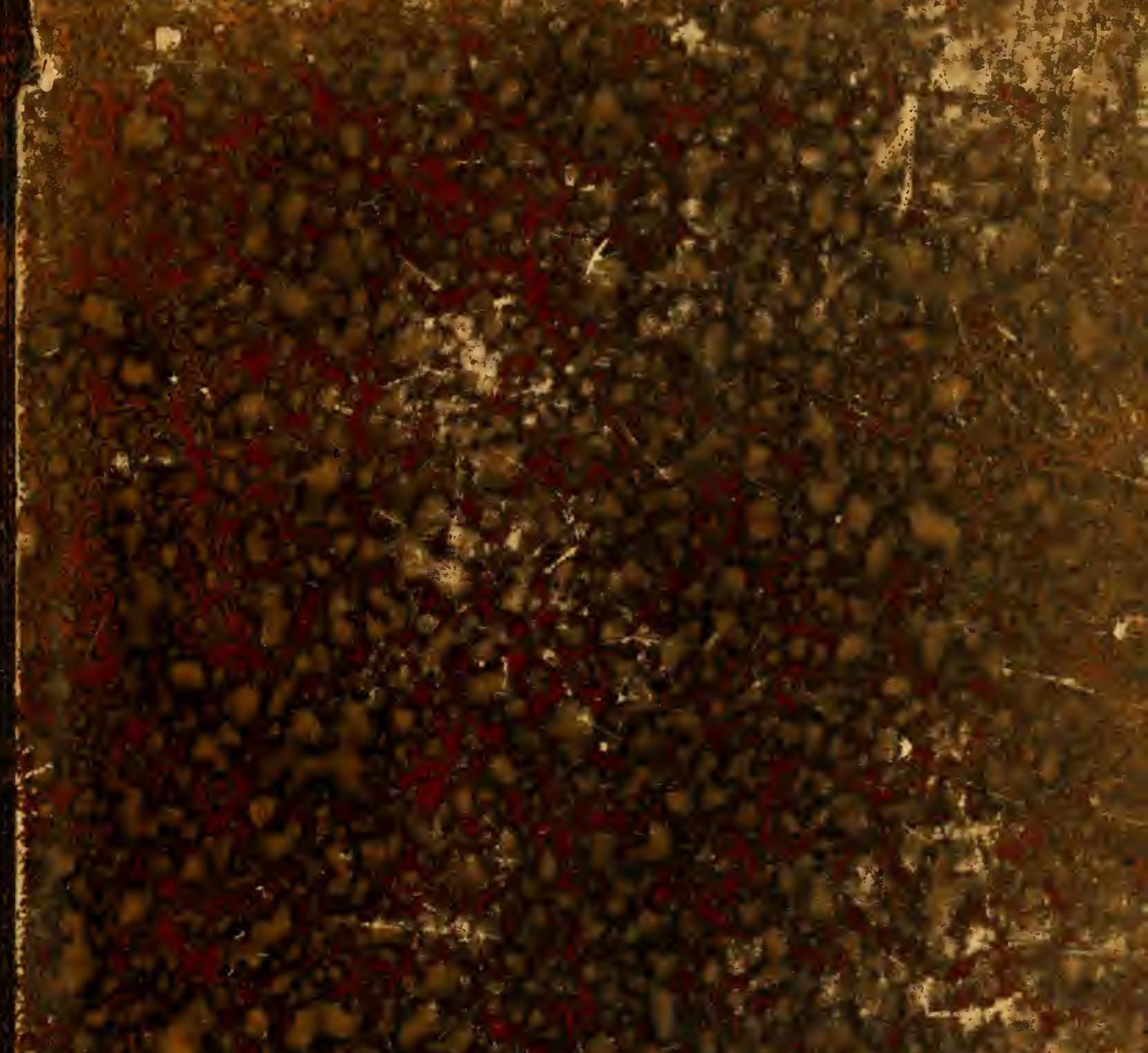

$$
\text { (2) }
$$


MARINE BIOLOGICAL LABORATORY,

Received fula, 859

Given by I enteral fund

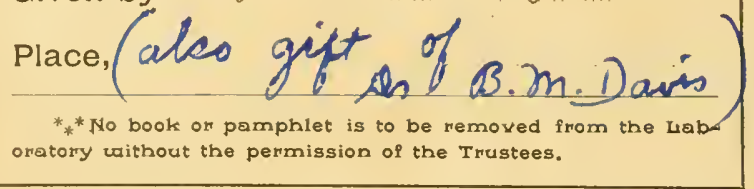





Die

\section{NEUERN ALGHNSYSTEME}

und

\section{VERSLCH ZUR BEGRÜNDUNG}

eines eigenen Systems der Algen und Florideen

$$
\text { von }
$$

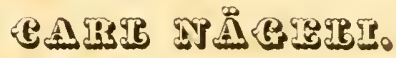

Mit 10 lithographirten Tafeln.

$\vdots$

\section{ZÜRICH,}

in hommission bei Friedrich solhullhens. 



\section{Inhaltsverzeichniss.}

\section{Kritische Darstellung der neuern Systeme.}

System von IIarvey

System von J. Agardh

System von Decaisue

System von Endlicher

System voll Kützing

Uebersichtliche Anordnung der Gattungen nach Endlicher

\section{Versuch zur Begründung eines eigenen Systems.}

A. Algæ.

1. Palmellaceæ

Pleurococcus vulgaris

Palmella

II. Yostochaceæ

Yostoc commune

III. Bangiaceæ .

\section{Lyngbyex}

Ulothrix zonata

2. Ulvea

Enteromorpha compressa

Porphyra vulgaris

IV. Mesoglœaceæ

1. Ectocarpeæ

Ectocarpus

Myrionema strangulans

3. Stilophoreæ

v. Zygnemaceæ

Myriotrichia

Spirogyra

VI. Protococcaceæ

VII. Valoniaceæ

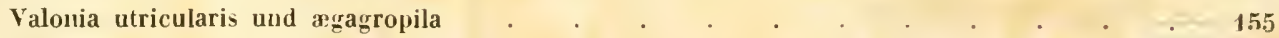

VIII. Confervaceæ

1. Confervea

2. Acetabularieæ

Acetabularia mediterranea

Dasycladus clavæformis

Acrocladus mediterraneus

3. Coleochrteæ 
X. Exососсасех 。 . . . . . . . . . . . . . . . . . 169

XI. Vaucheriaceæ . . . . . . . . . . . . . . . . . . 170

1. Bryopsideæ • , . . . . . . . . 171

Bryopsis . . . . . . . . -

Vaucheria. .0 .175$

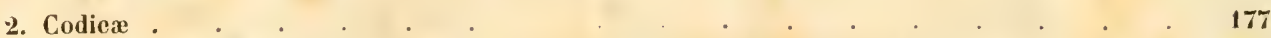

Udotea cyathiformis . . . . . . . . . . . . . .

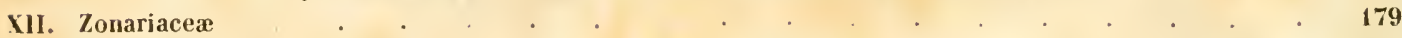

1. Chantransieæ

2. Padillez . . . . . . . . . . . . . . . . 180

Padina pavonia . . . . . . . . . . . . . . . . . . . . . .

3. Fucex . . . . . . . . . . . . . . . . . 183

Dictyota dichotoma . . . . . . . . . . . . . . . 184

B. Floridea. . . . . . . 187

1. Ceramiaceæ . . . . . . . . . . . . . . . 196

Callithamnion . . . . . . . . . . . . . . . 198

Antithamnion . . . . . . . . . . . . . . . 200

Pocilothamnion. . . . . . . . . . . . . . . . . 202

Ptilota plumosa. . . . . . . . . . . . . . . . . 206

I1. Delesseriaceæ . . . . . . . . . . . . . . . 208

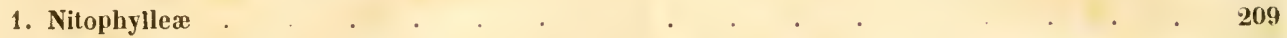

Nitophyllum punctatum . . . . . . . . . . . . . 210

2. Delesseriex . . . . . . . . . 212

Delesseria llypoglossum . . . . . . . . . . . . . . . . . . . 214

Gelidium corneum . . . . . . . . . . . . . 216

3. Rhodomelex . . . . . . . . . . . . 218

Laurencia . . . . . . . . . . . . . . . 220

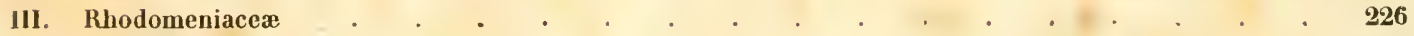

1. Plocamiex . . . . . . . . . . . . . . . . 227

Plocamium coccineum . . . . . . . . . . . . . . . . . . . 228

2. Chondrea . . . . . . 233

Cryptopleura lacerata. . . . . . . . . . . . . . . . 234

Leptophyllium bifidum . . . . . . . . . . . . . . 236

Rhodomenia laciniata . . . . . . . . . . . . . . . . . . . . 239

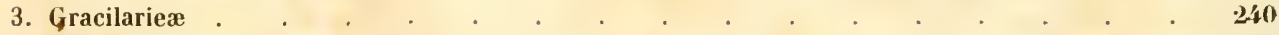

Gracilaria purpurascens . . . . . . . . . . . . . . . . 241

Dumontia filiformis . . . . . . . . . . . . . . 243

IV. Lomentariaceæ . . . . . . . . . . . . . . . . . 244

Lomentaria kaliformis . . . . . . . . . . . . . . 246

V. Phyllophoracex . . . . . . . . . . . . . . . . . . . . . . . 248

Peyssonellia squamaria.$\quad$. . . . . . . . . . . . . . . . . . -

Uebersicht der Ordıungen und Familien der Algen und Florideen . . . . . . . . 252

Erklärung der Abbildungen . . . . . . . . . . . . . . . . . . 255 
Das Studium der Algen erregt von Jahr zu Jahr mehr das Interesse der Botaniker. Nicht blos wächst die Zahl derjenigen Botaniker, welche, angezogen durch den zierlichen Formenreichthum dieser Gewächse, sich Sammlungen davon anlegen; sondern auch die wissenschaftlichen Forscher lenken mehr und mehr ihre Aufmerksamkeit auf die genannte Pflanzengruppe, um sie systematisch zu ordnen oder physiologisch zu begreifen.

Und mit Recht gebührt jetzt den Algen unter allen Pflanzen die erste Stelle, in Rücksicht auf das Interesse, welches sie für den wissenschaftlichen Botaniker haben. Nirgends lässt sich die Oekonomie des pflanzlichen Organismus besser erfassen als da, wo sie in so einfacher und dem Beobachter so leicht zugänglicher Gestalt auftritt. Die Zahl der einzelligen Algen, wo das Leben der Pflanzen mit dem Leben der Zelle identisch ist, steigt schon zu einer nicht unbeträchtlichen Summe. Von dieser Zelle aber, welche in sich alle Momente des vegetabilischen Lebens vereinigt, durchlaufen die Algen eine allmälige und alle möglichen Zwischenstufen berührende Entwicklungsreihe, in der die verschiedenen Lebensmomente nach und nach in verschiedene Zellen und in verschiedéne Organe ge- 
trennt werden. Die niedrigste Form des Algenreiches ist eine einfache kugelige Zelle, welche zugleich die Functionen der Wurzel, des Stammes und der Blätter ausübt, welche zugleich die vegetativen und die reproductiven Prozesse der Pflanze vollfühıt, indem sie rohe Nahrungsstoffe aufnimmt, dieselben zu organischen Stoffen assimilirt und überflüssige Stoffe ausscheidet, und indem sie zurefzt neue einzellige Pflanzen der gleichen Art erzeugt. Die höchsten Formen des Algenreiches dagegen bestehen aus Wurzeln, Stämmen und Blättern; sie besitzen vegetative und reproductive Stammachsen, vegetative und reproductive Blätter; sie erzeugen neue Individuen der gleichen Art theils durch Vermehrung oder geschlechtslose Keimzellenbildung, theils durch Fortpflanzung oder geschlechtliche Sporenbildung, bei welcher männliche und weibliche Organe mitwirken. Das Studium der Algen gewährt also dem Physiologen einen doppelten Vortheil : Einerseits zeigren einige der höhern Algen im Wesentlichen die gleichen Erscheinungen wie die höhern Pflanzen, nur sind dieselben wegen der anatomischen Einfachheit leichter zu studiren und sicherer zu denten. Anderseits findet sich bei den übrigen Algen der Weg vorgezeichnet, auf welchem die Natur zu jenen Erscheinungen der höhern Pflanzen gẹlangt, und es ist damit ein vorzügliches Mittel gegeben, um dieselben besser zu erkennen.

Von nicht geringerem Interesse ist das Studium der Algen für den Systematiker. Der Grundsatz, dass die systematisehe Erkenntniss einer Pflanze sich auf die physiologische Erkenntniss ihres ganzen Lebensprozesses stützen müsse, drängt sich dem Forscher nirgends so deutlich auf wie bei den Algen. Hier sehen wir, wie Physiologic und Systematik bei vollständiger Erforschung ihres Objectes sich so vereinigen, dass beide den gleichen Inhalt besitzen, und dass sie bloss in der Anordnung desselben differiren, indem die Physiologie denselben nach einzelnen Abschnitten des Lebensprozesses und nach einzelnen Organen, also nach Theilbegriffen. die Systematik dagegen nach den Totalbegriffen der Individuen eintheilt. Da bei den Algen eine vollkommene Uebereinstinmung der Plıysiologie und Systematik im materiellen Inhalte theils sich schon verwirklicht, theils deren Verwirklichung in Aussicht steht, so ist es gewiss, dass die Algen auch vor allen andern Pflanzen' dazu geeignet sind, einen Blick in das Wesen und in die Geselze der Systematik überhaupt zu gestatten, und diess un so eher, da bei ihnen 
eine so grosse Iannigfaltigkeit vorhanden ist. Und wenn es auch wahr ist, dass es auf jeder Stufe des Pflanzenreiches oder in jeder Classe besondere Merkmale gibt, welche die Arten und Gattungen unterscheiden, so ist es doch keinem Zweifel unterworfen, dass im Allgenieinen das Gesetz, wie das Höhere sich aus dem Einfacheren entwickelt, überall das gleiche ist. - Es ist überflüssig̣, ausser der Wichtigkeit des Algenstudiums in Rücksicht auf die Methode, noch zwei andere Punkte weiter auszuführen, nämlich dass die Algen, wie keine andere Pflanzengruppe die Bedingungen besitzen, um auf wahrhaft wissenschaftliche Weise eine natürliche Anordnung zu erfahren, und ferner, dass ohne die Kenntniss der Algen eine Erkenniniss des Pflanzenreiches überhaupt unmöglich ist, weil sie dasjenige Gebiet sind, auf welchem die ersten, die wichtigsten und die zahlreichsten Entwicklungen und Differenzirungen statt finden.

Die Algen haben in neuerer Zeit viele und tüchtige Bearbeiter gefunden. Vorzïglich hat die Systematik im Anfange dieses Jahrzehends manchen Fortschrit gemacht. Ich habe im ersten Theile dieser Schrift die Resultate der wichtigsten Bearbeitungen zusammengestellt. Der Zweck ist ein doppelter : 1) die Kenntniss der Algen selbst allgemeiner zu verbreiten, 2) zu zeigen, wie sich die wissenschaftliche Algologie entwickelt hat. Ich habe mit Harvey (1841), welcher noch meist der Methode der ältern Algologen folgt, den Anfang gemacht. Hhm folgen J. Agardte (1842) und Decaisne (1842), welche neue Bahnen brechen; ferner Endlicher (1845), welcher auf unübertreffliche Weise die bisherigen Ergebnisse zusammenstellt. Den Schluss macht Kützing (1845), welcher einen eigenen, von der Richtung der Wissenschaft in den nächst vorhergehenden Jahren verschiedenen Weg geht. Um die Fortbildung, welche die Algologie in dieser kurzen Zeit erfahren hat, anschaulicher zu machen, hielt ich es für zweckmässig, die Resultate mit den gleichen Worten wiederzugeben, wie sie von jedem'Forscher ausgesprochen wurden ; demn nirgends als in der Naturgeschichte ist es richtiger, dass die Terminologie das Verständniss der Begriffe, zugleich aber auch das Urtheil über dieselben in sich trägt. Ich hielt es ausserdem für angemessen, Mängel, wo sie vorkommen, sei es in der Methode oder in der Anwendung derselben, sei es in der natürlichen Anordnung zu erwähnen. Mögen diese Ausstellıngen nicht als ein absprechendes Urtheil gregen Männer erscheinen, die ich, je mehr ich mich mit ihren 
Werken beschäftigte, achten lernte. Möge vielmehr jede Ausstellung den Keim zu einem neuen Fortschritte in sich schliessen, und dadurch dazu beitragen, die Summe der Fortschritte, welche wir eben diesen Männern in der Algologie verdanken, zu vermehren.

Im zweiten Theile dieser Schrift versuchte ich es, ein eigenes System der Algen zu begründen, soweit es mir bis jetzt möglich ist, in diesem Gebiete sichere Begriffe auszusprechen; indem ich von dem Grundsatze ausging, dass die wesentlichsten und wichtigsten Merkmale in der Fortpflanzung gefunden werden, insofern dieselbe auf einer verschiedenen Entstehungsweise der Fortpflanzungszellen beruht, und dass die Merkmale von secundärer Wichtigkeit in den vegetativen Eigenthümlichkeiten liegen, insofern diese aus einer verschiedenen Zellenbildung hervorgehen. Um einen Ueberblick über das Reich der Algen zu gewähren, genügte es, die wichtigsten Ordnungen und Familien zu definiren. Eine detaillirtere Ausführung würde den Umfang dieser Schrift überschritten haben. 
Früher wurden die Algen nach ihrer Farbe, nach ihrem Aussehen, nach ihrer äussern Form, nach ihrer Consistenz eingetheilt. Eine richtige Erkenntniss ihres Wesens und ihrer natürlichen Verwandtschaft war bei dieser Methode unmöglich. Verwandte Gattungen wurden getrennt, solche, die in keiner Relation mit einander stehen, zusammengestellt. So finden wir z. B. in der Ordnung Confervoidece von Agardh ( $\left.{ }^{1}\right)$ beisammen 1) verschiedene Pilze, 2) Algen aus den verschiedensten Gruppen, 3) Florideen, 4) den Vorkeim der Moose, 5) die Characeen. Es sind diess vielleicht die Hälfte der wesentlichsten Pflanzentypen, welche, da sie äusserlich einige Analogie zeigen, zusammen eine einzige Ordnung eines Pflanzensystems bilden, welches 100 bis 200 Ordnungen und darüber enthält.

Jene äusserlichen Merkmale wurden in neuester Zeit fast ganz verlassen, und an deren Stelle Charactere der Fortpllanzung und des Baues gesetzt. Ich will hier nicht untersuchen, wie die neve Methode erst bei einzelnen Gattungen und Familien angewendet, nach und nach die alte verdrängte, sondern bloss auf die Systeme eingehen, welche sich mehr oder weniger nach der neuen Methode richten, nämlich die Systeme von Harvey, J. Agardh, Decaisne, Endlicher und Kützing.

\section{SYSTEM VON HAR VEY.}

Das System von Harrey $\left({ }^{2}\right)$ macht den Uebergang von der ältern Methode, welche künstlich nach äussern und unwesentlichen Merkmalen unterschied, zu der neuen natürlichen Methode, welche die wesentlichen Erscheinungen ins Auge

(') Systema Algarum, pag. XX.

(2) A Manual of the British Algae, London 1841. 
fasst und voranstelt. Es ist theils aus diesem Grunde interessant, theils deswegen, weil Harvey als der Repræsentant der englischen Algologen überhaupt gelten kann, die, wenn auch meist hinter den neuesten Fortschritten der Physiologie und Systematik etwas sich zurückhaltend, dafür durch genaue Untersuchung und nüchternes Urtheil sich rühmlichst auszeichnen.

IIarvey umgrenzt die Algen wie es his dahin geschehen ist. Zu dieser Pflanzengruppe rechnet er diejenigen cryptogamischen oder blüthenlosen Pflanzen, welche die charakteristische Vegetation des Wassers bilden. Ausgeschlossen werden natürlich diejenigen Wasserpflanzen, welche einer höhern Pflanzenclasse angehören, wie z. B. den Moosen. Hinzugefügt werden diejenigen nicht im Wasser wohnenden Pflanzen, welche keiner andern Classe angehören. Er definirt die Algen aber nicht, und versucht es auch nicht, denn nach ihm vermag die menschliche Analyse bloss bis zu einer gewissen Tiefe zu dringen, wo sie sich mil dem Sehen begnügen, und sich des Erkennens und Definirens enthalten muss.

Die Definition der Algen hat allerdings ihre bedeutenden Schwierigkeiten, und sie kann gewiss unmöglich genannt werden, so lange dieselben so umgrenzt werden, wie es von Harcey und von allen ältern und neuern Algologen geschieht. Diese Unmöglichkeit ist aber eine logische, weil die bisherige Classe der Algen Pflanzen aus vier verschiedenen Classen $\left(^{1}\right)$ vereinigt. Es ist übrigens nur bei der Classe selbst, wo den Verfasser diese Scheu vor der Definition befällt; er sucht die Familien, Gattungen und Arten so gut als möglich zu definiren.

Die brillischen Algen werden eingetheilt in 4 Reihen, die 5 ersten mit folgenden Diagnosen :

I. Metaxospermes: " Von olivengrüner oder olivenbrauner Farbe und von zelliger oder faseriger Structur; im Meere wachsend. Fructification in Capseln oder Receptaclen eingeschlossen, oder in besondern Fruchthäufchen (sori). Samen schwärzlich. »

II. Rhodosperuene: "Im Meere wohnend (mil Ausnahme der Gattung Trente-. pohlia), ron rosenrother, purpurner oder rothbrauner Farbe, blattartig . cylin-

(') Algen, Pilze, Florideen, welche nit den Leber- und Lambmoosen zusammen in Eine Classe gehoren und Characeen. 
drisch oder faserig. Fructification meist doppelt; die erste in Capseln und Receptaclen eingeschlossen, oder im Laube eingesenkt; die zweite (wenn sie vorhanden ist) aus kleinen Körnern bestehend, welche Fruchthäufchen bilden oder in besondern Receptaclen eingebettet sind. Samen roth oder rothbraun."

III. Chlorosperuede : "Im Meere, im süssen Wasser oder an feuchten Stellen wachsend; faserig, häutig oder ohne bestimmte Gestalt (shapeless); farblos oder von grasgrüner, sehr selten purpurner oder rother Farbe. Fructification bestehend in grünen oder purpurfarbigen Spörchen (sporules), welche entweder das Laub erfüllen, oder in Sporidien vereinigt, selten in äusserlichen Capseln eingeschlosssen sind."

IV. Diatonacede. Auf die vierte Reihe will ich nicht näher eintreten, theils weil diese Pflanzen nicht von allen Algologen bei den Algen aufgeführt werden, theils weil sie in Specialwerken (Ehrenberg, Külzing) gründlicher bearbeitet worden sind.

Unter den drei ersten Reihen unterscheiden sich die Rhodospermere von den beiden übrigen einzig durch die doppelte Fructification, obgleich Harvey bloss sagt, dass die Fructification meist doppelt sei. Für diejenigen Gattungen und Arten, wo sie es nicht ist, würde also ein unterscheidendes Merkmal noch mangeln. Die übrigen Charactere, welche Harvey noch bei dieser Reihe anführt, stehen theils auch in der Diagnose der beiden andern Reihen, theils sind sie durchaus nicht constant, wie es mit der Farbe der Fall ist.

Die beiden übrigen Reihen Melanospermece und Clorospermere werden vorzüglich durch die Farbe der Frons und die Farbe der Samen unterschieden. Die erstere soll bei den Melanospermeen olivenfarbig, bei den Chlorospermeen grün oder purpurn, die letztere soll bei den Melanospermeen schwärzlich, bei deı Chlorospermeen grün oder purpurn sein. Wie wenig aber die Farbe geeigntet ist, um ganze Reihen zu unterscheiden, beweist der Umstand, dass bei den Chlorospermeen mehrere Algen aufgeführt werden, die ebenso entschiedeı olivenfarbig sind als viele Gattungen der Melanospermeen selbst, ferner dass unter den Melanospermeen mehrere Algen stehen, deren Laub oder deren Samen 
nicht weniger grün genannt werden können, als die Samen vieler Chlorospermeen selbst. Beispiele für das erstere sind Lemania, Batrachospermum atrum, Chetophora Berkleyi, Myrionema, Rivularia atra, Stigonema, mehrere Arten von Oscillatoria, einige Arten von Palmella, Nostoc, endlich die meisten Diatomacece. Beispiele für das letztere sind Laminaria Phyllitis und debilis, Desmarestia ligulata, Dichloria, Elaeonema, Punctaria latifolia, Asperococcus comFressus, elc. - Die Fructification unterscheidet die beiden Reihen Melanospermece und Chlorospermea ebenfalls nicht. Denn bei den letztern wird als Character "äusserliche Capseln " aufgeführt, ein Merkmal, das auch einige Gattungen der ersten Reihe besitzen. Unter den drei Reihen finden wir also bloss bei den Rhodospermece einen Character, welcher den beiden übrigen Reihen mangelt, nämlich die doppelte Fructification. Die Melanospermex und Chlorospermex bleiben ununterschieden.

Wie mit der Definition, so ist es auch mit der Abgrenzung der Reihen bei den Rhodospermece am besten gelungen. Sie umfassen mit Ausnahme einer einzigen Pflanze (nämlich Trentepohlia pulchella) eine ganz natürliche und von den übrigen Algen rollkommen verschiedene Gruppe. Dagegen ist nicht abzusehen, wie die Melanospermece und die Chlorospermea natürliche Gruppen bilden sollen. Allerdings enthalten die erstern mehr die höher entwickelten, die letztern mehr die einfacher gebauten Algen, wenn wir bloss auf die vegetative Entwicklung sehen. Aber um natürliche Gruppen zu bekommen, genügt es nicht, vegetative Entwicklungsreihen da oder dort entzwei zu schneiden. Die natürliche Verwandtschaft liegt in dem Wesen der Fortpflanzung. Diese ist hier vernachlässigt, und daher bilden denn auch die beiden Reihen weiter nichts als künstliche Gruppen, denen noch überdiess der künstliche Character abgeht.

Harvey theilt, indem er vorzüglich Greville folgt, die brittischen Metanosperuene in 7 Familien ein: 1) Fucoidere, 2) Lichinece, 5) Laminariece, 4) Sporochnoidea, 5) Dictyotere, 6) Ectocarpeere, 7) Chordariere. Sie werden folgendermassen characterisirt :

1. Fucomese. "Meerbewohnend, von olivenbrauner Farbe, an der Luft schwarz werdend; von lederartiger oder holzartiger Substanz und faseriger Structur, mit Leichtigkeit in der Längsrichtung sich spaltend. Wurzel schildförmig ; in einigen 
Arten von kriechenden Fasern begleitet: Laub flach, zusammengedrückt oder fadenförmig, bei vielen gesonderte Blätter erzeugend, und in den meisten mit Lufthöhlen versehen. Fructification bestehend in kugeligen Haufen ron dunkeln Samen, die letzten sind von einem hellen Rande umgeben, in besondern gallertartigen Receptaclen eingebettet und werden zuletzt durch Poren nach aussen entleert."

Zu dieser Familie gehören die Gattungen Sargassum Ag., Cystoseira Ag., Halidrys Lyngb., Fucus Linn. Ag. und Himanthalia Lyngb. - Sie bilden zusammen eine sehr natürliche Gruppe, es mag dieselbe als Familie oder als Zunft betrachtet werden. Durch dic Stellung der Samen unterscheiden sie sich von allen übrigen Algen. Dieser Character ist aber gerade sehr schief aufgefasst; denn die "Haufen von Samen" sind nichts anders als vertiefte Fruchthäufchen (sori). indem hier die Epidermis sich cinstülpt und am Grunde der Einstülpung die Samen erzeugt.

2. Lichines: "Meerbewohnend, von schwärzlichgrüner Farbe, an der Luft schwarz werdend; knorpelartig, klein, verästelt, ohne Blätter. Fructification bestehend in Receptaclen, die mit einem Porus an der Spitze versehen " und mit einer farblosen, gallertartigen Masse von sehr zarten Fäden gefüllt sind, zwischen denen durchsichtige eiförmige oder längliche Samen in vielen ausstrahlenden rosenkranzförmigen Reihen liegen. " Grev. "

Diese Familie wird von der einzigen Gattung Lichina Ag. gebildet, welche aber nicht zu den eigentlichen Algen, sondern zu den Flechten gehört.

5. LaminarieaE : "Meerbewohnend, von olivenbrauner oder olivengrüner Farbe, an der Luft eher dunkler werdend; lederartig oder häutig, faserig-zellig. nicht netzförmig. Wurzel gelappt oder faserig. Laub gestielt, in eine blattartige Ausbreitung endigend, welche oft gespalten und zuweilen mit einer Mittelrippe oder verschiedenartig mit Nerven versehen ist. Fructification ungewiss: " soweit bis jetzt bekannt ist, bestehend entweder aus Samen, mit einer Masse von senkrechten gegliederten Fäden gemischt, oder aus rundlichen Körnern ohne Fäden; welche, in beiden Fällen, dichte sich ausbreitende Flecken oder Sori auf der Oberfläche des einen oder andern Laubtheiles bilden. "Grev."

Diese Familie enthält 2 Gattungen : Alaria Grev. und Laminaria Lamour. 
Dieselben bilden mit den tropischen Gattungen, welche noch dazu gehören, eine ziemlich natürliche Gruppe, indem sie früher meistens der Galtung Laminaria angehörten. Sie haben aber kaum das Recht für sich eine eigene Familie zu bilden, da andere Gattungen mit ihnen in der Fructification übereinzustimmen scheinen, und nur mehr oder weniger in den vegetativen Organen abweichen.

4. Sporochiomeas: "Meerbewohnend, olivenfarbig oder gelblichgrün, sehr verästelt, die Aeste meist zweizeilig; blatlartig, zusammengedrückl oder tadenförmig, ungegliedert, an der Luft schnell welk werdend; gewöhnlich in einer gewissen Periode ihres Wachsthums hinfällige Büschel von schön grünen Fäden tragend. Fructification unvollständig bekannt: " bestehend aus keulenförmigen, rosenkranzartigen, strahlenden Fäden, welche entweder sitzende Warzen bilden oder concentrisch in kleine, gestielte, keulenförmige Körper geordnet sind, die an ihrer Spitze pinselförmige, zarte Fasern tragen. Grev."

Diese Familie wird von 4 Gattungen gebildet: Desmarestia Lamour., Dichloria Grev., Sporochnus Ag. und Elconema Berkl. Die Fruchtbildung dieser Familie ist unrichtig aufgefasst, da die rosenkranzförmigen Gliederfäden, wenigstens bei einigen Gattungen, nur die Nebenfäden sind, zwischen denen die "Samen " oder vielmehr die Capseln, welche die Samen enthalten, sitzen. Diese Gattungen dürfen daher nicht von denjenigen der Familie Chordariere getrennt werden.

ॐ. Dictyoteas: "Meerbewohnend, von olivengrüner Farbe, und häuliger, biegsamer Substanz, selten knorpelartig, und kaum je gallertartig (juicy), mit einer sehr entschieden netzförmigen Structur. Laub cylindrisch oder flach, einfach oder verästelt, ungenervt (mit Ausnahme von IIalyseris), oft fächerförmig getheilt. Fructification bestehend in dunkeln, eiförmigen, oder birnförmigen Samen, mit durchsichtigen Hüllen, welche verschiedenartig angeordnet sind, entweder in Linien, in Häufchen, oder das ganze Laub bedeckend; und welche sehr selten innerhalb von Capseln liegen. "

Zu dieser Familie werden folgende 9 Gallungen gezählt: Cutleria Grev., Halyseris Tozzetli, Padina Adans., Dictyota Lamour. (diese 4 Gallungen mit filzähnlicher Wurzel); Dictyosiphon Grev., Striaria Grev., Punctaria Grev., Asperococcus Lamour., Chorda Stackh. (diese ¿ Gattungen mit nackter schildförmiger 
Wurzel). Die hier mit einander vereinigten Gattungen kömnen gewiss nicht in Eine Familie zusammengestellt werden, da sie zwei verschiedene Arten der Fruchtbildung besitzen. Bei den einen stehen die nackten Samen an der Oberfläche des Laubes; bei den andern liegen die Samen zu vielen in Multerzellen, welche ebenfalls an der Oberfläche des Laubes stehen.

6. Естосав pғaE : "Meerbewohnend, von olivengrüner, oder (selten) intensiv grüner Farbe, fadenförmig, oft haarförmig oder spinnwebeartig, gegliedert ; knorpelartig oder schlaff, nicht sehr saftig (juicy). Laub sehr verästelt, meist überall von gleichförmiger Structur; Glieder der Fäden meist sehr kurz. Wurzel gewöhnlich klein, bisweilen von wolligen Fasern begleitet. Fructification doppelt, oft an demselben Individuum : 1) Capseln mit dunkeln Samen ; 2) Körner in den erweiterten, oft farblosen Enden der Aestchen eingebettet. "

Diese Familie enthälı die 4 Gattungen: Cladostephus Ag., Sphacelaria Lyngb., Ectocarpus Lyngb. und Myriotrichia Harvey.

7. Chordafieas: "Meerbewohnend, von olivengrüner oder olivenbrauner Farbe, an der Luft dunkler werdend, von knorpelartiger oder gallertartiger Substanz, und zelligfädiger Structur. Laub fadenförmig (mit Ausnahme von Corynephora), sehr verästelt, cylindrisch, das Centrum oder die Achse entweder aus gehäuften, farblosen, gegliederten Längsfäden oder aus solidem Zellgewebe gebildet; die Peripherie bestehend aus gefärbten, einfachen oder verästelten, etwas keulenförmigen, rosenkranzartigen, gegliederten Fäden, die quirlförmig rund um die Achse stehen. Fructification : eiförmige oder birnförmige, olivenfarbige Samen (Capseln?)', mit durchsichtigen Hüllen, zwischen den peripherischen Fäden eingebettet, an deren Zweigen sie seitlich angeheftet sind. "

Hieher gehören 5 Gattungen : Chordaria Ag., Helminthocladia Harvey, Corynephora Ag.

Die brittischen Rhodospermese werden von Harcey, indem er wieder vorzüglich dem Beispiele von Greville folgt, in 6 Familien eingetheilt, nämlich 8) Gloiocladece, 9) Gastrocarpece, 10) Spongiocarpece, 11) Furcellarie(r, 12) Floridere, 15) Ceramiece. Die Diagnosen sind folgende :

8. Grotocladeae : "Meerbewohnend, von rosemrother oder purpurner Farbe, in süsses Wasser getaucht einen rothen Saft ausströmend, von gallertartiger, 


\section{$-14$}

schlüpfriger Substanz, und fädiger, selten zelliger Structur. Laub fadenförmig, verästelt, cylindrisch, solid oder röhrenförmig; die Peripherie (mit Ausnahme ron Naccaria, wo bloss die Endästchen so gebildet sind) bestehend aus gefärbten, rerästelten, quirlständigen Fäden, welche in einer verdünnten Gallerte liegen. Fructification: Häufchen oder Kügelchen von rothen Samen, welche zwischen den peripherischen Fäden eingebettet und an dieselben angeheftet sind. "

$\mathrm{Zu}$ dieser Familie werden gerechnet die 3 Gattungen : Mesogloia (Ag.) Harvey, Gloiosiphonia Carm., Naccaria Endl.

Die Gloiocladeæ sollen sich durch ihren Bau auszeichnen, indem die peripherische Schicht aus horizontal liegenden gegliederten Fäden gebildet wird, sowie durch ihre Fructification, indem die Samen zwischen jenen Fäden zu Häufchen vereinigt sind. Dem äussern Anscheine nach ist diese Gruppe allerdings natürlich. Die Entwicklungsgeschichte zeigt aber, dass wenigstens Mesogloia coccinea von Callithamnion durchaus nicht verschieden ist, und dasselbe vermuthe ich von Naccaria.

9. Gastrocarpeae: "Meerbewohnend, von hellrother, purpurner oder dunkelrother Farbe, von fleischiger, gallertartig-knorpeliger oder häutiger Substanz; " die Structur bestehend aus einer zelligen, äussern Haut und einer durchsichtigen, gallertartigen, innern Masse, welche meistens von farblosen, gegliederten Fäden durchzogen wird, die von der äussern Haut auslaufen. „ Grev. - Laub entweder cylindrisch, zusammengedrückt oder flach, ohne Mittelrippe oder Venen. Fructification: Kügelchen oder Häufchen von kleinen rothen Samen, welche in der innern Substanz der Frons eingebettet sind. "

Diese Familie besteht aus 4 Gattungen : Catenella Grev., Dumontia Lamour., Halymenia Ag., Iridca Bory.

Die Gastrocarpece unterscheiden sich zwar durch ihren Bau von den Floridece. Dieser Bau wird aber einzig dadurch hervorgebracht, dass die innern Zellen viel Gallerte bilden, wodurch es den Anschein gewinnt, als ob gegliederte, von der Rinde auslaufende Fäden in einer Gallerte liegen. In der Familie der Floridere erzeugen die innern Zellen ebenfalls Gallerte, aber meist nur in geringer Quantität, so dass die innere Substanz gewöhnlich zellig erscheint. Im Uebrigen finde ich keine wesentlichen Unterschiede zwischen den Gastrocarpeen und mehreren 
Gattungen der Florideen; und die einzige Differenz in der Quantität der Gallertbildung scheint mir kein hinreichender Grund, um eine besondere Familie aufzustellen. Gilt ja eine übermässige Bildung ron Gallerte und ein Mangel daran bei andern Algen oft nicht einnal als Grund um Gattungen zu trennen.

10. Sponglocarpene: "Mehrbewohnend, von dunkler purpurner Farbe, von. knorpelartiger oder fleischiger Substanz und faseriger Structur. Laub cylindrisch, gabelspaltig; der centrale Theil aus sehr dünnen, dicht gefügten Längsfasern zusanımengesetzt; der peripherische Theil aus strahlenden, dichotomischen Fäden gebildet. Wurzel schildförmig. Fructification doppelt (?); 1) nackte schwammige Warzen, bestehend aus strahlenden Fäden, zwischen denen Kügelchen von rothen Samen eingebettet sind; 2) kleine Körner, welche in der Substanz der leicht angeschwollenen obern Zweine liegen."

Diese Familie wird durch eine einzige Gattung: Polyides Ag. gebildet.

11. Furcellarieae: "Meerbewohnend, von dunkler, purpurner Farbe, von fleischiger Substanz und zelliger Structur. Laub eylindrisch, gabelspaltig; der centrale Theil dicht zellig; der peripherische Theil bestehend aus strahlenden, einfachen Fäden. Wurzel kriechend. Fructification : endständige, schotenähnliche, nicht aufspringende Receptaclen, innerhalb welcher, unter der äussern Rinde, eine Schicht von dunkel-rothbraunen Samen eingebettet ist. "

Diese Familie wird ebenfalls von einer einzigen Gattung : Furcellaria Lamour. gebildet.

Die beiden Gattungen Polyides und Furcellaria haben ein sonderbares Schicksal im Laufe der Zeiten und Systeme gehabt. Wegen der äussern Aehnlichkeit zuerst mit einander verwechselt, dann als Arten der Gattung Fucus neben einander gestellt, wurden sie später von Lamouroux und Agardh in verschiedene Gattungen und in rerschiedene Familien gebracht, von Lyngbye wieder in die Gattung Furcellaria vereinigt. Bei Gresille und Harsey machen sie wieder zwei besondere neben einanderstehende Familien, dann bei Endlicher zwei Gattungen Einer Familie, und bei Kïtzing endlich zwei Arten Einer Gattung aus. - Structurverschiedenheiten, wie sie Harcey beschreibt, kann ich nicht finden ; es handelt sich da bloss um ein unwesentliches Mehr oder Weniger. Es bleibt aber der wichtigere Unterschied in der Fortpflanzung. Polyz̈des hat doppelte Fructificationsorgane. Es frägt 
sich vor allem, ob die Fructification von Furcellaria mit einer der beiden von $\boldsymbol{P}_{0}$ lyëdes analog sei. Sicher ist sie es nicht mit der ersten, welche aus schwammigen Warzen besteht, in denen Häufchen von Samen liegen. Nach der Beschreibung wäre sie aber ebensowenig mit der zweiten Art der Fructification analog, denn obgleich die äussere Form der Frucht einige Uebereinstimmung zeigt, so werden die Samen bei Polÿ̈des "kleine Körner " (minute granules), bei Furcellaria " dunkel rothbraune Samen " (dark red-brown seeds) genannt. Harvey hat seine Exemplarè von Polyëdes mit dieser neuen Fructification von Mrs. Griffiths erhalten, welche dieselbe bei Sidmouth sammelte. Ich verdanke derselben Dame Exemplare mit der gleichen Fructification von dem gleichen Standorte. Hier finde ich nun aber ganz ähnliche Samen wie in Furcellaria, so dass es mir unbegreiflich ist, wie Harvey sie so ungleich benennen konnte. Ein Unterschied und zwar ein generischer ist jedoch zwischen den Samen von Furcellaria und denen ron Polyädes vorhanden. Bei der erstern sind die sogenannten Samen durch einen Schnilt erst in zwei Hälften, dann durch zwei mit dem ersten parallele Schnitte in vier, in einer Reihe stehcnde Sporen getheilt. Bei der letztern sind die Samen durch einen Schnitt in zwei Hälften, dann durch zwei auf dem erstern senkrechte Schnitte in vier, um ein Centrum gestellte Sporen getheilt.

Polÿ̈les und Furcellaria unterscheiden sich also 1) durch die Wurzel (welche bei der ersten Gattung schildförmig, bei der zweiten faserig ist) und 2) durch die eben beschriebene Sporenbildung. Die warzenfürmige Fruchtbildung von Polÿ̈des kann nicht als Unterschied benutzt werden, da die zweite Art der Fructification bei Furcellaria noch nicht aufgefunden ist, und es sich zum voraus nicht errathen lässt, ob sie gleich oder ungleich sein wird. - Wenn man daher bei den Algen nicht jede Gattung zur Familie erheben will, so darf man auch nicht die in Frage stehenden Gattungen in zwei verschiedene Familien verweisen. Es frägt sich weiter, ob die beiden Gattungen als besondere Familie von den Floridece unterschieden werden sollen. Ich sehe jedoch nicht ein, mit welchem Rechte sie von den Gattungen Chondrus, Phyllophora, Gigartina getrennt werden.

12. FlonineaE: "Meerbewohnend, von purpurrother oder schön rother Farbe, von lederartiger, knorpelartiger oder häutiger Substanz und zelliger Textur; die Zellen oft sehr ausgebildet. Laub entweder flach, blattartig, zusammen- 


\section{- $17-$}

gedrückı oder cylindrisch, bisweilen fadenförmig oder filamentos, ungegliedert. Fructification meist doppelt, und von getrennten Individuen derselben Art erzeugt : 1) Capseln oder Tuberclen, welche eine Masse von eiförmigen oder birnförmigen Samen enthalten : 2) Körner, welche zerstreut oder in kleine Gruppen versammelt sind, und entweder in der Substanz des Laubes oder in besondern Fortsätzen liegen. $\triangleright$

$\mathrm{Zu}$ dieser Familie werden folgende 17 Gattungen gezählt : A) mil rundlichen. an der Spitze nicht durchbohrten Capseln, welche eckige Samen enthalten : D $\ell^{-}$ lesseria Lamour., Nitophyllum Grer., Rhodomenia Grev., Chondrus Stackh., Phyllophora Grev., Plocamium Lamour., Spherecoccus Stackh., Chylocladia Grev., Gigartina Lamour., Geiidium Lamour, Hicrocladia Grer., Ptilota Ag. B) mit eingebetteten, zusammengehäuften, durchbohrten Tuberclen, welche eine Masse von freien, elliptischen oder rundlichen Samen enthalten : Graleloupia Ag. - C) mit eiförmigen, an der Spitze durchbohrten Capseln, welche einen Büschel von birnförmigen Samen enthalten: Odonthalia Lyngb., Rhodomela Ag., Bonnemaisonia Ag., Laurencia Lamour.

Die Gattungen dieser Familie sind wegen äusserer Aehnlichkeiten in der Structur und in der Fructification zusammengebracht worden. Unter ihnen gehören aber Plilota und Microcladia sowohl wegen ihres Baues, als wegen ihrer Fortpflanzung zu den Ceramiece, indem es etwas durchaus unwesentliches ist, dass sie dem blossen Auge als ungegliedert erscheinen. Die übrigen Galtungen gehören wenigstens zwei verschiedenen Typen an, von denen sich der eine (Lıurencia, Bonnem(isonia, etc.) durch einen besondern Strang von centralen Zellen, sowie durch die Samenbildung von dem andern (Chondrus, Rhodomenia, etc.) unterscheidet. Zu dem letztern Typus gehören auch die Gattungen der Gastrocarpece, sowie Polyzides und Furcellaria.

15. Ceraniede: a Meerbewohnend (mit Ausnahme von Trentepohlia), von rother, purpurner, oder rothbrauner, selten brauner Farbe, frisches Wasser mehr oder weniger roth färbend, von knorpelartiger oder schlaffer Substanz und von zelliger Textur. Laub fadenförmig, cylindrisch oder zusammengedrückt. gegliedert. Fructification doppelt : 1) Capseln mit einer Masse von Samen ; 2) Körner, in besondern Aestchen oder Receptaclen enthalten. " 
Diese Familie enthält 6 Meergattungen : A) mit eiförmigen, an der Spitze durchbohrten Capseln : Polysiphonia Grer., Dasya Ag. - B) mit kugeligen undurchbohrten Capseln: Ceramium Adans. Ag., Spyridia Harr., Griffithsia Ag., Ag., Callithamnion Lyngb, - ferner eine Süsswassergattung : Trentepohlin $\lg$.

Die letzte Gattung gehört wegen ihrer durchaus verschiedenen Fructification weder zu den Ceramieen noch zu den Rhodospermeen überhaupt. - Die übrigen Gattungen bilden zwei so verschiedene Typen als wir sie überhaupt unter den Rhodospermeen finden. Dass sie alle gegliedert erscheinen, darf uns nicht rerleiten, die Verschiedenheiten im Bau und in der Fortpflanzung zu übersehen. Es müssen daher Polysiphonia und Dasya entweder eine besondere Familic bilden, oder zu den verwandten Gattungen der vorhergehenden Familie (Laurencia, Rhodomeli, etc.) gestellt werden. Zn den Ceramieen müssen dann aber, nachdem diese Gattungen weggefallen sind, die verwandten Gattungen der Gloiocladece nebst Microcladia und Plilola hinzugefïgt werden.

Die brittischen Chlorospermeas zerfallen bei Itarrey in folgende 9 Familien: Lemaniea, Batrachospermere, Chaetophoroidere, Confervere, Siphonere, Oscillatoriere, Ulsacere, Nostochince, und Byssoidece, welche also characterisirt werden:

14. Lemaniese: "Süsswasserbewohnend, fadenförmig, ungegliedert, von knorpelig-lederartiger Substanz und zelliger Structur. Laub hohl, in unregelmässigen Zwischenräumen mit Quirlen ron Warzen besetzt, oder rosenkranzförmig. Fructification: büschelige, einfache oder verästelte, rosenkranzförmige Fïdlen, welche an die innere Fläche des röhrenförmigen Laubes angeheftet sind, und zuletzt in elliptische Sporen zerfallen. "

Diese Familie wird von der einzigen Gattung Lemania Bory gebildet.

Lemania stellt einen von allen übrigen Chlorospermeen verschiedenen Typus dar und macht daher mit Recht auf eine besondere Familie Anspruch.

13̆. Batrachospernea: " Süsswasserbewohnend; fadenförmig, gegliedert, nit Gallerte umhüllt. Laub) aus einem Strange von gehäuften, gegliederten Längsfasern bestehend, und in Zwischemräumen quirlförmig, mit kurzen, horizontalen, cylindrischen oder rosenkranżörmigen, gegliederten Aestchen besetzt. Fructification: (bei Butrachospermum) dichte, kugelige Massen, welche an die 


\section{$-19$}

Quirlästchen befestigt sind, und aus kleinen, strahlenden, dichotomischen : rosenkranzförnigen Fäden bestehen. »

Hieher gehören 2 Gattungen : Batrachospermum Roth., und Thorea Bory.

Diese Familie unterscheidet sich in der Fortpllanzung entschieden ron fast allen Chlorospermeen, nähert sich dagegen mehreren Gattungen der Melanospermeen.

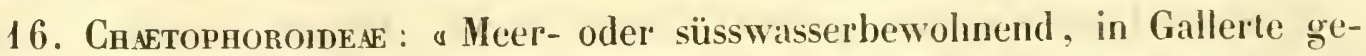
hüllt, entweder fadenförmig, oder (indem eine Zah! von Fäden zusammengehäuft ist) gallertartige, verästelte oder gestaltlose Massen bildend. Fäden gegliedert; die Glieder an den beiden Enden farblos, in der Nitte gefärbt. Fructification: soweit sie bekannt ist, kleine, an die Aestchen befestigte Capseln."

Diese Familie enthält 4 Gattungen : Bulbochete Ag., Draparnaldia Bory. Chcetophora Ag., Myrionema Grev.

Die Stellung von Draparnaldia und Chetophora wird im System noch so lange zweifelhaft bleiben, bis an ihnen die Fortpflanzung hinreichend bekannt ist. Aber gewiss gehören Bulbochcete und Myrionema nicht in ihre Gesellschaft, von denen die erstere wegen der Samenbildung offenbar mit den Zyynemaceen, die zweite eher mit einigen Gattungen der Mlelanospermeen verwandt ist.

17. Confervese: "Meer- oder süsswasserbewohnend, fadenförmig gegliedert, ohne bestimmt gestaltete Gallerte. Laub sehr mannigfaltig dem Ansehen nach, einfach oder verästelt; Glieder mehr oder weniger mit einer grünen, sehr selten braunen oder purpurnen körnigen Masse erfüllt, welche verschiedene Formen annimmt und von welcher vermuthet wird, dass sie zur Fortpflanzung diene."

In diese Familie grehören 7 Gattungen: Conferva Ag., Hydrodictyon Roth., Mougeotia Ag., Tyndaridea Bory, Zygnema Ag., Sphuroplea Ag., Aphanizomenon Morren.

Diese Gattungen, welche, mit Ausnahme ron Hydrodictyon, im Bau schr übereinstimmen, sind in ihrer Fortpflanzung sehr rerschieden und gehören ¿ Typen an, wovon Conferca den ersten, Mydrodictyon den zweiten. Mougeotia, Tyndaridea und Zygnema den dritten, Sphceroplea den vierten und Aphanizomenon den fünften bildet. 


\section{$-20$}

18. Sipionene: "Im Meer, im süssen Wasser oder auf feuchtem Grunde wohnend, von häutiger oder hornartiger durchsichtiger Substanz, mit grünem körnigem Stoffe gefüllt. Laub röhrigg, fadenförmig; die Fäden frei oder in schwammige Körper von verschiedener, nämlich krustenförmiger, kugeliger, cylindrischer oder flacher Gestalt vereinigt. Fructification : Aeusserliche Blasen (oder Coniocysten), welche oft gestielt sind und eine körnige Masse enthalten."

Zu dieser Familie werden gezälılt: Codium Stackh., Bryopsis Lamour., Vaucheria Dec., Botrydium Wallr.

Der Structur nach unterscheiden sich diese Gattungen allerdings von allen übrigen Algen und bilden daher eine höchst natürliche Familic, wenn nicht Botrydium, was ich vermuthe, in der Fortpflanzung sich von den übrigen unterscheidet.

19. Oscillatorieae : am Meere, im süssen Wasser oder auf feuchtem Grunde wohnend, von gallertartiger Substanz und fädiger Structur. Fäden dünn, röhrenfürmig ungegliedert, mit gefärbtem, körnigem, quergestreiftem Stoffe erfüllt, selten verästelt, obgleich oft zusammenhängend, als ob sie verästelt wären; gewöhnlich in breite, schwimmende oder sitzende Polster, von sehr gallertartiger Natur zusammengehäuft; zuweilen aufrecht und gebüschelt, und noch seltener in strahlende Reihen vereinigt, durch feste Gallerte verbunden, und dann ein kugeliges, gelapptes oder flachkrustenförmiges Laub bildend. Fructification : eine innere, durch Querwände getheilte Masse, welche zuletzt in rundliche oder linsenförmige Sporidien zerfällt. ’

Diese Fanilie umfasst 9 Gattungen : Rivuluria Roth., Stigonema Ag., Scytonema Ag., Calothrix Ag., Lyngbya Ag., Oscillatoria Vauch., Belonia Carm., Pelalonema Berk., Microcoleus Desmaz.

Vit Ausnahme von Lyngbya und Stigonema bilden die Oscillatoriee einen sehr charakteristischen, durch ihren Bau und ihre Fortpflanzung ausgezeichneten Typus. Lyngbya und Stigonema dagegen scheinen mit Sphceroplea verwandt zu sein.

20. Unvacen: "Im Meere, im süssen Wasser oder auf feuchtem Grunde wohnend; von häutiger oder gallertartiger Substanz und einfacher, unvollkommen-netzförmiger Structur. Laub entweder eine röhrige oder flache, fadenförmige oder ausgebreitete Haut, oder eine gallertartige, gestaltlose Masse; farblos, 


\section{$-21$}

ader, in Folge der Fructification, von grüner, purpurner oder röthlicher Farbe. Fructification: kleine, grüne oder purpurne Körner, durch das Laub zerstreut oder zu vier zusammengestellt. "

Zu dieser Familie werden 9 Gattungen gerechnet: A) häutig, nicht gallertartig: Porphyra Ag., Ulka L., Bangia Lyngb., Enteromorpha Link. - B) gallertartig: Tetraspora Link., Palmella Lyngb., Hydrurus Ag., Hamatococcus Ag., Protococcus Ag.

Harvey hat hier Gattungen zusammengebracht, welche vorher nie rereinigt waren, und es wird ihm auch gewiss niemand, der die betreffenden Pflanzen genaver studirt hat, folgen. Der Irrthum rührt von der Gattung Tetraspora her, welche der Verfasser mit Ulca verwandt glaubt. Aber obgleich früher und neuerdings wieder diese beiden zusammengestellt wurden, so ist zwischen ihnen doch weiter keine, als eine äussere Aehnlichkeit, dagegen eine innere totale Verschiedenheit. Die 4 ersten Gattungen dieser Fanilie müssen daher ohne Anders eine besondere Familie bilden; sowie auch die כ̈ letztern Gattungen zusammen eine ganz natürliche Gruppe ausmachen.

21. Nostochina: : "Im süssen Wasser oder in feuchten Localitäten wohnend ; von gallertartiger oder etwas lederartiger Substanz und einfacher Structur, bestehend aus verschiedenartig gekrümmten oder gedrehten, rosenkranzförmigen, einfachen Fäden, welche entweder in einem gallertartigen Laube von bestimmter Gestalt enthalten, oder ohne Ordnung in einer schleimigen gallertartigen Natrix zusammengehäuft sind, n

Diese Familie enthält drei genuine Gattungen: Nostoc Vauch., Monormiu Berk., Anabaina Bory., und zwei abweichende Gattungen: Echinella Ach., und Eutomia Harvey.

Die zwei lełzlern Gattungen gehören zu den Diatomaceen, die drei ersten Gatlungen dürfen von den Oscillatoriec, wie dieselben ungrenzt wurden, nicht getrennt werden.

22. Byssordene : "Fäden gegliedert, wasserhıel! oder gefärbt. Fructification sehr zweifelhaft. - Sie wohnen zwischen Moosen, auf vermodertem Holze, auf feuchtem Grunde, auf Glas oder in chemischen Lösungen und auf faulenden thierischen Substanzen; wenige in süssem Wasser oder in Meere. " 
Hieher werden gerechnet: Byssocladium Agr., Mycinema Ag., Chroolepus Ag., Protonema Ag., Hygrocrocis Ag., Leptomitus Ag., Scythymenia Ag.

Harrey selbst äussert Zweifel über die Algennatur dieser Familie; und es ist wohl keinem Zweifel unterworfen, dass Protonema bloss Vorkeime von Moosen enthält, und dass die übrigen Gattungen in die Classe der Pilze gehı̈ren. Als vierte Reihe folgen nun die Diatomaces, welche in 4 Familien zerfallen : 25. Desumieas mit den Galtungen Meloseira Ag. und Desmidium Ag.

24. Fragilarieae mit den Gattungen Fragilaria Lyngb., Striatella Ağ., Achanthes Ag., Isthmia Ag., Odontella Ag., Diatoma Ag., Exilaria Grer., Frustuliu Ag.

25. Styldarie@e mit den Gattungen Stylluria Ag., Heridion Ag., Licmophow a Ag.

26. Cymberleas mil den Gattungen Gomphonema Ag., Homøocladia Ag., Berkeleya Grev., Schizonema Ag. und C'ymbella Ag.

Werfen wir nun noch einen Blick auf das ganze System und auf die demselben zum Grunde liegende Methode, so sehen wir zwar überall das Bestreben, zu Fructificationsunterschieden zu gelangen. Es gelingt dieses aber wegen des unzureichenden Verfahrens, und wegen der noch mangelhaften Begriffsbestimmungen nicht. So reich daher das Werk an einzelnen sorgfältigen Beobachtungen ist, so wenig genügen die Anordnung und die Definitionen.

Dic Algen besitzen, im Vergleich mit andern Pflanzen, einen höchst einfachen Bau. Sie bestehen häufig aus ciner einzigen Zelle, häufig aus einer geringen oder einer beträchtlichen Zahl von Zellen, welche deutlich nach bestimmten Verhältuissen beisammmen liegen. Die Zelle ist daher ein vorzügliches Mittel. um durch sie die vegetativen und reproductiven Verhältnisse der Algen auszudrücken. Ja, es ist diess der einzige Weg, auf dem eine wissenschaftliche Erkenntniss möglich ist. Dennoch finden wir in dem vorliegendem Werke die Verhältnisse, so zu sagen, nie durch den Begriff der Zelle ausgedrückt und anschaulich gemacht. Vegetative und reproductive Eigenthümlichkeiten werden noch grösstentheils so, wie sie äusserlich erscheinen, beschrieben, und die unwesentlicheren Verhältnisse der Farbe, der Substanz, der Form mehr berücksichtigt, als sie es verdienen. 
Die Begriffsunterschiede sind bei Harvey noch schr schwankend. Der gleiche Begriff erscheint unter verschiedenen Benennungen, der gleiche Ausdruck wird für verschiedene Begriffe gebraucht. Die Zellen heissen Zellen, Faser'n, Fäden. Unter Zellen werden aber auch Abtheilungen oder Höhlungen im Zcllgewebe verstanden. Dic Zellen, welche zur Fortpflanzung dienen, heissen Samen, Körner, Spürchen (sporules) und Sporidien. Samen und Sporidien sind aber auch zuweilen die Mutterzellen, in denen mehrere Fortpflanzungszellen dicht beisammen liegen. Körner bedeuten nicht bloss die Fortpflanzungszellen selbst, sondern bei den Rhodospermeen werden unter Körnern häufig 4 in einer Mutterzelle beisammenliegende Sporen verstanden; das gleiche heisst bei andern Galtungen dieser Reihe "gedreite Körner" (ternate granules). Ausserdem hat Körner noch verschiedene Bedeutungen, wie z. B. Zelleninhalt, u. s. w. Das rertiefte Fruchtlager der Fucoideen heisst Haufen (cluster), Tuberculum oder Zelle, das vertiefte Fruchllager von Lichina heisst Receptaculum oder Capsel, das flache Fruclitlager der Laminaria heisst Flecken (spot) oder Sorus. Unter Capsel wird nicht bloss das vertiefte Fruchtlager von Lichina, sondern auch die eine und die andere Fruchtart der Rhodospermeen, nämlich bei Ceramium u. a. eine zusammengeballte Masse von Keimzellen, die mit Gallerte ungeben ist, in Callithamnion u. a. die Mutterzclle mit den 4 eingeschlossenen Sporen, ansserdem eine Menge anderer Sachen verstanden, welche äussere Aehnlichkeit mit einer Capsel haben. Die Mutterzellen mit den 4 eingeschlossenen Sporen, welche bei den Rhodospermeen so constant und characteristisch auftreten, dass sie sich von allen anderen Fortpllanzungsarten der Algen unterscheiden, werden bezeichnet als Kügelchen von Samen (globule of seeds), als Samen, als gredreite Körner, als Körner schlechthin, als dreisporige Capseln oder überhaupt Capselı. Es mögen diese Beispiele genügen, um zu zeigen, wie sehr die Algologie bis auf Harsey sich mit unmittelbarcr sinnlicher Anschaunng begnügte, und nicht zu festen wissenschaftichen Begriffen durchzudringen vermochte.

Um so mehr Anerkennung verdient es, dass trotz einer hemmenden mangelhaften Methode, im Einzelnen vicle Verhälınisse gut beobachtet und richtig gedeutet sind, und dass namentlich die Arten viel natürlicher ungrenzt werden, als diess von spätern französischen und deutschen Algologen geschehen ist. 


\section{SYSTEVI VON J. AGARIH.}

J. Agardh $\left(^{1}\right)$ definirt die Algen ebenfalls nicht. Er umgrenzt sie aber richtiger als seine Vorgänger, indem er die zu den Pilzen gehörigen Gattungen, die Charen und die Vorkeime der Laubmoose aus dem Spiele lässt. Dagegen werden die Corallinex und Halimedex, so wie die Diatomaceæ, obgleich sie in dem vorliegenden Werke nicht aufgeführt werden, doch zu den Algen gerechnet.

J. Agardh theilt die Algen in drei Familien ein : 1) Zoospermere, 2) Fucoidere, 5) Floridece. Die erste Gruppe entspricht den Chlorospermere, die zweite den Melanospermece, die dritte den Rhodospermece von Harcey. Sie werden folgendermassen characterisirt :

1. Zoospermeae: a Mit doppelter (immer?) Fruchtbildung versehen, die eine innerlich, aus veränderten, zuletzt mit sehr lebhafter Bewegung begabten Chlorophyllkörnern bestehend (Sporidia); die andere äusserlich, durch Bildung einer Zelle oder eines veränderten Astes entstanden, innerhalb einer durchsichtigen Sporenhülle zahlreiche Chlorophyllkörner, die in eine Spore ( $\left.{ }^{2}\right)$ vereinigt sind, enthaltend (Coniocystce). - Laub meist grün, selten olivenfarbig oder violett; aus Zellen. Gliedern oder Röhren, welche in eine Schicht oder in eine einzelne Reihe geordnet sind, bestehend; bald aus einzelnen, bald aus zahlreichen in einer gemeinschaftlichen Gallerte liegenden Individuen gebildet; fadenförmig, hautartig-ausgebreitet oder etwas laubartig. "

II. Fucoldeas : " Einhäusig (?), mit doppelter Fruchtbildung in denselben Individuen; die eine in einer durchsichtigen Sporenhülle, welche entweder nackt oder sehr häufig zwischen umgebenden Fäden mit der Basis angeheftel ist, eine einzelne Spore enthaltend, die andere aus Sporidien bestehend, welche mit sehr lebhafter Bewegung begabt, und in den Aestchen eines gegliederten Laubes oder in den die Sporen umgebenden Fäden enthalten sind (und häufig in Menge zu einem einzigen Keime verschmelzen?). — Laub olivenbraun, geglie-

(1) Alga maris mediterranei et adriatici. Parisiis 1842. 


\section{$-25$}

dert oder ungegliedert, cylindrisch, flach, zuweilen riesenhaft, und blattähnliche Organe hervorbringend. "

III. Flonmene : "Zweihäusig, mit doppelter, immer auf verschiedene Individuen vertheilter Fruchtbildung: die eine meist äusserlich, innerhalb einer fast gallertartigen oder zelligen Fruchthülle zahlreiche Sporen enthaltend; die andere meist eingesenkt, in einer durchsichtigen Sporenhülle vier Sporen erzeugend. Laub meist roth oder purpurn; seltener olivenfarbig oder violett, gegliedert oder ungegliedert, cylindrisch oder flach, sehr selten blattähnliche Organe besitzend. ")

Von diesen drei Familien unterscheidet sich nach der Diagnose die der Floridece ganz bestimmt von den beiden andern 1) durch das Characteristische der Einen Fruchtbildung, 4 Sporen in einer Sporenhülle zu erzeugen, 2) durch die Uebereinstimmung der beiden Arten der Fruchtbildung, welche nur unbewegliche Sporen erzeugen, während in den zwei übrigen Familien unbewegliche Sporen und bewegliche Sporidien unterschieden werden. So gut nun aber die Floridece in der Diagnose und in der Natur unterschieden sind, so wenig finde ich einen Unterschied heraus zwischen den Zoospermea und den Fucoidece, sowohl in der Diagnose als in der Natur. Den Zoospermeen werden bewegliche Sporidien, die aus veränderten Chlorophyllkörnern entstanden sind, zugeschrieben. Die gleichen beweglichen Sporidien sollen aber auch die Fucoideen besitzen; ihre Entstehung wird hier nicht angegeben, also bildet sie auch keinen Unterschied. Die Zoospermeen besitzen ferner Sporen, welche aussen sitzen und durch die Bildung einer Zelle oder eines veränderten Astes entstanden sind. Aber die Fucoideen besitzen ebenfalls nackte Sporen; ihre Entstehung ist ebenfalls nicht näher angegeben, kann also wieder keinen Unterschied begründen. Aber abgesehen davon, dass in der Diagnose vergeblich cine Verschiedenheit gesucht wird, so kann es gewiss als eine Unmöglichkeit erklärt werden, zwischen zwei Familien einen differentialen Character in der Fruchtbildung aufzufinden, von denen die eine die Gattungen Conferca und Vaucheria, die andere die Gattungen Ectocarpus oder Myrionema und Dictyota enthält, aus dem einfachen Grunde, weil Conferva mit Ectocarpus und Myrionema, und Vaucheria mit Dictyota in dem Wesentlichen der Fortpflanzung, nämlich in der Erzeugung der Fortpllanzungszellen, übereinstimmt. - In den vegetativen Organen ist ebenDeahsch. XEGELI. 
falls kein Unterschied vorhanden, indem die am höchsten entwickelten Zoospermeen den gleichen Bau besitzen wie die einfacheren Fucoideen. Es bleibt bloss noch die Farbe übrig, welche bei den einen olivenfarbig und bei den andern zwar meist grün, aber in einzelnen Fällen ebenfalls olivenfarbig ist.

Ich will nun die Beschreibung der drei Familien und ihre Eintheilung in Zünfte etwas näher betrachten. Die Zoospermene bestehen aus Zellen. Bei den Rivulariece und Oscillatoriea solten die Zellen röhrenförmig und ihr Inhalt zuletzt gliederartig getheilt scin. Die Betrachtung eines sich entwickelnden Fadens widerlegt diese Ansicht, indem zuerst die Zellenreihe entsteht und nachher erst durch die Zellen selbst die Scheide erzeugt wird. - Die irrige Ansicht Meyen's, dass die Zellmembran aus Fasern bestehe, wird von $J$. Agardh auch für die Zellen der Zoospermeen ausgesprochen, vorzïglich wegen einer faserigen Streifung, welche späterhin zuweilen an der Zelhwandung sichtbar ist. Aber es muss eingewendet werden, dass diese Streifung immer erst an alten Zellen gesehen wird, und dass es jedenfalls gerathener' wäre die Ursache dieser Thatsache aufzusuchen, als dieselbe für eine Theorie zu verwenden. Nach meiner Ansicht ist diese Streifung, welche in einzelnen Fällen überaus deutlich zu beobachten ist, die Folge davon, dass sich die äussersten und ältesten Schichten der Zellwandung zusammenziehen und dadurch etwas gefaltet oder gefurcht werden. - Jene Theorie erweist sich sogleich als fruchtbar und erzeugt eine neue von der Zellenbildung. Die Zellen sollen auf doppelte Art entstehen 1) durch Theilung (divisio intrautricularis), 2) an der Aussenfläche der alten Zellen durch die Fasern (formatio cellularum suprautricularis). Eine solche Zellenbildung an der Oberfläche der Zellmembran existirt aber bei den Zoospermeen nicht. Alle vegetative Zellenbildung geschieht durch die sogenannte Theilung.

Dic Sporidien sollen aus veränderten Chlorophyllkörnern entstehen, und eine lebhafte Bewegung zeigen. Sie sind zwar klein und grün, aber desswegen dennoch nicht aus Chlorophyllkörnern entstanden. Ich habe dafür einen doppelten Beweis. In Confersa glomerata marina sah ich sie nicht bloss in Zellen entstehen, welche einen ganz farblosen Inhalt besassen, sondern sie selbst waren zuerst ungefärbt, und färbten sich erst mit ihrer weitern Entwicklung grün. In Ulothrix sonata theilt sich die Mutterzelle wiederholt. Die letzten Tochterzellen sind die 


\section{$-\quad 27$}

grünen, sich bewegenden Sporidien $\left(^{1}\right)$. Die Sporidien sind nach J. Agardh bei den Draparnaldiece, Confersece, Zygnemece (Hydrodictyon), Ulsacece und Siphoneœ beobachtet worden. Ich habe die Ansicht aussprechen zu müssen geglaubt, dass diese beweglichen Zellchen nicht zur Fortpflanzung dienen, sondern durch Generatio sequivoca entstandene Infusorien seien $\left(^{2}\right)$. Ich wurde auf diese Ansicht durch eine Beobachtung an Conferca glomerata marina geführt und bin jetzt noch überzeugt, dass es dort Infusorien waren, welche in den Confervenzellen entstanden. Dagegen habe ich seither Gelegenheit gehabt, die Beobachtungen Kützing's über die Bewegung und das Keimen der Keinzellen von Ulothrix vollständig zu bestätigen, worüber ich auf die in der zweiten Hälfte dieser Schrift folgende Charakteristik der Bangiacece, 1 Lyngbyece verweise.

Die zweite Fruchtart sind die Coniocysten, ganze Zellen, welche viele Chlorophyllkörner enthalten. Da nun aber die Sporidien, wenn sie wirklich zur Fortpflanzung dienen, ebenfalls Zellen und keine veränderten Chlorophyllkörner sind (wie sich diess in Ulothrix ganz deutlich zeigt), so fällt der Unterschied zwischen Coniocysten und Sporidien weg. Ebenso ist es noch im höchsten Grade zweifelhaft, ob es Zoospermeen mit doppelter Fruchtbildung gibt, oder dann findet sie sich jedenfalls bloss bei einzelnen Gattungen. Die Fortpflanzungszellen rerhalten sich aber verschieden in Rücksicht auf Bewegung, ohne dass jedoch dieser Unterschied von Bedeutung wäre. In Ulothrix bewegen sie sich, in der ganz nah verwandten Lyngbya muralis bewegen sie sich nicht; in Vaucheria clacata zeigen sie Bewegung, in den übrigen Arten von Vaucheria dagegen nicht.

Zu den eigentlichen Zoosperimern rechnet J. Agardh die Ulsacere, Confercacee, Siphonere und Draparnaldiere; diesen Zünften seien wahrscheinlich beizufügen die Nostochinece, Oscillatoriece, Risulariece, Zygnemere und Batrachospermere. Die Diatomacese mit den Desmidiaceen bilden nach dem Verfasser wahrscheinlich eine besondere Familie; ebenso die Lemaniea.

Die Zoospermede des mittelländischen und adriatischen Meeres werden in folgende Zünfte eingetheilt : 1) Rivulariea, 2) Oscillatoriece, 5) Confercea, 4) $\mathrm{Ul}$ racece, כ̈) Siphonece.

(') Vergyl. unten: Versuch eines eigenen Systemes, I Algुæ, Bangiaceæ, Lyngybyeæ.

$\left(^{2}\right.$ Zeitschrift für wissenschaful. Botanik von Schleiden und Nägreli, Heft II, pag. 28. 


\section{$-28$}

Die erste Zunft Rirularieas enthält die Gattungen Gloiotrichia J. Ag., Rivularic Ag., Zonotrichia J. Ag. und Diplotrichia J. Ag. Es wird an ihnen eine doppelte Fructification vermuthet : 1 ) «dass die innern Ringe des Laubes (wie bei Oscillatoria) sich in Sporen verwandeln oder in Sporidien auflösen, "2) 2) dass, wie diess in Diplotrichia der Fall sein soll, “ die Fäden innerhalb besonderer Zellen oder Blasen entstehen. " Was die erstere Art der Fruchtbildung betrifft, so ist zu bemerken, dass J. Agardh dieselbe nicht beobachtet hat, ebensowenig sonst Jemand. Was die zweite Art der' Fruchtbildung betrifft, so wird sie von dem Verfasser für Diplotrichia also beschrieben: "Zwischen den Fäden des Laū̉es liegen Kügelchen, welche in einer durchsichtigen Membran einen körnigen Inhalt einschliessen; derselbe verwandelt sich allmälig in einen geringelten Faden, der im Anfange spiralförmig gewunden ist, zuletzt sich streckt und die Sporenhülle zu einer cylindrisch-eiförmigen Gestalt ausdehnt, bis der Faden den übrigen gleich geworden ist. $\triangleright-0 \mathrm{Ob}$ der Vorgang, wie er beschrieben wird, Schritt für Schritt beobachtet wurde, bezweifle ich fast, er scheint mir eher eine Hypothese, als eine Thatsache zu sein. Bei der Gattungsbeschreibung von Diplotrichia sagt nämlich der Verfasser bloss : «Nahe am Grunde der Fäden werden ziemlich grosse Säckchen beobachtet, welche aus einer durchsichtigen Membran bestehen, und welche zwei spiralig gewundene Fäden, von denen der eine grösser ist, und die an der Basis etwas zusammenhängen, einschliessen. Wie im Thierei der Embryo, so scheinen schon im Säckchen selbst aus dessen Inhalte die Fäden gebildet zu werden. „ Es wäre gewiss von der grössten Wichtigkeit über diesen Punkt in's Reine zu kommen, da das Keimen von Rivularia und den verwandten Gattungen noch nicht bekannt ist. Nach der zweiten angeführten Beschreibung, scheint es mir, als ob die Sache recht gut sich wie bei Nostoc verhalten könnte, wo die jungen Fäden zuweilen ebenfalls gekrümmt oder gewunden in einem Säckchen eingeschlossen sind. Dieses Säckchen ist aber nichts anders als die von dem Faden selbst gebildete Gallerte. - Die Zunft Rivulariece entspricht der alten Gattung Rivularia. Warum sie aber nicht mit den Oscillatoriex vereinigt wurde, von denen, wie J. Agardh selbst sagt, sie eigentlich nicht verschieden ist, sehe ich nicht ein.

Die zweite Zunft OscilLatorieas hat zwei Gattungsrepræesentanten: Lyngbya Ag. und Calothrix Ag. Die Fruchtbildung ist noch sehr zweifelhaft. Der Ver- 
fasser vermuthet sie in zweifacher Art: 1) a dass die innerhalb der Röhre beweglichen Ringe kugelförmig werden (heraustreten und in bewegliche Sporidien sich auflösen ?), 2) dass seilliche Coniocysten (?) vorkommen. „ Es ist aber sowohl das eine als das andere unrichtig, da die sogenannten Ringe oder Glieder, welche bei Oscillatoria heraustreten, unmittelbar zu Fortpflanzungszellen werden. Bei jeder Galtung ist überdem bloss eine einzige Art der Fortpflanzung vorhanden, die aber in verschiedenen Gattungen (Oscillatoria und Lyngbya) verschieden ist ; daher auch eine einzige Zunft nicht für alle Gattungen genügt.

In der dritten Zunft Confervaceas wird bloss die Gattung Conferca aufgezählt, ohne eine Bemerkung über deren Fortpflanzung.

Die vierte Zunft Ulvacese hat 4 Gattungen: Bangia Lyngb., Enteromorpha Link, Ulva Ag. und Porphyra Ag. Von der Fruchtbildung wird nichts weiter erwähnt, als dass bei Enteromorpha und bei Ulva « die Felder (areolæ) wenige Sporidien in unbestimnter 'Lahl enthalten. "

Die fünfte Zunft SiphoNeas wird dureh folgende Galtungen gebildet: Bryopsis Lam., Codium Ag., Dasycladus Ag., Valonia Ag., Anadyomene Ag., Caulerpa Lamour. - Bryopsis soll sich auf doppelte Art fortpflanzen 1) dureh bewegliche Sporidien, welche in den Zweigen entstehen, 2) durch Coniocysten, welche seitlieh an den Fäden angeheftet sind. Wenn beide Beobachtungen richtig sind, so wäre diess bis dahin das einzige sichere Beispiel, dass eine zu den Z rige Alge doppelte Fruchtbildung zeigt. Aus dieser Thatsache würde ich dann aber nicht, wie J. Agardh gethan hat, den Schluss ziehen, dass beide Fruchtbildungen gleichwerthig, und dass sie ein Merkmal für alle Zoospermeen seien; sondern ich glaube, es wäre dann vielmehr zu untersuchen, ob nicht eine von den beiden Fructificationen die niedrigere und daher als unwesentlich, als Vermehrung oder als Brutzellenbildung zu erklären sei, wie ja auch bei den höhern Cryptogamen neben der Fortpflanzung oder der Sporenbildung eine Vermehrung oder Brutzellenbildung vorkommt. Die Zunft der Siphoneen enthält sehr verschiedene Typen, die gleichwohl äusserlich etwelche Aehnlichkeit zeigen. Die einzelligen Gattungen sollten in zwei versehiedene Zïnfte, nämlich in die eine Bryopsis und Vaucheria, in die andere Valonia gebracht werden. Die mehrzelligen Gattungen Dasycladus und Anadyomene sollten wieder zwei Zünfte bilden. 


\section{$-30$}

Die Fucomeen sind die zweite Familie der Algen. Der Verfasser vermuthet an ihnen ebenfalls eine doppelte Art der Fruchtbildung. Die Sporen sind eine constante Erscheinung. Von den Sporidien dagegẹn wird zugegeben, dass sie noch nicht durch sichere Beobachtung nachgewiesen seien. - Die Gattungen dieser Familie, welche im mittelländischen und adriatischen Meere vorkommen, werden in folgende Zünfte eingetheilt: 6) Ectocarpere, 7) Sphacellariece, 8) Chordariece, 9) Dictyotece, 10) Sporochnoidece, 11) Laminariece, 12) Fucoidece.

Die sechste Zunft Ectocarpeae enthält die einzige Galtung Ectocarpus Lyngb. An ihr soll eine doppelte Fruchtbildung vorkommen " 1) sogenannte Capseln, welche innerhalb einer durchsichtigen Sporenhülle eine einzige Spore enthalten, 2) Sporidien, welche in den untern Gliedern der Aestchen sich entwickeln und mit Bewegung begabt sind; oft ballen sie sich zusammen und bilden, von der Membran des Gliedes umhüllt, den Keim einer einzigen Pflanze. " Rücksichtlich der von $J$. Agardh sogenannten Sporen, ist es mir auffallend, dass er darin die zahlreichen Samen nicht erkannt, und den alten richtigern Namen von Capseln in den unrichtigen von Sporen verändert hat. Was die beweglichen Sporidien betrifft, so möchte die Sache noch sehr zweifelhaft sein, da der Verfasser selbst an einem andern Orte sagt: "Bei Ectocarpus sah ich tebendige Sporidien, die aus der Pflanze entleert waren, aber den Ort, woraus sie entleert wurden (locum eruptionis), konnte ich nicht entdecken. "

In der siebenten Zunft Spiracellaniede werden die beiden Gattungen Sphacellaria Lyngb. und Cladostephus Ag. aufgezählt. Die Zunft wird so characterisirt: "Laub gegliedert vielröhrig. Fruchtbildung doppelt (?), Sporen einzeln (?) in den brandigen Endästchen, zuletzt durch dic sich öffnende Spitze heraustretend. Sporidien in veränderten Aestchen eingeschlossen, sehr häufig nicht zur Entwicklung gelangt, sondern mit der Sporenhülle in einen einzigen zuletzt freiwerdenden Keim sich verwandelnd. "Die brandigen Enden der Zweige sind solche, die nicht weiter wachsen, in denen der absterbende Inhalt braun geworden ist. Die noch zellenbildenden Zellen sind ungefärbt. Fortpflanzungszellen werden aber hier nicht erzeugt. - Die Sporidien sollen in seitlichen Organen entstehen, die man sonst wohl als Sporen betrachtete. Ich habe dieselben selbst nicht be- 


\section{$-31$}

obachtet, bin aber sehr geneigt, die Beobachtung $J$. Agardh's als richtig anzunehmen.

Die achte Zunft Chordariese enthält die Gattungen Myrionema Grev., Hildenbrandtia Nardo, Corynephora Ag., Myriocladia J. Ag., Mesogloia Ag. und Liebmannia J. Ag. Der Verfasser vermuthet auch hier eine doppelte Art der Fortpflanzung: 1) «Sporen, welche zwischen den Fruchtfäden über das ganze Laub vertheilt, einzeln, sitzend und mit einer durchsichtigen Sporenhülle umgeben sind, und aus einer gleichförmigen und ungetheilten körnigen Masse bestehen; 2) Sporidien, welche, wenn ich nicht sehr irre, von Mesogloia sermicularis entleert worden waren (denn in dem Gefässe waren mehrere Algen enthalten), welche Bewegung zeigten, sich etwas grösser erwiesen als die in dem Laube eingeschlossenen Körner und in der Farbe mit denselben übereinstimmten, zuletzt keimten.... n. Ich kenne zwar nicht die Fruchtbildung aller hieher gehörigen Gatlungen; aber von einigen (Hyrionema, Mesogloia) glaube ich mich überzeugt zu haben, dass dic von $J$. Agardh als Sporen betrachteten Organe Capseln sind, innerhalb welcher viele Fortpflanzungszellen entstehen. So wäre es möglich, dass die von demselben bei Mesogloia vermicularis beobachteten Sporidien aus den sogenannten Sporen entleert worden wären, und dass somit auch hier nur Eine Art der Fortpflanzung existirte.

In der neunten Zunft Dictyotese finden sich die Gattungen Halyseris Ag., Dictyota Lamour., Zonaria Ag., Padina Adans., Cutleria Grev., Asperococcus Lamour., Punctaria Grev., Striaria Grev. und Stilophora J. Ag. Die Fortpflanzung scheint dem Verfasser wieder eine doppelte zu sein : 1) "Sporen, welche in Häufchen von verschiedener aber bestimmter Gestalt zusammengelagert sind, eine verkehrt-eiförmige Gestalt besitzen, einzeln in einer durchsichtigen Sporenhülle, die von gleicher Gestalt und mit einer verschmälerten Basis angeheftet ist, liegen, und durch einfache Ausbildung (morphosi) der Epidermiszellen entstanden sind ; 2) Sporidien (? oder Sporen?), welche entweder zerstreut durch das Laub in einzelnen Zellen enthalten (Dictyota, Ilalyseris, Dictyosiphon), oder in den samentragenden (?) die Sporen umgebenden (Asperococcus, Cutleria, Stilophora) oder von denselben getrennt liegenden (Padina) Fäden eingeschlossen sind. " Die Sporen sollen nach J. Agardh bloss die erweiterten und 


\section{$-32-$}

hervorragenden Epidermiszellen sein. Ich kann dieser Ansicht nicht beistimmen, da ich gesehen habe, dass die Epidermiszellen auswachsen, und sich dergestalt in 2 Zellen theilen, dass die eine, welche die Spore ist, dem ausgewachsenen Theile, die andere dem ursprünglichen Lumen der Zelle entspricht. Was des Verfassers Sporidien in dieser Zunft sein sollen, ist mir nach der Besehreibung nicht klar geworden; eben so wenig habe ich in der Natur von einer zweiten Art der Fortpflanzung etwas gesehen. - Wenn die Gruppe übrigens natürlich sein soll, so muss Cutleria, welche in der Fruchtbildung durchaus abweicht, ausgeschlossen werden.

Die zehnte Zunft Sporochnoidese enthält die Gattungen Arthrocladia Duby und Desmarestia Lamour. Die Sporen sollen an der Spitze von gegliederten Fäden, durch Entwicklung des Endgliedes entstanden, sich befinden.

In der eilften Zunft Laminamiese werden die beiden Gattungen Laminaria Lamour. und Chorda Stackh. vereinigt. Die Fructification besteht in Fruchtlagrern (sori) ohne bestimmte Begrenzung, in denen die Sporen mit verkehrteiförmig-gestutzten ungegliederten Fruchtfäden gemischt stehen.

Die zwölfte Zunft FucaCfae enthält die Gattungen Fucus Ag., Cystoseira Ag. und Sargassum Ag. Ausser der bekannten Fruchtart wird noch eine andere in den Fäden der Receptaclen vermuthet.

Die Fronmeas bilden die dritte grosse Familie der Algen. Sie bestehen nach dem Verfasser aus Zellen, welche entweder in eine einfache Reihe gestellt, oder so in versehiedene Reihen geordnet sind, dass die Zellen der verschiedenen Reihen alle in der gleichen horizontalen Ebene endigen (gegliedertes Laub), oder endlich welche so in verschiedenen Reihen beisammenstehen, dass die Zellen der verschiedenen Reihen nicht in der gleichen horizontalen Ebene endigen (ungegliedertes Laub). Dieser Unterschied von gegliederter und ungegliederter Frons wurde allerdings von jeher in der Algologie gemacht, und doch ist vielleicht keiner, der mehr von Zufälligkeiten abhängt und daher mehr unwesentlich ist als dieser. Man braucht, um diess einzusehen, bloss gewisse Arten von Callithamnion, Ceranium, Polysiphonia etc. zu betrachten, welche gegliederte und ungegliederte Formen besitzen; oder die Entwicklungsgeschichte von einem halben Dutzend Gattungen aus verschiedenen Gruppen zu verfolgen und zu 


\section{$-33$}

beobachten, wie sehr viele der ungegliedert erscheinenden Arten eigentlich doch gegliedert sind, so gut wie andere, die es nicht bloss sind, sondern auch scheinen $\left({ }^{1}\right)$.

Die Zellen der Florideen sollen ebenfalls, wie diejenigen der Zoospermeen Membranen besitzen, welche aus Fasern bestehen, die in doppelter Richtung verlaufen. Ueber das Wachsthum in die Länge stellt $J$. Agardh folgende Theoric auf : "Die Zellen entstehen sehr häufig durch suprautriculäre Bildung ; die Fasern, aus denen die Zellmembran besteht, verlängern sich beständig, und wegen ihrer mehr oder weniger spiraligen Anordnung werden sie immerfort veranlasst, neue Zellen zu bilden; durch Verlängerung der Fasern von einer Zelle zur andern wächst so jede senkrechte Reihe in die Länge. » Offenbar ist der ganze Prozess eine blosse Vermuthung. Jedes Callithamnion, jede Griffithsia (um die einfachsten Beispiele zu wählen) zeigt aufs deutlichste, dass das Wachsthum in die Länge nicht durch suprautriculäre Zellenbildung, sondern durch Theilung der Endzelle von Statten geht.

Ueber das Wachsthum in die Dicke sagt der Verfasser : "Die Zellen wachsen aber auch in peripherischer Richtung und vermehren sich, d. h., nachdem sie einen bestimmten Durchmesser erreicht haben (bei Polysiphonia, Laurencia etc.) theilen sie sich der Länge nach durch intrautriculäre Zellenbildung. Einzelne Fasern trennen sich theilweise von der Membran, welche sie zusammensetzen; in den einen Fällen gehen sie von der einen Wand zu der andern hinüber, und wachsen zuletzt zu einer neuen Membran, welche die Zelle theilt, an; in den andern Fällen bildet sich ein leerer Raum in der aus lockern Fasern bestehenden Wandung, derselbe wird allmälig grösser und die einschliessenden Fasern erhärten zu einer Membran. " Auch das berulıt auf blosser Vermuthung und der Verfasser besitzt gewiss keine Beobachtung, welche die Theorie begründen könnte.

Die Combination der Zellenbildung in der Längsrichtung und der Zellenbildung in peripherischer Richtung giebt das gesammte Wachsthum der Pflanze. J. Agardh unterscheidet terminales, exoyenes oder peripherisch-terminalis

(') Vergyl. die Entwicklungsggeschichte von Delesseria Hypoglossum in Schleiden und Nágeli's Zeitschrift für wissenschaftl. Bot., Heft II. 
und endogenes oder terminal-centrales Wachsthum. So wie aber das endogene Wachsthum der Monocotyledonen auf unrichtigen Voraussetzungen beruhte, so verhält es sich mit dem endogenen Wachsthume der Florideen. Der Verfasser beschreibt bei den "vielröhrigen, gegliederten Florideen" grosse, peripherische Zellen, in denen fortwährend Zellenbildung thätig sein soll; " die jungen Zellen," heisst es, "nehmen immer den äussersten Theil der ältern Zellen ein, und drängen so die vor ihnen entstandenen Zellen nach der Peripherie hin. " - Das kann, nach meinem Urtheile, der Verfasser unmöglich gesehen haben, weil es nicht existirt $\left({ }^{1}\right)$.

Die Florideen besitzen nach dem Verfasser doppelte Fructificationsorgane. Die ersten sind die Sphcerosporce, welche " aus einer durchsichtigen Sporenhülle und einem zuletzt in 4 Sporen zerfallenden, körnigen Inhalt bestehen. "Diese Theilung geschieht auf dreierlei Weise, entweder so, "dass die Seiten jedes der 4 Theile sphærische Dreiecke bilden; oder sie geschieht durch drei Querlinien, so dass die mittleren Theile scheibenförmig, die äussern conisch-halbkugelig sind; oder endlich findet erst Quertheilung und dann in jeder Iälfte Längstheilung statt. "Diese drei Theilungsarten werden die dreieckige (triangularis), die zonenartige (zonata) und dic kreuzförmige (cruciata) genannt. - Die Sporenbildung ist auf solche Weise von dem Verfasser sehr richtig in ihren Gestaltungsverhältnissen erkannt worden. Dagegen könnte ich ilmm nicht beistimmen, wenn er sagt, dass die Sporen « bloss durch Theilung des Inhaltes entstanden scien, dass ihnen eine Membran mangele, und dass sie einzig durch Adhäsionskraft der Theilchen zusammengehalten werden. " Besitzen doch die 4 Zellen, in welche sich die Mutterzelle theilt (nämlich dic 4 Specialmutterzellen) unter allen jungen Zellen der Florideen gerade die dicksten Wandungen, und an mehreren freien Sporen ist die Membran deutlich zu sehen, obgleich in andern Fällen dieselbe, wegen des gefärbten Exosporium nicht unterschieden werden kann.

Die zweite Art der Fructificationsorgane sind die Capsulce, welche "innerhalb) einer Fruchthülle eine grosse Menge von Sporen enthalten. ๖ Ausser dem Unter-

(') Ich werde diese und andere Behaupungen in einer zusammenhỉngenden Darstellung über das Wachsthum der Pflanzenorgane beweisev. 


\section{$-55$}

schiede in der Zahl giebt $J$. Agardh noch vorzüglich zwei Unterschiede zwischen Sphærosporen und Capseln an. Die Sporen der erstern entstehen « aus dem vierten Theile des Inhaltes einer Zelle, die Sporen der Capseln dagegen entstehen aus dem ganzen Inhalte einer veränderten Zelle. " Doch hat $J$. Agardh die Entwicklung der Sporen in den Capseln nicht verfolgt, und gleichfalls kennt er diejenige der Sporen in den Sphærosporen nicht hinlänglich. Ich glaube, dass die umgekehrte Behauptung : die Sporen der Sphærosporen entstehen aus dem ganzen Zelleninhalte, nämlich einer Specialmutterzelle $\left({ }^{1}\right)$, die Sporen der Capseln entstehen bloss aus einem Theile des Inhaltes ihrer Mutterzellen, richtiger wäre. Doch möchte ich keineswegs diesen Unterschied zwischen den beiden Fortpflanzungsarten aufstellen; er würde immer schief bleiben. Der Unterschied muss in dem Totalen des Zellenlebens gesucht werden. - Der zweite angeführte Unterschied ist der, dass "die Sphrosporen in der äussern oder Rindenschicht der Frons entstehen und dass sie von unten nach oben sich entwickeln; dass dagegen die Sporen der Capseln in der innern Schicht der Frons gebildet werden, und dass ihre Entwicklung von oben nach unten fortschreite. "Für die Mehrzahl der Fälle lässt sich nun allerdings die Regel aufstellen, dass die Sporen der Sphærosporen näher der Peripherie, die Sporen der Capseln näher dem Centrum gebildet werden, obgleich sie nicht von allgemeiner Gültigkeit ist, indem z. B. in Polÿ̈les die Sache sich gerade umgekehrt verhält $\left({ }^{2}\right)$. Ferner werden einige Gattungen (Callithamnion und die verwandten) von diesem Unterschicde gar nicht berührt. - Wie aber der Verfasser dazu kommt, zwischen Sphærosporen und Capseln darin einen Unterschied zu finden, dass die erstern in aufsteigender, die Sporen der letztern in absteigender Ordnung sich entwickeln, ist mir nicht klar geworden. Wenn Splucerosporen und Capseln mit einander verglichen werden, so ist gewiss keine Verschiedenheit vorhanden; die einen wie die andcru entwickeln sich gewöhnlich von unten nach oben, zuweilen an dem einzelnen Gliede von oben nach unten (z. B. bei Callithamnion). Werden dagegen die Sporen mit einander verglichen, so ist wieder kein Unterschied vorhanden, in-

(') Vergyl. Schleiden und Nügeli's Zeitschrift fïr wissenschaftl. Bot., Heft I, pag. $\$ 3$.

(") Vergl. oben pag. 15. 
dem die Sporen der gleichen Shærospore sich immer, und die Sporen der gleichen Capsel sich häufig gleichzeitig entwickeln. Unerlaubt ist es aber die Sphcerosporen (also Aggregate von Sporen) und die Sporen der Capseln mit einander zu vergleichen, wie es von dem Verfasser geschehen zu sein scheint, obgleich auch diese Vergleichung kein Resultat liefern würde.

Dic Flonideas des mittelländischen und adriatischen Meeres werden in folgende 6 Zünfte eingetheilt: 1) Ceramiece, 2) Cryptonemece, 3) Chondriece, 4) Rhodomelea, 5) Sphcerococcoidece, 6) Delesseriec.

Die erste Zunft Ceramieae enthält folgende Gattungen : Callithamnion Lyngb., Griffithsia Ag., Wrangelia Ag., Spyridia Harv., Ceramium Ag., ausserdem die exotischen Bindera J. Ag., Ptilota Ag. und Microcladia Grev. Die Ceramiece werden characterisirt: " Laub röhrig gegliedert, sehr selten zellig. Frucht doppelt: 1) Favellen (favellæ), welche entweder nackt an den Aesten sitzen, oder von wenigen Aestchen oder einem fast regelmässigen Involucrum umhüllt sind, und welche innerhalb einer durchsichtigen, halb schleimartigen, zuletzt unregelmässig zerfallenden Sporenbülle locker beisammen liegende Sporen enthalten. 2) Sphcerosporen, welche aus einem Aestchen oder einer Zelle gebildet, durchaus äusserlich (oder sehr selten etwas eingeschlossen), und innerhalb einer durchsichtigen Sporenhülle dreieckig in 4 Sporen getheilt sind. D

Die Ceramiece bilden allerdings eine sehr natürliche Gruppe; es scheint mir aber unrichtig, wenn der Verfasser sie allgemein von den übrigen Florideen durch Favellen unterscheidet, indem Wrangelia wenigstens keine Favellen besitzt.

Die zweite Zunft Cryptonemese wird folgendermassen diagnostizirt: a Laub zellig.... Frucht doppelt : 1) Favellidien (favellidia), welche in der innern Schicht des Laubes liegen, oder am Grunde der Fäden der äussern Schicht eingesenkt, sehr selten innerhalb einer besondern Fruchthülle entstanden sind, und welche innerhalb einer häutigen, oft sehr zähen und sehr dicht umschliessenden, durchsichtigen Sporenhülle äusserst zahlreiche kleine Sporen, die in einen Knäuel zusammengeballt sind, enthalten; 2) Sphcorosporen, welche kugelig oder länglich, durch Entwicklung der peripherischen Zellen entstanden, und durch dreieckige, zonenartige oder kreuzförmige Theilung in 4 Sporen getheilt sind. $\_-J$. Agardh 
unterscheidet zwischen Favellen und Facellidien : in jenen sind die Sporen grösser und liegen locker, in diesen sind sie kleiner und liegen dicht beisammen. Im Allgemeinen mag sich die Sache als Regel so verhalten; aber diese Regel ist nicht allgemeines und absolutes Gesetz, und kann bei einigen Gattungen gewiss nicht als Unterscheidungsmerkmal benutzt werden.

Die Cryptonemea enthalten sehr verschiedene Gattungen; sie sind desswegen in Subtribus eingetheilt, die aber aus Mangel an hinreichender Erkenntniss der Fructificationsunterschiede, vorzüglich nach habituellen Merkmalen charakterisirt werden.

Die erste Subtribus Gloiocladece unterscheidet sich von allen andern dadurch, dass a die peripherischen rosenkranzförmigen Fäden von einander getrennt sind oder durch Schleim locker zusammenhängen. ๖ Hieher gehören die Gattungen Crouania J. Ag., Dudresnaya Crouan., Naccaria Endl., Gloiocladia J. Ag., Nemalion Duby, J. Ag.; ferner die exotischen : Heterocladia Decaisne, Gloiopeltis J. Ag., Gloiosiphonia Berk.

Die zweite Subtribus Nemastomece hat ein " häutig-fleischiges Laub, dessen peripherische rosenkranzförmige Fäden in eine feste Schicht vereinigt sind. Die Favellidien liegen in der peripherischen Schicht." Hieher werden gerechnet: Catenella Grev., Nemastoma J. Ag. und die exotische Gattung Endocladia J. Ag.

Die dritte Subtribus Spongiocarpece zeichnet sich dadurch aus, dass die Favellidien in besondern Fruchtwarzen sitzen, welche aus lockern rosenkranzförmigen Fäden bestehen. Dazu gehören Peyssonnellia Decaisne, Phyllophora Grev., Chondrus Grev. und die exotische Gattung Polÿ̈des Ag.

Die vierte Subtribus Gasterocarpece hat ein "gallertartig-häutiges Laub, dessen peripherische Zellen in eine dichte Schicht vereinigt sind, die Favellidien liegen innerhalb der peripherischen Schicht. "Hieher werden gezählt Halymenia Ag., Kallymenia J. Ag., und die exotische Gattung Dumontia Grev.

Die fünfte Subtribus Coccocarpece besitzt ein häutig-hornartiges Laub, und zeichnet sich durch die " halbvorstehenden Favellidien aus, welche innerhalb der einigermassen zu einer Fruchthülle umgewandelten äussern Schicht des Laubes liegen, und zuletzt durch einen fast regelmässigen Porus entleert werden. " Diese Subtribus enthält die Gattungen: Cryptonemia J. Ag., ? Gelidium Grev., 


\section{- 58}

Grateloupia Ag., Gigartina Lamour., Chrysymenia J. Ag., nebst der exotischen Gattung? Suhria J. Ag.

Der Verfasser unterscheidet die Zunft der Cryptonemece von den Ceramiece durch drei Merkmale. Die erstern haben ein "faserig-zelliges Laub, etwas eingesenkte Favellidien und eingeschlossene Sphærosporen. " Die zweiten haben ein " pöhrig-gegliedertes Laub, nackte Favellen und etwas aussenständige Sphærosporen. 》 Aber schon wie von J. Agardh die beiden Zünfte abgegrenzt wurden, besitzt keines dieser Merkmale eine constante Gültigkeit. Ceramium hat in einigen Arten ganz eingeschlossene (nicht aussenständige) Sphærosporen. Von IVrangelia, die zu den Ceramieen gehört, kann doch füglich nicht gesagt werden, dass sie nlackte Favellen besitze. Wir haben schon oben gesehen, dass kein constanter Unterschied zwischen Favellen und Favellidien sich finden lässt. Dudresnaya und Gloiosiphonia, welche zu den Cryptonemeen gezählt werden, besitzen einen von mehreren Arten der Ceramieen nicht verschiedenen Bau, indem bei jenen Gattungen ebenfalls ein früher übersehener, gegliederter Strang von Achsenzellen vorhanden ist. - Wenn aber, wie ohne Zweifel geschehen muss, einige Gattungen (vielleicht alle der Subtribus Gloiocladece) zu den Ceramieen gehören, dann verlieren vollends die Fructificationsmerkmale, wie sie ron dem Verfasser für Ceranieen und Cryptonemeen formulirt werden, allen Halt.

Die dritte Zunft Chondriese enthält folgende Gattungen : Chylocladia Grer. Laurencia Grev., Lictoria J. Ag., Bonnemaisonia Ag., dazu die exotischen : Champic Lamour., Calocladia Grev., Nammea J. Ag. Diese Zunft besitzt folgenden Character: a Laub zellig, ungegliedert oder gliederartig-zusammengezogen, aus kleinen Zellen gebildet. Frucht doppelt : 1) Keramidien (Keramidia) äusserlich am Laube sitzend, innerhalb einer zelligen Fruchthülle, welche an der Spitze regelmässigg geöffnet ist, birnförmige Sporen enthaltend, die mit einer verdünnten Spitze (apice) an cine centrale Placenta angeheftet sind, radienförmig daron ausstrahlen, und einzeln mit einer durchsichtigen Sporenhülle umgeben und getrennt von einander sind; 2) Sphcerosporen, welche in den Aestchen zerstreut liegen, aus den unter der Epidermis liegenden Zellen gebildet, und innerhalb einer durchsichtigen Sporenhülle in 4 Sporen dreieckig getheilt sind. " Die Keramidien unterscheiden sich von Facellen und Facellidien dadurch, dass die 
erstern « innerhalb einer zellig-häutigen, an der Spitze durch einen regelmässigen Porus geöffneten Fruchthülle birnförmige, an eine im Grunde befindliche Placenta angeheftete Sporen enthalten, o während bei den letztern beiden ein Haufen von Sporen in einer durchsichtigen (nicht zelligen) Fruchthülle liegt.

$\mathrm{Zu}$ der vierten Zunft Rhoponelese werden folgende Gattungen gezählt: Dasya Ag., Polysiphonia Grev., Rytiphloea J. Ag., Dictyomenia Grev. Alsidium Ag., Digenea Ag., Acantophora Lam.; ferner die exotischen Rhodomela Ag., Odonthalia Lyngb., Botryocarpa Grev., Amansia Lam., Polyzonia Suhr, Dictyurus Bory, Hemitrema Brown, Claudea Lamour. Die Diagnose für diese Zunft lautel: "Laub gegliedert oder felderig, sehr selten durch Zellentheilung den Anschein eines ungegliederten Laubes annehmend. Frucht doppelt: 1) Keramidien...... 2) Spharosporen, welche in oftmals veränderten und schotenförmigen Aestchen eingeschlossen, in eine einfache, zweifache oder vielfache Reihe gestellt (Stichidium), und innerhalb einer durchsichtigen Sporenhülle in 4 Sporen dreieckig getheilt sind. " - Die Rhodomelece, welche in den Keramidien vollkommen mit den Chondriea übereinstimmen, unterscheiden sich somit von denselben dadurch, dass bei jenen die Sphærosporen in Längsreihen, bei diesen zerstreut stehen. Der Verfasser giebt aber selbst zu, dass diese beiden Zünfte sehr nahe mit einander verwandt seien. Jedenfalls glaube ich nicht einmal, dass der angeführte Unterschied als künstliches Merkmal genüge, bloss um die Gattungen richtig zu sondern. Denn ich finde an Laurencia tenuissima zuweilen die Sphærosporen deutlicher in Reihen gestellt, als in einigen zu den Rhodomeleen gezählten Gattungen.

Die fünfte Zunft Spinerococcordene enthält die Gattungen Hypnea Lamour., Gracilaria Grev., Rhodomenia Grev., Sphcerococcus Ag., nebst der exotischen Heringia J. Ag. Die Diagnose ist folgende: "Laub zellig, ungegliedert, aus runden oder eckigen Zellen bestehend. Frucht doppelt : 1) Coccidien (coccidia) äusserlich am Laube stehend, innerhalb einer zelligen, zuletzt geöffneten Fruchthülle verkehrt-eiförmige Sporen erzeugend, welche in den Gliedern von rosenkranzförmigen, von einer centralen Placenta auslaufenden Fäden gebildet werden, und in einen Knäuel gehäuft sind. 2) Sphcerosporen, welche in Haufen ohne bestimmte Grenze über die Frons zerstreut, klein, kugelig oder länglich, innerhalb einer durchsichtigen Sporenhülle in 4 Sporen dreieckig oder kreuz- 
förmig (?) getheilt sind. D - Die Coccidien unterscheiden sich von Favellen und Favellidien durch die zellige (nicht durchsichtige und structurlose) Fruchthülle; von den Keramidien dadurch, dass die Fruchthülle durch Ausdehnung oder Zerreissung sich öffnet, dass die länglichen Sporen in den Gliedern von rosenkranzförmigen, an die Placenta gehefteten Fäden entstehen und dicht in einen Knäuel gehäuft sind; während bei den Keramidien die Fruchthülle sich an der Spitze mit einem regelmässigen Porus öffnet und die birnförmigen freien Sporen selbst an die Placenta geheftet sind. - Die angegebene Structur der Coccidien ist bei einigen Gattungen allerdings recht deutlich, so in Plocamium, in einigen Arten von Delesseria etc. In andern Gattungen kann ich es bloss als willkührliche Deutung ansehen, wenn die Capselfrucht Coccidium statt Keramidium oder statt Favellidium und Favella genannt wird. In Nitophyllum ocellatum z. B. scheint mir die Kapselfrucht vollständig in der Vitte zwischen Coccidium und Keramidium, wenn nicht näher der letztern zu stehen. Ferner sehe ich nicht recht ein, warum die Favellidien in Gigartina, Rhodomenia u. a. desshalb Coccidien sein sollen, weil sie in besondern Aest_ chen liegen, obschon ihnen gewiss keine placenta centralis und keine fila moniliformia zugeschrieben werden können.

Die sechste Zunft Delesseriese enthält die Gattungen Plocamium Grev., Nitophyllum Grev., Solieria J. Ag. und Delesseria Grev., ausserdem die exotischen : Thamnophora Ag. und Hymenea Grev. Sie wird so definirt: "Laub... Frucht doppelt : 1) Coccidien.... 2) Sphcerosporen, welche in Haufen von bestimmter Pegrenzung oder in besondern Sporenblättern liegen, von kugeliger oder länglicher Gestalt und innerhalb einer durchsichtigen Sporenhülle in 4 Sporen dreieckig oder zonenartig getheilt sind. " - Die Delesseriece, welche im Laub und in den Coccidien durchaus mit den Sphorococcoiden übereinstimmen, unterscheiden sich von denseiben. bloss dadurch, dass die Sphærosporen nicht zerstreut am Laube stehen. Dieses Merkmal lässt zwar diese Zunft von der vorhergehenden unterscheiden; ich möchte aber fast zweifeln, ob die blosse Stellung der Sphærosporen mehr als zur Unterscheidung ron Gattungen benutzt werden dürfe, und ob durch dieses Merkmal natürliche Gruppen von Gattungen herausgebracht werden können. 
Betrachten wir nun noch das J. Agardh'sche System im Allgemeinen, so ist vor allem aus an demselben zu rühmen, dass es principiel sich auf die Fortpflanzung gründet. Es war diess ein Fortschritt, der nur durch zahlreiche eigene Peobachtungen möglich war. J. Agardh ist aber bei seinen Beobachtungen zu zwei allgemeinen Resultaten gelangt, die für sein System massgebend und nach meiner Ansicht irrig sind. Das erste Resultat ist, dass die beiden Fortpflanzungsarten der Florideen gleichwerthig seien. Kann nun aber allgemein eine Pflanze sich auf zwei Arten, die gleich wesentlich sind, fortpllanzen? Dass die sogenannten Sporen der Sphaerosporen und der Capseln gleichmässig keimen, beweist bloss, dass beides Fortpflanzungszellen, nicht dass beide gleichwerthig seien und mit dem gleichen Namen ron Sporen bezeichnet werden müssen. Wo bei andern Pflanzen melıfache Arten der Fructification rorkommen, da werden dieselben nicht coordinirt, sondern nur die eine wird als die wesentliche betrachtet (so bei den Lebermoosen). Da J. Agardh den Sphærosporen und den Capseln einen gleichen Werth beilegte, so benutzte er für die Eintheilung der Florideen natürlich dasjenige Organ, welches die grösste und am leichtesten in die Augen tretende Mannigfaltigkeit darbot, die Capseln. Sein System beruht rorzüglich auf den verschiedenen Formen, unter denen die Capsel erscheint, nämlich als Facella, Facellidium, Keramidium und Coccidium. Damit ist aber, wie ich glaube, für die Florideen nicht der Grund zu einem natürlichen Systeme gelegt, weil die Sphxerosporen die wesentliche Fortpflanzungsart ausmachen.

Das zweite Resultat, auf das J. Agardh geführt wurde, ist, dass auch die Zoospermeen und die Fucoideen eine doppelte Fruchtbildung besitzen. Diese in der Allgemeinheit, wie sie ausgesprochen wurde, gewiss irrthümliche Annahme wurde offenbar von den Florideen durch Analogie auf die übrigen Algen ausgedehnt. Wenn aber die Florideen doppelte Früchte besitzen, so folgt daraus noch nicht, dass es auch bei den andern Algen der Fall sein müsse, so wenig als sich die Laubmoose nach dem Beispiele der Lebermoose richten. Damit will ich nicht sagen, dass die doppelte Fortpflanzung für die Zoospermeen und Fucoideen eine Unmöglichkeit sei. Sie ist bei den höhern Gattungen dieser beiden Familien gewiss so gut möglich als bei irgend einer Pflanze; aber sie ist keine Nothwendigkeit, und es darf nicht jedes zweifelhafte Factum als cine Bestätigung der Theorie 


\section{- 42}

in Anspruch genommen werden. Diese Theorie hat denn auch nach meinem Urtheile J. Agardh öfter in der Deutung der Fortpflanzungsorgane der Zoospermeen und Fucoideen Irrthümer begehen lassen, und dadurch zuweilen wenig natürliche Zusammenstellungen hervorgerufen .

Nicht bloss darin, dass die Fortpflanzung die oberste Norm für die Classification der Algen geworden ist, auch darin hat die Methode bei J. Agardh einen bedeutenden Fortschritt gemacht, dass die Begriffsbestimmungen viel genauer und schärfer geworden sind, als sie früherhin waren. Durchgängig wird ein Begriff nur durch das gleiche Wort bezeichnet, und ein Wort nur für den gleichen Begriff gebraucht. Doch treffen wir auch da einige Ausnahmen an. Die Fortpflanzungszellen der Florideen heissen Sporen, sie mögen in den Spharosporen oder in den Capseln entstanden sein, obgleich $J$. Agardh ein verschiedenes Verhältniss zum Zelleninhalte bei ihrer Entstehung annimnt. Warum werden denn die Fortpflanzungszellen der übrigen Algen in Sporidien und Sporen unterschieden? Ebenso ist es nicht zu billigen, dass die Sporen der Zoospermeen mit ihrer eigenen und der Membran der Mutterzelle den besondern Namen Coniocysten bekommen haben. - Die Begriffe von Sporenhülle (Perisporium) und Fruchthülle (Pericarpium) sind nicht genau genug bestimmt, was um so nothwendiger wäre, als zuweilen beide in der gleichen Frucht angenommen werden (so bei den Coccocarpeen). Zuerst heisst es allgemein, dass die Capseln der Florideen innerhalb einer Fruchthülle die Sporen enthielten. Diese Frachthülle wird für die Favellen und Favellidien als durchsichtig bezeichnet. Dann heisst diese durchsichtige Fruchthülle aber in der 'Zunft der Ceramieen und Cryptonemeen allgemein Sporenhïlle. In der letzten Subtribus der Cryptonemeen tritt auf einmal neben der Sporenhülle, welche viele Sporen umschliesst, die Fruchthülle auf. Bei den Keramidien und Coccidien ist jede einzelne Spore von einer Sporenhülle, alle von einel Fruchthülle ungeben. Ausserdem wird der Ausdruck Sporenhülle allgemein für die Sphserosporen gebraucht. Es folgt daraus, dass Sporenhïlle und Fruchthïlle, auf die sich doch hauptsächlich das System gründet, schwankende legriffe sind. 


\section{SYSTEVI VON DECAISNE.}

In der Abhandlung von Decaisne $\left(^{1}\right)$ werden die Algen selbst nicht defunirt: sie werden aber so ziemlich auf gleiche Weise ungrenzt, wie es von J. Agardh geschehen ist. Die Diatonaceen und Desmidiaceen werden nicht ausgeschlossen, bleiben aber einstweilen weg.

Decaisne theilt die Algen in 4 Abtheilungen:

I. Zoosporear (= Nostochincie, Confervacece, Ulvacex): "Die Spore bildet sich auf Unkosten des grünen Inhaltes, der im Innern eines jeden der Glieder oder Zellen entsteht, welche die ganze Pflanze zusammensetzen; jedes dieser Organe kanu eine einzige oder mchrere Sporen enthalten. "

II. Synsponene (= Conjugata): “Die Spore bildet sich im Innern eines Gliedes durch die Zusammenhäufung des grünen Inhaltes, welcher aus der Vereinigung zweier getrenuter Fäden oder Zellen hervorgeht. »

III. Aplosponene (= Batrachospermex, Fucacere) : Die Spore ist äusserlich, unabhängig' von dem umgebenden Gewebe, und insgemein von Fäden begleitet, an deren Basis sie angeheftet ist."

IV. Choristosporeae (= Ceramiex, Rytiphlea) : "Die Spore ist in einer innerlichen oder äusserlichen Zelle eingeschlossen, und zur Zeit der Reife in 4 Fortpflanzungskörper (corps reproducteurs) von rother Farbe getheilt. "Später wird. was hier Spore heisst, von dem Verfasser Sphrerospore oder Tetraspore, - was hier corps reproducteur heisst, Spore genanut.

Diese Eintheilung ist in formeller Rücksicht genauer und bestimmter als irgend eine der frühern. Sie entspricht allen wissenschaftlichen Anforderungen, da sie auf die Entstehung und auf die Natur der Fortpflanzungszellen selbst gegründet ist. Es ist nun aber vorerst zu untersuchen, ob die Thatsachen sich unter diese

(1) Essais sur une classification des Algues et des Polypiers calcifères de Lamouroux: Annales d. Sc. nat. Sec. Sér. Tom. XVII. 
Form fügen, und ob sie eine eben so bestimmte Sonderung erlauben. Dic Choristosporece, welche den Florideen von J. Agardh und den Rhodospermeen von Harrey entsprechen, unterscheiden sich nach Decaisme von den übrigen 5 Abtheilungen durch das besondere Verhalten der Sporen, welche sich in $4 \mathrm{Körper}$ theilen. Da die Choristosporeen, wenn auch dieser Character theils unrichtig theils mangelhaft ist, eine von den ïbrigen Algen scharf geschiedene Gruppe bilden, so will ich, dem Verfasser folgend, zuerst das Verhältniss der drei übrigen Abtheilungen zu einander untersuchen.

Die Synsporece unterscheiden sich von den Zoosporece bloss dadurch, dass die Spore nicht aus dem Inhalte einer einzigen Zelle, sondern ans dem vereinigten Inhalte zweier durch Copulation verbundener Glieder (verschiedener Individuen) entsteht. Dieser Unterschied erweist sich aber sogleich als unbrauchbar, wenn man Fäden ron Spirogyra, oder Zygnema sieht, wo alle oder einzelne Zellen Sporen bilden, ohne dass sie sich mit einer andern Zelle verbunden hälten. Diese Thatsache beweist, dass die Copulation der Conjugaten durchaus keine so wesentliche Erscheinung ist, als Decaisne annahm, und dass sie nicht einmal für den Character eines Genus, geschweige für den einer Hauptabtheilung der Algen benutzt werden darf. Es wären somit ohne Anderes die Sy"nsporece mit der Abtheilung Zoosporece zu vereinigen.

Es bleiben zwei Abtheilungen Zoosporew und Aplosporece übrig. Bei den erstern entstehen die Sporen in irgend welehen Zellen der Pflanze. Bei den letztern sind die Sporen äusserlich angeheftet. Es müssen aber gegen diese Unterscheidung zwei Einwürfe gemacht werden. Der erste ist der, dass in vielen von den Verfasser zu den Aplosporeen gestellten Gallungen die sogenannten äusserlichen Sporen keine Sporen sind, sondern Mutlerzellen, in denen sich erst die Sporen in grösserer Zahl entwickeln. Es müssten somit entweder alle diesc Gattungen mit den Zoosporeen vereinigt, oder die Definition der Aplosporeen müsste erweitert werden. - Der zweite Einwurf ist der, dass nach der gegebenen Definition eine scharfe Unterscheidung der Gatlungen nicht möglich wird. Es gibt Arten, wo die sogenannten Sporen bald seillich sitzend, bald gestielt sind (Ectocarpus etc.) Das beweist, dass auch die Arten und Gattungen mit gestielten Sporen unter die Aplosporeen aufgenommen werden müssen. In diesem Falle 


\section{$-45$}

sind die Sporen das Endglied oder in dem Endgliede eines gegliederten Fadens. Da nun aber das Endglied gewiss ein Theil des Fadens ist, und die Abheilung der Zoosporeen solche Algen enthält, bei denen die Sporen in einer Zelle des Laubes entstehen $\left({ }^{1}\right)$, so würden diese Pflanzen eben so gut zu den Zoosporeen gehören. Es ist diess also ein zweiter Punkt, in welchem die Differenzialcharactere von Zoosporeen und Aplosporeen ungenügend sind.

Die Zoosporese werden von dem Verfasser in zwei Gruppen gebracht: Arrhiza (Wurzellose) mil den Familien Nostochinere, Rivulariere, Oscillatoriece, Palmellea, Ulsacere, Confersacese, Hydrodictyee. Chetophoroidere und Lemaneece; und Nematorrhize (mit fadenförmigen Wurzeln) mit den Familien Halymedece, Caulerper, Acetabulariece und Siphonew. Ob Auwesenheit und Abwesenheit von Wurzelorganen dazı dienen können, über natürliche Verwandtschaft zu entscheiden, und eine Norm für die Gruppirung von Gattungen oder Familien zu geben, möclıte ich doch bezweifeln. Allerdings mangelt das Vermögen, Wurzeln zu bilden, einigen Algenfamilien absolut, so den Noslochineen, Palmelleen etc. Andere besitzen dagegen das Vermögen, Wurzeln zu erzeugen, aber sie realisiren dasselbe bloss unter günstigen Verhältnissen, oft sehr selten, so die Confercaceen. Jedenfalls müssen, wenn man nach der Bewurzelung eintheilen will, die Ulvaceen, Conforsaceen, Chcetophoroideen und Lemaneeen, welche von Decaisne zu den Airhize gestellt werden, zu den Vematorhize wandern; indem alle diese Familien in grösserm oder geringerm Masse Wuřeln bilden, und zwar gleiche fadenförmige Wurzeln wie die Nematorrhizae.

Die erste Familie der Zoosporece sind die Nostochineas mit folgenden Gattungen : Aphanizomenon Morren, Anabcena Bory, Monormia Berk, Belonia Carm.. Sphcerozyga Külz., Spirularia Külz., Sclerothrix Kütz., Undina Fr., Nostor Vanch., Scythymenia Ag,, Stereococcus Kütz. Nematococcus Kütz.

(') In der Definition lıeisst es zwar, dass in jeder der Zellen, welche die ganze Pflanze zusammensetzen, die Sporen entstehen. Ein flïchtiger Blick auf die Gattungen, welche von Decaisne zu ren Zoosporeen gebracht werden, zeigt aber, dass alle Gattumgen wo die Sporen nur überhaupt in einer Zelle des Laubes sichı bilden, die nicht seitlich und aussenständig ist, anch wenn nur eine einzige Zelle odel nur wenige Zellen fructifiziren, hielıer gehören sollen. Ich verweise auf die Gattungen Nostoc, Spharozyga, Rivularia, Gloiotrichia, Zonotrichia, Diplotrichia, Bolbochecte, Lemanea. 
Die zweite Familie Rivulariese enthält die Galtungen Rivularia Roth, Gloiotrichia J. Ag., Diplotrichia J. Ag., Zonotrichia J. Ag. - Der Verfasser weiss nichts über die Fortpflanzung dieser beiden ersten Familien.

Die drilte Familie Oscinlatōinea umfasst die Galtungen Oscillatoria Vauch., Calothrix Ag., Lyngbya Ag., Scytonema Agg., Pelalonema Berk. und Microcoleus Desmaz. Der Verfasser glaubt bei dieser Familie, gestützt auf eine Beobachtung an Calothix, ein Lebendiggebähren annehmen zu dürfen. In kurzen Aesten sollen sich da neue Individuen gebildet haben, welche heraustraten und frei wurden. Es scheint mir aber, als ob dieses Faktum zu wenig in Einklang gebracht worden sei mit den Erscheinungen, welche die Oscillatorieen in Rücksicht auf Wachsthum und Fortpflanzung zeigen, um ohne weiteres die gegebene Erklärung zu gestatten.

Zn der vierten Familie Paluedrea werden gerechnet: Hamatococcus Ag., Cryptococcus Kütz., Palmella Lyngb. und T'etraspora Link.

Die fünfte Familie Ulvaceas enthält die Gattungen Bangia Lyngb., Stigonema Ag., Enteromorpha Link und Ulca L. Die Zellen theilen sich in 4 Partieen, ron denen jede später zur Spore wird.

In der sechsten Familie Confervaceas stehen die Gattungen Conferca L., Sphreroplea Ag., Microdictyon Decaisne. In einer Zelle bilden sich eine oder mehrere Sporen.

Die siebente Familie Hyorodictyeat besteht aus der einzigen Gattung Iydrodictyon Roth.

Die achte Familie Cinetrophonomene enthält die Gattungen Bolbochete Ag., Diraparnaldia Bory, Chetophora Ag., Anhallia Schwb. und Iydrurus Ag. Der grüne Inhalt der Zellen vereinigt sich in mehrere kleine Kugeln, welche heraustreten und die Sporen sind (so in Draparnaldia). Bei Bolbochete bilden sich die Sporen bloss in den Gliedern, auf denen die Borsten stehen, und zwar eine cinzige Spore in einem Glied. Der Inhalt ron einem oder von zwei untern Gliedern soll in jene Mutterzelle übergehen, und demnach die Spore auf ähnliche Weise entstehen, wie in den Conjugaten.

Die neunte Familie Lemaneese enthält die einzige Gattung Lemaner.

Die zehnte Familie Hatymedene enthält die beiden Gattungen Ilalymeda La- 


\section{$-47$}

monr. und Udotea Lamour. Dieselben gehören aber, wenigstens die letztere, ihrer Fruchtbildung nach zu den Aplosporeen.

Die eilfte Familie Caulerpea enthält die zwei Gattungen Caulerpa Lamour. und Tricladia Decaisne.

Die zwölfte Familie Acetabularitea besteht aus den Gattungen Polypleyia Lamour. und Acetabularia Lamour.

Die dreizehute Familie Siphonew umfasst die Gattungen Bryopsis Lamonr., Penicillus Lamark., Valonia Ag., Dictyospheria Decaisne und Amadyomene Lanour. Auch einige von diesen Gattungen gehören zu den Aplosporeen (wie z. B. Bryopsis). Die andern dürfen wegen der Verschiedenheit ihres Baues nicht eine einzige Familie bilden.

Die zweite Abtheilung Synsporeas wird nicht weiter in Familien getheilt. Sie umfasst die Gattungen Mongeotia Ag. Tyndaridea Bory, Zyynema Ag. und Closterium Nitzsch.

Die dritte Abtheilnug Aplosporeae wird in zwei Gruppen gesondert : 1) EcoRTicatae mit den Familien Vancheriece, Ectocarpere, Spongodiece, Aclinocladere, Batrachospermere und Chordariece, 2) Cortscatas mit den Familien Sphacelariere, Sporochnoider, Dichotee, Laminariece und Fucacere. Ich sehe aber nicht ein, warum Batrachospermum, Liagora, Chordaria, Chorda, Leathesin u. a. bei der Gruppe der Unberindeten stehen, während Myriotrichia, Sporochenus, Stilophora u. a. zu der Gruppe der Berindeten gestellt werden. Abgesehen aber hievon, glaube ich, dass es überhaupt unmöglich sei, ganze Gruppen von Algen nach der Berindung zu characterisiren. Nicht bloss ist die Rinde bei jeder einzelnen Pflanze. wo sie rorhanden ist. gewöhnlich nicht absolut geschieden von dem innern Gewebe: sie geht meist mehr oder weniger allmälig in dasselbe über. Eben so wenig kann man sagen, dass in der Entwicklungsreihe des ganzen Pflanzenreiches die Rinde oder die Epidermis bis auf eine gewisse Stufe absolut mangele, - und dann plötzlich auftrete und nothwendig vorhanden sei. Die eigentliche Rindenbildung besteht in einer Sonderung des Gewebes in horizontaler Richtung, welche allmälig auftritl. so dass es nicht bloss Algen gibt, bei denen man zweilelhaft ist, ob man schon eine besondere Rinde annehmen könne oder nicht (so z. B. bei Stiloshor a); sondern auch nahverwandte Gatlungen. oder Arten der gleichen Gattung, von 


\section{$-48$}

denen die eine keine Spur einer Rinde besitzt, während die andere deutlich berindet ist (so z. B. Sphacelaria cirrhosa und filicina einerseits, und Sph. scoparia anderseits.

Die erste Familie Vaucherie besteht aus der einzigen Gattung Vaucheria DC.

Die zweite Familie Ectocarpfas besteht aus der einzigen Gattung Ectocarpus L.gh. Sie wird mit Unrecht zu den Aplosporeen gestellt, da sie keine seitlichen Sporen, sondern Capseln, weiche viele Sporen enthalten, besitzt.

Die dritte Familie Spoxgonese enthält die beiden Gattungen Spongodium Lamour. und Codium Slackh. Die Sporen bilden sich nach dem Verfasser wie bei V'ancheria. indem ein kurzer Ast durch eine Scheidewand als besondere Zelle sich abtrennt.

Die vierte Familie Actinocladeas enthält die Gallungen Dasycladus Ag., Neomeris Lamour., und Cymopolia Lamour.

Die fünfte Familie Batracospermeae umfasst die Gattungen Trentepohlia Ag., Batrachospermum Roth, Liagora Lamour., Dichotomaria Lamark., Thorea Bory. und Myriocladia Ag. "Die Fructification unterscheidet sich dadurch von derjenigen der übrigen Familien der Aplosporeen, dass sie Knäuel oder Bouquets bildet, welche aus Sporen und aus sehr kurzen Fäden, auf deren Basis die Sporen entstehen, zusammengesetzl sind. "

In der sechisten Familie Chordariene sind folgende Gattungen vereinigt: $\boldsymbol{M y}$ rionema Grev., Chordaria Ag., Chorda Stackh., Mesogloia Ag., Liebmannia J. Ag., Nemalion Duby und Lealhesia Gray. - Die meisten dieser Gattungen gehören aber sicher nicht zu den Aplosporeen, weil sie nicht seitliche Sporen sondern seitliche Sporencapseln besitzen.

Die siebente Familie Sphacelariea enthält die Galtungen Sphacelaria Lyngb., Myriotrichia Harv. und Cladostephus Ag. Die Sporen sollen sich von den übrigen Familien dadurch unterscheiden, dass sie an der Basis oder in der Achsel der Aeste in Trauben beisammmenstehen. Ich habe bis jetzt die Fortpflanzung von Sphacelaria und Cladostephus nicht gesehen; aber die Fructification ron Myriotrichia zeigt nicht die geringste Aehnlichkeit mit dem eben angeführten Character von Decaisne; und überdem gehört wenigstens diese Gattung zu den Zoospermeen.

Die achte Familie Sporochrondene wird von der eimzigen Gattung Sporochnus 
Ag. gebildet und zwar bloss von denjenigen Arten, deren Fructification in einer Art Pompon besteht, gebildet von keulenförmigen Fäden, an deren Grunde die Sporen sitzen. $D$

Die neunte Familie Drctrotese enthält die Gatlungen Padina Adans., Hildenbrandtia Nard., Zonaria Ag., Iydroclathrus Bory, Asperococcus Lamour., Punctaria Grev., Striaria Grev., Stilophora J. A., Cutleria Grev., Dictyosiphon Grev. und Halyseris Tozz. Die Sporen stehen an der Aussenfläche des Laubes. Cutleria, welche sich in Bezug auf die Reproduction anders verhält, wird von dem Verfasser mit Unrecht hieher statt unter die Zoosporeen gestellt.

Die zehnte Familie Laminarieas umfasst dic Gattungen Laminaria Lamour., Ilaligenia Decaisne, Agarum Bory, Capea Montagne, Alaria Grev., Ecklonia Rud., Lessonia Bory, Macrocystis Ag. Die Fruclification bildet Fruchtlager. welche mehr oder weniger weit über die Oberfläche des Laubes verbreitet sind. Sie besteht aus Fäden, die aus den äussersten Zellen entstehen und an ihrer Basis eine eiförmige Spore tragen.

In der eilften Familie Fucacese stehen die Gattungen Fucus L., Myriadenia Decaisne, Himanthalia Lyngb., Durvillea Bory, Splachnidium Grev., Hormosira Endl., ferner die Sargassum-ähnlichen Gattungen Coccophora Grev. Halidrys Lyngb., Blossevillea Decaisne, Cystoseira Ag., Sargassum Rumph, Turbinaria Bory, Phyllospora Ag., Marginaria A. Rich., Seirococcus Grev., Scytothalia Grev. Die Fructification sitzt in Höhlungen, welche durch eine Oeffnung nach aussen communiziren, und Conceptacula genannt werden. Die Sporen sind theils an der Wandung des Conceptaculum, theils an der Basis der Fäden, welche sie begleiten, befestigt.

Die Choristosporeas zeichnen sich vor den übrigen drei Abtheilungen der Algen dadurch aus, dass, wie der Verfasser zuerst sagt, "eine Spore sich in 4 Fortpflanzungskörper theilt » oder, wie er später sagrt, dass " der Inhalt einer Mutterzelle sich in 4 Sporen theilt. $n$ Diess ist die Fortpflanzung durch Sphrerosporen, wie sie ron J. Agardh genannt wurde. Ausser diescr "normalen Fruchtbildung " findet sich noch eine "abnormale "; es ist diess die, welche früher mit dem Namen Capselfrucht bezeichnet wurie. "Diese letztere ist nach den Verfasser nicht anders als ans metamorphosirten Spharosporen entstanden. Die 
Favellen sollen veränderte Spharosporen; dic Coccidien und Keramidien sollen veränderte Aeste oder Lappen des Laubes sein, in denen sich die Spharosporen abnormal entwickeln. Ausserdem vergleicht der Verfasser die Coccidien den Keimbehältern von Marchantia. So sehr diese letzte Ansicht mir die richtige scheint, so wenig könnte ich im Uebrigen die Theorie von Decaisne billigen. Die in den Capseln enthaltenen Sporen können aus zwei Gründen nicht aus veränderten Sphaerosporen entstanden sein, 1) weil beide aus verschiedenen Zellen entstehen, 2) weil beide sich nach verschiedenen Zellenbildungsgesetzen entwickeln. Nach des Verfassers Ansicht unterscheiden sich die Choristosporeen von den übrigen Algen bloss durch das besondere Verhalten der normalen Fruchtbildung der Sphærosporen, welche darin besteht, dass in einer Mutterzelle 4 Sporen entwickelt werden. Er scheint aber zu vergessen, dass er die Fortpflanzung der Ulvaceen, welche zu den Zoosporeen gehören, auf ähnliche Weise beschreibt, so dass in der That zwischen Zoosporeen und Choristosporeen kein Unterschied übrig bleibt.

Die Choristosporeas werden eingetheilt in dic Familien Ceramiece, Rytiphlece, Polyphacece. Thamnophorea, Heterocladiece, Corallinece, Anomalophyllece, Cryplonemea, Furcellariea, Chondriece, Spharococcoidece und Gasterocarpece.

Die erste Familic Cerameas enthält die Gattungen Callithamnion Lyngb., Dasya Ag., Wrangelia Ag., Griffthsia Ag., Ballia Harv., Ceramium Ag., Spyridia Harv., und Digenea Ag.; die beiden letzten Gattungen sollen eine besondere Section bilden.

Dic zweite Familie Rrtupulene enthält die Gattungen Bindera Ag., Polysiphonia Grer., Rhodomela Ag., Odonthalia Lyngb., Dictyomenia Lamour., Spirhimenia Decaisne, Rytiphloea Ag., Amansia Lamour., ferner eine Seclion mit den Gatlungen Leveillea Decaisne und Polyzonia Suhr, eine Section bestehend aus der Gatlung Acanthophora Lamour. und eine Section bestehend aus der Galtung Dictyurus Bory.

Die dritte Familie Pournacens enthält die Gattungen Polyphacum Ag. und Scaberia Grev. Sie gehören nach J. Agardh zu den Fucoideen.

Die vierte Familie Tunninophoneas umfasst die Gallungen Plilala Ag., Plocamium Lamour., Alsidium J. Ag. und Tannophora Ag.

Die fünfte Familie Heterocianies besteht aus der einzigen Heterocladia Decaisne. 
Die sechste Familie Conaldinene enthält dic Galtungen Melobesia Lamour., Mastophora Decaisne, Jania Lamour., Amphiroa Lamour., Corallina Tourn. Arthrocardia Decaisne. "Die Fructification bestelıt in Keramidien. in deren Grunde die Sphærosporen angeheftet sind. ฉ

Die siebente Familie Anomalophyldese wird durch die einzige Gattung Clandea Lamour. gebildet.

Die achte Familie Cryptonfmese enthält die Gattungen: Crouania J. Ag., Dudresnaya Bonnem., Gloiocladia J. Ag., Naccaria Endl. und Gloiosiphonia Carm.

Zur neunten Familie Funcrldariese gehören die beiden Galtungen Furcellaric Lamour. und Polÿides Ag. Der Verfasser bestreitet das Vorkomnien von birnförmigen Samen bei Furcellaria, wie sie Greville beschrieben und gezeichnet, aus dem Grunde, weil er sie nicht gesehen hat. Doch beweist das, gegenüber einer so deutlichen Abbildung, bloss, dass Decaisne keine Exemplare mit dieser Art der Fructification besass. Ich verweise auf die oben $\left({ }^{1}\right)$ gemachte Bemerkung, und füge hier bloss bei, dass durch eine Entdeckung ron Dectisne die beiden Gattungen Furcellaria und Polyüdes nun alle wünschbaren Eigenschaften von ganz normal sich verhaltenden Florideengattungen erlangt haben. Derselbe hat nämlich an Furcellaria innerhalb der Rindenschicht kugeclige Haufen von rothen Körnern (Sporen) gefunden. Ich würde demnach die beiden Gattungen folgendermassen characterisiren: $\boldsymbol{P}_{0}$ lÿ̈des, Sphærosporen innerhalb der Rindenschicht, kreutzförmig getheilt; Favellidien in äussern Warzen. Furcellaria, Sphærosporen innerhalb der Rindenschicht, zonenartig getheilt; Favellidien innerhalb der Rindenschicht.

Die zehnte Familie Chondriese umfassl die Gattungen Champia Lamour., Corallopsis Grev., Chondria Ag., Chrysymenia J. Ag., Lomentaria Lyngb., Catenella Grev., Dumonlia Lamour., Gracilaria Grev., Microcladia Grev., Solieria J. Ag., Phyllophora Grev., Botryocarpa Grev., Asparagopsis Montagne und Bonnemaisonia Ag.; die letzten heiden Gattungen bilden eine besondere Section.

Die eilfte Familie Sprinrococcordene enthält die Gattungen Gloiopellis J. Ag. , Gigartina Lamour., Gelidium Lamour., Mammea J. Ag., Chondrus Lamour., 


\section{-}

Gruteloupia Ag., Heringia J. Ag., Spharococcus Stackh., Suhria J. Ag., ferner eine besondere Section mil den beiden Gattungen IIypnea Lamour., und Calocladia Grev., und eine Section mit der Gattung Peyssonelia Decaisne.

Die zwölfte Familie Gasterocarpede besteht aus folgenden Gattungen: Delesseria Lamour., Martensia Her., Nitophyllum Grev., Rhodomenia Grev., Acropeltis Montagne, Halymenia Lamour., Nemastoma J. Ag., Hymenena Grev. und Iridaea Bory.

Ich habe die Eintheilung der Choristosporeen ohne weitere Bemerkung mitgretheilt, weil ich nicht glaube, dass sie Nachahmung finden möchte. Decaisne geht zwar von dem richtigen Grundsatze aus, dass die Sphærosporen die eigentliche und wesentliche Frucht seien; aber er verfällt durch zu weit getriebene Analogie in den gleichen Fehler wie $J$. Agardh, nur in umgekehrter Anwendung. J. Agardh nämlich ging von der doppelten Fortpflanzung der Florideen aus, und trug sie auf die übrigen Algen über. Decaisne geht von der einfachen Fruchtbildung der Algen und anderer Pflanzen aus, und zieht daraus nicht bloss den Schluss, dass bei den Choristosporeen die eine Fruchtart wesentlicher sei als die andere, sondern er geht weiter und behauptet, dass die andere gar nicht zu berücksichtigen sei. Er geht hier aber offenbar in der Consequenz zu weit, und wird dann durch die Anwendung des Grundsatzes auf Resultate geführt, welche der Natur weniger entsprechen, als diejenigen Resultate, welche von J. Agardh durch das entgegengesetzte Verfahren erzielt wurden.

Ich stimme Decaisne bei, dass die Sphrerosporen die wesentliche und normale Fruchtbildung seien; ebenso dass, wenn einmal ihre Verhältnisse genau bekannt sind, dieselben durchaus hinreichen müssen, um eine Pflanze vollständig zu charakterisiren und sie von allen andern Choristosporeen zu unterscheiden. Diess ist aber, wie der Verfasser zugiebt, beim jetzigen Stande unserer Kenntnisse noch nicht möglich. Desshalb nimnt er seine Zuflucht zu Merkmalen, welche von den vegetativen Organen hergenommen sind. Es ist nun aber neben jener wesentlichen und normalen Fortpflanzung noch eine zweite Fruchtbildung vorhanden, die wenigstens eben so häufig gefunden wird, wenn sie auch nicht so wesentlich ist. Sie zeigt eine grosse Mannigfaltigkeit in Aeussern; sie steht offenbar in engem Verhältniss zu der vegetativen Entwicklung und kann gewisser- 


\section{- 95}

massen als der Ausdruck dieser letztern betrachtet werden. Waruma sollte man nicht, in Ermangelung von etwas Besserem, sich ihrer als Merkmal bedienen, da ihre Verschiedenheiten oft leichter zu erkennen und auszudrücken sind, als die vegetativen Eigenthümlichkeiten der Pflanze? Der beste Beweis für meine Behauptung ist die Anordnung der Choristosporeen von Decaisne selber, in welcher, um ein einziges Beispiel zu geben, die Gattungen Callithamnion (mit Ceramium), Ptilota, Dudresnay a und Microcladia in vier verschiedene und durch andere Familien getrennte Familien gebracht werden. Der Bau ist verschieden, die Structur der Favellen aber fordert eine Vereinigung; die Entwicklungsgeschichte zeigt nun, dass diese Gattungen in keinem wesentlichen Punkte verschieden sind, und dass also die Favellen die wahren regetativen Verhältnisse richtiger ausdrücken als der anatomische Bau selber.

Ich füge noch einige Bemerkungen über die Theorie von Decaisne, betreffend die Sporenbildung, bei. Derselbe berücksichtigt etwas mehr, als die frühern Algologen, die Zelle. Namentlich sucht er die Verhältnisse der Fortpflanzung auf Verhältnisse der Zelle zurückzuführen. Ich begreife aber nicht, warum er die Sporen von Vaucheria durch eine Concentration des Inhaltes entstehen lassen will wie bei den Conjugaten, (an einer andern Stelle jedoch wird gesagt, dass keine Concentration bei Vaucheria vorzukommen scheine); ich sehe in dieser Beziehung keinen Unterschied zwischen der Sporenbildung von Vaucheria und der übrigen wahren Aplosporeen. Gleichfalls sehe ich nicht ein, warum der Verfasser die Synsporeen als besondere Abtheilung von den übrigen Zoosporeen vorzïglich aus dem Grunde trennen kann, weil bei ihnen die Sporen durch Concentration des Inhaltes entstehen, während er bei den Zoosporeen gar nicht zeigt, dass die Sporen auf eine andere Weise entstehen. Denn wenn als Thatsache angeführt wird, dass der Inhalt Sporen bilde, so ist damit noch nicht bewiesen, dass diess nicht durch Concentration geschehe. Uebrigens sagt der Verfasser von der Fruchtbildung der Ulcaceen, welche zu den Zoosporeen gestellt werden, wörtlich, dass hier " das Phänomen der Theilung einer Zelle in 4 Abtheilungen, und dasjenige der Concentration des grünen Inhalies (jeder Abtheilung), um cine Spore zu bilden, zu den deutlichsten gehöre. "

Der Verfasser nimmt bei den Sporen der Aplosporeen eine doppelte Hülle an, 


\section{$-54$}

die äussere nennt er Perisporium, die innere Episporium. Das Episporium soll frei in dem Perisporium liegen und bloss mil der Basis an dasselbe befestigt sein. Die Spore soll sogar bei der Reife aus dem Perisporium heraustreten und dasselbe an der Pflanze zurücklassen. Dass die Wandung der Sporen wie die Wandung anderer 'Zellen zuweilen aus zwei oder sogar aus mehr Schichten besteht, ist sehr wahr. Aber diese Schichten haben nach meiner Ansicht keine andere Bedeutung als in den vegetativen Zellen, und dürfen auch keine besonderu Benennungen erhalten. Ich möchte gleichfalls sehr bezweifeln, ob die $\mathrm{Mem}$ branschichten in der Art trennbar von einander seien, dass die innere Schicht mit dem Inhalte die äussere verlassen könne. Wenigstens habe ich nie etwas dergleichen bemerkt. Dass man bei Untersuchungen häufig leere Membranen findet, hat seinen natürlichen Grund theils darin, dass der Inhalt wegen Verletzungen verschiedener Art die Zelle verlassen hat, theils darin, dass, wie ich oben bemerkte, viele der sogenannten Sporen Capseln sind, welche viele Sporen enthalten und dieselben bei der Reife enleeren. Dass bei Padina nach der Aussaat der Sporen membranartige Ueberreste zurückbleiben, hat seinen Grund in der Gallerte und in der membranartigen Epidermis, womit die Sporenhaufen früher bedeckt waren. Das Heraustreten der sich bewegenden Sporen von Vaucheria clasata ist ein vereinzeltes Factum, so wie ihre Bewegung eine Ausnahme unter den Aplosporeen bildet; schon bei den andern Arten von Vaucheria findet ein solches Heraustreten durchaus nicht mehr statt, sondern die Sporen mit il'r. ganzen Wandung fallen ab.

Der Verfasser sucht auch eine Darstellung des Wachsthums der verschiedenen Algentypen zu geben. Es ist diess aber ein Punkt, dem er offenbar keine ernstliche Untersuchung widmete. So Vorzügliches er in der Aufklärung der Fortpflanzungsverhältnisse leistete, so wenig hat er in Betreff der Vegetations-, namentlich der Wachsthumsverlälınisse das Rechte getrnffen.

\section{SYSTEM VON ENDLICIIER.}

Endlicher, die Arbeiten seiner Vorgänger, namentlich ron J. Agardh, Decaisne, Meneghini und Montagne sorgfältig bemutzend, gab eine systematische Auf- 
zählung aller bekannten Gattungen und Arten $\left({ }^{4}\right)$. Die Algen werden nicht definirt. Der Verfasser behält die in den Genera plantarum gegebene Definition : * Axenlose Pflanzen (thallophyta), ringsumsprossend und wurzellos; ohne Gegensatz von Stamm und Wurzel; mit Sporen, welche beim Keimen sich nach jeder Seite verlängern können; ohne Gefässe; ohne Geschlechtsorgane. " Diese Merkmale sollen die Algen mil den Flechten und Pilzen gemein haben. "Urpflanzen (protophyta), ohne Dammerde entsehend, überall Nahrungsstofle aufnehmend, unbegrenzt sich fortpflanzend. "Diese Eigenschaften sollen den Algen mit den Flechten gemein sein. "Wasserpflanzen von fädiger Structur. " Dieser Character soll die Algen von den Flechten unterscheiden.

Was den ersten Charakter betrifft, denjenigen, welchen dic Algen mit Flechten und Pilzen theilen sollen, so wäre er richtig, wenn er bloss für einige wenige der niedrigsten Algenfamilien ausgesprochen wäre, wie z. B. für die Gattungen Palmella, Nostoc, Oscillatoria. Für die grösste Zahl der Algenfamilien muss das Gegentheil gesagt werden. Eine bestimmte Achse mit oberm und unterm Ende besitzen alle Algen von den Rivularien an aufwärts. Das Wachsthum von den Conferven an ist das gleiche wie in den Laub- und Lebermoosen. Alle Familien von den Conferven und den Siphoneen an aufwärts besitzen Wurzelorgane und Lauborgane (frons), oder Wurzelorgane, Stammorgane und Blattorgane. Die keimende Spore der Florideen und vieler anderer Algen zeigt keinen Unterschied von den keimenden Sporen der Moose und Farren. Geschlechtsorgane können den Florideen nicht mit grösserm Rechte abgesprochen werden als den Moosen. Charen und vollends den Farren und Equisetaceen.

Der zweite Character, derjenige, welchen die Algen mit den Flechten gemein haben, sagt ron ihnen aus, dass sie ohne Humus entstehen. Die meisten Algen entstehen im Wasser, das Kohlensäure, Ammoniak und Salze gelöst enthält. Diese vier Hauptbedingungen finden sich aber auch im Humus. Es lässt sich daher gewiss kein begründeter Unterschied aufstellen zwischen humushaltigen und humuslosen Localitäten, in der Art, dass er zugleich einen Unterschied für ganze Pflanzenklassen begründen würde. Dass diess richtig sei, beweist zur Genüge das

(1) Mantissa bolanica altera sistens generum plantarum supplementum lertium. 1843. 


\section{$-36$}

Verhalten der übrigen Wasserpflanzen, z. B. von Lemna und Riccia. Aber wenn man auch das Wasser dem Humus gegenübersetzen wollte, so wäre der Ausspruch dennoch, wie ich glaube, nicht für alle Algen gültig. Denn es gibt Gattungen, welche sich bloss auf schlammigem Boden entwickeln, z. B. Süsswasseralgen, die auf feuchtem Schlamme wachsen, und Meeralgen (wie Caulerpa), welche in dem Boden festwurzeln. - Die Algen sollen ferner mil ihrer ganzen Oberfläche Nahrungsstoffe aufnehmen. Wir können zwar als gewiss annehmen, dass bei den Algen Aufnahme und Ausscheidung von Stoffen nicht in so beträchtlichem Masse geschieden sind wie bei den meisten höhern Gewächsen. Da aber bei diesen letztern alle Theile, wenn auch in ungleicher Menge, zugleich aufnehmen und ausscheiden, so kommt immer bloss ein relativer Unterschied heraus, der so lautet : die unterirdischen Theile nehmen vorzugsweise Nahrungsstoffe auf, die überirdischen Theile scheiden vorzugsweise Stofie aus. Diess gilt jedoch bloss für die in der Luft wachsenden Pflanzen, nicht für die iu Wasser lebenden. Nun ist aber gewiss unzweifelhaft, dass auch bei den neisien Algen, nämlich bei denen, welche terminales Wachsthum hesitzen, die Aufrahme und Abgabe der Stoffe ungleich vertheilt ist. Es ergiebt sich schon daraus, dass diese Pflanzen Wurzeln besitzen, und zwar sehr häufig Wurzeln, die keine Haftwurzeln sind. Wozu soll ilmen diess Organ dienen, wenn nicht zu einer vermehrten Stoffaufnahme? Ferner bestehen dic Laubachsén und Stammachsen der Algen von unten nach oben aus Zellen, welche in ihrer Ausbildung stetig anders erscheinen. An dem untern Theile der Achsen sind die Zeilen abgestorben, obne Lebensfunctionen in ihrem Inbalte. Dann kommen auf eine grössere Strecke Zellen. welche sich nicht weiter verändern, und welche bloss in dem gleichen Zustande bis zu ihrem Absierben verharren; in ihnen sind die Lebensprozesse auf ein Minimum reducirt. und gewiss auch die Aufnahme und Abgabe von Stoffen. Dann kommen gegen die Spitze hin Zellen, weiche in ihrer Entwicklung begriffen sind, welche sich beträchtlich ausdehnen und grosse Veränderungen in ihrem Inhalte erleiden; diese müssen als die Elemente betrachtet werden, welche vorzüglich Nahrungsstoffe aufnehmen; hier ist es auch, wo die Wurzeln sich bilden. Die Spitze selbst besteht aus meist kleinen Zellen, die meist mit farblosem Schleime gefüllt sind, und in denen Zellenbildung thätig ist; diese 


\section{-}

Partie der Achse nimmt nach meiner Ansicht wenig oder vielleicht fast keine Nahrungsstoffe auf; was namentlich auch dadurch bewiesen wird, dass in mehreren Gattungen die Spitze vertieft und von dem übrigen Gewebe der Achse überwachsen ist, wie in Fucus, Cystoseira, Laurencia etc. Das eben beschriebene Verhalten ist vorzüglich an kriechenden Algen zu sehen, und ich glaube nicht, dass eine kriechende Polysiphonia, oder ein kriechendes Gallithamnion, oder selbst die kriechende einzellige Caulerpa prolifera in Bezug auf die Aufnahme von Nahrungsstoffen sich wesentlich anders verhalte, als kriechende Phanerogamen, und vollends als phanerogame Wasserpflanzen. - Die Algen sollen endlich unbegrenzt fructifiziren. Allerdings verhalten sich viele Algen genau wie die Phanerogamen mit unbegrenzten Blüthenständen, aber nicht alle. Alle einzelligen zu den Palmelleen gehörigen Gattungen pflanzen sich nur cin einziges Mal und gewöhnlich nur durch zwei Zellen fort. Hydrodictyon, Hydrogastrum und viele andere Algen mit begrenztem Wachsthume erzeugen ebenfalls nur einmal neue Individuen. Bei vielen höhern Algen endlich muss man, wie bei den Phanerogamen, zwischen begrenzten und unbegrenzten Fruchtständen unterscheiden.

Der dritte Character, derjenige, durch den die Algen sich von den Flechten unterscheiden, ist der, dass sie im Wasser leben. Es kann aber dieses Merkmal nicht ernstlich gemeint sein, da, wenn auch die meisten Algen im Wasser wohnen, eine gute Zahl davon eine Ausnahme macht.

Endlicher umgrenzt die Algen so ziemlich wie es von J. Agardh und Decaisne geschehen ist. Die Wasserpilze, die Moosvorkeime, die zu den Flechten gehörende Lichina, und die Characeen bleiben mit Recht weg. Dagegen sind, gemäss der Behauptung Ehrenberg's, auch die Diatomaceen und Desmidiaceen weggelassen worden; was gewiss unrichtig ist. Wenn Palmelleen und Desmidiaceen, die in allen wesentlichen Eigenschaften so sehr übereinstimmen, nicht zusammengestellt werden, worin sind denn überhaupt natürliche Verwandtschaften zu suchen?

Der Verfasser theilt die Algen in 5 Ordnungen : Confervacese, Phycee und Floridece. Sie werden folgendermassen characterisirt :

I. Confervaceae: "Zellen einzeln oder zu mehrern, kugelig, elliptisch, cylindrisch oder röhrenförmig, bisweilen verschiedentlich verästelt, bald in einer 
gallertartigen Unterlage zerstreut oder ohne Ordnung vereinigt, oder regelmässig in eine Reihe auf einander gestellt und eine gegliederte Frons bildend; bald in mehrfacher Reihe neben einander gestellt, ein ausgebreitetes Lager darstellend, sehr selten netzförmig verbunden. Wachsthum durch merismatische Zellenbildung; Verästelung aus einer seitlichen Verlängerung der Zellen, welche durch eine Scheidewand sich abtrennt. Fortplanzung durch Sporidien (endogene Zellen oder durch eine gallertartige, zuletzt zu Zellen sich umbildende Substanz), welche innerhalb jeder Zelle, einzeln oder in bestimmter oder in unbestimmter Zahl entstehen, aus dem Inhalte einer oder mehrerer Zellen, bisweilen durch die Copulation verschiedener Individuen gebildet, und durch eine Oeffnung oder nach Auflösung der Mutterzelle ausgestreut werden. ')

II. Phyceae : “Frons einröhrig, aus einer einzigen Zelle bestehend, bisweilen continuirlich-verästelt, oder sehr häufig vielröhrig, aus sehr vielen Zellen bestehend, die von mannigfaltiger Gestalt, entweder übereinander oder in ein Gewebe neben einander gestellt sind, unberindet oder berindet, gegliedert oder ungegliedert, fadenförmig oder verschiedentlich gestaltet, nicht sclten in eine Art Strunk (Stamm) und Blattfläche geschieden. Wachsthum durch merismatische Zellenbildung; Verästelung durch seitliches Wachsthum oder durch unbestimmte Prolification. Fortpflanzung : Sporen (endogene Zellen), in äussern, oft blasenförmig angeschwollenen Zellen (Schläuchen), aus deren Inhalt einzeln entstehend, aus einem einfachen, mit einer eigenthümlichen Zellmembran (Episporium) bekleideten Kerne gebildet, und zuletzt durch eine Oeffnung der durchsichtigen Mutterzelle (Perisporium) entleert. Schläuche (primäre Mutterzellen) über die ganze Frons zerstreut, oder an bestimmten Stellen (sehr häufig an der Spitze der Aeste), die bisweilen sich zu einem besondern Receptaculum gestaltet haben, grelegen, nackt oder von Blättern (Aestchen) gestützt. D

Da die dritte Ordnung, Floridew, sich gleichmässig von den beiden ersten Ordnungen unterscheidet, so will ich zuerst das Verhältniss dieser beiden zu einander und ihre Eintheilung betrachten, und nachher zu der Definition der Florideen übergehen. - Der Verfasser folgt in der Bestimmung der Ordnungen ganz dem Vorgange von Decaisne, nur vereinigt er die $S_{y}$ nsporea mit den Zoosporece in die Ordung der Confervacece. Die Phycece entsprechen den Aplosporea. 
Die vegetativen Organe enthalten keinen Unterschied für die beiden Ordnungen; denn wenn auch die erste Ordnung mit einfacheren Pflanzen beginnt, und die zweite Ordnung mit complizirteren Pflanzen endigt, so giebt es doch eine gute Zahl von den höchsten Gattungen der ersten Ordnung und von den niedrigsten Gattungen der zweiten Ordnung, welche in vegetativer Entwicklung vollkommen auf der gleichen Stufe stehen.

Die Verschiedenheit von Confersaceen und Phyceen liegt demnach einzig in der Fortpflanzung. Der Verfasser folgt dem von Decaisne vorgeschlagenen Unterschiede, nur giebt er demselben eine bestimmtere Fassung. Indem ich auf das schon oben Gesagte verweise, will ich hier bloss einige Bemerkungen beifügen. Betrachten wir zuerst das Formelle, so reducirt sich der Unterschied darauf, dass die Sporenmutterzellen bei den Confervaceen nicht äusserlich, bei den Phyceen dagegen äusserlich sitzend oder gestielt sind. Bei der erstern Ordnung bildet sich in einer Mutterzelle Eine oder mehrere, bei der zweiten Ordnung immer nur Eine Fortpflanzungszelle. Auch nach dieser Formulirung der Begriffe scheint es mir unmöglich, Ectocarpus mit gestielten Utriculis und Bulbochcete, wo der Utriculus das unterste Glied eines Astes ist, als den Phyceen angehörig, und Rivularia dagegen als zu den Confervaceen gehörend zu erkennen; weil in allen drei Gattungen die Fortpflanzungszellen am Ende eines gegliederten Fadens stehen. Und warum sollen die Fortpflanzungszellen von Rivularia nicht ebensogut ein Utriculus mit einer Spore sein, als es von denjenigen der Phyceen angenommen wird? - Der Verfasser braucht bei den Confervaceen die Benennung Sporidien, bei den Phyceen die Benennung Sporen. Beides sind éndogene Zellen; von den Sporen heisst es aber, dass sie mit einer eigenen Zellmembran (Episporium bekleidet seien. Sind denn das die Sporidien nicht? Ich kann mir wirklich keinen Unterschied denken zwischen den Sporidien der Confervaceen und den Sporen der Phyceen, welcher diese Verschiedenheit der Benennung rechtfertigte. Wollte man darin einen Unterschied finden, dass bei den Phyceen die Sporenzelle der Wandung der Mutterzelle anliegt, bei den Confervaceen nicht, so wäre das einerseits in seiner Allgemeinheit nicht richtig, weil bei Nostoc, Rivularia u. a., welche zu den Confersaceen gehören, die Fortpflanzungszellen durchaus wie in den Phyceen gebildet sind. Anderseits müsste man dann con- 
sequent die Fortpflanzungszellen der Flechten Sporidien nennen und bei den Pilzen einen ganz unnatürlichen Unterschied zwischen Sporidien (Ascophora, Erysibe, Peziza) und Sporen (Saccharomyces, Uredo, Verticillium, Agaricus) machen. Ueberdem fällt es einem schwer, die grossen Fortpflanzungszellen von Spirogyra und den verwandten Gattungen als Sporidien, und die kleinen Fortpflanzungszellen von Liagora, Batrachospermum dagegen als Sporen zu bezeichnen.

Ueber das Materielle der gegebenen Begriffe will ich nur weniges wiederholen, nämlich dass ich im höchsten Grade zweifle, ob man an den Fortpflanzungsorganen der Phyceen zwischen Episporium und Perisporium unterscheiden dürfe. Ich sehe nichts als Eine Zellmembran, an der zuweilen zwei oder mehrere Schichten erkannt werden können; ebenso sehe ich, mit Ausnahme von Vaucheria clavata nie ein Heraustreten der Spore aus dem sogenannten Perisporium. - Ganz sicher aber ist es, dass eine Zahl von Gattungen der Phyceen nicht äusserliche einsporige Schläuche (oder Sporen) besitzt, sondern Mutterzellen, in denen viele Sporen liegen, die aber wegen ihrer Kleinheit und ihrer dichten Lagerung bisher übersehen wurden. Es gehört also jedenfalls eine Zahl von Gattungen, die bei den Phyceen stehen, zu den Confervaceen.

Der Verfasser theilt die Confervaceen in 6 Unterordnungen ein : Palmellex, Vostochinece, Oscillatoriece, Confersoidece, Siphonece und Ulsacees.

1) Palmeldeae: "Zellen fast kugelig oder elliptisch, frei und mehr oder weniger getrennt, oder durch eine schleimige Unterlage in ein Laub vereinigt. "

Diese Unterordnung bildet ein höchst natürliches Ganze, was ihre vegetativen Verhältnisse betrifft; weil jede Pllanze eine kleine rundliche Zelle, oder weil jede Zelle des Lagers für sich ein Pnlanzenindividuum ist. Der Verfasser, sowie seine Vorgänger, scheint zwar diese Meinung nicht zu theilen, da er die Zellen durch eine schleimige Unterlage zu einem Laube (frons) sich vereinigen lässt; eine Annahme, deren Unrichtigkeit sich schlagend in den Gattungen Palmella und Coccochloris zeigt, wo die Unterlage, also indirekte die Frons, " unbestimmt begrenzt" genannt wird. Nun kann aber wohl ein Aggregat von Individuen, ein Wald u. dergl. ohne bestimmte Begrenzung auftreten, aber gewiss nicht ein individueller Organismus. - Unter den aufgeführten Pflanzen sind einige, die offenbar nicht hieher gehören, nämlich Botrydina und einige Arten von Micraloa. 
2) Nostochinew: "Zellen fast kugelförmig oder elliptisch, in eine fadenförmige einfache oder verästelte Reihe verwachsen; mehrere Reihen durch eine gallertartige, verschiedentlich gestaltete Unterlage verbunden. » Von den 5 hier aufgeführten Gattungen scheint mir Anhaltia in die folgende Unterordnung und zwar zu den Rivulariece zu gehören. Diese zeichnen sich unter den Verwandten gerade dadurch aus, dass sie ein unteres dickeres und ein oberes fadenförmigverschmälertes Ende besitzen, während die Fäden der Nostochineen zwei gleiche Enden liaben.

5) Oscillatorieas: "Zellen röhrenförmig, nackt oder mit einer schleimigen oder gallertartigen Unterlage versehen, ungegliedert; durch den gliederförmig zusammengezogenen oder geringelten Inhalt scheinbar gegliedert. s Diese Definition ist unrichtig, da die Fäden nicht rührenförmige Zellen, sondern Zellenreihen sind. - Die Fäden sind, wie es auch mit denjenigen der vorhergehenden Unterordnung der Fall ist, jeder für sich ein Pflanzenindividuum. Es ist daher auch hier unpassend, wenn es bei den beiden Zünften, woraus diese Unterordnung besteht (Rivulariece und Oscillatorince), heisst, a die Fäden seien in ein Laub vereinigt oder verwoben. ")

4) Confervoineas : "Zellen gliederförmig, in ein Netz oder häufiger in cinfache oder verästelte, getrennte oder durch einen gemeinsamen Schleim verbundene Fäden zusammengestellt. "Diese Unterordnung unterscheidet sich in den vegetativen Organen von der vorhergehenden bloss durch den äussern Habitus; indem die grösseren Zellen der Confervoideen deutlicher, die kleinern Zellen der Oscillatorieen undeutlicher als Glieder erscheinen. Die Fortpflanzung allein konnte hier einen Unterschied begründen. Nun sind aber in dieser Unterordnung gerade fast alle möglichen Fortpflanzungsarten der Ordnung vereinigt, da $H_{y}$ drodictyon, Zygnema, Myxonema (zonatum) und Confervà sich auf vier verschiedene Arten vermehren. Die Zunft der Hydrodictyea ist übrigens auch in ihrem Bau so abweichend, dass sie gewiss schon desshalb als besondere Unterordnung anerkannt werden sollte. Im Uebrigen wären ohne Zweifel auch IIydrurus und Hydrocoryne auszuschliessen, und der erstere zu den Palmelleen zu stellen.

V. SiphoneaE : a Laub bald einröhrig, aus einer einzigen, meistens verschiedenartig verästelten Zelle, mit ungegliederten oder gegliederten, getrennten 


\section{$-62$}

oder verschiedenartig vereinigten Aesten bestehend; bald mehröhrig, aus mehrern röhrenfürmigen Zellen bestehend, welche neben einander gestellt, verästelt, verschiedenartig zusammengefügt oder durch Intercellularsubstanz verbunden sind. o Unter den zu dieser Unterordnung gestellten Gattungen sind einzellige und mehrzellige; zu jenen gehört vorzüglich Caulerpa, Udotea und IIalymeda (unrichtig werden bei letzterer die Aeste gegliedert genannt); zu diesen gehört vorzüglich Acetabularia und Anadyomene. Die erste und die zweite Reihe von Gattungen scheinen mir wenigstens eben so sehr verschieden als die einzelligen Palmelleen und die mehrzelligen Nostochineen, und sollten daher wohl auch zwei besondere Unterordnungen bilden.

6) Ulvaceae : "Laub flach oder hohl, aus nebeneinander gestellten Zellen bestehend, weiche je 4 Sporidien einschliessen. "Von den hieher gestellten Gattungen muss Tetraspora, die zu den Palmelleen gehört, ausgeschlossen werden. — Die ganze Unterordnung würde übrigens wohl besser nach den Oscillatoriece stehen, da Bangia und Stigonema, die bei den Ulvaceen aufgeführt werden, eine so grosse Verwandtschaft mit Lyngbya, welche zu den Oscillatoriece gehört, besitzen, dass es in Frage kommt, ob sie überhaupt nur in zwei verschiedene Unterordnungen gestellt werden dürfen. - Nach der Definition sollen in jeder Zelle 4 Sporidien sich bilden; es ist diese Zahl aber durchaus nicht constant; sie varirt nicht bloss bis auf 8 und 12, sondern in einzelnen Fällen bis auf viel höhere Zahlen.

Die zweite Ordnung Phyceas wird von dem Verfasser in 3 Unterordnungen eingetheilt: Vaucheriece, Halyseridere, und Fucacere.

1) VAucherieae : a Laub ein- oder mehrröhrig, unberindet. Schläuche einen Seitenast darstellend, oder durch das äusserste, selten das unterste Glied eines Astes gebildet. " Diese Unterordnung enthält sehr verschiedene Typen. Das natürliche System, wenn es Gruppen von ungefähr gleicher Gattungszahl aufstellen will, wird immer auf eine unausweichliche Unnatürlichkeit geführt. Es werden zulerst die grossen Gruppen ausgeschieden, von denen jede nach Einem Typus gebaut ist. Dann bleibt in der Regel eine Zahl von Gattungen übrig, welche in nichts mit einander übereinstimmen, als dass sie zu keiner der bereits abgeschiedenen grossen Gruppen gezählt werden künnen. So ist es mit der Unterordnung Vau- 
cheriece, welche alle Gattungen der Phyceen enthält, die nicht zu den Halyseridece und Fucacea gehören. Sie würde daher wohl auch am besten durch diesen rein negativen Character definirt. Durch das positive künstliche Merkmal, dass die Vaucherieen unberindet sind, möchte es wohl unmöglich sein zu erkennen, dass Liagora, Myrionema, Chordaria, Leathesia zu dieser Unterordnung gehören, während Sphacelaria, Myriotrichia, Stilophora davon ausgeschlossen sein sollen. - Bei den Vaucheriew stehen einige Gattungen, die zu den Confersaceen gehören, so IIydrogastrum, Valonia, Leibleinia, Chantransia und Ectocarpus, Bulbochcete, Myrionema, vielleicht auch noch andere. Unter den Uebrigbleibenden sind aber wenigstens zwei verschiedene Typen, die zu Unterordnungen erhoben werden sollten, die einzelligen (Vaucheria, Bryopsis, Codium) und die mehrzelligen Gattungen (Batrachospermum, Thorea).

2) HaLyserideae: "Laub mehröhrig, berindet, gegliedert oder ungegliedert. Schläuche über die Oberfläche des Laubes zerstreut, oder in Häufchen vereinigt. " Wenn einige Gattungen, die zu den Confervaceen gehören (wie Myriotrichia, Cutleria und wahrscheinlich noch andere), ausgeschlossen worden sind, so bleibt in dieser Unterordnung ein characteristischer Typus übrig, welcher sich dadurch auszeichnet, dass die Schläuche durch Auswachsen der Epidermiszellen entstehen.

5) Fucacese: "Laub mehrröhrig, oft blasentragend. Schläuche in hohleu Behältern (conceptacula), die durch eine Einfaltung des Laubes hervorgebracht werden und mit einem Porus sich öffnen, von Flocken gestützt ; Behälter zerstreut oder in Fruchtböden (receptacula) vereinigt. " Mit Ausnahme von der ganz abweichenden Lemanea bilden die Gattungen eine höchst natïrliche Gruppe. - Die Bedeutung des Ausdruckes "Fruchtboden" (receptaculum), der zwar von jeher bei den Fucaceen in diesen Sinne gebraucht wurde, widerspricht dem Begriffe, den er bei den Phanerogamen hat. Consequenter wäre es wenigstens, den Behälter Fruchtboden zu nennen, und dabei an die Analogic mit Ficus zu denken. Aber gewiss der passendste Ausdruck für den Behälter wäre Sorus, da die wahre Analogie bloss in der Fructification der Farren gefunden werden kann. Das jetzige Receptaculum wäre dann weiter nichts als ein "Fruchtast." Es ist übrigens unbegreiflich, wie Decaisne und mit ihm 
der Verfasser Fucus nodosus zu der Abtheilung ohne Receptaculum stellen können.

Die dritte Ordnung Florideae, welche den beiden ersten Ordnungen Conferraceæ und Phyceœ sich gegenüber stellt, wird folgendermassen characterisirt:

"Zellen verlängert-röhrenförmig oder verkürzt-abgerundet oder vieleckig; bald in eine einzige Reihe übereinandergestellt, oder in mehreren parallelen Reihen nebeneinandergestellt und gleichlang, ein gegliedertes Laub bildend; bald in mehreren Reihen nebeneinandergestellt und ungleichlang, ein zelliges Laub darstellend.

"Schichten an dem zelligen Laube wenigstens doppelt, eine innere, welche der Länge nach verläuft und die Achse bildet, und eine äussere, welche horizontal liegt und von der innern etwas bogenfürmig ausgeht. Die innere oder Lïngsschicht besteht aus runden oder röhrenförmigen, meist leeren und wasserhellen, seltener gefärbten oder mit Stärkekörnern erfüllten Zellen. Die viunden Zellen der innern Schicht sind meist unregelmässig gestellt, so dass die innersten kleinern von äussern grössern, oder die innersien grössern von äusseren allmälig kleinern umschlossen sind, oder dass alle von gleicher Grösse radienförmig eine grössere Zelle umstellen, oder eine centrale, durch besondern Inhalt ausgezeichnete Röhre umgeben. Die röhrenförmigen Zellen, wo sie in der innern Schicht vorkommen, sind unregelmässig verwoben oder netzförmig anastomosirend, bisweilen an der innern Wand des hohlen Laubes zerstreut, oder einen einzigen ungegliederten oder gegliederten Faden bildend. Die peripherische oder horizontale Schicht besteht aus Zellen, welche sehr häufig gefärbt und viel kleiner sind, bald eine einzige Reihe bilden, bald vielreihig sind, die innere Schicht gleichsam radienförmig umgeben, meist sehr dicht zusammengefügt sind oder seltener in freie Fäden auslaufen. Das Wachsthum geschieht, wie es scheint, bloss durch merismatische Zellenbildung.

"Die Vermehrung (?) findet durch Körner, welche in unbestimmter Zahl innerhalb eines zelligen oder gallertartigen Sporenbehälters (perisporangium) entstehen, oder durch Büchsen (thecx) statt; die Fortplanzung durch Sporen, welche innerhalb einer durchsichtigen Sporenhülle (der Mutterzelle) zu je 4 gebildet werden, oder durch Sphcerosporen. 
"Die Büchsen heissen nach Verschiedenheit von Gestalt und Bau Favellen oder Favellidien, Coccidien oder Keramidien. Die Favellen enthalten innerhalb eines gallertartig-durchsichtigen Sporenbehälters eine Masse locker gelagerter Körner, und sind bald nackt, bald ron dünnern Aestchen umgeben oder von einer besondern Hülle bedeckt, achselständig, oder seitlich an den Aestchen sitzend, oder auf einem besondern Aestchen endständig. Die Favellidien enthalten innerhalb eines gallertartig-durchsichtigen Sporenbehälters eine eng umschlossene Masse von dicht zusammengelagerten Körnern, und sind nackt oder ron Acstchen gestützt, oder häufiger unter der peripherischen Schicht des Laubes gelegen und zuletzt heraustretend. Die Coccidien enthalten innerhalb eines kugeligen, zelligen, zuletzt reissenden Sporenbehälters längliche Körner, welche dicht zusammengelagert und von einer grundständigen Placenta erzeugt worden sind. Die Keramidien enthalten in einem eiförmigen oder krugförmigen, oder seltener fast kugeligen, zellig-häutigen, zuletzt durch einen Porus geöffneten Sporenbehälter birnförmige, an die grundständige Placenta angeheftete Körner.

"Die Sphcerosporen finden sich auf getrennten Individuen und nie auf dem gleichen Individuum mit den Büchsen, sind sehr häufig eingesenkt, bald einzeln und nackt an den Aestchen stehend, bald zu mehreren an der innern Seite eines nicht selten veränderten Aestchens reihenweise geordnet (eine Schleimfrucht, gloiocarpus, bildend), oder in der Endzelle eines Aestchens entwickelt, oder in einem veränderten schotenförmigen Aestchen (Reihenfrucht, stichidium) liegend, oder unterhalb der peripherischen Zellschicht des Laubes entwickelt, zerstreut oder in Häufchen vereinigt oder in besondere Sporenblätter (sporophylla) versammelt. Die Sporen sind aus dem Inhalte der Mutterzellen entstanden. und bestehen aus einem Kerne, welcher zuerst einfach, dann aber quer (zonenartig) oder überzwerch (kreutzweise und dreieckig) sich in 4 theilt, ohne ein Episporium (eine besondere Zellmembran). »

Die vegetativen Organe unterscheiden die Florideen nicht von den Confervaceen und Phyceen. Der Unterschied ist in der Reproduction zu suchen. Der Verfasser lässt mit Recht bei den Florideen die Art sich sowohl durch Vermehrung als durch Fortpflanzung erhalten. Bei den Confercaceen und Phyceen dagegen ist bloss von Fortplanzung die Rede. In der Entstehung der Fortpflanzungs- oder 
Vermehrungszellen selbst wird kein Unterschied angegeben, der die Florideen gegenüber den beiden andern Ordnungen auszeichnen würde. Es bleibt also als Differentialcharacter bloss, dass für die Erhaltung der Art bei den Florideen auf doppelte, bei den Confervaceen und Phyceen bloss auf einfache Weise gesorgt ist. Dieser Differentialcharacter ist aber bloss dann richtig, wenn, was $J$. Agardh von der doppelten Fruchtbildung der Zoospermeen und Fucoideen angibt, als unrichtig angenommen wird. Wie der Verfasser zwischen Vermehrung und Fortpflanzung unterscheidet, so nennt er auch zum Unterschiede die Vermehrungszellen Körner, die Fortpflanzungszellen Sporen, und es ist wohl nur einem Irrthume zuzuschreiben, dass später in den Zünften Sphcerococcoidea und Delesseviece die Körner der Coccidien überall «Sporen ๖ genannt werden. Der Ausdruck Körner für ein Gebilde, das gewiss immer, und in einzelnen Fällen sehr deutlich eine Zelle ist, erscheint übrigens als sehr unpassend.

Die Fronideer werden von dem Verfasser, indem er ziemlich genau dem Vorgange von $J$. Agardh folgt, in 6 Zünfte eingetheilt: Ceramiea, Cryptonemea, Lomentariea, Rhodomelece, Sphcerococcoidece, Delesseriea.

1) Ceraniese: a Laub röhrig-gegliedert oder sehr selten zellig. Fruchtbildung doppelt : Favellen, die nackt an den Aesten sitzen, oder von wenigen Aestchen oder einem fast regelmässigen Involucrum umhüllt sind, und die innerhalb einer durchsichtigen, halb schleimartigen Sporenhülle, welche zuletzt unregelmässig zerfällt, zahlreiche, locker liegende Körner enthält. Sphærosporen, die aus einem Aestchen oder aus einer Zelle gebildet, durchaus äusserlich oder sehr selten etwas eingeschlossen sind, und innerhalb einer durchsichtigen Sporenhülle sternförmig in 4 Sporen getheilt sind. $\mathrm{x}$

2) Cryptonemeas : « Laub zellig, aus doppelter Schicht zusammengesetzt; innere Schicht aus mehr oder weniger verwobenen Fäden, oder sehr selten aus einer einzigen Röhre oder aus kleinern Zellen bestehend; äussere Schicht bald aus freien oder von Schleim eingelıüllten und in eine festere Schicht verwachsonen rosenkranzfürmigen Fäden, bald aus rundlichen, sehr häufig strahlenförmig angeordneten Zellen bestehend. Fruchtbildung: Favellidien, welche in der innern Schicht des Laubes oder am Grunde der Fäden der äussern Schicht eingesenkt, sehr selten innerhalb von besondern Behältern (conceptacula) entstanden sind, 
und die eine hăutige, durchsichtige, oft sehr dünne Sporenhülle besitzen, welche äusserst zahlreiche, kleine, in einen Knäuel zusammengeballte Körner sehr enge umgiebt. Sphærosporen kugelig oder länglich, aus den peripherischen Zellen entstanden, und dreieckig, zonenartig oder kreuzförmig in 4 Sporen getheilt. $D$

3) Lonentarieas: a Laub zellig, ungegeliedert oder gliederartig zusamméngezogen, aus kleinen Zellen gebildet. Fruchtbildung doppelt : Keramidien äusserlich, innerhalb einer zelligen Fruchthülle, welche an der Spitze regelmässig geöffnet ist, birnförmige Körner enthaltend, welche mit einem verdünnten Ende von einer centralen Placenta radienförmig ausstrahlen, mit einem durchsichtigen Balge (peridium) umgeben und getrennt von einander sind. Sphærosporen in den Aestchen zerstreut, aus den Zellen der unter der Peripherie liegenden Schicht gebildet; der Kern innerhalb der durchsichtigen Sporenhülle dreieckig getheilt. D

4) Rhononeleas: "Laub gegliedert oder felderig. Fruchtbildung doppelt: Keramidien... Sphærosporen in oftmals veränderten, schotenförmigen (stichidium) Aestchen eingeschlossen, ein-, zwei-, mehrreihig, der Kern innerhalb einer durchsichtigen Sporenhülle dreieckig viergetheilt. § Die Keramidien sind vollkommen gleich wie in der vorhergehenden Zunft.

5) Sphaenococcoineae: a Laub zellig, ungegliedert, aus runden oder eckigen Zellen bestehend. Fruchtbildung doppelt : Coccidien am Laube äusserlich, innerhalb einer zelligen, zuletzt geöffneten Fruchthülle verkehrt-eiförmige Körner ( a Sporen ") enthaltend, welche in den Gliedern von rosenkranzförmigen, von einer centralen Placenta auslaufenden Fäden gebildet werden. Sphærosporen in Haufen ohne bestimmte Grenzen, die über das Laub zerstreut sind, klein, kugelig oder länglich; Sporenhülle durchsichtig; Kern dreieckig oder kreuzförmig viergetheilt. $D$

6) Dejesseriede: a Laub.... Coccidien..... Sphærosporen in Haufen ron bestimmter Begrenzung oder in besondern Sporenblättern versammelt, kugelig oder länglich; Kern innerhalb einer durchsichtigen Sporenhülle dreieckig, kreuzförmig oder zonenartig viergetheilt. \ Laub und Coccidien wie in der vorhergehenden Zunft. 
Da die Eintheilung der Florideen ganz dem von $J$. Agardh vorgeschlagenen Systeme folgt, so verweise ich auf die früher zu diesem gemachten Bemerkungen. Ich werde die ganze Endlicher'sche Anordnung der Aigengattungen, welche das Gesammtresultat aller bis zum Jahre 1845 in diesem Gebiete angestellten Forschungen enthält, später noch mit der Kützing'schen Anordnung zusammenstellen.

\section{SYSTEN VON IËTZING.}

Kützing $\left({ }^{1}\right)$ definirt die Algen so : "Geschlechtslos oder cryptogamisch, inr Wasser lebend, zellig. Structur perenchymatisch, epenchymatisch, parenchymatisch. Frucht: Nacktfrüchte, Hüllenfrüchte, Vierlingsfrüchte und Capselfrüchte; Samen olivenbraun oder purpurfarbig. » Um dem Verfasser in seinen Definitionen folgen zu können, müssen wir zuerst seine Darstellung der Anatomie und Physiologie der Tange mit ihm durchgehen, weil er für cigenthümliche und neue Begriffe überall auch eigentliümliche und neue Ausdrücke gebraucht.

Der Verfasser bezeichnet zuerst die Algen als Wasserpflanzen, und stellt sie als solche nicht etwa bloss den Flechten, sondern allen andern Pflanzen als Luftpflanzen gegenüber. Es ist diess aber, wie schon früher erwähnt, factisch unrichtig, da nicht alle Algen Wasserpflanzen sind, und da auch andere Pflanzen als nur Algen im Wasser leben. Es ist ferner unrichtig, weil, wenn man etwas nähıer die vegetativen und reproductiven Verhältnisse der Pflanzen betracbtet, es gewiss Niemandem einfallen wird, die Pflanzen, wie es der Verfasser thut, in 2 Gruppen einander gegenüber zu stellen, von denen die eine bloss die Algen (und noch dazu die Algen wie sie von Kützing umgrenzt werden) enthielte. Es ist zu begreifen, wenn man Pilze und die übrigen Pflanzen, wenn man geschlechtslose und Geschlechtspflanzen, wenn man Cryptogamen und Phanero-

(1) Phycologia generaljs oder Anatomie, Physiologyie und Systemkunde der Tangoge, 1843. 
gamen, wenn man Zellenplanzen und Gefässpflanzen einander gegenüberstellt. Das alles gicbt uns Gruppen, die doch in wesentlichen Mcrkmalen sich auszeichnen. Aber ich sehe nicht ein, durch welches wesentliche Merkmal sich die Algen des Verfassers allein allen andern übrigen Pflanzen gegenüberstellen könnten.

Diese Ansicht von der Wassernatur der Algen ist denn nicht ohne Folgen, indem das Reich der Algen bei dem Verfasser sich wieder weiter ausdehnt. Ausser den Diatomeen und Desmidieen, welche mit Recht wieder aufgenommen sind, werden auch die Wasserpilze (Leptomitus, Hygrocrocis, etc.) und Gährungspilze, die Moosvorkeime (Protonema) und die Characeen wieder herbeigezogen. Warum werden die Eroberungen, um das Wasserreich vollständig zu arrondiren, nicht auch gleich auf die Wassermoose und auf die im Wasser lebenden Phanerogamen ausgedehnt? Dann hätte das Ganze doch den Schein einer physiologischen Einheit erhalten. — Obgleich aber der Verfasser in der Definition die Algen als Plantee aquatice ohne Beifügung bezeichnet, so werden natürlich doch alle in der Luft lebenden, den übrigen Algen ähnlichen Formen ebenfalls aufgeführt. Nachdem nun diese Abweichung ron der gegebenen Definition geschehen ist, so ist wieder kein Grund rorhanden, warum nicht eine Menge von Fadenpilzen, und warum nicht Lichina und die Flechten alle ebenfalls zu den Algen gebracht worden sind. Die Fadenpilze unterscheiden sich in ihrer Mehrheit, was die Fortpflanzung und den Bau betrifft, ebensowenig von vielen wirklichen Algen als von den Wasserpilzen. Lichina ist darin von den Algen ebenfalls nicht verschieden, und mit ihr die andern Flechten. Wenn daher die ganz oder theilweise in der Luft wachsenden Genera Polycoccus, Protococcus, Botrydium, Prasiola, Hormosira, Oscillaria, Nostoc, Schizogonium, Hormidium, Rhizoclonium, Vaucheria, Chroolepus etc. etc. als Aigen betrachtet werden, warum nicht auch die Pilze und die Flechten? Nicht dass ich den Unterschied zwischen Algen, Pilzen und Flechten nicht fühlte, aber nach der Begriffsbestimmung des Verfassers und nach der Art, wie die Anwendung dieser Begriffsbestimmung begonnen wurde, müsste consequent die Vereinigung der drei Gruppen rollführl werden.

Der Verfasser unterscheidet an der Zelle 5 Theile : Gelinzelle oder Gelin- 


\section{$-70$}

membran, Amylidzelle und gonimischer Zelleninhalt. Die "Gelinzelle » oder "Gelinmembran » ist das, was die Botanik sonst Zellwandung oder Zellmembran nennt. Sie besteht aus einer oder zwei a Membranen $\nu$ sonst Membranschichten genannt. - Die a Amylidzelle o ist das, was ich Schleimschicht $\left({ }^{1}\right)$ und was Mohl $\left(^{2}\right)$ Primordialschlauch genannt hat. Der a gonimische Zelleninhalt ” ist das, was sonst fester Zelleninhalt heisst.

In Bezug auf die Amylidzelle walten verschiedene Irrthümer. Der Verfasser glaubt, dass sie ihrer chemischen Zusammensetzung nach den gummi- und stärkemehlartigen Bildungen nahe trete. Sie besteht aber aus Schleim (aus quaternären Stoffen), was ihr Verhalten auf Alcohol und auf Jod beweist, und was von Mohl und von mir nachgewiesen worden ist. - Der Verfasser sagt ferner, dass die Amylidzelle in ihrer Form sich nicht immer nach der Form der Gelinzelle richte, sondern dass sie innerhalb derselben zuweilen selbstständige (eckige oder verzweigte) Formen zeige. Die Abbildungen, welche Kützing hievon giebt, sind richtig. Allein ich glaube, dass im unveränderten und lebenskräftigen $\mathrm{Zu}$ stande der Zelle die Schleimschicht (Amylidzelle) immer dicht an der innern Oberfläche der Zellwandung liege. Dies finde ich wenigstens gewöhnlich an Schnitten aus einem gesunden Gewebe, welche schnell unter das Microscop gebracht werden. Hier ändert sich der Anblick aber bald, um so mehr je dünner die Schnitte sind, und wenn man sie, insofern sie an Meeralgen gemacht sind, mit süssem Wasser befeuchtet. Die Schleimschicht zieht sich zusammen, und bleibt nur da an der Zellwandung befestigt, wo in dieser Poren liegen. Dadurch erhält sie eine strahlenförmige oder zuweilen verzweigte Form. - Der Verfasser sagt ferner, dass die Amylidzelle zuweilen bloss stellenweise die Gelinzelle aushleide; in Ulothrix bilde sie bloss eine Querbinde, in Zygnema zackige kugelige orler sternförmige Figuren, in Spirogyra spiralige Bänder. Auch hier geben mir meine Untersuchungen ein anderes Resultat. Die Schleimschicht überzieht die ganze innere Oberfläche der Zellwandung. Weingeistige Jodtinctur lässt sie bestimmt in dieser Art erkennen. In Ulothrix bildet das der Schleimschicht an-

(') Schleiden und Nägeli's Zeitschrift Tü wissenschaftl. Bot., Beft I, pary. 95.

(2) Botan. Zeitung, 1841 , pag. 273. 
liegende Chlorophyll bloss einen Gürtel ; in Spirogyra bildet es spiralige Bänder ; in Zygnema endlich ist meistens die Schleimschicht ganz frei von Chlorophyll; das letztere liegt im Zellenlumen, ohne die Schleimschicht zu berühren. Wie Kützing dazu kommt, die Samenfäden im Charenantheridium aus der veränderten Schleimschicht entstehen zu lassen, ist mir nicht klar. Dieselben bilden sich innerhalb der Kernbläschen $\left({ }^{1}\right)$. - Es geht aus den mitgetheilten Thatsachen hervor, dass die Schleimschicht mit Unrecht Amylidzelle genannt wird, weil sie mit der Stärke nichts zu schaffen hat. Es ist aber auch keine Zelle, weil sie zum Inhalte gehört, und als dessen äusserste Schicht betrachtet werden muss. Somit wird auch überhaupt die Benennung Gelinzelle überflüssig, da ihr der Gegensatz mangelt; und man wird wohl consequenter und richtiger wie bisher die Zelle einfach aus Membran und Inhalt bestehen lassen, und an dem letztern die Schleimschicht und die übrigen Theile, aus denen er besteht, unterscheiden.

Der a gonimische Zelleninhalt " (oder der feste Zelleninhalt) soll nach dem Verfasser in chemischer Hinsicht a gummiartig sein, wenn er durch Jodtinctur braun, stärkeartig, wenn er durch Jodtinctur blau gefärbt wird. o Im erstern Falle ist er aber nicht gummiartig, sondern schleimartig (oder eiweissartig). In anatomisch-physiologischer Beziehung werden 3 Formen des gonimischen Inhaltes unterschieden : 1) « kryptogonimische Zellenflüssigkeit , 2) monogonimischer Zellenkern, 5) polygonimischer Zelleninhalt. „ Die "kryplogonimische Zellenflüssigkeit ” ist das, was man sonst gefärbten Zellsaft und homogenes Chlorophyll nannte. Der «monogonimische Zellenkern " ist das, was nach der gewöhnlichen Terminologie als dichter, homogener, das ganze Lumen ausfüllender Zelleninhalt bezeichnet würde. Der a polygonimische Zelleninhalt s ist das, was sonst körniger Inhalt genannt wird. Ganz mit Körnern erfüllte Zellen heissen s polygonimische Vollzellen. § Zellen, in denen der körnige Inhalt an der Peripherie liegt, heissen a polygonimische Hohlzellen. o

Um diese Definitionen besser zu begreifen, müssen wir die Ansicht des Verfassers über die chemischen Bestandtheile der Zelle kennen lernen. Sic sind

(') Schleiden und Nägeli's Zeitschrift für wissenschaftl. Botanik, Heft I, pag. 54. Die Beobachtung wurde von Mettenius bestätigt (Bot. Zeitung, 1S45, pag. 17). 


\section{$-72$}

" unorganische und organische. " Die " unorganischen " sind, ausser den gewölnnlich so genannten Stoffen, noch der "Zucker, die Farbstoffe, wie das Chlorophyll, Phykokyan, Phykoerythrin und Phykohämatin, und ferner die Oele und Harze. "Die "organischen " Bestandtheile sind der "Schleim » (Intercellularsubstanz), das "Phytogelin " (Pflanzengallerte), das "Amylid " (Schleimschicht, Primordialschlauch) und die "Zellenkügelchen oder Gonidien. " Als Criterium für den Unterschied von Organischem und Unorganischem gilt dem Verfasser der Grundsatz, dass zum erstern alles gehört, was organisirt oder der Organisation fähig ist. Ich will hier nicht auf die Inconsequenz, die Unrichtigkeit und die Unvollständigkeit der Eintheilung der chemischen Bestandtheile eingehen, sondern wieder zu der anatomisch-physiologischen Eintheilung der Zellen und ihrer Theile zurückkehren.

Der Verfasser unterscheidet, wie wir vorhin gesehen haben, Gelinzelle, Amylidzelle und gonimischen Zelleninhalt. "Der letztere umfasst alles "Organische " (Kützing) innerhalb der Amylidzelle, also die Zellsaftkügelchen und diejenigen Substanzen, welche Zellsaftkügelchen erzeugen können. Der Verfasser nimmt nun an, dass in jeder Zelle gonimischer Inhalt liege, denn er theilt, wie ich bereits bemerkte, die Zellen ein in "kryptogonimische, monogonimische und polygonimische." Es ist diess aber eine willkührliche Annahme, denn wie Kützing unterscheidet, kann er nicht beweisen, dass diejenigen Zellen, deren Flüssigkeit zeitlebens homogen-roth oder homogen-grün erscheint (viele der sogenannten cryptogonimischen und hologonimischen Zellen) ausser den "unorganischen" Bestandtheilen (Wasser, Salzen, Zucker und Farbstoffen) noch etwas anderes (nämlich "gonimischen Inhalt ") einschliessen. - Es liessen sich noch mehrere Einwendungen gegen die Kützing'sche Darstellung machen, so z. B. das derjenige Inhalt, welcher am allereigentlichsten den Namen des gonimischen oder zeugenden verdient, gar nicht erkannt wurde, es ist der Schleim $\left({ }^{1}\right)$, einc Mischung von Proteïnverbindungen mit löslichen, ternären, organischen Stoffen,

(') Nicht der Schleim Kützing's, welcher synonym mit Intercellularsulstanz, nicht der Schleim der meisten Chemiker und Pflanzenphysiologen, welcher synonym mit Gummi und Pflanzengallerte, und nicht der Schleim Schleiden's, welcher synonym mit Proteinverbindungen ist (vergl. Schleiden und Niggeli’s Zeitschirift für wissensch. Bot., Heft III und IV, pag. 53). 


\section{$-73$}

vorzüglich mit Gummi und Zucker. - Ich will jedoch auf die möglichen Einwendungen gegen die Theorieen des Verfassers über die physiologische Eintheilung der Zelle und ihrer Theile nicht weiter eintreten, da dieselben mehr von allgemeinem, als von besonderm Interesse für die Algen sind. Für die Auffassung der Formverschiedenheiten des Inhaltes, auf die es eigentlich abgesehen ist, und die in der systematischen Anordnung des Verfassers eine wichtige Rolle spielen, sind die allgemeinen Theorieen und Benennungen gleichgültiger.

Kützing lässt also den gonimischen Inhalt unter 5 Gestalten auftreten, 1) als kryptogonimische Zellenflüssigkeit, 2) als monogonimischer Zellenkern, 5) als polygonimischer Zelleninhalt. Es sind dieses allerdings verschiedene Formen, unter denen der Zelleninhalt erscheint; aber sie lassen sich nicht als besondere Begriffe unterscheiden und benennen, da sie bloss relativ von einander verschieden und durch zahllose Mittelstufen verbunden sind. Der kryptogonimische Inhalt unterscheidet sich vom monogonimischen Inhalte bloss durch den verschiedenen Grad der Dichtigkeit; diese beiden Formen des Inhaltes unterscheiden sich von dem polygonimischen Inhalte bloss in der verschiedenen Zahl der Zellsaftkügelchen : in jenen beiden sind keine oder wenige, in diesem viele Kügelchen vorhanden. Ich weiss zwar wohl, dass bei Kützing die Begriffe überhaupt bloss einen relativen Werth haben sollen; aber so wenig dieses Princip in die Systematik Eingang finden darf, so wenig darf es auch in der Physiologie geduldet werden.

Die polygonimischen Zellen werden eingetheilt in polygonimische "Vollzellen und Hohlzellen. $\nu$ Warum werden consequenterweise nicht auch die hologonimischen und kryptogonimischen Zellen je in zwei Unterabtheilungen Vollzellen und Hohlzellen unterschieden? denn bei ihnen tritt der gleiche Unterschied auf, wenn auch die Hohlzellen seltener sind.

So ist denn für den Zelleninhalt eine neue Terminologie an die Stelle der alten getreten; aber nicht, wie ich glaube, dass dadurch die bestehenden Verhältnisse besser und naturgemässer ausgedrückt würden. Sie ist überdem weniger passend als die alte Methode, da sie einen Gegenstand in einer Weise systematisiren will, wie es gewiss nie möglich sein wird, und da sie die Vorstellung von bestehenden Begriffsverschiedenheiten erzeugt, welche in der Natur nicht existiren. 


\section{$-74$}

Der Verfasser theilt die Zellen aber nicht bloss ein in a kryptogonimische, monogonimische und polygonimische Zellen.» Mit dieser Eintheilung kreuzt sich eine andere in "Kernzellen, Amylidzellen und Gelinzellen, " je nachdem in ihnen eines der drei Elementarorgane: "die gonimische Substanz, die Amylidmembran (oder Amylidzelle) oder die Gelinmembran (oder Gelinzelle) " vorherrschend entwickelt sei, während die übrigen beiden als « unentwickelte Nebengebilde " ihm untergeordnet sein sollen. Kützing behauptet nun, dass "bei den Tangen die Kernzellen vor den Amylidzellen und diese wieder vor den Gelinzellen entwickelt seien " und glaubt, "da ihm ähnliche Verhältnisse bei andern Pflanzengruppen nicht bekannt sind, es möchte sich daher durch dieselben der wahre - und vielleiclıt auch einzige - physiologische Character der Tange aussprechen. "Der Ausdruck " die Kernzellen sind entwickelt oder herrschen vor den Amylidzellen, etc. ", kann nur zweierlei heissen ; entweder : die, Kernzellen treten bloss bei den niedern, die Gelinzellen treten bloss bei den höhern Algen auf; oder : alle Algenzellen sind zuerst Kernzellen; die einen derselben verwandeln sich in Amylidzellen; die einen unter den letztern in Gelinzellen. Im ersten Falle wäre es verkehrt, diess als den physiologischen Character der Tange zu bezeichnen, denn der physiologische Character einer Pflanzengruppe sind die allen Gliedern dieser Familie gemeinschaftlichen physiologischen Eigenthümlichkeiten. Im zweiten Falle wäre es unrichtig, darin einen Unterschied zwischen den Algen und den übrigen Pflanzen zu finden, da die Erscheinungen, welche die Geschichte der meisten Algenzellen von Anfang bis zu Ende zeigt, vollkommen die gleichen sind, wie wir sie in den meisten Zellen der übrigen Pflanzen beobachten.

Die Unterscheidung in "Kernzellen, Amylidzellen und Gelinzellen 》 ist aber überhaupt zu verwerfen, da sie ebenfalls bloss auf relative Verschiedenheit gegründet ist. Jede Zelle besteht aus Membran, Schleimschicht und Inhalt. Bloss in jungen Zellen bildet zuweilen die Schleimschicht und der homogene Schleiminhalt ein untheilbares Ganze. Ob nun der eine oder andere Theil quantitativ stärker entwickelt sei, ist zwar für das Leben der Zelle und das Leben des Gewebes, von dem dic Zelle einen Theil ausmacht, nicht ohne Wichtigkeit; aber es berechtigt ein solcher relativer Unterschied noch lange nicht, die Zellen systema- 


\section{$-7 \ddot{5}$}

tisch in 5 Cathegorieen zu theilen. Wir werden überdem in der Folge noch sehen, dass die Eintheilung sich auch auf factische Unrichtigkeiten stützt.

Wie der Verfasser $\mathbf{5}$ Zellenarten annimmt, so giebt es auch $\mathbf{5}$ Arten von Zellgewebe: «1) Perenchym oder monogonimisches Gewebe, aus Kernzellen bestehend, 2) Epenclym oder Amylidgewebe und 5) Parenchym oder Gelingewebe." Die Entstehung der Gewebe beruht auf der Zellenbildung, und geschieht auf 6 Arten : 1) a durch Theilung olne Trennung (divisio), 2) durch unnittelbares Verwachsen (conjugatio) mehrerer schon fertiger Zellen oder Gonidien, 5) durch Zwischenlagerung (interpositio), 4) durch Eindringen in die Intercellularräume oder zwischen ganze Partieen des amylidischen Gewebes (interplicatio), כ) durch Umwachsung einer Hauptzelle von andern kleinern Zellen (circumplexus), 6) durch Ansetzung junger (Brut-) Zellen an der Aussenseite einer Mutterzelle (appositio)."

Von diesen 6 verschiedenen Arten der Gewebezellbildung ist aber in der

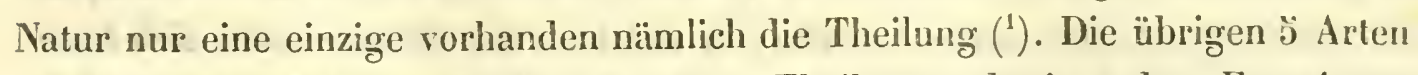
der Zellenbildung beruhen entweder in der Theilung, oder in andern Functionen des Zellenlebens. Von den drei Arten der Gewebe findet sich in der Natur nur das Parenchym, denn jede Zelle ist nit einer vollständigen und undurchbrochenen Gelinmembran umschlossen.

Bei dem Epenchym soll sich die Theilung bloss auf die Amylidzellen erstrecken; " es findet hiebei niemals zwischen den Amylidzellen die Bildung einer Gelinmembran statt." Diess ist nun entschieden unrichtig. Würde die Scheidewand von den sogenannten Amylidzellen, also von der Schleimschicht gebildet, so müsste sie durch Jod braun gefärbt werden. In grössern Formen von Lyngbya und Oscillaria, welche beide aus Epenchymzellen bestehen, bleibt sie aber deutlich ungefärbt: - Ebenso verhält es sich beim Perenchym; auch da hat jede Zelle eine vollkommen geschlossene Gelinmembran.

Der Verfasser lässt bei Halimeda und Corallocephahus, bei Mesogloca, Chordaria, Liagora, Chorda, bei den Fuceen und andern Pflanzen das Gewebe « durch Copulation» entstehen. Zellen oder Fäden, die anfangs frei nebenein-

(1) In dem Sinne, wie sie von mir als wandstinndige Zellenbildung beschrieben wurde : Zeitschrift füt' wissenschaftl. Bot., Heft I, pagr. $73 \mathrm{ft}$. 


\section{$-76$}

ander liegen, sollen später seitwärts mit einander verwachsen. Zu diesem unbegreiflichen Ausspruche ist der Verfasser ohne Zweifel auf dem Wege gelangt, dass er von der Conjugation des Zygnemeen ausging, und dieselbe in andern Pflanzen, wo el eine entfernt ähnliche Anordnung der Zellen fand, sofort annahm, ohne sich im Geringsten von dem Vorgange durch Beobachtung zu überzeugen. In der Wirklichkeit liegen diese sogenannten conjugirten Zellen alle zuerst in einem dichten parenchymatischen Gewebe beisammen und berühren sich überall; nachher trennen sie sich theilweise von einander, indem zwischen ilinen Intercellularsubstanz gebildet wird; sie bleiben aber an einzelnen Stellen init einander verbunden. Um sich von diesem Vorgange zu überzeugen hat man nur nöthig, bei einer der genannten Pflanzen einen senkrechten Durchschnitt durch die Spitze eines wachsenden Astes zu führen, und ihn unter dem Microscop zu betrachten. In den Fucoideen z. B. sieht man unmittelbar unter der Spitze ein parenchymatisches zartes Gewebe, in welchem die Zellen so sehr sich überall berühren, dass nicht die geringsten Intercellularräume übrig bleiben. Statt dass also, wie Kützing angibt, die Zellen zuerst frei sind und nachher theilweise mit einander verwachsen, sind sie im Gegentheil zuerst ganz miteinander verwachsen und trennen sich nachher theilweise. Der Vorgang ist der gleiche, wie er bei der Entstehung des schwammförmigen Gewebes der höhern Pflanzen statt hat, und man würde daher jenes Gewebe wohl auch am besten, wie dieses, schwammförmiges Gewebe nennen.

Der Verfasser lässt ebenfalls Amylidzellen, Kernzellen und Gonidien (Zellsaftkügelchen) sich copuliren. Die Zeichnungen, die er dazu liefert, sind allerdings richtig. Aber auch hier hat er sich, wie es scheint, bei keiner einzigen Art darum bekümmert, wie ein solches Gewebe in jüngerm Zustande aussehe. Die Entwicklungsgeschichte der sogenannten copulirten Kernzellen ist die gleiche wie diejenige der copulirten Gelinzellen, von der ich vorhin gesprochen habe. - Die sogenannte Copulation der Amylidzellen aber rührt hauptsächlich davon her, dass, wie ich schon oben gesagt habe, in Folge äusserer schädlicher Einflüsse (des Schneidens, der Endosmose, etc.) die Schleimschicht in der Zelle sich zusammenzieht und bloss mit den Poren durch Fortsätze verbunden bleibt. In ältern Geweben, wo die Zellen abgestorben sind, verhält sich die Schleimschicht 


\section{$-77$}

habituell so, wenn sie nicht aufgelöst wird. Da nun bei den Algen, wie bei den Phanerogamen, die Poren zweier benachbarter Zellen aufeinander treffen, so scheint es, als ob an diesem Punkte (wo die beiden Schleimschichten durch Fortsätze mit den Porus verbunden bleiben) die Schleimschichten sich copulirt hätten. Uebrigens mangelt an der Porusstelle selbst die Gelinwandung durchaus nicht; wie bei den höhern Pflanzen ist auch bei den Algen bestimmt eine dünne Scheidewand da, welche den Poruscanal abtrennt. - Von der Richtigkeit des Gesagten wird man sich leicht überzeugen, wenn man bei einer geeigneten Pflanze (Gracilaric purpurascens, etc.) einen Durchschnitt durch cin nicht allzualtes Gewebe macht, denselben schnell unters Microscop bringt, und dann die Veränderungen beobachtet, welche süsses Wasser oder schwache Salpetersäure hervorbringt. Man wird finden, dass auch hier die sogenannte Copulation nicht auf einer theilweisen Verwachsung eines früher freien, sondern auf der theilweisen Trennung eines früher verbundenen Organes ber'uht.

Die Annahme einer Bildung des Tanggewebes "durch Zwischenlagerung" ist ebenfalls unrichtigg. In den Intercellulargängen älterer Zellen entstehen nach dem Verfasser neue kleinere Zellen aus dem Schleime (der Intercellularsubstanz). "Schon nach den allgemeinen physikalischen Gesetzen muss der flüssige Schleim im Intercellularraume zusammenfliessen, wenn die Gelinzellen einander näher rücken. Es bedarf daher nur des Erhärtens des Schleimes, um eine neue Gelinzelle zu bilden. "Kützing hat es vorgezogen, das Gewebe durch eine Theorie, als unter dem Microscope, entstehen zu lassen. Hier entsteht es allerdings anders. Die ältern Zellen eines meist aus ellipsoidischen oder langgestreckten Zellen bestehenden Gewebes wachsen mit ihrem untern Ende aus, und erzeugen, indem sich der ausgewachsene Theil durch eine Scheidewand abtrennt, gleichsam eine Astzelle. Diese wächst nach unten in die Länge, theilt sich, und wird nach und nach zu einem gegliederten und verästelten Fadien, welcher sich überall zwischen den schon vorhandenen Zellen hindurch drängt. Da nun alle oder fast alle der innern Parenchymzellen in gewissen Gattungen solche Fäden bilden, so erhält dann das Gewebe die Structur, wie sie von Kützing abgebildet und beschrieben wird.

Die Bildung des Tanggewebes "durch Einwachsen $"$ ist mit der eben be- 
schriebenen identisch. Der Verfasser sagt hier richtig, " dass die Zellen durch Proliferiren anderer Zellen entstehen, deren Fortsetzungen sich zu Gliederfäden entwickeln, die (gleich Wurzeln) in die Zwischenräume des lockern Gewebes eindringen und dasselbe sowohl in die Quere als Länge durchziehen. " Die Abbildungen zeigen freilich bloss das spätere Verhalten, nicht aber die Art des Vorganges selbst. Ueberdem kann ich dem Verfasser nicht ganz beistimmen, wenn er sagt, dass das Einwachsen vorzüglich von der Peripherie zum Centrum gehe, und darin einen Unterschied findet mit der folgenden Art der Gewebebildung, mit der "Umwachsung", welche vom Centrum zur Peripherie gehen soll. Das Einwachsen geschicht an dem Orte und aus den Zellen, wo wir die Fäden finden. Diese letztern kommen durchaus nicht etwa von der Peripherie und gehen nach dem Centrum. Im Gegentheil, es geschieht gewöhnlich insofern das Ungekehrte, als die Bildung der Gliẻderfäden innen beginnt und nach aussen hin fortschreitet. Die Angabe Kützing's, dass beim Einwachsen die Corticalschichten nach innen zu proliferiren, lässt fast vernuthen, dass er den Ursprung der gegliederten wurzelähnlichen Fäden in den meisten Fällen nicht gesehen hat.

Bei der Bildung des Tanggewebes durch "Umwachsen " vermengi der Verfasser zwei durchaus verschiedene Arten der Gewebebildung. Die erste ist eine regelmässige Zellenbildung durch Theilung, welche zuerst einen gegliederten Faden erzeugt; die Gliederzellen theilen sich darauf in horizontaler Richtung; diese Theilung schreitet in der Regel von der Achse aus nach der Peripherie hin fort, und folgt immer ganz bestimmten Regeln $\left({ }^{1}\right)$. Diese Zellenbildung erzeugt bald bloss einen Gliederfaden, bald um denselben eine "Pericentralschicht", wie sie der Verfasser nennt, bald um die "Pericentralschicht " eine "Rindenschicht. "Von dieser Art der Gewebebildung total verschieden ist eine Erzeugung von gegliederten verästelten Fäden, welche aus verschicdenen an der Oberfläche gelegenen Zellen entspringen und un die innern Theile gleichsam ein Geflecht bilden. Diese Fäden sind denjerigen vollkommen analog, welche sich bei der

${ }^{\left({ }^{2}\right)}$ Ich habe fïr diese Zellenbildung ein Beispiel durch die Wachsthumsgyeschichte von Delesseria Hypoglossum geliefert : Zeitschrift tür wissenschiftl. bot., Heft II, pagr. 121. 
sogenannten "Zwischenlagerung " und bei dem sogenannten "Einwachsen " bilden; nur liegen sie am einen Orte mitten in dem gewöhnlichen Gewebe, am andern Orte an dessen Oberfläche. Bei Batrachospermum, Callithamnion etc. entspringen die gegliederten wurzelähnlichen Fäden aus den untersten Zellen der Aeste; bei Ceramium und Polysiphonia aus den sogenannten "Pericentralzellen. " Der Verfasser begeht nun einen doppelten Fehler, einmal, dass er die Pericentralschicht in vielen Gattungen erst nach der aus gegliederten Fäden gebildeten Rindenschicht entstehen lässt, was nie der Fall ist, denn diese entspringen gerade (bei Ceramium so gut wie in Polysiphonia) aus den "Pericentralzellen n, sind also immer die spätere Bildung; - ferner dass er keinen Unterschied kennt zwischen einer Rinde, welche sich durch regelmässige Gewebebildung, und einer solchen, welche sich durch gegliederte wurzelähnliche Fäden bildet.

Die letztere Art der Gewebebildung geschieht nach dem Verfasser" durch " $A p$ position. " Ein Kügelchen oder Bläschen soll sich an der Aussenfläche einer ältern Zelle erzeugen, vergrössern und mit derselben in Verbindung bleiben. Als Beispiele werden angeführt Batrachospermum, Chara, Dasycladus und Callithamnion. Die Abbildungen zeigen weiter nichts als Zellen, welche an andern Zellen befestigt sind. Die Entwicklungsgeschichte mangelt auf den Tafeln ganz. Auch hier hat der Verfasser, statt sich nach Thatsachen zu bemühen, um daraus eine Theorie abzuleiten, diese unmittelbar und willkührlich construirt. Diese vier Gattungen waren mir nun zufällig vor einiger Zeit Gegenstand genauer Untersuchungen, und ich kann versichern, dass die Astbildung in keiner Weise verschieden ist von der Astbildung in Confersa. Ebenso ist mir bei den übrigen Algen, sowie bei allen andern Pflanzen kein Beispiel bekannt, wo eine an der Aussenfläche einer 'Zelle liegende Zelle auf irgend eine andere Weise entstanden wäre, also entweder durch unmittelbare Theilung oder durch Theilung nach vorausgegangenem Auswachsen in einen Ast.

Die 6 Arten der Gewebebildung, welche der Verfasser unterscheiden zu müssen glaubte, reduciren sich somit auf folgende einfache Sätze : alle vegetative Zellenbildung der Algen geschieht durch wandständige (merismatische) Zellenbildung (oder durch Theilung). Die Gewebebildung ist doppelter Art, 1) eine 


\section{$-80$}

eigentliche Gewebebildung, welche regelmässig von unten nach oben und von der Achsenlinie nach der Peripherie hin fortschreitet, und bei welcher die Zellen ursprünglich überall mit einander verwachsen sind, 2) eine uneigentliche Gewebebildung, welche darin besteht, dass durch Auswachsen der schon gebildeten Zellen gegliederte und verästelte Zellfäden erzeugt werden, welche theils das Gewebe als ein intercellulares Geflecht durchziehen, theils an der Oberfläche liegen und dieselbe als ein peripherisches Geflecht überziehen. - Diess sind die zwei wesentichen Verschiedenheiten der Gewebebildung : weitere untergeordnete Differenzen entstehen aus ungleicher Ausdehnung der Zellen und aus ungleicher Entwicklung der Intercellularsubstanz. - Die copulirten Fäden der Zygnemeen sind kein Gewebe, denn ein Gewebe entsteht nicht durch Zusammensetzung verschiedener getrennter Individuen, sondern durch endogene Entwicklung eine ursprünglich einzigen und ungetheilten Elementarorganes.

Kützing nennt das Ganze eines Algenindividuums "Tangkörper (phyeoma)", und unterscheidet zuerst zwischen Tangkörper " ohne und mit bestimmter Form. " Der formlose Tangkörper ist " eine gesellig-freie, aber auch darum äusserlich unbestimmt-begrenzte, daher formlose Vereinigung" von Zellen. Ein "formloser Körper, Tangkörper, oder Thallus, Laub " etc. ist aber, wie ich schon oben bemerkte, ein Widerspruch in sich. Ein Bienenschwarm hiesse eben sowohl ein formloser Thierkörper. Der "Tangkörper oder das Phycom " wurde früher Laub (frons) genannt, und ich weiss nicht, warum dieses Organ nun für die Algen einen besondern Namen erhalten hat.

Unter den Tangkörpern mit bestimmter Form werden zuerst diejenigen aufgeführt, welche aus "schlauchförmigen Gelinzellen " gebildet werden. Bisher wurden zwar von dem Verfasser mehrere Zellenarten unterschieden; die Schläuche oder schlauchförmigen Gelinzellen wurden aber nicht als besondere Art characterisirt, sondern bloss beiläufig die grössern Gelinzellen so benannt. Doch es leuchtet ron selbst ein, dass die Grösse allein keinen qualitativen Unterschied, um den es sich hier doch handelt, begründen kann. In der That, wenn die Zellen von Chara und von Anadyomene Schläuche genannt werden, so weiss ich nicht, wo denn überhaupt eine Grenze zwischen Schlauch und Nichtschlauch gesetzt werden will. Die Schläuche bilden nach dem Verfasser dreierlei Arten von Tang- 


\section{$-81$}

kürpern a den Schlauch (coeloma), den Schlauchstamm (phycoma coelomaticum) und den Schlauchfadenstamm (trichoma colomaticum). "Im ersten Falle soll die Pflanze aus einem einzigen Schlauche, im zweiten und dritten Falle aus mehreren Schläuchen bestehen. Von diesen drei Formen sind die zwei ersten von allen andern Tangkörpern total verschieden. Hier hat der Name Schlauch eine Bedeutung; es ist eine Zelle, welche fortwährend an der Spitze sich verlängert, ohne neue Zellen zu bilden. Den a Schlauchgliederstamm ๖ weiss ich in keiner Weise von andern ähnlich gebauten Stämmen, welche Kützing \& Faser- oder Fadenkörper " nennt, zu unterscheiden.

Die kleinern Gelin-, Amylid- und Kernzellen erzeugen nach dem Verfasser wieder mehrere Arten Tangkörper; daron erhalten einige besondere Namen, nämlich 1) "Faser-oder Fadenkörper (trichoma), 2) Blattstamm (phylloma) und 5) Caulom. " Bei der ersten Art sind die Zellen linienförmig, bei der zweiten Art flächenförmig verbunden. Der " Faser- oder Fadenkörper » ist das, was sonst gegliederter Faden, der "Blattstamm » das, was sonst flaches Laub genannt wird. Das «Caulom D ist der Stiel oder Strunk eines flachen Laubes. Die ältere Nomenclatur für Phyllom und Caulom scheint mir einen entschiedenen Vorzug zu besitzen, indem sie dem allgemeinen Begriffe des Laubes, welcher überall der gleiche ist, die nähern Bestimmungen von flach und gestielt beifügt. Dass Phyllom und Caulom keine verschiedenen Organe seien, wird schon aus der Bemerkung des Verfassers selber klar, dass « bei allen wesentlichen Unterschieden doch beide Theile allmälig in einander übergehen, so dass man in vielen Fällen nicht den Anfang des einen und das Ende des andern genau bestimmen kann. " Wenn zwei Dinge in einander übergehen, ist es ein Beweis, dass sie gerade durch keine wesentlichen Verschiedenheiten getrennt werden. Ein Organ ohne bestimmte Grenze ist ein Unding, so gut wie eine Pflanze ohne bestimmte Form. Zwei Organe, zwischen denen keine bestimmte Grenze vorhanden ist, sind nur Ein Organ, denn eine unbestimmte Grenze ist gar keine Grenze. - Bei den Sargasseen und Halochloen sollen wahre Blätter und wahre Stengel vorkommen. Ausser dem äusserlichen Anscheine ist aber sonst kein Beweis dafür gegeben. Die übrigen Formen des Phycoms stellen einen einfachen oder ästigen, drehrunden oder plattgedrückten Fadén dar. Sie erhalten keine bestimmten Benennungen. 


\section{$-82$}

An den "Tangkörpern, welehe eine höhere Entwieklung als der Fadenkörper besitzen, " unterscheidet der Verfasser eine "epigenetische (aufwüchsige), diplogenetische (doppelwüchsige), perigenetische und amphigenetische »Bildung. Bei der " epigenetischen Bildung " liegen die Schichten aufeinander (d. h. in der Richtung der Achse hintereinander); die untere Sehicht vertritt die Wurzel, oder sendet Wurzelfasern aus. Bei der "diplogenetischen Bildung" legen sich die Schichten von beiden Seiten flächenförmig aneinander. Bei der "perigenetischen und amphigenetischen Bildung " unterscheidet man mehrere concentrische Lagen. "Perigenetische und amphigenetische " unterscheiden sich dadurch von einander, dass bei der erstern die concentrischen Schichten um eine reale Achse, bei der letztern um eine ideale Achse stehen. - Diese anatomisehe Eintheilung hat einiges sehr treffende. Im ganzen ist aber zu bedauern, dass nicht zum voraus zwvischen eigentlichem und uneigentlichem Zellgewebe unterschieden wurde, wic ich es oben angedeutet habe (denn diess ist der wiehtigste Untersehied), und dass bei der Darstellıng des eigentlichen Gewebes nicht Rücksicht auf die Wachsthumsgeschichte genommen wurde.

Als « besondere Nebenorgane des Tangkörpers 》 füh»t der Verfasser auf : 1) " die Ueberhaut (peridermis), 2) Schleimgefässe (vasa mucifera), 5) Luftbehälter (ä̈rocystæ), 4) Fasergrübchen (cryptostomata). " Die "Ueberhaut » ist das, was sonst Cuticula heisst. Unrichtig ist es aber, wenn der Verfasser behauptet, dass bei Verwundung die Culicula sich regenerire, indem aus der Wunde Schleim hervordringe und erhärte. Das letztere hat freilich statt, aber der hervordringende und erhärtende Schleim ist wirklicher Schleim, der aus dem Zelleninhalte kommt und vorzüglich aus Proteïnverbindungen besteht, und nicht Intercellularsubstanz, wie Külzing angiebt. Die Culicula ist in chemischer Hinsicht der Intercellularsubstanz und nieht dem an quaternären Stoffen reiehen Zelleninhalte gleich. Die "Schleimgefässe " sind das, was man sonst Gummigänge heisst. Die "Luftbehälter 》 werden sonst Lufthöhlen genannt. - Die "Fasergrübchen 》 sind kleine Vertiefungen auf der Oberfläche des Phycoms, welche gegliederte Fäden, "Sprossfüden (eryptonemata)" enthalten.

Die Tange pflanzen sich durch Zellen fort, welche von dem Verfasser Samen, Spermatia oder Sämlinge, Spermatidia genannt werden. Entweder bilden die 
Samen ohne weiteres die Frucht, welche dann Nacklfrucht (gymnocarpium) heisst, oder mehrere Samen werden von einer Fruchthülle (spermangium) umschlossen, und bilden dann eine Mïllenfrucht (angiocarpium). Wenn eine Vercinigung mehrerer Hüllenfrüchte statt findet, so entsteht cin Fruchtlager, Fruchtköiper (carpoma). Diese Eintheilung der Frucht in Nacktfrucht und IIüllenfrucht, welche zuerst ganz allgemein gemacht wird, kommt jedoch späterhin bloss bei der einen Hälfte der Algen in Anwendung; bei der andern Hälfte wird eine andere Eintheilung durchgeführt.

Die Samen und Sämlinge sind nach dem Verfasser hologonimische Amylidzellen, welche hïufig mit einer einfachen oder doppelten Gelinmembran umgeben sind. Diese Gelinmembran wird Samenhïllle oder Samenhaut (epispermium) genannt. So wenig ich aber Kützing beistimmen konnte, dass es vegetative Kernzellen und Amylidzellen ohne vollständige Gelinmembran giebt, so wenig kann ich zugeben, dass es so organisirte Zellen gebe, welche zur Fortpflanzung dienen. Ebenso ist es nicht zu billigen, dass die Zellmembran hier "Samenhülle oder Samenhaut» genannt wird (Ausdrücke, welche sonst eine ganz. andere Bedeutung haben), und dass die neuen Namen "Spermatia und Spermatidia " an die Stelle der seit langem gebräuchlichen Sporæe und Sporidia treten sollen.

Bei den Isocarpeen oder gleichfrüchtigen Algen, wo sich die Frucht auf allen Individuen gleichartig entwickelt, ist dieselbe entweder eine "Nacktfrucht 》 oder eine "Hüllenfrucht. " Die "Hüllenfrucht " ist das, was von den andern Algologen meist Tuberculum, von Endlicher Conceptaculum genannt wird. Alle übrigen Fruchtarten der Algen heissen "Nacktfrucht. » Die Hüllenfrucht entspricht somit einem bestimmten Begriffe. Ob der Name gut gewählt sei, ist eine andere Frage. Ich möchte es bezweifeln, weil mir sowohl der Name Frucht, wie er sonst definirt wird, als der Name Hülle, wie er gewöhnlich gebraucht wird, hier nicht zu passen scheint. Die Benennung Sorus (Häufehen), mit einer nähern Bestimmung seiner besondern Eigenthümlichkeit, hätte mir viel passender geschienen. - Wenn aber auch die Hüllenfrucht einem bestimmten Begriffe entspricht, so hat dagegen die "Nacktfrucht » keinen positiven Begriff für sich, sondern bloss den negativen, keine Hüllenfrucht zu sein, denn wir finden hier 
sowohl aussenständige, wirklich nackte oder umhüllte, einzeln stehende oder in Häufchen vereinigte, als auch in Mutterzellen eingeschlossene, oder ganz im Gewebe verborgene Samen.

Bei den Heterocarpeen oder ungleichfrüchtigen Algen, wo die Frucht stets in zweifacher Form bei verschiedenen Individuen auftritt, ist die Frucht entweder Vierlingsfrucht (tetrachocarpium) oder Capselfrucht (cystocarpium), erstere synonym mit Sphrerosporen (I. Ag.), letztere mit Capseln oder Theca (Endl.).

Die Vierlingsfrucht entsteht aus einer Zelle, welche, wie der Verfasser sagt, zuerst mit den übrigen Zellen in Verbindung ist, nachher sich aber deutlich von denselben absondert, indem ein grösserer Zwischenraum um sie herum sich bildet. Diese Darstellung ist nicht ganz richtig, indem dieser Zwischenraum nichts anders als die gallertartig-verdickte Wandung der Mutterzelle ist, eine Verdickung, wie wir sie bei der Pollenbildung und der Sporenbildung der übrigen Cryptogamen ebenfalls mehr oder weniger dentlich antreffen. - Kützing lässt die Mutterzelle sich in 2 Hälften, jede Hälfte dann wieder in zwei theilen. Gehen die Theilungsflächen einander parallel, so entstehen vierjochige Sämlinge (spermatidia quadrijuga); bilden die Theilungsflächen einen Winkel, so heissen die Sänlinge Doppelzwillinge (spermatidia quadrigemina). Die letztern sind entweder rechtwinklige oder schiefwinklige, je nachdem die Theilungsflächen senkrecht oder schief zu einander stehen. - Die « vierjochigen Sämlinge " entsprechen der Divisio zonata, die a rechtwinkligen Doppelzwillinge s entsprechen der Divisio cruciata, und die a schiefwinkligen Doppelzwillinge o entsprechen der Divisio triangularis (I. Ag.) Der Verfasser irrt aber, wenn er die Mutterzelle sich immer erst in zwei Hälften theilen lässt, denn bei fast allen sogenannten schiefwinkligen Doppelzwillingen, also bei der grössten Zahl der Tetrachocarpien theilt sich die Mutterzelle sogleich in 4 tetraëdrisch-gestellte Theile oder Specialmutterzellen, wie es meistens auch bei der Pollenbildung der Fall ist $\left({ }^{1}\right)$.

Die Capselfrucht ist entweder innerhalb oder ausserhalb des Phycoms. Sie besteht nach dem Verfasser aus drei Theilen: 1) den Samen (spermatia), 2) dem Samenboden (spermopodium), worauf die Samen sitzen, und 5) der Fruchthülle

(') Nägeli, zur Entwicklungsgeschichtc des Pollens, Zürich 1842, pagg. 13 ff. 


\section{$-8 \ddot{3}$}

(spermangium). Bei vielen Capselfrüchten sind diese drei Theile allerdings vorhanden, bei andern finde ich davon bloss einen, so namentlich bei den Callithamniaceen und Ceramiaceen. Dass auch hier eine Anheftungsstelle vorhanden ist, versteht sich von selber; aber dieselbe hat, wie die Entwicklungsgeschichte zeigt, eine andere Bedeutung als der Samenboden oder die Placenta bei den übrigen Arten der Capselfrucht. Ferner ist die Gesammtheit der Samen bei den genannten Familien von Gallerte umhüllt, aber diese Gallerte entspricht der Cuticula des übrigen Phycoms, und darf somit nicht "Fruchthülle 》 genannt werden. Ueberdem scheint die Hülle bei eingesenkten Capselfrüchten, wie der Verfasser selbst sagt, öfter zu fehlen.

Der Verfasser lässt (wie $J$. Agardh) die Capselfrucht aus der Centralschicht, die Vierlingsfrucht aus der Corticalschicht des Phycoms entstehen. Je nachdem sich die eine oder die andere Schicht kräftiger entwickelt, so bildet sich die eine oder die andere Fruchtart. Da wo sich beide Schichten in einem Individuum das Gleichgewicht halten, so erzeugt die heterocarpische Alge, nach dem Verfasser, keine Frucht. "Sie bleibt steril, und sucht sich dann auf eine andere Artdurch Schösslinge, Sprossen, Spermatoidien u. s. w. - fortzupflanzen. "

Ausser den eigentlichen Samen oder Sämlingen unterscheidet Kützing noch samenähnliche Nebengebilde, nämlich : 1) Spermatoidien, 2) Scheinsamen (opseospermata) und 5) Nebensamen (paraspermata). Sie kommen bei Isocarpeen und Heterocarpeen vor, und " scheinen die Samen durchaus zu vertreten, obgleich die Art und Weise ihres Vorkommens, ihre Entstehung und Form zeigen, dass sie von den wahren Samen abweichen."

Die Spermatoidien sollen sich durch ihren Inhalt von den Samen unterscheiden. Jene stellen einen Körper dar, a dessen Inhalt aus einer Anzahl von Gonidien besteht; in diesem Körper sind die Gonidien sowohl in Querals in Längsreihen geordnet, und wenn sie auch in einigen Fällen so dicht stehen, dass sie sich zu berühren scheinen, so sind sie dagegen in andern Fällen wieder durch deutliche Scheidewände von einander getrennt. " Es ist mir aus diesen Worten zweifelhaft geblieben, ob der Verfasser die Spermatoidien für einfache Zellen hält oder nicht; dafür sprechen die Ausdrücke Inhalt und Gonidien, dagegen die Ausdrücke Körper und Scheidewände zwischen deı 
Gonidien. Wie dem nun sein mag, das Spermatoidium bei den Isocarpeen ist keine Zelle sondern ein Aggregat von Zellen. Wenn daher eine Vergleichung mil den wahren Samen angestellt werden soll, so muss es nicht zwischen Spermatoidien, sondern zwischen den einzelnen Zellen der Spermatoidien und den Samen geschehen. - Ich wähle nun zur Vergleichung die Gattung Ectocarpus. Hier sollen sowohl "seilliche Samen " als "Spermatoidien" vorkommen. Die Spermatoidien sind aus mehreren hintereinanderliegenden Zellen entstanden, von denen jede mehrere nebeneinanderliegende Zellen erzeugt. Jede dieser letztern Zellen, welche sich abrundet und mit Inhalt füllt, ist ein wahrer Same. Die sogenannten seillichen Samen aber sind keine Samen sondern Capseln, welche viele kleine Zellen enthalten, die aber dicht in einander liegen und daher nur selten unterschieden werden können. Diese Samen werden aus den Capseln entleert, und sind denjenigen analog, welche in den sogenannten Spermatoidien erzeugt werden. Auch in den letztern liegen sie zuweilen so dicht, dass man das ganze für eine mil Inhalt gefüllte Zelle ansieht und werden erst als solche sichtl)ar, wenn sie aus dem Spermatoidium heraustreten. Ich finde daher in Rücksicht auf die Entstehung und die Keimfähigkeit der Samen von Ectocarpus zwischen den sogenannten "Spermatoidien " und den sogenannten "Samen » keinen andern Uuterschied als den, dass in der Regel die wirklichen Samen in den erstern lockerer, in den letztern dichter liegen, was, wie ich glaube, mit der Form der beiden Gebilde zusammenhängt. Es giebt allerdings noch andere Verschiedenheiten von morphologischer (hinsichtlich der Entstehungsweise des ganzen Organs) und von physiologischer Bedeutung (hinsichtlich des Unterschiedes von lortpflanzung und Vermehrung), worauf ich in dem zweiten Theile dieser Schrift näher eintreten will. - Im Allgemeinen glaube ich, dass die Spermatoidien bei den Isocarpeen nichts anders sind als eine Anhäufung von wahren Samen.

Bei den Heterocarpeen dagegen sind die Spermatoidien ganz etwas anderes; es sind Organe, die in keiner Weise sich von den Antheridien der Moose, Farren, Charen verschieden zeigen und ebenfalls Antheridien genannt werden müssen,

Die Scheinsamen (opseospermata) sind a solche Gebilde, denen die nöihige Grösse und die eigenthümliche Umhüllung der wahren Samen mangelt. "Beide 


\section{$-87$}

Merkmale sind aber gewiss nicht hinreichend, un eine besondere Art von Samen zu begründen. Was erstens die Grösse betrifft, so könnte dieselbe von einigem Werthe sein, wenn sie bei den wahren Samen constant wäre, da sie es aber nicht ist, da die wahren Samen selbst untereinander so verschieden sich zeigen, dass die einen vielmal grösser als die andern sind, da es sehr kleine wahre Samen griebt (ja eben so kleine, als die sogenannten Scheinsamen, weil mehrere bisher für Samen gehaltene Organe in Wahrheit erst die Capseln sind, in denen die Samen liegen, wie in dem vorhinerwähnten Beispiele von Ectocarpus), so kann die Grösse im Mindesten keinen Unterschied begründen. Eben so wenig kann der Mangel einer eigenthümlichen Umhüllung die Scheinsamen unterscheiden, da nach dem Verfasser die "Samenhülle " den wahren Samen mehrerer Algen ebenfalls fehlt. Die Gelinmembran ist aber, wie bei den wahren Samen, so auch bei den Scheinsamen vorhanden, nur sehr dünn, dass sie nicht leicht eikannt werden kann. - Ob nun alles, was der Verfasser "Scheinsamen " nennt, wirkliche Samen seien oder nicht, will ich nicht entscheiden. Ich sehe aber keinen Grund, warum sie es bei Ulothrix, Stygeoclonium und Fischeria nicht sein sollten, da sie die einzigen Samen sind und keimen. Wo sie bei den Laminaricen ror'kommen, da sind in der nämlichen Gattung ebenfalls keine andern Samen bekanut. Unter den Isocarpeen ist Diplostromium die einzige Gattung, bei welcher Kützing ausser den "Scheinsamen " noch "Samen und Spermatoidien " annimmt. Es scheint mir aber, dass die Zeichnungen, welche der Verfasser dazu liefert, noch andere Erklärungen zulassen, und dass sie jedenfalls, als einziges Beispiel unter den Isocarpeen, nicht die Annahme einer dreifachen Samenbildung begründen können. Ich selber kann an Punctaria temuissima Grev. (mit welcher Diplostromium tenuissimum synonym sein soll) nur Eine Art von Samen fiuden. - Bei den Isocarpeen führt der Verfasser zwei Beispiele von Scheinsamen auf, nämlich bei Sphterococcus Lamberti und Ctenodus Labillardieri. In Ctenodus sind es "längliche solide feste Körperchen, " die in der Corticalschicht zwischen den Gewebe liegen. Der Abbildung nach scheinen es noch unentwickelte oder abortirte Mutterzellen der Vierlingsfrüuchte su sein. In Sphor'ococcus könnten es ebenfalls Vierlingsfrüchte sein, denn für diese ist die Vierzahl zwar Regel aber nicht Gesetz. Der Verfasser selbst bildet bei Plocamium Vierlingsfrüchte ab, die aus mehr als 


\section{$-88$}

4 Sämlingen bestehen. Ich selbst glaube sie in dieser Gattung in der Zahl von 5 bis 9 beobachtet zu haben; ebenso kommen bei der Pollenbildung der Phanerogamen statt der regelmässigen Zahl 4 , zuweilen ausnahmsweise $5-8$ Pollenkörner in einer Mutterzelle vor. Ich glaube daher, dass es näher liegen möchte, die sogenannten Scheinsamen von Sphcerococcus Lamberti für Vierlingsfrüchte mit exceptioneller Spermatidienzahl, als für samenähnliche Nebengebilde zu erklären.

Die Nebensamen (paraspermatia) kommen bei den Isocarpeen nur unter den Hüllenfrüchtigen vor. Sie erzeugen sich entweder neben den wahren Samen oder treten auch an deren Stelle allein in den Hüllenfrüchten auf. Sie haben überhaupt mit den Spermatoidien viel Aehnlichkeit, und entstehen auch auf ähnliche Weise, mit dem Unterschiede jedoch, dass sie als eine einzelne Vollzelle auftreten. Von den Samen unterscheiden sie sich dadurch, dass sie kleiner und heller gefärbt (hellbräunlich) sind, und dass sie aus den Aesten besonderer, büschelartig verzweigter Nebenfäden entstehen, während die Samen unmittelbar an der innern Wand der Fruchthülle an der Basis ihrer Nebenfäden sich bilden. - Der Verfasser macht mit Recht auf diese besondern Organe der Fucaceen aufmerksam, die bis dahin den Algologen entweder entgangen oder von denselben unrichtig als junge Samen betrachtet worden waren. Er beweist vorzüglich aus den zeitlichen und xäumlichen Verhältnissen ihres Vorkommens, dass sie ein von den Samen verschiedenes Gebilde sind. - Ich kann aber Kützing nicht beistimmen, wenn er die Nebensamen als einzelne Vollzellen betrachtet, und sie dadurch von den sogenannten Spermatoidien unterscheidet. Es sind Mutterzellen oder Kapseln, in welchen viele kleine Zellen enthalten sind; sie öffnen sich und entleeren ihren Inhalt. - Bei den Heterocarpeen will der Verfasser Nebensamen in der Kapselfrucht gefunden haben. Er führt als Beispiele wenige Gattungen an. Man findet aber die Erscheinung mehr oder weniger deutlich in allen den Kapselfrüchten, welche von $J$. Agardh Coccidien und Keramidien genannt wurden. Es sind jedoch keine Nebensamen, sondern junge, noch unentwickelte Samen. In den bezeichneten Kapselfrüchten entwickeln sich die Samen nicht zu gleicher Zeit mit einander, sondern nacheinander. Man trifft daher vollkommen ausgebildete Samen neben solchen, welche erst entstehen, und ausserdem häufig alle Mittelstufen zwischen beiden. 
Fassen wir nun noch das Gesagte über die samenähnlichen Nebengebilde des Verfassers zusammen, so ergiebt sich folgendes: Die « Spermatoidien » der Isocarpeen sind Haufen von wahren Samen. Die «Spermatoidien » der Heterocarpeen sind Antheridien. Die «Scheinsamen » der Isocarpeen sind wahre Samen. Die « Scheinsamen $n$ der Heterocarpeen sind wahrscheinlich ebenfalls ein Stadium der wahren Samenbildung. Die Nebensamen der Heterocarpeen sind noch unentwickelte wahre Samen. Bloss die "Nebensamen " der hüllenfrüchtigen Isocarpeen sind ein besonderes Gebilde, dessen Verhältniss zur Fortpflanzung noch unbekannt ist.

Nachdem ich das Wesentlichste der physiologischen und anatomischen Darstellung kurz betrachtet habe, so will ich zu dem Srstem des Verfassers übergehen. Derselbe theilt die Algen in zwei Classen: Isocarpeen oder Gleichfrüchtige und Heterocarpeen oder Ungleichfrüchtige. Die erstern sind solche, deren " wahre Früchte, bei derselben Species, cinerlei Bildung und Form haben. "Die zweiten sind solche, deren wahre Früchte, bei derselben Species, in zweierlei Gestalt auftreten. " Die erstern entsprechen den Chlorospermeen und Melanospermeen von IIarcey, den Zoospermeen und Fucoideen von J. Ayardh, den Zoosporeen, Synsporeen und Aplosporeen von Decaisne, den Confervacecin und Phyceen von Endlicher. Die zweiten entsprechen den Rhodospermeen von Harvey, den Florideen von J. Agardh und Endlicher, und den Choristosporeen von Decaisne. Diese Eintheilung der Algen in zwei Gruppen ist ein wesentlicher Fortschritt. Wenn sie bisher in drei oder vier Gruppen eingetheilt wurden, so waren diese einander nicht logisch coordinirt; sondern die zwei oder drei ersten Gruppen gehörten demselben allgemeinen Begriffe an, und waren logisch bloss durch diesen von der letzten Gruppe verschieden. So sehr nun aber der Verfasser durch das Materielle der Anordnung das Natürliche und Richtige getroffen hat, so wenig genügt, wie ich glaube, die Form des Unterschiedes. Die Isocarpeen sollen sich bloss durch Eine Art, die. Heterocarpeen durch zwei Arten von wahren Samen fortpflanzen. Kützing lässt die Isocarpeen sich nicht bloss durch « Samen, • sondern auch durch « Scheinsamen s (Ulothrix) und durch « Zellenkügelchen oder Gonidien » fortpflanzen. Er hat aber keinen bestimmten und festen Begriff von a wahren Samen, aufgestellt, und somit auch nicht bewiesen, dass die - Scheinsamen " und "Gonidien, D wodurch dic Isocarpeen sich fortpflanzen, 


\section{$-90$}

nicht ebenfalls wahre Samen seien. Hälte er die Entwicklungsgeschichte der keimenden Gonidien untersucht, so würde er gefunden haben, dass es gar keine Gonidien, sondern wirkliche Zellen sind. Bei den Heterocarpeen hält der Verfasser beide Arten von Samen für wahre Samen, doch auch bloss aus äussern Gründen. - Nach meiner Ansicht ist consequenterweise nur zweierlei möglich. Entweder man erklärt alle Zellen, wodurch sich die Algen fortpflanzen, für wahre Samen. Dann müssen nicht bloss die Heterocarpeen, sondern auch die sogenannten Isocarpeen, vorausgesetzt, dass die Angaben des Verfassers selbst über das Keimen der Gonidien richtig sind, als ungleichfrüchtig bezeichnet werden. Oder man setzt für die wahren Samen einen bestimmten morphologischen Begriff fest, welcher aber natürlich nur je für eine Stufe des Pflanzenreiches gültig ist. Dann besitzen sowohl die Isocarpeen als die sogenannten Heterocarpeen bloss eine einzige Art von wahren Samen, und müssen beide als gleichfrüchtig bezeichnet werden ; durch die wahren Samen geschieht die Fortpflanzung, durch die unächten Samen die Vermehrung.

Die Isocarpeen zerfallen nach dem Verfasser in Gymnospermece a ohne zellige Fruchthülle, " und in Angiospermece " mit zelliger Fruchthülle. "Durch diese Eintheilung wird zwar eine natürliche Gruppe von dem Ganzen ausgeschieden, aber die beiden Abthcilungen sind einander durchaus nicht logisch coordinirt, weil sie nicht durch den allgemeinsten und wesentlichsten, sondern durch einen untergeordneten Begriff verschieden sind. Die Angiospermeen enthalten einen cinzigen, die Gymnospermeen enthalten eine ganze Menge von Typen, von denen einige mil den Angiospermeen weit mehr, als mit den übrigen Gymnospermeen verwandt sind.

Die Gymospennede werden in 5 Ordnungen eingetheilt : 1) Eremospermece "mil oberflächlichen, vereinzelten Nacktfrüchten, " 2) Cryptospermece " mit Nacktfüchten, welche der Rinden-oder Markschicht des Phycoms eingesenkt sind, „ 5) Pycnospermece a mit oberflächlichen, in Häufchen vereinigten Nacktfrüchten. " Hier wird das gleiche Verfahren, wie bei der Eintheilung der Isocarpeen, wiederholt: es werden zwei Gruppen, die Pycnospermeen und Cryptospermeen ausgeschieden, und alles was übrig bleibt, so wenig es auch zusanmen passen magg, muss eine eigene Ordnung Eremospermeen bilden. Ueberdem 


\section{$-91$}

sind die Ordnungen nach einem äusserlichen und unwesentlichen Nerkmale bestimmt, und können daher bloss als künstliche einen Werth haben, wenn sie dazu dienen, die Pflanzen leicht aufzufinden. Ich glaube aber nicht, dass das letztere erreicht worden sei. So würde es einem, der mehrere Algen genau untersucht hat, aber noch nicht weiss, wohin sie im System gehören, doch schwerlich einfallen Protococcus, Microcystis, Nostoc, Bangia, Ulothrix, Spirogyra, Itydrodictyon, Ulva, etc. unter einer Abtheilung zn suchen, welche durch " oberflüchliche, vereinzelte Nacktfrïchte 》 definirt ist. Es möchte ihm schwerlich einfallen Chcetophora, Thorea, Batrachospermum, etc. in einer Ordnung $z u$ suchen, bei welcher die Nacktfrüchte in der "Rinden-oder Markschicht » liegen sollen. Es möchte ihm endlich schwerlich einfallen, Spatoglossum und Stypopodium oder verschiedene Formen von IIalyseris und Dichophyllium (wo der Verfasser selbst die Samen zerstreut nennt) in einer Abtheilung zu suchen, bei welcher die Nacktfrüchte in "Ï̈ufchen vereinigt » sein sollen; ebenso wenig Chorda, wo die Samen die ganze Oberfläche dicht bedecken (überhaupt ist nicht einzusehen, wie Chorda und Chordaria in zwei verschiedene, durch die Fructification definirte Ordnungen gestellt werden können).

Die erste Ordnung ERemospermeae wird in כ Unterordnungen eingetheilt : 1) Mycophycece "meist farblos, selten gefürbt, pilzartig;" 2) C'hamcephycece " meist klein, microscopisch, grün (selten purpurn), einzeln oder in eine formlose Schicht vereinigt, sehr selten fadenförmig; " 5) Tiloblastece "fädig (trichomatisch), zellig; „4) Dermatoblastece " häutig (phyllomatisch), zellig; ” 引) C'cloblastece "schlauchfürmig (coelomatisch). " - Wie alle nach den regetativen Organen gemachten Eintheilungen, wenn sie consequent durchgeführt werden, unnatürlich ausfallen, so auch diese 5 Unterordnungen. Die erste zwar, nänlich die der Mycophycece, ist sehr natürlich, da sie bloss Pilze enthält, aber auch unter den übrigen Ordnungen sind noch einzelne Pilze vertheilt, so wenigsiens die Chroolepusarten. - Die zweite Unterordnung Chamephycece enthïlt meist einzellige Pflanzen, darunter aber einige Gattungen, welche mehrzellig sind, und welche daher nicht hieher gehören, wie Scenodesmus, Micrasterias, Splucerastrum, Botrydina. - In der dritten Unterordnung Tiloblastece sind namentlich in Bezug auf Fortpflanzung die verschiedenartigsten Typen vereinigt. Sie zer- 


\section{$-92$}

fallen daher in Unterabtheilungen, welche theils nach der An- und Abwesenheit von Wurzeln und nach der Natur der Zellen (perenchymatisch und epenchymatisch oder parenchymatisch), theils nach der Stellung der Samen definirt werden. Was die Natur der Zellen betrifft, so ist, wie ich schon oben sagte, eine Verschiedenheit in der Art, wie sie der Verfasser aufstellt, gar nicht vorhanden; und selbst der äussere Anschein, welcher zur Aufstellung jenes Unterschiedes Veranlassung gab, ist so variabel, dass es mir wenigstens unmöglich ist, zwischen mehreren Tiloblasteen mit perenchymatischer und epenchymatischer Structur und mehreren Tiloblasteen mit parenchymatischer Structur irgend einen Unterschied zu finden. Die An- und Abwesenheit der Wurzel ist, wenigstens für die Unterscheidung, ein eben so unsicheres Merkmal. Denn wenn es auch richtig ist, dass nur die einen Tiloblasteen das Vermögen besilzen, Wurzeln zu erzeugen, so mangeln doch diese Wurzeln so häufig (in vielen Gattungen sind sie sogar nur ausnahmsweise vorhanden), dass sie wenigstens nicht als Unterscheidungsmerkmal gebraucht werden können. Besser dagegen sind die von der Stellung der Samen hergenommenen Unterschiede, und die Abtheilungen Asemospermece mit " unbekannten Samen, " Mesospermece mil "zwischenständigen Samen, "Paraspermece mit "seitenständigen Samen, "Hypospermece mit " unterständigen Samen, " Endospermece mit "innenständigen Samen » und Ectospermece mit " seiten- oder endständigen Samen ๖ bilden, wenn auch nicht nalïrliche, doch künstliche und meist erkennbare Gruppen. - Die vierte und fünfte Unterordnung Dermatoblastece und Cœloblastece enthalten, obwohl sie klein sind, jede wieder eine Menge ganz verschiedener Typen. - So wenig die fünf Unterordnungen der Eremospermeen der Natur entsprechen, so sind sie dagegen im Allgemeinen leicht zu erkennen, jedoch mit einigen Ausnahmen. So würde man nach den Diagnosen wahrscheinlich Micrasterias und Tetraspora unter den Dermatoblasteen statt unter den Chamaphyceen, Anadyomene unter den Dermatoblasteen statt unter den Coeloblasteen, die Chareen unter den Tiloblasteen statt unter den Coeloblasteen suchen. - Die zweite und dritte Ordnung der Gymnospermeen, nämlich die Cryptospermece und Pycnospermece werden in keine Unterordnungen eingetheilt; ebenso zerfällt die zweite Zunft der Isocarpeen, nämlich die Angiospermece weiter in keine Ordnungen und Unterordnungen. 


\section{$-93$}

Die zweite Classe der Algen, die Heterocarpeae, wird so definirt: "Ungleichfrüchtig, purpurn oder rosenfarbig. Früchte zweihäusig : 1) Capselfrüchte vielsamig, mit Samen, die aus der Markschicht entstehen; 2) Vierlingsfrüchte viersamig mit Sümlingen, die aus der Rindenschicht entstehen. \$ Ich habe oben schon über diesen Character der Heterocarpeen gesprochen und gezeigt, dass er nicht ganz genügt, um sie von den Isocarpeen zu unterscheiden. Er passt auch nicht ganz für alle Heterocarpeen; die Farbe gilt durchaus nicht für alle Arten ; dass die Samen der Capselfrüchte aus der Markschicht, die der Vierlingsfrüchte aus der Rindenschicht entstehen, ist für die Callithamniaceen entschieden unrichtig; dass die Vierlingsfrüchte viersamig sind, trifft bei Plocamium nach des Verfassers eigener Zeichnung nicht ein.

Die Heterocarreen werden in zwei Zünfte getheilt : 1) Paracarpece, "Vieplingsfrüchte entweder hervorstehend, oder ohne Ordnung in der Rindenschicht liegend, zwischen den Zellen (nicht in besondere Fächer eingeschlossen); " 2) Choristocarpece, "Vierlingsfrüchte (nie hervorstehend), in besondere Fächer der Rindenschicht eingeschlossen. " Es frägt sich nun vor allem aus, was diese "Fächer " der Choristocarpeen sind. In dem Capitel über die Fruchtbildung der Algen sagt der Verfasser, dass die Vierlingsfrüchte bei den Paracarpeen " ohne Ordnung wie jede gewöhnliche Zelle zwischen den Zellen liegen, dass dagegen bei den Choristocarpeen die umgebenden Zellen ordentliche Fächer bilden, in welchen die Vierlingsfrüchte bequem einlogirt sind. "Vergleicht man nun aber mit diesen Angaben die Abbildungen, oder besser die Natur, so sieht man, dass die Fächer bloss durch die gallertartig verdickten Mutterzellen erzeugt werden. Die Vierlingsfrüchte der Choriostocarpeen liegen gerade so zwischen den Rindenzellen wie diejenigen der Paracarpeen. Bei jenen ist aber die Mutterzelle (Gelinhülle, Gelinzelle) in der Regel dicker, bei diesen ist sie in der Regel dünner; bei jenen liegen daher die Samen der Vierlingsfrüchte mehr getrennt von den übrigen Zellen, bei diesen sind sie ihnen mehr genähert. Die umgebenden Zellen verhalten sich in beiden Fällen gleich passiv in Bezug auf die Vierlingsfrüchte, und wenn man von denselben in dem einen Falle, mit Recht oder Unrecht, sagt, dass sie ein "Fach " bilden, so wird man es im andern Falle, ganz mit dem gleichen Rechte oder Unrechte, ebenfalls thun mïssen. - Studirt 


\section{$-94$}

mau nun aber vollends die Entwicklungsgeschichte, so findet man, dass der von dem Verfasser angegebene Unterschied zwischen Paracarpeen und Choristocarpeen im Geringsten nicht vorhanden ist; ebenso zeigt es sich, dass man überhaupt nicht von Fächern sprechen darf, oder man wollte denn jede von Zellen umgebene Zelle in ein Fach einlogirt sich denken. - Abgesehen nun davon, dass der Unterschied zwisehen Paracarpeen und Choristocarpeen rein quantitativer Natur ist, und dass er daher keine besondern Begriffe begründen kann ; so ist er auch bloss als künstliches Unterscheidungsmerkmal untauglich, weil alle möglichen Uebergangsstufen vorkommen und weil daher in einzelnen Fällen nicht der Character entscheidet, wohin eine Pflanze gehört, sondern ihre natürliche Verwandtschaft.

Die Zunft der Paracarpeae zerfällt in 5 Ordnungen : 1) Trichoblastece, a Phycom fadenförmig, oft berindet; Capselfrüchte ausserhalb, mit häutiger, gallertartiger Fruchthülle, welche mit kugeligen, dicht zusammengeballten Samen ausgefüllt ist (ohne Samenboden);》 2) Epliblastece, "Phycom aufwüchsig, bald hautartig, bald fadenförmig; Capselfrüchte entweder eingesenkt oder ausserhalb, endständig, mit zelliger Samenhülle und verlängerten Samen (Samenboden fast fehlend) ; " 5) Periblastece, "Phycom bald pereginetisch, bald amphigenetisch; fadenfürmig oder blattartig; Capselfrüchte entweder eingesenkt oder ausserhalb, mit kugeligen Samen, welche an einen besondern Samenboden befestigt sind. „ - Die erste dieser drei Ordnungen ist sehr natürlich. Die zweite dagegen enthält zwei Typen, die gewiss so verschieden als möglich sind, nämlich Porphyra und die Corallincen. Porphyra, welche zu den Isocarpeen gehört, wird von dem Verfasser, in Folge von oberfächlicher Betrachtung der Samenbildung, zu den Heterocarpeen gestellt. Die Samenbildung in Porphyra ist aber, was die Zellenbildung betrifft, ganz versehieden von der Entwicklung der Vierlingsfrüchte, stimmt dagegen vollkommen mit der Samenbildung von Ulva überein ; mit dem Unterschiede jedoch, dass in Ulsa in Einer Zelle gewöhnlich 4 neben einander liegende Samen entstehen, während ich in Porphyra sulgaris in Einer Zelle 4 bis $\$$ und 12 , ja bis 60,100 und darüber neben und hinter einander liegende Samen finde (nicht 4, wie der Verfasser für Porphyra capensis angiebt). Wenn Porplyra wieder an ihre Stelle, wohin sie gehört, gebracht ist, so blei- 


\section{$-95$}

ben in dieser Ordnung noch zwei Typen übrig, die gewiss auch nicht zusammenpassen, auf der einen. Seite Iildenbrandtia und Peyssonelia, auf der andern Seite die Spongitece und die Corallinece. Welche Stelle die letztern beiden Familien im System einnehmen sollen, scheint mir noch sehr zweifelhaft. Unrichtig aber werden von Kützing denselben längliche Samen zugeschrieben, denn in den meisten Gattungen sind diese sogenannten Samen Mutterzellen, welche sich in vier (vierjochige) Samen getheilt haben; in Melobesia membranaeea finde ich sie bloss aus zwei Zellen bestehend. - Aus der dritten Ordnung müssen die Gattungen IIelminthora und Naccaria in die crste Ordnung gebracht werden.

Die zweite Zunft Choristocarpese wird ebenfalls in 5 Ordnungen getheilt: 1) Axonoblastere, "Phycom fadenförmig, mit gegliederten, confervenartigen, fruchttragenden Aestchen besetzt. Structur perigenetisch. Capselfrüchte seitlich, gesondert, von einer deutlichen Capselöffnung durchbohrt; Samen verlängert, birnförmig, gebüschelt, am Grunde in einen Stiel verschmälert; Samenboden fehlend. Vierlingsfrüchte in besondern Fruchtästen oder in Nebenästchen. Spermatoidien sehr deutlich. Nebensamen mangelnd; " 2) Cooloblastece, "Phycom meist fadenförmig, röhrig, selten sackartig. Structur parenchymatisch. Capselfrüchte seillich; Samen rundlich, zuerst an einem baumartigen Samenboden angeheftet. Vierlingsfrüchte bald in mehr oder weniger deutlichen Fruchtästen, bald in Phycom eingesenkt. Nebensamen zwischen den Samen liegend, gehäuft (Spermatoidien mangelnd); " 5) Platynoblastece, "Phycom blattartig, gestielt, parenchymatisch. Capselfrüchte ausserhalb, gesondert, mit runden Samen, welche an dem Samenboden angeheftet sind. Vierlingsfrüchte bald im Blattkörper, bald in besondern, oft blattartigen Fruchtästen. (Deutliche Spermatoidien oder in Trauben vereinigte Nebensamen). " Die Unterschiede reduciren sich darauf, dass die Axonoblasteen ein fadenförmiges, die Coeloblasteen ein hohles, die Platynoblasteen ein blattartiges Phycom besitzen. Es ist diess eine künstliche Eintheilung, welche zwar die Pflanzen nicht nach ihren natürlichen Verwandtschaften zusammenordnet, nach welcher es aber, wenn sie consequent angewendet wird, möglich sein mag, die Galtungen zu erkennen. Wie der Verfasser die Gattungen eingetheilt hat, ist diess aber nicht möglich. Bei den Axonoblasteen, welche durch ein "fadenförmiges Phycom * definirt sind, giebt es mehrere Ar- 


\section{$-96$}

ten und Gattungen, welche der Verfasser selber a zusammengedrückt 》 oder " flach n nennt. Bei den Platynoblasteen, welche durch ein " blattartiges Phycom » definirt werden, stehen mehrere Gattungen, welche der Verfasser selbst «fadenförmig und zusammengedrückt oder verflacht " nennt. Was für ein Unterschied ist nun zwischen jenen und diesen Gattungen, und warum stehen sie in zwei Ordnungen, welche verschieden definirt werden? - Die Gestalt des Phycoms ist zwar nicht der einzige Unterschied zwischen den drei Ordnungen; es werden noch zwei andere Unterschiede erwähnt, die aber nicht vorhanden sind. Bei den Axonoblasteen sollen die Samen a verlängert birnförmig, " bei den Coeloblasteen sollen sie "fast rund, " bei den Platynoblasteen "rund" sein. Aber in Bonnemaisonia, welche bei den Coeloblasteen und in Rytiphloea, welche bei den Platynoblasteen steht, sind die Samen der Capselfrüchte eben so schön verlängert, als bei den Gattungen der Axonoblasteen. - Die Axonoblasteen sollen eines Samenbodens ermangeln, die Coeloblasteen und Platynoblasteen sollen einen solchen besitzen. In der ersten Ordnung entstehen nun aber die Samen eben so gut an einem Samenboden, als in den beiden letzten Ordnungen.

Es würde mich zu weit führen, wenn ich mehr ins Specielle der Phycologia generalis von Kützing eingehen wollte. Ich bedaure, dieses nicht zu können, da ich dem Verfasser in der Begründung natürlicher Familien und Gattungen und in der Aufklärung von manchen Irrthümern eine verdiente Anerkennung zollen müsste, welche ich ihm bei der Aufstellung grosser allgemeiner Gruppen meistens zu versagen genöthigt war. Kützing besitzt eine Menge eigener Untersuchungen und Beobachtungen, wie keiner der neuern Algologen. Er hat ferner, wie es vor ihm keiner versuchte, die anatomischen, physiologischen und systematischen Verhältnisse der Algen durchaus auf die Zelle zurückgeführt; er hat sich somit bestrebt, der Phycologie eine rein wissenschaftliche Grundlage zu geben. So sehr ich nun aber das Ziel, das sich der Verfasser geselzt, als ein richtiges anerkenne, so wenig kann ich mit seiner Methode einverstanden sein. Die Nethode Külzing's ist ein systematisches Aufheben jedes absoluten Unterschiedes. Rr hat dieser Methode eine grössere Anwendung zu geben versucht, als es bis dahin geschehen ist. Kützing erkennt keinen absoluten Unterschied zwischen Thier und Pflanze an, denn « niedere thierische Bildungen gehen unmittelbar 


\section{- 97}

in vegetabilische, und umgekehrt letztere in erstere über v; a die Diatomeen führen ebensowohl ein regetabilisches als animalisches Leben »; \& Infusorien verwandeln sich in niedere Algen. " Kützing erkennt keine absoluten Unterschiede zwischen den einzelnen Arten, Gattungen, Familien, Ordnungen, Classen des Pflanzenreiches an, denn Protococcus viridis verwandelt sich in Schizogonium, Prasiola, Alyspheria, Parmelia und Palmella; - Protococcus umbrimus geht in Chroolepus und Lecidea über; aus Lyngbya obscura entwickelt sich Enlothrix, Leptothrix, Mastichonema; - Gongrosira entsteht aus Vaucheria und zwar so, dass " die Alge unten an der Basis noch ganz eine Vaucheria ist, und sogar noch Seitenzweige besitzt, welche Vaucherienfrüchte tragen; „ nach oben zu vel-wandelt sich der Vaucherienschlauch in gegliederte Fäden, die sich höchst regelmässig dichotomisch verzweigen, und deren "Glieder zuletzt torulos werden und, wenn sie zu hologoninischen Samenzellen geworden sind, abfallen; " - aus Protococcus entsteht Botrydium, aus Botrydium entwickeln sich bald Vaucherien bald Protonemaarten und Moose; - Protonema entsteht aus Moosblättern und verwandelt sich wieder in junge Moospflanzen, etc., etc. - Sowic Kützing in der Systematik den absoluten Unterschied nicht gelten lässt, so verwirft er ihn auch in der Physiologie und Anatomie. Er nimmt keine absolute Verschiedenheit zwischen Gonidien oder Zellenkügelchen und Zellen an ; denn die Gonidien gehen in Zellen über, und eine Art von Zellen (die monogonimischen Zellen) heisst auch Gonidien. Kützing unterscheidet zwar verschiedene Zellenarten, aber lässt sie in einander übergehen. Er nimmt keinen absoluten Unterschied zwischen Zelle und Tangkörper an, denn es giebt Formen, wo " der Algenkörper mit demselben Rechte in der gesellig-freien, aber auch darum äusserlich unbestimmt begrenzten, daher formlosen Vereinigung zu suchen ist, wie in der cinzelnen Zelle. " Es sollen ferner zwischen den besondern Arten der Tangkörper keine absoluten Unterschiede vorkommen u. s. w.

Dieses principielle Vernichten der absoluten Unterschiede hat denn die nothwendige Folge, dass nirgends bestimmte, feste und sichere Begriffe entwickelt werden. Der Verfasser, welcher die absoluten Begriffe aus Grundsatz verwirft, begnügt sich überall mit relativen Begriffen. Dadurch entsteht sowohl in der Physiologie und Organographie als in der Systematik eine schwankende Unbe- 
stimmtheit, welche das Verständniss und das Bestimmen sehr erschwert. Doch das ist nicht die einzige Folge der Külzing'schen Methode. Eine zweite ist die, dass dieselbe Pflanze in verschiedenen Entwicklungsstadien zuweilen mehrfach in verschiedenen Familien nnd Ordnungen aufgeführt wird. Eine dritte Folge ist ein unbegrenztes Vermehren ron Gattungen und namentlich ron Arten; es ist diess natïrlich, denn ein relativer Unterschied ist unendlich theilbar.

Es kann hier nicht der Ort sein, die Methode Kützing's zu widerlegen. Es lässt sich zwar, wie ich glaube, theoretisch zeigen, dass sie unrichtig ist, weil sie den Gesetzen der Logik widerstreitet, und weil ihre Consequenzen ad absurdum führen. Aber ein theoretischer Reweis, und möchte er auch noch so mathematisch richtig sein, genügt mit Recht in unserer Zeit nicht mehr. Der Gegner würde sich immer der Einsprache bedienen: die Thatsachen sind doch so. Die Kützing'sche Methode muss demnach durch Thatsachen und Begriffe widerlegt werden. Es muss nachgewiesen werden, dass die Beobachtungen, auf die sie sich stützt, theils ungenau sind, theils naturgemäss anders erklärt werden müssen. Es muss ferner nachgewiesen werden, dass es wirklich möglich ist, absolute Unterschiede aufufinden, und denselben eine solche Form zu geben, dass die Annahme von Uebergängen und Verwandlungen von selbst unmöglich wird.

Abgesehen nun davon, dass der Verfasser bloss relative Unterschiede und Begriffe sucht, ist ferner ein davon unabhängiges, schwankendes und ungenaues Verfahren bei den Definitionen nicht zu billigen. Es contrastirt dieses Verfahren gegen das Bestreben nach exacten Begriffsbestimmungen, welches sich sonst in den neuern systematischen Werken zeigt, und welches auch mit relativen Begriffen vereinbar ist. Ich rechne daher, 1) dass für den gleichen Begriff verschiedene Ausdrücke und nicht ein einziger constanter Ausdruck gebraucht werden; ferner dass zuweilen der gleiche Ausdruck für verschiedene Begriffe angewendet wird; 2) dass die allgemeinen (Ordnungs- oder Familien-) Begriffe nicht selten so definirt werden, dass einzehe Gattungen mit dieser Definition im Widerspruche stehen. So heisst, um ein Beispiel für das crstere zu geben, die gleiche Zellenar'i abwechselnd " monogonimische Zelle, monogonimischer Zellenkern, Zellenkern, Kern, Gonidium, Kügelchen, Körnchen, und Glied „ (beim fadenförmigen Phycom). Die gleiche Art des Tangkörpers heisst " blattartiges 
Phycom (phycoma foliaceum), naches Phycom, blattartiger Theil des Phycoms, Phyllom, phyllomatisches Phycom, membranartiges Plıyeom. D Die Reihe von Achsenzellen, welche bei vielen Algen getroffen wird, heisst "fadenförmige gegliederte Centralachse, " anderswo "Trichom; " - ausserdem bedeutet aber Trichom gewöhnlich einen confervenartigen Zellfaden, welcher für sich ein ganzer Algenkörper (nicht bloss 'Theil eines solchen) ist; - der Familie der Hormidiece wird ein "hologonimisches Trichom mit einfachen oder längsgetheilten Zellen " zugeschrieben; bei den Gattungsbeschreibungen heisst dieses Trichom aber "zelliges Phycom, " ein Ausdruck der sonst von Trichom ganz rerschieden ist; - endlich bei Chcetophora und andern Gattungen bedeutet Trichom bloss die einzelnen Gliederfäden, welche zusammen den Algenkörper bilden; in andern Familien heissen die gleichen Gliederfäden gewölunlich Aeste oder Fäden. - Ich habe schon bei den Zünften, Ordnungen und Unterordnungen gezeigt, dass die Diagnosen nicht immer fïr alle ihnen subordinirten Gattungen passen. Das gleiche finden wir auch bei den Familien, z. B., Desmidiece, "aus symmetrisch greordneten Zellen zusammengesetzt; v dieser Character mangelt den Gattungen Closterium, Hicrotheca, Pentasterias, Euastrum; - Palmellea " gestaltlos, gallertartig; " es giebt nun aber mehrere Gattungen mit "kugeligem Phycom, " und mehrere Arten, welche ein "pulverartiges " Lager bilden ; - Hydrococcece "gallertartig;" das Phycom der Gattung Entophysalis heisst "knorpelartig, hart. „ Ich will keine Beispiele weiter anführen. Sehr oft wird eben ein Merkmal als allgemein güllig hingestellt, während es durch ein " meist, gewöhnlich, in der Regel » beschränkt sein sollte.

Die neuern Algologen versuchten die Algen nach der Fortpflanzung einzutheilen. Kützing trennt bloss die beiden Classen Isocarpeen und Heterocarpecn nach Merkmalen der Samenbildung. Die Unterabtheilungen werden nach Verschiedenheiten der Fruchtstellung und des anatomischen Baues gemacht. Es sind dieses beides reggetative Merkmale, denn die Fruchtstellung überhaupt, und namentlich wie sie hier berücksichtigt wird, hängt allein von dem Bau der Pllanze ab. Erst bei den Familien wird wieder auf die Samenbildung Rücksicht genommen. In dem Systeme Kützing's sind daher die Isocarpeen sowohl als die Heterocarpeen so ziemlich nach ihrer vegetativen Entwicklung in eine Reihe gestellt. 
Pflanzen, die ihrer Fructification nach einander nahe verwandt sind, stehen weit von einander, wie z. B. die Palmelleen, die Hormidieen, die Ulkaceen, Cutleria und Porphyra. Pflanzen, die ihrer Fructification nach möglichst verschieden sind, stehen beisammen, so die Ulotricheen, Conferceen, Zyynemeen, IJ drodictyeen und Chantransieen; oder die Enteromorpheen und Vaucherieen; oder die Dasycladeen und Chareen, etc. - Es ist gewiss sehr zu bedauern, dass der Verfasser mit seinem reichen Material von Beobachiungen nicht versucht hat, eine wenigstens für die Hauptgruppen einzig durch die Samenbildung characterisirte systematische Eintheilung herzustellen. Es hätte das nicht bloss die Erkenntniss der Algen in systematischer Hinsicht sehr gefördert, sondern gewiss auch manchen physiologischen Punkt sicherer festgestellt.

\section{ANORDNUNG DER GATTUNGEN NACH ENDLICHER.}

\section{A. CONFER VACEE.}

Fortpflauzung durch Sporidien, welche aus dem Inhalte einer jeden Laubzelle einzeln oder zu mehreren entwhen.

I. PALveLLEAE. Zellen fast kugelig, einzeln oder lagerförmig beisammen.

1. Protococcoidleae. Ohne schleimige Unterlage.
1. Profococcus $\mathrm{Ag}$.
2. II aemulococcus $\mathrm{Ag}$.
5. Chlorucorcum Grev.

4. Pleurococcus Menegh.

5. Stereococcus kütz.

๖. Coccochloreae. Mit deutlicher schleimiger Unterlage.
6. Palmella Lyngb.
7. Coccochloris Spr.
8. Microcyslis Kütz.
9. Anacyslis Menegh.

10. Oncobyrsa Ag.

11. Micraloa $\Lambda$ g.

12. Bolrydiwa Breb.

11. NOSTOCHINEAE. Zellen fast kugelig, reihenweise in Fäden geordnet; Fäden in einer schleimigen Unterlage. 


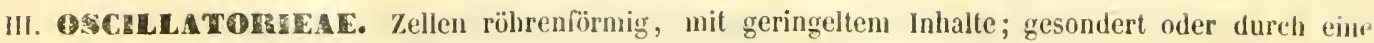
schleimige Unterlage vereinigt.

1. Fivalan'icae. Röhren von einer durchsichtigen kugelfürmigen Zelle ausgehend.

16. Gloiotrichia J. Ag.

17. Rivularia Roth.
18. Zonolrichiı J. Ag.

19. Diplotrichin J. As.

2. Oscillatorinae. Röhren cylindrisch.

20. Oscillaria Bosc.

21. Hicrocoleus Desm.

22. Calothrix Ag.

¿5. Lyngbya $\mathrm{Ag}$.
24. Scytonema As:.

23. Sphueroplea $\mathrm{Ag}$.

26. Beggiatoa Trevis.

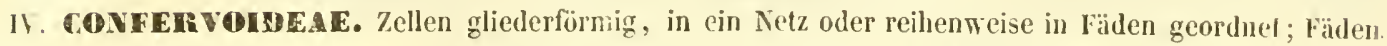
gesondert oder durch eine schleimige Unterlage rereinigt.

1. Kydrodictyeac. Zellen in ein netzförniges Laub vereinigt.

27. Ilydrorliclyon Roth.

28. Hicrodiclyon Dec.

29. Tularodiclyon Endl.

2. Zygmemeac. Gliederfäden zuerst frei, dann durch Querröhren copulirt.

50. Mougeotia Ag.

51. Zygnema Ag.

52. Spirogyra Link.

כ. Conferereac. Gliederfäden einfach oder ästig, frei.
35. Myxonema Fries.
54. Conferca Fries.
5ว. Ilormiscia Fries.

56. Nodularia Mert.

57. Tiresius Bory.

58. Drepasnaldia Bory.

4. Chaciophoreac. Gliederfäden ästig, durch eine schleimige Unterlage vereinigt.

59. Chaetophora Schrank.

40. Hydrurus Ag.

41. IIydrocoryne Schwab.

1. SHPMONEEE. Laub aus einer verïstelten Röhrenzelle mit gegliederten oder ungegliederten Aesten, oder aus melıreren nelseneinander liegenden, ästigen Rölırenzelleı gebildet.

1. Cameropeac. Laub einröhrig, verästelt ungegliedert, mit netufürmigen Faser!n grefüllt. 42. Caulerpa Lamour.

45. Tricladia Decaisne.

2. Acetabulardeac. Laub einröhrig, gegliedert, am Ende radienförmig - oder ficherförmig - verüstelt.

44. Polyphysa Lamour.
43. Acetabularia Lamonr.

46. Rhipidosiphom IUont.

Ђ. Hatymedeac. Laub vielröhrig, Röhren ungegliedert, oder gliederförmig-verästelt. a. UDпте.. Rölıren ungegliedert-rerästelt.

47. Vdolca Lamour.

48. Araincillea Decaisne. 


\section{$-102$}

b. Euhalymedes. Röhren ungegliedert; mit gegliederten Aesten.

49. Malymeda Lamour.

51. Espera Decaisse.

50. Penicillus Lamour.

c. Axadronexes. Röhren gegliedert-ästig, anastomosirend, in ein flaches Laub rereinigt.

52. Analyomene Lamour.

55. Dictyosphacria Decaisne.

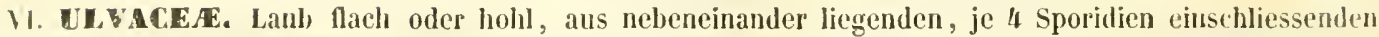
Zellen gebildet.

ธั4. Telrespora Desv.

55. Bangia Lyngb.

j6. Sligonema $\mathrm{\Lambda g}$.
;7. Zignoa 'Trevis.

58. Viqu $\Lambda \mathrm{g}$.

39. Porphyra $\Lambda$ ge.

\section{B. P H Y E E.}

Fortprlanzung durch sporen, welche einzeln in aussenständigen Schlïuchen liegen, und aus einem einfilchen Kerne bestehen, der mit Episporium (Membran der Sporenzelle) und Perisporium (Membran des Schlan(lles) bekleidet ist.

1. VUCDERMEAE. Lauh ein- oder mehrröhrig, unberindet; Schlïuche seitlich, oder aus dem nnter'I oder obern Endgliede eines Astes entstanden.

1. Hydrogastreac. Laub aus einer einzelnen Blase oder Röhre, oder aus mehreren ungegliederten, locker verwobenen Röhren bestehend.

i. Vaúcheriej Ver.e. Blase oder einzelne verästelte Rölne.
60. IIydrogastrum Desv.
62. Bryopsis Lamour.
61. Tuncheria DC.
65. Ialonia Gin.

b. Spoxgode. Mehrere, locker zu einem Laube vereinigte Röhren.

(j). Codium Stackh.

2. Dasycladeac. Laub einröhrig, ungegliedert oder gegliedert, verticillirt-ïstig. Aeste gegipfelt, gegliedert, mil endständigen schläuchen.
63. Chainaedoris Mont.
67. Neomeris Lamour.
66. Dasycladus $\Lambda \mathrm{g}$.
68. Cymopolia Lamour.

5. Ectocanpeac. Aestige Gliederfäden mit seillichen silzenden oder gesliellen Schläuchen.
69. Leibleinit Endl.
70. Chantrensia Fries.

71. Ectocarpus Lgb.
72. Bulbochaete Ag.

4. Batmehospemmeac. Laub vielröhrig, aus einem Itauplfaden, der von gleichlaufenden vebenlïden umgehen ist, bestehend. Schlïuche gelhäuft, endsländligr oder seitenständigr.

75. Batrachospermum Roth.

7h. Liagora Lamour.

75. Aclinolrichia becaisne.
76. Galaxaura Lamour.

77. Thorea Bory.

78. Myriocladia J. Ag. 


\section{$-105$}

:. Chordaneac. Laub vielrührig, mil überall von der Markschicht abgehenden, an der Oberfläche freien Flocken.

79. Crutoria Fries.

82. Chovduria $\mathrm{Ag}$.

80. Myrionema Grev.

85. Leathesia Gray.

81. Alesogloia $\mathbf{\text { gg. }}$

S't. Liebmannia J. Ig.

II. IA ISEREDEE. Laub vielröhrig, berindet, gegliedert oder ungegliedert; Schläuche an der (16erfläche des Laubes zerstreut oder in Iäufclıen.

1. Sphacelanicac. Laub gegliedert; Schläuche einzeln, seitlich.

83̈. Sphacelaria Lyngb.

87. Cladostephus Ag.

86. Myriotrichia Harv.

(2)

2. Dictyoteac. Laub ungegliedert, lıäulig; Schläuche von Flocken umgehen in lläulchen, oder auf der obern Laubfläche zersireul.

8S. Halyseris Targ.

89. Dictyosiphon Grev.

90. Dictyola Lamour.

9. Zonaria J. Ag.

92. Padina Adans.

95. Cutleria Grev.

94. Arthrocladia Duby.
93. Scytosiphon Ag.

96. Soranthera $\mathrm{P}$. et $\mathrm{k}$.

97. Punctaria Grer.

98. Asperococcus Lamour.

99. Striaria Grev.

100. Stilophora J. Ag.

? 101. Hildenbrandlia Nardo.

5. Camatตan'ieac. Laub ungegliedert, lederartig; Schläuche zerstreut oder in Iïufchen, von Flocken umgeben, auf beiden Laubflächen.

102. Lessonia Bory.

10天. Hacrocystis Ag.

104. Nereocystis P. et $\mathrm{R}$.

103. Ecklonia Hornem.

106. Laminaria La mour.

107. Capea Nont.
105. IIaligcniı Decaisne.

109. Alaria Grev.

110. Thalassiophyllum. 1'. el R.

111. Agarum Grev.

112. Costaria Grer.

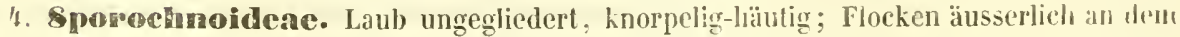
kopfförmigen Receplaculum, die Schläuche tragend.

115. Sprorochus Ag.

114. Desmarestia Lanour.

III. TECACED. Lauh vielröhrig, Schläuche von Flocken umgeben, in hohlen Behältern, welehe, aus einer Einfaltung des Lauhes entstanden sind und sich mit eincm Portus nach aussen ölnen; Behïlter zerstreut oder in ein Receptacuiam v'r'einigt.

2. Eerzancere. Laub lıohl, sich ganz in ein Receptaculum verwandelnd.

115. Lemenea Bory.

2. Fucoldeae. Behälter nicht in ein Receptaculum vercinigt.

116. Fucus L.

117. Carpodesmia Grev.

118. Miyriodesma Decaisnr.

1 19. Ifimanthatia Lingb.

120. Xiphophora Mont.
121. Splachnidium Grev.

12.. Durvillaea Bory.

123. Hormosira Endl.

124. Castraltia A. Rich. 


\section{- 104}

5. Cystoseix'eac. Behälter in besondere keceptacula vereinigt.

123̈. Coccophora Grev.

126. Hulidrys Lyngb.

127. Blosserillea Decaisne.

128. Cystoseira $\mathrm{Ag}$.

129. Sargassum Rumph.

150. Tubinaria Bory.

151. Carpacanthus kït.
152. Phyllospora Ag.

135. Carpophyllum Grev.

154. Marginaria A. Rich.

155. Scytholhalia Grev.

156. Seirococcus Crev.

157. Polyphacum Ag.

\section{FLORIDEE}

Vermehrunc durch hörner, welche innerhalb eines zelligen oder gallertartıgen sporenbehälters in untrestimmler Zahl entstehen; Fortpflanzung durch sporen, welche innerball, einer durchsichtigen Sporenhülle (Uutterzelle) zu jo 4 gebildet werden (Spharosporen).

1. Ceramieae. Laub meist geglieder. Sphærosporen meist äusserlich. Favellen nack an den Aesten oder von wenigen Aestehen oder einem Involuerum umhiilt, innerhalb einer durehsiehtigen Sporenhülle iocker liegende körner enthaltend.

138. Cullithamnion Lyngb.

159. Griffithsin $\mathbf{A g}$.

1/10. I'rangelin $\mathrm{Ag}$.

141. Spyridia IIarr.

142. Eimdera J. Ig.
145. Ceramime Nans.

1ว乡. Plilota Ag.

143. Microclatia Gres.

?116. IIaplolegma Mont.

2. Cryptonemeae: Laub zellig, Spharosporen in der Rinde. Favellidien in der innern Schicht des Laubes, oder an der Basis der Fäden der äussern Schicht, sehr selten in besondern Behältern; innerhalb einer durchsichtigen, läutigen, enge umschliessenden Sporenhïlle kleine in einen knäuel zusammengeballte Körner enthaltend.

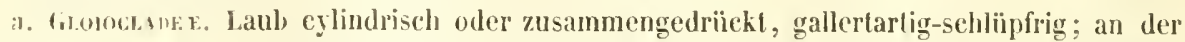
Oberlläche mit rosenkranzörmigen, freien oder durch Sehleim locker zusammenhängenden Fäden bedecbt, Favellidien in emen Geflecht von umhüllenden Fäden liegend, an der äussern Flïche fast nacht.

147. Crouania J. Ag.

148. Dudresnaya Bomwem.

130. Gloiorladia J. Ag.

149. Neccaria Endl.

131. Gloiopellis $\mathrm{J}$. Ig.

15. Yemalion Targ.

b. Neматтоме £. Laub fleischig-hänlig; die peripherisehen rosenhranzförmigen räden in eine feste Schicht verwachsend. Favellidien in der Schicht der rosenkranzförnigen Fäden, von aussen wenig sichthar. Spharosporen zonenförmig gretheilt.

155. Catienella Gres.

15\%. Endocladia J. A.

153. Millaca Bory. 


\section{- 105}

1. Spmgrocure.e. Laub fleischig-häntig : die peripheriselien Fäden oder Zellen in cine finte sehicht verwachsend, an der fruchttragenden Pflanze in eine schwammige, zuweilen warzenförmige, aus lockern, rosenkranzförmigen Fäılen bestehende schicht auswachsend. Faveltidien zwischen den Fäd'n der schwammigen Sehicht und ron denselben betecht. Spharosporen hronzförmig-getheılt.

1ว6. Furelluria Lamour.

160. Stenogramma Har.

137. Polyides $1 \mathrm{~g}$.

161. Chondrus (ires.

15̈S. Peyssonclliu Decaisne.

162. Desyphloea Hont.

139. Plyllophora Grev.

4. (isteroc rerwachsend. Farellidien von der peripherisehen Schicht bedecht. sphtrorosporen (immer?) dreieckig-gretheilt.

16.). Dumontia Lamour.

16.5. Kullymeniu J. Ag.

164. Italymenia $\mathrm{Ig}$.

166. Ginamia Mont.

2. Coccoc trpke. Lauh häutig-hornartig, peripherische Zellen oder Fäden in eine dichl" Schicht verwachsend. Favellidien unter der äussern Sckicht des Lanhos in einer lialbumgew andelten Fruchthülle liegend, hall, vorstehend, mut zuletzl durch eine fast regelmässige Mündung sich entleerend. Sphax'ısporen dreieckig-getheilt.

167. Cryptonemia J. Ag.

168. Gelidium Lamour.

169. Sulvia J. Ag.
170. Gratelonpia $\mathrm{Ag}$.

171. Gigartinu Lamour.

172. Chrysymenia J. I․

․ Lomentarieae. Laub zellig; Sphrerosporen dreieckig-getheilt, zerstrent in den Aestchen. heranidiru äusserlich, innerhalb einer zelligen, an der Spitze reggelnässį̣ geöffneten Fruchthiille birnförmige, mit einem verdïnnten Ende von der centralen Placenta ausstrahlende, mit einem durchsichtigen Balge ungel)enr, unter sich freie Körner enthaltend.

175. Lomentaria Lyngb.

174. Champiu Ag.

175. Laurencia Lamour.
176. Asparagopsis Mont.

17T. Bonnemaisonith $1 \frac{\mathrm{r}}{\mathrm{c}}$.

1. Ribodomeleae. Lauh gegliedert oder felderig; Sphwosporen dreiechig-getheilt, in oftmals reränder ten, schotenförmigen Aestchen, ein-, zwei-, mehreihig. Kerantich bei 5 . Lomentarier.

178. Disya $\mathrm{\Lambda g}$.

179. Polysiphonia Grev.

180. Heterosiphonia Mont.

181. Alsidium Ag.

182. Digenea $\mathrm{Ag}$.

185. Rhodomela Agr.

184. Acanthophora Lamour.

185. Dictyomenia Grev.
186. Bolryocarpa Gres.

157. Odonlhalia Lyngb.

158. Ryliphloea $\mathrm{Ig}$.

1s!). Potyzonia Suhr.

190. Leveillea Decaisne.

19!. Amansia Lamour.

192. IIterocladia Decaisnc. 


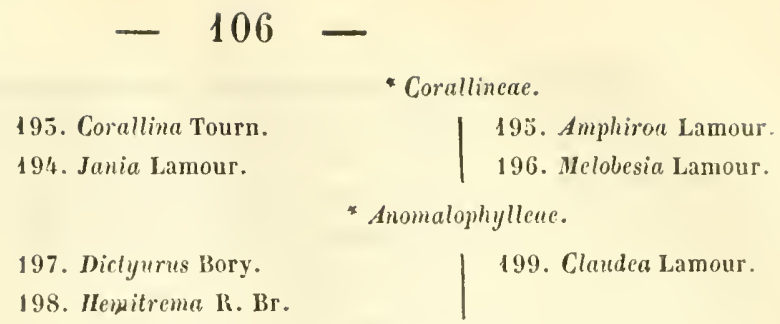

200. Thanmasia Ag.

5. Sphaemococcoideae. Laub zellig, Sphrosporen in IJaufen olne beslimmte Grenzen über das Laub, zerstreut. Coccidien äusserlich, innerlıalb einer zelligen, zuletzt zerrissenen Fruchthiille verkehrt-eiförmige Körner ( Sporen") entlaltend , welche in den Gliedern von rosenkranzförmigen, von der centralen Placenta auslaufenden Fäden gebildet werden.

201. Iypnca Lamour.

202. Plocaria Nees.

205. Rhodomenia Grev. 204. Sphaerococcus Grev.

6. Delesseriene. Laub zellig; Splıærosporen in bestimmt begrenzten IIäufchen, oder in besondern sporenblättern. Coccidien wie in 5.. Sphlerrococcoidea.
205 Plocaminm Grer.
206. Thamnoplora Ag.
207. Aglaophyllum Hont.
208. Iymenena Grer.

209. Delesseria Lamour.

210. Sotieria J. Ag.

211. Acropeltis Mont.

? 212 Hydropuntia Mont.

\section{ANORDNUNG DER GATTUNGEN NACH IÜ̈TZING.}

\section{A. I S OCARPEE.}

Meist grün oder olivenfarbig (sehr selten farblos oder purpurn), mit einerlei Früchten bei derselben $\Lambda$ rt; Samen olivenbraun.

I. ISOCARPE fE GYMNOSPERMEe. Samen an der Oberfläche foder im Gewebe des Tangkörpers, ohne eine zellige Fruehthïlle.

A. EIB EVIOSPERVE E. Samen oberfl̈̈clılich, einzeln stehend.

a. Mycophyceae. Meist farblıs, selten gefärbt, pilzartig.

1. Cryptococceæ. Formlos; Kügelchen schleimig, sehr klein, ohne Ordnung iı eine Schicht vereinight.

Cryplococcus. Ulsina. Spharotilus.

2. Leptonıte. Trichomatisch, farlılos (zarte, gegliederte Fäden).

Hyrocrocis. Sirocrocis. Leptomitus. Hycolhammion. Chamanema. Nematococcus. Chionyphe. 


\section{$-107$}

3. Saprolegrief. Colomatisch, farblos (ungegliederte Schlauchfäden). Saprolegniu. Mycocatium.

4. Рhieosene. Trichomatiseh, braun (gegliederte oder ungegliederte Fäden). Stereonema. Phaonema.

๖. Chamaephyceae. Meist klein, mikroskopiseh, grïn (selten purpurn), einzeln oder in ein formloses Lager vereinigt, sehr selten fadenförmig.

§. Desuıdex. Zierlich gestaltet, aus symmetrisch geordneteı Zellen zusammeıgesetzt.

Clostcrium. Nicrotheca. Pentasterias. Euastrum. Xunthidium. Staurastrum. Crucigenia. Merismopadiu. Scenodesmus. Tessarthra. Micrasterias. Sphorastrum. Gomphospheria. Desmidium. Ditymoprium. (Trochiscia. Tetraëdron. Pithiscus. Stauroceras. Phycastrum. Gramatonema. Iyulotheca. Bambusina. Isthmosira. Eucampia. Geminella. Pediastrum. Rhaphidium. Sorastrm.')

6. Palyelle.e. Fornlos, gallertartig; Zellen rund, ohne Ordnung vereinigt.

Protococcus. Microhalua. Botryocystis. Micrucystis. Botrydina. Polycoccus. Patmelle. Inoderma. Coccochloris. Claocapsu. Tetraspora. Palmogleea. (Trichodictyon.)

7. Hydrococce.. Bestimmt-gelormt, gallertartig; Zellen rund, in Linien georduet.

Actinococens. Entophysalis. Hydrococcus. Hydrurus. Hetminthonema. (Palmodictyon.)

c. Tiloblasteac. Faserig (trichomatisch), zellig.

1. GLOEOSIPIEA. Wurzellos, perenchymatisch oder epenchymatisch.

๙. ASEMOSPERIE E. Samen unbekannt.

8. Oscillarie.e. Fäden sclinell und durch spiralige Bewegung wachsend; von gemeinselıaflichem Schleim oder einer geöffneten, schr zarten Scheide eingrehiillt, in ein unbestimmt-begrenztes, schleimiges Lager vereinigt; Glieder sehr kurz, scheibenförnig.

Spirulina. Oscillaria. Actinocephulus. Phormidium. Mydrocoleum. Chthonoblastus.

9. Leptothicıe.. Fäden ohne Bewegung, von gemeinschaftlichem Schleine oder einer Selıeide eingehüllt, in ein meist unbestimmt-begrenztes Lager vereinigt; Glieder kaum sichthar, meist zusammenfliessend.

Leplothrix. Asterothrix. Symphyolhrix. Synploca. Dictyothrix. Entothrix. Inactis.

(') Die in hlammeru eingeschlossenen Gattungen sind aus der Phycologia germanica von Kützing entnommen; sie sind theilweise synonym mit den andern. 


\section{$-108$}

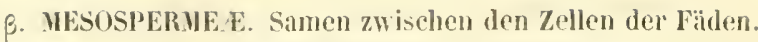

10. Lıмуосnцde. Fïden röln'ig, seitlich verwachsen.

Limnorhlide.

11. Nostoce.r. Fäden rosenkranzförmig, of zu cinem Plı̣com vereinigl.

Nostoc. Hormosijhon. Anubrne. Spherozygu. Cylindrospermum. Spermosira. Toduluria.

12. Scrtovene.e. Fäden gegliedert, bescheidet; Glieder sehr kurz, oder kngeligr Drilosiphon. Siylonema. Synchaela. Symphyosiphon. Sirosiphom. (Arthrosiphon.)

$\gamma$ PARASPERHE E. Samen seillich.

15. LxтвуE.. Fïden bescheidel, einfach.

Siphoderma. Amphithrix. Leibleinia. Lyngbya. Blennathix.

14. C.uoturiche£. Fäden bescheidel, ästig.

Tolypollerix. Culothrix. Hyphcolhrix. Schizolhrix. Schizodiclyou. Dicfyonema

j. HYposperuE E. Samen am Grunde des Fadens.

15̆. Mastichotrichex. Fäden frei.

Merizomyria. Maslichothrix. Haslichonema. Schizosiphon. Geocychs.

16. Ruvulariex. Fïden slrallig, in ein bestimmt-geformles Pliycom vereinigt.

Physactis. Hateractis. Charlaractis. Ainaclis. Limmactis. Risulariu. Dasyactis. Euaclis. (Diplotrichia. Inomeria.)

2. DERMATOSIPHEA. Wurzelnd, parenchymatisch.

\%. ENDOSPERMEE. Samen zwischensländig, in den Zellen eingeschlossen.

17. Honunies. Gliederfiden schleimig oder gallertintig, ans einkernigeis, rinfachen oder längsgetheilten Vollzellen gebildet.

Hormidium. Goniolrichum. Allogoninm. Glocotilu. Schizogoninm. Schizomeris. Bangia.

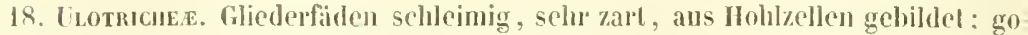
nimische Sulsstanz in Querbinden geordnet, zuletzt durch meist vierfache Theilung zu Scheinsamen sich entwickelnd.

Ulothrix. Stygeoclonimm.

19. Covferve. Gliederfiden niemals copulirt, aus IIohlzellen gebildet; gonimische Substanz ansgebreitet oder in deulliche Figuren vertheilt.

Oedogonium. Psichohumium. Conferre. Spongopsis, Rhizoclomium. Sphuroplea. Gadophora. Crenacumlha. Aegagropila. Spongomoryha. Periplegmalium. Pilimin. Fischeria. (Chalomoryha. Hormotrichum. Bulbochale.) 


\section{$-\quad 109$}

20. Zxgrene. Gliederfiden zuletzt copulirt; gonimische Substauz ausgebreitet oder in deutliche Figuren rertheilt.

Mougeotia, Sirogonium. Stauraspermum. Spirogyra. Zygnema. Zygogonium.

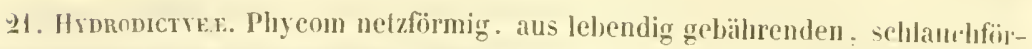
migen Zellen zusammengesetzt.

Hydrodictyon.

5. ECTOSPERME£. Sanen seitlicli oder endständig.

22. Protosene. An der Luft wachsend; Gliederfiden mit langen W urzilu. aus Hohlzellen gebildet; Samen endständig oder seitlich.

Gongrosira. Protonema. Chtorotylium.

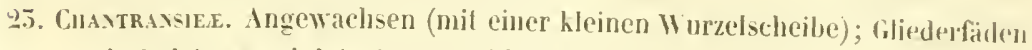
in Polster vereinigt; Samen seitlich.

Chrootepus. Chantransia.

21. Drap.irraldeze. Gallertarlig; schlïfrig; Gliederfäden verschieden gestaltef, sehr ästigy; Samen seitliel.

Draparnaldia.

2马․ Ectocarpez. Meerbewohnend; Gliederfäden aus Hohlzellen gebildel: sameu und Spermatoidien seitlich.

Ectocarpus. (Corticularia. Spongomorpha.)

26. SpHacelıRie. Meerbewohnend; Plycom fadenförmig, gegliedert, nachl oder deutlich-berindet, innerhalb aus geordneten, längsgetheilten Zelten bestelıend; Samen seillich.

sphacetaria. Halopteris. Siypocantom. Ballia. Chatopteris. Cladosteplus. (Myriotrichia.)

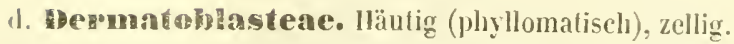

27. Ulvace.E. Blatlartig, ans einer einzigen Zelischicht bestehend.

Phyllactidium. Protoderma. Prasiota. Ulsa. (Desmotrichum.)

28. Prircosenidex. Blattartig, aus mehreren Zellschichten bestehent.

Phycoscris. Diplustromium. Phycolatuthum.

29. Evteronorpie. Häuhg-röhrig.

Enteromorpha. Chtorosiphon. Stictyosiphon. Dictyoxiphon.

P. Coeioblasteac. Schlauchformig (colomatisch).

30. Vatcucrıes. Ein einziger, wurzelnder, ungegliederter, blasentörmiger odel röhrenförmiger, einfacher oder ästiger Schlauch; Samen seitlich. Botrydium. Iancheria. Bryopsis. Valonir.

31. Caclerpes. Wurzelud und kriechend; Schlanch sehr zähe, einfach oder ästigg oder gefiedert, mit locker-verwobenen Fasern erfïllt.

Caulerpa. 


\section{$-110$}

32. Contex. Verlïngerte, freie und ästige Schlïuche in ein berindetes oder nacktes Phycom locher vereinigt; Samen cinzeln, seillich an den Schläuchen.

Codium. Rhipozonium. Halimeda. Corallocephahs. Rhipocephahs.

53. Axabronexex. Blatlartig, fücherförmig, geatert, gestielt; der Sticl aus mehreren parallelen Längsschläuchen, der Blaltkörper aus radienförmig und fächerförmig geordneten Schlanchzellen bestehend.

Anadyomene.

34. Polypnsed. Gestielt, rerkalkt, der Stiel ein einfacher Gliederfaden, an der Basis in röhrige Wurzeln getheilt, an der Spitze mit einer Krone von schlauchförmigen, strahlig-gestellen, samentragenden Zellen versehen. Samen kugelig, zahlreich, eingeschlossen.

Polyphiyse. Acetubularia.

55. Dasycladex. Schlauchförmig, ästig, Aesle schlauchig, oft tricholomisch, am Grunde eingclenkt. Samen einzeln, äusserlich, an den Aesten.

Cymopolia. Desycladus. Ascothamnion.

56. Сhares. Fadenförmig, spiralig-gestreift, mit quirlförmigen fruchttragenden Acsten. 1) Nackifrïchte (Samen) mit Stärkemchl gefïllt, mit doppelter Samenhülle; die innere membranartig, hart und brïchig; äussere aus fünf spiralig-gedrehten Röhrchen bestehend. 2) Scheinfrüchte zinnoberroth, berindet (mil 8 dreickigen, platlgedrückten, am Unfange eingeschlilzten Zellen), mit einem Knïıеl von farblosen Gliederfäden gefüllt, welche von einem Ilaufen grösserer centraler Zellen ausgehen.

Nitella. Charopisis. Chara.

B. CRY PTOSPERMEAE. Samen in der Rimlen- oder Harkschicht eingesenkt.

37. Lemanes. Etwas lederartig; Phycom aus 5 Schichten gebihlet; die Markschicht aus lockern Gliederfäden, die Znischenschicht aus grösscen. blasigen, locker verbundenen Ilohlzellen, die Rindenschicht aus kleinern, dicht verhundenen Vollzellen zusammengesetzt. Samen aus den Markzellen entstehend.

Thermocelim, Lemania. IIalysizm.

58. Снеториоке. Gallertartig, Phycom unberindet, ans ästigen Gliederfäden zusammengesetzt; Samen an den äussern Fäden seitlich, einzeln.

Cheelophare. Chaloderma (Cnoria). Thorea.

59. B.trachosperues. Gallertartig, rosenkranzförmig; Phycom ans einem berindeten, centralen Gliederfaden und (puirlförmigg geläuften, ästigen Fäden bestehend. Samen kugelig, in knäuel vereinigl, zwisthen den Quirlfäden.

Batrachospermum.

10. Ladgorex. An den Spitzen gallertartig, unten verkalkt, Phycom fadenförmig, ästig, aus 2 Schichten bestehend; die Markschicht locker parenchyma- 
tisch, die Rindensehicht aus dichotomischen Gliederfiden gebildet. Samen länglich-birnförmigg, geknäuelt, mit Nebenfäden rersehen, zwischen deı Rindenfiden.

Liagora.

11. Mesogloeace.e. Gallertartig, Phyeom aus zw ei Schichten bestehend, die centrale locker, parenchymatiseh, die Rindensehijeht ans strahlenden Gliederfäden gebildet. Samen einzeln, am Grunde der Rindenfaden.

Cladosiphon. Myriactis. Phycophila. Corynophtara. Corynephoru. Mesogloen. Chordaria. (Myrionema, Elaclista.)

C. PYCNOSPERMEAE. Samen oberflächlich, in Häufchen vereinigt.

19. Cuonde. Röhrig; dıe innere Sehicht aus verlängerten, zu Längsfasern veleinigten Zellen, die Rindenschicht aus kleinern Vollzellen gebildet; Samen dicht-gedrängt, mit rebenfäden verseheı.

Chorda. Spermalochus. Hatorhiza.

15. Excoeliex. Röhrig oder sachförmig; die innere Schicht aus runden Zelten, die Rindensehicht aus kleinen Volizellen gebildet; Samen in bestimmte lläufchen dicht vereinigt, mit Nebenfäden umgeben.

Encelium. Halodictyon. Striaria.

44. Dictrote.. Flach oder blattartig, gestielt, mehrschichtig; die Rindenschicht aus kleinern dunklern Zellen gebildet; Samen in IJäufchen (selten zerstreut), mit Nebenfäden versehen; Spermatoidien gehäuft, elliptiseh, an ästigen Nebenfäden sitzend.

Dichophyllium. Cutleria. Stœchospermum. Spatoglossum. Haloglossum. Halyseris. Stypopodium. Phycopteris. Zonaria. Phyllitis. (Stiftia.)

45. Sporocnxex. Flach oder fadenförmig, solid, aus einem centralen Strange und zwei besondern Schichten bestehend. Samen in einen Fruchtkörper dichtvereinigt, mit zahlreichen Nebenfäden rersehen.

Sporochnes. Carpomitra. Dcsmarestia. Arthrocladia.

46. Lanixarie.e. Blattartig und gestielt, oder mit beblättertem Stengel; Samen oberflächlich, in formlose Flecken dicht-vereinigt. (Scheinsamen oberflächlich oder unter der Rinde; Blätter am Grunde oft eine Luftblase enthaltend: ästige, berindete Stammwurzel).

Phloorhiza. Laminaria. Hafgygia. Phycocastamum. Alaria. Costeria. Agarum. Thulussiophyllum. Lessonia. Macrocystis. Tercocyslis.

II. ISOCARPE ANGIOSPERMEE. Samen in einer zelligen Fruchthülle eingeschlossen. (Lederartig, ungegtiedert.)

17. Fuces. Nicht in Stengel und Blätter geschieden; die Hïllenfrüchte durch die ganze linde zerstreut, oder in besondere Fruchtäste vereinigt, Nebensamen auf strauchartigen Nebenfälen. (Luftbfasen eingesenkt.)

Splachnidium. Durcillaca. Hormosira. Echlonia. Himanthatia. Fucus. Carpoglossum. Pliysocaulon. (Ozolhallia.) Scylothatia. Phyllospora. Sirococcus. 


\section{$-112$}

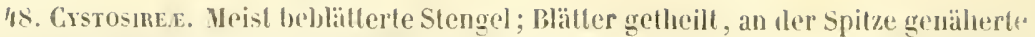
IḦ̈llenfrïichte enthaltend. oder in besondere Fruchtkörjes' anschwellend (unterwärts oft zu tuftblasen aufgetrieben); Vebensamen diclit zu Trauben vereinight.

Treptacantha. Halerica. Phyllecentha. Cystosira. Hormophysa. Hatidrys. Pycnopleycus.

49. Sargassex. Beblätterte Stengel (sehr sellen blattlos); Fruchtkörper gesoullert (nicht mit den Blätterı verwachsen), traubenfömig oder ästig, arhselständig; Nebensamen fast sitzend, gelsüschelt, mit kleinen Nebenfiden genischt (Luflb]asen seilliclı, gestielt).

Plerocaulon. Sargassum. Turbinaria. Carpopliyllum. Phycobotrys.

50. Hsıocilox. Beblälterte Stengel (selır selten blattlos); Fruchtkörper gesondert (nicht mit den Blältern verwachsen), cimzeln, gestielt, seitlich an der Spitze der Aeste; Nehenfaden Iraubig (Luftblasen seillich).

Blosserillen. Syongucarpus. Helochloa. Myntgropsis. Carpacenthus. Sirophysulis. Cocrophora. Saberia. Carpudesmia.

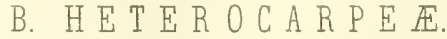

Purpurn oder rosenfarbig; Frïchie diöcistisch: 1) Capselfrïchte viehe Samen, 2) Vierlingsfrichte 4 Sïnlinge enthaltend.

III. HETEROCARPE FARACARPEE. Vierlingsfrüchte ausserbalb oder wischen den Rindenzellen liegend (nicht in hesondern Fächern).

A. Trichoblasteac. Ein (oft berindeter) Gliederfaden; Capselfiuche ausserhalb, mit einer liäuligen, gallertartigen Fruchthiille; Samen kugeligr, dicht zusanmengelallt (kein Samenboden).

51. Callithames. Ilaarförmig, gegliedert, nackt oder berindet; Vierlingsfrüchte ausserhall, an den unberindeten $\mathrm{Zweigen.}$

Callithmuion. Griffithsia. Inelurns. Phlebolhamnion. "rangelia. Spyritia. Plitota. (Cototiclyon. Dudrestitya.)

52. Cerames. Fadenförmig, ununterbrochen - oder unterbrochen - berindet: Vierlingsfrïchte aus den Zellen der Rindenschicht entstehend.

Hormoceras. Gongroccras. Echinoceras. Acanthoceres. Ceramium. Centroceras. Microclatit.

B. Epiblasteas. Plıycom aufwïchsig, lantarlig oder fadenförmig; Capselfrïchıte eingesenkt oder ausserhalb, endständig, mit zelliger Fruclıthïlte; Samen verlängert (Samenboden fast mangelud).

:35. Ponpuynex. Blallartig, aus regrelmässigg geordncten Vollzellen gebildet; Vierlingsfriiclıte I)opjelzwillinge.

Porphyra. IItenbrandia. Peyssonclia. 
34. Sporgıte.E. Eine oft geschichtete, aus Vollzellen gebildete, durch Kalk rersteinerte Kruste; Capselfrüchle eingesenkt.

Hapalidium. Pneophyllum. Melobesia. Spongites.

53. Conalune.e. Durch Kalk versteinert, sehr brüchig, fadenförmig, äslig, durch die Unterbrechungen der Rindenschicht gegliedert; Capselfrüchte init einer Oeffnung versehen.

Amphiroa. Corallina. Innia.

C. Perdblastea. Perigenetisch oder amphigenetisch, fadenförmig oder blallartig; Capselfruichte eingesenkt oder ausserhalb; Samen kugelig, an einem besondern Samenboden befestigt.

56. Gymopulaces. Gallertartig, schlüpfrig, ohne besondere Veberhaut; Markfäden der Länge nach parsllel; Rindenfäden gleichlang, lıorizontal abgehend; Capselfrüchte in des Rinde eingesenkt, aus geknäuclten, mit einer gemeinsamen Gallerthülle umgebenen Samen bestehend.

Gymophlaa. Helminthora. Naccaria.

37. Cuetangies. Knorpelig (perenchymatisch); Vierlingsliüchte in Behälterı unter der Rinde, mit Nebenfiden versehen; Capselfriichte eingesenkt. mit wandständigen, zwischen Nebenfäden sitzenden Samen.

Chatangium. Thamnoclonizm. Sarcophycus.

38. HaLruexrex. Gallertartig, schlüpfrig; mil sehr weicher Leberlaut; Bau wie 5̆6 Gymophlieacea ; Capselfrüchte eingesenkt, etwas herrorstehend, mit einer Oeffnung und einer besondern, faserigen Fruchthülle versehen; Samen auf einem baumartigen Träger gelıäuft; Vierlingsfrüchte cingesenkt, in Doppelzwillingen.

Myelomium. Ilalymenia. Dumonlia. Ialarachnion. Catenella. (Gimania.)

59. Caulacartues. Gallertartig-knorpelig, fadenförmig, ästig; Fäden der Pericentralschicht von einer einfachen Aclıse ausgehend; Vierlingsfrïchte eingesenkt oder ausserhalb, in Reihen, Doppelzw illinge; Capselfrüchte ausserhalb.

Caulecanthus. Acanthobolus.

60. Gigartinea. Knorpelartig, fadenförmig oder blatlartig; Structur faserig; Capselfrüchte mit kugeligen Samen an einem netartig verwobenen Samenträger; Vierlingsfrüchte unter der Rinde in IIaufen, Doppelzwillinge.

Iridceu. Chondrodictyon. Grateloupia. Mastocurpus. Chondrus. Chondracanthus. (Chondroclonium.) Euhymenia. Conslantinea. Callophyllis. Sarcophyllis. Solieria. Furcellaria. Gigartina. (Gloiocladia.)

61. Rurscuococcex. Knorpelartig, fadenförmig oder blatlartig; Capselfrüchte ausserhall, ; Sanen zweitheilig, langgestielt, strahlenlörmig an dem centralen Samenträger angeheftet; Vierlingsfrüchte im Plıcom zerstreut, rierjochig.

Rhynchococeus. Calliblepharis. 


\section{- $114-$}

62. Crstoclovie.. Knorpelartig, fadenfürmig; Capselfrüchte eingesenkt; Samen eckig-kugelig zwischen einem netzartig verwobenen Samenboden; Vierlingsfrüchte in bestimmten Fruchlästen, vierjochig.

Cystoclonium. Hypnophycus.

65. Geudiex. Knorpelartig, fiederig-ïstig. Capselfrïchte ausserhalb, mit sehr kleinen kugeligen Samen. Vierlingsfrüchte in besondern Fruchtästen, Doppelzwillinge.

Acrocarpus. Echinocaulon. Gelidium. Ctenodus.

61. SpHzrococces. Knorpelartig, fadenförmig oder hautartig. Capselfriichte ausserlıalı, mit kugeligen oder elliptisehen, dem centralen Samenboden angehefteten Samen; Vierlingsfriichte in der Rinde, meist gehäuft.

Bowiesia. Spharocaccus. Trematocarpus.

6i.. Trlocarpex. Knorpelartig, fadenförmig oder blattartig, innen parenclıymatisch; Vierlingsfrüchte in Reilıen, zu einem Kettenpolster vereinigt.

Tylocarpus. Oncolylus. Pachycarpus. Phyllotylas. Coccotylus. Phyllophora Acanthotylus.

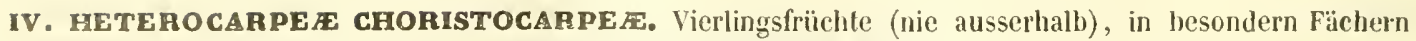
der Rindenschicht eingeschlossen.

1. Axomoblasteae. Fadenförmig (nicht hohl), oft mit gegliederten, fruchttragenden Aestclıen besetzt; Capselfrïchte mit verlängerten, bïnförnigen, gebüsehelten Samen, ohne Samenboden; deutliche Spermatoidien; keine Nebensamen.

66. DAsre.. Gallertartig, schliipfrig; Hauptfaden berindet, mit zarten Gliederfäden bedeckt; Fruchtäste gegliedert, mit quirlständigen Vierlingsfrïchten.

Dasya. Eupogonizm. Trichothamonion. (Eupogodon.)

67. Polrstphoniex. Gegliedert; Aeste gegliedert, vietröhrig, an der Spitze mit einem Büschel von Gliederfïden versehen; Fruchtäste gegliedert.

Polysiphonia. Ilelicothemnion. IIalopithys. Digenea. Bryothamnion. Physcophora. Alsidium.

68. Chovdriex. Knorpelartig, ungegliedert; Aeste und Fruchtïste ungegliedert (bisweilen an der Spitze mit einem Büschel von Gliederfäden).

Loplura. Carpocanton. Chondria. Acanthophora.

P. Cocloblastea. Meist fadenförmig, röhrig, selten sackartig; Capselfrïchte, mit rundlichen, zuerst an einem baumartigen Samenträger befestigten Samen; Nehensamen zwischen den Samen gehäuft; keine Spermatoidien.

69. Cinovdrosipner. Rölırenförmig, ohne innere Scheidewände.

Bonnemaisonia. Chondrothamnion. Chondrosiphon. Halosaccion.

70. Culampieæ. Hohil, durch zellige Scheidewände in Fächer getheilt.

Champia. Lomentariu. Gastroclonium. 


\section{$-115^{\circ}$}

r. Platymoblastea. Blattartig, gestielt; Capselirichte mil runden, an dem Samenboden befestigten Samen; deutliche Spermatoidien oder traubig-gehäufte Nebensamen.

71. Delesserie.e. Blaltartig, berindet, parenchymatiseh; Zellen an der Oherflärhe ohne Ordnung; Vierlingsfrüchte in blaltartigen Fruchtästen oder im Blatthörper, Doppelzwillinge.

Aeglophyllum. Schyzoglosxum. Inochorion. Cryptopleura. Phycodrys. Ilypoglossum. Delesseria. (Rhizophyllis).

72. Botrvocarpe.e. Blattartig, berindet, epenchymatisch oder perenchymatisch ; Zellen an der Oberfläche olne Ordnung; Vierlingsfrüchte in blattartigen Fruchtästen, Doppelzwillinge.

Neuroglossum. Bolryocurpa.

73. Ansssıe. Blatlarlig, gefiedert, unberindet; Zellen in parallele, gebogent

Zonen geordnet; Vierlingsfriichte in kłeinen blattartigen oder ladenfiirmigen Fruchtïsten, Doppelzwillinge.

Polyzonia. Amansia.

74. Ritipul. exce.e. P'latl, geliedert, berindet; innere Zellen in parallelen (querzonen; Vierlingsfrüchte in den Fiederblättchen oder in besondern Fruchıtästen, Doppelzwillinge.

Ryliphlaa. Diclyomenia.

75. Carpoblepharides. Platl, fiederspaltig, berindel; innere Zellen der Länge nach an einander gereilıet; Vierlingsfriichte in besondern, wimperarligen Fruchtäsien, Doppelzwillinge.

Carpoblepharis. Odouthalia.

76. Plocame.e. Aeslig, gefiedert berindet; innere Zellen grösser, der Länge nach an einander gereilıt; Vierlingsfrïchte in besonderu Fruchtästen vierjochig.

Plocamium. Thamnocarpus. Thamnophora.

77. Clacdex. Gefiedert, nelzförnnig; Vierlingsfrüchte in den Fieder'n, Doppelzwillinge.

claudea. 


\section{VERSUCH ZUR BEGRÜNDUNG EINES HIGENEN SYSTEMS DER}

\section{ALGEN UND FLORIDEEN.}

\section{A. A L G E.}

(Diatomacece, Chlorospermece et Melanospermece Harvey. - Zoospermece et Fucoidece J. Agardh. - Zoosporece, Synsporece et Aplosporece Decaisne. Confervacece et Phycece Endlicher. - Alyce isocarpece Kützing.)

Zelleninhalt theilweise aus Stärketörnern und Farbbläschen bestehend; keine Urzeugung; Fortpflanzung geschlechtslos, durch Keimzellen.

Diess sind die einzigen Merkmale, welche den Algen als solchen gemeinsam sind und welche sie zugleich von allen übrigen Pflanzen unterscheiden; namentlich von den Pilzen, Florideen, Moosen u. s. w. Dabei ist aber sogleich zu bemerken, dass nach dieser Definition auch die Flechten einen Theil der Algen ausmachen.

Bisher sind immer die Florideen (Rhodospermeen, Choristosporeen, Heterocarpeen) mit den eigentlichen Algen in Eine Gruppe zusammen gestellt worden. Es war diese Gruppe eine höchst unnatürliche, weil sie die verwandten Flechten ausschloss, und dagegen die ganz abweichenden Florideen aufnahm Diese un- 
natürliche Vereinigung machte es bis jetzt unmöglich, für die Algen eine gute Definition festzustellen. Indem ich nun die bisherige Classe der Algen in zwei Classen theile, will ich der einen den alten Namen Algen lassen, der andern den gewohnten Namen Florideen, den sie schon als Unterabtheilung der frühern Algen besass, beilegen, indem ich zeigen werde, dass die Florideen keine Algen sind.

Die Algen unterscheiden sich von den Pilzen durch die Natur des Zelleninhaltes. Bei den Pilzen ist nach Vogel $\left({ }^{1}\right)$ keine Stärke vorhanden. Ich habe bei vielen Untersuchungen ebenfalls keine angetroffen $\left(^{2}\right)$. Den Pilzen mangeln ferner nach meinen Beobachtungen die Chlorophyllbläschen (Chlorophyllkörner) und andere Farbbläschen $\left(^{3}\right.$ ) (gefärbte Zellsafikügelchen). Bei den Algen dagegen ist wahrscheinlich keine einzige Zelle, welche nicht zu irgend einer Zeit ihrer Lebensperiode Stärkekörner und Clorophyllbläschen oder andere Farbbläschen enthielte.

Die Algen unterscheiden sich ferner von den Pilzen durch ihre Entstehungsweise und ihre Lebensart. Die Algen entstehen nur aus Samen. Die Pilze entstehen ebenfalls aus Samen, sie können aber auch durch Urzeugung aus der Zersetzung von organischen Stoffen hervorgehen. Dieser Ausspruch wird zwar von zwei Seiten Anfechtungen erleiden, 1) von denen, welche die Generatio spontanea sowohl bei Algen als bei Pilzen annchmen, 2) von denen, welche dieselbe sowohl bei Pilzen als bei Algen verwerfen. Kützing $\left(^{4}\right)$ behauptet, dass die einfachern Algen (nämlich die gallertartigen, fadenförmigen, schlauchartigen und einfachen hautartigen) nicht bloss aus Samen, sondern auch durch Urbildung erzeugt werden. Die Thatsachen aber, welche als Beweis angeführt werden, sind noch lange nicht so, dass sie die Annahme nothwendig forderten; sie können eben so gut auf die eine wie auf die andere Art gedeutet werden. Man könnte versucht sein, die Urzeugung bei den Algen wegen der Analogie der Pilze an-

(') Linnæa, 1S41, pag. 65.

(2) Dagegen wollen Schlossberger und Dopping (Ann. d. Chem. und Pharm. L. II. $106-120$ ) einzelne Stürkekörner gefunden haben.

$\left({ }^{3}\right)$ Vergl. über diesen Ausdruck Schleiden und Nageli's Zeitschrift für wiss. Bot.. Heft 3, p. 110.

(4) Phycologia general., pag. 129. 


\section{$-118$}

zunehmen, weil beide Classen Pflanzen der gleichen Organisationsstufen enthalten. Ich wïrde dieser Analogie unbedingt beistimmen, wenn die Erscheinungen bei der Entstehung und die Lebensweise bei Algen und Pilzen die gleichen wären. Sie sind aber total verschieden. Wenn Algen irgendwo entstehen, so geschieht es nie in cinem ganz abgeschlossenen Raume; es geschieht ferner so, dass sie anfangs in kleiner Menge auftreten, und dass ihre steigende Zunahme aus der Fortpflanzung erklärt werden kann; es geschieht endlich in einem Medium, das häufig bloss aus Wasser mit gelöster Kohlensäure, Ammoniak und Salzen besteht, und gewöhnlich keine unzersetzten organischen Stoffe enthält. Die Pilze dagregen entstehen häufig an ganz abgeschlossenen Stellen; ferner zugleich in einer Menge, welche durch die Fortpflanzung nicht wohl erklärt werden kann; endlich in Medien, welche organische Stoffe in Zersetzung, also auch noch unzersetztes Gummi und Eiweiss, die nothwendigen Bedingungen für organische Neubildung enthalten. Es ist somit klar, dass, wenn auch die Urzeugung für die Pilze erwiesen wird, eine Uebertragung derselben auf die Algen durch Analogie nicht gestattet werden kann.

Die Generatio spontanea der Pilze wird von vielen bestritten. Es ist zwar nicht zu läugnen, dass sie sehr häufig aus Samen entstehen. Es giebt aber neben vielen Fällen, wo die Urzeugung im höchsten Grade wahrscheinlich, einige, wo sie sicher vorhanden ist. Zu den letztern gehören diejenigen Fälle, wo die Pilze in verschlossenen Räumen entstehen, so dass keine Samen hinein gelangen konnten. Ich verweise hiebei auf die Pilzbildungen, die ich innerhalb geschlossener Zellen beobachtete $\left(^{1}\right)$. Roestelia entwickelt sich tief im unverletzten Gewebe des Blattes. In Bremia Lactucce $\left(\right.$ Regel $\left.^{2}\right)$ fand ich die Sporidien des Pilzes grösser als die Oeffnung der Hautdrüsen, aus denen der Pilz hervorwächst. Aus diesen und andern Thatsachen schliesse ich, dass die Pilze durch Urzeugung entstehen können.

$\mathrm{Zu}$ dem Unterschiede, dass die Algen bloss aus Samen, die Pilze dagegen sowohl aus Samen als durch Urzeugung aus organischen Substanzen sich bilden,

(') Linnæa, 1S'42, pag. 278, tab. XI.

() Botanische Zeitung von Mohl und Schlechtendal, 1843, pag. 665. 
geselit sich ein analoger Unterschied in der Lebensart. Die Algen leben in feuchter Luft oder in klarem Wasser, meist auf unorganischen oder auf lebenden organischen Unterlagen; sie nehmen höchst wahrscheinlich keine andern Nahrungsstoffe als Wasser, Kohlensäure, Ammoniak und Salze auf. Die Algen verhalten sich also vollkommen gleich wie fast alle übrigen Pflanzen. Die Pilze bedürfen zu ihrer Unterlage gewöhnlich organische Substanzen, welche in Gährung, Fäulniss, Verwesung sind; sie ernähren sich ohne Zweifel nicht bloss aus unorganischen, sondern auch aus löslichen organischen Stoffen.

Wenn nach den oben angegebenen Merkmalen consequent Algen und Pilze geschieden werden, so müssen aus der Classe der Algen mehrere Gattungen wegfallen, welche früher als Wasserpflanzen dahin gebracht, und neulich von Kützing in der Phycologie wieder aufgezählt wurden. Als Wasserpilze, und nicht als Algen, müssen betrachtet werden, z. B. die Gattungen Hygrocrocis, Leptomitus, Achlya, die Gährungspilze, und wahrscheinlich alle, welche Kützing in der Abtheilung Mycophycece aufführt. Zu den Pilzen gehört ebenfalls die Gattung Chroolepus, welche von Kützing zu der Familie der Chantransiere gestellt wird.

Von allen übrigen Pflanzen unterscheiden sich die Algen dadurch, dass sie geschlechtslos sind, und dass somit zur Fortpflanzung nicht zweierlei Organe erfordert werden. Während bei Florideen und Moosen die Fortpflanzungszellen oder die Sporen durch männliche Samenzellchen befruchtet worden sind, so sind die Fortpflanzungszellen der Algen ohne weiteres keimfähig. Ich nenne sie desshalb zum Unterschiede von den Sporen Keimzellen. - Ich muss hicr aber ausdrücklich bemerken, dass Geschlechtsdifferenz und doppelte Fructification, welche Begriffe bei den Cryptogamen so häufig verwechselt wurden, durchaus nicht synonym sind. Dass die Florideen doppelte Fructificationsorgane besitzen, desswegen sind sie nicht geschlechtlich, sondern desswegen, weil ausser diesen beiden Fructificationsorganen, von denen das eine weiblich ist, noch männliche Geschlechtsorgane vorhanden sind. Wenn es Algen gibt, welche sich auf doppelte Art fortpflanzen, so ist damit keineswegs ihre Geschlechtsdifferenz nachgewiesen. Ich glaube, dass dieser Umstand von denen, welche bisher männliche und weibliche Fortpflanzungsorgane bei den Algen angenommen haben, zu wenig berücksichtigt wurde. Männliche Organe da anzunehmen, wo sie allenfalls vorhanden sein könnten, 
wie in den Nebenfäden: - oder bei einer Art, welche zweierlei Arten von Zellen besitzt, von denen man sich keine Rechenschaft geben kann, - oder bei Pflanzen, wo ausser den eigentlichen Fortpflanzungszellen noch kleinere bewegliche Zellen oder scheinbare Körner vorkommen : das darf in der jetzigen Zeit nicht mehr geschehen. Entweder müssen die Samenfäden oder eine mit den Antheridien der höhern Cryptogamen im Wesentlichen übereinstimmende Structur der Organe nachgewiesen werden. - Wenn aber Kützing " die Differenzen in der Fruchtbildung allerdings für Andeutungen der Geschlechtsorgane, so weit man dieselben bei Cryptogamen überhaupt annehmen kann, wenn sie auch für die wirkliche Fortpflanzung der Algenspecies als befruchtende Organe keine weitere Bedeutung haben sollten " erklärt, so ist mir diese Erklärung unverständlich. Entweder besilzt eine Pflanze die Möglichkeit, ein Organ zu erzeugen, oder sie besitzt diese Möglichkeit nicht. Im erstern Falle entwickelt sich das Organ unter günstigen Verhältnissen immer, im zweîen nie. Die Entwicklung kann aber im ersten Falle unter ungünstigen Verhältnissen auf jeder Stufe stehen bleiben. In diesem Falle sind bloss Andeutungen vorhanden, aber Andentungen von einem Organ, welches der Pflanze begriffsmässig angehört. Andeutungen von Organen, die erst bei höhern Organismen in ihrem vollen Begriffe auftreten sollen, sind gewiss in der Natur nirgends vorhanden, denn dieselbe stellt auf jeder ihrer Entwicklungsstufen ein vollständiges und für sich abgeschlossenes Ganze dar. - Wenn aber auch die Natur überall bloss vollkommene Begriffe entwickelt, so schreitet dagegen die menschliche Erkenntniss, bis sie zu diesen Begriffen gelangt, durch eine Reihe von "Andeutungen " guter Beobachtungen und richtiger Beurtheilungen fort; aber die eigenen Schwächen sollen wir nicht der Natur aufbürden.

Ich habe für alle Fortpflanzungszellen der Algen die Benennung Keimzellen, im Gegensatz zu den Sporen, vorgeschlagen. Es ist möglich und sogar wahrscheinlich, das die Keimzellen der Algen einmal verschiedene Namen erhalten müssen. Es wird diess dann der Fall sein, wenn sicher nachgewiesen ist, dass bei derselben Algenart verschiedene Fruchtarten wirklich vorkommen. Es dürfte sich dann zeigen, dass die Keimzellen nicht bei allen Algen die gleiche Bedeutung haben, und dass sich die besondere Keimzellenbildung der niedern Algen neben 


\section{$-121$}

der besondern Keimzellenbildung bei höhern Algen wiederholt, wie sich die Keimzellenbildung überhaupt neben der geschlechtlichen Fortpflanzung bei den Florideen und Lebermoosen wiederholt. Aber ich glaube nicht, dass diess jetzt schon als ganz gewiss ausgesprochen werden dürfe, und noch viel weniger, dass jetzt schon die verschiedenen Begriffe begründet werden könnten.

Ausser den in der Definition angefülırten Merkmalen gibt es keine, welche den Algen als solchen gemeinschaftlich wären. Lebensweise, Standort, Bau, Entstehung der Keimzellen sind so verschieden, dass sich nichts allgemeines feststellen lässt. Alles Uebrige aber, was bei allen Algen vorhanden ist, gilt theils für grössere Gruppen von niedern Pflanzen, theils für alle Pflanzen überhaupt.

Da die Algen aus Zellen bestehen und sich durch Keimzellen fortpflanzen, so können die Verschiedenheiten, welche sie untereinander zeigen, bloss in 5 Momenten gefunden werden : 1) in der Natur der Zellen selbst, 2) in der Entstehungsweise der entwickelten Pflanze aus der Keimzelle, 5) in der Entstehungsweise der Keimzellen an der entwickelten Pflanze.

In Rücksicht auf die Natur der Zellen finden wir bei den Algen wesentliche Verschiedenheiten in drei Beziehungen : 1) in der Gestalt der Zelle ; 2) im Zelleninhalte, und 5) im Zellenwachsthum. Die Gestalt der Zelle ist vorzüglich bei den einfachsten Algen wesentlich, nämlich bei den Diatomeen, Desmidieen, und Palmelleen. Die Beschaffenheit und Gestaltung des Zelleninhaltes ist ebenfalls nicht bei allen Algen wesentlich, sie ist es bei vielen der genannten einzelligen Algen und bei einigen der mehrzelligen Algen (z. B. in den Zygnemaceen). Das Zellenwachsthum, ob allseitiges oder Spitzenwachsthum, ist namentlich für die einzelligen Gattungen (Palmelleen und Siphoneen) von grosser Bedeutung.

In Rücksicht auf die Entstehungsweise der entwickelten Pflanze aus der Keimzelle ist eine sehr grosse Manigfaltigkeit vorhanden. Bei den einen Gattungen mangelt die vegetative Zellenbildung ganz (bei den einzelligen Algen). Bei den übrigen Algen ist sie vorhanden, bewegt sich aber nach verschiedenen Gesetzen. Die Wachsthumsgesetze geben die hauptsächlichste Norm für die Unterscheidung von Gattungen, Familien und Zünften.

In Rücksicht auf die Entstehung der Keimzellen an der entwickelten Pflanze sind 


\section{$-122$}

vorzüglich in zwei Beziehungen Verschiedenheiten vorhanden, nämlich : 1) welche bestimmte Zellen an der Pflanze Mutterzellen werden, 2) auf welche Weise die Keimzellen aus der Mutterzelle sich bilden. Was den ersten Punkt betrifft, so findet sich da eine sehr grosse Mannigfaltigkeit von Verschiedenheiten, welche für Gattungen, Familien und Zünfte wichtig sind. Was den zweiten Punkt betrifft, so sind mir folgende Verhältnisse bekannt: 1) Eine Zelle der Mutterpflanze wird ohne Weiteres zur Keimzelle (Nostoc); 2) der ganze Inhalt einer Zelle oder zweier copulirter Zellen vereinigt sich in eine Masse und bildet eine freie Keimzelle ( $Z_{y}$ gnema); 5 ) die Mutterzelle theilt sich durch einmalige wandständige Zellenbildung (Theilung) in 2 oder 4, oder durch wiederholte Zellenbildung in 4 und mehr Keimzellen (Ulothrix); 4) im Inhalte der Multerzelle entstehen durch freie Zellenbildung eine oder mehrere Keimzellen, in bestimmter oder in unbestimmter Zahl (Valonia); す) dic Mutterzelle wächst in einen Ast aus, welcher sich entweder ganz (wenn er kurz ist) oder nur an seinem Ende (wenn er lang ist) durch wandständige Zellenbildung zur Keimzelle umbildet (Vaucheria); 6) die Mutterzelle wächst in einen kurzen Ast aus und theilt sich durch wandständige Zellenbildung in zwei Zellen, von denen die eine dem ursprünglichen Lumen der Mutterzelle, die andere dem ausgewachsenen Theile der Zelle entspricht, welche letztere zur Keimzelle wird (Padina) $\left.{ }^{1}\right)$. Diese verschiedenen Verhältnisse, nach denen sich die Keimzellen bilden, sind die wesentlichsten Merkmale, welche die Algen besitzen; sie sind es vorzüglich, welche die Ordnungen begründen.

Nach diesen Grundsätzen muss einst das System der Algen aufgebaut werden. Die Ausführung bis ins Einzelne ist jetzt noch unmöglich; da wohl die Kenntniss der anatomischen Verhältnisse, namentlich durch die Untersuchungen Kützing's, wesentliche Fortschritte gemacht hat. Aber sie genügen nicht, weil FertigGleiches auf verschiedene Weise entstehen, und daher verschiedene Begriffe repräsentiren kann. Ueber die Entstehungsweise aus Zellen, über das Wachsthum durch Zellenbildungsgesetze ist bis jetzt nichts bekannt. Ebenso ist die Kein-

(1) Das Năhere ủber diese Zellenbildungsverhảltnisse findet sich in Schleiden und Ncegcli's Zeitschrift für wissenschaftl. Bot., Heft 3, pag. $51 \mathrm{fr}$. 


\section{$-125$}

zellenbildung noch lange nicht so erforscht, wie es für ein gutes System durchaus nothwendig wäre; an vielen Ảgen ist noch nicht einmal Fruchtbildung gesehen worden, an manchen nur eine sehp̧ zweifelhafte Fruchtbildung. So wenig es dieser Uebelstände wegen möglich ist, eine natürliche Eintheilung jetzt schon bis ins Detail auszuführen; ebensowenig ist es möglich, bei den jetzigen Kenntnissen, die Classe der Algen in die nächsten grossen Unterabtheilungen zu sondern, weil der gegenseitige Werth der verschiedenen Keimzellenbildungen noch nicht hinreichend bestimmt werden kann. Ich glaube daher, dass vor der Hand weiter nichts geschehen kann, als dass einzelne natïrliche Gruppen herausgehoben und genau definirt werden, sobald sich ein Typus durch seinen Begriff als ein besonderer, von allen übrigen verschiedener zu erkennen giebt. Dieses Verfahren wird zu wahrhaft natürlichen Ordnungen führen. Weiteremı Studium bleibt es überlassen, die Grenzen der Ordnungen zu ziehen, indem man bestimml, welche Gattungen zu denselben gehören, - und die Ordnungen in Gruppen unter allgemeinere Begriffe zusammen zu stellen. Die bisherigen Systeme, die ich diesem Verfahren gegenüber bloss als künstliche gelten lassen kann, werden als Systeme so lange ihren praktischen Werth behaupten, bis das natürliche System seine innere und äussere Vollendung erreicht hat.

\section{Palmellagere.}

Zelle ohne Spitzenwachsthum, ohne Astbildung und ohne vegetative Zellenbildung. Fortpflanzung durch wandständige Zelleabildung (Theilung) in 2 oder 4 Zellen. Jede Zelle ist für sich ein Pflanzenindividuum. Die Zelle besitzt bloss allseitiges Wachsthum und in Folge dessen immer ein bestimmtes Verhältniss der verschiedenen Durchmesser, und somit eine bestimmte Gestalt. Sie ermangelt des Vermögens Aeste oder Wurzeln zu treiben. Alle Zellenbildung ist reproductiv; die Tochterzellen, deren 2 oder 4 zugleich in einer Mutterzelle entstehen, sind eben so viele neue Pflanzen; ein Unterschied von vegetativen und von Keimzellen ist noch niclıt vorhanden.

Zu den Palmellaceen gehören die Diatomeen, Desmidieen und die meisten Palmelleen der Autoren. 


\section{$-124$ \\ Plenrococens vulgaris Menegh.}

(Protococcus viridis Auct. Chlorococcum vulgare Grev.)

TAF. I, Fig. $1-13$.

Auf elwas feuchler Baumrinde liegt ein grünes Pulver, das aus mikroskopischen Körnchen besteht. Ein solches Körnchen ist enlweder eine einzelne Zelle, oder mehrere mit einander verbundene Zellen. Die Art, wie die Zellen mit einander verbunden sind, ist durch bestimmte Regeln der Zellenbildung bedingt.

In dem Pleurococcus-Pulver findet man 1) einzelne sphärische Zellen (Fig. 1), 2) 2 zusammenhängende Zellen (Fig. 2), 5) 4 zusammenhängende Zellen, die in einer Fläche liegen (Fig. 5), 4) 8 zusanmenlängende Zellen, welche in 2 Flächen von je 4 Zellen liegen (Fig. 1), b) 16 zusammenhängende Zellen, welche in 2 Flächen von je 8 Zellen liegen (Fig. 5), 6) 52 zusammenhängende Zellen, welche in 4 Fläclıen von je 8 Zellen liegen. - Die Zellenbildung ist folgende. In der einfachen Zelle (Fig 1) entsteht, nachdem sie sich etwas in die Länge gedehnt hat, eine centrale Scheidewand (Fig. 2). Angenommen, die ursprüngliche Zelle habe sich von Süd nach Nord in die Länge gestreckt, so ist die Scheidewand senkrechl und von Ost nach West gerichtet. Jun dehnen sich die beiden Zellen (Fig. 2) wieder in die Länge, und zwar diessmal von Ost nach West, also parallel mit der entstandenen Scheidewand. Sie theilen sich wieder durch eine senkreehte Wand, welche jefzt von Sïd nach Nord geht (Fig. 5, 1). Es liegen nun 4 Zellen beisammen und bilden eine Fläche; wenn dieselbe unter dem Vikroskope um einen rechten Winkel um die eigene Achse gedreht wird, so sind natïrlich bloss 2 Zellen sichtbar (Fig. 5, II). - Jede der 4 Zellen dehnt sich wieder in die Länge, und zwar von unten nach oben, und theilt sich dann durch eine Wand, welche horizontal liegt. Dadurch entsteht ein IFäufchen von 8 Zellen, das die Geslalt eines Cubus hat. Von oben (Fig. 4, I) sieht man die 4 Zellen, welche sich in Fig. 5, I grebildet lıatten; ron der Seite dagegen (nachdem das Häufehen $90^{\circ}$ um seine $\Lambda$ chse gedreht wurde) erblickt man bloss 2 von jenen 4 Zellen, die aber elliplisch greworden sind, und jede sich eben in 2 Tochlerzellen getheilt hahen (Fig. 4, II). - Von den 8 Zellen dehnt sich jede wieder in die Länge und zwar von Süd nach Ford, und theilt sich darauf durch eine von Ost nach West gerichtete verticale Wand (Fig. 5, I). Dieses Zellenklümpchen $90^{\circ}$ um seine Achse gerollt, zeigt 4 Zellen (Fig. 5̆, II); es besteht aus 16 Zellen. - Jede der 16 Zellen theilt sich darauf (nachdem sie sich vorher von ost nach West in die Länge gedehnt hat) durch eine von Süd nach Nord gehende verticale Wand. - Dann bildet sich in jeder Zelle eine horizontale Wand; später wieder eine von Ost nach West gerichtete senkrechte Wand, dann eine von Süd nach Nord laufende senkrechte Wand, dann eine horizontale Wand u. s. f. - Die Zellenbildung geschieht also auf lie Weise, dass immer in 1 Multerzelle sich vermitlelst Theilung 2 Tochterzellen bilden, wodurch die Mutterzelle unmittelbar zu Grunde geht, und uechsett mit den 5 Richtungen des Raumes in den successiven Generutionen ab.

Von diesem allgeneinen Gesetze giebt es keine Ausnahmen. Es realisirt sich aber in verschiedener Art; die Abweichungen betreffen die Zeit oder die räumliche Richtung der Zellenbildung. Entweder bilden alle Zellen einer Generation zu gleicher Zeit neue Zellen; wenn diess geschicht, so bestehen die Zellenhäufchen nur aus einer \%ellenzall, , die eine Potenz von 2 ist: $2,4,8,16,52$. - Oder die Zellen der gleichen Generation bilden nicht zu gleicher Zeit, sondern die einen früher, die andern später, neue Zellen; in diesen Falle können die Zellenhäufehen natürlich aus jeder beliebigen Zahl von Zellen bestehen.

Entweder theilen sich die Zellen einer Generation in gleicher Richtung; dann zeigen die Zellen in den Hăufchen diejenige Stellung, die ich oben beschrieben habe. Sind es $\|$, so liegen sie in einer Fläche; sind es 8 , so liegen sie in 2 Flächen von je 4 Zellen und bilden einen Würfel; sind es 16 Zellen, so liegen sie in 2 Flächen von je 8 zellen, u. s. w. - Oder die Zellen einer Generation theilen sich nicht in der grleichen Richtung. Von den 2 Zellen, aus denen ursprünglich ein zusammengesetztes Korn besteht, theilt sich nur die Eine durch rine verticale, von Süd nach Nord gerichtete Wand (Fig. 6, I, a), nachdem sie sich von Ost nach West ausge- 


\section{$-\quad 125$}

dehnt hat; die andere dehnt sich von unten nach oben in die Länge und theilt sich durch eine horizontale Wand; diese Zelle erscheint daher, von oben angesehen, kreisrund (Fig. 6, 1, b); wenn das Korn aber $90^{\circ}$ um seine Achse gedreht wird, so zeigt sie eine elliptische Gestalt, und eine mittlere theilende Wand (Fig. 6, II, b), während dann die andere Zelle des Korns rund und ungetheit erscheint (Fig. 6, II, a); dieses Korn besteht nun aus 4 Zellen, welche nicht in einer Fläche, sondern wie die Ecken eines Tetraëders beisammen stehen $\left(^{1}\right)$. Von den 4 Zellen dieses Kornes theilen sich die 2, welche durch eine verticale, von Süd nach Nord gerichtete Wand entstanden, durch eine horizontale Wand; die 2 anderen aber, welehe durch eine horizontale Wand entstanden, theilen sich durch eine verticale, von Süd nach Nord gehende Scheidewand. Das Koru besteht nun aus 8 Zellen, die zusammen einen Würfel bilden; und von denen je 4 in einer Fläche liegen. Dieser Zustand stinmt seinem realen Bestande nach, mit dem in Fig. 4 abgebildeten ziemlich überein; die Zellen sind aber in einer andern Reihenfolge von Generationen entstanden, und werden auch auf eine andere $\Lambda \mathrm{rt}$ neue Zellen bilden. - Einen hieher gehörigen Fall habe ich auch in Fig. 7 abgebildet. Das Korn besteht aus 16 Zellen, von denen 8 sichtbar sind. Je 2 von den 4 Mutterzellen haben sich nach einer anderen Richtung verlängert und Zellen gebildet : die elliptischen Zellen a, a durch eine von Sïd nach Nord; die elliptischen Zellen b, b durch eine von Ost nach West gerichtete Wand.

Durch die angeführten Verschiedenheiten in der Zellenbildung, indem die Zellen einer Generation theils gleichzeitig, theils ungleichzeitig, theils in gleicher räumlicher Richtung, theils in ungleicher räumlicher Richtung Tochterzellen bilden, geschieht es, dass die Pleurococcuskörner in Zahl und Stellung ihrer Zellen sehr mannigfaltig sind, und unregelmässig $\left({ }^{2}\right)$ scheinen. Das oben formulirte Gesetz für die Zellenbildung bleibt aber in allen Modilicationen dasselbe.

In den bis jetzt zu Pleurococcus vulgäis gezogenen Formen findet man noch ein zweites Gesetz der Zellenbildung. In einer Iutterzelle (Fig. 8) entstehen zu gleicher Zeit 4 Tochterzellen (nicht erst 2, und dann wieder 2), welche sich in das Lumen und den Inhalt der Iutterzelle theilen, und wie die Ecken eines Tetraëders $z u$ einander gelagert sind. Je nach der Lage des Korns sieht man 5 Zellen in der gleichen horizontalen Eluene, indem die vierte über oder unter derselben liegt (Fig. 9, 11), oder je 2 Zellen in der gleichen Ebene (Fig. 10). Jede der 4 Zellen (Fig. 11) theilt sich wieder auf gleiche Art in 4 Tochterzellen, wie es die Mutterzelle gethan hatte (Fig. 12). Das Korn besteht nun aus 16 Zellen (Fig. 12 und 13). Theilt sich jede der 16 Zellen noch einmal, so besteht das Korn aus 64 Zellen. Diese Zellenbildung geschieht demnach so, dass immer in 1 Mutterzelle vermiltelst Theilung sich 4 tetraëdrisch-gestelle Tochterzellen bilden, was unmittelbar den Untergang der Hutterzelle zur Folye hat ( $\left.{ }^{3}\right)$.

Dieses zweite Gesetz ist eben so constant und ausnahmslos wie das erste. Die Verschiedenheiten, welche

(1) Ich mache hier daranf aufmerksam, dass auf ganz analoge Weise bei der Pollenbildung, wenn sich zuerst 2 primäre Specialmulterzellen bilden, diese beiden primären Specialmutterzellen entweder in gleicher Richtung oder in verschiedener Richtung sich theilen. In ersten Falle stehen die 4 seeundären Specialmutterzellen in einer Flächı, im zweilen Falle sṭehen sie tetraëdriseh beisammen. Vergł. Nogeli, zur Entwichlungsgeschichte des Pollens, pag. 18. Tab. II, 19, 20, 21 .

() Dennoch sind die Körner nicht bis auf den Grad unregelmässig, wie sie von Meneghini Monographia Nostochincar italicarum t. Y., f. 1, gezeichnet sind. Dem Verfasser ist theils das Gesetzmässige der Zellenbildung entgangen; theils sind, namentlich in der obern Partic ron Fig. 1, Organismen abgebildet, welche vielleicht die ersten Entwickelungsstadien von Flechten, gewiss aber nicht Formen von Pleurococeus vulgaris sind.

$\left({ }^{3}\right)$ Diese Zellenbildung ist die gleiche wie wir sie auch bei der Bildung der Speciałmutterzellen in den Antheren der Plranerogamen und in den Sporangien der 4 sporigen Cryptogamen finden. Vergl. Nageti l. c., pag. 13 ff., tab. 11I, 55. 36, und Zeitschrift für wissensełatft. Botanik son Schleiden und Nügeli, Iftft 1, pag. 7 ? fl. 
innerhalb des Gesetzes auftreten, treffen auch hier die zeillichen und räumlichen Verhältnisse der Generationszelten zu cinander. Diese Verschiedenheiten sind aber hier vicl schwieriger zu erkennen, weil namentlich die räumlichen Differenzen, der Natur der Sache nach, bedeutend geringer sein mïssen.

Die Plenrococenshörner, welche durch die erste und die zweite Zellenbildung entstehen, wachsen zu einen kleinern oder grössern Umfange an. Dann trennen sich ihre Elenente ganz oder theilweise von einander, indem in jedem Theile die Zellenhildung ohne Unterbruch sich fortsetzt. Die Körner können somit schon nach der ersten oder zweiten Generation, oder sie können erst nach der dritten, vierten, fünften Generation u. s. w. in ihre Zellen zerfallen. Sie können ferner g̈̈nzlich in die einzelnen Zellen, oder sie können auch nur in Ï̈ufchen von Zellen (in kleinere Körner) sich theilen. Z. B. ein aus 16 Zellen bestehendes, nach der ersten Zellenbildung entslandenes Korn kann in 2 Körner von je 8 Zellen, oder in 4 Körner von je 4 Zellen, oder in 8 Körner von je 2 Zellen, orler in 16 Zellen zerfallen. Ein aus 16 Zellen bestehendes, nach der zweiten Zellenbildung entstandenes Korn kann in 4 Körner von je 4 Zellen oder in 16 einzelne Zellen auseinandergehn. Man muss also im Allgemeinen sagen, dass ein Pleurococcuskorn in die Producte einer beliebigen (aber der gleichen) Generation sich tremnen kann. Sind es die Producte der letzten Generation, so sind es die einzelnen Zellen; sind es die Producte der vorletzten Generation, so gicbt es Köpner von je 2 (nach der ersten Zellenbildung) oder von je \& Zellen (nach der zweiten Zellenbildung); sind es die Producte der drittletzten Generation, so giebt es Körner von je 4 (naclı der ersten Zellenbildung) oder von je 16 Zellen (nach der zweiten Zellenbildung) u. s. w. Der Cmstand, ob die Körner früher oder später, so oder anders sich theilen, ist zufällig und hängt von äusseren Ursachen ab. Jedenfalls aber lejdet die Vermelırung der Zellen dadurch keinen Unterbruch; sie steht überhaupt in keinem Verlältnisse zur Trennung der Körner in ihre Theile.

Nach Feststellung dieser Thatsachen will ich mich zuerst an die Beantwortung der Frage machen: was ist bei Pleurococcus vulgaris eine Pflanze? Die Systematiker lassen diese Frage, deren Beantwortung doch allein die Stellung von Pleurococcus im System sichern, und eine richtige Diagnose der Gattung an die Itand geben kann, unentschieden; sie versuchen meist nicht einmal deren Lösung. Denn wenn die Gattung definirt wird : "Cellulæ matrices subglobosæ solitariæ v. in stratum crustæforme aggregatx, cellulas quaternas includentes " $\left({ }^{1}\right)$, oder so: "Cellulæ liberæ, in stratum indefinitum expansa" $\left({ }^{2}\right)$, so steht es dem Leser frei, nach Beliehen entweder die "cellułæ matrices" " cellulæ liberæ" d. h. die Pleurococcuskörner, oder das "stratum crustiforme " "stratum indefinitum " d.h. eine geringere oder grössere Menge von Pleurococcuspulver als die Pflanze anzusehen. Ich halte aber das ẹne, wie das andere für unrichlig. Dass das ganze Stratum kein Pflanzenindividum sei, so wenig als ein Wald oder ein Kornfeld, dafür bedarf es wohl keines Beweises. Dass aber das Pleurococcuskorn ein Pflanzenindividum sei, wie es von Meneghimi behauptet wird $\left(^{5}\right)$, dagegen gibt es 5 Gründe: 1) weil die Zellen, die zu einem Korne vereinigt sind, Jurchaus keine gemeinschaftliche Function, namentlich nicht zum Belıufe der Fortpflanzung ausüben, 2) weil die Körner sich beliebig in ihre Theile trennen können, olne dass dadurch der Lebensprozess irgendwie modificirt w ürde; 5) weil zuweilen einzelne Körner. die bloss aus ciner einzigen Zelle bestehen, sich, nachdem die Zelle sich fortgepflanat hat, sofort in neue einzellige Körner trennen.

Bei Pleurococcus ist jede einzelne Zelle ein Pflanzenindividum ; die Körner sind Familien von mehreren oder vielen Individuen. Ob die Individuen frei oder mit einander verbunden seien, das ist für sie zufällig. Der einfachste Fall ist derjenige, wo eine freie Zelle sich in 2 (nach der ersten Zellenbildung) oder in 4 Tochterzellen (nach der zweiten Zellenbildung) theilt, und diese Zellen dann sogleich wieder sich von einander trennen, und jede für sich ein neues freies Individuum darstellt. Diesen Vorgang habe ich bestimmt beobachtel; er ist

(1) Endlicher, generum plant. supplement. tert. gen. 4.

(2) Kützing, Phỵcologia generalis, pag. 167.

$\left(^{5}\right)$ L. c P. 2. Globulus resiculosus individuum constitit. • 
aber seltener. - Gewöhnlicher bleiben die Individuen zu Familien verbunden. Das Bindemittel ist theils die, zwar geringe, Extracellularsubstanz, theils die Nembran der Yutterzelle. Wird dieses Bindemittel ganz oder theilweise aufgelöst, so trennen sich die Familien (Körner) ganz, d. h. in die einzelnen Individuen, oder theilweise, d. l. in kleinere Familien. Wie schnell aber das Bindemittel aufgelöst werde, das hängt sowohl von seiner Consisten\%, als von der Menge und Beschaffenheit der umgebenden Feuchtigkeit ah.

Wir finden also in Pleurococcus alle Bedingungen erfïllt, welche wir fïr dic Annahme stellen müssen, dass jede einzelne Zelle ein Pflanzenindividuum sei. Jedes Individuum rermehrt sich. Es bleibt ber natiirlich da liegen, wo es entstanden ist. Ausserdem sind immer die Scliwesterindividuen eben so natürlich ron einer Membran umhiilt, nämlich der Mutterzelle, in der sie entstanden sind. Wird nun diese Membran von aussen nicht aufgelöst, so rerbindet sie die Schwesterindividuen in ein Zellklümpchen. Wie sie auf zufïlige, d. h. ilınen äusserliche Weise verbunden wurden, so werden sie auch auf zufällige Art wieder von einander getrennt. - Pleurococcus besitzt nur eine einzige Zellenbildung, diejenige, durch die sich die Individuen fortpflanzen. Alle Pflanzen, die aus mehreren oder vielen Zellen bestehen, besitzen wenigstens 2 verschiedene Zellenbildungen, eine für das Wachsthum des Individuums und eine für die Fortpflanzung des Individuums. Besser lässt sich der Unterschied zwischen einzelligen und mehrzelligen Organismen so ausdrücken : bei den erstern verhalten sich alle zur gleichen Art gehörende Zellen in Bezug auf Zellenbildung gleich; bei den letztern Iritt wenigstens Ein Untersclied auf, indem einige Zellen auf eine andere Art Zellen bilden, als es die übrigen thun, und dadurch die Grenze zwischen den Individuen bezeichnen. - Dieser Umstand ist bisher bei der Definition der niedern Algen ganz unberücksichtigt geblieben, und desswegen sind Gatlungen und Ordnungen noch so unbestimnt und auch unrichtig characterisirt.

Die Definition der Gattung Pleurococeus ist nun folgende : Die Pflanze ist eire einfache spharische Zelle, welche sich durch wandständige Zellenbildung in 2 oder 4 gleiche Tochterindividuen theilt. Dazu schlage ich einstweilen die 2 Untergattungen vor:

I. Dichococeus, in 1 Zelle bilden sich 2 Tochterzellen;

II. Tetrachococcus, in 1 Zelle bilden sich 4 Tochterzellen.

Ob diese beiden Untergattungen wirklich auf ein constantes und gesetzmässiges Merkmal gegrïndet seien, ob sie vielleicht se!bst zu Galtungen erhoben werden müssen, dass kann ich noch nicht entscheiden. Bis jetzt habe ich den Uebergang der einen Art der Zellenbildung in die andere Art noch nicht beobachten können. Dass die beiden Arten der Zellenbildung, wodurch sich Pleurococcus fortpflanzt, bei der Pollenbildung keine spezifische Gültigkeit haben, und neben einander in der gleichen Anthere gefunden werden, bewesst noch keineswegs, dass sie desswegen bei Pleurococcus auch bloss relatir (nicht absolut) verschieden sein müssen; denn es ist bekannt, dass ein Character oft in der einen Classe oder Ordnung wesentlich ist, während er in andern Classen und Ordnungen sich als unwichtig erweist.

Dass die Individuen gewöhnlich zu kleineren oder grösseren Familien verbunden bleiben, und dadurclı mehr- oder vielzellige Körner bilden, kann in die Diagnose der Gattung nicht aufgenommen werden, da es auch freie Individuen gibt. - Kützing (') nennt die Körner (die Anhäufungen von Individnen) " polygonimische Zellen ", die freien Individuen aber a monogonimische Zellen. „ Es scheint mir diess aut einer Verwechslung der Begriffe zu beruhen, welche sogleich bei vollständiger Kenntniss der Entwicklungsgeschichte, wie sie oben mitgetheilt wurde, und bei richtiger Beurtheilung derselben schwinden muss.

Aus Prolococcus viridis (Pleurococeus vulgaris) lässt Kützing $\left(^{2}\right)$ verschiedene andere Algen und Flechten entstehen. Von andern genauen Forschern wird nichts der Art berichtet; bei vielen Untersuchungen fand ich nie eine Spur davon. Ich erlaube ınir daher hierüber, trotz der beslimmten Behauptungen Kü̈zing's noch

(4) Phycologia generalis, pag. 167.

(') L. C., pag. 167. 
einige Zweifel, welche gewiss um so eher gereehtfertigt sind, wenn man einerseits bedenkt, wie leicht freie Pleurococeuszellen und die Keimzellen von versehiedenen Algen und Flechten mit einander verwechselt werden können, ferner wie leicht Pleurococeuskörner und die ersten Entwicklungsstadien von Algen und namentlich von Flechten, wegen des gleichen Slandortes und wegen äusserer Aehnliehkeil mit einander rerwechselt werden können $\left({ }^{1}\right)$, insofern nicht das Gesetzmässige der Zellenbildung beachtet wird; wenn man ferner bedenkt, dass man mit der Annahme von Kützing's Theorie zugleich alle bisher in der Naturgeschichte gültigen Grundsätze vernichtét, indem an die Stelle der generellen und speciellen (absoluten) Begriffe relative und von äussern Zufälligkeiten abhängende Vesehiedenheiten، gesetzt werden.

\section{P a 1 ni e 11 a Lyngb.}

TAB. I, Fig. $14-29$.

Ich nehme die Gattung Palmella wieder in dem Umfange, wie sie von Lyngbye und Agarlh aufgestellt wurde. Sie ist in neuerer Zeit in mehrere Gattungen und in noch mehrere Arten zersplittert worden. Es gehören hieher Arten der Gattungen Palmella Auct., Microcystis Kütz. Nenegh., Gloecapsa Kütz. etc. Keine der neuen Gallungen stützt sich auf die Kenntniss der Entwicklung und der Fortpflanzung und auf eine bestimmte Ansicht über die Individualilät der Pflanze. - Ich will hier bloss das Verhalten der Gatlung untersuchen und werde daher auf die einzelnen Arten keine Rüeksicht nehmen.

Palmella zeigt immer in einer bestimmt-gestalteten oder formlosen Gallerte kugelige Zellen, welche mehr oder weniger von einander entfernt sind. Kützing $\left({ }^{2}\right)$ nennt diese Zellen " absque ordine consociatæ. "Wie dieser Ausdruck aber schon für die Gattung Pleurococcus unrichlig war, so ist er es in gleichem Masse fïr Palmella, welche nach demselben bestimmten Gesetze Zellen bildet wie Pleurococcus. - Man trifft in der Gallerte von Palmella theils einzelne Zellen, theils Iläufchen von 2, 4, 8, 16, 52 Zellen u. s. w. Sind es einzelne Zellen, so liegen sie entweder unmitlelbar in der gemeinsamen Gallerte, oder sie sind von 1, 2 oder mehreren concentrisehen Ringen umgeben (Fig. 14, 15, 16). Diese Ringe bezeichnen die Gallertschichten, welche von der Zelle ausgesehieden wurden; sie sind die geschichtete Extracellularsubstanz. Die Dicke der Extracellularsubstanz ist sehr versehieden; sie ist bald geringer als der Durchmesser der Zelle, bald übertrifft sie denselben ein oder mehrere Male. - Sind dıe Zellen zu Häufchen vereinigt, so ist das ganze Häufehen und ebenso einzelne Partieen des Häufchens von Ringen umschlossen (Fig. 21).

Die Zellenbildung ist folgende. Jede einzelne Zelle, sie mag nun frei oder mit anderen Zellen zu einem Häıfehen vereinigt sein, dehnt sich zu einer ellipsoidisehen Gestalt in die Länge, und theilt sich dann dureh eine, den langen Durehmesser unter einem rechten Winkel schneidende Wand. Jede der beiden Tochterzelren hat znerst die Geslalt eines hallen Ellipsoids (Fig. 17). Dann runden sich die Zellen ah, werden spluärisch (Fig. 18), entfernen sich von cinander (Fig. 19), verlängern sich wieder zu einem Ellipsoid (Fig. 20) und theilen sich darauf in 2 Toehterzellen (Fig. 21). Alle diese Ersclıeinungen, welche die Zellenhildung begleiten, wiederholen sich von Generation zu Generation. Die räumliche Lage der Seheidewände wechselt, wie in der ersten $\Lambda$ rt der Zellenbildung von Pleurococcus, in den 5 Ausdehnungen des Raumes. Ist die Wand einer bestimmten Generation senkrecht von Süd nach Nord gerichtet, so laufen die Wände der nächslfolgenden Generation senkrecht von Ost nach West, und diejenigen der zweitfolgenden Generation sind horizontal. Die

(') Wie es höchst wahrscheinlich auch von Meneghini, 1. c., tab. V, fig. 1, geschehen ist. wie ich schon oben bemerkte.

(2) Phycologia gen. pag. 159 . 
vierle Generation erzengt Zellen in gleicher Lage wie die erste, die fünfte wie die zweile, und überhaupt die $n^{\text {te }}$ Generation wie die $n-5^{\text {te }}$ Generation. Wir finden demnach lier vollkommen das gleiche Gesetz der Zellenbildung, wie wir es oben für Pleurococcus kennen gelernt laben.

Der Untersehied in der Zellenbildung von Pleurococeus und ron Palmella liegt darin, dass bei dem ersteren die Zellen dicht aneinander liegen, bei der letzteren dagegen durch einen Zwischenraun getrennt sind. Dieser Zwischenraum ist von gelatinoser Extracellularsubstanz ausgefüllt. Die beiden Schwesterzellen liegen, unmittelbar nach ihrem lintstehen, mil ihren Membranen noch dicht aneinander (Fig. 17, 18). Jede derselben scheidet an ihrer ganzen Oberfläche Gallerte aus, welche eine oder mehrere concentrische Schichten bildet (Fig. 19, 20). Dadurch werden die beiden Schwesterzellen von einander getrennt. Wenn eine jede derselhen ihrerseils wieder 2 Tochterzellen bildet, so liegen je 2 in einer gemeinschaftlichen IIülle, nämlich innerhalb der Extracellularsubstanz, welche ron der Nullerzelle gebildet wurde (Fig. 21, b). - Eine Zelle von Palmella ist also von versehiedenen Ilïllen umgeben : 1) von einer primären, eigenthümliclıen Ilülle, welehe die Zelle selbst bildet. und von der nur sie allein bekleidet ist (Fig. 14, 15, 16, a ; 19, 20, b; 22, e); 2) von einer secundären Ilülle, welche ihr mil der Schwesterzelle gemeinsam ist, und welche von der Mullerzelle stanmt (Fig. 17 - 20, a : 21,22, b); 5) von einer tertiären Hïlle, welche sie mit der Schwesterzelle und den 2 andern Zellen der gleichen Generation theilt, und welche von der gemeinsamen Grossmutterzelle gebildet wurde (Fig. 21, 22, a); u. s. w. Diese Einschachtelung in immer allgemeinere und weilere Ilïllen geht auf die gleiche Weise unbestimmt weil, je nach der Zahl der Zellen, welche zusammen in Einem Häufehen vereinigl sind.

Das Geselz der Zellenbildung fïr Palmella ist also folgendes : In einer Wutterzelle bilden sich immer durch Theilung 2 Tochterzellen, wodurch die Mutterzelle zu Grunde geht; die Zellenbildung wechselt mit den 5 Richtungen des Raumes in den successiven Generationen ab; nach ihrer Eulstchung und bis zu ihrer Auflösung durch die Fortpflanzung scheiden die Zellen Gallerte aus.

Mit diesem Gesetze verhält es sich bei Palmella wie hei Pleurococcus. Es ist in seiner Allgemeinheit ausnahmslos, trilt aber in versehiedenen Modificationen auf. Entweder pflanzen sich die Zellen einer Generation zu gleicher Zeil oder zu verschiedener Zeit fort; im erstern Falle bestehen die Zellenhänfchen aus einer Zellenzahl $=2^{\mathrm{n}}$, nämlich $2,4,8,16,52,64$, ele.; im zweiten Falle können die Iläufclıen jede beliehige Zellenzahl enthalten. - Entweder zeigen die Scheidewände in den Zehlen der gleichen Generation die nämliche Lage oder eine verschiedene Lage, wodureh die Stellung der Zellen in den Häufchen mannigfaltig wird. Das Speciellere. was ich über diesen Punkt bei Pleurococcus anführte, gilt auch für Palmella.

Eine andere Reihe von Jodificationen hetrifft noch die Ausscheidung von Gallerte. Die ausgeschiedene Gallerte ist dichler oder dïnner, betrüchllicher oder geringer, wird schneller oder langsamer aufgelöst. Dieser an sich unbedeutende Umsland, inden er vorziiglich von dem kräftigeren oder schwächeren Lebensprozess der Zelle, von der Nalur der aufgenommenen Aahrungsflüssigkeit und von der Nalur der umgebenden Feuchtigkeil oder Flïssigkeit abhängt, erzeugt dennoch einen so verschiedenen Haluitus des l'almellaschleimes sowohl für das unbewaffnete als für das bewaffnele Auge, dass nicht bloss eine Menge Arten, sondern sogar melırere Galtungen darnach gemacht wurden. Entweder ist die Gallerte verdïnnt, dann scheinen die Zellen unmittelbar in einer structurlosen und homogenen Gallerte 7.u liegen, welche anch, besonders wenn sie in grösserer venge vorhanden ist, nach aussen keine bestimmle Begrenzung hat. Oder die Gallerle ist dieht. dann ist sie nach anssen bestimmt hegrenzt und zeigt anch in Innern eine mehr oder weniger deutliche Struclur. - Die Gallertansscheidung ist beträchlliclser oder geringer, und in Folge dessen sind die Zellen näher oder entfernter. - Die (iallerte wird entweder langsamer aufgelöst, was vorziiglich in feuehter Luft der Fall ist, sie bildet zusammen eine einzige, formlose oder gelappte vasse. Oder sie wirl schneller aufgelüst. dann sind meist mehrere kugelförmige, kleinere Massen vorhanden, wie man sie häufiger im Wasser findet. Entweder sind die Gallertausscheidungen der verschiedenen Generationen gleich oder ungleich. Sind sie ungleich, so werden dadureh eine Menge von verschiedenen Modilicationen erzeugt, die es schwer halten wiirde 
alle aufzuż̈hlen. Z. B. die ausgeschiedene Gallerte ist verdünnt, mit Ausnahme der von der letzten Generation erzeugten; dann liegen die Zellen in einer strueturlosen Gallerte, nur ist jede einzelne mit einer deutlichen Ilülle versehen. Oder die Gallerte ist verdïnnt, mit Ausnahme der von der zweitletzten Generation trzeugten; dann liegen die Zellen in einer structurlosen Gallerte: nur sind je zwei Zellen mil einer gemeinschaftlichen deutlichın Hülle umgeben. Oder die Gallerte ist verdünnt, mit Ausnahme der von der drittetzten oder viertletzten Generation ausgeschiedenen, daun liegen die Zelten in einer structurlosen Gallerte, nur sind je 4 oder je 8 Zulten mit einer gemeinschaftlichen deutlichen Hülle ungeben. Es können nun atich die Hïllen zweier successiver oder diskreter Generationen, oder die Ilüllen von 5, it successiven oder diskreten Generationen dielıter und deutlich sein, während die der ülbrigen Generationen verdünnter und undeuflich sind; etc. etc. Vle diese Jodificationen scheinen mir bloss einen relativen Werth zu besilzen. Ieh finde darin nirgends eine Constanz und nirgends eine bestimmle Grenze, innerhalı welcher sich ein Typus nothwendig bewegte. Daher ist es mir denn auch unmöglich, alle diese Modifieationen in Gattungen oder in Untergatungen zu trennen. such der Speciesbegriff muss viel weiter gefasst werden, als es in neuerer Zeit geschehen ist. Nicht nur finde ich zuweilen in derselben gemeinschaftlichen Gallerte Formen, welche verschiedenen Arten einer Gatlung angehören, sondern sogar Formen beisammen, welche verschiedenen Gattungen der neuern Autoren angehörel.

Ausser dieser ersten Art der Zellenbildung kommt bei Palmella, wie bei Pleurococcus, noch eine zweite Irt der Zellenbildung vor. Eine kugelige Zelle (Fig. 25) scheidet Gallerte aus (Fig. 24), und theilt sich in 4 Zellen (Fig. 26). Die vier Tochterzellen nehmen eine sphärische Gestalt an (Fig. 27), und jede bekleidet sich wieder mit einer Gallerthiille (Fig. 28). Darauf erzengt jede Tochterzelle von Nenem 4 Tochterzellen, wie es die Mutterzelle that. - Wenn sich die Zellen als Häufchen gruppiren und mit gemeinschaftlichen Hüllen umschlossen sind, so thun sie es in der Regel in der Zahl 4, 16, 64 ete. - Zuweilen erkennt man hier in jeder Zelle einen centralen Kern. Elhe die Zellenbildung auftritt, sind statt dessen 4 kerne vorlauden (Fig. 25), von denen jeder der künlige centrale Kern der einen Tochterzelle ist. (Fig. 26) (1). - Das Geselz für die zweite irt der Zellenbildung in Palmella heisst demnach so: In jeder Zelle entstehen durch Theilung 4 tetraëdrischyestellte Tochterzellen, uodurch die Intterzelle zu Grunde geht; nach ihrer Entstehung und bis zu ihrer Aufösung durch die Fortpflanzung scheiden die Zellen Gallerte aus.

Innerhalb dieses Gesetzes sind die gleichen Modificationen vorhanden, wie bei der ersten Zellenbildung. Entweder trilt die Fortpflanzung in den Zellen der nämlichen Generation zu gleicher Zeit oder zu ungleicher Zeit auf. Im er'sten Falle besichen die Zellenläufclıen aus einer Zellenzahıl $=4^{\mathrm{n}}$, nämlich 4, 16, 64, 2 วั6. Im zweiten Falle ist die Zellenzahl eines Hüufchens $4+n \times 5$, nämlich 4, 7, 10, 15, 16, 19, 29 etc. - Die zellenbildung in den Zellen der nämlichen Generation geschieht in glescher oder in ungleicher Richtung. Die Gallertausscheidungen sind beträchtlicher oder geringer, und dadurch stehen die Zellen einander näher oder ferner. - Die Gallertausscheidungen sind verdïnnt und fliessen zusammen : die Zellen liegen in einem structurlosen Schleime, oder die Gallertausscheidungen sind dicht und bestimmt-begrenzt : die Zellen sind von deutlichen concentrischen primären, seeundären, tertiären etc. Hüllen umgelıen. - Die Gallertausscheidungen der versehiedenen Generationen verhalten sich in Bezug auf ilıre Consistenz gleich oder ungleich. In letzlerm Falle liegen die Zellen in einer structurlosen Gallerte; sie sind aber in der Zahl von je $4^{\text {a }}(4,16,64 \ldots)$ oder je $\downarrow+\mathrm{II} \times 5(4,7,10,15 \ldots)$ in gemeinschaftlichen Ilüllen vereinigt, oder die einzelnen Zellen sind von besonderen Hüllen umsehlossen. Z. B. in Fig. 29 liegen in einer formlosen und structurlosen Gallerte 4 Zellenhïufchen $(\mathrm{a}, \mathrm{b}, \mathrm{c}, \mathrm{d})$, welche zusammen in Eines vereinigt sind, doch ohne gemeiaschaftliche Hülle. Sie ent-

(4) Das Gleiche finden wir bei der Bildung der Specialınutterzellen für die Pollenzellen und die Sporenzellen der isporigen Kryptogamen, vergl. Nägeli, zur Entwicklungsgeschichle de' Follens, tab. III, 3̈з und 36 ; und Zeitschrift fïr wissenschaft. Bolanik can Schleiden und Nägeti, Heft 1, pag. $77 \mathrm{n}$. 


\section{$-151$}

standen zwar aus einer gemeinsehaftlichen Multerzelle, von der aber nichts mehr zu sehen ist. Jede der Zelleı a, b, c, d hat sich in 4 Zellen getheilt, welche Zellen in b, c, d von neuen je 4 Zellen erzeugt haben. Das ganze

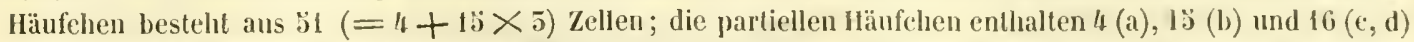
Zellen. Die von der ursprïnglichen Hutterzelle ausgeschiedene Gallerte ist verdümnt; sie stellt dalier keine deutliche Hïlle um das Iräufehen dar. Die von ihren Tochterzellen abgeschiedene Gallerte dagegen ist eonsistenter, und als deutliche tlïllen um die Häufchen der zweiten Generation zu erkennen (a, b), c, d). Die von den Zellen der dritten und vierten Generation secernirte Extracellularsubstanz ist wieder verdünnt und ohne bestimmte Begrenzung in einander fliessend. Desswegen scheinen die Zellen innerlalb der gemeinsehaftlichen Jlüllen a, b, c, d bloss in einem formlosen Schleime zu liegen.

Suf die Frage nach der vegetabilischen Individualität muss für Palmella, wie für Pleurococcus, die gleiche Antwort folgen: Jede einzelne Zelle ist eine Pflanze. Die Gründe dafür sind die gleichen, die ich oben schon für Plenrococeus angab. Bei denjenigen Formen von Palmella, welche in Wasser wohnen (besonders wenn noch eine relativ geringe Zahl ron Individuen in einer gegebenen Wassermenge, z. B. in einem Wasserglase lebt), sah ich mehrmals, dass die ausgeschiedene Gallerte schnell aufgelöst und dadureh die Individuen immer bald wieder frei wurden. Han findet dann z. B. viele Zustände, wie Fig. $25-28$ und Fig. $14-20$ sie darstellen, neben einander. Ilier ist eine andere Annahme, als dass jede Zelle ein Pflanzenindividuum sei, ganz unnöglich, weil jede Zelle für sich lebt und sich selbstständig fortpflanzt. Die Zellen schwimmen getrennt in Wasser, theilen sich danı in 2 oder 4 Tochterzellen; die Toehterzellen gehen aus einander, jede leht frei, um wieder 2 oder 4 Tochterzellen zu erzeugen. Wenn nun aber die Zellen durch die gelatinosen Excretionen der Yutterzellen verbunden bleiben, so sind die Individuen in kleinere oder grössere Familien vereinigt. - Ganz unrichtig wird selbst noch ron den neusten Algologen die ganze Gallertmasse von Palmella als die Pflanze erklärt und ihr der Name von "Frons" oder "Phycoma " ertheilt. Die Zoologen würden mil dem gleichen Rechte ein Wespennest als ein Thier besehreiben. Sobald man das Wachsthum und die Forlpflanzung von Palmella erkannt hat, was mit der geringsten Mühe geschehen kann, und sobald man einen bestimmten Begriff mit Pflanzenindividuum verbindet, kann man keinen Augenblick anstehen, bei Palmella die einzelne Zelle als solches zu erklären.

Die Definition der Gattung P'sunla ist folgende: Die Pflanze ist eine einfache spharische oder ellipsoidische Zelle, welche Gallerte in beträchtlicher Menge ausscheidet, und durch wandständige Zellenbildung sich in 2 oder 4 gleiche Tochterindiriduen theilt. Die Gattung sondert sich in die beiden Untergatlungen:

I. DITOCE $\left({ }^{1}\right)$, in I Zelle bilden sich 2 Tochterzellen; und

11. TETRATOCE, in I Zelle bilden sich 4 Tochterzellen.

Yon diesen Untergattungen gilt das Gleiche, was von den analogen Untergaltungen ron Pleurocuceus gresagt wurde.

Wir finden also in Palmella und Pleurococcus die gleichen Erscheinungen, sowohl was die allgemeinen Gesetze der Zellenbildung, als was die speciellen Modificationen betriff, denen jene allgemeinen Gesetze unterworfen sind. Der einzige Unterschied beruht in der verschiedenen Gallertausseheidung. liei Palmells ist dieselhe beträchtlich. Bei l'leurococcus scheint diesellse auf den ersten Blick zu mangeln; sie ist aber auch hier vorhanden, nur in sehr geringem Masse; sie bildel eine schmale, die Zellmemlıran überziehende Sehicht. Reicht nun diese Verschiedenheit der Gallertaussonderung hin, um die Begrïndung ron 2 Gattungen, Palmella und Pleurococcus zu rechtferligen? Ich will die Frage hier nicht entscheiden, olygleich ich Formen mit sehr versehiedener Häehtigkeit der Extracellularsubstanz gesehen, und in ihnen Uebergänge zwischen den beiden Gatlungen vermuthe.

(") Doskss, Zwillinge gebährend. 


\section{$-152$}

Es mag hier noch eine Bemerkung über Zellenbildung am Platze sein. Man hat diesclbe früher für Palmella und ähnliche Pflanzen häufig so dargesteltt, als ob die Gallerte ("Schleimunterlage, Urschleim ") das primäre sei, und als ob sie die darin liegenden Zellen erzeuge. Diese Ansichl ist auch in neuerer Zeil noch ausgesprochen worden $\left({ }^{1}\right)$. Sie ist aber nun entschieden unrichlig, da uns die Beobachlung lehrt, dass die Zellen zuerst vorhanden sind, und dass erst nachher die concentrischen Gallertschichten auftreten (rergl. Fig. 18 und 19 ; 21 und 22; 25 und 24; 27 und 28), wejche erst, wenn die Individuen in hinreichender Menge beisammen liegen, eine zusammenhängende Gallertmasse darstellen.

\section{NOSTOGHACEZE.}

Durch regetative Zellenbildung entsteht eine Zellenreihe; einzelne Zellen derselben werden unmittelbar zu Keimzellen.

Das Pflanzenindividuum ist eine Zellemreihe, deren Zellen weder das Vermögen Aeste noch Wurzeln zu bilden, besitzen. Eine oder mehrere Zellen einer Reihe trennen sich von den übrigen los und werden zu Keimzellen. Wie bei den Palmellaceen nur Eine Art der Zellenbildung (nämlich reproductive) vorhanden ist, so findet sich auch bei den Nostochaceen in jedem Individuum zwar ebenfalls bloss Eine Zellenbildung, aber nur vegetative. Dagegen zeigt die Zellenbildung in den verschiedenen Individuen eine Verschiedenheit, nämlich eine räumliche. Die Grenze zwischen zwei Individuen (Mutter und Tochter) wird dadurch bezeichnet $_{i}$, dass in einer Zelle des Einen eine räumlich verschiedene Zellenbildung beginnt, wodurch der Anfang zn einem neuem Individuum gegeben ist. Der Unterschied von vegetativen und von Keimzellen tritt somit hier in seiner einfachsten Gestalt auf : Mit der Keimzelle beginnt ein Zellenbildungsprozess; alle durch denselben entstehenden Zellen sind vegetativ, und unter einander sowohl als mit ihren Mutterzellen gleich, indem sie auf gleiche Weise Zellen bilden können. Nur eine oder einige wenige Zellen besondern sich, und werden von allen übrigen verschieden, indem sie sich aus der individuellen Vereinigung lostrennen und einen neven, zwar analogen aber doch individuell-verschiedenen Zellenbildungsprocess einleiten: es sind die Keimzellen.

Zu den Noslochaceen gehören die Nostochineen, die Rivularieen und die meisten Oscillatoricen der Autoren.

(1) Yergl. Endlicher und Inger, Grundzïge der Botanik, $1845,571-74$. 


\section{$-\quad 153$ \\ Nostoc commnne Vauch.}

ТАв. I, FIG. $50-56$.

In einer homogenen structurlosen Gallerte liegen gebogene Zellenreihen von kuglichten, an beiden Polen ınehr oder weniger abgeplatteten grünen Zellen. Diese Zellenreihen entstehen auf folgende Weise. Ursprünglich ist eine einzige sphärische Zelle vorhanden (Fig. 50). Diese verlängert sich zu einer elliptisehen Gestalt und theilt sich durch eine den langen Ellipsendurchmesser unter einem rechten Winkel schneidende Wand (Fig. 51). Die beiden neuen Zellen runden sich ab, bleiben aber mit einander verbunden. Jede derselben dehnt sich wieder in die Länge, und zwar in der gleichen Richtung, wie es die Mutterzelle that, und theilt sich dann durch eine Wand, welche mit der in der Mutterzelle entstandenen Wand parallel läuft (Fig 52). Die Zellenreihe besteht jetzt aus 4 Zellen. Jede dersellen rerhält sich wie ilre Hutterzelle. rundet sich ab, verlängert sich und erzeugt 2 Tochterzellen. Dieser Prozess wiederholt sich fortwährend auf gleiche Weise. Jede Zelle theilt sich in 2 Tochterzellen (Fig. 5j, a, a). Die Zellenbildung geschieht imner in der gleichen Richtung wie in der Mutterzelle, also auch in der gleichen Richtung wie in der ursprïnglichen Zelle, aus welcher de Zellenreihe entstanden ist; die Wand ist parallel mit der einen (wenn es eine Endzelle ist) oder mit beiden (wenn es eine mittlere Zelle ist), an andern Zellen anstossenden Endfächen. Jede der beiden Tochterzellen (Fig. 5̄ welche ihre, die Mittelpunkte der beiden Endflächen verbindende Achse bezeichnet; die übrigen Durclımesser der Zelle dagegen, welche mit den beiden Endflächen parallel laufen, ändern sich nicht. Darauf theilt sich jede der beiden Zellen von neuem. - Durch den Umstand, dass je die Tochterzellen in der gleichen Richtuny Zellen bilden wie ihre Iutterzelle, und dass die Zellen mit einander verbunden bleiben, entstelıt eine Zellenreihe. Dadurch dass je die beiden Tochterzellen fortpflanzungstähig sind, entsteht eine in allen ihen Elementen wachsende Zellenreihe.

Das Wachsthum der Zellenreihen, insofern es von der Zellenbildung und der Zellenausdehnung abliängt, zeigt keine anderen Erscheinungen als die angegebenen. Innerhalb der Zellen ist indessen eine lehhafte Assimilation des aufgenommenen Nahrungsstofles thätig. In Folge derselben wird eine beträchtliche Menge von Gallerte ausgeschieden. Dass dieselbe wirklich secernirte Extracellularsubstanz sei, wird vorzüglich durch die Analogie von Palmella klar, indem die sonst gewöhnlich structurlos erscheinende Gallerte doch zuweilen ähnliche, in Gencrationen abgetheilte Schichtung erkennen lässt, wie wir es bei Palmella kennen gelerut haben. - Ueber die Zellenbildung labe ich für Nostoc keine directen Beobachtungen. Die Analogie mit den übrigen Algenzellen erfordert hicr, wic bei Palmella und Plcurococeus, die Annahme, dass die Zellen dureh wandständige Zellenbildung (um den ganzen Inhalt) entstehen.

Die Vermehrung der Zellenreihen geschicht auf folgende Art. Eine Zelle in der Mitte wird grösser, und nimmt dabei cine vollkommen spharische Gestalt an (Fig. $\overline{5} \overline{5}, g$ ). Die Grössenzunahme beträgt höchstens \% ihres frühern Querdurelımessers; zuweilen ist sie null. Diese Keimzelle, wie ich sie nennen will, finde ich zuerst immer in der Nitle einer Zellenreilue. Nachher lösen sich die beiden Ilälften der Zellenreihe von ihr los, und sie liegt frei; löst sich die eine Ifälfte zuerst los, so steht sie an dem Ende einer Zellenreilıe, unt gewälurt den Anschein, als ob sie eine veränderte Endzelle sei. Aus der freigew ordenen Keimzelle entsteht cine neu⿰ Zellenreihe, auf die beschriebene Art. Dabei ist aber zu bemerken, dass die Richtung der Zellenlbildung im Raume für die Keimzelle, und dıe aus ihr entstehende Zellenreihe eine andere zu sein seheint als in der Ilutterzellenreihe. Die Differenz beträgt $90^{\circ}$. Sind z. B. die Scheidewände in einer Zellenreihe (Fig. 5j) senkrecht und von Ost nach West gerichtet, so sind die Scheidewände in der Keimzelle (g) und in den Zellen der aus ihr hervorgehenden neuen Zellenreihe vertical von Süd nach Nord oder horizontal gelegen. Liegen die Wände einer Mutterzellenreihe horizontal, so laufen die Wände der Tochterzellenreihe vertical entweder von Ost nach 
West oder von Sïd nach Nord. Die Umwandlung einer bestimmten Zelle der Zellenreilse in eine Keinzelle besteht also darin, dass dieselbe ihr Zellenbildungsvermögen in einer bestimmten Rielıtung, welches ihr als Element der Zellenreihe eigenthümlich ist, verliert, und slatt dessen das Vermögen erlı̈̈l, in einer anderen Richtung des Raumes Zellen zu erzeugen. -

Diese Verhältnisse werden dann klar, wenn eine Keimzelle schou Zellen zu bilden anlängt, ehe sie sich noclı vollständig aus der Yulterzellenreihe losgelöst hat. In Fig. 54 ist a das Ende einer Zellenreilıe, g - g die Keinzelle, welche in einer andern Richtung sich in die Länge gedehnt und in 2 Tochterzellen getheilt hat, als es die Zellen jener Zellenreihe thun. - In Fig. 55 ist a - a ein kleines Stück aus der Nitte einer Zellenreihe, g die Keimzelle. An der letztern bemerkt man beiderseits 2 kleine zapfenartige Vorsprünge, welche zwar nicht der Durchschnitt einer ringfürmigen vorspringenden Leisle sind, wie sie bei der Pollen- und Sporenbildung der Entstehung der Specialmutterzellen vorausgeht, - welche aber dennoch ebenfalls eine bestimmte Beziehung zur Richtung der künftigen Zellenbildung zu haben scheinen. - In Fig. 56 sind ausser diesen beiden Vorsprüngen noch 2 kleine Zellenkerne vorhanden. Beide Erscheinungen bezeichnen übercinstimmend die Richlung $g-g$ als die Richlung der künftigen Zellenbildung in der Keimzelle und als dic Riclılung der entstehenden Zellenreilıe. Ich bemerke jedoch hier ausdrücklich, dass ich die in Fig. $\breve{4} 4$ und 56 gezeiclıneten Zustände jeden nur ein einziges Val beobaclıtet labe, und dass ich daher über ihre Constanz nichts ausspreclıen kann.

Wenn eine Zellenreihe sich fortpflanzt, so geschieht es also durch eine ihrer mittleren Zellen, weiche sich in cine Keinzelle unwandelt. Dadureh theilt sich dîe Zellenreihe in 5 Partieen, in die Keimzelle und in 2 doppelt kürzere Zellenreihen, als sie selbst war. Jede der beiden letzteren wächst durch Zellenbildung in allen ihren Elementen, wie es die Yutterzellenreihe that, und verhält sich auch in allen Stücken wie diese letztere. Yan kann also sagen, dass bei der Fortpflanzung aus 1 Zellenreilıe 5 Zellenreihen hervorgehen.

Nach Feststellung dieser Thatsachen ïber das Wachsthum und die Fortpflanzung der Zellenreihen von Nostoc commune und über das Entstehen der Galler'masse, in welcher sie liegen, geht die erste und wichtigste Frage nach der Individualität der Pflanze. Die neusten Algologen stimmen darin überein, dass die ganze Gallertmasse mit allen Zellenreihen, die sie enthält, eine Pflanze sei, denn in der Diagnose der Gattung heisst es: "Cellutæ subglobosæ, coalitæ in series moniliformes.... frondem gelatinosam.... farcientes " ( $\left.{ }^{1}\right)$ oder "Phycoma peridermide cinctum,... intus ex trichomatilus... massa gelinea communi involutis, compositum " $\left({ }^{2}\right)$. Das Pflanzenindividuum wird aber bei Nostoe nicht durch die ganze Gallertmasse, sondern durch jede einzelne Zellenreihe dargestellt. Die Gründe dafür sind die nämlichen, warum bei Palmella nicht elsenfalls die ganze Gallertmasse, sondern dort jede einzelne Zelle als Pflanze angesehen werden muss. Die ganze Gallertmasse mit allen eingeschlossenen Zellenreihen ("Frons, Phycoma") übt keine gemeinschaftliche Function aus, sie lıesitzt als Ganzes kein Leben; denn es sind keine Erscheinungen vorhanden, welche auf ein solches gemeinsames Leben schliessen liessen. Die Gallerte ist weder die gemeinsame Erzeugerin, wie früher angenommen wurde, für die Zellenreihen, noclı ist sie deren gemeinschaftliches Produkt und Organ; sondern sie ist die Summe der von allen einzelnen Individuen erzeugten Excretionen, welche durch plyysicalische $\Lambda$ dhäsion zu einen Ganzen rerbunden bleiben. Külzing lässt zwar sein "Phycoma " durch eine "Peridermis " umschlossen sein ; aber diese sogenannte Peridermis ist nichts anderes als der äusserste und zugleich älteste Theil der ausgeschiedenen Gallerte, welcher durch äussere plyysicalische Einflüsse verändert wurde. - Die Gesamntmasse von vostoc besitzt rorzïglich auch keine Fortpflanzung als Ganzes und kann daher auf keine Weise die Pflanze sein.

Bei Nostoc können fernẹ dic einzelnen Zellen nicht als pflanzlıche Individuen angesehen werden, wie es bei Pleurococeus und Palmella geschelien muss. Denn die Zellen sind Theile der Zellenreihen, welche als solche Lchensäusserungen besitzen; diese bestehen darin, dass sie sich fortpflanzen. Bei Pleurococcus und Palmella

(') Endlicher, gen. pl. suppl. I1I. gen. 15.

() Külzing, phycologia gen., pag. 205. 


\section{- 155}

konnten die aus mehreren (bei ersterer Gattung dicht aneinander liegenden) Zellen bestehenden Körner und Häufchen nieht als Individuen angesehen werden, weil sie sich als solche nicht fortpflanzten, weil sie überhaupt bloss eine einzige Zellenbildung zeigten, welche nicht zugleich der Vegelation und der Reproduction angehören konnte. Ich habe dort sehon als Grundsatz ausgesprochen, llass eine mehrzellige Pflanze venigstens 2 Arten der Zellenbildung besitzen müsse, eine für das $I$ achsthum des Individuums und eine für die Fortpflanzung desselben.

In Nostoc finden wir nun die allereinfachste Anwendung dieses Grundsatzes. Die eine Zellenbildung, welehe immer in der gleichen räumlichen Richtung statt findel, dient bloss dazu, das schon vorhandene Individuum zu vergrössern; die andere Zellenbildung dagegen, welche eine andere räumliche Riehtung einschlägt, dient dazu, ein neues Individuum zu erzeugen. Dabei muss ich die Frage noch unentschieden lassen, ob die Keimzelle bloss eine grösser gewordene Zelle der Zellenreihe sei, oder, ob es eine neue Zelle sei, die erst in einer grösser werdenden Zelle der Zellenreihe, als einzige Tochterzelle, entstanden ist. Ich will einstweilen das Erstere als das Einfachere und Wahrscheinlichere annehmen. Die Entseheidung dieser Frage isl wichtig für den Begriff der Gattung; sie ist aber gleichgültig für die Frage, ob die Zellenreihen Pflanzenindividuen seien; denn sie sind es in beiden Fällen. - Die Individuen von Nostoc sind also Zellenreihen. Sie entstehen aus einer einfachen Zelle (Keimzelle), und waclısen allseitig (d. h. in allen ilıren Elementen) durch Zellenbildung. Der Begriff des Wachsthums besteht darin, dass in jeder Zelle durch undstündige Zellenbildung 2 Tochterzellen erzeugt uerden, und dass die Zellenbildung in einer Zelle immer die gleiche Richtung befolgt, wie sie die Zellenbildung in ihrer Multerzelle befolgte. Die Elemente der Zellenreihen sondern Gallerte aus, welche ein Bindemittel für alle beisammenliegenden, und möglicherweise aus einem einzigen Individuun entsprungenen Individuen abgibt, und dieselben in grössere oder kleinere Familien vereinigt. - Eine Zelle der Zellenreihe wandelt sich in eine Keimzelle um. Der Begriff der Fortpflanzung besteht darin, dass eine Zelle des Individums der vïumlichen Richtung nach eine andere Zellenbildung besitzt, als alle übrigen Zellen desselben Indiviluums.

Die Grundlage für eine Definition der Gattung Nosтос muss jedenfalls in folgenden Merkmalen gefunden werden: Die Pflanze ist eine Zellenreihe mit allseitigem Wachsthume; sie pflanzt sich durch eine mittlere Zelle fort, welche zur Keimzelle wirl und als solche in einer anderen räumlichen Richtung (als die übrigen Zellen des Individums) Zellen bildet. Ob dieses der ganze Gatlungsbegriff sei, oder ob noch einige speciellere Bestimmungen hinzukommen müssen, um Nostoc von andern verwandten Gattungen zu unterscheiden, bleibt für einmal dahin gestellt.

Räthselhaft sind die Nostoefiden in Collema. Nach Kützing $\left(^{4}\right)$ verwandeln sich Nostocarten in Collemaarten. Derselbe giebt dabei an, dass die Nostocähnlichen Zellfäden nach unten in sehr feine Fäden übergehen, indem die Glieder sich verdïnnen und verlängern. Bei einer frühern Untersuchung fand ich in Collema zweierlei Zellfäden unier einander gemengt, 1) grüne, nostocälnnliclıe, mit weiteren, abgerundeten Zellen, und 2) farblose, mit sehr schmalen, langen cylindrisehen Zellen. Andere Collema-Arten besitzen neben den farblosen dünnen Fijden, statt dẹ Nostocfäden, Häufehen von Zellen, welche Palmella täuschend älınlich sind. Einen directen Uebergang von den Nostoc-ähnlichen Fäden in die dünnen, farblosen Fäden sah ich nicht, eben so wenig Gebilde, welehe zwischen beiden die Mitte gehalten hätten. Auch benerkte ich gleiehfalls nichts von einem Uebergehen der Palınella-ähnlichen Zellenhäufehen in die dünnen, farblosen Fäden. Dabei stiegen mir Zweifel auf, of wirklich diese beiden heterogenen Elemente der Flechte angehören, oder ob nicht Nostoc und Paimella parasitisch in Collema wohne? Diese Vermuthung ist nichts weniger als sicher; ich spreche sie bloss aus, damit sie bei allfälligen künftigen Untersuchungen berücksichtigt werde.

(') Phycologia general, pag. 205. 


\section{$-156$}

\section{BANGIAGE正.}

Durch segetative Zellenbildung entsteht eine Zellenreihe oder eine Zellschicht; einzelne Zellen derselben erzeugen durch wandständige Zellenbildung (Theilung) mehrere Keimzellen.

Das Pflanzenindividuum ist eine Zellenreihe oder eine Zellschicht, deren Zellen meist das Vermögen besitzen, Aeste oder Wurzeln zu bilden. Einzelne, häufig die meisten Zellen (nie alle, - eine Ausnahme machen wenigstens die Endzellen sowohl der Spitze als der Basis) werden zu Mutterzellen, aus deren jeder durch einmalige oder durch wiederholte Theilung 2, 4 oder mehrere Keimzellen hervorgehen.

\section{LYNGByeae.}

\section{Zellenreihe.}

Jedes Individuum ist eine Zellenreihe, bald ohne, bald mit (wahrer) Verästelung. Einzelne Zellen, meist die untersten, treiben Wurzeln. Die vegetative Gewebezellenbildung findet immer in der gleichen Richtung statt, und stimmt in dieser Beziehung mit derjenigen der Nostochaceen überein. Von ihr unterscheidet sich die reproductive Zellenbildung, indem die Theilung andere räumliche Richtungen einhält. Dieses Umschlagen der räumlichen Richtung der Zellentheilung bezeichnet den Anfang der reproductiven Zellenbildung, welche sich gewöhnlich melırmal, und zwar abwechselnd in den verschiedenen Dimensionen des Raumes wiederholt, und deren letztes Product die Keimzellen sind. Während daher die vegetativen Zellen bloss in einer Linie hinter einander liegen, so liegen die Keimzellen körperförmig neben und über einander. Von den Nostochaceen unterscheiden sich die Lyngbyeen begriffsmässig einzig durch die Fortpflanzung; die letzlern können häufig aber auch bei mangelnder Reproduction durch die Anwesenheit von kleinen Wurzeln erkannt werden.

Zu den Lyngbyeen gehören mehrere Arten der Gattung Lyngbya, ferner die Gattungen Hormidium Kützing, Ulothrix Kützing, Draparnaldia Bory, Stygeoclonium Kützing, Bangia Lyngb., Stigonema Ag. 
Ulothrix zonata kütz. (1)

(Conferva zonata Web. et Mohr. Myxonema zonatum Fries. ${ }^{2}$ )

TAB. I, FIG. $47-54$.

Kützing hat diese Pflanze nach ihren regetativen und reproductiven Eigenthümlichkeiten gut beschrieben und abgebildet $\left({ }^{5}\right)$, so dass ich nicht viel beizufügen habe.

In dem Yomente, else die Keimzellen' sich zu entwickeln anfangen, finde ich sie in der Regel kugelig (Fig. 17, 48). Der rothe Punkt, von dem ich später noch reden werde, liegt irgendwo an der Wandung. Auf einer Seite wächst eme dünne, wenig gefärbte Wurzel hervor (Fig. 49). Am entgegengeselzten Ende verlingert sich die Zelle in einen gegliederten Faden (Fig. כ̌0, 5̈1). Der rothe P’unkt ist in der erslen, zweiten, oder dritten Zelle sichtbar (Fig. \$1). Die Zellenreihe wächst so, dass sich alle Zellen theilen. Die Wurzel verlängert sich ebenfalls, und besteht zuletzt aus einigen schmalen und langrestrecklen Zellen (Fig. "̈2).

Der Zelleninhalt ist eine wasserhelle Flüssigkeit im Innern; an der Wandung liegt homogenes Clorophyll. Dasselbe überzieht zuweilen die ganze Cylinderfl̈̈che; häufiger bildet es an derselben bloss eine grössere oder kleinere mittlere Querzone; in seltneren Fillen ist das Chlorophyll auch bloss in so geringer Nenge in den Zellen vorhanden, dass es nur einen kreisförmigen oder elliptisehen Fleck an der Cylinderflïehe bildel. Die Endfï̈chen bleiben immer frei und ungefärbt. Auf die Anordnung des Chlorophylls hat die Gestalt der Zellen Einfluss, indem in den relativ kürzern Zellen (deren Querdurchmesser beträchtlicher ist als der Längsdurchnesser) die ganze Cylinderlläche oder ein grösserer Theil derselben mil Chlorophyll bedeckt ist, in den relatir längeren Zellen dagegen (deren Längsdurchmesser beträchtlicher ist, als der Querdurchmesser) bloss eine kleinere Zone oder auch nur ein kreisförmiger Fleck durch Clorophyll bedeckt wird.

In der Clorophyllsehicht liegen ein oder mehrere Körner. Ihre Zahl steht in direclem Verhältnisse zur Grösse der Chlorophyllschicht, ist diese bloss ein kleiner Fleck, so liegt gewölnnlich mitten in demselben ein einziges Korn. In einem schmalen Chlorophyllbande befinden sich meisł zwei, in einem breilern drei bis sechs Körner. Um die Köıner herum ist die sonst ziemlich dïnne Chlorophyllschicht verdickt. Die Körner scheinen Stärkekörner zu sein; doch isl das bei ihrer Kleinheit nicht mit Sicherheit auszumitteln.

Die Fäden sind sehr verschieden dick. Der Durchmesser varirt von 0,004 "'l $-0,018^{\prime \prime \prime}$. Der gleiche Faden ist ziemlich gleich dick, oder er wird nach einer Seite hin wenig und ganz allmäligg dünner oder dicker. Die Zellen besitzen eine sehr verschiedene Lünge; absolut varirt diesellse von 0,002 "'l bis 0,020 "'/; relativ zum Querdurchmesser rarirt dieselbe so, dass in den einen Zellen die Länge bloss $\%$ der Breite, in den andern Zellen sogar '̌ mal die Breite beträgt. Im gleichen Faden varirt die Länge der Zellen gewöhnlich um nicht mehr als um das Doppelte (").

Wenn die Zellen fructifiziren sollen, so werden sie zuerst ellipliseh (früher waren sie cylindrisch), indem sich die obere und die untere Kante abrundet (Fig. 55, b). Der grüne Inhalt mehrt sich, indem er mun entweder eine ziemlich breite Sehicht an der ganzen innern Oberfläche bildet oder das Zellenlunen ganz ausïilit.

(1) Diese, so wie die meisten übrigen Galtuugsmonographicen wurden in Frühjahre 184 ä gesclıriehen. Wo die neuerı Werke ron Kïlzing und IIassall zu Bemerkungen Anlass gaben, sind sie in Anmerkungen beigefügt.

() Lyngbya zonata IIassall.

(3) Phycol. general., pag. $231 .$, tab. 80.

( $\left.{ }^{4}\right)$ Kiüzing hat in der Phycologia germanica (pag. 196) 18 Arten von Ulothrix unterschieden, welche vorzïglich durch die Dicke der Fäden und die Lünge der Glieder sich auszeichnen. Ich könnte kützing nicht beistimmen, dass diesen Formen ein specifischer Werth beigemessen werden dürfe. In einem Rasen finde ich häufig melırere der Külzingschen Arteu beisammeu, aber zugleich mit allen möglichen blittelstufen. 


\section{$-138$}

Die Zellen theilen sich dann durch eine gewöhnlich senkrechte Wand in zwei Tochterzellen (Fig. 55, c), von denen jede wieder, wie die Nutterzelle, entweder ganz mit grünem Inhalte erfüllt oder an der Wandung überzogen ist. Jede der beiden Tochterzellen theilt sich wieder, und zwar nun gewölınlich durch eine horizontale Wand (Fig. $85, d, e)$. Diese Theilung wiederholt sich ein, zwei, drei, viermal, so dass aus einer Gliederzelle bald bloss 4, bald bis auf 10 und 20 Zellen gebildet werden. Jede dieser Zellen ist eine Keinzelle.

Die Gliederzellen öffnen sich seitlich und lassen die Keimzellen heraustreten. Diese, sobald sie ins Wasser kommen, bewegen sich sehr lebhaft. Sie schwimmen schnell vorwärts, indem sie sich um ihre Achse drehen, welche in ter Richtung ihrer Bewegung liegt. Zuweilen drehen sie sich bloss um ihre Achse, ohne rorwärts zn rïcken; es findet diess aber, wie ich glaube, bloss dann statt, wenn die Achse senkrecht steht, so dass wahrscheinlich der llangel einer progressiven Bewegung bloss davon herrührt, dass sie an eines der beiden Ohjectglïschen, zwischen denen sie liegen, anstossen. Obgleıch nun diese Bewegung eine grosse Aehnlichkeit mit der Bewegung der Infusorien hat, so scheint sie mir doch im Ganzen regelmässiger und steliger zu sein. bic Keimzellen rïcken melır in gerader Richlung und mit einer gleichmässigern Schnelligkeit vorwärts als die Infusorien. Ferner ist ihre Gestalt starr und unveränderlich. Einen fadenlörmigen Anhang sah ich nicht.

Die Keimzellen sind ganz oder bloss theilweise grün. Der grüne lnlıalt füllt entweder das ganze Lumen der Zelle aus, oder, was häufiger der Fall ıst, er lässt auf der einen Seite eine freie ungefärbte Stelle; oder er liegt auch bloss an der Wandung, indem das Innere mit wasserheller Flüssigkeit gefülil ist. - Die Gestalt der Keimzellen ist beim Ileraustreten aus der Gliederzelle unregelmässig. Wenn sie aber frei im Wasser liegen, so werden sie balıl eiförmig oder kugelförmig. - An der Wandung liegt ein rothes Korn, das von aussen entweder rund oder länglich und wie ein kurzes Stähchen aussiebt. Zuwellen sind es dentlich zwei gesonderte, neben einander liegende Körner (Fig. 48). Diese rothen Körner liegen in der Zellwandung, und es hat sogar fast den Anschein, als ob sie ausserhalb derselben lägen, wenigstens zeigt dort die Wandung einen kleinen, der Grösse des Kornes entsprechenden Vorsprung. - Das rothe Korn liegt entweder im grïnen oder im farblosen Thęile der Membran. Es hat bezüglich zur Bewegung der Keinzellen kein bestimmtes Lagerungsverhältniss. indem es bałd im Pol, bald im Aequator der sich drehenden Zelle liegt. - Kützing nennt das rothe Korn "Augenpunkt, " die farblose Stelle der Wandung, wo kein Chlorophyll derselben anliegt, " Miundstelle; " Dentungen, wie sie von Ehrenberg für Infusorien und wahrscheinlich ebenfalls für die beweglichen Keimzellen, insofern er dieselben nämlich fïr Infusorien hielt, angewendet nurden. Statt nun aber die Augen von den Infusorien, wo sie eine blosse Vermuthung sind, auf die Keimzellen ïberzutragen, würde ich es für richliger halten, von den Keimzellen aus, wo die rothen Punkte sicher keine Augen sind, zu schliessen, dass die gteichen rolhen l'unkte in den Infusorien ebenfalls keine Augen sein können. Die sogenannte Iundstelle ist offenbar etwas ganz anderes als die wahre Mundöffnung vieler Infusorien. Kützing sagt, dass die Keimzellen vich mit der Mundstelle ansaugen, und dann sich zu einem gegliederten Faden entwickeln. Meine Beobachtungren stimmen damit nicht überein. Wenn die Keimzellen zur Ruhe gelangt sind, so besilzen sie gewöhnlich eine kugelförmige Gestalt; das Chlorophyll liegt auf verschiedene Weise in der Zelle; es überzieht die ganze Wandung (so dass die sogenannte Mundstelle mangelt), oder es überzieht bloss einen grössern oder kleinern Theil der Wandung. Die Wurzel aber wächst aus der Keinzelle hervor olne Rücksicht anf die Anordnung des Chlorophylls. Die Wurzel selbst ist farblos oder wenigg gefärbt, und dadurch wird es denn leicht möglich, dass man irriger Weise die Wurzel mit jener hellen Stelle an der Peripherie für identisch häll.

Wenn ein Faden oder ein Theil eines Fadens fructifizirt, so geschicht es in der liegel durch alle Zellen ohne Lnterschied. bie Keimzellenbildung schreitet dabei gewöhnlich von einer Seite nach der andern fort, so dass der eine Endtheil des Fadens bloss aus wasserhellen entleerten Gliederzellen besteht, der mittlere Theil fructifizirende und der andere Endtheil bloss noch unveränderte Gliederzellen enthält (Fig. 5ั4, 55). Es ist mir wahrscheinlich, dass die Keimzellenbildung an einem Faden von oben nach unten fortschreile. 


\section{$-139-$
2. ULVEAE.}

Zellschicht.

Die Ulveen unterscheiden sich dadurch ron den Lynglyeen, dass sie nicht aus einer Zellenreihe, sondern aus einer Zellschicht bestehen. Diese Zellschicht ist entweder offen, und bildet eine blattartige, einschichtige Fläche; oder sie ist geschlossen und bildet eine schlauchförmige Fläche. Im letztern Falle ist sie entweder mit Wasser gefüllt, und stellt einen mehr oder weniger cylindrischen Schlauch dar; oder sie ist nicht mit Wasser gefüllt, sie ist ein leerer Schlauch, dessen Wände aneinander liegen, und sie bildet somit ebenfalls eine blattartige, aber scheinbar zweischichtige Fläche. Man darf aber nicht, wie es bisher geschah, sagen, dass die Frons der Ulveen wirklich zuweilen aus 2 Zellschichten gebildet sei, in dem Sinne, wie dieser Ausdruck sonst verstanden werden muss. Die wirklich zwei- oder mehrschichtige Frons ist in ihrer Entwicklung zuerst eine einfache Schicht, deren Zellen sich dann theilen'. Die Entwicklungsgeschichte der sogenannten zweischichtigen Ulseen ist aber eine ganz andere; sie wachsen fortwährend als einfache Schicht. - In Bezug auf die Keimzellenbildung stimmen die Ulseen ganz mit den Lyngbyeen überein. Eine Zelle theilt sich in zwei, und die Theilung wiederholt sich mehr oder weniger, so dass aus der ursprünglichen Mutterzelle 4 oder mehr Keinzellen entstehen.

Zu den Ulceen gehören die Gattungen Prasiola Kütz., Porphyra Ag., Phycoseris Kütz., Ulva Auct., Enteromorpha Auct., Zignoa Trevis.

Ich wähle als Beispiel für die vegelative Entwicklung Enteromorpha, für die Fortpflanzung Porphyra.

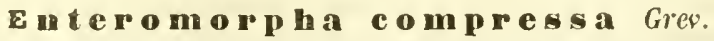

(Ulva conıressa L. Solenia compressa Ag.)

$$
\text { TAF. 1, F1G. כว }-58 \text {. }
$$

bie Pflanze ist verästelt; die Aeste sind röhrenförmig; die Wand besteht aus einer einfachen Zellschicht: die Höhlungen aller Aeste communiziren miteinander und sind mit Wasser gefüllt.

Jeder Ast ist zuerst eine einzige Zelle, nämlich irgend eine Zelle der Mutterachse, welche sich besondert. Diese Zelle verlängert sich naclı aussen und etwas sehief nach oben, und theilt sich durch eine, ihre $\Lambda$ chse unter einem rechten Winkel schneidende Wand in zwei Zellen, von denen die untere und innere so ziemlich dem ursprünglichen Lumen der Mutterzelle entspricht, die letztere aber an der Seite der Vutterachse frei herluervorragt. Dass diese äussere, einer Astzelle gleichende Zelle die zweite und nicht etwa die erste Zelle der 


\section{- 140}

neuen Achse, also nicht eine Astzelle (wie wir sie sonst gewöhnlich bei der Verästelung antreffen) sei, beweist das weitere Verhalten der innern Zelle. - Die äussere Zelle verlängert sich in der Richtung ilırer Achse, und theilt sich dann durelı eine horizonfale Wand in eine (obere) neue Scheitelzelle und in eine (untere) Gliederzelle. Diese Zellenbildung wiederholt sich fortwährend in der jeweiligen End- oder Scheitelzelle. Untersucht man die Spitze irgend eines Astes, namentlich eines dïnnern Astes, so fiudet man, dass seine Spitze in einem kürzern oder längern gegliederten Faden endigt (Fig. 5ั3). Zu äusserst steht die Seheitelzelle (a), hinter derselben mehrere Gfiederzellen (b). Die Seheitelzelle verlängert sich immer in der Längsrichtung des Astes und theilt sich durch eine, diese Richtung unter einem rechten Winkel schneidende Wand in eine neue Scheitelzelle und in eine Gliederzelle.

Die Gliederzellen theilen sich darauf durch eine senkrechte Wand in zwei nebeneinander liegende, halbeylinderförnige Zellen (Fiğ. כ̌̆, d, e). Jede derselben theilt sich wieder durch eine senkrechte Wand, welche mit der ersten Wand einen rechten Winkel bildet, in zwei gleiche Zellen, welche die Gestalt eines Cylinderquadranten besitzen. Auf diese Weise haben sich aus der Gliederzelle 4 neben einander liegende gleiche Zellen gebildet, welche regelmässig un die Aclıse des Astes gestellt sind. Fig. 56 giebt einen horizontalen Durchschnitl von diesem Entwicklungsstadium. Die Zellen tremen sich nun in der Mitte von einander, indem sie Wasser ausscheiden (Fig. 57). Dann theilen sie sich jede in zwei nebeneinander liegende Tochterzellen (Fig. 58), und diese Theilungr wiederholt sich nun fortwährend: die Selıeidewände sind entweder horizontal oler radial-senkrecht (nie tangental-senkrecht). Wir finden daher auf horizontalen Querschnitten nach und uach eine grössere Zahl von Zellen; ebenso vermelıren sich die Zellen in senkrechter Richtung, und zwar so ziemlich in gleichem Masse, so dass sie immer ungefälır gleich hoch und gleich breit sind. Wie sich die Zellen vermehren, so scheiden sie auch im Verhältnisse Wasser nach der innern Höhlung aus, so dass diese immer mit der gehörigen Quantität Wasser erfüllt ist.

Auf gleiche Weise wie sich die übrigen Gliederzellen in 2, dann 4 und melır Zellen theilen, so theilt sich auch die unterste, zwisehen den Zellen des Iutterastes liegende Gliederzelle eines $\Lambda$ stes. Daher kommt es, dass die Ilöhlungen des Vutter- und Tochterastes mit ein ander communiziren. Diese Thatsache zeigt auch, wie die Astbildung bei Enteromorpha zu erklären sei. Die sich besondernde Zelle eines Asles ist die erste Zelle und zwar die erste Scheitelzelle des neuen Isles; sie verlängert sich nach aussen und theilt sich in die (äussere) zweite Sclieitelzelle und in die (innere) erste Gliederzelle. Wäre jene äussere Zelle eine $\Lambda$ stzelle und somit die rrste Scheitelzelle, so müsste auch die erste Gliederzelle ausserhalb stelıen, und die Ilöhlung des $\Lambda$ stes, welche durch die Theilung der Gliederzellen erzeugt wird, könnte bloss lis aussen an die Zellen des Mutterastes reichen, also nicht mit der Jöhlung des letztern in Verbindung stehen.

Das Wachstlım von Enteromorpha, insofern es von Zellenbildung ablı̈ngig ist, lässt siclı also folgenderurassen ausspreehen: Das Wachsthum geschicht an der Spitze durch eine einzige Zelle (Scheitelzelle), welche sich fortwälırend durch eine horizontale, die Achse unter ennem rechlen Winkel schneidende Wand, in eine (obere) neue Scheitelzelle und in eine (uniere) cylindrische Gliederzelle theilt. In den Gliederzellen beginnt einc sielı fortwährend wiederholende Zeltenbildung, deren characteristisches Merkmal darin besteht, dass bloss radial-verticale und horizontale Wünde gebildet werden, welche die jeweilige Iutterzelle m zwei gleiche Tochterzellen theilen. Dadurch dass die Zellen nach innen Wasser ausscheiden, werden die Achsen zu hohlen, mit Wasser gefültten Sehläuclıen. Die Aeste entstelıen dadurch, dass eine Zelle des Mutterastes sich besondert und zur ersten Scheitelzelle für den neuen $\Lambda$ sl wird.

\section{Porphyra valgaris $A g$.}

TAB. I, FIG. $59-62$.

Porphyra ist eine ofiene Zellschicht. Der Durschelnitt zeigt daher immer eine Zellenreihe (Fig. 59). Die Zellen sind anfinglich viereckig und bloss durch schmale Wände getrennt (Fig. 59). Späterhin wird von den 


\section{$-141$}

Zellen beträchtlich viel Gallerte gebildet, so dass dieselben nun rundlich oder ellipsoidisch werden und lose in der Gallerte liegen, beim Schnitte auch leicht herausfallen (Fig. 60). An diesen freigewordenen Zellen erkennt man eine sehr zarte Vembran. Kützing sagt von andern Algen, dass dic "Amylidzellen " herausfallen, d. h. der Zelleninhalt mit der Schleimschicht (Primordialschlauch). Die Membran, welehe die lıerausíllenden Zelleı von Porphyra besitzen, ist gallertartig, und überzieht die Schleimschicht. Das gleiehe, glaube ich, findet auch bei den meisten übrigen Zellen statt, welche beim Zerreissen des Gewebes aus der Intercellularsubstanz frei werden. - Die Zellen besitzen in ihren Centrum einen freien Kern, und rothen homogenen Inlsalt, welcher. theils um den Kern gelagert, denselben gewöhnlich verbirgt, theils als radienförnige Strömungsfäden Kerı und Zellwand rerbindel (lig. 60, a).

Wenn die Zellen fruetifiziren, so füllen sie sich mit Inhalt; sie werden dunkler und intenser gefärbt. Sie theilen sich durelı eine mit der Zellsehicht parallele Wand in zwei gleiche Tochterzellen. Die Theilung wiederholt sich abwchsclud in den drei Richtungen des Raumes. Fig. 61 zeigt einen Durelıschnitt dureh einen Theil der Pflanze, wo die Fortpflamzung begonnen hat. Die Zelle b hat sich in 2 , $\mathrm{c}$ in 5 , $\mathrm{d}$ in 4 , e in 10 Zelten getheilt. In Fig. 62, c liegen schon 18 Zcllen ncben einander, die aus einer ursprünglichien Mlufterzelle entstanden sind. Die Ansicht von der Fläche zeigt ebenfalls Zellen, welche erst in 2, dann in 4 und unehr Zelten getheilt sind. Die Zellenbildung, man mag sie im Durehschnitle oder von der Fläche betrachten, erzeugt zuerst immer Wände, wetche sich unter rechten Winkeln berühren; späterhin aber treten häufig auch schiefe Wände auf.

Aus einer Zelle entsteht somit ein ganzes Häufchen ron kleinern Zellen. Die Zahl derselben ist sehr verschieden. Ob es ein Minimum dafür giebt, und welches, weiss ich nichıl. Da aber die Zellen sowolıl von der Fläche als im Durchschnitte wenigstens eine Theilung in 4 Zellen zeigen, so möchte die Zahıl in der Regel nicht unter 16 fallen. Da hingegen in andern Fällen auf beiden Ansichlen (sowohl von der Fläche als auf dem Durchschnitte) bis auf 18 und 20 Zellen neben einander liegen, so möehte in den gü̈nstigsten Fällen die Zahl der aus einer Zelle entstandenen Zellen bis auf 100 betragen. Die Zellen, welclıe das letzte Produet dieser Zellenbildung sind, stellen die licimzellen dar. Wenn die Żellhäufchen zerfallen, so trennen sie sich zuerst in 2 oder 4 grössere Particen, und nacliher werden die eimzelnen Keinzellen frei.

Die Keimzellenbildung beginnt oben und am Rande des blattartigen Laubes und schreitet nach innen und unten hin fort. In jedem einzelnen Theile fructifiziren entweder alle Zellen (was seltener der Fall ist), oder einzelne Zellen bleiben steril und sterben ab, indem sie kleiner werden, und ilı lnhalt sich entfärbt und als eine ölartige, farblose Nasse das ganze noch ülıriglbleibende Lumen der Zelle erfuillt.

\section{MESOGLOEACEE.}

Durch regetative Zellenbildung entsteht eine Zellemreihe, Zellschicht oder Zellkörper, welche kurze Seitenästchen bilden, deren (silzende oder gestielie) Scheitelzelle durch wandständige Zellenbildung (Theilung) mehrere Keimzellen erzengt.

Die Mesogloeaceen unterscheiden sich von den Bangiaceen dadurch, dass nicht wie dort die Zellen des Laubes selbst fructifiziren, sondern dass erst durch Astbildung seilliche, ein- oder melırgliederige, im letztern Falle unverästelte oder rerästelte Fäden erzeugt werden, deren Endzellen mehrere Keimzellen bilden. 
Die vegetative Zellenbildung bringt einen gegliederten ästigen Faden (Zellenreihe), oder eine Zellschicht, oder einen unverïstelten oder verästelten Zellkörper hervor. Die Gliederzellen der Zellenreihe, die Flächenzellen (nicht die Randzellen) der Zellschicht oder die Epidermiszellen des Zellkörpers bilden durch Auswachsen eine (ïussere) Astzelle. Diese Astzelle wird zur Mutterzelle für die Keimzellen; oder sie entwickelt sich zu einer mehrgliederigen Zellenreihe, deren Endglied zur Keimmutterzelle sich umwandelt; oder sie bildet eine verästelte Zellenreihe, deren Aeste theils steril, theils in eine Keimmutterzelle enden. - Es scheint zuweilen, als ob nicht bloss die Scheitelzelle, sondicrn als ob eine grössere oder kleinere Zahl der letzien Glieder einer Zellenreihe (also die Scheitelzelle und die nächstfolgenden Gliederzellen) Keimzellen bildeten. Dieser Anschein rührt daher, weil die fructifizirende Scheitelzelle in der Regel sich zuerst mehrmals durch horizontale, die Längenachse rechtwinklig schneidende Wände theilt. Man könnte nun glauben, dass die Thatsache beide Erklärungen gleich mässig erlaubte, und dass es überhaupt ein Streit un lecre Worte sei, ob die Keimzellen bloss aus der sich durch horizontale Wände theilenden Scheitelzelle, oder aus der Scheitelzelle und mehrern Gliederzellen entstehen. Dem ist aber nicht so. Einerseits hat die Entscheidung der Frage eine physiologische und systematische Bedeutung, wie man aus der Vergleichung der Ectocarpeen mit den Lyngbyeen sehen wird. Anderseits liegt der Theorie nicht eine willkühliche Deutung der Thatsachen zum Grunde; sie setzl im cinen und im andern Falle verschiedene Thatsachen voraus. Die endliche Form ist allerdings die gleiche; denn wenn sich die Scheitelzelle in 2, 4, 8 oder noch mohrere hintereinander liegende Zellen getheilt hat, so sicht man es diesen Zellen nicht mehr an, ob sie alle als gleichwerthige Tochterzellen einer ursprünglichen Mutterzelle zu betrachten seien, oder ob die Endzelle unter ihnen als Scheitelzelle, die übrigen als Gliederzellen angesehen werden müssen. Im erstern Falle aber wird vorausgesetzt, dass die Scheitelzelle sich in zwei gleiche Tochterzellen theile, und dass in beiden dic Zellenbildung sich gleichmässig wiederhole. Im zweiten Falle wird rorausgesetzt, dass die Scheitelzelle sich in 2 ungleiche Zellen : eine Gliederzelle und eine neue Scheitelzelle theile, dass die letztere, in die Länge wachsend, sich wieder auf gleiche Weise theile u. s. w., dass also, wie in einem vegetativen Gliederfaden, das 
Wachsthum nach der Spitze hin fortschreite. Die Beobachtung zeigt mir nun, dass die Entwicklung auf die erstere Art, und nicht auf die zweite Art geschehe, und dass somit gesagt werden müsse, die Keimzellen entstehen nur aus der Scheiteizelle.

\section{Ectocarpene.}

Zellenreihe (rerästelt); die Keimmutterzellen sind Astzellen oder die Scheitelzellen kurzer Aeste, welche seitlich aus den Glicderzellen entstehen.

Die Ectocarpeen stimmen im Bau und im Wachsthume mit den Lyngbyeen überein. Sie unterscheiden sich von denselben durch die Fructification. Bei den Lyngbyeen findet die Keimzellenbildung in den Gliederzellen und zwar meistens fast in allen Gliederzellen statt. Die Scheitelzellen bilden in einigen Gattungen (wo die Zellenreihen in haarförmige Spitzen auslaufen) bestimmt keine Keimzellen; und höchst wahrscheinlich ist es Gesetz für alle Lyngbyeen, dass nur die Gliederzellen, nicht die Scheitelzellen zu Keimmutterzellen werden können. Bei den Ectocarpeen dagegen fructifiziren die Gliederzellen nicht, sondern sie wachsen seitlich aus, bilden eine Astzelle, und diese Astzelle wird entweder zur Mutterzelle für die Keibazellen oder sie erzeugt einen kurzen gegliederten Ast, dessen Scheitelzelle Keimmutterzelle wird. Es gibt keine Art unter den Ectocarpeen, denen diese Keimzellenbildung in den Scheitelzellen mangelte. Dagegen gibt es mehrere Arten, welche ausser derselben noch in einzelnen Gliederzellen Keimzellen erzeugen. Es scheint mir, dass diese zweite Art der Keimzellenbildung eine Wiederholung der Foripflanzung der Lyngbyeen sei, und ich vermuthe daher, dass man bei den Ectocarpeen ausser der Fortpflanzung durch Keimzellenbildung in den Scleitelzellen der Aeste, noch eine Vermehrung durch Keimzellenbildung in den Gliederzellen annehmen müsse.

\section{Ectocan'pus Lyngl.}

TAB. II, Fig. 1 - 6.

Die Keimzelle, welche sich zu einer Pflanze entwickelt, dehnt sich in die Länge und theilt sich durch eine horizontale Wand in zwei Zellen. Die obere der beiden Zellen wäcbst in gleicher Richtung in die I.änge und 


\section{$-144$}

theilt sich wieder. Der gleiche Prozess wiederholt sich fortwährend: an der wachsenden Achse steht an der Spitze eine Scheitelzelle, welche eine neue Seheitelzelle und eine Gliederzelle bildet. Ausserdem theilen sielı aber auch die Gliederzellen in zwei neue gleiehe Gliederzellen. Das Wachsthum der Zellenreihen ist begrenzt; sowohl die Theilung der Scheitelzelle als die Theilung der Gliederzellen wiederholt sich hloss eine begrenzte Zahl ron Halen. Die Zellenreihen, in denen das Wachsthum beendigt ist, gehen entweder in mehrere lange, dïnne, bald abfallende Borstenzellen, oder seltener in eine aus allmïlig kleineren Zellen gebildete Spitze aus. - Die Zellenreihen verästeln sich dadurch, dass einzelne Gliederzellen auswaehsen und eine Astzelle bilden, welehe sich zu cinem Aste entwiekelt.

Der Zelleninhalt besteht gewöhnlich aus Chlorophyllbläschen (Chlorophyllkügelchen), welche an der Sehleimschicht liegen, und cinem eentralen Kerne, von welehem radienförmige Schleimfäden nach der Peripherie hin ansstrahlen (Fig. 1; die Schleimschicht hat sieh in den 4 Eeken von der Zellmembran losgelöst und zurückgezogen). Die Chlorophyllbläschen liegen bald zerstreut an der Schleimschicht, bald bilden sie verschiedene, mehr oder weniger regelnässige Figuren. Die Farbe des Chlorophylls ist im natiirliehen Zustande meistens gelbbraun; dureh Liegen im süssen Wasser sah ich sie mehrmals sehön grïn werden.

Die Keimmutterzellen sind seillieh an den Aesten, silzend oder gestielt. Sie wurden frïher richlig als Capseln bezeichnet; die neuern Algologen erklärten sie unrichtig fïr Keimzellen oder für Mullerzellen, welehe eine einzige Keimzelle dicht umschliessen. - Die Keimmutterzellen enthalten viele Keimzellen; die lelztern sind z.war nicht inmer deutlich innerhalb der erstern zu sehen: zuweilen jedoch habe ich sie bestimmt beobachtet (Fig. 5, h). Ectocarpus verhält sich in diesem Punkle ähnlich wie Llothrix. Während bei der letztern Gattung meistens die Keimzellenbildung deutlich zu sehen ist, indem man theils die wiederholte Theilung, theils später die Keimzellen sellst innerhalb der Mutterzelle erkennen kann, so ist dagegen zuweilen in andern Pfliuzen oder in andern Zellen der gleiehen Pflanze von beidem nichts żu sehen, und man erkennt die Keimzellen als solche erst, wenn sie die llullerzelle verlassen. In Ectocarpus geschicht es nun häuliger, dass man die Keimzellenbildnng nicht sieht; seltener, dass man die allmälig auftretenden Theilungen der vutlerzelle oder später die Keimzellen innerhalb jener erkennl. Es mag diess namentlich auch davon herrühren, dass die Keimmutterzellen als angeheftete Zellen nicht in eine beliebige Lage gebracht werden können. Es ist aber natürlich, dass eine Anhïufung von vielen kleinen Zellen, wenn die scheidewände dünn sind, allemal als nicht- oder als undeutlich-getheilte Inhaltsmasse erseheint, wenn nieht die Ilauptscheidewände vollkommen senkreeht stehen. Man kann sieh daron am besten durch die Betrachtung von mehrern Pleurococcusarten überzeugen, bei welchen die hörner, je nachdem man sie um einen geringen Winkel dreht, bald als einfache, bald als vielfachgetheilte Zellen erseheinen, - Ausserdem gibt es noch zwei Grïnde, welche für die Ansicht sprechen, dass Ectocurms seitliche Keimnutterzellen, nicht seitliche Keimzellen erzeugt. Die Zellen fallen nämlich meist nieht ab, wie es bei Fatcheria, Thorea, Patlina cte. gesehieht, sondern sie öfnen sich an der Spitze und entleeren ihren Inhalt; sie bleiben noch einige Zeit lang als entleerte Capseln an der Pflanze stehen (Tig. 5, a). Ferner sind die Keimmufterzellen meist beträlehtlieh grösset' und weiler als die übrigen Zeilen der Pflanze, namentlich als die Keimzellen oder die untersten Zelten jungr Pflanzen (vergl. Fig. $\mathbf{3}$, a und Fig. $\mathbf{2}$, a).

Die Keimuntlerzellen sind kugelıg oder eiförmig oder länglich. Es gilst nun aber anch lanzettliche oder lineale Caps:lu, welche ebenfalls wiederholi, ersi durch hopizontale (Fig. 4, b), nachlier dureh senkrechte Winde (Fic. 1, c) sich theilen, dam eine Menge Keimzellen einschliessen und, indem sie sich an der Spitze ïfnen, die himzellen entlecren. Sie beiben dann, wie dic eigentlichen heimmulterzellen, noch einige Zeit als entlecrte Capseln an den Aesten siben (Fig. 1, a). kïlzing hat diese Organe Spermatoidien genannt, da er die keimmutterzellen für rinfache simen hielt. Woun die Keinmutterzellen und die sehotenfömigen Capseln entwickelt siud, so sche ich heine andern Lutersehiede an ihnen als relalire; die Keimmutterzellen sind meist eiförmig tnd lassen die dichten Keimzellen meht deutlich erkennen; die sehotenfömigen Capseln sind meist lanzeltlich-lineal und lassen die mehr lockern keimzellen deutlieh erkennen. Aber sowohl in der 


\section{$-145$}

Form, als in der Lagerung der Keimzellen, gil) es Uebergänge; in den sehotenförmigen Capseln ist die Keimzellenbildung zuweilen ebenfalls, wie in den eigentlichen Keimmulterzellen, nicht zu sehen. - Es frägl sich nun, ob beide Organe sich auch auf gleiche Weise entwickeln, ob also die schotenförmigen Capseln ebenfalls bloss aus Scheitelzellen entstehen. Ich kann die Frage nicht mit Bestimmtheit entscheiden. Während auf der einen Seile die Mittelglieder zwischen kugeligen keimmulterzellen und linealen Capseln nicht zu verkennen sind, so schien es mir dagegen in einigen Fällen, als ob die letzlern veränderle Aeste wären, als ob sie nämlich wie Aeste durch Zellenbildung in der Endzelle wiehsen und als ob die Keimzellen dann durch Theilung der Gliederzelleı und der Selıeitel\%clle entsländen. Wenn diese Beobaclıtung richlig ist, so miiste man neben der einen Fruchthildung, wo bloss die (sitzenden oder gestielten) Scheitelzellen zu Keimmulterzellen werden, noch eine andere Fruchtljildung unterseheiden, wo ein melı- oder vielgliederiger Ası fructifizirt, wo also Scheitelzellen und cliedertellen (alle oder alle unit Ausnahme weniger, an der Basis gelegener, und für deı Fruchtast einen Stiel darstellender Gliederzellen) zu Keimmutterzellen werden.

Es gieht aber bei Ectocarpus noch eine andere Art der Forlfflanzung. Bei E. littorulis seliwellen cinzelne Glieder der Aeste an (Fig. .̈) und theilen sich wiederholt durch horizontale und verticale Wände in eine Venge ron Keimzellen. Die Endzellen dieser Aeste werden nie zu Keimmutterzellen; sondern sie werden dümner und länger, und fallen von oben naclı unten ab. Đie Zahl und Stellung der zu Keimmutterzellen sich verändernden Gliederzellen ist sehr unregelmässigr und veränderlich; entweder sind es bloss einzelne, welche unter den übrigen zerstrent stehen; oder es sind fast alle, unter denen die sterilen Glieder zerstreut stehen. Da die Theilung auch hier zuerst durch horizontale vände statt findet, so trift man die torulosen, fruchttragenden Glieder hïutig in bestimunten Zahlen (nämlich $2,4.8,16,3,6,12$ ) beisammen. Die Keimzellenbildung ist anch hiel' meistens nielıt deullieh zu sehen. Zuweilen aber kann man sowohl die Bildung der Scheidewände (Fig, 6, il, b, e), als auch machher die Keimzellen in der Hulterzelle erkennen.

Aus dem VItgetheilten ergiebt sich, dass man bei der Gattung Ectocarpus wahrscheinlich 5 Arten der Fruchtbildung unterscheiden muss : 1) Die Scheitelzelle eines ein- oder weniggliederigen Astes wird zur Mutterzelle; 2) die Scheitelzelle und die Gliederzellen eines kurzen, veränderten Fruchlastes werden zu Hulterzellen;

5) ciuzelne Gliederzellen ('ines umverïnderien Astes werden zu Mutterzellen. Die Keimzellenhildung seheint aber in allen diesen Fruchthildungen auf gleiche Weise statt zu finden. Von diesen drei Fuchlbildungen ist dic erste die eigentliche Fortpflanzung. Die dritte und ebenfalls die zweite Fruchlbildung (insolern diese wirklich von der ersten versehieden ist) sind als V'rmehrung zu betraluten. Sie entsprechen, wie jede Vernehrung, der Forlpflanzung einer tiefern Stufe des Pflanzenreiches, und zwar hier der Fortpflanzung der Lynugbeen, wo die Keinzellen ehenfalls durch wiederholte Theilung der Gliederzellen entstehen.

\section{MYRIONEMEAE.}

Zellschicht: Keimmutierzellen an der Fläche derselben sitzend"oder gestielt. Die Byrionemeen stimmen mit den Ectocurpeen in der Keimzellenbildung üherein. Sie unterscheiden sich von denselben durch die regetative Entwicklung auf gleiche Weise, wie sich die Ulieen von den Lyngbyeen unterscheiden.

\section{Ty}

TA13. 11. Fig. $51-51$.

Die pRanze ist eine auf tkeen, vorzüglich auf Enteromorpha compressa dicht aufliegende. meist hreisfïrmigr Zellschicht. An dïnncren Aesten der Enteromorphu schliesst sic sich zuletzt zu einem Gïrtel. Jic 


\section{$-146$}

Zellschicht ist strahlig-gestreift. Sie besteht eigentich aus gegliederlen Fäden (Zellenreihen), welche sich von dem Centrum nach der Peripherie hin fortwälırend verästeln und, indem sie einander seillich berühren, eine Zellsehicht bilden. Fig. 51 stellt einen Querschnitt durch die Wandung von Enteromorpha mit dem darauf sitzenden IIyrionema yor; a - a sind die Zellen der erstern, b - b die Zellen der lelztern.

Die Zellschlicht wäichst am Umfangre dadurch, dass jede ladiale Zellenreihe für sich wächst, und sich dabei verästelt (1ig. 52). Die Verästelung tritt immer in gleichem Masse auf, wie es der sich concentrisch vergrö̈ssernde Raum nöthig macht. Wäre diess nicht des Fall, so müssten entweder Lüchen in der Zellschicht entstehen, wenn nämlich die Verästelung in geringerm Masse statt hälte, oder die Zellenreihen müssten sich ïbereinander schieben, wenn nämlich die Verästelung in grösserm Masse stalt fänden, als es gerade die Vermelirung des Raumes erfordert.

Die unlere Fläche der Zellschich ist auf Enteromorph festgewachsen. Die obere Fläche trägt verschiedene Organe. Aus einzelnen Zellen entspringen lange, einfache, farbiose llaare, deren untere Zellen kurz, die oberil lang sind (Fig. 55, c). Bei den Zellen der Haare schreitet namlich die Ausdehnung vou oben nach unten, so dass zuerst die Endzelle, dann die nächsi folgende u. s. w. anfangen, sich ausamtehnen. In gleicher Richtung schreitet auch das Ablallen der Zelsen fort, indem zuerst die oberste, dann die zweit-oherste, dann die driltwbersle Zelle u. s. w. abfallen.

Nur wenige Zelien erzeugen solche lange, farblose Haare. Aus den meisten entspringen kurze, einfache, etwas keulenförmigge Haare (Fig. 55, d). Sie bestehen meist aus 5 , seltener aus $\$$ Zellen, und sind braun-grün gefärbt. Die Endzelle ist elwas grösser', und kugelig oder eiförmig, die ïbrigen Zellen sind schmäler und etwas̉ bauchig. Diese kurzen IIaare bilden auf der Zellschicht eine dichte Behaarung. Zwischen ihnen liegen zerstreut die Keimmutterzellen (Fig. 55, e, f). Dieselben hängen an der Basis gewöhnlich mit cinem kurzen Haare zusammen, und zwar so, dass beide auf einer gemeinschaftlichen Zelle stehen (Fig. 55̈, f), welche auf der Zellschicht ruht. Ausserdem scheint es, als ob die Keinmulterzellen auch noch unmittelbar aus den Zellen der Zellschicht entspringen können (Fig. 55, e). - Ich vermulhe daher, dass die heimmulterzellen sich folgendermassen entwickeln. Die Zellen der Zellschicht wachsen aus, und erzeugen eine frei hervorragende Asizelle. Diese wird zur sitzenden Keimmulterzelle. Oder sie dehnt sich in die Lünge und theilt sich in 2 Zellen, von denen die obere (Scheilelzelte) zur (gestielten) keimmutterzelle wird, die untere aber gewöhnlich durch seitiiches Auswachsen und Zellenbildung ein kurzes keulenförmiges Haar erzeugt. Die meisten übrigen Zellen der Zellschicht erzeugen blos kurze keulenförmige IIaare.

Die keimmulterzellen wurden bisher für Samen gehallen. Es ist diese Ansicht unrichtig. Sie theilen sich in viele kleine Zellen; man sıeht diese Theilung sowohl von oben (Fig. 54) als von der Seite (Fig. 55, e). zuletzt werden die Keimzellen wie in Eciocurpus entleert.

\section{STILOphoreat.}

Zellkörper (einfach oder verästelt); Keimmutterzellen an der Oberfläche desselben, sitzend oder gestielt, auf einfachen oder verästelten, aus Zellenreihen bestehenden Sticlen.

Die Stilophoreen unterscheiden sich von den Ectocarpeen und den Myrionemeen durch den vegetativen Bau. Mit diesem Unterschiede slimmäüberein derjenige 
in der Fruchtstcllung. Bei den Ectocarpeen sind dic Keimmutterzellen Astzellen oder die Scheitelzellen kurzer Aeste, die aus den Zellenreihen entspringen. Bei den Myrionemeen stehen sie seillich an der Ze!lschicht oder an Haaren, welche die Zelsshicht bedecken. Bei den Stilophoreen sind die Keimmutterzellen entweder unmiltelbar aus den äussersten oder den Epidermiszellen des Zellkörpers hervorgegangen, und an denselben befestigt, oder sic sitzen an den Haaren, womit die Oberfläche des Zellkürpers bekleidet ist. Bei der Gatung Stilophora z. B. bestehen die äsligen Haare aus drei verschiedenen Arten von Achsen, 1) aus mehrern kuizen, nach oben rerdickten und rosenkranzförmigen Zellenreihen, 2) aus einigen langen, dünnern und cylindrischen Zellenreihen, und 5) aus ziemlich grossen, fast birnförmigen Multerzellen, die bisher unrichtiger Weise Samen genannt wurden und in denen die Keimzellen sich bilden.

$\mathrm{Zu}$ den Stilophoreen gehören die Gallungen Hyriolrichia Harr., Sphacelaria Lyngb., Cladostephus Ag., Elachista Fries, Leathesia Gray, Mesogloea Ag., Chordaria Ag., Stilophora J. Ag., Scylosiphon Ag., Culleria Grev. etc.

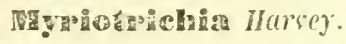

TAB. HI, Fig. $13-20$.

Diese, Galtung' zeigt, in der Fanilie der Stiloptoreen wohl das einfachste Verhallen. Der Hauplstamm ist unverästelt; er ist zuerst eine zellenreiłı, ma hesteht späler auf dem Durchschnitte zuweilen bloss aus vier, gewölnlich aber aus mehr Zellen. E: ist zuerst kahl, nachher überall mit seitlichen zellenreihen (Ilaaren) besetzt, welche zuletzt, wie der Haupistamm, durc!l Zellentheilung ebenfalls zu cylindrischen Zellkörpern werden.

Die sich entwickelnde Keimzelle wächst zu einer einfachen Zellenreilıe aus. Dieselbe wächst theils an der Spitze, indem je in der Scheitelzelle eine neue Scheitelzelle und eine Gliederzelle entsteht. Sie wïchst theils aber auch in ilrer ganzen Länge, indem auch die Gliederzellen sieh fortwährend jede in zwei neue Gliederzellen theilen (Fig. 15). - An einzehnen Zellen dieser Zellenreihe entstehen durch seillicht's Auswathsen Istzellen, aus welchen ebenfalls zellenreihen hervorgehen (Fig. 1/4, b). Dieselben verwandeln sieh iı wasserhelle llaare, deren Zellen von der Spitze nach der basis lin sich ausdehnen (Fig. 14. c) und in der gleichen Richtung nach einander abfallen. Man findet daher an diesen Itaaren gewöhnlich nehrere kurze Zellen an der basis und einige langgesireckle Zellen an der Spitze.

An der spitze der aus der Keimzelle eutstandenen Zellenreihe steht elenfalls ein solches farbloses wasserlielles IIaar (Fig. 1/4, a). Die obersten Zellen der Zellenreihe nämlich bleiben schmäler als die iibrigen; es entwickelt sich in ihnen äusserst wenig Chlorophyll. Zuerst dehnen sich die äussersten aus und fallen ab; Ausdehinung und Abfallen der Zellen schreitet nach unten hin fort.

I)ie übrigen Giliederzellen enthalten einen körnigen, bräunliclt-grünen Inhalt. Sie werden bedeutend dicker als die zellen des endständigen Ilaares. Sie theilen sich seitlich, so dass die Zellenreihe sich in 


\section{- 148}

eimen eylindrischen Zellkörper verwandelt. Es bildet sich zuerst eine senkrechle Wand, so dass die beiden Tochterzellen einander vollkommen gleich und halbeylindriseh sind (Fig. 14). Jede dieser beiden Zellen theilt sich wieder durch eine senkrechte, auf der ersten Wand rechtwinklig stehende Wand in zwei gleiche Zellen. Aus der ursprïnglichen Gliederzelle sind somit 4 nebeneinander stehende Zellen hervorgegangen, von denen fjede die Gestalt eines Cylinderquadranten besilzt (in Fig. 15 ist ein Querdurchsehnit dargestellt). Zuweilen bleibt die vegetalive Zellenbildung dabei stehen, gewöhnlich theilen sich aber die vier Zellen noch weiter sowohl durch verticale als horizontale Wände. - Die ursprüngliche Zellenreihe ist somit dureh Zellenbildung zu einem cylimdrischen Zellkörper geworden, der auf dem Durchschnitte selten bloss 1t, gewöhntich melır als 4 neheneinander liegende Zollen zeigt. Dic untersten und die obersten Gliederzellen bleiben liäulig ungetheilt.

Die äussern oder Epidermiszellen des cylindrischen Zellkörpers wachsen in einen kurzen For'tsatz aus, wolder stch als $\Lambda$ stzelle abtheilt (Fig. 16, a). Fast alle Epidermistellen bilden nach und nach solehe Astzellen; lieselhen werden entweder zu Keimmutlerzellen (Fig. 16 b, e), oder sie wachsen in Zellenreihen aus (Fig. $16, e)$. Die Keimmutlerzellen füllen sich mit hraungrïnem, körniggem Inlalte, und werden bedeutend grösser als die ïhrigen Zellen der I’llanze. Sie sind kugelig-eiförmig (Fig. 16, b), verlängem sieh dann an der Spitıe in eine kurze, warzenförmige Spitze (c), öfnen sich dasellost und entleeren ilıren Inlıalt (d). Man findet gewïhnlich noeh mit Inhalt gefïllte und entleerte Zellen nebeneinander. Dass dieselhen wirklich Keimmutterzellen und nicht kieimzellen seien, ergeiebt sich theils daraus, dass sic vich grösser sind als „lie unterste Zelle und die übrigen Zellen einer jungen, noch aus einer kurzen Zellenreihe bestehenden Jflanze, theils daraus, lass sie regelmässsig ilıen Inhalt entleeren. Sie gyleinhen übrigens vollkommen denjenigen Keimmutterzellen von Ectocarpus, welche wegen Kleinheit und gedrängler Lage der Keimzellen als ungetheilte mit Inhalt erfïllte Zellen erscheinen. Diese Analogie mit Ectocarpus und mit mehreren Gattmigen der Stilophoreen bestimmi mich denn anch vorzüglich, anzunehnen, dass die Keinzellenhildung innerhalb jener grossen Zellen durch wiederholle Theilung vor sich gehe, obgleich ich weller die scheidewände, noch die heimzellen innerlalb der intierzelle gesehen hale.

Jicfandern Astzellen entwickeln sich zu Zellenreihen. Dieselben werden entweder vollstïnlig zu einem farlulosen ilare, dessen Glieder von ohen nach unten sich verlingern und dann ahfallen. Oder es wird bloss der Endheil 'einer solcheu Zellenreiłe zu einem farblosen Haare, dessen Glieder von der Spitze nach der Basis hin abfallen,' während, de äbrige untere (grössere oder kleinere) Theil der zellenreihe sich vollkommen iuf 'gleiche Weise entwickell, wie der Hauptstamm. Dic Zellenreihe verwandelt sich nämlich erst in einen rylindrischen Zelliörper, dann bilden 'die äussern oder Epulermiszellen desselben Astzellen, welche theils heinmulterzellen werden, theils sich zu Zellenreilıen (Haaren) enlwicheln.

Zahl und Stelhungsverhähtnisse der Keimmulterzelien und der seitlichen Aeste sind'sehr verschieden. Doch kann nan 'als Regel annelmen, dass die Keimmulterzellen sich zuerst bilden (Fig.|16), und dass nachher immer noeh einzehne, später entstehende zwischen die seilliehen lestehen gemischt sind (Fig. 20), ferner dass die erstern in behotend geringorer Zilnl gehildet werden als die letztern. - Die Epidermiszellen wachsen balt a lle zu gleicher Zeil aus, un dic seillichen Acsle zu erzengen, dann erscheint die ganze Planze, oder ein ganzer Theil derselben, in ersten Stadium warkig (Fig. 17), und späler dieht-behaart (Fig. 20). Bald beginnt die Astbildung an cinzelmen Stellen; damn ist die Iflanze ztiepst zerstrent warzig (Fig. 19), oder sie ist ron Warkngïrteh umgeben (Fig. 18). Im Ganzen scheint es mir, als ol) die Bildung sowoln der Keimmulter-

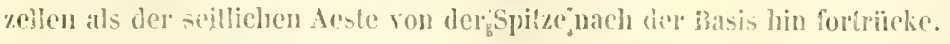

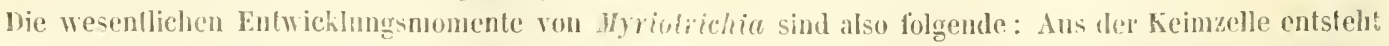

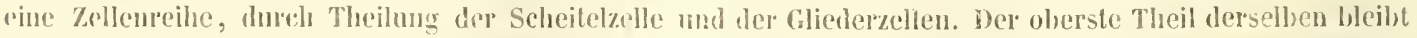
dünner und bilket eine hatrförnige Spitze, deren zellen von when nach unten sich ausbilden und abfailen. ner unlere. Theil derselhen verwandelt sich durch wiederholte Theilung der Zellen in einen cylindrischen Zelkörper. Dic Aussenzellen des lethtern wachsen aus, und bilden theils Keimnutlerzelien, theils Astzellen, 


\section{$-\quad 149$}

welche in Zellenreihen auswachsen. Diese Zellenreihen verhalten sich vollkommen auf gleiche Weise wie dit: aus der Keimzelle entstelıenden Zellenreihen, nur mil dem Luterschiede, dass sie kürzer sind, und dass daher der untere, in einen Zellk̈̈rper sich ver wandelnde und fructifizirende Tỉeil ebenfalls kürzer ist und zuw eileı bei kurzen, mit allen zellen in ein Haar übergehenden Zellenreihen ganz mangelt.

bie Gattungsdagnose, welche Ilarey (1) zuerst gegeben, enthält zwei Irrthümer. Ër sagt, dass die Arste vierzeilig stehen, während sie lï̈chst selten und nur uwollkommen diese Anordnung zeigen und gew ̈̈hnlich nach allen Seiten gerichtet sind. Er sagt ferner, dass die endsländigen Haare dicholomisch seien, indess sir ohne Ausnahme muverüstelt sind. Ohne Zweifel hat sich Ilarey durch die in Zahlloser Henge und in versenicdenen Richtungen ühereinander liegenden Ilaare täuschen lassen, welche bei oberflächliches Petrachlung leicht als verästelt angeschen werden mögen. - Harrey hat später ${ }^{2}$ ) den Gatlungscharacter in dem einen Punkte veibessert, nämiich in Rücksicht anf die vierzeilig-gestellten Aeste, Während dieses Herkmal nuı aber mit als Differentialcharacter fïr die eine Art gehraucht wiłd. Allein es ist hier eben so wenig richlig. Invotrichia wird nämlich in zwei Arten getheilt: H. clasaformis und H. filiformis. Erstere soll mil vierzeiligen, nach obeil an Lïnge zunehmenden Aesten dicht-besetat sein; Jetztere soll bei einem schmächligern Bame nu' stellenweise mit kürzern Aestchen behleidet sein. Die vierzeilige Stellung der Aeste hann keincu Enterschied bilden, weil sie in der That nicht vorhanden ist. Im übrigen zeigt die Stellung und die Länge der seithchen Aeste so zahllose Verschiedenheiten, dass sich die beiden Formen clavaformis und filiformis wohl als extreme Glieder einer ganzen Formenpeihe, nicht aber als specifische, absolut-rerschiedene begriffe festhalten lassen. 'zwischen diesen heiden Formen giebt es eine Mienge von Zwischenstufen, die man mit gleichem Rechte zu Arten erhehen könnte. Lebrigens ist $M$. clateformis zuerst immer eine M. filifornis, welchw dadureh, dass alle Aussenzellen Łsizellen bilden und dass die obern Łeste sich stärk̉er entwicheln, eiı kenlenförmiges Ansehen bekommt. Die meisten Individuen bekommen aber diese keulenfürmige Gestalt nur in geringem Jlasse oder ga' nicht, weil nur ein Theil der Aussenzellen Aeste bildet, und weil diese Aeste hür'r.' bieiben. - Da die beiden Formen von Myriotrichice in Eine Art verenigh werden mïssen, so schlage ielı dafiir den Namen H. Ilarceyana vor; sie hat zwei Varieläten a) filiformis und b) clasaformis.

\section{ZYGNENACEE.}

Durch vegetative Zellenbildung entsteht eine Zellemeihe; in einzelnen oder in je zwei mit einander copulirten Zellen des gleichen Indiridums oder verschiedener Individuen bildet der yanze sich zusammenbullende Inhalt eine Keimzelle.

Die $Z$ ygnemaceen unterscheiden sich durch ihre characteristische Fruchtbildung von allen andern Algen. Der ganze Inhalt einer Zelle zieht sich zusammen und bildet, indem er sich an seiner ganzen Oberfläche mit einer neuen Membran

(1) Hooker, Junrnal of Bot., 1, pag. 300, t. 138.

(2) Manual of the Britt. Alg., P. 44.

Denkschr. N.EGELI. 
bekleidet, eine freie, kugelförmige oder ellipsoidische Keimzelle $\left({ }^{1}\right)$. Eine vegetative Zeile erzeugt nur eine einzige Keimzelle. Die Zygnemaceen stimmen in diesem Punkte mit den Nostochaceen überein; der Unterschied besteht darin, dass bei der letzlen Ordnung die vegetativen Zelhen ummittelbar zu Keimzellen werden, dass dagegen bei der erstern Orảning der Inhalt, indem er seine Form ändert, zu einer neuen, frei in der Höhlung der Mutterzelle liegenden Keimzelle wird. Zuweilen verbinden sich zwei Zellen der gleichen oder verschiedener Pflanzen miteinander durch kürzere oder längere Fortsätze, und stellen eine einzige Höhlung dar, indem die zwischen ihnen liegende Scheidewand resorbirt wird. Der Inhalt der beiden Zellen vereinigt sich in eine einzige Masse und bildet eine Keimzelle auf dieselbe Weise, wie es sonst der Inhalt einer einzigen Zelle thut. In diesem Falle entsteht also nur je aus 2Zellen eine Keimzelle.

Als Differentialcharacter der Zygnemaceen wird gewöhnlich angegeben, dass sich die Zellen verschiedener Fäden copuliren. Wie wenig dieses herkmal in seiner allgemeinen Anwendung richtig sei, beweisen die Thatsachen, dass bei Spirogyra in der gleichen Pflanze neben copulirten Zellen solche vorkommen, welche, ohne sich zu copuliren, cine Keimzelle bilden, dass ferner einzelne Pflanzen in allen Zellen Kcimzellen bilden, ohne sich zu copuliren, dass endlich die Rellen cinzehner Pflanzen sich bloss untereinander copuliren. Nicht bloss ist aher die Copulation bei Spirogyra gar wenig constant, sondern es gibt anch einige Galtungen, welche in der Keimzellenbildung mit Sprirogyra, Zygnema, Mougeotia vollkommen übereinstimmen, ohne dass sie sich je copuliren, so z. B. Fulbocheete und Confersa capillaris.

Zu den Zygnemaceen gehören somit, ausser den gewöhnlich dazu gerechneten Gattungen, noch Dedogonium Link, Bulbochcete Ag. und wahrscheinlich Rhizoclonium Kütz.

\section{Spirrogyra.}

TAB. 111, N1G. 21 - 25.

Jedes Individuum ist eine einfache Zellenreihe, deren Zellen sich alle forlgeselzt in zwei neue gleiche Gliederzellen theilen. Went die Iffanzen schwimmend gefunden werden, so scheinen sie alsdann grosse $\Lambda$ ehnlich-

$\left.{ }^{4}\right)$ Vergl. Schleiden und Nïgeli's Zeitschrift f. wissenschaftl. Bot., Ieft 3 und ', p. 26 . 
keit nit Yostoc zu besizen, indem die Zellenreihen des letatern elenfalls frei (nicht angewachsen) sind, weder oberes noch unteres Ende besilzen und durch Theilung aller Glieder wachsen. Dem ist aher in der WirklichLeit bei Spirogyru nichl so. Die Zellenreihen sind zuerst festgewachsen, sie reissen sich aber nachlıer häufig los und sehwimmen danı frei herum. Da sie durch fortwährende zellenbildung sehr lang werden, nucl man gewöhnlich keine Enden oder nur die Enden entweigerissener Füden sichı, so hann man leicht auf len Gedanten konmen, dass sie zwei gleiche Enden (d. h. weder oberes noch unteres Ende) besilzen. Nun sind aber einige Arten wirklich angewachsen. Ich sah an Sp. admatu, dass sie sich rasenweise rom Grunde des Wassers enhob und f:ei im Wasser schwamm. An Sp. quimina fund ich zuweilen Enden mil einigen kurzen, farblosen Wurzcln. Es ist mir daher im höchslen Grade wahrscheinlich, dass Sprogryru in Bezug auf das Wachsthum nicht mit sostor, sondern mit tothrix zu vergleichen ist, und dass die Zellenthen, wie bei der letztern, theils durch Theilung der Seheitelzelle, theils dureh Theilung der Gliederzallen sich verlängern. Dis Wachsthum der Zellenreihen durch Zellenbildung dauert eine bestimmle Zeit fort, Lrid hört ziemlich zu gleicher Zeit im ganzen Faden anf.

Die Zellen sind zuerst an der innern Oberfäche ihrer Wandung mit einer vollkomaren continuirlichen und undurchbrochenen schicht ron homogenem Chırophyil überzogen (Fig. 21). Von der Fläclıe erscheint daher die Wandung licht-grün : an den beiden Scitenrändern zeigt cin dunkelgrüner Streif die Dicke der Chlorophỵlischicht. Nur die Cylinderfläche ist damit überzogen; die beiden Endflächen bleiben frei. In der Ch'orophyllschicht liegen zerstreut Stärhekörner, welche in diesem Zustande meist hoh! sind. - Das Chlorophyll lässt an den beiden Seitenräncern in bestimmten Zwischenräumen einen hohlen Raum zwischen sich und der Zellwandung. Diese hohlen Räume sind die Durchschniltsstellen von einem oder mehreren Canälen, welche zwischeı dem Claloroplyll und der Membran schrauhenfürmig ron dem einen Ze!lenend bis zum anderu verlaufen. Es sind die ggleichen Canäle, welche späterhin in der Milte der Chloropliylbänder liegen.

Die Chloroplıyllschicht trenut sich nun in Bänder. Diese Trennung geschieht geaau in der Miltellinie zwischen zwei Canälen. Es entşelıt daselbst ein hellerer Streif, welcher zuletzl ganz farb!os wird (Fig. 22). Man findet am gleichen Faden Zellen, welche noch continuirich mit Chlorophyll überzogen sind, und solche, in denen sich das Chlorophyll mehr oder weniger deullieb in Bänder getrennt hal. Mit diesem Vorgange ist ein Wachsthum der Zelle in clie Lünge verl)unden, und zwar genau in dem gleichen Masse wie die Chlorophyllbänder aus einander rïcken. Han sieht daraus, dass das Chlorophyll nichl elwa dadurch, dass es sich selbst zusanmenzieht, sondern dadurch, dass die Zelle sich in die Länge strecht, während es sich selber nicht ausdehnt, in Bänder zerfältt. Denn die grünen Bänder neỉmen später so ziemlich den gleichen Raum ein, wie früher die continuirliche Chlorophylischicht. - Die Bänder sind anfänglich gar nicht scharf von einander geschieden, sondern sie verlieren sich an den beiden Rändern allmähig in den Zwischenraum; später aber grenzen sie sich bald scharf ab.

Die Biỉlung der kicimzellen hei Spiroygra ist bekannt. Ich will daher nicht näher auf diesen Punkt eintreten. Die Zellen zweicr rebeneinander liegender Fäden wachsen in kurze, sich begegnende Fortsäıze aus, die durch Resorption der Scheidewand z.u Canälen werden, wodurch der ganze Inhalt der einen Zelle in das Lurinen der andern Zelle hinüher fritt, um da mit dem ganzen Inhalte der andern Zelle eine freie Keimzelle zu erzeugen. - Es giebt aber häufig einzelne Zellen, welche allein, ohne Copulation, eine Keimzelle erzeugen. Es gibt zuweilen ganze Planzen, welche bloss auf diese Weise Keimzellen bilden.

Ausserdem copuliren sich zuweilen je zwei aufeinanderfolgende Zellen der gleichen Pflanze mit einander. Ich beobachtete diess an spiroyyru quimina (Fig. 25). Zwei Zellen wachsen unnitlelbar bei der Scheidewand nach der gleichen Seile hin in kurze Fortsälze aus. Dieselben berühren einander seitlich (Fig. 2/t); die Wand zwischen ihnen wird resorbirt, und man sieht bloss noch zwei schwache linien an der Perijherie (Fig. 23j). bie beiden Zellen communizipen nun miteinander. Die Ahłösung der grünen Bänder, ihr Zusammenflessen iu eine formlose Masse, und der Cehertritt des einen Zelieninlalles in das Iumen der andern Zelle sind Ersehei- 
nungen, welehe vollkommen auf die gleiche Weise von Statten gehen, wie bei der gewöhnlichen Copulation. Wenn alle Zellen in einer Zellenreilıe sich copuliren, so bildet sich je in dem zweiten Gliede eire hieimzelle (Fig. 25). !Häfig aber copuliren sich einzelne Zellen nicht. Dieselben treiben dam meist ans der Witte einen Fortsatz (Fig. 25, a) wie es bei der gew öhnlichen Copulation der Fall ist; und olne zweifel können sie sich durch diese Answïchse auch nach der gewöhnlichen Art copuliren, wenn dieselben auf ähnliche Fortsätze benachloarter Pflanzen treffen.

Die Keimzellen sind zuerst schön grün; später werden sie neist dunkel und fast schwärzlich, indem sie sich nit Stärkekörnern füllen.

Ich erlaube mir noch einige Bemerkungen über die specifischen Merkmale bei Spirogyru. Die Arien werden rortüglich unterschieden nach der Henge der Chlorophylbänder und nach der Menge der Windungen in einer Zelıe, nach dem nälıern oder entfernteren Beisanmenliegen dieser Bänder, nach dem Verhällnisse der länge zur Breite der Zellen, und nach dem Unstance, ob die Pflanze angewachsen ist oder schwimmt. Aber alle diese Versehiedenleiten sind bloss relativ; sic gehen alle durch Zwischenstufen, die wir bei verschiedenen Individuen finden, ineinander üher, oder wir finden selhst zwei verschiedene Merknale, welehe sonst fï: specilisch gelten, an derselben Pflanze. Die Menge der Chlorophllbünder hegründet keinen specifischen Lnterschied; denn bei Spirogyre quinina, welche bloss Ein Band hat, finden sich an der gleichen Pfanze zuweilen einzelne Gliederzellen nit zwei Bändern. Sp. decimina, welche 2 Bänder besitzt, zeigt znweilen Zellen mit hoss linem Bande. Ich finde nun auch Pflanzen, weiche aus eben so vielen Gliedern mit einem, als aus cliedern nit 2 Bändern bestehen, und welche daher so gut den einen als den andern Namen in Anspruch nehmen können. Bei $\mathrm{Sp}$. adnuta giebt es Individten, die in allen Zellen bloss 2 Bänder zeigen: ferner solehe, wo die pinen Zellen 2, die andern 5; solehe, wo die einen Zelien 2 , andere 5 , andere 4 Bänder cn halten; endich Indivi-

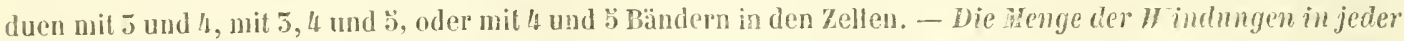
Zelle macht keimen specifischen Unterschied. Ich will als Beispiel sp. adnata und Sp. animina anfïhren. Bei der erstern finden sich an gleichen Individum Zellen mit $t$ und mit 2, odes Zellon mit 1, 2 und 2.12, oder Zellen mit 2 und 5, oder Zellen mit 5 und 4, oder Zellen mit 5, 4 und phyllbänder $1 \%$ bis 8 Windungen, und zwar so, dass wir je mehrerc Zahlen beisammen an der gleichen Pflanze finden, z. 3. 1\% , 2 und 5, oder 2,5 und 4 , oter 5,4 und 5 , oder $4,8,6$ und 7 , oter $5,6,7$ und 8. - Das nühere oder entferntere Beisammentiegen der Bünder giebt kein sprecifisches Herkmal; denn an gleichen Individuum finden sich Zeilen mit weilen un! mit mässig-weiten Windungen, oder Zeillen mit mässigweiten und mit engen Windungen. Bei Sp. longata z. B. beobaciten wir in der Regel weile, oft selsr weite Windungen, bei sp. quinima dagegen meist enge, oft sehr enge Windungen. Aber bei sp. lomgatu giebt es theils einzelne Zellen, theils ganze Individuen mit engern Windungen, als sie bei den am weitest gewundenen Formen von Sp. quiminu vorkommen. Bei Sp. quinime sehen wil nicht selten theils eimelne Glieder, theils ganze Pflanzen, wo die Windungen weiter sind als an den enger gewundenen Formen von Sp. longalu. Jas Verhïltwiss der Länge zur Dicke der Zellen macht keinen specifischen Unterschied. An der gleichen Pflanze varirt die Zellenlänge gewöhnlich so, dass die einen doppelt so lang sind als andere, dass also die einen \%. B. 9 mal, die andern $4 \mathrm{mal}$ so lang sind als breit. Dieser Uhstand rithrt olne Zweifol daher: Wenn die Zellenbildung in einer Zcllenreihe aufhört, so geselnicht es, wie ich oben sagte, in allen Zellen zicmlich steichzeitig; die einen Zellen haben sich eben getheilt, die andern Zallen wollten sidh eben theilen; jene sind nalürtich einmal kürzer als diese; diese Ungleichleit bleibt nun häutig zeiltebens. - An der gleichen P’ilanze sind die einen Zellen aber nicht bloss zweinal so lang als die anderu, sondern die Differenz ist grewöhnlich noch ptwas (mehr oder weniger) grösser, so dass die längsten Zellen $2 \% 3,2 \% 2,5$ nal so lang sinł ais die kür'zesten zellen. hei Spirogyra quinima finde ich nun Fäden, wo die kürzesten so lang sind als lreit, dic längsten

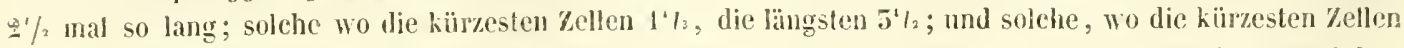
$\left\{1 \ell_{2}\right.$, die längsten 4 bis : mal so lang sind als breit. Ausserden, dass wir solehe Verschiedenheiten bei den 


\section{$-155$}

gleichen Individuum finden, so kommen dann ferner an verschiedenen Individuen alle möglichen Grössenverhällnisse vor, welche Z» ischenglicder bilden. - Endlich ist der Lmstand, ob die Pfanzen angeucachsen sind oder schtimmen, nicht son specifischem Werthe; weil wahrscheinlich alle Arten zuerst angewachsen sind, und weil jedenfalls einzelne Arten in beiden Zuständen vorkommen.

Die bisher zur Lnterscheidung der Arten von Spirogyra gebrauchten Merkmale sind somit keine ahsoluten specifischen Merkmale; weil alle variabel sind, und theils an verschiedenen Individuen Uelıergänge bilden. theils namentlich in soleher Verscliedenheit am gleichen Individuum vorkommen, dass man sie alle als individuell erklären mıss. Wenı es nun aus den mitgetheilten Thatsachen augenscheinlich ist, dass die für dif Arten von spirogyra bisher gebrauchten Charactere nicht absolut und daher anch nicht specifisch sind, so ergiebt sich als unuittelhare Folge die weitere Frage, ob die bisherigen Arten wirkliche Arten oder bloss Varictäten seien. Ich warge diese Frage, nicht zu entscheiden, obgleich die Wandelbarkeit der Herkmale und die vielen Uebergangsformen zwischen den einzehnen Arten zu beweisen scheinen, dass es nur Varietäten einer Art sind. - Es ist nämlich auf zweierlei Weise möglich, dass sie dennoch Arten wären, entweder wenn die wahren specifischen Lnterschiede noch nicht gefunden und erkannt worden, oder wenn die lehergangsformen Basturde sind. Hybridität wäre aber bei Spirogyra, trotzdem dass keine Gesclılechlsdifferenz. vorhanden ist, möglich, wenn die Individuen verschiedener Arten sich miteinander copulirten und keimzellern erzeugten. Jch spreche dieses bloss als Möglichkeit aus; beobachtet habe ich die Copulation nie zwischen vorschiedenen Formen, sondern nur zwischen den Individuen derselben $A r t$, und sogar gewöhnlich nur zwischen den Individuen, welche auch äusserlich namentlich in der Dicke miteinander übereinstimmten ( ${ }^{1}$ ).

\section{DROTOCOCGACER.}

Zelle ohne Spitzenwachsthum, ohne Astbildung und ohne cegetative Zellenbildung; sie pflanzi sich durch freie Z ellenbildung in mehrere einzellige Individuen fort.

(') Die beiden Werke Kitzing's Imycologiu germanicu und Hussall's History of the british freshnuler Algxe (London 1843̈) veranlassen mich noch zu einigen nachträgtichen Bemerhungen. Ilussall hat -chon früher die Copulation zwischen Zellen des gleichen Fadens beobachtet. Er macht daraus eben so viele besondere Arten und stellt sie zusammen in die Section mit nicht conjugivten Füden. Mir scheint es jedoch, als ob ohne Cuterschied an der gleichen Art Keimzeltenbildung ohne Copulation und mit den beiden Arten der Copulation vorkommen könne. - Iassall nennt die keimzellen unrichtig sporangia, denn die hörner, welche sie enthalten, sind keine Zetlen, sondern Stärkehörner. - Kützing und IIassall haben die Zahl der Arten bedeutend rermehrt, indem sie neben den frühern Characteren noch vorzüglich anf die vorschiedene Dicke der Fäden und auf den Imsland achteten, ob die Scheidewände Falten bilden oder nicht. Blussall henntzte überdiess die verschiedene Art der Copulation oder den Mangel derselben, die Gestalt der Mutterzellen und der Keimzelten u. s. w. Auf diese Weise hat Külzing 20 deutsche, Hussall sogar 42 englische Arten crhalteu. Es ist dies. ejne natürliche Folge der Hethode. Sobald man einmal in die quantitativen oder relativen Lnterschiede hineingeräth. so muss man consequenterweise bei jeder neuen Abstufung oder bei jeder neuen Combination neue Arten schaffen. Ich brachte kürzlich aus einem Graben einen schwimmenden Rasen von Spirogyre nach Hause. Beim Uutersnchen fand ich nicht weniger als 16 Formen darunter, welche nach den specifischen Merhmalen Kützing's als besondere Arten z.I betrachten wären. Zwei Orittheile dersetben waren neu; bloss ein Drittheil fand ich in der Phycologia germanica beschrieben. Aber zwischen alten diesen Formen, wie characteristisch sie einzehn waren, gab es viele llittelstufen. so dass ich sie fïr nichts anderes anschen konnte, als für Varietïten der gleichen Art.

Devkschr. Nigkti. 


\section{$-134$}

Die Protococcaceen stimmen in ihren vegetativen Verhältnissen vollkommen mit den Palmellaceen überein. Jede Pflanze ist eine einfache Zelle mit allseiligem Wachsthume, ohne das Vermögen, Aeste oder Wurzeln zu bilden. In der Fortpflanzung stimmen beide Ordnungen darin überein, dass die Tochterzellen unmittelbar wieder vollkommene Individuen sind, dass also ein Uuterschied von vegetativen Zellen und von Keimzellen im Grunde noch nicht vorhanden ist. Die Tochterzellen entstehen aber bei den Protococcaceen auf eine andere Art als bei den Palmellaceen. Dort bilden sie sich in unbestimmter Zahl frei im Zelleninhalte aus kleinen Partieen dieses Zelleninhaltes; sie besitzen eine kugelige Gestalt. Hier bilden sie sich in bestimmter Zahl (2 oder 4) aus dem ganzen Inhalte der Mutterzelle, welcher zu diesem Behufe sich in eben so viele Partieen theilt; sie besitzen die Gestalt, welche durch die Theilung der Mutterzelle sich ergiebt, und sind nie kugelig bei ihrem Entstchen. Bei den Protococcaceen verweilen die Tochterzellen noch einige Zeit innerhalb der Mutterzelle und ernähren sich von ihrem Inhalte. Dann wird diese aufgelöst und die Tochterindividuen werden frei.

Zu den Protococcaceen gehören vorzüglich die Gattungen Protococcus Ag., Hermatococcus Ag. und Chlorococcum Grev. Doch müssen von allen 5 Gattungen einzclne Arten ausgeschlossen werden, welche zu den Palmellaceen gehören.

\section{VALONIAGERE.}

Zelle mit Astbildung und Spitzenwachsthum in den Aesten, obne vegetative. Zellenbildung; sie erseugt durch freie Zellenbildung mehrere Keimsellen.

Die Valoniaceen sind mit den Protococcaceen nahe verwandt. Beide Ordnungen besitzen bloss reproductive, keine vegetative Zellenbildung; bei beiden entstehen dic Tochterzellen als kleine kugelige Zellen frei im Inhalte der Mutterzelle. Die Zellen der Protococcaceen besitzen aber bloss allseiliges Wachsthum, keine Acsle, keine Wurzeln. Die Zellen der Valoniaceen dagegen können in Zellïste auswachsen, welche durch Spitzenwachsthum sich verlängern. Diese 


\section{- 1 Ðั}

Zelläste sind Wurzeln oder wahre Aeste. - Ich glaube daher, dass man bei den Vuloniaccen mit Recht die Tochterzellen Keimzellen nennen kann, weil sie nicht schon ursprünglich wie bei den Prlmellaceen und Protococcaceen vollständige Individuen sind, sondern erst später sich zu vollkommenen Individuen entwickeln.

Zu dieser Ordnung gehört ausser Valonia Ginnan., wahrscheinlich auch $H_{y}$ drogastrun Desr. (Botrydium Wallr.), Caulerpa Lamour. und Anadyomene Lamour.

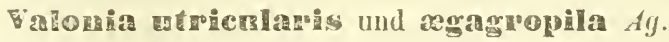

TAB. II, FIg. $7-2 !$.

Diese beiden, ron fgardh als besondere Arien betrachteten Formen gelören Einer Art an, welche aber in ihrem äussern Auschen sehr mannigfaltig ist. In Sorrento bei Neapel fand ich sie als freic, einfache Zellen mit länglich-heulenförmiger, cylindrisc!-heulenförmiger oder auch mit cylindrischer Gestalt (Fig. 7, : ) : ferner als Stöcke, die aus melıreren Zellen bestanden und gewöhnlich an der Spitze quirlförmig- oder büschelig-verästell waren; dic Verüstelung ist mur cimmal vorhanden (Fig. 11, 12. 15), oder sie wiederholt sich ein- oder mehrfach (Fig. 14); - endlich als melı oder weniger hugelige hasen, die aus mehreren, in einander geflochtenen Stöcken bestanden. Die ersteren Formen sind $\boldsymbol{V}$. utricularis, die letztere $\boldsymbol{V}$. agagropila. - Külzing $\left(^{1}\right)$ schreibt ralonia ein "Coloma fastigiato-ramosum continuum, "Endlicher ( $\left.{ }^{2}\right)$ einen "Tubulus continuus, articılatim constrictus " zu. leh habe lebend keine anderen Valonien als die beiden angefühten Formen untersucht. Itier bestelıt jedes Glied aus einer geschlossenen Zelle. Man kann die Zellen von cinander trennen, ohne sie zu verletzen. Man kann einzelne entlceren, ohne dass die anderen dadurch afficirt werden.

Die Gestalt der Zellen ist in Rücksicht auf ihre versehiedenen Durchmesser sehr verschieden, und varirt vom rerkehrt-eiförmigen bis zum cylindrischen. Die Querdurchmesser ändern sich von einem Achsenende zum andern gleichmässig oder ungleichmässig. Die Achse ist gerade oder gebogen. Gewöhnlich ist die Zelle einfach, selten gelappt (Fig. 9, 10; 15, a). Das Wachsthum der Zelle ist begrenzt, ihre Länge beträgt im ausgewachsenen Zustande $1 / 2-1{ }^{\prime} / 2$ Zoll; ihre Breite varirt von $1-5$ Linien. Die Lappen der Zelle (Fig. 9, 10, 1, l) können als kurze Aeste angesehen werden, und dann muss ron der Zelle gesagt werden, dass sic, wie begrenztes Wachsthum, so auch begrenzte Verästelung besilze. Diejenigen Zellen, Welche unten nicht auf andern Zellen befestigt sind, wachsen häufig in Wurzeln aus (Fig. 8, 11, r). Die Wurzeln sind nur Zelläste; sie werden nicht zu besondern zellen.

Die Zellwandung ist fest und ziemlich dick; sie besteht aus der Zellmembran und einer breiten Schicht vou Extracellularsubstanz, an der man häulig 2 versehiedene Lagen unterscheiden kann (Fìy. 18, a, b). - Die Zelle ist ganz mit Wasser angefüllt; sie fülılt sich desswegen bei der Berülnrung hart an, und ber'stet h)ei stärkerem Drucke. Das Wasser ist selır salzig und scheint selbst, dem Geschmache nach, mehn Salz zu enthalten,

(') Phycologia gen., pag. 307.

() Gen. plant., suppl. III, gen. 65 . 


\section{- 190}

als das Meerwasser. - Die innere Oberfläche der Wanhling ist ïberall mit der Schleimsehichıt ausgekleidet; die letztere besteht ans homogenem oder körnigem S(hleime und hat an ihrer innern Fläche zuweilen ein Netz von Sehleimfiden, wie Bryopsis, die Maschen sind jedoch viel grösser (Fig. 19). In der ganzen Schleimschicht liegen Chlorophyllbäschen und Amylumkïgelchen. Die Lagerung der beiden Jetztern ist in rerschiedenen Zellen verschieden. Wenn ein Strömungsnetz vorlıanden ist, so liegen beide in den Schleimfäden, besonder's in den Winkeln, wo mehrere Fäden zusammenstossen (Fig. 19); diess vorzüglich in jüngeren Zellen. Oder sic hehalten, nachdem das Strömungsnetz rerschwunden ist, dieselbe Lage, in der sie entstanden sind, umd liegen daher in cinem Netz, mit leeren Naschen (Fig. 20), und zwar in einer oder mehreren Reihen. Oder 'ndlich sie liegen zerstreut und ohne Ordnung, weiter auseinander oder enger beisammen (Fig. 21, 22).

Die Chlorophyllbläschen besitzen eine ungefïrbte Miembran und einen homogenen gränen Inhalt, in dessen Nitte cin Amylumkernchen befindlich ist. Sie sind plattgedrückt und liegen mit der Vläche all der Schleimschicht. Von der Seite angeselıen, exscheinen sie als dïnne Stäbehen (Fig. 25, a II; b II); das liernchen ist kaum zu erkennen. Yon der Fläche angesehen, sind sie rund, oder länglieh̀, oder selbst linienförmig; der Rand ist meist meben und wellig (Fig. 22; 25, a I, 1, 1). In den schmalen und langgestreckten Formen erkennt man entweder nur undeutlich ein Kernchen, oder gar nicht; in den rundlichen und elliptischen Formen ist dasselhe gew öhnlich deutlich. Wenn die Chlorophỵlbläschen netzförmig angeordnei sind, so zeigen die in den Winken liegenden cine l'undliche Gestalt, die in den Linien liegenden dagegen eine langgestreckte Gestalt, und zwar gelıt ihr Längendurchmesser parallel mit den Linien des Netzes (Fig. 20). - Die jüngern Chlorophyllb]äschen scheinen sich zu theilen.

Die Amylumkiïgelchen treten auf zweierlei Art auf, entweder als kernclıen in den Amylumbläschen oder frei. Frei konmen sie besonders in ältern Zellen, und in Keimzellen, welche sich noch nicht entwickeln, ror. Die freien Amỵlımkügelchen entstehen innerlalb der Chlorophyllbläschen, wachsen und werden zuletzt (hurch Resorption derselben frei. In kieimzellen, wo sich Chlorophyll und Amylum bildel, findet man an der Schleimschicht ausser kleinen Chlorophyllbläschen (Fig. 21, a), grössere, in denen cin Kernchen als kleines piinktehen sichtlbar ist (Fig. 21, 1), noch grössere mit einem deutliehen Amylumkernclien (Fig. 21, c); ron diesem Zuslande an wäehst das Chlorophyllbläschen wenig, das Amylumkernchen bedeutend; das letzter" füllt endlich das erstere ganz aus (Fig. 21, c - l). Das Bläschen wird nun aufgelöst; das Amỵlumkïgeichen scheint noch zu wachsen, nachdem es frei geworden ist (Fig. 21, e); wenigstens liegen neben den Chlorophyllhlïschen nicht nur gleich grosse Amylumkügelchen, sondern auch viele solehe, die 1/s mal und sellost doppelt so gross sind.

Die Keimzellen entstehen in heträchtlicher Menge in den Mutterzellen. Sie liegen hïufig in dem untersten Theile der Nutterzelle (Fig. 11, g); oder wenn die letzlere schief steht, an der untern Seitenfäche (Fig. 1/t, g). Einzelne kömnen da und dort an der Seilenflëehe liegen, und mehrere (1, 2...6) stehen gewöhnlich am Scheilel der Zelle. Die Keimzellen sind plattgedrïrkt und liegen mit ihrer läiche in der schleimschicht. Von der seite erscheinen sie als schmale Stäbe (Fig. 16, g); von der Fläche sind sie rund, wenn einzeln (Fig. 1/, g; 15), parenelı̣matisch, wenn gedrängt beisammen liegend (Figg. 15). thre Grösse ist sehr ungleich und heträgt von 0,040 "', bis 0,200 "' und darüber im Durchmesst'. Sie gleichen der Multerzelle, indem sie ehenfalls Schleim, Amylumhïgelehen und Chlorophyllbläschen enthalten. bie letztern sind in grösserer Henge vorhanden und gebn den Keimzllen tine dunkelgrïne Farbe. - Die keinzellen beginnen als kleine Schleimkügelchen, an lenen man noch keine Membran mnterscheiden kann, und die nichts weiter als ein Tröpfehen homogenen, farblosen Schleimes zu sein scheinen (Fig. 2h, al). Sie werden grö̈ser und etwas körnig (b). Dann zeigen sie sich noch deutlichıer gekörnt und fürben sieh grïnlieh, die Membran ist sichthar (c). Noch grösser, sind sie fricht als \%eltchen mit Sehkim und kleinen Chloroplyylbläschen zu erkennen (Fig. 2h, d).

Von den Keimzellen gelangen diejenigen, welehe in der obern Partie der Mutterzelle liegen, frühzeitig zur kntwicklung. Jie flachen heimzellen (Fig. 16, g) (rheben sich mit ilırer äusseren Fläche und werden halh- 
kugelig (Fig. 17, g) dann kegelförmig, nachher verkehrt-eiförmig und keulenförmig. Sie durchbrechen gleich anfangs bei ihrem Wachsthume die Wandung der Mutterzelle, bleiben aber mit derselben fest verbunden. Die Mutterzelle trägt nun an der Spitze so viele Tochterzellen als Keimzellen zur Entwieklung gelangten (Fig. 11 bis 14). Die Tochterzellen erzeugen ihrerseits wieder Keimzellen, diese können sich ebenfalls entwickeln (Fig. 14, $\mathrm{n}, \mathrm{n})$. So pflanzt sich Generation auf Generation und es entsteht ein verästelter Stock. Jedes Glied desselben ist eine Zelle und besitzt ursprünglich eine ununterbrochene Membran. Dieselbe wird durch die Entwicklung der Keimzellen durchlöchert, weil diese die Wandung der Mutterzelle durchbrechen. Das Lumen jedoch bleiht gesehlossen; denn in dem Augenblicke, wo die Wandung von der Keimzelle durchbrochen wịd, füllt diese die Oeffnung wie ein Pfropf aus (Fig. 17). Später aber bildet die Zelle wieder eine neue Menbran an der Stelle, wo sie dieselbe verloren hat. Man kann sich davon auf zweierlei Weise überzeugen. Reisst man sorgfiltig eine entwickelte Keimzelle (wie m, m in Fig. 11 - 15) von der Mutterzelle los, so b]eiben beide Zellen vollkommen gesehlossen, macht man dagegen nit der feinsten Nadelspilze eine kleine Oeffnung in eine Zelle, so entleert sie augenblicklich ihren flüssigen Inhalt, während alle andern mil ihr verbundenen Zellen strotzend bleiben. Untersucht man die alogerissene Stelle unter dem Vikroskope, so findet man eine der übrigen Zellmembran ganz analoge Membran. Macht man einen Durchsehnitt durclı die Stelle, wo die beiden Zellen mit einander verbunden sind, so sieht man daselbst das neugebildete Membranstück der Mutterzelle ïber die Basis der Tochterzelle hinweggehen (Fig. 18, e). Diese Membranìildung, um die unterbrochene Continuität eineı' Zellmembran herzustellen, ist, besonders bei Algenzellen, nichts Lngewöhnliches; ich vermeise auf mehrere analoge Fälle, die ich anderswo ( $\left.{ }^{1}\right)$ milgetheilt habe.

Die Algologen betrachten einen ganzen Stock (wie z. B. Fig. 14) als Pflanzenindividuum, und nennen ihn a Frons; " dis einzelnen Zellen heissen Aeste. leh muss diese Ansicht für unrichlig halten und die einzelne Zeile als Pflanze erklären. Die in Fig. 7 abgebildele Pflanze gilbt uns den einfachsten Fall an die Hand. Die Planze ist hier eine Zelle; sie erzeugt Keimzellen in ihrem Innern. Die Multerzelle wird aufgelöst, wahrscheinlich erst in Herbste, und die Kemmellen entwickeln sich zu neuen Planzen, wahrscheinlich erst im Früljahıe. In andern Individuen gelangen einzelne Keimzellen sogleich zur Entwicklung; sie sind lebendiggebährend (Fig. 11, m); indessen andere Keinzellen $(11, g)$ ihr latentes Leben fortführen, un erst zu gehöriger Zeit, d. h. nach Auflösung des Mutterindividuums, zu vollkommenen Indiviluen sich auszubilden. Die Gründe warum die cinzelne Zelle als l'flanze angesehen werden muss, sind die gleichen für $r$ ralonia, wie die oben für Protococcus und Palmella angefïhrten. 1) Findet sich bei Valonia nur Eine Art der Zellenbildung, die reproductive; während mehrzellige Pflanzen wenigstens 2 versehiedene Arten der Zellenbildung besitzen mïssen, eine regetative und eine reproductive. 2) Zeigen die Stöcke von V́alonia keine gemeinschaftliche. Lebensäusserung, weder in der Yegetation, noch in des Reproduction. 5) Giebt es einzellige Slöche, wo die. Zelle alle Bedingungen eines Pflanzenindividuums erfüllt (Fig. 7, 9).

Die Diagnose der Galtung Valovi, wie sie bisher gegeben wurde, ist unriehtig. Sie muss siclı auf folgende Merkmaic gründen: Die I'flanze ist eine einzige Zelle mit begrenztem Spitzenuachsthume und begrenzter I'eräsllung. Die Keimzellen entstehen durch freie Zellanbildung in unbestimmter Zahl. Dass die Individuen lebendig gebähren oder proliferiren, und dass dadurch haumartige oder rasenförmige Familien von Individuen, die mit cinander verbunden flleiben, entstelıen, gehört nicht in den Galtungrsbegriff, da diese Erseheinung zufällig̣ ist und nicht allen Individuen angehört.

(') Schleiden und Yägeli's Zeitschrift f. wissenschaft1. Bot., Heft 1, pag. 90 fr. 


\section{GONFERVAGERE.}

Durch vegetalive Zellenbildung entsteht eine meltrzellige Pftanze (meist eine Zellenreihe oder Zellschicht), deren Zellen durch freie Zellenbildung mehrere Keimzellen erzeugen.

Diese Ordnung unterscheidet sich von den zwei vorhergehenden dadurch, dass die Pflanze mehrzellig (dort einzellig) ist, und dass regetative und reproductive (dort nur reproductive) Zellenbildung vorhanden ist.

\section{Conferveae.}

Zellenreihe; die Keimzellen entstehen in den Gliederzellen.

Ich habe die Keimzellenbildung bei Conferva noch nicht beobachtet. Nach Decaisne $\left({ }^{1}\right)$ und nach Hassall $\left({ }^{2}\right)$ bilden sich in den Gliederzellen bewegliche Keimzellen, welche durch eine Oeffnung der Mutterzelle entleert werdeı, und die wohl ohne Zweifel durch freie Zellenbildung entstanden sind.

\section{Acetabularieae.}

Einzelliges Laub oder Stamm, mit vielzelligen Haaren oder Blättern.

\section{Acetabularia mediterranea Lamour.}

Tab. III, Fig. $1-12$.

Die Pflanze ist 1 - 2 Zoll hoeh und trägt auf einem cylindrisehen, dünnen Stiele einen zienlieh flachen, ron oben wenig coneaven Schirm, der radial gestreift und im Centrum genabelt ist. Der Bau dicser Pfhanze

(') Youv. annales d. sc. nat., XV11, pag. 535.5.

(') British freshwater Algæ, pag. 214, tab. LVI. 
ist höchst merkwürdig. Stiel und Schirm bestehen aus einer einzigen Zelle. Dieselbe ist cylindriseh und an der Spitze etwas angeschwollen; an der Anschwellung trïgt sic cine Menge von einfachen und gleichlangen Aesten, Helche sich z.ı einer Fläche dieht aneinander gelegt haben. Macht man einen senkrechten Durchschnitt durch die Mitte des Schirmes, so sielit man, (lass die Höhlung des Stieles (Fig. 1, 2, a) continuirlieh in diejenigen der Strahlen des Schirmes übergeht (Fig. 1, 2, b). Fülırt man dagegen den senkrechten Durchsclnnitt in der Richtung einer Secante, so igleicht derselbe einer Zellenreihe, wo jede scheinbare Zelle einem durchschnittenen Zellenaste entspricht (Fig. 4, b). Die Zahl der Zellenäste oder Strahlen des Schirmes betı̈̈口t gegen 100; ihr inneres Ende ist bedeutend sehmäler als ihr äusseres Ende (Fig. 1, s). - Zwischen dem Sticle und dem Schrme betinden sich wulstartige Vorsprünge (Fig. 1, 2, c). Dieselben sind halb-ellipsoidisch; ihr radialer Durclımesser ist länger als der verticale und tangentale Durchmesser. Wenn man den Schirm ron unten betrachtet, so erscheinen die Wülste als eben so viele elliptische Zellen (Fig. 11, c, e). Sie sind nicht in gleicher Zahl vorhanden wie die Strahlen des Schirmes, sondern etwas zahlıeicher. - Diese Wiülste sind mach innen und unten durch eine tiefe Einfalung der Membran (Fig. 2, d) von andern Wülsten geschieden (Fig. 1, 2, e), welche nach unten zu mehr oder weniger merklich alggesetzt sind, und von der untern Fläche ebenfalls als Zellen erscheinen, die nach innen geschlossen oder geöffnet sind (Fig. 11, e, e). Sie ersclıeinen als geschlossenc Zellen, wenn die Wülste plötzlich enden; sie erscheinen als offene Zellen, wenn dic Wülste allmälig in den sticl übergehen. Die beiden Kreise von Wülsten bilden den untern Ring. - Zwischen dem Schirme und dem Nabel Iiegt elenfalls eine ringförmige Reihe von Wülsten (Fig. 1, 2, l; Fig. 5 stellt einen einzigen Wulst dar). Sic sind halbellipsoidisch, wobei der radiale Durchmesser mehrmals länger ist als der verticale und der tangentale Durchmesser. Betrachtet man den Schirm von oben, so erscheinen auch diese Wülste als Zellen (Fig. 10, f). Sie sind in gleicher Zahl vorhanden wie die Strahlen des Schirmes und bilden den obern Ring. Auf jedem dieser obern Wïlste steht eine radiale Reilıe von Wärzchen (Fig. 2, g; Fig. 5, g). Es ist mir nicht recht klar geworden, ob es besondere Zellen oder bloss Auswüchse der einen Zelle, aus del die übrige Pflanze besteht, seien. Sind es Auswüchse, so communiziren sie mit dem Wulste dureh einen engen Schlund; sind es Zcllen, so besitzen sic einen Porus nach dem Wulste hin (Fig. 5). Da ich keine Wand in dem verbindenden Kanale erkennen konnte, so bin ich eher geneigt, sie als Auswüche der Zelle anzusehen. Von aben erscheinen sie als Zellen (Fig. 10, g). - An der Basis trägt der Stiel Wurzeln, welche sich in sein Lumen öffnen (Fig. 7, r).

Acetabularia mediterranea hat also folgenden Bau. Ihre Frons bestelit aus einer einzigen Zelle, welche einen einfachen cylindrisehen Sticl bildet (Fig. 1, 2, a), an der Basis in kurze Wurzeln (Fig. 7, r) und an der erweiterten Spitze in viele, einen Verticill bildende, einfache Aeste auswächst (Fig. 1, 2, b). Die Aesle legren sich mit ihrer Seitenfäche in einer einfachen Schicht aneinander, und bilden eine schirmförmige Flächı (Fig. 1, s). Zwischen dem Schirme und dem Stiele trägt die Zelle wei coneentrische Reihen von vorragenden Wülsten (Fig. 1, 2, c und e; Fig. 11, c und e). Zwischen dem Schirme und dem nabelförmigen Scheitel befindef. sich eine concentrische Reile von vorragenden Wülsten (Fig. 1, 2, f; 10, f). Jeder dieser obern Wïlste träigt eine radiale Rcihe von Wärzchen (Fig. $2,5, \mathrm{~g} ; 10, \mathrm{~g}$ ).

Der Bau von Acetabularia ist schwer zu ermitteln; im natürlichen Zustande macht die Sprödigheıt der Wandungen, welche durch den grossen Kalkgehalt hervorgebracht wird, einen guten Durelıschnilt fast unmöglich; ist der Kalk durch Säure entfernt worden, so wird die Schlafflıeit der Wandungen zu einem andern, zwar geringern Hindernisse. Die Angaben üher die Organisation dieser Pflanze weichen selır von einander ab. Die vollständigste Anatomie giebt Kützing ('). Meine Untersuchungen, die ich in Jahre 1842 an Golfe von Neapel anstellte, und die ich eben mifgetheilt habe, differiren bedeutend im Resultate. Külzing saygt, dass der

(4) Pbycologia general., pag. 311, tab. 41; und teber dis polypiers calciferis des Lamouroux, pag. 6. 
Stiel einige Gliederung zeige, die aber nicht immer deullich sei, und dass die Glieder ungleiche Länge besitzen. Alle Exemplare, die ich beobachtete, zeigten von der lasis bis zur Spitze des Stieles, keine Spur einer Scheidewand. Scheinbare Gliederung, durch ungleiche Vertheilıng des Inhaltes, namentlich durch das kohlensaure Gas hervorgebracht, welches bei Anwendung von Säure sich innerhalb des Stieles entwickelt, sah ich bei schwächerer Vergrösserung. Kützing zeichnet aber den Sticl wie einen Confervenfaden. Wenn man bedenkt, wie fast ausnalımslos die übrigen einzelligen Pflanzen, Caulerpa, Bryopsis etc. ohne Gliederung sind, und dass, wenn einnal die Gliederung auftritt, diess nur Folge eines krankhaften und abnormen Prozesses ist ('), - so wird man wohl nicht anstehen, auch die Frons von Acetabularia als einzellig, und allfällige Scheidewände im Stiele als abnorme Bildung zu erklären. - Kü̈zing nennt ferner die Zellenäste welche in den Schirm verwachsen sind, Zellen; ebenso lässt er zwischen dem Schirme und dem Stiele einen untern Ring von „ concentrischen Zellemreihen, und zwischen dem Schirme und dem Nabel einen obern Ring von einer Zellenreihe bestehen; endlich liegen nach ihm innerhalb der Zellen des obern Ringes Kugeln oder Zellen. Es sind diess alles unrichtige Angaben, welche von dem Mangel eines Durchschnilles herrihren. - Nach Kützing's Theorie über den Bau von Acetabularia liesse sich die Zahl der Zellen, aus denen die Frons bestünde, auf 800 bis 1000 berechnen; während sie in der That einzellig ist. Und wenn auch die Wärzchen auf dem obern Ringe, von denen ich es zweifelhaft liess, ob sie Zellenausw üchse oder wirkliche Zellen seien, sich als Zellen erweisen sollten, so bleiben immerhin noch 400 Zellen zu viel angegeben.

Die Zellenwandung ist überall verdickt und an einigen Stellen von sehr bedeutender Stärke. Sie besteht aus der Zellmembran und der Extracellularsubstanz. Ist die lelztere hinreichend dick, so unterscheidet man an ihr ¿ Lagen: eine innere concentrisch-gestreifte, durchsichtige Gallerte (Fig. 8, b), und eine äussere, undurchsichtige, Körnige Masse (Fig. 8, c). Die körnige Beschaffenheit der äussern Lage rührt von Kalkablagerungen her. Sie ist ebenfalls concentrisch gestreift; die Streifung rühıt von dem Umstande her, dass die Kalkkörner theils in concentrischen Reihen liegen, theils durch concentrische, hellere und streifenförmige Stellen voneinander getrenut sind. Diese Anordnung der Kalkkörner ist aber ohne Zweifel Folge der schichtenweisen Anlagerung der ausgeschiedenen Gallerte. - Die Kalkablagerung in der Extracellularsubstanz ist an der ganzen Fläche der Zellwandung vorhanden, selbst in den Scheidewänden des Schirmes wird sie oft zwischen den beiden Membranen deutlich gesehen. - Wenn durch Säure der Kalk aufgelöst wird, so fält dic äussere kalkhaltige Lage der Extracelularsubstanz zusammen, während die innere kalkfreie Lage, durch die Wirkung der Sïure auf die Gallerte, elwas aufschwillt. Dabei füllen sich der Stiel und die Strahlen des Schırmes theilweise mit Gas.

Die Strahien des Schirmes enthallen winzige Schleimkörnchen, kleine Chlorophylblïschen, und Amyiumkürnchen. Der Stiel enthält vorzïglich Sehleimkörnchen und Anylumkörnchen. Die letztern sind einfach oder zusammengesetzt, und von verschiedener Grösse (Fig. 7, 9, B). Sie liegen zuweilen an der Wandung in der Form einer abgestutzten Kugel. - Külzing sagt, dass an dem Stiele hier und da kreisförnigg-gestellte, runde Oefinungen vorkommen, von denen er früher vermulhete, dass daselbst andere Sclll̈̈uche oder Aeste eingelenkt gewesen seien. Es ist mir auffallend, dass Kü̈ting diese Löcher nicht im Durclısehnitte zeichnet, da sie doch bei der Grösse ihres tangentałen Durchmessers und bei der bedeutenden Dicke der Waudung sehr leicht gesehen wejden miissten. Verner ist es mir auffallend, dass er von den an der Wandung liegenden Stärkekügelchen nichts bemerkt. Meine Zeichnnngen stellen nun aber die Stärkekïgelchen von oben und ron der Seite ähnlich dar, wie Kützing die angeblichen Löcher zeichnet. Ich finde sogar unter meinen Zeichnungen einigemal kreisförmig gestellte kïgelchen. So dass ich fast vermulhen möchte, dass, wie früher die poren der Phanerogamen für Körner und Bläschen, diessmal nmgekehrt die Amylumkörner für l'oren angeschen worden

(1) Vergl. über zufallige Iembranbildung in Schlciden und Vïgeli's Zeilschrift f. w. B., Heft I, pag. 91. 


\section{$-161$}

seien. Ich kann ausserdem heifügen, dass für Löcher oder Poren am Stiele ron Acetabularia weder eine Analogie noch eine Erklärung zu finden wäre, dem Schläuche, Aeste oder Iblätter, durch deren Alufalleu sif erzergt werden kömnten, hesitzt Acetabularia njeht.

Es nuss noch eines Oroganes ertähnt werden, ïber dessen Ban und dessen Bedeulung früherlin viele murichlige Annahmen herrschten. die von Kützing herichtigt worden sind. Fs siud Haare mit doldenförmiger Verzweigung, welehe zwisehen dem Schirme und dem Aabel im hreise steben, und ungefälır so lang als die Strahlen des Sehirmes sind. Sie sind mil einer Basiszelle auf dem Jaube befestiggt: diesclbe trägl an der Spitze $5-7$ Zellen, daron trägt jede an ilıres Spitze $5-5$; jede von diesen $2-5$, und eine jede dieser letzlern gewöhn̊lich 2 Zellen (Fig. 12). Die Basiszelle entspringt ans einem der Wärzchen, dı zw ischen dem Schirme und dem Valbel stehen (Fig. 2, g, h). Ein sulches Wärzchen verlangrert sich zu einer cylindrischen Zelle (lig. $\left.2, h^{\prime}\right)$. In diesem Falle ist das Wärchen bestimmt eine Zelle, und wenn es, wie ich vermuthe, ursprïnglich bloss ein Zellenauswuchs ist, so verwandelt es sich, ehe es sich verlängert, durch Zellenlyildung in eine Zelle. niese Zelle hat begrenzles Wachsthum. Elwas unterhalb des ersterhenden Punctum regclationis wachsen mehrere vertscillirte l'unkte aus und bilden nene Zellen, die ihrerseits wieder begrenzl wacisen und unterhalb ihres Scheitels wieder einen Verticill ron seitlich-endständigen Zellen erzeugen. Bie Zahl und die Grösse Jer Tochterzellen ninmt ron unten nach oben al, (Fig. 12). Külzing zeichnet die unterste Zelle hinrz und fast quadratisch; ich finde sie lang und cylindrisch lind viel grö̈ser als die ïbrigren Zellen. - Die Ilaare von Acetabularia sind sehr mannigfallig, 1) weil die Erzeugung ron Tochterzellen sich an rerschiedenen Haaren nicht gyleich oft wiederholt; $\boldsymbol{z}$ ) weil sie an den Strahlen des gleichen Ifares bald gleich-, bald ungleich-oft auftritt; 5) weil die Zellen einer Ordung an verschiedenen Iaaren nicht gleich viele Tochterzellen erzeugen. z. B. in einem Haare 6 , in dem andern 8 , in dem einen 8 , in dem andern $1 ;$;) weil die Zellen einer Ordnung an denselben Ifaare bald gleich-, hald ungleich- vicle Tochterzellen bilden. Der gewöhnlichte Fall ist der" dass die Jlaarzellen in 3 Ordnungen stehen, wovon die erste 1 , die zweite 6 , die dritle $6 \times 4$, dre vierte $6 \times 4 \times 5$, die fïnfte $6 \times 4 \times 3 \times 2$ Zellen enthilt, so dass das ganze llaar aus $2 \mathbf{s}_{7}$ Zellen besteht.

Die Wandung der Haarzellen ist selu dïnn und zart. Han erkennt an ihnen ausser der Zellmembran keine deufliche Extracellularsubstanz. Kalkablagerungen sind keine rorlanden. - Der lnhalt ist anfänglich homogener, farbloser Schleim; dann wird er feinkörnig; nachlıer gröber-grekörnt, dunkel und etwas grün gefürbt; er fülll das ganze Lumen der Zellen aus. Yachlıer, wenn die letztern hedeutend grösser gew orden sind, so liegt der körnige Inhalt in geringer Henge und fast ohne Färbung an der Membran. Er überzicht bald grleichmässig die ganze innere Zelltäche, inden bloss einzelne runde oder elliptische Räume frei bleilen, bald ist er in ein Netz geordnet, balı bilde! er hloss kreisförmige Linen wie an weit gewundenen Ringyefässen. - In den Haarzellen, namentlich in den grössern der untern Ordnungen, finde ich ülserdem kleinere und grössere, sphärische Zellen mit zarten Wandungen. Sie besitzen einen Durchmesser ron $0.002^{\prime \prime \prime}$ bis 0,014 "I'. Die kleinsten sind homogen-schleimig und farblos; etwas grössere erscheinea kürnjg, dann fürben sie sieh grünlich; die grössten besitzen einen gellıgrünen, der Hembran anliegenden, gleichmässigr oder ungleichmäissig rertheilten, grelbgrïnen, kïrnigen Inhalt.

Die Bedeutung dieser Zellen, elsenso wie die Bedeutung der Haare ist mir unlsckannt. Ich wäre geneigt gewesen, sie fragsweice als Keimzellen zu bezeichnen. Nun bildet aber Kützing die Samen innerhalb der Strahlen des Schirmes ab, und nach der deutlichen und bestimmten Zrichnung kann ich nicht anstehen, sic als die wahren keimzellen anzuerkennen. Bei meinen Untersuchungen in Yeapel fand ich in dem schirme ausser feinkörnigem Inhalte hin und wieder grössere Amylumkügrlchen und znweilen grössere Kugeln von zusammengeballten Inlıalte, welche aber, wie es mir schien, immer durclı die Wirkung der Säure entstanden waren, nie wahre Zellen. - Die Entscheidung der Frage, wo die Keimzellen entstehen, ist wichtig fïr dic Deutung der Organe. Wïrden sie, wie ich früher glaubte, in den Zellfiden mil doldenlörmiger Verästlung erzeugt, so müssten diese, wie die gleielggebauten Organe in Dasycladus, als Plätler bezeichnct werden. 
Ind die grosse Zelle, welche den Stiel und den Sehirm bildet, wïre der Stamm, wie in der genannten Galtung. Wenis nun aher, nach Kützing, die Keimzellen un den Strahlen des Schirmes entstehen, so muss, wie ich glauhe, die grosse Zelle cher Frons oder Laub, und die doldenförmigen Zellíaden Haare genannt werden.

\section{Dasyclades clava formutis $A g$.}

T.M. 1V, FIG. $1-19$.

bic Pflanze ist ein $\%$ bis 2 Zoll hoher, cylindrisch-kenlenfömiger, sehwammiger, braun-griner Körper, ¿ bis 5 Linien diek. Eine einfache, senkrechte, cylindrisehe Zelle nimmt die Achse ein und bildet den Stamm. in der Stammzelle slehen in kurzen Zwischenräumen verticillirte Aestehen, welehe sich einigemal doldenfïmig theilen; ich will sie die Bläller nennen.

Die Blätter stehon elwa je zn 12 in cinem Quirl. Jedes Blalt ist mil einer einfachen cylindriselıen Zelle an Jem Stamme befestigrt (Fig. 1, f, f). Auf dem Seheitel dieser Zelle stelen $2-6$ fast gleich-lange Zellen. die "thas kleiner sind. Auf dem Ende jeder dieser Zellen sind wieder $2-6$ gleichlange noch kleinere Zellen hefindlich. Diese Zellen enden frei, oder tragen noch einmal je 2 bis 4 Spitzenzellen (Fig. 1, 2, 5). Die blälter sind sonil 2 - Glomisch-ver̈̈stelte Zelfäden, die aus $5-4$ Phalangen bestehen, mil andern Worten, an denen die Ferästlung sich 2 oder 5 mal wiederholt. Je nachlem nun die Verïstlung seltener oder bäufiger suftrilt und an der Spize je einer Zelle mein oder weniger Spitzenzellen beindlieh sind, so entstehen verschiedene Blalformen. Diese Modifieationen sind so mannigfaltig, der Nalur der Sache nach, dass man sie fast unzühlbar nennen hann; ich habe in Fig. 1, 2 und jeinige Formen abgebildet. Külzing $\left(^{1}\right)$ nennt die leste "trichotomisch. "Diess bezeichnet aber nicht eine Verïstelung, welche aussehliesslich, sondern nur rine solehe, welelse vorzugsweise vorhanden ist. Es ist kein absoluter, sondern ein relaliver Charaeter, und darf nieht in die Diagnose der Gattung aufgenomnen werden.

Die Slanmzelle wïlıst an der Spilze wie Bryopsis, Caulerpa etc., nämlieh dureh Spitzenwachsthum; sie wäehst so lange das Individum lobt, also unbegrenzt. Das P’unktum vegetationis (Fig. 4, a) bietet die gleichen Erseheinungen dar, wie an den beiden genannten Gaflungen. Die Wandung ist dasellst russerst dïnn und zart und besteht bloss aus der sich bildenden Zellmembran. Der Inlalt ist ein homogener farbloser Selıleim; nac! unten wird er körnig und färbt sich dann almälig grün, indem hleine chlorophyllblaschen in ihm entstehen. Die Wandung wird yon der Spilze an abwïts sletig dieker und besteht aus der Zellnembran und der Extraccliularsubslanz. Die erstere ist überall ziemlich gleich dick, die leztere hingegen nimmt von unten nach oben an Släke ab. An obern Theile des Slammes ist die Extracellularsubstanz gleichförmig, gallertartig und schwach gestreift (Fig. 1:). An der Fläche erkennt man ein nicht unregelmässiges Nelz von feinen Linien; die Linien dieses Netzes stellen sich auf dem Iturchschnitle als oberflähliche Spallen dir (Figr. 15), welche von aussen bis auf eine geringe. Tiefe in die ausgesehiedene Gallerte hineinreiehen. Am untern Theile des Stammes, wo die Wandung sehr dick ist $(0,060$ " und mehr), unterscheidel man an der Extracellilarsubstanz 2 verschiedene Lagen: 1) eine innere, fas! homogene oder schwach-gestreifte, mehr verdiinnte Gallerte (Fig. 17 , 18, m), und 2) cine äussere, feinkörnige, etwas dichlere Gallerle (Fig. 17, 18, II). Das körnige Ansehen rührt von Kalkniedersehlägen her. Von der Fläche angesehen, zeigt die Extracellularsulstanz cin doppeltes Netz, nämlich grössere Haschen mil slärkeren Linien und kleinere Maschen mit schwäeheren linien (Fig. 16, b, b). Die stärkeren Linien zejgen sieh auf Durchsehnilten als Spalten, die an der äusseren Oberfäehe befindlich sind (Fig. 17, n); die sehwächern Linien erkenne ich anf dem turehsehnifle nicht.

Die Zellen der Blätler wachsen elenfalls an der Spitze; daselbst ist die Membran dünn und zart, der Inhalt

(") Phỵculogia gen., pag. 515 


\section{$-163$}

farhlos und homogen-schleimig (Fig. bै, a; 10, a). Nach unten wird he Membran dicker, der lnhalt erst fein-

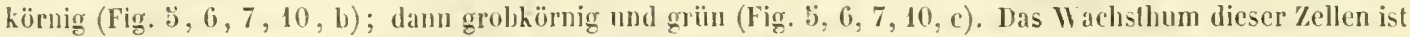
begrenzt. - Die Wandung der ausgewachsenen Blattzellen bestcht aus der Zellmenuran und einer gleichförmigen Schicht von Gallerte, welche an den Endzellen ilıe gröste Stälhe an der spilze derselben hat (Fig. 14). - Der Inhalt der ausgewachsenen Blathellen ist Wasser und eine wandsländige Schleimschieht, in welcher Chlorophyllblïschen befindlich sind. Die Chlorophyllbläscho'll sind ähnlich denen von Bryopsis, nur kleiner; sie zeigen sich von der Fläche rundlich, oval oder clliptisch, von der Seile zusanmengedrücht mit einer nabelförnigen Erhabenheit in der Ville; sic enthalten daselbst cin kleines Amylumheruchen. Ausserdem gieht es zusammengeselzte Körner, welehe aus melıreren Chlorophyllıläschen gebildet sind. Die Körner haben eine kugelichte Gestalt und besitzen im Centrum einen hohlen sternförmigen Raum zwiselıen den Bläschen (Fig. 20). .

Ich muss noch einer Erscheinung erwälnen, welche die Veränderung des Zelleninhaltes in Folge der Endosmose von Wasser betriff. Ich sah einigemale, dass unter dem Nicroscope die Schleimschieht des obern Theiles der Stammzelle sich in regelmässigen Zwischemriumen vou der Wandung zurïckzog. Es geschah in Form eines Jetzes, dessen Felder den losgelösten Particen der Schleinschicht, und dessen Linien den anluaftenden Partieen derselben eutsprachen (Fig. 19). Daraus geht hervor, dass nicht alle Theile der Selıleimschicht gleich innig mil der Zellmentban verbunden sind. Bei andern Algen und nansentlich bei Florideen trilt eine älnnlichErscheinung auf; hier ist es sicher, dass an denjenigen stellen, wo die Schleimschichı fester mit der Zelle nuembran vereinigt ist, da es die I'oren sind, der Stoffy echsel zwisclien 2 Zellen von Stalten geht, und dass an allen ïbrigen Stellen Extracellularsubstanz gebildet oder iiberhaupt die Zellwandung verdicht wird. Da nun bei Dasycladus die Stchlen, wo Schleimishalt und Hembran inniger zusanımenhängen, als Linien cines Nelzes erscheinen; da fernerclie Saftströmung in verwandten Pflanzen (Bryopsis, Confersa ele.) ebenfalls als Linien eines wandständigen Xetzes auftrill; da endlich auch die Gallertausscheidung, wie wir oben gesehen, der Quantität nach an den einzelnen Theilen der Viembran ungleich ist, und diese Lngleichbeit ebenfalls die Gestalt eines Netzes hat: so möehte man daraus den Schluss ziehen, dass ảle diese Erscheinungen in beziehung p.u einander stehen und dass die Sloffaufnahme nicht gleichmässig durch die ganze Zellmembran, sondern vorzüglich durch bestimmte Theile derselben, welche die Linien vines Nelzes bilden, geschehe; dass diesem Netze der Stoffaufnahme ein gleiches der Saftströnung entspreche, und dass durch die übrigen Theile der Menlıran, welche ausser den Netzlinıen liegen, also durch die Nelzfelder, vorzugsweise die Verdickung der Membran bewirkt werde.

Die unterste Blattzelle entsteht aus der Stammzelle durch Auswachsen der Membran und Zellenhildung in dem ausgewachsenen Theile. Dieser Prozess wiederholt sich fortwährend hinter der wachsenden Stammspitze und ist unbegrenzt wie diese. Es ist eine ganz älnliche Erschcinung, wie sie bei der Blatlbildung von Bryopsis rorkommt, mil dem Untersehiede, dass in Bryopsis cinzelne seitliche l'unkte der Memuran bloss in neue Ichsen der gleichen Zelle auswachsen, in Dusycladus dagegen wirklich zu neuen Zellen werden.

Das Wachsthum dieser Zellen ist begrenzt; es erstirbt nach einer gew issen Dauer. Slatt dessen erhchen sich I bis 6 P'unkle der ijembran, etwas unlerhalb des nun ruhenden Punhtum regetationis (Fig. 6, 7, 8, 9), und wachsen in neve Achsen aus. Diese Bildung von neuen Aclsen ist gew ̈̈hnlich gleichzeilig, selten ungleiclızeitig (Figg. 8. 9). Jede derselhen wird zur besondern Zelle. Veher Zellenlildung ist nichts au sehen. Es wird zuerst eine zarte Wand sichtbar, gewöhnlielı wenn der auswaclisende Theil etwa 0.005 "' lang greworden ist. - Diese Wand erscheint doppett, wenn dic neue Zelle 0,020"ll lang ist (Fig. 10). - Anf gleiche Weise entstehen die zweiten und dritten Phalangen der Blätter. - Das Wachsllum der Blälter ist liegrenzt, nicht nur weil die cimzelnen Zellen limitirt sind, sondern auch weil die Erzengung von nenen Zellen sich nur wenige Vale wiederholt. - Das Wachsthun der Blätter von Lasycladus hat grosse Analogie mit dem Wachsthume der Markröhren ron Udoteu. An beiden Orten verlängern sich die Achsen durch Mcmbranbildung an der Spitze 


\section{$-164$}

nur eine bestimmte Zeit lang, dann erstirht dieselbe; dagegen werden 2 oder mehrere I'unkle unterhalb der Spitze lebendig, indem neue Menbranbildung in ilnen auftrilt, um cbenfalls nach eincr begrenzten Dauer atffuhören. Der Unterschied liegt darin, dass in Ldoteu jede neue Achse Theil der Multerzelle bleibt, in Dasyclatus dagegen zur neuen Zelle wird.

Zwischen je 2 Zellen, die cinander berihtren, ist ein einziger Porus; also zwischen der Stammzelle und den ersten Blattzellen, zwischen den ersten und zweiten, zwischen den zweilen und dritten, zwischen den dritten und vierten Blattzellen (Figg. 11, 12, p; 15, 17). Von der Fläche angesehen erscheint der Porus rund oder elliptisch (Fig. 11; 16, a). Yon der Seite oder auf Durchschnitten zeigt er sich als eine Verdünnung der Wandung. Diese Verdïnnung rührt daher, dass an diesel Stelle keine Extracellularsubstanz gebildet wurde (Fig. 12, p; 15, 17, 18). Die Wand, welche den Porus in 2 Hälften trennt, besteht also bloss ats den beiden Zellmembranen. Diese Wand ist von Decuisue ïbersehen worden, während er den Porus sonsh richtig abbildet ( $\left.{ }^{4}\right)$. - Die Stammzelle besitzl so viele Poren, als sie Blälter trägl. Dieselben sind anfänglich rundlich oder eler in horizontaler Richtung elliptisch-verlängert (Fig. 1, 11); zuletat erscheinen sie als verticale Ellipsen (Fig. 16). Wenn die Bläter an alten Stämmen abfallen, so sind die letztem mit verticillirten Punkten bedeckt, welche die Poren siml. - Jede Blallzelle besilzt einen Porus an der Bilsis und 2 - 6 Poren an der Spilze, nil Ausnahme der Endzellen, welche nur einen Porus an der basis haben.

Die Fortpflanzung an Dusyctudus ist noch mbekannt. Ich finde zuweilen in den Blaltzellen freie, kugelige Zellen in unbestimmter Menge und unbestimmler Grösse. Diese Zellen besilzên die grösste Analogrie mit den Keimzellen von Irulonia, und ich bin geneigt sie auch als solche zu erkïiren, obgleich ich das heimen derselben nicht beobachtete. Diese Keimzellen erscheinen anfinglich als ganz kleine Tröpfchen honogenen Schleimes. Sie verörössern sich, der Schleim wird körnig; sie werden noch grö̈sser, der kürnige Schleim fierbt sich grün, die Membran wird sichtbar. Endlich sind es kugelige Zellen von 0,010 " $-0,040$ "' im Durchmesser, welche von den der Membran anliegenden, enge in einander stehınden Chlorophyllhläschen fast dunkelgrün gefärbt sind. Die Entwicklungsgeschichte ist die gleiche, wie ich sie in Tab. 11, Fig. 2/t fïr die heimzellen von

Valoniu dargestellt habe. In Dasycludus bleiben die Keimzellen kugelig, wälırend sie in V'alonia nachher platt-zusammengedriickt werden.

Der Galtungsbegriff von Dasrcubus muss in folgenden Herkmalen gefunden werden : Der Slamm ist cylindrisch und einzellig; er wïchst unbegrenzt an der Spritze und erzengt unbegrenzl dureh seilliches duswachsen der Membrun und Zellenbiltung in dem ausyeurachsenen Theile Bläterverticille. Die Blälter bestehen uus einzelligen Achsen mit doldenfürmiger Verïstlung; die Bludtzellen huben begrenzles Spitzenuchehs-

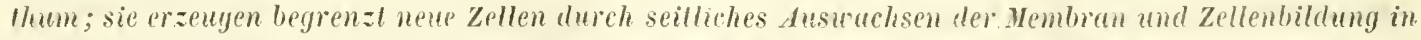
dem ansyewachsenen Theile. Die Keimzellen entshen in den Blallzellen durch freie Zellenbildung.

\section{frocladus mediterpancus Nüg.}

TAв. 1 , Fig. $25-57$.

Diese neue Pflanze fand ich im Golfe von Neapel auf der Insel Ischia. Sie wird ungefähr 1 Zoll hoch und wächst im Rasen. Der Stamm ist eine einfache cylindrische Zelle, elwa \%, Linie dick (Fig. 25, e). An der Basis verzweigl sich die Stammzelle in Wurzeln, welche sich wenig verïsteln, und mit der liöhlung des Slammes communiziren (Fig. 25, r; 21). Dic cinzelnen Wurzeln endigen häutig̨ in eine unregrelnässige, schildförmige

(1) Nour. annales des sc. Dat., XVII, tab. 17, fig. 1.̃. 
Frweilerung, mit der sie aufsitzen (Fig. 23, wo die Spitze einer Wurzel slürker vergrössert ist). - In dem obern Ende erweitert sich die Stammzelle, indem sie entweder ganzrandig bleiht (Fig. 27, c), oder sich lappenfömig theilt (Figr. 28, c), oder selbst einen kurzen Ast bildet (Fig. 29, a).

Aif dem erweilerten Stammende und ebenfalls auf dem Aste, wenn ein solcher vorhanden ist, steht rin Büschel von blätlem (Fig. 95, 27, 28, 29, f). Es sind verästelte Zellfiden, welche in der Zahl von 7 bis 14 vorhanden sind. Sie haben einen sehr verschiedeneı Bau. Es sind einfache Zellen (Fig. 50); Zellenreiłen, dir aus 2 Zellen bestehen (Fig. Jl); solche, die ats 5 Zellen bestehen; Zellen, welche an der Spitze 2 (Fig. 52), oder 5 Zellen (Fig. 5j) tragen etc. etc. Die Blätler werden durch alle möglichın L ehergangsstıfen complicirteł (rig. 5ij), bis sie aus 50 bis 40 Zellen bestehen. Die Zelten sind cylindrisch, ron verschiedener tänge und Breite.

Die Blälter von Acrocladus besitzen Aehnlichkeit mit den Blättern von Dasycladus und mit den Haareli ron Acelabuluria. Boch sind wesentliche Verschiedenheiten vorhanden. Bei den Organen der beiden grenannten Gittungen stehen die Tochterzetlen doldenförmig auf der Itutterzelle, indem der cigentliche Scheitel dieser letzlern frei endigt, und sind von gleicher Länge. An den Blältern von Acrocledus dagegen sind div Toclıterzellen ungleich lang; eine daron ist die längste, sie steht unmiltelbar auf der Spitze der Mutterzelle; die übrigen Tochterzellen stchen seitlich. In den Blättern von Dasycladus und den Ilaaren von Acetabulariu ist jede Zelle für sich eine besondere Achse. In den Blätern von Ácrocladus dagegen isi inuner eine der. Tochterzellen die directe Fortsetzung der Achse der Nutterzelle, während die ibrigen Tochterzellen neue Achsen darstelten. Das Blatt ist daher eine Zellenreihe von $2,5,4,3$ GJiedern, an welcher seilliche (Ast-) zellenreihen stehen.

Dieser Unterschied im Ban zwischen den Orgenen von Dasycladus und Acetabularia und denjenigen vos! Acrocladus beruht auf einer Differenz. im Wachsthume. In den erstern wächst eine Zelle bis zu einer bestimmten Länge; danin abortirt ılı Spitzenwachsthum, und statt dessen wachsen mehrere verticillirte Punkte der' Membran unterhalb der spitze ans; die ausgewachsenen Theile schnïren sich als Tochterzellen ab. In den !lättern ron Acrocladus lingegen verlïngert sich eine Zelle nicht bloss bis zu des ilı qukommenden Länge, sondern noch darüber hinaus, und theilt sich damn in 2 übereinanderstehende Zellen (Fig. 51, 5't). Die obero dieser beiden Zellen verlängert sich von neuem durch Spitzenwachshnm und erzengt wieder 2 Tochterzellen. Die Glieder, welche hinter der Endzelle liegen, wachsen mit ihrem obersten Seitentheile in einen Fortsat\% aus (Fig. 56, a), welcher durch Zellenbildung zur besondern Zelle wird; das gyleiche Glied kann noch 1 oder 2 mal in gुleiche Fortsäize auswachsen und Astzellen erzeugen. Das Wachsthum der Blätter von Acrocladıs ist demnach rolikommen das gleiche wie an Conferca glomerala. Dieses Wachshum durch Zellenbitdurg steht aber tu dem Wachsthme der Organe ron Dusycludus und Acelcbularia in dem gleichen Verhälnisse, wie dar Spitzenwachsthum durch Iembranbildung und Astbildung von Bryolsis oder Canlerpa zu demjenigen der Yarkïülren von tóloted.

Die Wandungen des Stammzelle, der Wurzełäste und der Blattzellen bestehen aus der Zellmembran und aus Extracellularsubstanz. In der letzlern ist eine geringe JIenge von Kalk abgelagert; man erkennt zuweilen, das. sie, wie in Caulerpa, Dasycladus und Acetabularia aus 2 verschedenen Lagen besteht, einer äussern kalklıaltigen, und einer innern kalkilosen, obgleich die ganze Wandung des Stammes viel schmäler ist als an den genannten frattungen, und nicht über $0.005-0,003^{\prime \prime \prime}$ betrïgt. - Die Stammzelle ist mit Wasser gefïllt. An der innern Fläche der Membran liegt die Schleimschicht: Darin befinden sich Chloroplıyllbłäschen, welche von der Fläche rund oder elliptisch (Fig. 57), von der Seite zusammengedriickt (Fig. 57, b) erscheinen, und milten im homogenen Chloroplyll ein kleines Amylumkernchen einschliessen; ferner Chloroplythbäschen, welchw fast ganz von einem Amylumkügclchen ausgefïltt werden; ferner freie Amylumkügelchen, welche sich durch Jod bratun, durelı Jod und Schwefelsäure aher blau fäben; endlich Schleimkörnchen. Die Blattzellen besitzen den gleichen Inlialt, nur sind sie wegen stärkeren Vorherrschens des Chlorophylls und Zurücktretens der 


\title{
$-166$
}

Stärke intensiver grün gefärbt. In den Wurzeln dagegen ist mehr Stärke und wenig Chlorophyll vorlianden.

Die Wurzeln sind, wie oben gesagt, ungegliedert. Einmal faud ich Gliederung (Fig. 26). Dieselbe ist aber uicht durch normale Zellenbildung entslanden, sondeì durch abnornale Menbranbildung wegen krankhafter Veränderung des luhaltes. Die ursprïngliche Zellnembran setzi sich ununterbrochen über den abgestorbenen haum i hinweg; die neugebildeten Membranen dagegen endigen da, wo sie an die ursprüngliche Membran angelehnt sind $\left({ }^{1}\right)$.

Ich habe an der Wanrlung des Stanmes eine andere Erscheinung beobachtet, die ich nicht zu deuteit weiss, weiche aber vielleicht mit einer ähnlichen lisscheinumg an der Culicula der höhern Pflanzen analog isi. Von (fer Füche angesehen zeigie sie Streifung in verschiedener Richtung: 1) Längsstreifung, 2) schiefe Streifung ron rechts nach links und von links nach rechts, und 5) Duerstreifung. Die erste war durch die slärksten, die Ietżte durch die schwächsten Linien vertreten. Ueberhaupt war die Streifung um so deutlicher und gröber, je melir sie sich der vertiealen Richtung, um so undeutlicher und feiner, je nehr sie sich der horizontalen Richtung nuäherte. Entweder waren an der gleichen Stelle un einzelne oder alle Arten der Streifung zugieich vorhanden. VIahscheinlich hat die Streifung ihren Sitz in der Exiracellularsubstanz; vielleicht sind, wenn versehiedene Irten zugleich vorkonmen, dieselben in versehiedenen Schichten zu suelien. Die Jursache ist mir aber unbikannt.

In den Blattzellen finde ieh zuweilen kleinere und grössere Zellen, wie in den Blättern ron Dasycladus. Vielleicht, dass es Keimzellen sind.

lch will noch den Gattungsbegriff von Acrocladus mit denjenigen von Dasycladus und Acetabularia zusammenstellen. Acrocuancs: Der Siamm ist cylindrisch nul einzellig; er hat begrenztes I/ achsthum und erzugt dicht unterhulb der abortirten Spitze durch seilliches Ausuachsen der Hembran und Zellenbildumg in trm rusgenachsenen Theile einen Blatterticill. Die Bläller besiehen azs verästellen Zellemeihen, welche ditreh Zelienbildung in der Endzelde beyrenst uachsen, wnd durch seilliches Auswachsen und Bildung ron Astzellen sich begrensi verïsteh. Die Keimzellen (?) entstehen in den Blattzellen durch freie Zellenbildung. - Acroctathes unterscheidel sich von Dasycludus durch das begrenzle Wachsthum des Stamnes, durch die begrente (einnalige) Blattbildung, und durch das verschiedene Wachsthum der Blätter; von _Aceichnlaria dureh den Mangel des Schirnes, dureh das versehiedene Wachstlum der Blälter und Haare, und llurch den verschiedenen Ort für die Entslehung der Keimzellen, vorausgesetzt, dass die Angaben Kützinys ïber die Samenbildung von Acelabularia und meine Vermuthungen über die Zortpfanzung von Acroclacius vichlig sind.

\section{Coleochineten.}

\author{
Zellschicht (durch Vereinigung von verïstelten Zellenreihen entstanden); die \\ Kécinzellen entstehen in einzelnen Randzellen (d. h. Scheitelzellen jener Zellen- \\ reihen).
}

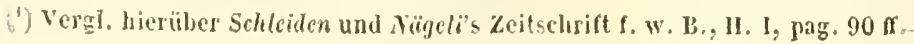




\title{
Colecthate seutat Bréb.
}

\author{
('hỵllactidium Coleochrete Kütz.)
}

T.B. V., FIG. $22-51$.

Coleochcete hat rolkommen den gleichen Bau und den gleichen Habilus wie Myrionema. Sie bildet eine? zienlich kreisförmige Zellschicht, welche mil ilrer ganzen Flïche auf Sïsswasserpflanzen festsitzt. Zuweilen hat sie bloss die Gestalt eines Kreisausschnittes, ist also keilförmig. Ausserdem zeigt sic sich hüutig verschiedeutlich gelappt (Fig. 22). Die Zellschicht entsteht aus veräslelten Zellenreilıen, welche dieht in einer Fläche aebeneinander liegen. Sim sie zahlreich genug, so schliessen sie sich zu eiuem vollkommenen hieise; sind sic in geringeres Henge yor!handen, so bilden sic bloss cinen Jlalbkreis, cincn Zirkelquadranten oder noch schü̈lere keilfürmige Figuren. - An der Zellschicht, sie mag die Gestalt eines hreises, Hallhreises oder hreisausschnittes besitzen, ist Centrum und Peripherie zu unterscheiden. Im Centrum hat das Wachsthum und die Verästelung der Zellenıeihen begonnen, dort liegt die Keimzelle. An der l'eriplıerie wächst die Zellschicht oder vielmehr die Zellenreihen, aus denen sie besteht. Die Randzelien (Scheitelzellen der Zellenreihen) theilen sich in zwei hintereinander liegende Zellen (Figr. 2h, b, b), eine nene Randzelle (Scheitelzelle einer Reihe), und in eine innere oder Tlächenzelle (Gliederzelle der Reilıe). Die letztere Tochterzelle theilt. sich nieht, die erstere verhält sich wie die hutterzelle. Die Randzellen theilen sich aber nicht bluss in 2 hinter einandel liegende, sondern, so oft der concentrisch grösser ferdende Raum es erfordert, in zwei neben einander liegende neue Randzellen, dirch eine radiale Wand (Fig. 24, a). Dadurch rerästeln sich die Zellenreihen dichotomisch. - Enlweder wachsen die Zellenreihen der Zellschicht alle gleichmässig; dann bildet der Rand inmer eine concentrische Linie, und die Gestalt der Pflanze ist regelmässig. Oder die einen Zellenreihen wachsen mehr als dic andern; dann wird die Zelsehicht am Rande buchtig oder gelappt. - Auf der Zellsehicht stehen Borsten (Fig. 2t, d, d); bald sind selı wenige davon vorhanden, bald ist sie damit dieht bedeckt. Aus einer Zelle entspringt eine einzige Borste, gewöhnlich etwas oberhall, der Hitte. Dic Borste ist eine farblose, wasserlelle, ziemlich cylindrische, an del ctwas verengten Spitze geölfnete Zelle, aus welcher ein langer, äusserst dünner Faden hervorragt, er fehlt häufigr, namentlich an getrockncten Pflanzen. Nähern Aufschluss über dieses merkwürdige Ferhalten kaun ich keinen geben, da ich an der lebenden Pflanze (welehe ich in Karlssulıe beobachtele) nur wenige borsten fand, und an getrockneten Exemplaren, welehe viele Borsten besitzen, eiue genaucre Untersuchung nicht möglich ist. - Külzing ( $\left.{ }^{1}\right)$ sagt, dass die IRandzellen mit einer llaarloorste rersehen seien. Ich finde aber nie Borsten auf den Randzellen, sonderı bloss auf den innerhalb des Randes grelegenen Zellen.

Feun dic Pflanze fructifizirt, so verwandeln sich einzelne Randzcilen in Keimmutterzelien (Fig. 2j, c). Statt dass sie, wie es dhe Randzellen sonst thun, durch vegetative Zellenbildung sich in zwei radial oder tangental neỉeneinander liegende Zellen theilen, werden sie grösser und füllen sich mit hnhalt. Indessen wäclsst die Zellsehicht durch die übrigen landzellen weiter, so dass die Keimmutterzelien bald innerhalt) des Randes liegen, und da die Zellenreilien siclı ausserlıalb von ihnen durch Verästelung wieder in einen continuirliehen Rand zusammensehliessen, so sind dann die keimmulterzellen rings von Zellen ungeben (Fig. 2', c). Gewöhnlich tritt diese T'mwandlung einzelner Rand atlen in Keimmulterzellen an der ganzen Peripherie ziemlich zu gleicher Zeil ein. Daher bilden die keimmutterzellen auch spätgrlin gew öhnlich einen concentrisehın Kreis (Fig. 22).

(') Phỵcol. german., pag. 240. 


\section{$-168$}

Mäufig stehen sie in bestimmten $\mathrm{Ab}$ ständen von einander, so dass sie durch je zwei oder drei Zellen von einander getrennt sind. Nicht selten liegen aber auch theils zwei oder mehrere dicht neben einander ; theils werden sic durch grössere Zwischenräiume von einander gesondert.

Brébisson (") erwähnt einer Tar. soluta, wo die radialen Fäden oder Zellenreihen frei und nicht zu einer Zellsehicht rereinigt sind. Ich stimme demselben vollkommen bei, diese Forn nicht als besondere Art zu unterscheiden. Denn es giebt zahlreiche Uebergänge zu der gewöhnliehen Form. Uebrigens ist die Entwicklungsgeschichte der Zellschicht aus der Keimzelle noch unbekannt, und daher ist es noch zweifehaft, wie sieh die beiden Formen zu einander verhalten. Mir ist es wahrscheinlich, dass die gelöste Form cine niedrigere Entw ickiungsstufe darstellt. , dass ihre Zellenreihen entweder wegen Mangel einer radialen Theilung der Scheitelzellen sich nicht zu einer Zellschicht entwickeh, oder dass sie, statt sich zu ciner Schicht zu vereinigen, getrennte Aeste bleiben. Häufig findet man an der gleichen Pflanze theils Zellenreihen, theils schmälere oder breitere Zellenschichten.

An der gelösten Form ron Coleochaete werden die Scheitelzellen der Zellenreihen zu Keımmutterzellen (Fig. 9.), c). Diesclben werden, wie in der gewöhnlichen Form, grösser, und füllen sich mehr mit Inhalt. Sie bleiben selten frei; gewöhnlich wachsen aus der Glicderzelle, auf weleher sie stehen (Fig. 25, 26, 27, d) eine oder mehrere Astzellen hervor, welche durch Zellenbildung sich weiter entwiekeln und einen grössern oder kleineren Theil der Keimmutterzelle mit kleineren Zellen bedecken. Entweder bildet sich nur Eine seitliche Astzelle, welche in eine Zellenreihe auswächst, die auf eine kleinere oder grössere Strecke der Keimmutterzelle anliegt (Fig. 27, b) oder selbst einen vollständigen Ring un dieselbe bildet (Fig. 27, c). Oder es entstehen zwei Astzellen, welche zwei seitliche, meist zu einem vollständigen Ringe sich schliessende Zellenreihen erzeugen (Fig. 26, b). Oder es entstehen aus der Gliederzelle nicht bloss seilliche Astzellen, sondern auch eine oter mehrere zugekehrte Astzellen (Fig. 28), aus denen eine Zellschicht hervorgeht, die die Keimzelle theilweise oder ganz bedeckt (Fig. 29, a stellt eine Keimzelle dar, welche vollstündig mit einer Zellschicht ïberzogen ist. Fig. 50 ist ein Querschnitt einer solchen). Diese Zellen, welche die Kemmutterzelle umgehen oder ïberziehen, werden späterhin meist braun gefirbt.

Die vegetativen Zellen der Pflanze sind zuerst grün. Sie enthalien Chlorophyll, welches entweder die ganze innere Oberfläche der Wandung überzieht, oder es bleiben freie dïcken in dieser continuirlichen Schicht, oder es sind bloss einzelne getrennte, grüne Stellen vorhanden. Im Centrum liegt ein Kern. Zuletzt verschwinden Chlorophylt und Kern; die Z̈ellen werden farblos und wasserhell. - Vie Keinmutterzellen gleichen zuersi den vegetativen Zellen, indem ihre innere Oberfläche mit riner Chlorophyllschicht ïberzogen ist. Späler füllen sie sich ganz mit grünem Inhalte, in dessen Mitte ein deutliches Kernbläschen liegt. Das Chlorophỵll entfärb! sich etwas und wird feinkörnig. Nachher sieht man in der Hutterzelle mehrere freie kug elförmige kieimzellen (Fig. 51), an denen man eine Membran und einen grünlichen Inhalt unterscheidet.

\section{LICHENACEE⿱一𫝀口.}

Durch regetatice Zellenbildung entsteht ein Zelliörper: an der Oberfläche einzelner Partieen desselben sitzen die Mutterzellen, welche durch freie Zellenbildung mehreve Keimzellen (in bestimmter Zuhl) erzeugen.

(1) Annales d. sc. nat., troisieme série, I, pag. 29. 
Die Lichenaceen oder Flechten stimmen mit den Stilophoreen und den Fuceen in vegetativer Beziehung überein; sie sind von denselben durch die Fortpflanzung verschieden. Mit den Protococcaceen, Valoniaceen und Confersaceen dagegen sind sie durch die Fortpllanzung verwandt, indem die Keimzellen frei in der Mutterzelle entstehen; doch weichen sie von diesen drei Ordnungen schon darin ab, dass die Keimzellen in bestimmter Zahl, nämlich zu $S$ (auch zu 4 oder 6 ?) in jeder Hutterzelle auftreten ; vorzüglich aber sind sie von denselben durch den vegetativen Bau und die Stellung der Keimmutterzellen verschieden. Bei den Confervaceen nämlich ist die Pilanze (oder deren Organe) eine Zellenreihe oder eine Zellschicht, die Keimmutterzellen sind Theile dieser Zellenreihe oder Zellschicht; bei den Flechten ist die Pflanze ein Zellkörper, welcher die Keimmutterzellen als ron seinem Gewebe verschiedene Organe trägt. Das Verhältniss der Flechten zu den Confervaceen ist das gleiche wie das der Mesogloeaceen (vorzüglich der Stilophoreen) zu den Bangiaceen.

$\mathrm{Zu}$ dieser Ordnung gehören ausser Lichina die meisten der bisher zu den Flechten gestellten Gattungen. Einige der letztern, wie z. B. die Calycieen, Graphideen müssen zu den Pilzen gebracht werden $\left({ }^{1}\right)$.

\section{EXOCOCGAGEF.}

Zelle ohne Spitzemuachshthm, ohne regetative Astbildung und ohne regetative Zellenbildung; die neuen Individuen entstehen durch wandständige Zellenbildung je eines in einem kurzen Aste.

(1) Schleiden (Grundzüge 11, p. 58, erste Anfl.) rechnet zu den Flechten die meisten Pyrenomyceten, viele Gasteromyceten und die ssporigen Hymenonyceten, inden er als characteristischen Unterschied zwischen Flechten und pilzen festhält, dass bei den ersteren die Sporen zu mehreren in einer grösseren Mutterzelle, bei den letzteren einzeln in einem fadenförmigen Fortsalze der Jutterzelte entstehen. Darnach würden auch noch einige andere Pilze zu den Flechten gestellt werden müssen, wie z. B. Achlya, Leptomitus, Ascophora, Arucor elc., was doch kaum die Absicht sein kann. Von einigen andern Pilzen, welche weder auf die eine noch auf die andere, sondern anf eine dritte Art ihre Sporidien bilden, wäre es zweifelhaft, wohin sie gehörten. - Wenn man die Pilze wegen ihrer ron allen ührigen Pflanzen abweichenden Intslehungsweise, Lebensart und Beschaffenlicit des Zelleninhaltes (vergl. oben pag. 116) nicht als besoldere Pflanzengruppe bestehen lassen will, so gibt es gewiss kein Merkmal der Fructification, 
Die Ordnung der Exococcaceen schliesst sich in Rücksicht auf die vegetativen Verhältnisse durchaus an die Palmellaceen und an die Protococcaceen an. Jede Pflanze besteht aus einer einzigen kleinen Zelle ohne Spitzenwachsthum, ohne vegetative Ast- und Wurzelbildung, ohne vegetative Zellenbildung. Die Tochterzellen werden aber nicht innerhalb der Mutterzelle gebildet, wie bei den Palmellaceen und Protococcaceen, sondern die Mutterzelle wächst in kurze Aeste aus, von denen jeder zu einer bald abfallenden Tochterzelle wird. Wie bei den beiden genannten Ordnungen ist hier ein Unterschied von vegetativen und von Keimzellen noch nicht vorhanden.

Von dieser Ordnung kenne ich bloss eine Pflanze, nämlich Exococcus ovatus, den ich bei Zürich fand. Die Zellen sind eiförmig; ihr Durchmesser beträgt im Durchschnitte $0,004^{\prime \prime \prime}$; der Inhalt ist homogen-grün. Sie gleichen vollkommen einzelnen Pleurococcuszellen, aber die Tochterzellen entstehen ausserhalb, wie bei Saccharomyces.

\section{VAUGHERIAGEE.}

Zelle mit vegetativer Astbildung und Spilzenwachsthum in den Aesten; die Keimzellen entstehen durch wandständige Zellenbildung je cine aus einem kurzen Aste, oder aus dem Endtheile eines längern Astes.

Diese Ordnung stimmt mit den Exococcaceen in der Fortpflanzung überein. Sie unterscheidet sich von derselben durch die Vegetation, indem sie Aeste und Wurzeln bildet, welche sich durch Spitzenwachsthum verlängern. Von den Valoniaceen, womit diese Ordnung in Rücksicht auf das vegetative Verhalten übereinstimmt, unterscheidet sie sich durch die (reproductive) Zellenbildung. Die Tochterzellen entstehen aus dem ganzen Inhalte eines kurzen Astes, oder aus

wonach sich Algen, Flechten und Pilze trennen liessel,, weil alle Arten der Samenbildung der Pilze auch bei den Algen sich finden, und es bliebe keine andere Wahl, als sie alle zusammen zu werfen und dann die ganze Masse nach Bau und Fortpllanzung in Gruppen zu theilen, und dabei fortwährend Pilzgattung neben Algengattung zu stellen, was aber gewiss zu einer ganz unnalürlichen Anordnung führen würde. 


\section{$-171$}

dem ganzen Inhalte des Endheiles eines längern Astes. Sie führen mit Recht den Namen Keimzellen; denn, nachdem sie abgefallen sind, entwickeln sie sich zu einer vollständigen Pflanze. Bei den Exococcaceen dagegen kann man so wenig als bei den Paimellaceen und den Prolococcaceen von Keimzellen sprechen, weil die Tochterzellen für sich schon die ganze Pflanze sind.

Wenn, woran ich nicht zweifeln will, die Beobachtung $J$. Agardh's über die Bildung von freien, sich bewegenden Keimzellen (Sporen) bei Bryopsis richtig ist, so haben wir auch bei den Vaucheriaceen ein Beispiel für eine doppelte Fruchtbildung, wovon die eine äussere Keimzellen durch wandständige Zellenbildung aus einem Aste erzeugt und als Fortplanzung bezeichnet werden muss, die andere dagegen innere Keimzellen durch freie Zellenbildung; in dem Inhalte eines Astes hervorbringt und als Vermehrung gedeutet werden muss.

\section{Bryopsideae.}

Die Verästelungen der ZZlle sind frei.

\section{Bryopsis Lam.}

TAB. I, FIG. $57-45$.

Bryopsis isł eine cinzige, cylindrische, verästelte Zelle. Beim Keimen verlängert sich die Keimzelie und wird cylindrisch. Sie verästelt sich in ein aus vielen Achsen zusanmengesetztes System. Das "I achsthum geschieht an der Spitze der Achsen. Han überzeugt sich leicht davon, wenn man den Zelleninhalt und die Zellwandung an der Spitze und in den übrigen Theilen der Achsen vergleielıt, und wenn man die Entsteluung der Acste berücksicligt. Man muss aher zweierlei Arten von Achsen genau von einander unterscheiden, welche sich in Bezug auf diese Punkte ganz ungleich verhalten, ich will sie Stämme und Blätter heissen. Die erslern wachsen unbegrenzt und erzeugen 1) neue Stämme (Aeste) und 2) Blätter. Die Blälter dagegen haben begrenztes Wachsthum und verästeln sich nicht.

Die Zellwandung lat im ganzen Verlaufe der Stämme eine ziemliche Dicke und besteht aus der eigentlichen Zellmembran (Fig. 43, 4:5, a) und aus der gallertartigen Extracellularsubstanz (Fig. 45, 45, b). Die letztere ist nach aussen durch eine starke Linie, wohl auch durch 2 Linien begrenzt (Fig. 45 , c); sie bezeichnen ohne Zweifel die äusserste, durch äusscre Einflüsse veränderte Schicht der ausgeschiedenen Gallerte, und sind somit analog der an der Oberfäche befindlichen und zu einer scheinbaren Membran erhärtenden Gallerte bei Nostoc. Nur an der Spitze der Stämme wird die Zellwandung allmälig schmäler (Fig. 58). Man unterscheidet daselbst nicht melır Membran und Extracellularsubstanz. Im Punktum vegetationis ist die Wandung äusserst schmal (Fig. 58, a). - An vollkommen ausgewaclsenen Blättern ist die Wandung im ganzen Umfange dick: 


\section{$-172$}

und aus der Membran und der Extracellularsubslanz gebildet. Unmittelbar an der Spilze ist die letztere an nächtigsten und daher auch daselbst die Wandung am dicksten (Fig. 59, a). An jungen noch wachsenden Blätlern (Fig, $58, \mathrm{f}, \mathrm{f}$ ) verhält sich die Hembran wie an Stammende; sie ist eine schmale Gallertschicht, an welcher Membran und Extracellularsubstanz nicht unterschieden werden können, und welehe nach dem Punctum regetationis hin an Zartheit zunimmt.

Der Zelleninhalt in den ausgewachsenen Theilen der Stämme und in den ausgewachsenen Blältern besteht aus einer das ganze Lumen erfüllenden, wasserhellen Flüssigkeit, und aus halbílüssigen oder festen Stoffen, welehe an der innern Fläche der Zellmembran liegen (1 ig. 59). Die letztere ist mit einer continuirlichen Schicht von honıgenem oder körnigem Sehleime, der Schleimschicht, überalı bekleidet, welche oft den $\Lambda$ nschein einer dritten, innern Membran gewährt. An der Schleimschicht ist zuweilen ein sehönes Netz von Sehteimfäden (Strömunģsfäden) sichtbar (Figg. 40). Dasselbe liegt, wie man sich durch Veränderungen des Focus ïberzeugt, an der innerı, nach dem Lumen der Zelle gerichteten, freien Fläche der Schleimschicht. Ausser homogenem und feinkörnigem Schleime enthält diese Schicht ferner noeh deutliche Sehleimkörnelıen und Chlorophyllbläschen. Vehel das weitere merkwürdige Verhalten der Schleimschicht in verletzten Zellen, besonders über die Regeneration der Zellmembran muss ich auf einen frühern Aulsatz verweisen $\left({ }^{1}\right)$. - Im Punetum vegetationis der Stämme und Blätter ist bloss ein homogener, farlbloser Schleim rorhanden (Fig. 58, a, f, f). Nach unten wird dieser Schleim körnirg. Dann färbt er sich grünlich (Fig. 58, b); dort beginnt die Bildung des Chlorophylls. Weiter nach unten ist er grün; das Chlorophyll ist gebildet, liegt aber noch mit dem Schleime im ganzen Lumen der Zelle zerstreut. Später tritt das Chlorophlyll und der Schleim an die Wandung und bildet die schleimschicht.

Ans diesen beiden Reihen von Thatsachen, betreffend das Verhalten der Zellwandung und des Inhaltes in verschiedenen Theilen von Bryopsis geht herror, dass die Achsen unsschliesslich an der Spitze uachsen, ferner dass die Stiöme anbegrenzt, die Blïter dagegen begrenzt wachsen. Das Spitzenwachsthum $\left(^{2}\right)$ besteht aus 2 verschiedenen Momenten, 1) der Membranbildung und 2) der Ausdehnung der Mtembran. Die Membranbilurng ist bei den Stämmen unbegrensi; sie verlängern sich ohne Ende. Die Slämme und Aeste lıaben eine sehr ungleiche absolute Länge, al)er ihre spitze ist immer im Zustande des Wachsthums beyriffen; sie zeigt immer eine zarte Hembran und einen farblosen, schleimigen Inhalt. Die Ausdehumg der Henbrun ist bei den Stämmen begrenzl. Die Stämme, sie mögen noch so lang sein, haben in ihrem ganzen Vrrlaufe ungefihr die gleiche Dicke, an der Spilze werden sie allmälig dünner. Daraus folgt, dass die Membran sich später nieht mehr in die Breite ausdehnt, sondern zu einer bestimmten Zeit die Ausdehnung beendigt. bie IBätter an den Stämmen oder die Narben der abgefallenen Blätter (Fig. 57, 44) zeigen an ganzen Stamme ungefähr die gleiche, verticale Entfernung; an der Spitze jedoch rücken sie in einander; ein Beweis dafür, dass die Membran sich später auch in die Länge nicht melu ausdehnt. - An den Blättern ist die Membranhilduig und die Ausdehnung der Nembran begrenzt. In allen Blätlern, mit Ausnahme der jungen, noch unrntwiérelten, zeigt die Wandung und der Inhalt im ganzen Imlange das gleiche Verhalten wie an denjenigen Theilen des Stammes, wo alles Wachsihum aufgehört hat. Ferner besitzen alle Blätter ungefähr die gleiche länge und ungefihr die gleiche Dieke.

Wie die Stammachsen sich unbegrenzt verlängern, so erzeugen sie auch ohme Ende Blätter und einzelne nene Stammachsen. Die Entstehung eines Blattes oder Astes beginnt damit, dass in einem I'nnkte der Zelimembran neue Itembranbildung auftritt ( 1 ig. $58, f^{\prime}$ ), und, indem dieselbe fortdauert, eine neue Achse erzeugt (FIg. 58, f, f, f). Ist diese Membranbildung von begrenzler Dauer, so ist das Produkt ein Blatt; ist sie von umbegrenzter Dauer, so ist es ein Ast. An einer Stammachse entstehen vicl mehr Blätter als Aeste. Während

(1) Schleiden und Nägeli's Zeitschrift f. w. Bot., Heft 1, pag. 90 ff.

(2) Vergl. a. g. 0. Heft 1, pag. 159 ff., und Heft 3 und 4, pag. 75. 


\section{$-175$}

der Stamm a -'b in Fig. 57 z. B. über 100 Blätter erzeugte, bildete er bloss 2 Aesle. An der Spitze der Stäume stehen junge, sich entwickelnde Blätter (Fig. 57, a ; Fig. 58); nach unten folgen ausgebildete Blätter (Fig 57 . f, f). Nachdem die Blätler einige Zeil an den Stämmen gestanden haben, so fallen sie ab, dessuegen sind die Stämme und Aeste in eiıer gewissen Entfernung von der Spitze nach unten zu iilserall nackt (Fig. 57, c b, e d), während die Stammspitzen immer mil Blättern bedeckt sind. Man kann hıxufig die Narben der alogefallenen Blätter sehen, besonders da, wo die Narben noch jung sind (Fig. $57 \mathrm{c}-\mathrm{b} ; 4$ ! , a, b).

Die Blïtter trennen sich nicht unmittelbar an der Basis rom Stamme, sondern sie reissen etwas oberhalb der Basis entzwei. In Fig. 43 bezeichnet a b - a b einen Theil der Wandung des Stammes, und e den Rest des al)ggefallenen Blattes. Da die Blätter nur Theile einer Zelle sind und mit den übrigeu Theilen derselben communiziren . so müsste das Lumen der Zelle sich beim Abfallen der Blätter nach aussen ölfinen und das Leben der Zelle zerstörenden Einflüssen preis geben, wenn nicht durch eine besondere Erscheimung diess verhindert wïrde. Unmittelbar ehe das Blatt abfäll, bildet sich zwischen dem Lumen des Blattes und dem Lumen des Stammes eine gallertartige Scheidewand (fiig. 430 , d). Dadureh schliesst sich das Lumen der ganzen Zelle gegen dasjenige ilıres abgestorbenen Theiles (des Blatles) und somit gegen aussen ab. Auf welehe Arl diese Wand sich bilde, ist mir nicht recht klar geworden. Am häufigsten salı ich sie, wie sie in fig. 45 , d gezeichnet ist. Jederseils geht rom Rande bis auf eine gewisse Tiefe eine Spalte, man sicht deutlich, dass sich die Membran nach innen faltet. Im Centrum ist aber nichts als eine homogene gallertartige Nasse sichtbar. Oft auch erscheint die ganze Scheidewand homogen und struclurlos. Die Beobachlungen an Bryopsis liessen mich ïber die Entstelsung und die Natur der Scheidewand durchaus im Ungewissen. In der verwandten Gattung Codium, wo auf gleiche Weise das Lumen der begrenzten Achsen sich ron der ïbrigen Zelle abschliesst, geschieht es durclı eine reichliche, kreisförmige Absonderung von Gallerte. Dadurch wächst die Zeliwandung an der Basis der begrenzten Achsen ringsum nach innen, bis sie zuletzt im Centrum zusammentrifft; der Canal verengert sich dabei mehr und mehr und oblitterir' zuletzt. - Bei Caulerpu haben die Blälter ; wie bei Bryopsis, ebenfalls eine kürzere Lebensdauer als der Theil des Stammes, an dem sie befestigt sind. Aber dort wird die abschliessende Wand in dem absterbenden Blatte dureh einen Pfropf von Caoulchoue gebildet $\left(^{1}\right)$.

Die Stellung der Blätter an Stamme ist an kein bestinmmtes Geselz gebunden. Bei der gleichen Art ( $z$. B. Br. Balbisiana, oder Br. plumosa) findet man zweizeilige, regelmässig-spiralig gestellte und unregelmässigzerstreute Blätter. In Fig. 44 z. B. zeigen die Narben eine g̨anz regelmässige spirale.

An den unterslen Theilen der Slämme belinden sich Wurzeln. Sie sind ebenfalls bloss Zellenäste, und conımuniziren somit mit dem Lumen der übrigen Zelle. Die Wurzeln sind dünner als die Stämme und enthalten nu’ wenig Chlorophyll. Sie besitzen begrenztes Wachsthum und rerästeln sich unregelmässig.

Für die Stammoryane von Bryopsis muss folgender Begriff fesigestallt werden : Achsen, uelche durch fortgesetzte Veubilumg von Iembran an der spitze unbeyrenzt uachsen, durch gleichmässige, begrenste Ausdehnung der Membran zu Cylindern con yleichförmiger Dicke werden, und welche hinter ler uchsenden Spitze unbegrenzt Blätter erzengen. Die beschreibende Botanik unterselıeidel an Bryopsis Stännne, Aeste und Aestchen ( Fila, Rami und Ramuli " oder "Fila, Pinnæ und Pinnulæ "). Diess sind aber keine verschiedenen. sondern bloss im Alter und in der Grösse von einander abweichende Stammorgane. Alle haben unbegrenzles Wachsthuın uıd sind der nämlicheu Entwicklung fähig. lis ist aber natïrlich, dass die jüngereı auch kleiner sind, - Zum Begriffe des Stammorganes gehört nicht, dass es fortwälırend Wurzeln erzeugt. Wir diess bei Caulerpa der Fall ist. Caulerpa hat kriechende Stamme, an denen die Wurzeln immer vor den Blältern eutstehen.

Die Blattoryane sind Achsen, welche durch Neubildung von Membran an der Spitse begrenst wachsen und durch begrenzte und gleichmässige Ausclehnung eine gleichförmig-cylindrische Gestalt annehmen.

(1) Schleiden und Mïgeli's Zeitschrift f. w. B., Heft I, pag. 148.

Denbischr. Y.eger.1. 
mul welche an dem obrn Stammende entstehen und nach oben yerichtet sind. Die Systematiker nennen die Blïlter "Ramenta ", eine sehr wilkührliche Benennung, da sie wenig Aehnlichkeil mil dem bei höhern Pflanzen diesen Jamen tragenden Organe besitzen. Ich habe sie Blätter genannt, weil sie in den wesentlichen Merkmalen mit diesen Organe ïbereinstimmen. Die allgemeinen Begrifle der Organe bei den Pflanzen setzen nicht eine bestimmte Organisation voraus, sondern nur cin bestimmles Verhältniss zu andern Organen. Die seitlichen begrenzten Achsen an Bryopsis, wiewohl sie bloss der Theil einel Zelle sind, verdienen den Namen Blatt abensowoht, als die sehr hoch organisirten Blätter der Leguminosen, weil ihr Verlältniss zu den unbegrenzt Wachsenden (Stamm-) Achsen das nämliehe ist. - Andere Punkte sind zwar nicht entscheidend, verdienen aber (loc:l ciner Epwähnung, weil sie anch bei höhern Classen des Gewächsreiches vorzugsweise Attribute der Blætter sind, wie $z$. B., dass die Blätter in Bryopsis ihren Lelensprozess friiher vollenden als der Theil des Stammes, an lem sie stchen, und dass sie daher abfallen; dass es bei Bryopsis ebenfalls regetative und reproductive Blaftorgawe gieh, und lass bei der verwandten Gattung Canlerpa die Blätter eine gesticlte flächenförnige Gestalt haben.

Die $/ 1$ irzeloryane sind Achsen, welche drereh Neubildung con Membran an der Spitze begrenzi wachsen, and durch begrenzle und gleichförmige Ausclehmung der Membran eine gleichförmig-cylindrische Gestalt umehnen, welehe sich begrenst rerästeln, und xelche am untern Stammende stehen und nach unten yerichtet sind.

Die her'sehende Ausicht in der Botanik geht dahin, den Algen die Blætter und die Wurzeln abzusprechen. sie werden desshalb mit Pilzen und Flechten "Laulpflanzen, Thallophyten, Wurzellose, Arrhize, Blattlose, Aphylle»" geheissen. Und doch passen die Organe von Bryopsis und von Caulerpu ( ${ }^{1}$ ) (un nicht von andern IIgen zu reden) so gut auf den von der jetzigen Botanik aufgestellen Begriff von Stamm, Blatt und Wurzel, dlass sie consequenter Wcise auch dafür erklärt und danit benannt werden müssen. Sobald man sich streng an die Begriffe hält, wird man finden, dass in allen Klassen der Cryplogamen Laubpflanzen und Pflanzen mit Slamm und Blatt rorkommen. Die Unterscheidung der Klassen kann dann nieht mehr auf den Mangel oder die Inwesenheit von Organen, sondern sie muss lediglich auf die Reproduction und auf durchgreifende Organisalionsrerhältnisse begründet werden. Dagegen wird der Mlangel oder die Auwesenheil von Organen, Familien and Gattungen unterscheiden.

In die Gattungsdiagnose von Bryopsis müssen folgende Bestimmungen aufgenommen werden : Die Pflanze ist cine cinzige rerïstelte Zelle, welehe an den Achsenenden dureh Neubildung ron Membran und durch Iuskhommy der neugebildeten Membran wächst, mit umbegrenzten, eylindrisehen und rerüstelten Stammachsen, die an ihrem obern Ende fortuihreud begrenzte, eylindrische und einfache Bläter erzeugen.

Die Chlorophylllïschen liegen, wie schon oben gesagt wurde, zuerst zerstreut durch das Lumen der Zelle im Sthleiminhalte. Nachher, wenn der Schleim sich als eine peripherische Schieht an die innere Oberfliche der Zellmembran anlegt, so befinden sich die Chlorophylbbäschen an der innern Oberfläche der Schleimschicht ( Vig. 59, 15, p). Vou der Vläche angesehen erselıeinen sie oval oder länglich (Fig. 41, a, b, e, d, e); von der Seite ind sie zusanmengedrüickt mit einem nach innen vorstehenden Nabel in der Mitte (rig. 41, f). Wenn sie durch Zerreissung der Zelle frei in's Wasser treten, so zieht sich der hand zusammen, so dass sic eine concave festalt lekommen; in Fig. 11, g ist die Ansicht des Durchschnitles gezeichnet. Besassen sie ror der Verïnderung ciue längliche Form, so lassen sie sich, nachdem sie concav geworden, am besten mit einem schmaien Offiziershute vergleichen (Fig. 41, h). - De Chlorophyllıläschen sind von einer zarten farblosen Membran grbildet, in welchel homogenes Chlorophyll eingeschlossen ist. Im Centrum des Bliesehens liegt ein kleines Slärkckügèchen; zuw eilen jedoch liegt es, zwar in der Nitte des Blaschens, an der Wand; zuweilen sind auch y und of Amylumkïgelchen in 1 Bläschen eingeschlossen (fig. $41, d ;$ e). Diese Amylumkügelchen bleiben imuer klein, in Verhältniss zum Chlorophyllblaschen; frei werden habe ich sie in Bryopsis nicht gesehen.

(') A. g. 0., Heft I. jag. 151 ก. 


\section{-17 -}

Die Clorophyllblæselıen von Bryopsis haben eine grosse Analogie mit den Kernblæschen der übrigen Pflanzen. Diese enthalten in einer geschlossenen Membran Schlein und 1 oder mehrere Schteimkernchen. Die Chlorophyllblaschen enthalten in eiucr geschlossenen Menbran Chlorophyll und I oder melırere Stærkekernchen. - Ihre bleschenartige Natur wird besonders deutlich, wenn sie im absterhenden Zelleninlsalte sieh verændern, um nachlier sich aufzulösen. Sie werden gerösser und kugelig; das Chlorophyll entfarht sich und geht über in kleine Körnchen, die in einer wasserhellen I'lüssigkeit liegen; die Nembran des Blæsclıens ist daun sehr deutlich zu erkennen (Fig. 16).

Die Chlorophyllbaeschen pflanzen sich auch fort. Wenigstens beohachtete ich in dem ansgetretenen Inhalte von jungen Stammtheilen und Blxttern zarte Chlorophyllblæschen mit 1 kernchen, mil 2 Kernchen und 2 dicht beisammen liegende, wie durch Theilung eines Mutterbleschens entstandene kleinere Blaschen, jedes mit 1 Kernchen (Fig. 42 a, b, c, d, e).

Von Bryopsis ist noclı einer Merkwürdigkeit zu erwæhnen, dass man næmlich zuweilen in æltern Stæmmen freie, nur mit den beiden Enden an entgegengesetzte Punkte der Nenuran befestigte Fasern findet, wie sie Caulerpa hat. Bei Caulerpa sind dieselben aber eine constante, hei Bryopsis eine ausnalımsweise Erscheinung; auch treten sie in letzterer Gattung nur vereinzelt auf und erreiclien keine bedeutende Starke.

\section{Gaucheria $D C$.}

TAB. IV, FIG. $21,22$.

Die Keimzelle wæehst in einen Ast aus, weleher sich durch Spitzenwachsthum verlangert. Durch seitliches Auswaclısen bildet er neue Aeste, welche ebenfalls ą der Spitze wachsen. Die Vaucherien bestehen also, wie bekannt, aus einer einzigen, fadenförmigen, veræstelten Zelle, welcher die vegetative Zellenbildung mangelt. An altern Theilen der Zellenæste bilden sich zuweilen Querwande; aber es geschieht diess nur da, wo die Zelle verletzt wird, oder wo stellenweise der Inhalt krankhaft verændert oder ahgestorben ist. Die Wandbildung an Vancheria ist daher, wie bei Bryopsis, immer ein abnormaler Vorgang und nicht als vegetative Zellenbildung zu bezeichnen ( $\left.{ }^{1}\right)$. - Die Aeste von Vaucheria sind grün, indem die innere Flxche der Wandung mit Chioroplỵltblæschen bedeckt ist; im Atter werden die Aeste entfærbt, indem die Chloroplıyllblæselien ganz oder theilweise durch hleine Anylumkügelchen ersetzt werden.

Wenn die Pflanze fructifiziren soll, so entstehen Seitenæeste. Sind dieselben kurz, so bildet sich der ganze Inhalt durch wandstandige Zeltenbildung in eine Keimzelle um. Sind sie lang, so besondert sich der Inhalt des Astendes und crzengt auf gleiche Weise durch wandstandige Zellenbildung eine Keinzelle. Bei einigen Arten ( $\boldsymbol{r}$. clacuta) verlassen die Keimzelien die Mutlerzellen und bewegen sich m Wasser. Bei allen übrigen Arten fallen die Keimzellen mit der sie umkleidenden Membran der Mutterzelle zugleich ab und sind unbeweglich.

veben den kurzen Aesten, in welchen de Keimzellen erzeugt werden, stehen hæufig dünne, hackenförmiggekrïmmte Aeste. Vancher hielt sie für mænnliche, den Antheren analoge Organe, indem er angiebt, dass ihr Inhalt ausgestreut werde. Sie hahen allerdings eine Bezichung zur Keimzellenbildung, olme aher desswegen macunliche Organe zu sein. Die Jlackenastchen stehen bei Vancheria sessilis dicht nelen den dickeren Aestchen, welche die Keimzelle erzeugen sollen (Fig. 21). Sie sind länger als die letztern und gehogen, so dass die Spitze oder der obere Seitentheil den Scheitel des dickern Keimästchens berühırt. Die Hackenästelıen sind anfangrs ganz grün. Später entfärbt sich ihr Endtheil, indem er seinen Inhalt rerliert: welcher in das Keimästchen ïlıergeht. Obgleich ich dieses Vehertreten selbst nichıt gesehen habe, so ist es doch der übrigen

(') Vergl. Zeitschrift für w. Bot., Heft 1, pag. 90 ff. 


\section{$-\quad 176$}

Erscheinungen wegen unzeifelhaft. Denn eimmal sieht man die beiden Aestchen zuerst in Berührung; ferner sieht man, dass das dünnere Aestchen den lıhalt seiner obern Hälfte verloren lıt; endlıch sicht man später, wenn sich die beiden Aestchen wieder von einander getrennt haben, dass beide an der Spitze eine Oeffnungr hesitzen, und dass die Oeffnungen aufeinander passen (Fig. 22). Das Hackenästchen legt sich also nicht bloss an das Keimästchen an, wie bisher geglaubt wurde, sondern die Scheidewand zwischen beiden wird resorbirt, wie bei Zygnema, Spirogyra, Mongeotia, und der Inhalt des einen tritt in das Lumen des andern hinüber. Hätten sich die beiden Aestchen bloss an einander angelehnt, so inüsste nach der Trennung an dem cinen oder deọl andern, oder an beiden eine verschliessende Wand sichtbar sein. - Das Hackenästehen verliert nicht seinen ganzen Jnhalt, sondern je nach seiner Länge bloss den Inhalt seiner obern Hälfte oder eines noch kleinern Theiles. Entweder sind alle festen Stofe (Schleim und Chlorophyll) in das Kein)ästehen übergegangen, oder es sind späterhin noch einzelne kleine Particen sowohl in dem Jackenästchen selbst (Fig. 22, d), als in dem von demselben an dem Scheitel des Keimästchens zurïckgebliebenen Theile (Fig. 22, g) zu sehen. Der untere Theil des Hackenästchens, welcher seinen Inhalt behält, schliesst sein Lumen durch eine neugebildete Scheidewand, welche an der freigewordenen Oberfläche des zurückgebliebenen Inhaltes entsteht (Fig. 22, b, d). Doch ist es auch möglich, dass die Wand sehon vor der Ergiessung des Inhaltes sich bildete, und dass somit die übertretende luhaltsmenge durch die Grösse der entstandenen Zelle bestimmt wïrde, - obghleich mir die erstere Erklärung wahrscheinlicher ist. - Die Trennung der beiden Aestehen erfolgt nach vollendeter Copulation; sie seheint vorzüglich dadurch veranlasst zu werden, dass das Irackenästchen durch Ausdehnung sich verlängert, und dadurch seine Spitze von dem Scheilel des Keinästchens wegdrängt. Mit dem Längerwerden krümmt es sich immer mehr, und erscheint zuletzt of eingerollt.

Die Copulation ist nicht nothwendig für die Keimzellenbildung; denn nicht selten entstehen die Keimzellen ohne dieselbe, indem nämlich die IIackenästchen ganz mangełn. Zuweilen geschieht es auch, dass die Copulation nicht slatt findet, weil die beiden Aestchen einander verfehlen. Diess ist in Fig. 29, f der Fall, wo der Inhalt des Endtheiles des Hackenästchens in eine farblose, schleimartige Hasse zusammen geflossen ist, und die Keimzelle sich aus dem Inhalte des Keimästchens allein gebildet hat. Wie es sich mit denjenigen Arten verhatte, wo neben einem Hackenästchen mehrere (2 - 5) Keimästchen stehen, ob hier alle Keimästchen oder bloss einzelne sich mit dem llackenästchen copuliren, muss dureh fernere Beobachtung ausgemittelt werden. Bei Varcheria geminata, wo sich hei cinen IJackenästchen zwei Keimästchen finden, sehe ich in der Regel an beiden eine von ler Copulation herrïhrende Narbe am Scheitel.

Die Copulation bei I'aucheria und bei den Zygnemaceen scheint vollkommen derselbe Vorgang zu sein, und die gleiche Bedentung zu besitzen. Sie ist hei Vancheria, wo sich die Aestehen der gleichen J'flanze und sogar bloss des gleichen Astes mil einander verbinden, um so begreiflicher, seit auch bei Spiroyyra $\left(^{1}\right)$ Copulation zwischen den Zellen des gleichen Fadens bekannt ist. So wenig übrigens bei den Zygmemaceen die Copulation ein wesentliches IIerkmal ist, so wenig ist sie es bei raucheria, da sie an beiden Orten in der Regel zwar statt findet, aber eben so gut mangelu kann.

Der Inhalt des Keimästehens besondert sich in kugelförniger oder ovaler Gestalt, und erzeugt an seiner ganzen Oberfläche eine Zellmembran. Dieselbe ist an die Wandung des Keimästehens angelehnt, bloss an dem Scheitel (wenn Copulation statt findet) und an der Basis ist sie frei (Fig. 22, B); wenn keine Copulation statt findet, so ist bloss das untere Ende der Keimzelle frei (Fig. 22, e). Die Keimästchen reissen unterhalb der Keimzellen ab, wolurch diese ausgestreut werden. Das Lumen des Astes, welches dadureh sich öffuct, schliesst ich sogleich, indem der Inhalt an dieser Stelle Hembran bildet. - Die Keimzellen sind dicht mil Chlorophyll ınd Stärkemehl gefüllt; das erstere wird nach und nach durch das letztere fast ganz rerilrängt.

(1) Virgl. pag. 134. 


\title{
$-177-$
}

2. CODIEaE.

\begin{abstract}
Die Verästelungen der Zelle legen sich in ein Gerebe zusammen, und bilden scheinbar einen Zellkörper.
\end{abstract}

\section{Udotea cyathiformis Decaisne.}

(Flabellaria Desfontainii Lam. Codium flabelliforme und C. membranaceum Ag. Rhipozonium lacinulatum und Desfontainii Kütz.)

TAв. 1I, F1G. $2 \ddot{0}-50$.

Udotea cyathiformis ist eine gestielte, blattarlige Frons. Der Stiel wird bis $\%$ Zoll lang und ist cylindrisch oder zusammengedrückt; die Fläche der Frons ist $1 / 2$ bis 2 Zoll lang und ebenso breit, und belrägt in der Dicke kaum $0,040^{\prime \prime \prime}-0,050 / \prime$. Dem äusseren Anscheine nach stellt sich Udotec als eine aus Zellgewebe bestehende Frons dar, wie z. B. Padina Paconia. Die microseopische Untersuchung zeigl aber einen ganz abweichenden und höchst merkwürdigen Bau. Auf horizontalen oder verticalen Durchsehnitten, welche senkrecht zur Fläche der Frons sind, erkennt man 2 verschiedene Straten, ein farbloses Nark und jederseits eine grün-gefärbte Rinde. Kützing $\left({ }^{1}\right)$ erwähnt der Rinde nur beim Sliel der Frons, den er "Cauloma " nennt; sie ist aber an der Fläche der Frons ( Phylloma " Klzg.) ebenfalls rorhanden. Das Stïck, das der Verfasser auf Tab. 42 (III, 2) darstellt, und das nur geringe Andeutumgen von Rindensubstanz enllält, ist rom obern Rande der Frons, wo die Rinde noch in der Entwicklung begriffen ist; weiter nach unten bedeckt sie die Markschicht rollkommen.

Das Mark (Fig. 2\%, m - m) besteht aus senkrechten, parallelen Röhren. Diese Röhren liegen in der Achsenfläche der Frons, meist in einer einfachen Schicht, so dass man auf dem verlicalen Querschnilte eine einzige Röhre, auf dem horizonlalen Querschnille eine einfache Reihe durchschnittener Röhren sieht. Sie bilden ein sehr lockeres Gewebe, indem sie sowohl unter sich als ron der Rinde durch sehr verdünte Gallerte getrennt sind. Sie sind darch die ganze Länge der Frons continurlich und ohne Scheidewände. Sie theilen sich hin und wieder dicholomisch, so dass sie nach oben an Zahl zunehmen (Fig. 26, I theilt sich in a und c; Fig. 27, a ill b und b, b in $\mathrm{c}$ und c). Auch an diesen Theilungsstellen sind keine Scheidewände (Fig. 27, m, n), so dass also alle Röhren einer Frons mil einander communiziren, und eine einzige, fadenförmige, sich vielfach verästelnde Zelle darslellen.

Die Rinde an der Fläche, wie am Stiele der Frons, erscleeint, von aussen betrachtet, als ein Zellgewebe (Fig. 28), und Kützing bezeichnet diesen Anschein richtig durch "cortex cellulosus tennissimus. " Es wäre aber unrichtig, diess so zu verstehen, als ob sie aus vielen Zellen gebildel sei. Die Marhröhren geben hin und wieder nach beiden Seiten Lestchen ab (Fig. 26, b, b); diese Acslchen verzweigen sich auf manigfaltige Weise in grössere und kleinere Lappen (Fig. 26, d, d). Diese Lappen der versehiedenen Rindenästchen sind es, welehe sich enge aneinander legen und eine Rinde erzeugen, die das Hark vollsländig abschliesst. Jeder

(') Phycologia gen, pag. 509 .

Denkschr, NEGEL1. 


\section{$-178$}

Lappen erscheint ron aussen betrachtet als besondere Zelle (Fig. 28). Die Vertheilung der Rindenästchen und die Gestalt der Lappen ist sehr rerschieden; oft sind beide ganz unregelmässig; oft bieten sie ziemlich regelmässige Formen dar, (so z. B. Fig. 29, wo ein solcher Lappen, von aussen angesehen, dargestellt ist). Die Rindenïstchen besitzen eine continuirliche Ibölılung, welche auch mil dem Lumen der Markröhren communizirt; sie sind also bloss Verzweigungen der Zellenïste, welche das Mark hilden.

Udoted besteht sonach aus einer einzigen, rielfach rerästellen Zelle mit zueierlei Achsen, von denen die einen dus Mark, die andern die Rinde bilden.

Der Zelleninhalt besteht vorziiglich aus Chlorophyll, welehes an der Wandung liegt, und aus $\Lambda$ mylum. Die Rindenästchen sind inwendig dicht mit Chlorophyllbläschen bedeckt, und dadurch intensiv grün gefärbl; nur die lełzlen Lïppchen an den Rindenäslchen sind fasl farblos. Die Markröhren enthalten kleine Amylumkügelchen und sehr wenig Chlorophyli; sie erscheinen desshalb schwärzlich in der farblosen, durchsichtigen GalJerte, in welcher sie licgen. In den wachsenden Spiłzen der Markröhren (Fig. 27, c, c) und in den jungen wachsenden Rindenäsichen (Fig. $27, \mathrm{~d}, \mathrm{e}, \mathrm{f}$ ) ist zu äusserst bloss ein homogener, ungelärbter Schleim, welcher nach unten hin körnig wird.

Die Markü̈ıren wachsen an der Spilze, wie die Achsen von Bryopsis und Caulerpu. Beweise dafür sind auch hier das Verhalten des Inhaltes und der Membran an der Spitze und in den ïbrigen Theilen der Markröhren, das Verzweigen derselben und die Erzeugung von Rindenästchen. Das Wachsthum ist besonders leicht an der Form $z$ beobachten, welche Agardh Codium flabelliforme, Kützing Rhipozonium lacinulatum genannt lıat. Die Achsen der Markæölıren wachsen nicht unbegıenzt, sondern bloss bis auf einen bestimmten Punkt und theilen sich dann dicholomisch (Fig. $26 \mathrm{~m} ; 27, \mathrm{~m}, \mathrm{n}, \mathrm{n}$ ). Das Spitzenwachsthum besteht dariu, dass in einem Punkte der Membran (im Scheiter der Achse) die Membrambildung fortdauert, und die neugebildete Membran sich dann bis zu der erforderlichen Weite austehut. Die Membranbildung dauert nun an den Markröhrenachsen nur eine bestimmte Zeit, dann hört sie auf (so in den Punkten m, n, n, Fig. 27). Statt dessen tritt in 2 andern, etwas seillich von der Spitze gelegenen, opponirten Punkten neue Membranbildung aut und dauert eine gewisse Zeit lang fort. Dadurch entstehen 2 neue Achsen (Fig. 27, b, b, welehe die Tochterachsen der Achse a sind); auf gleiche Weise theilen sich diese beiden Achsen später wieder, jede in 2 Tochlerachsen (Fig. 27, c, c , c , c), u. s. 1. Das Spitzenwachsthum dev Markröhren ist also dichotomisch. Die Dichotomieen liegen in der gleiehen Ebene und zwar in der Achsenflïche der Frons.

Die Rindenästchen entstelıen aus den Markrühren dadurch, dass in einzelnen Punkten der Seitenwandung neue Membranbildung beginnt. Die Rindenästchen ejner Markröhre stehen in 2 gegenüberliegenden, senkrechten Linien (Fig. 26, b, b; 27, e, f, g); sie liegen also ebenfalls in Einer Fläche, diese Fläche schneidet die Fläche der Dichotomieen der Markröhren unter einem reelıten Winkel. Selten stehen 2 Rindenästchen ejnander gegenüber; gewöhnlich wechseln sie Initeinander ab, so dass ihre Stellung an den Markrölıren regelnässig oder unregelmässig alternirend-gefiedert genannt werden muss. - Die Rindenästchen wachsen ebenlalls an der Spitze, und zwar begrenzt; sie geben nach eines' Seite hin (nach aussen) Zweige al), welche gelappt sind, und durch enges Aneinanderliegen die Rinde constituiren. - Die Entstelıung der Rindenästchen, oder das $\Lambda$ uswachsen der Membran zu deren Bildung schreitet an den Markïhren von unten nach oben fort; sie ist für jede einzelne $\Lambda$ chse begrenzt, wie es diese selbst ist; an der ganzen Frons ist sie aber unbegrenzt, indem sie so lange dauert, als diese wächıst.

Das Wachsthum der Frons ron Udotea besteht dennach in folgenden Momenten. Alle Achsen wachsen an der Spitze durch Veubildung von Membran und Ausdehnung der neugebildelen Membran; sie verästeln sich dadurch, dass in einzelnen seillichen Punkten der Itembran neue Membranbildung auftritt. Das Wachsthum ICr IIarkröhrenachsen ist begrenzt; es wiederholt sich aber immer wieder (unbegrenzt) in 2 seillichen P'unkten unterhalb des erslerbenden Punktum vegelationis, die alle in der gleichen Ebene liegen. Die Entstehung der Rindenästchen an den Markröhren schreitet in gleicher Richtung, wie das Wachsthum dieser letatern, 
vorwärts, und geschieht in einer Ebene, welche senkrecht zu der Ebene ist, in der sich die Markröhrenachseı wiederholen. Das Wachsthum der Rindenästchen ist begrenzt, und ebenso ilıre Verïstlung.

Das Wachsthum von Udotea besitzl eine grosse Analogic mit den Waclısthume von Bryopsis. Es ist in beiden das Spitzenwachsthum und die Verästlung ciner einzigen Zelle. Die Zelle lat I verschiedene Arten von Achsen, welche nach oben wachsen; in Bryopsis sind es unbegrenztc Stanm!aclisen und begrenzte, seitliche Blattachsen; in Ldotea sind es begrenzte Marhaclısen, die sich aber unbegrenzt wiederlolen, und begrenzte seilliche Rindenachsen mit hegrenzter Verästelung. Ein wichtiger Unterschied zwischen den beiden Gattungen liegt darin, dass in Bryopsis die Achsen der Zelle frei bleiben, dass in Latotea dagegen die Achsen der Zelle sich in ein Geuebe aneinander legen. In Bryopsis sst jede Achse der Zelle für sich ein Organ: Stamm, Blatt oder Wurzel. Jede Aclıse ist frei, iiberall von äussern Medien ungeben, und den Einflüssen derselben ausgesetzt; sie nimmt von aussen Stofle auf und giebt nach aussen Stoffe ab. In Udotea dagegen bilden alle Achsen zusammen ein Organ: die Frons. Sie legen sich in ein Gewebe aneinander und sind nur insofern versebieden, als sie besondere Systeme in diesem Gewelse (Mark und Rinde) darstellen. Nur ein kleiner Theil der Zellmembran der ganzen verästelten Zelle, nämlich die äussere Fläche der Rindenästchen kommt nit dem umgebenden Wasser in Berührung und nimmt von aussen Nahrungsstoffe auf. Alle übrigen Theile der Zellmembran (die Markrölıren und die innere Fläche der Rindenästchen) sind nach aussen von anderen Theilen bedeckt und nelımen die Nahrungsstoffe nicht unmiltelbar auf.

Die Frons ron Udotea kann auf doppelte Weise durch Prolification sich fortpflanzen: aus dem obern Rande (Fig. 50, b, b) oder aus der Fläche (Fig. 50, a). Es geschicht dadurch, dass einige (mehr oder weniger) Markröhren über den Rand oder die Fläche hinaus sich verlängern, und dann dureh dichotomiselıe Theilung den Stiel und später die Fläche einer neuen Frons erzeugen.

\section{ZONARIAGE正.}

Durch segetative Zellenbildung entsteht eine Zellenreihe (Zellschicht), oder ein Zellkörper; die Keimzellen entstehen durch uandstündige Zellenbildung, je eine aus dem auswachsenden Theile der Gliederzellen oder der Rindenzellen.

\section{Cifantransieje.}

Die Achsen sind Zellenreihen.

Diese Familie unterscheidet sich von den beiden folgenden durch die vegetative Entwicklung, indem die Achsen bloss Zellenreihen sind, während bei den Padineen und den Fuceen die Pflanze aus einem einfachen oder verästelten Zellkörper besteht. Damit stimmt der Unterschied in der Keimzellenbildung überein, indem bei den Chantransieen die Keimzellen an Zellenreihen, bei den beiden übrigen Familien seitlich an den Rindenzellen entstehen. Bei den Chantransieen entstehen die Keimzellen nun gewöhnlich so, dass die Gliederzellen der Aeste 
seitlich auswachsen und eine Astzelle bilden, welche zur Keimzelle wird. Es ist aber möglich, dass sie auch sich seillich an den Scheitelzellen bilden, oder dass die Scheitelzellen selbst zu Keimzellen werden. Die Abbildungen, welche von verschiedenen, zu dieser Familie gehörigen Gattungen gegeben werden, machen die beiden letztern Annahmen wahıscheinlich ; ich habe bisjetzt bloss den erstern Vorgang mit Sicherheit beobachtet. Für die Möglichkeit der beiden übrigen Vorgänge spricht aber namentlich auch die Analogie der Callithamniaceen, welche in Rücksicht auf ihren vegetativen Bau vollkommen mit den Chantransieen übereinstimmen, und wo sich die Sporenmutterzellen bald als Astzellen an den Gliederzellen, bald an den Scheitelzellen bilden, bald die Scheitelzellen selber sind. - Von den Ectocarpeen und den Conferceen, mit denen die Chantransieen im vegetativen Verhalten übereinstimmen, unterscheiden sie sich durch die Fortpflanzung.

Zu dieser Familie gehören die Gattungen Chantransia Fries, Batrachospermum Roth, Thorea Bory.

\section{Padineae.}

Flacher Zellkörper, welcher durch viele Zellen am Rande (nicht durch Eine Scheitelzelle) in die Lïnge wïchst.

Padiua Pavonia Lamour.

(Zonaria Pavonia Ag.)

TAв. V, Fig. $1-9$.

Die blattarlige, nervenlose Frons besteht aus 2 bis 5 Zellschichten. Auf einem senkrechten Durchschnitte nämlich zähIt man unterhalb des obern Randes 2, weiter nach unten 5, gegen die Basis der Frons hin 4 und

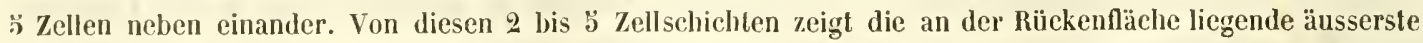
Schicht auf verticalen Qnerdurchschnitten doppelt-kleinere Zellen (Fig. 6, e - e) und stellt eine besondere Rinde dar. Die ïbrigen Zellen sind alle gleich loch und gleich breit, und liegen in horizontalen Querreihen (Fig. 6, b, c, d); sie bilden das Mark; die Rinde mangelt an der vorderen Fläche des Laubes.

Am obern Rande ist die Frons nach innen eingerollt. Macht man einen senkrechten Querschnitt durch diesen Theil der Frons, so findet man an der Spitze immer eine emzige Zelle (Fig. 1, a). Es ist eine Randzelle, in welcher das Längenwachsthum seinen Sitz hat. Diese Zelle dehnt sich nämlieh in die Länge und theilt sich dann durch eine Wand, welche sowohl ihre Achse als die Achsenfläche der Frons unter einem rechten Winkel schneidet, in 2 Tochterzellen. Die obere der beiden Tochterzellen verhält sich immer wieder wie die Mutter- 
zelle, so nämlich, dass sie in gleicher Richtung sich verlïngert und in gleicher Richtung Zellen bildet. Aul diese Weise sind in Fig. I die 2 Zellen a und b in der Randzelle entslanden, und a wir. sich wieder so theilen. In Fig. 9 ist der obere Rand der Frons, von der Fäche angesehen, dargestellt. Die Zellen a - a sind die nebeneinander liegonden Randzellen. Von diesen haben zwei (m, m) sich eben getheilt, während die ïbrigen sich eben theilen wollen. Für das Lïngenwachshum von Palinu nuss demnach als Gesetz ausgesprochen werden: Das " urhsthum in die Länge geschieht durch sime Reihe son Rundzellen, wedch" den obern Rand der Frons bilden. In je einer Rumbelle entstehen durch rine horizontale, die Laublïche unter rinem rachten $/ 1$ inkel schneidende Hand 2 ungleiche Tochterzellen, von denen immer die vbere vieder eine Ramizelle, lie untere eine Flïchpuselle ist.

In den Randzellen trilt aber zuweilen, statt der ebengenannten, eine andere Zellenbildung anf. Die Scheidewand ist dann senkreeht, und die beiden Tochtertellen Jiegen neheneinander, nicht übereinander. Jede derselben hat die Gestalt der untterzelle und ebenfalls das gleiche Vermögen, Zellen zu bilden. In Fig. s haben sich zwei Randzellen auf solche Weise in 2 gleiche Tochtermellen $(n, n$ und $n, n)$ getheilt, dureh die Wand 0. Durch diese Zellenbildung vermehren sich die Randzellen; dadurch wächst die Frons in die breile. Die ficherfornige Gestalt erklïrt sich einfach ans diesem Vorgange. Das Wachsthum beginnt mit Einer Zelle, der heinzelle. Es dehnt sich bald in die Breile, indem die am obern Rande gelegenen Zellen sich vermehren; erst ist 1 , damn sind 2, dann 5, 4, 5, endlich sehr viele vorhanden. Eime Verminderung derselben hann nieht eintreten, der obere Rand kann mit dem Alter nur an Ausdehnung znnehmen. Der Breitendurchmesser, den eine Frons an jeder Zone zeıgt, ist die Folge von der grösseren oder geringern Zahl von Randzellen, welehe die P'hanz' besass, als der wachsende Rand die Stelle jener Zone einnalım. Ein zweites Gesetz lautet demnach so: Dus Irachsthum in die Breite yeschieht dadurch, duss die Randzellen un Zuht zunehmen; indem in einer und

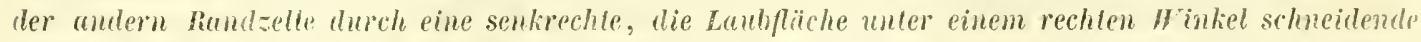
Wrand 2 gleiche Tochierzellen entstehen, fon deren jede eine Randzelle ist.

Durch die erste Zellenbildung entstehen in einer Randzelle 2 ungleiche Zellen. Die obere, der Miutler\%elte? gleich, ist eine neue Randzelle. Die untere verme!nt sich durch eine von der ersten und zweilen verschiedene Zelienbildung. Jeh will sie Flïchenzelle nemen. Die Flächenzelle theilt sich durch eine mit der Flïche der Frons parallele Wand, in eine sclmälere und etwas lïngere hintere (Fig. 1, e), und eine breitere und etwas kürzere vordere Zelle (Fig. 1, d). Die hintere Zelle ist schmäler als dic vordere, weil die Scheidewand seitlich von der Achsenfläche liegt. Die hintere Zelle ist länger als die vordere, wegen des Eingerolltseins der Frons. Bei der ersten Zellenbildung liegen dic Tochterzellen übereinander, bei der zweiten nelbeneinander, und bei dieser drilten hintereinander. Die letztere dient dazu, die verschiedenen Zellschichten zu erzeıgeı. Von den beiden Tochterzellen verhält sich die vordepe wieder wic die llutterzelle. Sie theilt sich nämlich durch eine mil der Laubnäche parallele Wand in eine grössere innere (Fig. \%, a) und eine kleinere äussere Zelle (Fig. 光, b). Diese Zellenbildung Iritt aber erst elwas später anf; in Fig. 2, 5 und /\% B. hat sie sich noch nicht realisirt. Häufig beibt nun die Frons in diesem Zustande, so dass sie also aus 5 Zellschichten hesteht. Iäulig iheilı sich anch die mitllere Zelle noch einmal durch eine gleiche Wand (Fig. 6, c und d) : die Frons entlält 4 Zellschichten. Tritt die nämliche Zellenbildung in einer der beiden miltleren Zellen noch cimmal auf, so hat sie 5 sehichten. Bas dritte ?Gesetz lantet: Dus II uchsthum in die Dicke yeschieht dudurch, duss in der Flïchenzelle durch eine mil der Lublü̈he parallete, excentrische Wund, 2 ungleiche Tochtersellen entstehon, con denen die hintere der Mutterselle ungleich und eine (primäre) Rindmatle ist; und duss in der vorderen Zolter dieser Zellenbildungsprozess (Theilung durch sentrechte, mit dev hathfäche parallele II ände) sich noch ein oder zucimal wiederholt, wodureh dus Mark prapugt wirh.

Von den beiden, in der ursprïnglichen Flïchenzelle entstandenen Tochterzellen, hat die vordore das nämliche Vermögen sich fortzupflanzen wie die Hutterzelle; die hintere dagegen resmehrt sich anf cine verschichlene Weise. Ieh wiil sie primäre lindenzelle nennen, da die aus ilı hervorgehende Zellschicht analog ist der linde 


\section{- 182}

der Fuceen. Die primäre Rindenzelle theilt sich dureh eine horizontale Wand in 2 gleiche Tochterzellen (Fig. 1, i und k; ferner 1, m, n, o, p). Bei senkrechten Querschnitlen finde ich regelmässig nach aussen von ciner Miltelzelle 2 doppelt-kleinere Rindenzellen (Fig. 2-8). Ob dieselben sich auch noch cinmal durch eine senkrechte, die Laublïche unler einem rechten Winkel schneidende Wand theilen können, so dass eine Mittelzelle der Frons demnach auf ihrer Rückenfläche von 4, in einer lläche liegenden Zellen bedeckt wäre, ist mir nicht genau bekannt. Die Riudenzellen liegen ursprïnglich so auf den inneren Zellen, dass die beiderseitigen Kanten und Seilenwände genau auf cinander treffen (Fig. 1, i, k, l). Spälerlin ist diess nicht melır der Fall, indem die Zellen sich ungleich ausdehnen (Fig. 1, n, o p). Das vierle und lelzle Gesetz fïr die vegetative Zellenbildung in Padina heisst: Das II achsthum der kinde geschieht dadurch, dass in den primären Rindenzellen durch eine horizomale (und eine verlicale?), die Laubfüche unter einem rechten Winkel schneidende I/ and je 2 gleiche Tochterzellen entstehen.

Ausser diesen 4 Arten der Zellenbildung werden in dem Laubkörper von Padina keine neuen Zellen gebildet. Auf der Rï̈ckenfläche (oder auf der Rinde) stehen Vebenfüden und Keimzellen, in horizontal-conrentrische Gï̈rtel georlnet. Ein Gürtel enthält mehrere Reihen von Nebenfäden oder Keimzellen. Die Keimzellen-Gürtel sind breiter als die Nebenfäden-Gü̈tel; die letzlern entstehen frülıer (Fig. 2, p). Beide Arten wechseln unregehnässig mil cinander ab. Die kimzellen und die Nebenfäden entspringen aus den Rindenzellen, indem diese sich nach aussen erheben (Fig. 7, 1, f), und durch eine mit der Laubläche parallele Wand in a Zellen theilen. Die innere der beiden Tochterzellen hat die gleiche Grösse und Gestalt, und nimmt den gleichen Kaum ein, wie die Mullerzelle (Fig. $5, r, r ; 8, r, r)$. Die äussere der beiden Tochierzellen entspricht dem ausgewachsenen Theile der Mutlerzelle, sie ist bloss mit der Grundfäche befestigt und mil der übrigen Membran frei. Diese Zelle ist entweder die Keimzelle (Fig, 7, k; 8, k), oder diejenige Zelle, aus welcher unmiltelbar der Nebenfiden herrorgeht. Die Keimzellen sind einfache Zellen, die Nebenfäden sind Zellenreihen. - bie keimzcllen können, wie es scheint, ans allen Rindenzellen ohne Interschied entstehen. Die Nebenfäiden fand ich gewöhnlich je auf der zweiten Zelle (Fig. 5). Diese Zelle ist anfänglieh so gross, als die neben ilir liegende; sie bleibt dann bei der weiteren Entwicklung mehr oder weniger hinter dieser zurück (Fig. 4 und $b, r, r$ ).

Die Xebenfäden und die Keimzellen sind zuerst mil einer zarten Ilaut bedeckt. Es ist die Culicula, welehe die Rindenzellen nach aussen bedeckt, und an diesen Stellen emporgehoben wurde (Fig. 5, 7, e). Dre Cuticula ist die von den Rindenzellen nach aussen abgesonderte Gallerte. Aber nicht nur die Rindenzellen scheiden Gallerte aus; die aus denselben entspringenden jungen keimzellen und jungen Nebenfäden thun diess in noch beträchllicherem Viasse. Die Exlracellularșubslanz, nimmt an den Giïrteln eine bedeutende Dicke an (Fig. 3; Fig. 7). Man unlerseh(idet hier in jüngern Zuständen die Gallertportionen, welche von den einzehen Nebenfäden odter Keimzellen ausgeschieden wurden, deullich auf Querechnillen (Fig. 5). - Von der Flärhe angesehen, iehalten diese Slïcke der Cuticula auch in ältern Zuständen cine netzförmige, scheinlıar zellige Struetur. Die Linien des Nelzes entsprechen den Kanten zwischen den Keimzellen oder jungen Nebenfäden. Ein älınliches Verhallen ist auch an der Cutieula höherer Pflanzen bekannt. Külzing nennt die emporgehobene Partic der Culicula, unler welcher die Nebenfäden und die Keimzellen liegen "Indusium " oder "Schleier. " Es seheint mir aber überflüssig, einen andern Namen als den von Cutieula anzuwenden, und nicht passend, eincn Namen zu wähılen, der schon ein bestimmles, aus Zeblen gebildetes Organ bezeiclnet.

Die Zellen von P'adina besitzen ein freies centrales Kernbläschen, das aber nur in jungen Zellen deullich zu sehen ist (Fig. 1). In den ältern Zellen wird es von den anliegenden körnern bedeckt. Die Randzellen sind mit lromogenem und körnigem Schilrine erfüllt (rig. 1, a). Die Fï̈chenzellen und Rindenzellen enthalten ursprünglich verlältnissmässig eine geringe Nenge fosten Schleimes; derselbe ungiebt den Kern und bildel die Strömungsăden, die den Kern mit der Membran verhinden (Fig. 1). Nachler färben sich diese Zellen grïnlich. spälerhin enthatten die kindenzellen und die an der vorderen Fläche liegenden Zcllen vicle Chlorophyllbläs- 
chen, die theils an der Membran, theils am Kerne gelagert sind (Fig. 6, e und b). Die Mittelzellen dagegen besitzen nur wenige Chlorophyllbläschen, die an der Wandung, und kleinere Amylumkügelehen, die um deı Kern liegen (Fig. 6, e und d). - Von dem Kerne gehen immer die Strömungsfäden nach der Wandung; ausser dieser radialen Saltströmung (Fig. $5, \mathrm{e}, \mathrm{a})$ ist noch eine peripherische vorhanden, welche die wandständigen Chlorophyllbläsehen mil einander verhndet (Fig. 5, $\mathrm{e}^{\prime} \mathrm{a}^{\prime}$ ).

Die Keimzellen sind dicht mit Amylumkügelchen und Schleimkörnchen gefüllt und besitzen ein freies centrales Kernbläschen. Die Wandung besteht aus der Zellmembran und der Extracellularsubstanz, an welcher man zuweilen 2 Schichten unterscheidet. Beim keimen treten statt des ursprünglichen Kernes 2 neue Kernbläschen auf und zwischen ilınen wird eine scheidewand sichtbar $\left({ }^{4}\right)$. - Auf gleiche Weise entstehen durelı wandständige Zellenbildung alle übrigen Zellen, indem anstatt des Kernes der Multerzelle 2 neue Kerne (Fig. 1, g) und dann eine trennende Wand erscheinen. - Das Keimen beginnt häufigg schon, wenn die Samen noch an der Frons liegen. Dann scheint es, als ob dieselben auch zwei und mehrzellig wären. Diess ist aber nicht der Fall, sondern die Keimzellen gelangen bloss zu frühzeiliger Entwicklung. Meneghini $\left(^{2}\right)$, der diese Thatsache auch anführt, sebeint ihr, mit Unrecht, eine andere Erklärung geben zu wollen.

\section{FuCEaE.}

\section{Zellkürper, dessen Achsen durch Eine Scheitelzelle in die Länge wachsen.}

Ich vereinige in diese Familie alle Algen, deren Achsen Zellkörper sind, die mit einer einzigen Zelle an der Spitze wachsen, und an denen die Keimzellen durch Auswachsen der Rindenzellen entstehen. Gewöhnlich werden die mit der Gattung Fucus verwandten Algen, wo die Keimzellen in einem sogenannten Conceptaculum oder in einer Hüllenfrucht (Kützing) beisammen stehen, in eine besondere grössere Abtheilung gebracht. Bei Kützing machen die Fuceen im engern Sinne des Wortes sogar eine der beiden Hauptabtheilungen der eigentlichen Algen aus und werden Angiospermeen genannt. Das Conceptaculum oder die Hüllenfrucht ist aber nichts anderes als ein vertiefter Sorus, und die Keinfruchtzellen entstehen in ihnen bloss aus den Epidermiszellen. Fig. 58 auf Tab. IV, stellt ein junges Conceptaculum von Cystoseira dar; Fig. 59 zeigt die Keimzellenbildung in einem ältern Conceptaculum der gleichen Pflanze. Da nun auch bei einigen Gattungen, die nicht zu den eigentlichen Fuceen gehören, die Sori in geringem Masse vertieft sein können, so ist noch sehr die Frage, ob die geringere oder grössere

(1) Schleiden und Nägeli's Zeitschr. f. w. Bot., Heft 1, tab. 2, Fig. 4, 5.

(2) Alghe ital. e dalmat. Fasc. 3, p. 243. 
Vertiefung des Sorus mehr als ein relativer Unterschied sei. Ich vereinige daher mit den eigentlichen Fuceen auch alle Gatlungen, wo die Keimzellen an der ebenen, nicht vertieften Oberfläche entstehen, in eine einzige Familie.

\section{Dictyota dichotoma Lamour.}

(Zonaria dichotoma $\Lambda \mathrm{g}$., Dichophylliıı vulgare und dichotomum Külzing.)

TAв. V, Fig. $10-21$.

Die nervenlose, papierdünne Frons ist linear und dicholomisch. Sie besteht aus 5 einfachen Zellsehichten, einer Markschicht und 2 Rindenschichten. Auf Querschnitten liegen immer nur 5 Zellen im Querdurchmesser neheneinander (Yig. 10, 11). Die Rindenzellen sind in ggrösserer Zahl vorhanden als die Markzellen. Doch giebł es dafür kein bestimmtes Verhältniss. Iuf verticalen Querschnitten gehen je $1 \% \frac{1}{2}, 2,2 \%_{2}$ und 5 Rindenzellen auf 1 Markzelle (Fig. 10). Auf horizontalen Querschni!ten dagegen gehen je 5, 4, \$, 6, 7, 8 Rindenzellen auf 1 Markzelle (Figg. 11). Diese ungleichen Verhältnisse trelfen mit dea Unstande zusammen, dass sowohl die Rindenzellen untereinander, als die IIarkzellen untereinander ungleich gross sind. Durchschnitlich zählt man der Länge nach je 2 Rindenzellen, der Breite nach je $4-$ s Rindenzellen auf 1 Iarkzelle. Die letztere wird daher auf jeder der beiden Flichen durelsschnittlich von 8 bis 10 Rindenzellen bedeckt; diese Zahl kann aber bis auf 4 und כ̆ fallen und his auf 20 und mehr sieigen. Die Markzellen sind gewöhnlich cubisch, mit wenig überwiegendem senkrechtem Durchmesser. In den Rindenzellen sind die horizontalen (nänlich der Breitenund der Dicken-) Durchmesser ungefäh ggleich, der verticale Durchmesser aber ist 2 bis 4 mal lïnger.

An der Spitze jeder Acise steht eine einzige Zelle: Scheitelzelle (Fig. 12, a). Sie theill sich durch eine horizontale, von oben concave, yon unten convexe Wand in 2 ungleiche Tochterzellen. Die untere ist kleiner , scheibenförmig und gebogen (Fig. 12, b). Die obere is! ein kurzer Kegel mit convexer Grundnïche. Diese Zelle dehnt sich wieder zu der Grösse aus, welehe die Initerzelle besass, ehe sie sich theilte, um wie diese 2 neue Zellen zu erzeugen. Diese Theilung der Scheitelzellen durch eine horizontale Wand erfolgt so lange, als die Achse in die Länge wächst. Dis erste Gesetz ist demuach folgendes : Das I'achsthum in die Länge geschieht durch eine einzige, am Ende jeder Achse gelegene Scheitel:elle, welche sich durch eine horizontale, die

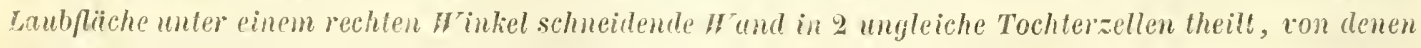
immer die obere wieder eine Scheitelzelle, die untere eine Gliederzelle ist.

Die untere der beiden Tochterzellen oder die Glieder\%elle theilt sich durch eine senkrechte Wand in 2 gleiche Tochterzellen (Fig. 12, c und c). Die Scheidewand fällt mit der Lauba(hse zusammen und schneidet die Laubfläche unter einem rechten Winkel. Jede der beiden Tochterzellen pflant sich auf gleiche Weise, wie die Mutterzelle, durch eine senkrechte Wand fort, welrhe parallel mit der Laubachse und senkrecht auf die Laubfläche ist, und die Zelle in 2 gleiche Irälften trennt (Fig. 12, $\mathbf{d}-\mathbf{d}$ ). Das Glied besteht nun ans 4 Zellen. - Dieselben theiten sich von neuem durch Wände, die mit den früher entstandenen Wänden parallel laufen, in 8 Zellen (Fig. 12, e - e). Ius iluen entstehen dann 16 Zellen (Fig. 12, f - f), nachher 52 Zellen (Fig. 12, $g$-g). Das Wesen dieser Zellenbildung besteht darin, dass je eine Mutterzelle sich in 2 gleiche, in derselben horizontalen Reilı nebeneinander liegende Zellen tireilt. Die Wände sind nicht vollkommen parallel; sondern weil diese Reihe gohogen ist, convergiren sie nach dem Punclum vegetationis hin. - Dieser Zellenbillungiprozess ist begrenat, aber dic Grenze ist unbestimmt, so dass also die Gliederzellen in eine unbestimnte Zahı von Zellen sich theilen. Dieser Zellenbildungsprozess schreitet ferner nicht gleichmässiģ fort und lıört auch in den verschiedenen Theilen eines Gliedes nicht gleichmässig auf, so dass also die Gürtel selten 


\section{$-185$}

aus der regelmäissigen Zalıl von 52, 64 Zeilen hetstelıen, sondern gewöhnlicher aus $52 \pm x$ und $64 \pm x$ Zellen. Dagegen sind die Zahlen 2, h, 8, 16, mit denen die Zellenbildung beginnt, constant. - Die Gliederzelle löst sich somit in einen Gürtel von Zellen auf; ich will sie Flächenzellen nennen, da sie für die Entwicklungsg̣eschichte des Lanbes eine gleiche Bedentung haben, wie die Flächenzellen in I'adina. - 1)as zweite Gesetz heisst: Das Wachsthum in dir Breite geschieht dadurch, dass die Gliederzelle und die darans herorgehenden Zellen sich je durch pine senkivehte (nach dem Scheitel der Laubachse yerichtete) und die Lanbflïche untor einem rechten $\|$ inkel schneidende $W$ and in 2 gleiche Tochterzellen theilen, woraus eine horizontuls Reihe sou Fliichenzellen entsteht.

Die Flächenzellen eines Gliedes, mit Ausnalıme der beiden am Rande stehenden, werden ron 6 Flächen begrenzt. I Flächen, eine obere, eine untere und 2 seitliche, sehneiden die Laubfläehe unter cinem rechten Winkel. Sie sind mit andern Zellen verbunden: die obere mit dem nälchst höheren Gliede, die untere mit d('m näehst tieferen Gliede, die beiden seitlichen mit Flächenzellen des g̨leichen Gliedes. Die 2 Randflächen tagegren sind parallel mit der Laubfläche und sind frei. - Die Flächenzellen theilen sich uun dureh eine excentrischı . mit der Laubläche parallele Wand in 2 ungleiche Tochterzellen, von alenen die kleinere cine Rindenzelle ist. Die grössere theilt sich noch einmal dureh eine ebenfalls excentrische, der ersten gegenüberstehende und rinit derselben parallele Wand in eine zweite Rindenzelle und eine Markzelle. Aus jeder Flächenzelle entstehen demnach 5 Zellen, eine nittlere oder Markzelle und 2 seitliche oder Rindenzellen. - Als drittes Gesetz muss ausgesprochen werden : Dus II achsthum in die Dicke geschieht dudurch, dass in der Fliichenzelle, durch eine mit der Laubfläche paraliele, excentrische "I and, 2 ungleiche Tochterzellen, pine minëre himdenzelle und eine secundïre Flächenzelle, und dlass in dieser letztem durch cine gleiche $/ 1$ and $\boldsymbol{H}$ icder 2 myleiche Tochterzellen, eine primüre Rindenzelle und eine Jurkzelle sich biluen.

ob die Markzellen sich ferner theilen oder nicht, ist mir unbekannt; wenn es geschieht, so ist wahrscheinlich, dass die Wände die Laubläche unter einem rechten Winkel sclıneiden (nicht parallel mit ihr laufen); denn auf Querschnitten sehe ich immer nur Eine Schicht von Markzellen. - Die primären Rindenzellen theilen sich. Ich habe oben angegeben, dass eine Iarkzelle durchschnittich von 8 bis 10 Rindenzellen bedeckt sei. und dass der Länge nach ungefähr je 2, der Breite nach ungefähr je 4 - ̧ Rindenzellen auf eine Markzelle gehen. Es ist dahel nothwendig, dass die ursprünglichen Rindenzellen sich durch mehrere senkrechte, zur Laubläche einen rechten Winkel bildende Wände und durch eine horizontale Wand theilen. Die horizontalen Wände kïnnen sich $1 \mathrm{mal}$, die verlicalen 1, 2, 5 mal wiederholen. Senkrechte mit der Laubfläche parallele Wănde bilden sich keine. Durch ungleiche Ausdehnung der Zellen verschieben sich die Wände dergestalt, dass Rindenzellen und Markzellen durchaus nicht mehr genau auf einander passen. - Das vierte Gesetz der Zeltenbildung heisst: Das $/$ uchsthun der kinde geschieht dadurch, dass in den mimüren Rindenzellen und deu duraus hervorgehenden Zellen, durch abuechselnde horizontale und rerticule, zur Laubläche einen rechten $\|$ inkel bildende $\|$ ände, je 2 gleiche Tochterzellen entstehen.

Die Frons von Dictyota ist dichotomisch. Die Vertheilung geschicht folgendermassen. Eine Scheitelzelle, statt eine nene Scheitelzelle und eine Gliederzelle durch eine horizontale Wand zu erzeugen, theilt sich durch eine senkrechte Wand in 2 gleiche Tochterzellen (Fig. 15, a). Jede derselben ist eine neue Scheitelzelle und der Anfang einer neuen Achse, welche einen spitzen Winkel mit der frühern Achse bildet. Die beiden neuen scheitelzellen theilen sich, nach den ersten Gesetze der Zellenbildung, durch eine gebogene, die Zellenachse unter einem rechten Winkel schneidende Wand, in eine neue Seheitelzelle (Fig. 14, a) und eine Gliederzelle (Fig. 14, b). Der Prozess wiederholt sich sletig (Fig. 15, 16) und dauert so lange, bis die betreffenden Achsen ausgewachsen sind, um sich dann neuerdıngs wieder in 2 Tochterachsen zu theilen. Ein fünftes Gesetz, welches die Vertheilung der Frons in sich fasst, heisst demnach: Die Verïstlung der Frons ist dichotomisch und geschieht so, dass in einzelnen scheitelzellen, durch eine in die Achse fallende, die Laubliiche unter einem. rechten Winkel schneidende $/ \boldsymbol{H}$ and, 2 neue Scheitelzellen sich bilden, welche in neue Achsen auswachsen. 


\section{- 186}

A IIf beiden Seiten der Frons stehen die Keimzellen lıafenweise oder auch wolıl vereinzelt. Olıne Ordnung sehen dazwischen die Nebenfaden, ebenfalls in Haufen. Die Entstehungsweise der Keimzellen und der Nebenfiden aus den Rindenzellen ist die gleiche, wie sie bei Padina beschrieben wurde (Fig. 19, 20, 21). Die Nebenfiden sind ebenfalls von der emporgehobenen Cutieula bedeckt (Fig. 19, c). Meneghini ( ${ }^{1}$ ) lässt die Nebenfaden atus den Markzellen entstelıen, und die Rinde ("Epidermis") von ilınen durchlırochen werden. Dem ist aber nicht so, sondern die Rindenzellen wachsen aus, theilen sich in 2 Zellen, von denen die innere dic Stelle der Intterzelle einnimmt, und die äussere sich durch Zellenbildung in einen Nebenfaden verwandelt (Fig. 19).

Der Zelleninhalt ist ursprünglich ein farbloser lıomogener Schleim. der körnig wird und dann Chlorophyllbläschen, Amylumkïgelchen und Oeltröpfehen bildet. Im Centrum einer jeden Zelle liegt ein freier Kern wie in Padina. - Die Wandung der Zellen besteht aus der Zellmembran und aus Extracellularsubstanz. Diese letzlere ist zwischen den Rindenzellen in sehr geringer Jenge vorhanden. Nach aussen bildet sie dıe Cuticula. Linzelne Ilarkzellen scheiden eine beträchıliche Menge von Gallerte aus (Fig. 17, e, e, e). Zwischen den Markzellen sind deutliche Poren (Fig. 18), welche dadurch erzeugt werden, dass stellenweise die Extracellularsubstanz mangelt.

Külzing $\left({ }^{2}\right)$ trennt die Art D. dichotoma in 2 Arten: Dichophyllium vulgare und D. dichotomm. Die erstere hat Keinzellen, die in IJüufchen vereinigt sind, die Jetztere solche, die einzeln stelıen. Die Stellung der Samen soll constant sein. Die Untersuchung meiner neapolitanischen Exemplare liefert mir ein anderes Resultat. An derselben Pflanze finde ich nebeneinanter einzelne Keimzellen, und solche, die in allen Mengen haufenweise beisammen licgen, nämlich je $2, \overline{5}, 4,5$ bis 10 und 20 , sogar bis 50 und 60 . Selten aber sind die lläufchen so rund und regelmässig, wie sie Greville (") zeichnet; sie sind länglich, lanzettlich und meist unregelmässiğ; läufig auch liegen die Keimzellen in hieroglyphischen Linien, wie Meneghini sie richtig benennt.

Die Gattungen Diclyota und Palina sind durch die Gesetze des Wachsllumns wesentlich von einander verschieden. Die Achsen von Dictyota verlängern sich durch eine einzige Scheitelzelle, die Achsen von Padina dagegen durch viele Randzellen, welche in einer horizontalen linie liegen. Das Wachsthum in die Breite geschieht in Dictyota durch Zellenbildung in den Gliederzellen, bei Padina durch Zellenbildung in den Randzellen. Beim Wachsthume in die Dicke erzeugt Dictyola eine Markschicht und jederseils eine Rindenschicht, Padina bloss eine Rindenschicht an der Rückenfläche. Die Frons von Dictyola verästelt sich dichotomisch; an Padina mangelt die Verästlung ganz, weil die Zellenbildung, die in Dictyola zur Emzeugung neuer Achsen dient, bei ihr das Wachsthum der Frons in die Breite bedingt; die Frons von Padina ist bloss gelappt.

(1) Alghe ital. e dalmat., fasc. III, pag. 213, « Si nell' un caso però che nell' allro riesce evidente ch'esse parafisi sorgono dallo strato immediatamente soltoposto all' 'pidermico, ,

(2) Phyc. gen., pag. 557 .

(5) Algx britann.. Tab. 1, Fig. … 


\section{B. FLORIDEEE.}

(Rhodospermece Harvey. - Floridece J. Agardh; Endlicher. - Choristosporee Decaisne. - Algee heterocarpece Kützing.)

Zelleninhalt theilweise aus Stärkekörnern und Farbblüschen bestehend; keine Urzeugung; Fortpflanzung geschlechtlich; männliche Geschlechtsorgane mit Samenbläschen (Samenzellchen), welche nicht in einen zelligen Sack eingeschlossen sind: weibliche Geschlechtsorgane ohne besondere Hülle (calyptra), mit Sporenmutterzellen, in denen 4 Specialmutterzellen, in jeder derselben eine Spore entstehen; Vermehrung (geschlechtslos) durch Keimzellen.

Durch den Zelleninhalt, welcher theilweise aus Stärke und aus Farbbläschen besteht, unterscheiden sich die Florideen, wie die Algen und die übrigen Pflanzen von den Pilzen. Die Farbbläschen enthalten bei den Florideen gewöhnlich einen rothen Farbstoff, der aber mit dem Chlorophyll sehr nahe verwandt ist, da er häufig schon in der lebenden Pflanze und gewöhnlich beim Absterben derselben in dasselbe übergeht. Von den Pilzen unterscheiden sich die Florideen ferner, so wie die Algen und die übrigen Pflanzen dadurch, dass sie nie durch Urzeugung, sondern bloss aus Samen entstehen. 
Von den Algen unterscheiden sich die Florideen durch die Fortpflanzung. Bei jenen ist noch keine Geschlechtsdifferenz vorhanden, ihre reproductiven Organe sind bloss Keimzellen, und wenn auch bei einzelnen Gattungen auf doppelte Weise für die Erhaltung der Art gesorgt ist, so dass man auch dort zwischen Fortpflanzung und Vermehrung unterscheiden muss, so bilden sich doch für den einen und den andern Zweck bloss geschlechtslose Keimzellen, und die Vermehrung ist bloss eine niedrigere Art der Keimzellenbildung. Die Florideen dagegen besitzen geschlechtliche Differenz und daher zweierlei Fortpllansungsorgane, nämlich männliche oder Antheridien mit Samenzellchen, und weibliche oder Mutterzellen, aus denen in der Regel vier Sporen entstehen. Ausserdem besitzen sie Organe der Vermehrung, welche geschlechtslos sind und Keimzellen hervorbringen.

Von den Leber- und Laubmoosen, denen die Florideen am nächsten verwandı sind, unterscheiden sie sich dadurch, dass die Calyptra ihmen mangelt, und dass die Antheridien keine Rindenschicht besitzen. Die Sporenmutterzellen stehen entweder seitlich an den Aesten, oder sind im Gewebe zerstreut oder in besondere Fruchtäste vereinigh, aber es mangelt diesen immer die besondere Unhüllung (Calyptra), welche die Capseln der Laub- und Lebermoose im Anfange besitzen. An den Antheridien sind die Samenzellchen nicht in einem aus einer Zellschicht bestehenden Sacke eingeschlossen wie bei den Leber- und Laubmoosen, sondern sie liegen frei.

Die Eigenthümlichkeit der Sporenzellen ("sporæ, sporidia, spermatidia ») wird gewöhnlich darin gefunden, dass sie zu 4 vereinigt, oder zu 4 in einer Mutterzelle entstanden sind ( Sporidia terna, ternate granules, sphærosporæ, tetrasporre, tetrachocarpia "). Die Zahl 4 bildet allerdings eine fast ausnahmslose Regel. Einzig in Plocamium schien es mir, als ob auch 5, 6, 7 und 8 Sporen in einer Mutterzelle entständen $\left(^{1}\right)$. Wie dem auch sci, so ist es sicher, dass nicht die Zahl, sondern die Entstehungsart das Wesen der Sporen ausmacht. Dafür

(') Da ich bei der Untersuchung von leḷenden Exemplaren diesen Punkt vernachlíssigyte, und mir jetzt bloss gretrocknete zu Gebote stehen, so kann ich kein sicheres Urtheil abgeben. Kützing's Abljildung (Phycol. gुen., tab. 64, Fig. S) und Erklürung (pag. 449) sind mir niclit recht deutlich 
giebt es 2 Gründe: 1) Ist die Zahl 4 bei der Pollenbildung, dic durchaus analog mit der Sporenbildung ist, cbenfalls nicht constant, sondern wechselt in einzelnen Fällen mit $\breve{~}, 6,7,8$ ab. 2) Giebt es auch eine Fortpflanzung bei den Algen, wo 4 Keinzellen in einer Mutterzelle entstehen, so nicht selten bei den Bangiaceen und zuweilen bei den Palmellaceen (vergl. oben Pleurococcus II Tetrachococcus, und Palmella II Tetratoce). Und dennoch sind diese Keimzellen keine Sporen.

Der gesetzmässige Verlauf der Sporenbildung ist folgender. Die Mutterzellen gleichen ursprünglich den übrigen vegetativen Zellen der Pflanze. Sie enthalten einen primären wandständigen Kern. Derselbe wird aufgelöst, und statt seiner tritt ein neuer secundärer Kern auf, welcher frei im Centrum des Lumens liegt, und gewöhnlich durch radiale Strömungsfäden mit der Membran verbunden ist. Darauf bilden sich zwei oder vier neue freie Kerne und der secundäre centrale Kern verschwindet. Zu gleicher Zeit verdickt sich die Mutterzelle gallertartig. Der Inhalt theilt sich in 2 oder 4 Partieen, je nach der Zahl der Kerne, so dass jede einen Kern einschliesst. Um jede Inhaltspartie entsteht eine Specialmulterzelle dnrch wandständige Zellenbilduug. Sind bloss 2 Specialmutterzellen entstanden, so sind es primäre. In jeder treten dann 2 neue freie Kerne auf, indem der primäre Kern resorbirt wird, und jede theilt sich in 2 secundäre Specialmutterzellen, wieder durch wandständige Zellenbildung. Die Kerne der 4 Specialmulterzellen werden resorbirt. In jeder bildet sich eine Sporènzelle, welche einen wandständigen primären Kern besitzt, wahrscheinlich durch freie Zellenbildung. Später entsteht ein secundärer grösserer Kern, welcher frei und im Centrum der Zelle gelegen ist. Die Sporenzelle scheidet Gallerte aus, welche derb und gefärbt wird, und das Exosporium bildet. Zu gleicher Zeit werden die Specialmulterzellen aufgelöst.

Ich habe diesen ganzen Vorgang nicht in allen seinen Einzelnheiten an den Florideen beobachten können. Einzelne Erscheinungen entlehnte ich von andern viersporigen Cryptogamen und von der Pollenbildung der Phanerogamen, nachdem ich mich überzeugt hatte, dass die Entstehung der Sporenzellen bei Florideen einerseits und den Laub- und Lebermoosen anderseits identisch sei, und dass sie 
mit der Bildung der Pollenzellen übereinstimme. Ich habe die Einzelnheiten schon an einem andern Orte weitläufiger besprochen $\left({ }^{1}\right)$.

Die Lagerung der Sporen in der Mutterzelle findet auf 3 Arten statt. 1) Sie stehen zu einander wie die Ecken eines Tetraëders, zeigen selbst mehr oder weniger die Form eines Tetraëders, und sind von 4 Ecken, 4 Kanten und 4 Flächen, 3 geraden und einer gebogenen, begrenzt. Die 4 Specialmutterzellen entstehen gleichzeitig. 2) Die Sporen liegen in einer Fläche oder ebenfalls tetraëdrisch ; sie besitzen aber die Gestalt eines Kugelquadranten und sind von 2 Ecken, 5 Kanten und 5 Flächen, 2 geraden und einer gebogenen begrenzt. In der Mutterzelle bilden sich zuerst 2 hemisphærische primäre Specialmutterzellen. Jede dieser theilt sich in 2 kugelquadrantische secundäre Specialmutterzellen. 5) Die Sporen liegen in einer Linie. Die beiden innern sind scheibenförmig, mit 2 kreisförmigen Kanten und 5 Flächen, 2 geraden kreisförmigen und 1 cylindrischen. Die beiden äusseren sind halbkugelig, mit 1 kreisförmigen Kante und 2 Flächen, einer geraden kreisförmigen und einer gebogenen. Die Ecken mangeln diesen Sporen ganz. Die längliche Mutterzelle theilt sich in 2 primäre Specialmutterzellen, und jede von diesen theilt sich abermals durch eine, mit der ersten parallellaufende Wand in 2 secundäre Specialmutterzellen. - Diese drei Arten der Sporenbildung werden wohl am passendsten als tetraëdrische, kugelquadraniische und zonenartige unterschieden. Kützing $\left(^{2}\right)$ verwechselte die erste Art, welche jedoch bei den Florideen die häufigste ist, mit der zweiten.

Die Samenblëschen $\left(^{5}\right)$ (Samenzellchen) sind die männlichen Fortpflanzungsorgane. Das Organ, das ihre Vereinigung darstellt, heisst Antheridium. Die Zellchen sind klein, farblos, alle von gleicher Gestalt und Grösse. Obgleich ich keine Bewegung an ihnen wahrnehmen konnte, und auch die Samenfäden nur undeutlich erkannte, so liess mir doch die sonstige vollkommene Uebereinstimmung mit den Samenbläschen der Laub- und Lebermoose keinen Zweifel über die Identität des Organs. Es giebt unter den Florideen eine Zahl von Arten, an denen man 3 verschiedene Organe findet: Sporangien mit Sporen, Keimzellen-

(1) Zeitschrift f. w. Bot., Eleft I, pag. 7\%, ff.

(9) Phycol. gen., pag. 100.

(3) Vergl. über diesen Ausdruck Zeitschrift für w. Bot., Heft 3 und 4, pag. 105. 
behälter mit Keimzellen, und ein drittes Organ, für das, wenn man es nicht als Antheridium erklären wollte, cine Deutung mangeln würde. Ferner sind die Zellchen, die es enthält, so ähnlich den Samenbläschen der Laub- und Lebermoose, dass man keine andere Analogie für sie unter allen Pflanzenzellen findet. Ihre grosse Kleinheit übrigens mag es erklärlich machen, warum es mir nicht gelang, deutlicher die Samenfäden zu sehen; und die geringe Zahl von Beobachtungen, die mir zu Gebote stehen; mag der Grund sein, warum ich keine Bewegung wahrnahm, da sich die Samenbläschen der Leber- und Laubmoose auch nicht immer bewegen. Ich verweise übrigens auf die unten folgenden Gattungen Poecilothamnion und Nitophyllum, so wie auf die anderwärts beschriebene Polysiphonia $\left({ }^{1}\right)$. - Lyngbye $\left({ }^{2}\right)$ zeichnet Antheridien an Hutchinsia violacea, hält sie aber für eine thierische Bildung. Agardh erwähnt ihrer bei mehreren Arten von Hutchinsia als Antheridien. Greville $\left({ }^{5}\right)$ bildet sie an Laurencia pinnatifida ab, ohne eine Meinung darüber zu äussern. J. Agardh $\left({ }^{4}\right)$ erwähnt der Antheridien ausserdem bei Callithamnion, Griffithsia, und hält sie für eine wuchernde Metamorphose der gewöhnlichen Fortpflanzung. Kützing $\left(^{5}\right)$ hat sie ferner bei Wrangelia und Odonthalia gefunden ; er erklärt sie für " samenähnliche Nebengebilde " und giebt ihmen den Namen Spermatoidia. Gegen J. Agardh's Theorie habe ich einzuwenden, dass die Antheridien und die Samenzellchen durchaus nach andern morphologischen Gesetzen sich entwickeln, als die Sporen und die Keimzellen, und daher nicht metamorphosirte Samen sein können. Kützing's Theorie dagegen ist mir unverständlich, da ich eine dritte Art der Fortpflanzung nicht heim zu weisen vermag. Alle übrigen Organismen besitzen höchstens 2 Arten der Fortpflanzung, geschlechtliche und geschlechtslose. Ausser den Sporenzellen und Keimzellen aber noch "Spermatoidien, SScheinsamen und Nebensamen " anzu nehmen, wie Kützing es thut, das scheint mir von der Natur weg in's Nass- und Gesetzlose zu gehen.

(1) Zeitschrift für w. Bot., Heft 3 und 4, pag. 224.

() Hydropliytologia dan., tal. 35, pag. 142.

$\left(^{3}\right)$ Algae britannica, pag. 110, tab. XIV.

( $)$ Alg. maris medit. et adriat., pag. 65.

(5) Pliycolog. gen., pag. 107. 
Die Keimzellen oder Brutzellen ("semina, spora, granula, spermatia ») sind die geschlechtslosen Fortpflanzungsorgane der Florideen. Sie sind zu Keimhëufchen (Bruthäufchen) vereinigt, und als solche häufig in Keimbehältern (Brutbehältern) eingeschlossen ( «tubercula, capsulæ, glomeruli, favellæ, favellidia, coccidia, keramidia, thecæ, cystocarpia »). Ueber die Keimzellen lässt sich, was ihre Entstehung und ihr weiteres Verhalten anbelangt, nicht viel Allgemeines sagen; ausser dass sie nicht befruchtet werden, wie es für die Sporen angenommen werden muss, dass sie kein Exosporium besitzen, und dass sie nie zu 4 in einer Mutterzelle entstehen. Ausser diesen wenigen gemeinsamen Eigenthümlichkeiten zeigen sie eine sehr grosse Mannigfaltigkeit in Besug auf ihre Entwicklungsgesetze und auf den Ort, wo sie sich an der Mutterpflanze entwickeln. Es ist daher unrichtig, wenn Kützing $\left({ }^{1}\right)$ den Cystocarpien allgemein eine "Fruchthülle, Spermangium, 》 J. Agardh $\left({ }^{2}\right)$ den Capseln ein "Pericarpium, " Endlicher $\left({ }^{5}\right)$ den Theca ein "Perisporangium» zuschreibt. Denn ausserdem, dass in vielen Gattungen (Ceramiaceen) die Keimzellenhäufchen bloss von der Gallerte umschlossen sind, die sie selber ausgeschieden haben, giebt es auch wirklich nackte Keimzellen (so in Wrangelia).

Gewöhnlich werden die beiden Fruchtarten der Florideen als gleichwerthig nebeneinander gestellt. Desswegen nennt sie J. Agardh beide Sporen. Kützing, der ebenfalls bloss einen morphologischen Unterschied annimmt, unterscheidet sie im Namen als Spermatidia und Spermatia (die erstern sind die Sporen, die letztern die Keimzellen). Decaisne $\left(^{4}\right)$ vergleicht die Keimbehälter theils mit dem gleichen Organe von Marchantia, theils lässt er sie durch eine Verdichtung des Gewebes (concentration du tissu) entstehen, theils hält er die Keimhäufchen für eine abnormale Entwicklung der Sporen. Dass die Keimzellen keine Hetamorphiose der Sporenzellen sein können, wird bewiesen 1) dadurch, dass die Entwicklungsgesetze für beide total verschieden sind, und 2) dadurch, dass sie meistens entweder an ungleichen Stellen der Frons oder auf verschiedenen

(1) Phycolog. gen., pag. 103.

(2) Algg. mar. medit. et adriat., pag. 60 .

$\left({ }^{3}\right)$ Gen plant., suppl. III, pag. 33.

(4) Ann. d. sc. nat., 1842 , pag. 354. 


\section{$-193$}

Achsen, aber nie oder jedenfalls nur höchst selten an dem nämlichen Orte entstehen.

Dass die fraglichen Organe der Florideen analog seien den Brutzellen und den Brutbehältern oder Bruthäufchen der Lebermoose, ergiebt sich deutlich aus einer genauen Vergleichung. Zwischen den Keimhäufehen der Ceramiaceen und den Bruthäufchen von Jungermannia ist kein Unterschied vorhanden. Die Keimbehälter von Nitophyllum und die Brutbehälter von Marchantia stimmen, in Rücksicht auf die Struktur des Organs und die Entstehung der Keim- oder Brutzellen, weit mehr mit einander überein, als die grleichen Organe verschiedener Florideen selbst.

Die Fortpflanzung unterscheidet somit die Florideen wesentlich von den Algen. Die Algen besitzen geschlechtslose Fortpflanzung und bloss neutrale Organe oder Keimzellen. Die Florideen besilzen geschlechlliche Fortplanzung und sexuelle Organe, nämlich Sporenzellen und Samenzellchen. Diess ist der wahre Unterschied; nicht der, dass die Florideen auf doppelte Weise, die Algen auf einfache Weise sich fortpflanzen. Denn von den Florideen, wie von den Leber- und Laubmoosen und den höhern Pflanzen kann man nicht sagen, sie müssen, sondern sie können Keimzellen erzeugen. Die Keimzellenbildung kann ihnen, als die niedrigere Art der Fortpflanzung, auch mangeln. Die geschlechtliche Fortpflanzung aber darf einer Art nicht mangeln, sonst gehörte sie nicht mehr zu den Florideen.

Die Foripflanzung trennt die Florideen weit von den Algen und bringt sie den Moosen sehr nahe. Man könnte sie füglich auch als Meermoose, im Gegensatz von Leber- und Laubmoosen bezeichnen. Sie müssen eine besondere Klasse bilden, und ihren Platz im Systeme unmittelbar vor den Hepaticæe einnehmen, da mit ihnen die Geschlechtspllanzen beginnen. Von den Leber- und Laubmoosen unterscheiden sich die Florideen durch den Mangel der Calyptra an den Sporangien, und durch den Mangel des zelligen Sackes an den Antheridien. Ein anderer Unterschied ist nicht vorhanden; denn die Struktur ist die gleiche, indem die Leber- und Laubmoose ebensowenig ein Gefässbündel besitzen, als die grösseren Florideen. Das Wachsthum ist ebcnfalls das nämliche, und endlich besitzen die Florideen bald eine Frons, bald einen beblätterten Stengel, so gut wie die Lebermoose. 
Ausser den in der Definition angegebenen Merkmalen gibt es keine, welche zum Begriffe der Florideen grhörten, indem alle übrigen allgemeinen Eigenschaften theils auch den Moosen oder den Algen, theils allen (geschlechtichen) Sporenpflanzen oder allen Pflanzen überhaupt zukommen. Doch können noch einige typische Eigenthümlichkeiten hervorgehoben werden, welche die Art und Weise und den Umfang bezeichnen, wie sich der Regriff realisirt. Dahin gehört erstlich, was die Lebensweise im Allgemeinen betrifft, dass die Florideen bloss im Veere wohnen, während die Moose nie daselbst vorkommen; - ferner , was das Zellenleben betriff, dass die Zellen der Florideen einen rothen Farbstoff enthalten, welcher leicht grün wird, während der Farbstoff der Moose ursprünglich grün ist, nachher aber zuweilen roth oder braun wird; - ferner ebenfalls in Bezug auf das Zellenleben, dass die Kerne bei den Florideen wandständig sind wie bei den Moosen, während sie bei den Algen meist central liegen; - endlich, was den Unfang der vegetativen Entwicklung betrifft, dass es bei den Florideen keine eimzelligen Pflanzen giebt, wie bei den Algen, sondern dass sie mit Pflanzen beginnen, die bloss aus Zellenreilien bestehen, und in allmäliger Entwicklung bis zu solchen sich erheben, deren Stamm ein Zellkürper, und deren Blätter Zellschichten oder ebenfalls Zellkürper sind, - dass somit die untersten vegetativen Entwicklungsstufen der Algen den Florideen mangeln, und dass diese letztern nur in wenigen Formen diejenige vegetative Entwicklungsstufe erreichen, welche der grossen Mehrzahl der Moose eigenthümlich ist.

Die Verschiedenheiten, welche die Florideen untereinander zeigen, können, da sie sowolıl in Bezug auf das Zelle:aleben als auf die Fortplanzung (Bildung der Sporen in den Specialmutterzellen, und Verhalten der Samenzellchen) im Allgemeinen übereinstimmen, nur in folgenden 5 Momenten liegen: 1) in der Entstehungsweise der entwickelten Phanze aus der Sporen- oder Keimzelle, 9) in der Entstehungsweise der Specialmutterzellen an der entwickelten Pflanze, 3) in der Entstehungsweise der Samenzellehen ebendaselbst.

In Rücksicht auf die Entstehungswcise der entwickelten Pflanze aus der Fortpflanzungszelle findet sich bei den Florideen zwar keine so grosse Verschiedenheit wie bei den Algen, aber doch eine viel betüichtlichere Mannigfaltigkeit als bei den Moosen. Wenu es auch keine einzolligen Pfanzen giebt, so zeigen doch die 
Achsen von dem einzelligen Zustande durch die Zellenreihe und Zellschicht alle möglichen Zwischenslufen bis zum ziemlich complizirten (flachen oder cylindrischen) Zellkörper. Diese Achsen entwickeln sich ferner, ohne Rücksicht auf ihren Bau, nach verschiedenen Zelleubildungsgesetzen, und stimmen darin bald vollkommen mit einzelnen Algen, bald mit vielen Mloosen übcrein. Abgesehen von dem Bau und der Entstehungsweise der Achsen ist bei den Florideen entlich die ganze Pflanze bald cin Laub (frons), bald ein beblätterter Stamm, ein Punkt, worin sie somil mil den Algen und besonders mit den Lebermoosen übereinslimmen. Diese Verschiedenheiten der vegetativen Entwicklung geben die vorzüglichsten Nerkmale für Galtungen, Familien und selbst für Ordnungen.

In. Rücksicht auf die Entstehungsweise der Specialmutterzellen an der entuickelten Pflanze sind in zwei Beziehungen Verschiedenheiten vorhanden, 1) welche bestimmte Zellen der Pflanze zu Mutterzellen werden, 2) auf wclche Weise in den Mutterzellen die Specialmutterzellen auftreten. W'as den ersten Punkt betrift, so finden wir da eine grosse Mannigfaltigkeit im Allgemeinen und zugleich eine grosse Constanz im Einzelnen, so dass für die Ordinungen, Familien und Gatlungen die Stellung der Mutterzellen (die Bezeichnung der Zellen, welche in Mutterzellen sich umwandeln) meist durch einen einfachen Ausdruck formulirt werden kann. Was den zweiten Punkt betrifft, so sind die oben angeführten drei Bildungsweisen für die Specialmutterzellen möglich : die tetraëdrische, kugelquadrantische und zonenförnige. Dieselben sind bloss für die Bestimmung von Gattungen anwendbar, scheinen hier aber ron ausnahmsloser Constanz zu sein.

In Rïcksicht auf die Entstehungsweise der Samenzellchen an der entuickelten Pflanze lassen die wenigen bekannten Thatsachen auf nicht unbedeutende Verschiedenheiten schliessen. Aber die jetzige Kenntniss der Antheridien bei den Florideen ist allzusehr fragmentarisch, als dass man irgend elwas über ihren Werth zur Begründung von Ordnungen, Familien und Gattungen sagen könnte.

Ich habe, bei der Betrachtung der Verschiedenheiten, welche die Florideen unter einander zeigen, und welche für die Begriffshestimmung der Ordnungen, Familien und Gattungen von Wichtigkeit sind, diejenigen Verschiedenheiten rernachlässigt, welche in der Entstchungsueise der Koimzellen liegen, nicht weil sie unbrauchbar oder unwichtig sind, sondern weil ihr Werth mehr 
ein zufälliger genannt werden muss. Entwickluugs- und Wachsthumsgeschichte, so wie die Fortplanzung sind für die Kenntniss einer Planze nothwendig, sie sind aber auch genügend. Wenn die Pflanze ausserdem eine oder mehrere Arten der Vermehrung besitzt, so kann das den Begriff der Pflanze nicht ändern auch nicht näher bestimmen, da die Vermehrung mit den reproductiven und namentlich mit den vegetativen Verhältnissen im innigsten Zusammenhange steht, und nichts anders als der modificirte Ausdruck oder die Ietamorphose einer Seite der Vegetation selbst ist. Wenn daher das Wachsthum und die Fortpflanzung einer Floridee vollständig bekannt ist, so wird die Kenntniss der Vermehrung ein blosser Pleonasmus sein. So lange aber die Erforschung, namentich der vegetativen Verhältnisse fragmentarisch bleibt, muss die Vermehrung als ein wichtiges und unentbehrliches Ergänzungsmittel betrachtet werden, welches die Wachsthumsgeschichte oft anschaulicher ausdrückt, als der anatomische Bau selbst, wie diess z. B. bei mehreren Ceramiaceen der Fall ist.

\section{GERAMIAGEFE.}

Mehrzellig, jede Achse besteht aus einer Zellewreihe, seltener aus einer Zelle; Sporenmulterzellen seitlich, silzend oder gestielt.

Die Ceramiaceen stimmen in vegetativer Hinsicht mit den Lyngbyeen, Ectocarpeen, Conferveen und Chantransicen unter den Algen überein. Es sind verästelte Zellenreihen, welche entweder ein Laub oder einen beblätterten Stamm darstellen. Die Blätter haben den gleichen Bau wie die Stämme, oder es sind unverästelte Zellenreihen, oder selbst einfache Zellen. - Das Wachsthum der Achsen geschiet so, dass die Scheitelzelle (primäre Zelle des $\mathbf{n}^{\text {ten }}$ Grades) sich durch eine horizontale IVand in eine neue Scheitelzelle (primäre Zelle des $n+1^{\text {ten }}$ Grades) und in eine Gliederzelle ( $n^{\text {te }}$ secundäre Zelle) theilt. Die Gliederzellen theilen sich nicht mehr, weder durch horizontale noch durch senkrechte Wände, so dass die Zellenreihen bloss durch Zellenbildung in der Endzelle wachsen. Für den Begriff der Ordnung ist besonders wichtig, dass die Gliederzellen sich nicht durch 
Gewebezellbildung in seitlich nebeneinander liegende Zellen theilen, dass somit die Achsen immer Zellenreihen bleiben, während sie in den folgenden Ordnungen zu Zellschichten oder Zellkörpern sich entwickeln. Die Gliederzellen besitzen aber das Vermögen auszuwachsen und Astzellen zu erzeugen, aus welchen Tochterachsen hervorgehen; diese sind je nach Umständen Laub-, Stamm-, Blatt- oder W urzelachsen.

Bei mehreren Gattungen, z. B. Ceramium, Spyridia, Ptilota, Dudresnaya u. s. w. scheint die anatomische Untersuchung auf den ersten Anblick darzuthun, dass die Hauptachsen nicht Zellenreihen, sondern Zellkörper seien; es wird daher bei diesen Gattungen immer von einer Rinde gesprochen. Aber es zeigt einerseits die Entwicklungsgeschichte, dass diese scheinbare Rinde nicht wie die ächte Rinde durch Theilung der Gliederzellen, sondern als ein Geflecht von Wurzelfäden entsteht; anderseits zeigt eine genaue Betrachtung des entwickelten Zustandes, dass die scheinbare Rinde nicht wie ein ächtes Zellgewebe, sondern bloss wie ein Geflecht von Zellenreihen sich verhält, indem nur die übereinander liegenden (Gliederzellen der gleichen Reihe) nicht die nebeneinander liegenden Zellen (Gliederzellen verschiedener Reihen) durch Poren verbunden sind.

Die Sporenmutterzellen sind bei den Ceramiaceen Scheitelzellen (primäre Zellen), entweder des ersten Grades, dann sind sie seitlich und sitzend, oder eines folgenden Grades, dann sind sie seitlich und (mehr oder weniger lang) gestielt. Bloss eine einzige Art (Callithamnion seirospermum Griff.) scheint von dieser Regel eine Ausnahme zu machen, indem die Sporenmutterzellen in Reihen stehen sollen; so dass sie dann also veränderte Gliederzellen wären. Ich sehe nun zwar diese erweiterten und dunklern Zellen, aber finde daran keine Theilung, um Sporen zu erzeugen. Da auch Harvey der Theilung dieser Zellen nicht erwähnt, so bleibt es mir immer noch sehr zweifelhaft, ob es wirklich Sporenmutterzellen seien. Mag dem aber sein wie ihm wolle, so unterscheidet die morphologische Bedeutung der Sporenmutterzellen die Ceramiaceen immerhin absolut von den Delesseriaceen, Rhodomeniaceen und Lomentariaceen, wo die Sporenmutterzellen immer im Gewebe liegen, und weder Scheitelzeilen (primäre Z.) noch Gliederzellen (secundäre Z.) sind.

Die Keimzellen stehen in Keimhäufchen beisammen, welche seitlich an den 
Hauptachsen (Laub oder Stamm) befestigt sind. Die Keimhäufchen sind nie im Gewebe oder in besondern Keimbehältern eingeschıssen, wie diess bei den drei folgenden Ordnungen der Fall ist. Selten findet man sie in das Geflecht der Wurzelfäden eingesenkt. Bei Wrangelia penicillata sind die Keimzellen getrennt und nicht in Häufchen vereinigt.

Zu den Ceramiaceen gehören die Gattungen Callithammion Lgb), Griffthsia Ag., Wrangelia Ag., Spyridia Harv., Ceramium Adans., Ptilota Ag., Crouania J. Ag., Dudresnaya Bonnem., nebst den verwandten Gattungen, - wahrscheinlich anch Bindera J. Ag., Microcladia Grev., Naccaria Endl., Gloiocladia J. Ag.

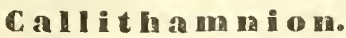

TAB. VI, FIG. $50-57$.

Die Pflanze besteht aus gegliederten, verästelten, confervenartigen Fäden (Fig. 50 - 52). Die Achsen sind also Zellenreihen. Sie beginnen mit Einer Zelle, nämlich mit der Sporenzelle oder der Keimzelle, wenn sie die erste Aelıse einer Pflanze, und mit einer Astzelle ( $F i g .50, d$ ), wenn sie irgend eine andere spätere Achse der I'flanze sind. Diese erste Zelle, in der das Wachsthum einer Achse beginnt, ist die Scheitelzelle oder die primäre Zelle des er'sten Grades $\mathbf{~}^{1}$. In Fig. 53 ist die Sporenzelle, in Fig. 54 eine Astzelle so bezeichnet. Diese Zelle wächst in der Richtung, welche die entstehende Achse bezeichnet, und theilt siclı durch eine Wand, welche die Aelıse ziemlich unter einem rechten Winkel schneidet (Fig. 50, e). Die untere der beiden Tochterzellen bildet keine Zellen meh', sie ist die erste secundäre Zelle, , II (Fig. 54, 56). Die obere der beiden Tochterzellen dagegen wächst wieder in der Richtung der Achse, und theift sich wieder durch eine horizontale Wand; sie ist die primäre Zelle des zweiten Grades, $I^{2}$ (Fig. 5/, 56). Ihre beiden Tochterzelten sind die zweite secundäre Zelle, ${ }_{2} I I$, und die primäre Zelle des dritten Grades, $\mathrm{I}^{\overline{5}}$ (Fig. 54). Die letztere theill sich abermals dureh eine horizontale Wand in die dritte secundäre Zelle, 3 II, und die primäre Zelle des vierten Grades, ${ }^{4}$ (Fig. 57).

Das Wachsthum der Achsen von Callithamnion geschieht allein durch die Zellenbildung in der Endzelle oder der primären Zelle. Es beginnt für jede Achse mit der primäıen Zelle des ersten Grades, und selzt sich fort durch die primäre Zelle eines folgenden Grades. Es lässt sich ausdrücken durch die Formeln: $\mathrm{I}^{1}=\mathrm{I}^{2}+, \mathrm{II}$;

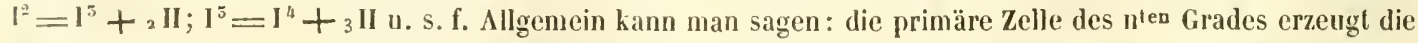
primäre Zelle des $n+1$ ten Grades und die $n^{\text {le }}$ secundäre Zelle :

$$
I^{n}=I^{n+1}+n I I\left(^{1}\right)
$$

Die Achsen von Callilhamnion bestehen mit Ausnahme der Endzelle aus secundïren Zellen, und zwar von Inten an gezählt ans der $1,2,5,4^{\text {ten }} . .$. , von olen an gezählt aus der $n-1, n-2, n-5, n-4$ ten $\ldots$, (Vig. 5 beiden Endnächen andere Zelten und haben eine fıcie Cylinderfäche. - An dem obern Ende einer Achse steht eine primäre Zelle, welche immer wieder neue Zellen bildet und eine cylindrisch-kegelförmige Gestalt lıat. mil angelehnter Grnndlläche nud freier Kegelfäche.

(1) Yergl. ïher diese Formeln Zeitschrift für w. B., lieft 2, pag. 121 n. 
Die Achsen sind abwechselnd-gefiedert. Die secundären Zellen wachsen mit dem obern Theile ilırer freien Cylinderfläche nach einer Seite hin aus (Fig. 50, c). Durch Zellenbildung wird der ausgewachsene Theil zur Astzelle (Fig. 50, d). Eine secundäre Zelle erzeugt bloss Eine Astzelle. Die Astzellen stehen abweclıselnd nach rechts und nach links. Die Ranificationen der Tochterachsen liegen in der gleichen Ebene nit denjenigen der Multerachse. Alle secundären Zellen bilden, wie es scheint, neue regetative $\Lambda$ chsen mit Ausnalıme von denen, welche Sporennulterzellen oder Keimhäufchen (oder Antheridien) erzeugen. An den Enden der $\Lambda$ chsen findet man wenigstens die Verästlung regelmässig vorhanden. An ältern Theilen, namentlich an der Basis der Achsen mangelt sie stellenweise, und es ist dann nicht auszunitteln, ob alle nackten secundären Zellen früher Fortpflanzungsorgane getragen haben. - Eben so scheint es zuw eilen an ältern Theilen der Achsen, als ob 2 Aeste zweier successiver Glieder nach der gleichen Seite gerichtel seien. Ich glaube aber, dass das daher rühır', dass die Tochterachse sich stärker entwickelte als die Ilauptachse, und daher als die Fortsetzung dieser letzlerı erscheint, wälırend die walıre Fortsetzung der Hauptaclıse seitlich gerückt und astähnlich ist.

Alle Achsen sind einander gIcich, und demnach Laubachsen. Sie wachsen unhegrenzt durch Zellenbildung in der primären Zelle, und erzeugen aus den secundären Zellen unbegrenzt Tochteraclısen.

In einigen Arten (C. roseum, C. tetricum etc.) wachsen die untersten Zellen der Achsen, also die ersten secundären Zelten (,II iı Fig. 5/4) nit dem untersten Theile der Cylinderfläche aus, und erzeugen eine Zelle : auf gleiche Weise wie sie nach oben die Astzellen bilden. Diese Zelle wächst in eine Zellenreihe aus, welche senkrecht nach unten sich verlängert, und die ich Wu'zelfaden nennen will. Die Wurzelfäden wachsen, wie die äbrigen Achsen von Callithammion, durch Zellenbildung in den primären Zellen. Sie verästeln sich selten. Die Wurzelfäden sind in grösserer oder geringerer Menge vorhanden, sie legen sich an die Laubachsen locker an, oder stehen etwas von derselben ab. Kützing $\left(^{1}\right)$ nennt die Wurzelfiden "Rinde, stratum corticale, " und baut auf deren Anwesenheit seine Gattung Phlebothammion. Gegen die Bezeichnung als Rinde spricht die lockere Verbindung, oder vielmehr der Mangel an Verbindung mit den Laubzellen, welche von ihnen bedeckt werden. Wo sonst an Florideen eine Rinde auftritt, da sind die Rindenzellen innig mit den innern Zellen verbunden, so dass sie nicht ohne Verletzung davon getrennt werden können; es sind ferner Poren zwischeı ihnen und den innern Zellen. Beides aber ist bei den Wurzelfäden von Callithammion nicht der Fall. Ebenfalls begründet die $\Lambda \mathrm{n}$ - und Abwesenheil dieser Gebilde keinen absoluten Unterschied zwischen den Arten von Callithamnion, so dass darauf die Diagnosen von 2 Gattungen gebaut werden könnten. Denn in den einen Arten sind sie zahlreich, in den andern spärlich, und treten erst an dem untern Theile älterer $\lambda$ chsen auf. Jüngere Individuen von $C$. tetricum, $C$. roseum pllanzen sich schon durch sporen oder durch Keimzellen fort, ehe noch eine Spur von Wurzelfäden vorhanden ist. Von fructifizirenden Exemplaren darf man aber gewiss annelımen, dass sie alle wesentliclıen und die fïr Gattungsdiagnosen allein zulässigen Eigenschaften besitzen. Allmälig hat sich die Ueberzeugung Bahn gebrochen, dass eine Pflanze erst dann als vollkommen betrachtet werden darf, wenn sie fructilizirt. Man hat desswegen eine Menge von Pilzgattungen beseitigt, welche bloss die Anfänge höherer Pilzformen waren. Umgekehrt muss ebenfalls als Regel festgelıalten werden . dass eine Pflanze dann schon als vollkommen betrachtet werden muss, sobald sie fruetifizirt, und dass alle spätern Veränderungen an ilır als unwesentliche aus den Diagnosen zu beseitigen seien. Man läuft sonst wieder Gefahr, das Gleiche dopjelt zu benennen.

Die Sporemmutterzellen stehen seitlich an den Laubachsen, je eine auf einer secundären Zelle, welche keine vegetative Tochterachse erzeugt hat. Man trift sie gewöhnlich an den untern Theile der Laubachsen, und zwar auf der der Multerachse zugekehrten Seite der secundären Zellen (Fig. 52). Zuweilen stehen auch noch einzelne Sporenmutterzellen in dem weiteren Verlaufe der Achsen, und dann nelımen sie die Stelle einer vegetativen Tochterachse ein. Sie entstehen auf gleiche Weise wie die $\Lambda$ stzellen durch Auswachsen der secun-

(') Phycol. gen... pag. 3is. 
dären Zellen und Zellenbiłdung in dem ausgewachsenen Theile. Sie unterscheiden sich dadurch von den Astzellen, lass sie in der Regel einzeilig, nicht zweizeilig stehen. - Die Zahl der Sporenmutterzellen, welehe an dem unlern Theilè einer Achse stchen, ist unbestimmt. Einzelne Glieder bleiben frei. - Die 4 Sporen lıaben eine tetraëdrische Stellung.

Die Keimhäufchen sitzen seitlich an den Laubachsen. Entweder steht nur eines auf einer secundären Zelle, welche sonst keine Astzellen und keine Sporenmutterzellen erzeugte; sie sind in diesem Falle bloss an den unter'ı secundären Zellen einer Laubachse vorhanden und nach der Intterachse gekehrt (Fig. 3l, g). Oder es stehen 2 Keimläufchen gegenüber an einer secundären Zelle, welche eine vegetative Achse trägt; jedes ist von der Insertionsstelle dieser letztern um $90^{\circ}$ entfernt. Die Zelle aus der ein Keimhäufchen entsteht, bildet sich, wie die Astzellen und die Sporenmutterzellen, durch Auswachsen des obern seitlichen Theiles einer secundären Zẻle. — Die Keimhäufchen bestehen aus einer Menge von Keimzellen, und sind mit einer starken Schicht von gallertartiger Extracellularsubstanz ungeben.

Der Inhalt aller Zelten ist rosenroth, auch der primären Zellen. Die Wurzclfäden sind schwach röthlich. Dic Sporenzellen und die Keimzellen sind intensiver gefärbt. - In der Scheidewand zwischen je 2 Zellen liegt ein centraler Porus, welcher, wenn die Wandung dick genug ist, deutlich zu sehen ist (Fig. 53).

\section{Antifhamaion.}

(Callithamnion cruciatum Ag.)

TAB. Vl, F1G. $1-6$.

Der Bau und das Wachsthum der Achsen verhält sich wie in Callithamnion. Es sind Zellenreihen, die aus secundären Zellen bestehen, und durch Zellenbildung in der primären Zelle wachsen nach der Formel: $1^{n}=1^{n+1}+{ }_{n} \mathrm{II}$. Von den beiden Tochterzellen, die in der primären Zelle, durch eine, die Achse unter einem rechten Winkel schneidende Wand, entstehen, ist die secundäre Zelle immer kleiner als die neue prinı̈re Zelle (Fig. 2, a und b; g).

Es giebt zwcierlci Arten von Achsen, unbegrenzte und begrenzte. In den erstern dauert das Wachsthun ader dic Zellentildung in der Endzelle immer fort, bis das Individuum zu Grunde geht. Sie sind Stammachsen. In den zweiten währt das Wachsthum nur eine gewisse Zeit. Sie sind Plattachsen. Für beide gilt die Formel $\mathrm{I}^{\mathrm{n}}=\mathrm{I}^{\mathrm{n}+1}+{ }_{\mathrm{n}} \mathrm{II}$, aber mit dem Unterschiede, dass $\mathrm{n}$ im Wachsthume der Stämme die Werthe $1,2 \ldots \infty$, im Wachsthume der Blätter 1, 2... p annehmen kann, wobei p eine unbestimmte aber limitirte Zahl ist.

Jedes Stammglied trägt 2 gegenüberstehcnde Blätter (Fig. 1, f, f; 2, e, e, g, g). Dic Blattpaare alterniren an den successiven Gliedern um einen rechten Winkel; die Blätter stehen somit in 2 Ebenen oder vierzeilig. Die secundären \%ellen der Stammachsen wachsen an 2 gegenüberliegenden Punkten aus (Fig. 2, c), und erzeugen 2 Astzellen (oder primäre Zelłen des ersten Grades) für die beiden Blätter (Fig. 2, e, e). Diese Blattbildung schreitet hinter der wachsenden Stammspitze fort, im gleichen Verhältnisse wie diese, und ist ebenfalls unbegrenzt wie diese. - Selten bilden die Stammaclısen eine neue Stammachse (einen $\mathbf{A s t}$ ). Dieselbe verhält sich in alten Stïcken, wie ihre Mutterachse. Sie wächst unbegrenzt durch Zellenbildung in der prinären Zelle und bildet immerfort Bläitter.

Die Błïtter (Fig. 1, 5, 4) verästeln sich in der gleichen Ebene; ilıre Aestehen sind zweizeilig. Diese Ebene ist tangental zum Stamme, d. h. sie bildet eimen rechten Winkel zu der Ebene, welche die Stammachse und die 
primäre Blattachse mit einander bilden. Die Verästelung der Blätter ist begrenzt; ausser der primären Achse werden gewöhnlich bloss secundäre und tertiäre Achsen gebildet, welche ebenfalls begrenzt sind. Das unterste Glied der primären Achse bleibt gewöhnlich ohne Verzweigung (Fig. 1, a; 3, 1). Ebenso sind die letzten $4-8$ Glieder nackt (Fig. 1, b). Die untern Glieder tragen häufiger gegenüberstehende, die obern häufiger einzelne urd abwechselnde Aestchen. Doch gielht es in dieser Hinsicht durchaus keine feste Regel. - Aus der untersten Blattzelle wächst zuweilen ein gegliedertes Wurzelhaar hervor (Fig. 4, r).

Ausser den Unterschieden zwischen Stämmen und Blättern, welche im Wachsthume und in den Stellungsverhältnissen der Achsen begründet sind, giebt es ferner Verschiedenlıeiten in Bezug auf die secundären Zelien. Diese sind einmal ungleich, wenn man bloss aut die Quantilät ihrer Ausdelınung Rüchsicht nimmt. Die secundären Stammzellen wachsen ron $0,002^{\prime \prime \prime}$ bis $0,080^{\prime \prime \prime}$ und $0,100^{\prime \prime \prime}$ in die Länge, von $0,003^{\prime \prime \prime}$ bis $0,020^{\prime \prime \prime}$ in die Breite, so dass ihr Längendurchmesser un das länfzigfache, ihr Breitendurchnesser um das Siebenfache zunimmt. Das Wachsthum der secundären Blattzellen ist bedeutend geringer. Ein wichtigerer Unterschied liegt in der $\Lambda$ rt und Weise, wie sie Astzellen bilden. Die secundären Stammzellen wachsen mit dem obern Theile ihrer Seitenfäche (Fig. 2, c), die secundären Blattzellen mit dem untern Tlıcile ilırer Seıtenfäche aus (Fig. 5, d, e). Desswegen sitzen die jungen Blätter oben an den Stammgliedern (Fiğ. 2, e, g), die jüngsten Seitenachsen der Blätter dagegen sitzen mehr unten an den Blattgliedern (Fig. $\bar{\jmath}, \mathrm{f}$ ).

Ein anderer wichtiger Unterschied zwischen den secundären Zellen der Stämme und der Blätter liegt in der $\Lambda$ rt und Weise, wie sie sich ausdehnen. Wie eben gesagt, sitzen die jungen Blätter an dem obern Theile der Seitenfläche der Stammzelle und berühren, so zu sagen, die obere Scheidewand. Sie behalten diesé Stellungr, bis die Stammzelle 0,020 "' lang geworden ist, und also fast das Zehnfache iłırer ursprünglichen Länge erreicht hat. Nun fängt das Blatt an, von der Scheidewand weg und nach unten zu rücken, indem sich die dazwischen gelegene Zellmembran ausdehnt. lch will den über der Anheftungsstelle des Blattes liegenden Theil der Seitenwandung $m$, den unterhalb derselben liegenden Theil $n$ und die ganze Länge der Stammzelle $c$ nenıen. Ichı finde an verschiedenen Gliedern der głeichen Stammachse folgende Verhältnisse :

\begin{tabular}{rl|l|l|l|l|l|l|l}
$c$ & $=$ & 0,004 & 0,013 & 0,020 & 0,023 & 0,070 & 0,080 & 0,087 \\
$n=0,002$ & 0,011 & 0,013 & 0,021 & 0,059 & $0,06 \Xi$ & 0,062 \\
$m=$ & 0 & 0 & 0 & 0,0003 & 0,003 & 0,009 & 0,013
\end{tabular}

Die Dimensionen sind in Linien angegeben. Aus diesen Thatsachen geht hervor, dass die Ausdehnung der Zellmembran an verschiedenen Theilen der Zelle ungleich ist. $n$ delınt sich um das Sichen-bis Achtfache aus. während dem $m$ unverändert bleilst. Dann beginnt auch das letztere sich zu vergrössern, und thut es viet rascher als $n$. Denn es dehnt sich mehr als um das Dreissigfache aus, indess $n$ nur 5 bis 4 mal langer wird. Endlich bleibt $n$ stabil, und $m$ nimmt noch ungefähr um das boppelte zu. Diese Facten beweisen, dass die Ausdehnung der secundären Zellen der Stammachsen von Antithammion in dem untern Theile beginnt, und thätig ist, während sie in dem obern Theile noch nicht angefangen lıat, und dass sie im obern Theiic noclı fortdauert, nachdem sie im untern Theile aufgehört hat.

Anders verhalten sich die secundären Zelten der Blätler. Dieselben wachsen, wie ich olsen gesagl, mit dem untern Theile der Seitenwand aus, und die dadurch gebildete Tochterachse nimmt ursprünglich die untere hälfte der Seitenwand ein, und berührt fast die untere Scheidewand. Wenn sich die Zellen in die Länge delınen, so rergrössert sich der Zwischenraum zwischen der Anheftungsstelle der Tochterachse und der ohern Scheidewand unbedeutend oder gar nicht. Dagegen erweitert sich der Zwischenraum zwischen der Seilenachse und der untern Scheidewand, der anfänglich fast 0 war, strtig bis auf $0,008^{\prime \prime \prime}$ und $0,010^{\prime \prime \prime}$. Daraus ergiebt sich für die Ausdehnung der secundären Zellen der Bläiter, dass dieselve in dem untern Theile der Nembran bedentender ist und länger dauert, als in dem obern; und man kanı sagen, dass die Ausdelınung oben zuerst 


\section{- 202}

beginne und unten zuletzt aufhöre, dass sie also das umgekehrte Verhältniss zeige von der Ausdehnung der secundären Stammzellen.

Die primären Zellen, wodurch die Stämme und die Blätter wachsen, enthalten einen homogenen, ungefärbten Schleim; ebenso die jungen secundären Zellen. In den letatern wird er körnig und röthlich. Er legt sich dann an die Zellwand, fảrbt sich intensiver und erscheint zulelzt als dünne, unregelmässig gekrümmte, der Membran anhaftende Fasern. In alten Zellen sind dicselben farblos. - Die Scheidewände zwischen 2 secundären Zellen der gleichen Achse, und ebenso diejenigen zwischen den secundären Zellen einer Achse und den ersten secundären Zellen ihrer Tochterachsen besitzen jede einen centralen Porus (Fig. 5, 6). Die Membranen berïhren sich nicht an der ganzen Porusfläche, sondern bloss am Umfange, in der Mitte weichen sie zu einem schmalen elliptischen Raume auseinander. Die Poren der Stammzellen (Fig. 6) sind beträchtlich grösser als diejenigen der Blattzellen (Fig. 5). Wenn durch äussere störende Einwirkung, durch Quetschen, durch Säuren etc. der Inhalt sich von der Membran loslöst und sich contrahirt, so bleibt er durch dünne Fortsätze mit diesen poren in Verbindung.

Die Sporenmulterzellen stehen seitlich an den secundïren oder tertï̈ren Blattachsen und zwar gewöhnlich an dem ersten, doch auch an dem zweiten Gliede (Fig. 1, 4, s, s). Die 4 Sporen stehen telraëdrisch beisammen. Die in Fig. 1 und 4 gezeịchncten Sporenmutterzellen sind verkümmert und mit dichtem, homogenem, farblosem schleime gelällt. Alle Exemplare, die ich in Sorrento bei Neapel fand, besassen solehe abortirte Multerzellen, vielleicht weil sie nicht befruchtet wurden; wenigstens konnte ich keine Antheridien auffinden.

Ich will noch die Eigenthïmlichkeiten der Stämme und der Blätter vergleichend zusanmenstellen, um zu sehen, mit welcher Berechligung bei Antithammion diese beiden Organe angenommen werden können. Die Stämme wachsen unbegrenzt. Die Blätter wachsen begrenzt. Die Stämme erzengen sowohl nnbegrenzte (Stamm-) als begrenzte (Blatt-) Achsen. Die Blätter erzengen bloss begrenzte (seitliche Blatt-) Achsen. Die secundären Stammzellen wachsen mil dem obern Seitentheile, die secundären Blattzellen mit dem untern Seitentheile der Membran aus, um eine Astzelle zu erzeugen. Die Ausdehnung der Membran der secundären Stammzellen schreitet von unten nach oben, die Ausdehnung der secundären Blattzellen von oben nach unten fort. Die Stämme vervielfültigen die Pflanze durch Erzeugung von neuen gleichen Stämınen, durch Sprossenbildung. Die Bläller tragen die sexuellen Fortpflanzungsorgane. Wir sehen somit, dass im Wesentlichen die Unterschiede zwischen Stamm und Blatt die gleichen sind wie bei den höhern Pflanzen; und es mïssen für diese Unterschiede auch die grleichen Benennungen gehraucht werden, weil die Begrifle die nämlichen sind, - obgleich die Blätter von \er gewöhnlichen Blatıform abweichen. Diese gewöhnliche Blatlform ist aber nicht die ausschliessliche, und wir finden für die Blätter von Antithammion unabweissbare Analogieen in den Blättern von Jungermannic trichophylla L. und J. setacea Web., deren Blattnatur nicht bestritten wird.

Die Gattung Antithammion unterscheidet sich von Callithammion dadurch, dass erstere cinen beblätterten Stamm besizl (wo an den unbegranzten, hin und wieder verästelten Stammachsen alternirende Blaltpaare stehen), während letzlere ein Laub hat (dessen unbegrenzle Achsen alternirend-gefiedert sich verästeln). Die einzige mir bekannte Art ist $A$. cruciatum (C. cruciatum $A g$.$) .$

\section{Pocilothamnion.}

(Callithamnion versicolor Ag., etc.)

TAB. VI, Fig. $7-29$.

Die Achsen sind Zellenreihen wie in Callithamnion. Das Wachslhum ist das nämliche : $\mathbf{I}^{\mathrm{n}}=\mathbf{I}^{\mathrm{n}}+\mathbf{1}+{ }^{\text {II. }}$. Alle Achsen sind einander gleich, also Laubachsen. Wenn man an einer Ilauptachse von oben nach unten 
nacheinander die Tochlerachsen untersucht, so findet man, dass sie stetig linger werden, dass sie also stetig und unbegrenzt sich verlängern. Dennoch ist das Spitzenwachsthum jeder einzelnen Achse begrenzt; die Achsen endigen in dünne lange Borstenzellen, in denen keine Zellenbildung mehr statt findet. In den secundxren Zellen der Achsen werden ebenfalls keine neuen Zellen erzeugt. Obgleich nun an Pocilothamion unbegrenzte Centralachsen und begrenzte Scitenachsen zu unterseheiden sind, so sind dieselben doch nieht den Stammorganen und Blattorganen in Antilhamnion analog. Denn auch die unbegrenzten Centralachsen enden in eine begrenzte Spitze; aber die Spitze wird immer wieder seitlich gerückt, indem fortwährend die sich starker entwickelnden Tochterachsen als die Fortsetzung der Centralachsen erscheinen. Da nun die Erzeugung neuer Tochterachsen unbegrenzt ist, so muss auch das Wachsthum der Centralachsen unbegrenzl sein. Die begrenzten Seitenachsen können immer auch wieder zu unbegrenzten Centralachsen werden, wenn sie sich unbegrenzt verasteln.

Das unbegrenzte Wachsthum von Pocilothammion beruht daher in einer unbegrenzten Wiclerholung von begrenzten Achsen. Die Centralachsen (welche Seitenachsen tragen) bestehen aus je dem untersten Gliede einer andern Achse; sie sind gemischte Achsen. Die letzten Seitenachsen dagegen, welche heine Veræstelungen tragen, sind reine Achsen. Die untersten secundxeren Zellen einer reinen Achse erzeugen Astzellen (durch Auswachsen des obern Theiles der Seilenwand und Zellenbildung in dem ausgewachsenen Theile). Sie werden dadurch Elemente von gemischten Achsen, indem die Tochterachse stærker sich entwickelt, und als die Fortsetzung der Mutterachse erscheint. So war in Fig. $7 \mathrm{a}-\mathrm{r}$ ursprïnglich eine reine Achse, $\mathrm{b}-\mathrm{r}^{\prime}$ war dereı Tochterachse, $\mathrm{c}-\mathrm{r}^{\prime \prime}$ war 'die Tochterachse von $\mathrm{b}-\mathrm{r}^{\prime}$. Durch das siærkere Wachsllum der Tochterachsen erscheint nun aber $b$ als die Fortsetzung von a, e von b, d von c, und damit ist die gemischte $\Lambda$ chse a - d entstanden.

An einer Centralachse stehen die Seitenachsen alternirend mit der Divergenz von "\% $\%$ (' $\%$ des Umfanges), je eine auf einem Gliede; sie sind also 4 zeilig (Fig. 7, 21, r, $\mathbf{r}^{\prime}, \mathbf{r}^{\prime \prime}$ ). Das erste Glied einer Seitenaclıse ver:estelt sich in einer Ebene, welche zur Centralachse tangental ist. - Die Astzelle, welche von der ersten secundæren Zelle einer reinen Achse erzengt wird, zeigt also eine horizontale Abweichung von $90^{\circ}$ von ihrem eigenen Anheftungspunkte an der Multerachse; und diese Divergenzen der suceessiven Tochterachsen, welche auf der ersten secundæeren Zelle stehen, schreiten ohne Unterbruch in der gleichen (schraubenförmigen) Richtung fort. - Die Astzelle, welche von der zweiten secundæren Zelle einer reinen Achse erzeugt wird, divergirt von der Aslzelle der ersten secundæren Zelle ebenfalls um einen Winkel von $90^{\circ}$. Dic Seitenachsen erscheinen hreufig dichotomisch (Fig. 11); es ist aber keine wahre Diehotomie, so dass je 2 Achsen derselben gleichwer(hig wæren; sondern die eine verhæll sich zur andern immer als Hutterachse zur Tochterachse. Durch raschere Entwicklung wird die letztere der ersteren xhnlich. Diese Pseudodichotomieen alterniren mit einer Divergenz ron $180^{\circ}$; es rührt diess daher, weil die Tochterachsen an der Nutterachse in der Spiralstellung von $4 / \pi$ stehen.

Sowohl aus der ersten (untersten) Zelle einer Seitenachse, als aus allen übrigen Zellen der gemischten älteren Achsen wachsen gegliederte und spærlich veræstelte Wurzelfäden nach unten. Aus einer Zelle kommen 1, 2. 5 solcher Faden hervor, sie liegen lose um die Mutterachsen, oder stehen von denselben ab. Ihre Zellen sind verhältnissmæssig længer und dünner, der Zelleninhalt spærlicher und blasser als in den Laubachsen.

Der Inhalt der jungen primæren Zellen und der jungen secundæren Zellen ist homogener ungefærbter Schleim. In etwas æeltern Zellen wird er körnig, færbt sich röthlich und legt sich dann in Form von rothen, hemisphærischen Klïmpchen, wahrscheinlich Farbblaschen, an die Wandung. Diese hemisphærischen Blaeschen dehnen sich mit dem Wachsthume der Zelle in die Længe. Sie werden dabei etwas schmæler und stellen unregelmxssige kleine Fasern dar, welche meistens die Richtung des Lengsdurelımessers der Zelle halten.

Die Sporemmuterzellen stehen zu 1,2 und 5 seihich an einer secundxen Zelle, welche ausserdem schon einen $\Lambda$ st tragl (Fig. 7), ziemlich in einer senkreehten Reilıe (Fig. 8, 9, 10). Diese Reihe, von welcher die 
miltlere Sporenmutterzelle, wenn 5 vorhanden sind, meist reclıls oder links etwas abweicht (Fig. 9), ist um $90^{\circ}$ von dem Punkte entfernt, wo auf der gleichen secundæren Zelle die Tochterachse sleht. Die Sporenmulterzellen entstelsen wie alle Istzellen: die Seitenwand der secundaren Zelle wachst in einen Fortsatz aus, welcher sich als besondere Zelle abtheilt. Dieser I'rozess schreitet ron oben nach unten fort, indem zuerst die wherste, zuletzt die unterste Sporemmutterzelle an einer secundaren Zelle sich bildet (Fig. 8, 9).

Die Sporenmutterzelle enthalt zuerst homogenen farblosen Selıteim. Derselbe wandelt sich in eine rothe, hörnige Masse um, in weleher man einen centralen, secundaren Kern erkenut. Er ist ein helles durchsiclutiges Blæsehen mit einem kleinen punktartigen kermchen (Fig. 8, b). Dieser secundxre Kern versehwindet; statt seiner trelen vier neue Kerne auf, und darauf theilt sich die Hutterzelle in die 4 tetraëdrisch-gestellten Specialmutterzellen, ron denen jede im Centrum einen der 4 Kerne entlıelt (Fig. 8, c). Diese Kerne sind schön roth gelärbt, was man an absterhenden Specialmutterzellen erkennt, wo der Inhalt grün geworden, die Kerne aber noch ihre ursprüngliche Farbe behalten haben $\left(^{1}\right)$. - Dic Stellung der Specialmulterzellen und somit auch der Sporen ist teträ̈drisch, heohachtel aber ausserdem keine liegel. Oft nimmt eine einzıge Zelle den Scheitel der Mutterzelle ein (Fig. 10, b); oft berühren denselben 2 oder 5 Zellen (Fig. 8, c). Ebenso erfuilit bald eine einzige sjore den untern Theil, bald geht eine trennende Linie bis zur Basis.

Die Aniheridien (Fig. 11 - 19) sind Anhæufungen ron kleinen runden, farblosen Zellchen, die auf einer Interlage von 2, 5 oder 4 kleinen röthlich geforbten Zellen ruhen. An einer secundieren Zelle sind 1, 2 oder 5 soleher IJäulchen befestigt, in derselben Lage wie die Sporenmutterzellen. Sie stehen nämlich in einer senkreehten Linie übereinander, welche $90^{\circ}$ von der Abganersstelle ler Tochterachse entfernt ist; das oberste liegt etwas unterlaalb dieser Stelle. Auch das haben sie mit den Sporenulterzellen gemein, dass zuerst das obere, zuletzl das unterste sich entwickelt (Fig. 12, 16, 17).

Die Bildungsgeschichte der Antlıeridien ist folgende. Sie erscheinen zuerst als einfache Astzelle, daciureh dass die secundare Zelle auswachst und sich abtheilt (Fig. 12, 16). Diese Astzelle theilt sich in 2, in eine untere und innere, und in eine obere und ixussere (Fig. 12, 15, 17). Jede derselben theilt sich wieder in 2 Zellen.

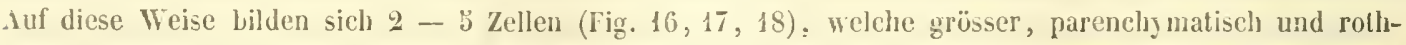
gefierl,t wesden. Die reussern Zellchen dagegen, welehe sphærisch, farblos und kleiner sind, scheinen durch Auswachsen und Abschnüren der zuerst gebildeten innern Zellen zu entstehen. Sie sind die Samenzellehen (Fig. 1ว - 19).

Die Samenzellchen sind alle von gleicher Gestalt und Grösse. Ilır Durchnesser betragt 0,005 '"'. Zuerst mit homogenem oder feinkörnigem Sclileine erfüllt (Fig. 20, a), werden sie dann wasserhell, und enthalten bloss noch cin wandstendiges Kürrachen (Fig. 20, b). Wenn dasselhe von der Seitenflache angesehen wird, so scheint as sich in cine erst dickere und almelig dïnner merdende Linje (Samenfaden?) fortzusetzen (Fig. 20, c, d). Iı diesem Stadium fallen die zellehen ah.

Die Keimzellenhüufchen silzen seillich an den secundicren Laubzellen, auf zwei gegenüberliegenden senkrechten Linien, "welelie $90^{\prime \prime}$ ron der Anheftungsstelle der Tochteraclise entfernt sind. Sie sind zu 2 oder 4 aı einen Gliede vorhanden, und je 2 einander opponirt (Fig. 21, 29). Auf den ersten Anblick scheinen sie Kapseln, d. h. grosse Mutterzellen zu sein, in denen eine Nenge von Keimzellen liegen. Die Entwicklungsgesehichte zeigt aher, dass diese Annahme unrichtig ist. Die secundaren Laubzellen wachsen in einen seillichen Fortsatz ans (Fig. 22, a), welcher zur hesondern Zelle wird (b). Diese Astzelle ist für das entstehende Keimhæufehen die primere Zelle des ersten Grades. Sie theilt sich durch eine die Achse unter einem rechlen Winkel sclıneidende Wand (Fig. 25) in eine erste secunditre Zelle (b) und eine primare Zelle des zweilen Grades (c): $I^{4}=I^{2}+, 11$. Die primare Zelle des zweiten Grades theill sich auf gleiche Weise in die primare Zelle des dritten Grades (Fig. 24, c) und in die zweite secundare Zulle (Fig. 2\%, l) $: I^{2}=I^{5}+.11$. Die Zellenbildung in

(1) Zeitschr. 1. W. Bot., IIeft I, tab. I. Fig. 26. 


\section{$-\quad 205$}

der primären (Scheilel-) Zelle sehreitet auf diese Weise fort, nach der Formel I ${ }^{\mathrm{n}}=I^{\mathrm{n}}+1{ }^{1}{ }_{\mathrm{n}} \mathrm{II}\left({ }^{1}\right)$. Dadurch entsteht ein Strang von secundären Zellen. Die erste, zweite, dritte oder vierte derselben bildet eine Astzelle (Fig. 26, r, r), wolche sich wieder als primäre Zelle des ersten Grades verhält, als solche Zellen bildet, und sich zu einer Tochterachse entwickelt. Alle foigenden secundären Zelten erzeuren ebeufalls $\Lambda$ stzellen und aus denselben Tochlerachsen. Yan kann die Zellenbildung bloss bis auf einen gewissen Junkt rerfolgen. Da aber diejenigen Zellen, welche sich zuerst bilden (die untersten in einem Keimbäufchen), eben so gut Keimzellen sind, als die später gebildeten, so muss angenommen werden, dass diese letztern auf gleiche Art entstehen, wie jene erstern. Die Zellenbildung in cinem Keimzellenhäufehen ist somit die gleiche, wie in einem jeden Aste der Laubachsen. Sie beginnt mit einer primären Zelle des ersten Grades, und bildet Zellen nach der Formel $I^{n}=I^{n}+1+{ }_{n} I I$. Ferner bilden die secundären Zellen der ursprünglichen Achse Astzellen. welehe in neue Achsen auswachsen. Diese Achsen tragen seillich wieder Tochterachsen ete, etc. Zellenbildung in den primären Zellen und Verästelung aus den secundären Zellen gehen unbestimmt weit, sie sind aber beide begrenzt.

Die Richligkeil dieser Annahme in Bezug auf die Entwicklungsgeschichte der Keimhäufehen lïsst sich noch auf eine andere Weise darthun. Wir haben bei Antithamnion cruciatum gesehen, dass die Zellen der gleichen Achse unter sich, und je mit der untersten Zelle der Tochterachse durch einen Porus verbunden sind. Das gleiche ist in der Gattung Poecilothamuion der Fall. Wir finden ferner bei andern Florideen, dass, wenn sich der Zelleninlalt dureh störende äussere Einflïsse von der Hembran zurückzieht, er durch Fortsälze mil den Poren verbunden bleibt; und dass, wenn dabei dureh Säuren die Zeltwände aufgelöst werden, der Inhalt der aneinander. liegrenden Zellen noch durch dünne Stränge zusammen hängt, in deren Mitte man den elıcmaligen Porus erkennt. Wenn nun die Keimzellenhäufchen von Pöcilothamnion vorsichlig mit verduinnter Salpetersäure behandelt und gedrückt werden $\left({ }^{2}\right)$, so gelingt es zuweilen, die ganze Zellenmasse so auseinander zu legen, dass je auf einer untern und innern Zelle 2 obere und äussere Zellen stehen, dass sich also die Zellmasse dichotomisch theilt (Fig. 28). Diese Dichotomie ist, wie diejenige der Aeste, eine falsche, indem yon den 2 Zellen, welche auf einer, z. B. der mlen secundären Zelle stehen, die eine die $m+1^{\text {te }}$ se-

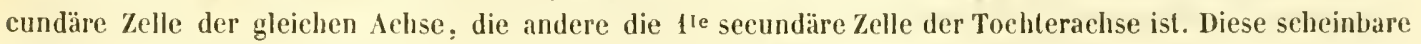
Dichotomie ist hier um so begreiflicher, da die Keimzellenhäufchen begrenzle Aehsen sind; denn bei begrenzten Organen treffen wir bei den Florideen gewöhnlich einen dichotomisehen Anschein im ausgewachsenen Zustande, auch wenn sie nicht dichotonisch entstanden sind, so z. B. bei den haarförmigen Błätlern $\left({ }^{5}\right)$.

Aus der Entwicklungsgeschichte ergiebt sich die morphologische Bedeulung der Keimbäufchen. Es sind metamorphosimle Laubachsen. Zellenbildung und Verästelung ist die gleiehe. Der Untersehied liegt darin, dass die Zellen klein bleiben und sıch nicht in die Länge dehnen, und dass die Achsen slatl sich auseinander zu breiten, sich gegen einander legen. Dadurch entsteht eine zusanmengeballte Zellmasse, wo die einzelnen Zellen dureh den Druck parenchynatisch werden. Die regetativen Achsen dagegen breiten sich aus, und die Zellen nolmen eine cylindrische Gestalt an. Der Ausdruck " metamorphosirte Laubachsen » darf aber nicht so verstanden werden; als ob jede vegetalive Achse sich beliebig in ein Keimhäufchen verwandeln könnte. Diess ist nicht möglich, da die lelztern neben und nach den vegetativen Aesten entstehen, und auch eint andere Stelle an der Itutterachse einmehmen als diese.

Da die Keimhäufchen aus primären, secundären, tertï̈ren elc. Achsen gebildet sind, so erkennt man oft an

(') Vergl. oben bei Callithamion.

${ }^{(2)}$ Ein ähnliches Verfahren giebt bei Polysiphonia Aufsehluss über die Stellungsverhältnisse der Zellen (vergl. Zeitschrift f. w. Bol., Heft 5 und 4, pag. 214.

$\left({ }^{3}\right)$ Vergl. bei Polysiphonia a. gl. 0., pag. 211.

Denkscbr. NiEgel 


\section{- 206}

ihnen grössere und kleinere Lappen (Fig. 27). Diess geschieht oft in rorzïglichem Masse, wenn sich die einen Aclssen stärker entwickelı als die andern. Häufig auch bildet der unterste $\boldsymbol{\Lambda}$ st des Keinuäufchens einen eigenen, heinern, von dem übrigen Keimhäufchen alggesonderten Lappen.

Die Keimzellen sind ursprü̈glich farblos, mit honogenem, nachher feingekörntem Schleime. Bei ilırer vollkonmenen Ausbildung besilzen sie alle ungefïhı gleiche Grösse $\left(0,006^{\prime \prime \prime}-0,008^{\prime \prime \prime}\right)$, und einen körnigen, intensiv rothgefärbten Inhalt. Die unterste, oder auch die 2 bis 5 untersten Zellen, welche den Träger des Keimhäufchens bilden, sind blasser gelärbt, unı besitzen weniger festen Inhalt; zuweilen sind sic grösser (Fig. 27, a) als die keimzellen; - es sind keine keimzetlen.

Bei ihren ersten Auftreten sind die Keimhäufehen noch nichıt von einer Membran umgeben (Fig. 22 - 26 ; Fig. 29 a). Diese erscheint allmälig nit dem fortschreitenden Wachsthume, und ist Gallerte, die von den Zellen ausgeschieden wird. Es ist daher unrichtig, sie als "pericarpium hyalinum, " oder " perisporangium gelalinoso-lıyalinum, " oder " spermangium membranaccum gelineum " zu bezeichnen. Als die nämliche Extracellularsubstanz, welche bei allen Zellen der Florideen in grösserm oder geringerm Masse angetroffen wird, darf sie atuch bier keine besondere Bezeichnung und kaumı eiue besondere Erwälnung erhalten.

Die 5 verschiedenen Fortpflauzungsorgane Sporen, Antheridien und Keimhäufehen finden sich auf verschiedenen Individuen. Sie sind trielinisch. - Sporen und Antheridien stimmen darin mil einander überein, dass sie entweder an begrenzten reinen Achsen oder an begrenzten (mit begrenzter Wiederholung) gemischten Achsen sich bilden. Die Keimhäufchen dagegen entstehen an unbegrenzten (mit unbegrenater Wiederholung) gemischten Aclisen.

Die Gattung Poecilothammion unterscheidet sich von Antithammion dadurch, dass sie ein Laub und nicht einen bebläterten Stamm besitz, - von Callithamnion dadurch, dass ihre Laubachsen begrenzt sind und in eine hinfăllige borstenförnige Spilze endigen, dass die Divergenz der Verästelung $\%$ l betragt, und dass die sporenmutterzellen zu melıreren auf Laubghedern stehen, welche schon eine vegetative Tochterachse tragen, wrhrend bei Callithamion die Laubachsen unbegrenzl sind, mit einer Divergenz von '\% sich veresteln, und die sporenmutterzellen einzeln auf Laubgliedern stehen, welehe keine vegelative Tochterachse erzeugten. Zu Poecilothammion gehören die Arten P. rersicolor (Callithamuion v. Ag.), P. corymbosum (Callithamnion c. Ag.) und P. spongiosum (Callithamnion sp. IIarv.)

\section{Piilota plamosa $A g$.}

Tab. Vi, Fig. $58-42$.

Itilota hat, wie melrere andere Gattungen der Ceramiaceen, ein continuirliches, scheinbar aus Zellgewebe gebildetes Laub. Ich will von derselben bloss die vegetative Entwicklungsgeschichte miltheilen, um die Vershiedenheit dieses Baues von dem del' folgenden Ordnungen zu zeigen. Am leichtesten ist sie bei Pl. plumosa $V^{\top}$ ar. temuissima Ag. (Pt. elegans Kütz.) zu beobachten. Die Enden der Achsen und alle jüngern Zweige sind Zellenreihen (Fig. 58), deren Wachstlıum mit denjenigen von Callithammion genau übereinstimmt, indem die Scheitclzelle sich fortwehrend durch eine horizontale Wand theilt, nach der Formel $1^{n}=I^{n}+1+{ }_{n}$ I. I) Gliederzellen theilen sich nicht durch Gewebezellbildung. Die Theilung der Scheitelzelle kann sich immer wiederholen; die Achsen siud daher ilırem Begriffe nach unbegrenzt. Doch verlangern sich die wenigsten wirklich ohne Ende, sondern in den meisten abortirt die Zellenbildung in der Scheitelzelle früher oder spaeter. Dieses Auflören des Wachsthums scheint aber von ausseren Einflüssen abzulıangen, da es ganz unbestimmt eintritt. Alle Achsen sind daher als einander gleich, somit als Laubachsen zu betrachten. 


\section{- 207}

Jede Gliederzelle erzeugt zwei gegenüberstehende Astzellen, indem sie mit ilırer obern Seitenfläche auswächst, und der ausgewachsene Theil sieh als besondere Zclle abtheilt. Aus jeder Astzelle entsteht eine Achse (Fig. 58, r, q - q, p - p, o- o, ete.). Alle Tochterachsen einer Achse liegren in der gleichen Elsene mit einander und zugleich mit allen ïbrigen Achsen der Pflanze, welche ich, da es noch andere Achsen giebt, primäre nennen will. - Nachdem die Gliederzelle jene zwei Astzellen er\%engt hat, und diese angefangen haben, sich zu neuen primären Aclısen zu entwickeln, so bildet sie zwei neue Astzellen, welche ebeufalls opponirt sind, die aber von den ersten zwei Astzellen um einen recluten Wiukel entfernt sind (Fig. 59, a; Fig. 58, zwischen $n-n)$. Die zweiten Astzellen liegen an einer Achse in жwei greraden Reihen, deren Fl̈iche die Fläche der ersten Astzellen (oder der Laubäste) unter einem rechten Winkel schneidet. Sie Wachsen nicht zu Laubästen aus, wie die ersten Astzellen, sondern bleilsen einzellige Zweige. Sie sind durehaus den grossen Gürtelzellen von Ceramium analog. Was ihre organographische Bedeutung betrift, so vermuthe ich, dass es secundäre, begrenzte, einzellige Laubachsen seien. Besondere Achsen sind es ohne Zweifel, weil sie sich wie Astzellen bilden und in ihrem ganzen Verhalten durehaus von den wahren Rindenzellen von Polysiphomia und der andern Gattungen der folgenden Ordnungen versehieden sind. Einzellig sind diese Achsen, denn sıe haben keine unmiltelbare Achsenfortsetzung.

An jeder der zweiten Astzellén, welche die seeundären Laubachsen darstellen, entstehen nach aussen 4 kleinere Astzellen, zwei unten, zwei oben, je eine rechts und eine links. Sie treten nach einander auf, und 7.war die untern zuerst (Fig. 59, b, c; Fig. 58 zwisehen $\mathrm{m}-\mathrm{m}, \mathrm{l}-\mathrm{l}$, bei $\mathrm{k}$, zwisehen $\mathbf{h}-\mathrm{h}$ ), nachher die obern (Fig. 59, d, e; Figr. 58, zwischen g- g, bei f; Fig. 40, d, e). Jede dieser 4 kleinen Astzellen wächst in eine gegliederte und veræstelte Zellenreihe (Wurzelfaden) aus, die beiden obern nach oben (Fig. 4t, b, e; Fig. 42, b, c; Fig. 58, zwisehen e-c), die beiden untern nach unten (Fig. 40, f; Fig. 41, d, e; Fig. 42, d, e; Fig. 58 , zwischen $\mathrm{d}-\mathrm{d}$ und $\mathrm{e}-\mathrm{e}$ ). Diese Zellenreihen wachsen durch Theilung der Scheitelzelle (die Gliederzellen theilen sich nicht), und verästeln sich dadurch, dass die Gliederzellen nit ihrer obern Seitenfläche auswachsen und Astzellen erzeugen; ihre Entwicklungsgesehichte ist also im Allgemeinen die gleiehe wie die der primären Laubachsen. Diese verästelten Zellenreihen legen sich dieht auf die Gliederzellen der primären Laubachsen und auf einander, und bilden ein gewebeähnliches Geflecht, welehes immer dicker wird, und die secundären Laubachsen bald vollständig, die primären Seitenachsen aber immer mehr an der Basis umhüllt. Es entspringen aber sulehe Wurzelläden nicht bloss aus den secundären einzelligen Laubachsen, sondern auch aus den untersten (ersten) Gliederzellen der primären Laubachsen, indem dieselben am untern Ende ihrer untern Seitenfläche eine Astzelle erzeugen (Fig. 40, h; $58, \mathrm{~h}$ ), welche nach unten sich zu einer verästelten Zellenreihe entwickelt (Fig. 40, i ; Fig. 58 , g, f, e, d, e).

Jede Gliederzelle, mit Ausnahme der ersten (also 2.....xII), erzeugt demnach an ihrem obern Ende 4 Astzellen, erst eine rechts und eine links, woraus die primären, der Mutterachse gleichen Tochteraehsen hervorgehen, später eine vorn und eine hinten, welehe die secundären einzelligen, der Iutterachse ungleiehen 'iochterachsen sind. Die unterste oder erste Gliederzelle einer Achse dagegen bildet ausser diesen 4 obern Astzellen noch eine untere, aus welcher ein Wurzelfaden wird. - Jede Gliederzelle, mit Ausnahme der untersten (also 2...x II), wird auf jeder der beiden Seiten von 6 Punkten aus mit Wurzelfäden überwaehsen: 1) von zwei Fäden, die aus den ersten Gliedern der beiden prinären Tochterachsen entspringen, 2) von zwei Fäden, welche aus der secundären einzelligen Tochterachse nach unten wachsen, und 5) von zwei Fäden, welche aus der secundären einzelligen Tochterachse der nächst untern Gliederzelle nach oben wachsen. Die unterste oder erste Gliederzelle einer Achse (,II) dagegen wird auf jeder Seite bloss von 4 Punhten aus mit Wurzelfäden überwachsen : 1) von zwei Fäden, die aus den ersten Gliedern der beiden primären Tochterachsen hervorgehen, und 2) von zwei Fäden, welche aus der secundären einzelligen Tochterachse nach unten wachsen. - Zum bessern Verständnisse muss ich hier übrigens noch besonders auf die Erklärung der Abbildungen rerweisen.

Intersucht man einen entwickelten Stamm von Ptilota plumosa, so findet man milten in der Zcilmasse eine 
Reihe von grossen Zellen (die primære Laubachse). An dem obern Seitentheile jeder dieser Zellen sind zwei Reihen ebenfalls grosser Zcllen befestigt, eine nach rechts und eine nach links; die Basis dieser beiden Reihen liegt in der Zellmasse des IIauptstanmes verhorgen, sie setzen sich nach oben in die Achsen der Scitenaste fort, und sind die primæren Tochterachsen. An dem obern Seitentheile jeder der grossen Achsenzellen eines Stanmes stehen ferner zwei grosse Zellen, eine nach vorn und eine nach hinten (die secundaren einzelligen Laubachsen), ebenfalls von der Zellmasse bedeckt. Diese Zellmasse, welche die grossen Achsenzellen, die Zelten der sceundaren Achsen und die untern Glieder der primaeren Scitenachsen umhällt, ist ein dichtes, gewebexhnliches, aus vielen Schichten bestchendes Geflecht von gegliederten und verxstelten Fxden, dessen Zellen in Ueber sinstimmung mit ilırer Entstehungsweise nicht so enge verbunden sind wie in einem Gewebe, sondern sich in verestelte Reihen trennen lassen, und nicht wie in einen wabren Gewebe mil allen anliegenden Zellen durch Poren verbunden sind, sondern bloss mit denjenigen Zellen, nit denen sie in eine Reihe zusammengehören. - Da bei Ptilota wie bei allen übrigen Ceramiaceen in der Scheidewand zwischen zwei Zellen immer nur Ein centraler Porus sich findet, so hat daher jede Gliederzelle einer primæren Achse (mit Ausnahme der untersten) 6 Poren, zwei unten und oben nach den Gliederzellen der gleichen Achse, zwei rechts und links nach den ersten Gliederzellen der primæren Seitenachsen, und zwei vorn und hinten nach den secundæren Seitenachsen. Die erste oder unterste Gliederzelle einer primæren Achse hat 7 Poren, næmlich noch einen nach dem Wurzelbaare, welches aus ihrcr untersten Ecke entspringt. Jede der Astzellen, welche die secundæren einzelligen Achsen darstellen, hat 5 Poren, einen an der inneren Flache nach der Gliederzelle ilırer Hutterachse, und vier an der xussern Flache (zwei oben und zwei unten) nacls den Wurzelfæeden, welche an ihr befestigt sind. Jede Gliederzelle eines Wurzelfadens hat zwei Poren, einen an der untern und einen an der obern Endfache nach den beiden Zellen, an die sie in ihrer Reihe anstösst, ferner einen dritlen, wenn sie einen Ast trægt. Aber sowohl zwisehen den Laubzellen und den Zellen der Wurzelfieden, welche auf jenen liegen, als zwisehen den Zellen verschiedener Wurzelfaden, welche seitlich einander berühren, finden sich niemals Poren, und somit auch kein inuiger Zusammenhang, dessen Ausdruck sie sind. Entwicklıngsgeschichte und fertiger Bau stimmen also darin übereiı, die Zellmasse, welche die Achsen von Ptilota umhüllt, nicht als ein Gevebe, und somit nicht als eine eigentliche Rinde, sondern als ein blosses Geflecht individueller Zellenreihen nachzuweisen.

\section{DELESSERIAGE正.}

Die Hauptachsen sind Zellschichten oder Zellkörper, deven Scheitelzelle sich durch horizontale Wände theilt; Sporenmutterzellen im Gewebe.

Diese Ordnung unterscheidet sich von der vorhergehenden dadurch, dass die Hauptachsen oder diejenigen, in welchen die Sporenbildung statt findet, nie Zellenreihen sind, sondern entweder eine Zellschicht, oder eine Zelischicht mit mehrschichtigen Nerven und Venen, oder ein flacher oder endlich ein cylindrischer Zellkörper. - Das Wachsthum der Achsen in die Länge geschieht so, dass die Scheitelzelle ( $\mathrm{I}^{\mathrm{n}}$ ) sich durch eine horizontale Wand in eine neue Scheitel- 
zelle $\left(I^{\mathrm{n}}+1\right)$ und in eine Gliederzelle $\left({ }_{n} \mathrm{II}\right)$ theilt. Das Wachsthum in die Dicke findet so statt, dass die Gliederzellen sich durch senkrechte Wände theilen, worauf sich die Theilung durch senkrechte (radiale oder tangentale), durch horizontale oder durch schiefe Wände wiederholen kann. - Die Achsen der Delesseritceen bestehen also ursprünglich aus einer Reihe von Gliederzellen, und sind somit alle in der Wirklichkeit gegliedert, wenn man auch an den meisten die Gliederung später nur undeutlich oder gar nicht mehr erkennt. - Characteristisch für diese Zellenbildung ist, dass die Gliederzellen nie in zwei gleiche, sondern immer durch excentrische senkrechte Wände in zwei ungleiche Zellen sich theilen, wodurch aus einer Gliederzelle zunächst immer eine mittlere und mehrere äussere Zellen hervorgehen. Das Wachsthum der Delesseriaceen unterscheidet sich durch diesen Punkt von denjenigen Algenfamilien, mit denen jene sonst mchr oder weniger im Bau übereinstimmen, nämlich von den Ulscen, Stilophoreen und Fuceen, indem hier die Gliederzellen sich durch centrale verticale Wände in zwei gleiche Tochterzellen theilen.

Die Sporenmutterzellen sind bei den Delesseriaceen immer im Gewebe eingeschlossen; sie sind daher nie Scheitelzellen oder Gliederzellen, wie bei den Cer'cmiaceen und den Phyllophoraceen.

Die Keimzellen sind in Keimbehältern, die an der Spitze geöffnet sind, eingeschlossen. Sie scheinen einen ziemlich durchgreifenden Unterschied zwischen dieser Ordnung und den Rhodomeniaceen zu bilden, wo die Keimzellen zu Kein. häufchen verbunden sind, welche im Gewebe der Achsen liegen.

\section{Nitophylleas.}

Zellschicht; die Sporenmutterzellen liegen in der Achsenflüche.

Diese Familie, welche grosse habituelle Aehnlichkeit mit einigen Pflanzen der folgenden Familie hat, unterscheidet sich von denselben sowohl durch den einfacheren Bau als vorzüglich dadurch, dass hier die Sporenmutterzellen in der gleichen Fläche mit den übrigen Zellen der Zellschicht liegen, während sie dort excentrisch und ausserhalb der Zellen der Achsenfläche liegen. 
Zu dieser Familie gehört die einzige Gatlung Nilophyllum, mit Ausschluss von mehreren Arten, nämlich von N. Gmelini Grev., N. Bonnemaisoni Grev., N. Hillice Grev., N. laceralum Grev.

\section{Nitoplayllan probctatesu Gres. (').}

TAB. VII, FIG. $1-13$.

Dic Pflanze ist eine Zellselicht, welche wiederholt sieh in dicholomische Lappen theilt. An den Spitzen der Lappen erkennt man, wenn sie sehmäler sind, die Seheitelzelle $\left(1^{\mathrm{n}}\right)$. Dieselbe theilt sich dureh eine lrorizontale Wand in eine neue Scheitelzelle $\left(I^{11+1}\right)$ und in eine Gliederzelle $(n I I)$, so dass also das Längenwachsthum nach der Formel $I^{n}=I^{n}+1+{ }_{n} I$ staltfindet. Diese Zellenbildung ist bloss an sclımälern, spitzern Läppchen des Laubes zu selıen. Sie ist legrenzt; denn jede $\Lambda$ chse der Pflanze wäelıst bloss bis zu einer gewissen Länge, und erzeugt dann an ilırer Spitze zwei (gabelförmige) Tochterachsen, in welchen das Wachsthum wieder mit $\mathbf{I}^{1}$ beginnt.

Die Gliederzellen lhıilen sich durch cine excentrische senkrechıte Wand, welehe die Laubfäehe unter einem rechten Winkel selıneidet, in eine grösscre und eıne kleinere Zelle. Die grössere theilt sieh wieder durch eine gleiche, mit der erslen parallele Wand in eine innere und eine äussere Zelle. Diese zwei Zellenbildungen sind die gleichen, wie sie in den Gliederzellen von Delesseria Hypoglossum auftreten, und können auch auf die nämliche Weise bezeichnet werden, nämlich $\mathrm{II}^{4}=\mathrm{II}^{2}+{ }_{3} \mathrm{II}$ und $\mathrm{II}^{2}=\mathrm{II}^{5}+{ }_{2} \mathrm{II}\left({ }^{2}\right)$. Aus einer Gliederzelle entstehen somil zunäehst 5 Zellen, eine nilllere und jederseils eine seilliche. - Die weitere Zellenbildung ist mir unbekannt. Wie es selıeint, theilen sich alle drei Zellen, so wie deren Toehterzellen, und zwar abwechselnd, durch lırizontale und dureh verticale Wände, welehe die Laubachse unter einem rechten Winkel schneiden. Vertieale, mit der Laubflïche parallele Wände treten beim vegelativen Wachsthume nicht auf, so dass das Laub einschichtig bleibt. Wenn das Wachsthum in die Breite aufgehört hat, so sind alle in gleicher Ilöhe nebeneinander liegenden Zellen ziemlich von grleiehır Grösse, und erscheinen, von der Fliche angesehen, parenchymatisch. Am Rande jedoeh liegt in der Regel eine Reihe von Zellen, welehe im Durchschnilte halb $\left({ }^{2} / 3-4 \%\right)$ so gross sind als die übrigen (Fig. 1, a). Zuweilen finden sich zwei Reihen solehel doppelt kleinerer Zellen an liande; dieselben situl entweder von gleicher Grösse (Fig. 1, b), oder die Zellen der äussersten Reihe sind lalb so gross als die der zweiten Reilıe, diese halb so gross als die übrigen (innern) Zellen.

Die entwickelten Zellen sind mil wasserheller Flüssigkeit gefüllt. An der Wandung liegt die Sehleimschicht; an dieser sind die blassıölhliehıen, hemisplürischen Farbbläschen befestigt. Dieselben bedecken die oberfläche entweder gleiclıförmig, oder es bleiben einzelne kreisförmige oder elliplische Stellen frei, oder die Farbbläschen bilden bloss netzförmige Masehen.

Die Sporenmulterzellen sind ïber die Laubfläche zerstreut, entweder einzeln, oder zu mehreren zu kleinen Häufchen vereinigt. Es werden einzelne Zellen des Laubes unmittelbar zu Sporenmulterzellen, indessen

(') Gewöhnlich wird eine schmächtige Varietät als besondere Art $N$. occllalum Grev. untersehieden. Mit Recht hat Uarvey dieselbe mit $N$. punctatum vereinigt. Unter einer Menge von Exemplaren fand ich in Neapel characteristische formen der einen und der andern Varietit, zugleich aber vicle vittelghieder, welche sich nicht bestimmen liessen.

(3) Vergl, Zeitschrift f, w. Bot., Heft a, pag. 125. 
sich die nächstliegenden Laubzellen theilen (vergl. Fig. 2 und 5, welche Quersehnitte darstellen). Diese Zellentheilung findet so statt, dass in einer Zelle eine excentrische, mit der Laubläche parallele Wand auftritt, wodurch zwei ungleiche Tochterzellen entstehen (Fig. 5, b), und dass die grössere Tochterzelle sich noch einmat auf gleiche Weise theilt. Das Resultat ist immer eine mittere und zwei äussere Zellen (Fig. 2, b, b). Diejenigen äusseren Zellen, welche an die Sporenmutterzelle anstossen, bedecken dieselbe theilweise, so dass beiderseits bloss ihr Scheitel frei bleilıt (lig. 2, c; 5, d). In Fig. 4 ist ein Sporenhäufchen von der Fläche dargestellt mit drei Sporenmutterzellen, welche in der Mitte an einem 4, 3 oder 6 eckigen Intercellularraume unbedeckt sind.

bhe die Laubzelten zu Sporenmutterzellen werden, enthalten sie, wie alle ïbrigen Zellen, eine wasserhell: Flüssigkeit und eine wandständige Schleimschicht mit Farbbläschen. Zuerst werden nun die Farbhl̈̈schen aufgelöst, und es bildet sich farbloser körniger Schleim, welcher als eine brcite Schicht der Wandung anliegt (Fig. 5, a). Später sammelt sich derselbe um einen centralen Kern und in radienförmige Strömungsfäden (Figg. 5, b). Der Schıleim mehrt sich und färbt sich gelblich; die centrale Masse wird grösser, die Fäden zahıtreicher. Statt des centralen Kernes werden zwei neue Kerne (Fig. 5, c), und dann eine trennende Wand (Fig. 5, d) sichtbar. Jede der beiden Tochterzellen theilt sich noch einmal auf gleiche Weise in zwei kugelyuadrantisehe Zellen. Der Inhalt ist indessen bräunlich-orange, dann braunroth gewordea. Wenn die 4 Sporen anssgebildet sind, so erseheinen sic sehön roth und dicht mil feinkörnigem Inhalte erfüllt.

Die Antheridien sind Anhäufungen von kleinen Samenzellchen, welche die beiden Fläichen des Laubes stellenweise bedecken. In Fig. 8 ist ein Theil eines Antheridiums ron der Fläche, in Fig. 6 der ganze Querschnitt eines solehen dargestellt. Das Laub ist an dieser Stelle selır wenig verdickt; wenn sein ülsriger Durelımesser $z$. B. 0,012 "' beträgt, so ist das Antheridium 0,01/ "' dick. Die sterilen Laubzellen selbst sind Jeträichtlich schmäter (Fig. 7, b) ; dic Samenzellchen liegen meist in zwei Schichten (Fig. 7, c). Aus der Entwicklungsgeschichte der Antheridien habe ich nur einige wenige Zustände gesehen; ich vernuthe aber, dass sie folgendermassen entstehen. Die Laubzellen theilen sich in drei Zellen, auf ähnliche Weise, wie die die Sporenmulterzellen umgebenden Zellen (Fig. 2, b). Davon bleibt die mittlere steril (Fig. 7, b). Die seitlichen theilen sich wiederholt, zuerst durch Trände, welche zur Laubfläche rechtwinklig sind, zuletzt dureh Wände, welehe mit derselben parallel laufen. Die letzten Zellen sind die Samenzellchen; oder, was mir wahrscheinlicher ist, in den letzten Zcllen bilden sich (iı jeder eines) die Samenbläschen. - Die Samenzellehen sind zuerst parenchymatisch, 4, 3, 6 eckig, mit homogenem Schleime crfüllt und einem Pünklchen (Kernehen) an der Wandung (Fig. 9); nachlıer werden sie kugelig und wasserhell (Fig. 10); das wandständige lïnktehen ist etwas grösser; von demselben geht ein wandständiger, allmälig dïnner werdender Faden aus (Fig. 10, a). Dic: Samenzellehen sind alle gleich gross, kumm über 0,002 "II dick. Bewegung oder freie Samenfïien sah ich nicht.

Die Keimzellen sind in Keimbehïlter eingeschlossen, welehe in der FḦiche des Laubes liegen, und an der Spitze durch eine warzenförmige llïndung sich öfnen. Die Keimzellen entstehen an einem miltelständigen Samenträger. Fig. 11 zeigt einen Keimbelı̈̈lter im Querschnitte. Die Entwicklungsgeschichte ist folgende. Alle an einer kreisförmigen Stelle befindlichen Laubzellen theilen sich durch eine excentrische, mit der Laublïho parallele Wand in zwei ungleiche Zellen (we Fig. 15, b). Die grössere derselben theilt sich noch einmal dureh eine gleiche Wand (wie Fig. 15, c). Aus einer Laubzelle sind somit drei, eine mittlere oder Achsenzelle und zwei Seitenzellen entstanden. Die eine Schicht von Seitenzellen erhebt sich an der ganzen kreisfömigen Stelle, und dabei theilt sielı jede Zelle in der Regel noch einmal : es ist diess die Decke des Keimbehälters (Fig. 1:i, d- $\mathbf{l}$; Figg. $11, \mathrm{e}-\mathrm{e}$ ). Im Mittelpunkle derselben bildet sieh eine Oelfnung; sie tritt nach aussen warzenförmig vor, und ist aus kleinern Zellen gebaut (Fig. 11, f). - Die andere Sehicht von Seitenzellen mit den Achsenzellen bildet den Boden des Keimbehälters (Fig. 11, c - c). Diese Seitenzellen theilen sich ebenfalls in zwei oder drei Zellen (Fig. 1\%, e). Die Achsenzellen bleiben, wie mir scheint, im Unfange immer ungetheilt (Fig. 15, f). In der nitte des Keimbehälters dagegen erheben sie sich nach oben, und füllen sich mit rothem körnigem 


\section{$-212$}

Inhalte (Fig. 1\%, g), und theilen sich dann wiederholt, so dass aus jeder Achsenzelle eine Reihe von Zellen entsteht (Fig. 15, h), die ich Keimhaar nennen will. Die Keimhaare sind frei (nicht mit einander verwachsen), meist einfach, doch auch spärlich verästelt. Die Zellen der Keimlsaare verwandeln sich in Keimzellen, inden? sie grösser werden, sich dicht mit braunrothem Inhalte firben, und abfallen. Zuerst entwickeln sich die Endzellen (Fig. 12, 15), nachher geht die Entwicklung von Zelle zu Zelle nach unien hin. - Die jungen Keinzellen sind mit fast homogenem braungelblichem Inhalte, die ausgebildeten Keimzellen mit braunrothem, grobkörnigem Inhalte erfüllt (Fig. 14). In beiden bemerkt man ein centrales Kernbläschen.

Die Sporenmutterzellen, die Antheridien und die Keimbehälter finden sich auf getrennten lndividuen. lch fand alle drei im Mai 1842 bei Neapel in fast gleicher Individuenmenge. Dass alle drei besondere und morphologisch von einander unabhängige Organe seien, dass man also nicht etwa die einen als den metamorphosirten oder verkümmerten Zustand der andern ansehen dürfe, wird am besten durch die Entwicklungsgesehichte bewiesen, da alle drei aus verschiedenen Zellen entstehen, nemlich die Sporen aus ungetheilten Laulızellen, die Samenzellchen aus den Seitenzellen des getheilten Laubes, und die Keimzellen aus den Achsenzellen des getheilten Laubes.

\section{Delessiritak.}

Zellschicht mit mehrschichtigen Nervationen, oder flacher Zellkörper (mit einer Reihe con Achsenzellen, deren jede zunüchst son nicht mehr als 4 Zellen umgeben ist); Wachsthum in die Breite und Dicke geschieden, ersteres in der Richtung der Achsenflüche eine Zellschicht erzeugend, letzteres senkrecht zu derselben die einfache Schicht in mehrere theilend; die Sporenmutterzellen liegen nach aussen con den Zellen der Achsenflüche.

Die Gattungen, welche zu dieser Familie gehören, stimmen, in Rücksicht auf das Wachsthum, darin mit einander überein, dass die Gliederzellen (II ${ }^{1}$ ) zuerst durch eine senkrechte excentrische Wand, welche die Laubfläche unter einem rechten Winkel schneidet, in eine grössere $\left(\mathrm{II}^{2}\right)$ und eine kleinere $\left({ }_{1} \mathrm{III}^{1}\right)$ Zelle sich theilen, dass die erstere durch eine gleiche Wand eine innere $\left(I^{5}\right)$ und eine äussere ( $\left.{ }_{2} \mathrm{III}^{1}\right)$ Zelle erzeugt, dass dann die innere Zelle sich durch eine senkJ'echte excentrische, mit der Laubfläche parallele Wand in eine grössere (II $\left.{ }^{4}\right)$ und eine kleinere Zelle $\left.{ }_{5}{ }_{5} H{ }^{1}\right)$ theilt , und dass endlich aus der grössern dieser beiden Zellen durch eine gleiche Wand eine Achsenzelle (II ${ }^{5}$ ) und eine äussere Zelle $\left({ }_{1} \mathrm{III}^{\mathrm{i}}\right)$ entstehen. Das Resultat dieser Zellenbildung ist eine Achsenzelle $\left(\right.$ II $\left.^{3}\right)$, welche von 4 tertiären Zellen $\left({ }_{1} \mathrm{HI}^{1}, 2 \mathrm{II}^{1},{ }_{5} \mathrm{III}^{1},{ }_{4} \mathrm{III}^{1}\right)$ umgeben ist, von 


\section{$-215$}

denen die zwei gegenüberstehenden, in der Achsenfläche liegenden zuerst entstanden sind. Wenn die Zellenbildung, wie es gewöhnlich der Fall ist, weiter geht, so verhalten sich dabei die 4 tertiären Zellen untereinander ungleich. Die beiden zuerst entstandenen, opponirten, tertiären Zellen des ersten Grades $\left({ }_{1} \mathrm{III}^{1}\right.$ und ${ }_{\varrho} \mathrm{III}{ }^{1}$ ), so wie ihre Tochterzellen theilen sich bloss durch Wände (horizontale, senkrechte, oder schiefe), welche die Achsenfläche unter cinem rechten Winkel schneiden, nie durch solche, welche mit derselben parallel laufen, so dass aus dieser Zellenbildung zunächst eine einfache Zellschicht entsteht. Dann theilen sich alle oder einzelne Zellen dieser Schicht durch verticale, mit der Achsenfläche parallele Wände, und diese Zellenbildung wiederholt sich durch Wände, welche entweder zur Achsenfläche rechtwinklig oder mit derselben parallel sind. Die gleiche Zellenbildung tritt auch in den beiden zuletzt entstandenen, opponirten, tertiären Zellen des ersten Grades $\left({ }_{5} \mathrm{HI}^{1}\right.$ und $\left.{ }_{4} \mathrm{III}^{1}\right)$ auf. - Ausser dem Wachsthume in die Länge kann man also bei den Delesserieen zwei Arten des Wachsthums scharf unterscheiden: 1) das Wachsthum in die Breite, welches zuerst auftritt und welches bloss durch Wände, die die Achsenfläche unter einem rechten Winkel schneiden, stattindet; - dazu gehört die Bildung der beiden ersten tertiären Zellen des ersten Grades $\left({ }_{1} \mathrm{III}^{1}\right.$ und $\left.{ }_{2} \mathrm{III}^{1}\right)$ sowie aller Zellen, die aus denselben in der gleichen Richtung hervorgehen; das Resultat dieses Wachsthums ist eine einfache Zellschicht, welche, wenn sie auch in der Regel als solche nicht gleichzeitig vorhanden ist, doch immer successiv in die Erscheinung tritt; - 2) das Wachsthum in die Dicke, welches erst auf das Wachsthum in die Breite folgt, und welches theils durch Wände, die mit der Achsenfläche parallel laufen, theils durch solche, welche zu derselben rechtwinklig stehen, stattindet; dazu gehört die Bildung der beiden letzten tertiären Zellen des ersten Grades $\left({ }_{5} \mathrm{IH}^{1}\right.$ und $\left.{ }_{4} \mathrm{IHI}^{1}\right)$, sowie alle Zellenbildung, welche sowohi aus diesen Zellen als aus den übrigen Zellen der ursprünglichen Zellschicht hervorgeht; das Resultat dieses Wachsthums ist ein mehrschichtiger Zellkörper. - Die vegetativen Verschiedenheiten der Nitophylleen, Delesserieen und Rhodomeleen lassen sich einfach so ausdrücken : bei der erstern Familie ist bloss ein Wachsthum in die Breite vorhanden; bei der zweiten Familie ist das Wachsthum in die Breite und dasjenige in die Dicke qualitativ, quantitaliv und zeitlich versehieden; bei der dritten 
Familie ist das Wachsthum rings um die Achsenlinie gleichzeitig und radienförmig.

Die Sporenmutterzellen liegen ausserhalb der Relien der Achsenfläche, bald an dieselben anstossend, bald von denselben entfernt weiter nach aussen in der Rinde; eine Verschiedenheit, welche, sobald die hinreichende Kenntniss der Thatsachen es erlaubt, wahrscheinlich die Trennung der Delesseriece in zwei Familien veranlassen muss.

Zu den Dclesserieen gehören die Gatiungen Delesseria Lamour. (Hypoglossum Kütz., Phycodrys Kütz., Aglaophyllum Nont. excl. spec.), Odonthalia Lyngb., Spherococcus Grev. nec Ag. (Rhynchococcus Kütz.), Acanthophora Lam., Bonnemaisonia Ag., Gelidium Lam. etc.

\section{Delesgeria Hypoglosstum Lamour.}

IIypoglossum H'oodwardi Kütz.

TAB. VII, Fig. $16-23$.

Ich habe an einem andern Orte das Wachsthum dieser Pflanze, soweit es die Zellenbildung in die Länge und Breite betrift, ausfülırlicher geschildert $\left({ }^{1}\right)$, und indem ich darauf verweise, führe ich hier bloss kurz die Resultate an. Das Wachsthum in die Länge geschielıt durch eine Scheitelzelle oder primäre Zelle des nlen Grades, welche sich fortwährend durelı eine horizontale Wand in eine neue Scheitelzelle des folgenden Giades und in eine Gliederzelle oder $n^{\text {te }}$ secundäre Zelle theilt : $!^{n}=I^{n+1}+n^{4}$. Das Wachsllum in die Breite beginnt in den Gliederzellen $\left({ }^{1}{ }^{1}\right)$, indem sich dieselben zweimal durch senkrechte, die Laubfäche unter einem rechten Winkel schneidende Wände theilen, in eine neue secundäre Zelle des folgenden Grades und in eine tertiäre Zelle: $\mathrm{II}^{4}=\mathrm{II}^{2}+{ }_{1} \mathrm{II}^{1}$ und $\mathrm{I}^{2}=\mathrm{II}^{3}+{ }_{2} \mathrm{II}^{1}$. Das Wachsthum in die Breite setzt sich fort in den tertiären Zellen ( $I^{1} I^{1}$ und $2 I^{1}$ ) durch schiefe, die Lanbfläche unter einem rechten Winkel schncidende Wände: III $^{\mathrm{n}}=\mathrm{III}^{\mathrm{n}+1}+{ }_{\mathrm{n}} \mathrm{IV}^{4}$; und beendigt sich in den quartären Zellen durch fast senkrechte, die Laubflïche unter einem rechten Winkel schneidende Wände: $I V^{n}=I V^{n}+1+{ }_{n} V .-$ Das Resultat dieser Zellenbildung ist eine Zellchicht, welche in der Mitte aus einer Reihe von secundären Zellen des dritten Grades ( II $^{3}$ ), :ı! Rande aus einer Reilie von tertï̈ren und quartären Zellen versehiedener Grade, und zwischen der Mitte und dem Rande aus quintären Zellen (V) besteht.

Das Wachsthum in die Dicke trifft nun die secundären Zellen des dritten Grades und melırere der nächst liegenden quintären Zellen. Es beginnt durch senkrechte excentrische Wände, welche mit der Laubläche? patrallel laufen, und selzt sich fort abwechselnd durch senkrechte zur Laubläche rechtwinklige, durch horizon-

(') Zeitschrift f. w. Bot., lleft 2, pag. 121, Tab. 1. 
tale und durch senkrechte, mit der Laubfliche parallele Wände. Die Foige davon ist, dass die Zahl der Zellen von innen nach aussen (in die Dicke) sowohl in horizontaler als in verticaler Richtung zunimmt. Das Wachsthum in die Dicke unterscheidet sich dadurch wesentlich von dem Wachsthume in die Breite, inden bei den letztern die Scheidewände bloss in zwei Dimensionen abwechseln, und desswegen die Zellen bloss in senkrechter lichtung von innen nach aussen zunehmen, in horizontalen Durchschnitten dagegen auf eine innere Zelle immer nur Eine äussere folgt. Dieser Unterschied des Wachsthums in die Breite und in die Dicke tritt aber nur bei stärkeren Exemplaren deullich auf, meist zeigl er sich bloss in sehr beschränktem Hasse; in einzelnen schmächtigern Individuen oder an einzelnen dünnern Stellen tritt das Wachsthum in die Dicke so sehr zurück, dass sieh seine Eigenthümliehkeit gar nicht realisirt. Ein solcher Zustand ist in Fig. 18 im Querschnitte gezeichnet. Die secundäre Zelle des dritten Grades (a - a) und die zwei innern quintïren Zellen (b $-b, b-b)$ haben sich jede in 5 Zellen getheslt. Fig. 16 und Fig. 17 zeigen den gewöhnlieheren Bau im Querschnitte, erstere durch den Stiel, letztere durch den Mittelnerv des blattartigen Laubes. Die secundäre Zelle des dritten Grades (a - a) hat sich in 7 Zellen geiheill; auf die Aehsenzelle folgt jederseits erst Eine, dann zwei Zellen. Dic nächsten quintären Zellen $(b-b, b-b)$ haben jede sich in 5 Zellen getheilt, eine (c - c in Fig. 16) erst in zwei Zellen. In Fig. $2 t$ und 22 sind zwei Glieder im Längsschnitte dargestellt, wovon das erstere a - a in Fig. 17, das letztere b- b in Fig. 17 entspricht.

Mit dem beschriehenen Wachsthume des Laubes in die Länge, in die Breile und in die Dicke ist die gesel\%mässige vegetative Zellenbildung rollendet. Die Zellen dehnen sich aus, bilden ihren Inhalt um, rerdicken ilıre Wandungen, runden ihre Eeken ab. Nun beginnt eine neue Zellenbildung, welche aber als zufällig betrachtet werden muss, da sie unregelmässig und in ganz unbestimmten Verhältnissen auttrilt. Bald seheint sie fast zu fehlen, bald ist sie in sehr beträchtlichem Masse vorhanden. Sie besteht darin, dass das untere seitliche Ende einer Zelle auswächst und eine Astzelle bildet, aus welcher ein gegliederter, zuweilen verästelter Faden entsteht, der nach unten wächst. Alle Zellen besitzen das Vermögen, solehe Fäden zu erzeugen, sowohl die innern und die äussern Zellen des Mittelnerven als die quintären Zellen der Zellschicht. Die Zellfäden, welehe an der Oberfl̈̈che entstehen, wachsen aussen über die Zellen nach unten, und bedecken dieselben, wenn sie in grösserer Ienge vorhanden sind, als ein peripherisches Geflecht. Diejenigen, welche im Innern des Gewebes entstehen, drängen sich zwischen den Zelien nach unten, und bilden ein intercellulares Geflecht. In Fig. 19 ist ein Querschnitt durch einen Mittelnerv dargestellt, wo sowohł zwischen als ausserhalb der grössern Gewebezellen die durchschnittenen Zellfïden sichtbar sind; cbenso befinden sich solehe an den quintären Zellen (a). Fig. 25 ist ein senkrechter Durchschnitt, weleher in der Richtung b - b von Fig. 19 gefïhrt wurde. - Diese zelffaden sind die nämlichen, welche bei den Ceramiaceen, bei Polysiphonia und bei einer Menge von Florideen vorkommen. Weun ihnen irgend ein besonderer Name beigelegt werden soll, so glaube ich, dass $/$ wr:elfüden der passendste sein möehte. Die Zellmasse, welche sie in grösserer Zahl darstellen, ist bein Geveb’, sondern ein Geflechl $\left(^{1}\right)$.

Die Sporenmulterzellen liegen zwar noch in Mittelnerven, aber seitlich von der Mitte, zerstreut. Sie sind also bloss in dem Gewebe befindlich, welches aus quintären Zellen entstanden ist; und zwar sind es die unmittelbar an die Zellen der Achsenfläche anstossenden Zellen, welche zu Sporenmutterzellen werden. Dieselbeı dehnen sich aus, verdicken ihre Wandung und theilen sich dann tetraëdrisch in 4 Specialmulterzellen (und $/ 1$ Sporen). Dic anliegenden Zellen werden dabei häufig so comprimirt, dass sie fast unsichtbar werden. In Fig. 20 ist ein Querschnitt durch einen sporenbildenden Mittelnerv gezeichnet; die Stelle, welche der secundären Zelle des dritten Grades und den innersten quintären Zellen entspricht, ist beiderseits vertieft (a), weil die übrigen seitlichen Theile des Hittelnerven dureh die Sporenbildung aufgetrieben wurden.

(2) Vergl. über die gleichen Fäden bei Plilola, pag, 207. 


\section{Gelidium corneam Lamour.}

Taв. VIl, Fıg. $24-56$.

Das Laub dieser Pflanze ist zusammengedrückt und fiederig-verästelt. Es besteht aus zwei Zelllagen : 1) einem Mark, das von langgestreckten, schmalen, faserälulichen, der Länge nach verłaufenden Zellen gebildet wird, clicht, gallerllos und farblos ist, und 2) einer Rinde, ін welcher die kurzen, rothgefärbten Zellen in horizontalen, radienförmigen Reihen liegen, und von innen nach aussen an Breite ab, an Zahl zunehmen und eine intensivere Farbe zeigen. - Külizing $\left(^{1}\right)$ unterscheidet drei Straten "corticale, subcorlicale und medullare;" die beiden erstern gehen aber allmälig in einander ïber, während sie von dem letztern ziemlich scharf geschieden sind.

Jas Waclisthum kann wegen der Kleinheit der Zellen und wegen der breilen Abrundung der Achsenenden mul sehr unvollkommen erforscht werden. Soviel ist sicher, dass das Läugenwachsthum durch eine einzige

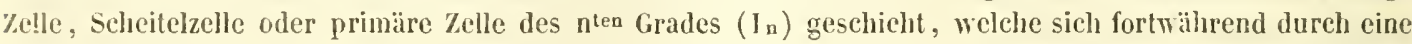
horizontale Wand in eine neve scheitelzelle $\mathrm{I}^{\mathrm{n}}+1$ und in eine Gliederzelle $\left(\mathrm{n} \mathrm{I}^{1}\right)$ theilt, nach der Formel $I^{n}=I^{n+1}+{ }_{n} I^{1}$. - Fig. 2/ zeigt die Spitze eines Aestehens von G. corneum Var. capillaceum; zu äusserst steht die Scheilelzelle I ${ }^{\mathrm{n}}$ (a), unter derselben eine Gliederzelle, $\mathrm{n}-\mathrm{II}^{\mathrm{s}}$ (b). Fig. 23 und 26 , weiche die Enden von dünneren Aestchen der gewöhnlichen Form darstellen, zeigen dasselbe. In Fig. 27 ist das P'unktum regetationis schon efwas vertieft, so dass nan kaum noch die beiden obersten Zellen, $I^{\mathrm{n}}$ und $\mathrm{n}-\mathrm{II}^{\mathrm{s}}$, sieht. An Fig. 18 ragt bloss noch die Scheitelzelle über das Gewcbe hervor. In Fig. 29 liegt das Punktum vegetationis so sehr vertieft, dass man nichts mehr davon sieht; es rührt diess daher, dass die Zellenbildung in die Breite und Dicke rascher vor sich geht als die Zellenbildung in die Länge.

Das Wachsthum in die Breite beginnt in den Gliederzellen $\left(\mathrm{II}^{1}\right.$ ) auf gleiche Weise wie bei Delesseria Hypoylossum. Sie theilen sich durch eine excentrische, die Laubfläche unter einem rechten Winkel schneidende Wand (Fig. 2/, c), worauf sich die grössere Zelle durch eine der ersten gegenüberstehende, gleiche Wand theilt (Fig. 2\%, d). Aus einer Gliederzelle gehen also zunächst 5 Zellen hervor, eine mittlere und zwei seitliche. Bie Zellenbilohng in den letzern ist nun aher versehieden von derjenigen in Delesseria Hypoglossum. Die seitliche Zelle lheill sich nämlich durch eine schief-senkrechte, mit ihrer innern Fläche parallele Wand in eine innere und eine änssere Zelle (Fig. 26, c). Davon bildet die äussere zelle auf gleiclıe Weise zwei Tochterzellen (Fig. 26, d; Hig. 23, c), u. s. f. - Auf diese Weise verwandelt sich eine Gliederzelle in cine horizontale Reihe in der Achsenfïiche liegender gleichlanger Zellen. In diesen Zellen beginnt das Wachsthum in die Dicke, und zwar, wie es scheint, aut ăhnliche Weise wie in Delesseria Hypoylossum. Wenigstens unterscheidet man, Jachdem die Zellenhihlung ferlig ist, eine Schicht ron Zellen, welehe die Achsenfläche des Laubes einnehmen. Es beweist diess, dass auch hier in den Zellen der Zellschicht, aus welcher das Laub besteht, nachdem das II achsthum in die Breite vollendet ist, die Theilung durch verticale, excentrische, nit der Laubfliche parallele Wande beginnt, so dass jene Zellen sich zuerst in zwei ungleiche, lintereinander liegende Zellen theilen, Wovon die grrössere sich auf gleiche Weise in eine innere und eine äussere Zelle tlıeilt. Die innere Zelle ist ein liement jener Zellschicht, welche die Achsenfläche einnimmt; in den äussern Zellen setzt sich das Wachsthum

(') Phycol. gen., pag. 406. 
in die Dicke fort. - Das Wachsthum in die Dicke trifft bei Gelidium die ganze Breite, während es bei Delesseria IIypoglossum auf einen mittleren Streifen beschränkl ist.

Die Sporenmutlerzellen liegen in der Rinde junger kurzer Aeste. Sie sind zuerst länglich; ilır Längendurchmesser ist horizontal von innen nach anssen gerichtet. Sie theilen sich durch eine, den Längendurchmesser unter einem rechten Winkel schneidende Wand in zwei primäle Specialmutlerzellen (Fig. 50 ); worauf sich jede derselfen durch eine auf der ersten Wand senklechte Wand in zwei secundäre Specialmutterzellen theilt (Fig. 51, 52). Gewöhnlich stehen die Wände in den beiden primären Specialınutterzellen selıst rechtwinklig zu eiuander, so dass eine Ansicht immer nur drei Zellen zeigt (Fig. 51, I und 11); sclten laufen jene Wände parallel, so dass man von einer Seile alte vier, von der andern bloss zwei Zellen erblickt (Fig. 52, I und II). Die kurzen Aeste, welche die Sporenmutterzellen enthalten, heissen bei Külzing "besondere Fruchtäste " (Carpoclonı). Es sind aber ganz gewölnnliche junge Aeste, welche weiter wachsen und sich rerästeln, und welche dalıer auch nicht anders als junge Aeste genannt werden dïrfen. - Die Sporenlildung ist kugelquadrantisch; unrichtig wird sie ron $J$. Agarlh und von Endlicher dreieckig (nucleo triangulatim quadridiviso) genannt.

Die Keimzellen sind in Keimbehälter eingeschlossen, welehe zu zweien gegenüber in der hillellinie cines kurzen Astes liegen. Die Keimbelülter sind Höhlungen in llarke, welche, von der Fläche angeschen, kreisförmig, ron der Seite znsammengedrückt erscheinen, und sich nach aussen durch einen l'orus öfinen. Fig. $\mathbf{5 j}$ gieht einen horizontalen, Fig. $5 /$ einen senkrechten Querschnitt durch die Milte zweier Keimbeläller; b bezeichnet das Rinden-, c das Vlarkgewebe. In Fig. 50 ist ein Theil von Fig. $5 \overline{5}$ stärker vergrössert. Die Scheidewand, welche die beiden Höhlungen von einander lrennt, wird durch Markgewebe gebildel (in Fig. 50 , a im Durchschnilte gezeichnet). Sie ist der Samenboden, an welchem die Keimhaare (Fig. 330 b) entspringen. Die Wand, welche die Iöhılıngen nach aussen bedeckt, besteht ans zwei Zellagen, einer schmälern, innern, faserigen und farblosen, aus Narkgewebe gebildeten lage, deren Fasern senkrecht verlaufen (in Fig. 53 , c, im Durchschnitte gesehen), und einer breitern, äussern, parenclymatischen und gefarbten, aus Rindengewebe bestehenden lage, deren Zellen in horjzontalen, ron innen nach aussen sich rerdoppelnden Reihen liegen (Fig. 5̈, e). Durch die Höhlungen der keimbehälter rerlaufen freie Fasern, einfach oder verästell, welche den Boden und die Decke mit einander verbinden (Fig. 5:, d); sie bestehen in ihrer ganzen Länge gewöhnlich aus zwei, seltener aus 5 cylindrischen, farblosen, mit dicken Wandungen rersehenen Zellen, die etwas stärker sind als die Markfasern. - Die keimzellen entstehen aus kurzen, gegliederten, verästelten, büscheligen Haaren (Keimhaaren), an denen die letzten (obersten) Zellen sich in Keimzellen umwandeln (Fig. 56). Diese sind rerkehrt-birnförmig, oft mit zugespitztem Scheitel. - Nach Endlicher sollen bei Gelidium die Kermzellen in ein "Favellidium peridio lyyalino granulorum oblongorum glomerulum includente " zusammengeballt sein. Sie sind nun aher offenbar nicht in ein hemhäufchen rereinigl, sondern in einem keimbelıälter samenbodenständigr, also in einem Keramidium (nach der Teruninologie J. Agardh's) enthallen. Gelidium unterscheidet sich aber nicht bloss durch die keimzellenbildung von den Gallungen (Gigartina Lamour., Chrysymenia J. Ag.), mil denen es zusammengestellt wird; es ist von denselben auch durch das Wachsthum verschieden, und gehört nach heiden Merkmalen entschieden zu den Delesseriaceen. - Külzing beschreibt die Keimzellenbildung ebenfalls nicht richtig durch "spermatiis in glomerulum centrate, fibris, parictalibus affixun conglobatis. "Es mïssen auch hier die Keimhaare sammt den keimzellen und dem Samenträger' zusammen als eine gleichförmige, aus Keimzellen gebildete Zellmasse angesehen worden sein. 
3. Rhodoneleas.

Cylindrischer, selten zusammengedrückter Zellkörper (mit einer Reihe von Achsenzellen, von denen jede zunächst meist von כั oder mehr Zellen umgeben ist); Wachsthum in die Breite und Dicke nicht geschieden, son der Achsenlinie nach allen Seiten gehend.

Durch das Längenwachsthum entsteht zunächst eine Reihe von Gliederzellen $\left(I^{1}\right)$. Dieselben theilen sich durch eine excentrische senkrechte Wand in eine grössere $\left(\mathrm{II}^{2}\right)$ und eine kleinere Zelle $\left({ }_{1} \mathrm{III}^{1}\right)$; in der erstern wiederholt sich die gleiche Zellenbildung, aus ihr entsteht wieder eine grössere $\left(\mathrm{II}^{5}\right)$ und eine kleinere Zelle $\left({ }_{2} \mathrm{III}^{1}\right)$. Je in der grösseren der beiden Tochterzellen tritt wieder die gleiche Theilung durch eine excentrische, zur Achse tangentale Wand auf, nach der Formel $\mathrm{II}^{\mathrm{n}}=\mathrm{II}^{\mathrm{n}}+1+{ }_{\mathrm{n}} \mathrm{II}^{1}$. Das Resultat dieser Zellenbildung ist eine mittlere (Achsenzelle) und eine ringförmige Reihe gleichlanger, dieselbe umgebender tertiärer Zellen. - Die Zellenbildung, welche in den Gliederzellen der Rhodomeleen statt findet, stimmt im Allgemeinen mit derjenigen der Delesserieen überein, indem die Formel des Prozesses die gleiche und das Resultat jedenfalls ein ähnliches ist. Sie ist dadurch verschieden, dass bei den Delesserieen nie mehr als 4 tertiäre Zellen des ersten Grades entstehen, wovon 2 gegenüberliegende sich zuerst bilden, dass dagegen bei den Rhodomeleen 4 oder gewöhnlich mehr tertiäre Zellen des ersten Grades auftreten, deren Bildung von einem peripherischen Punkte ausgeht, und gleichmässig nach dem gegenüberliegenden Punkte fortschreitet. Aber nicht bloss die Reihenfolge, in welcher die tertiären Zellen des ersten Grades erzeugt werden, ist bei den beiden Familien verschieden; noch mehr differirt die Art und Weise, wie aus diesen Zellen das weitere Wachsthum hervorgeht. Bei den Delesserieen wird durch die beiden zuerst entstandenen, gegenüberstehenden, tertiären Zellen des ersten Grades $\left({ }_{1} \mathrm{III}^{1}\right.$ und $\left.{ }_{2} \mathrm{III}^{1}\right)$ die Bildung einer Zellschicht eingeleitet; senkrecht auf dieselbe beginnt dann das 


\section{$-219$}

Wachsthum in die Dicke. Bei den Rhodomeleen dagegen ist das Wachsthum in die Breite und in die Dicke nicht getrennt; sondern in allen tertiären Zellen des ersten Grades beginnt zugleich die Zellenbildung in die Dicke, in jeder in derjenigen Richtung, welche durch den Radius, den sie mit der Achsenzelle bildet, bezeichnet wird; die Scheidewände sind abwechselnd radial (horizontal oder vertical), tangental, oder auch schief zwischen radial und tangental.

Dem Begriffe nach sind Rhodomeleen und Delesserieen durch das Wachsthum scharf und absolut von einander geschieden. Bei der Anwendung des Princips zeigen sich zwei bedeutende Schwierigkeiten. Die erste ist die, dass wegen der Kleinheit der Zellen oder wegen anderer ungünstiger Verhältnisse das Wachsthum nicht deutlich erkannt werden kann. Die zweite besteht darin, dass die äussere Gestalt und zum Theil der innere Bau nicht als ein sicheres Merkmal für das Wachsthum gelten können. Bei den Delesserieen ist zwar die Gestalt immer flach, und die Achsenzellen sind immer von 4 Zellen umgeben; bei den Rhodomeleen ist zwar in der Regel die Gestalt cylindrisch und die Achsenzellen werden von mehr als 4 umgebenden Zellen begrenzt; aber es giebt auch einzelne Rhodomeleen mit flachgedrueckter gestalt, wie z. B. Ryliphloea, wo dennoch das Wachsthum nicht in Breiten- und Dickenwachsthum geschieden ist und wo die Achsenzellen von כૅ Zellen begrenzt werden; es giebt ferner einzelne Rhodomeleen (mit cylindrischer Gestalt), wie z. B. Arten von Polysiphonia, wo DIE ACHSENZELLEN BLOSS YON 4 ZELLEN UNGEBEN SIND, welche aber nicht in der Ordnung wie bei den Delesserieen entstehen. Für die Rhodomeleen und Delesserieen bleibt also kein anderer begrifflicher Unterschied, als der in dem Wachsthume durch Zellenbildung begrïndete.

Die Sporenmutterzellen liegen bald dicht an den Zellen der Achsenreihe, bald von denselben entfernt in der Rinde. Dieser Unterschied begründet zwei natürliche Gruppen; für die eine derselben kann Polysiphonia, für die andere Laurencia als Typus gelten.

Zu den Rhodomeleen gehören die Gattungen Polysiphonia Grev., Dasya Ag., Alsidium Ag., Digenea Ag., Rhodomela Ag., Rytiphloea Ag., Laurencia Lamour. etc. 
Für diese Familie mögen zwei Beispiele dienen, einerseits die Caltungen Polysiphonia und Ilerposiphonia, deren regetalive und reproductive Verlältnisse ich an einen andern Orte ausführlieh besehrieben habe, und worauf ich lier bloss verweisen will $\left(^{1}\right)$, und anderseits die Gallung Laurencia.

\section{Lamencia Lamour.}

TAB. VHI, Fig. $1-27$; TAB. IX, Fig. $1-5$.

Laurencia besteht aus ungegliederten, cylindrischen Zellkörpern, an deren Spitzen dichotomische, gegliederte, harähnliche Fäden befestigt sind; die erstern sind die Slämme, lelztere die Blätter. Das Wachsthum der Stanmachsen in die Lïnge geschicht durch eine Scheitelzelle $\left(I^{\mathrm{n}}\right)$, welche sich fortwährend durch eine horizontale, die Aclıse unter einem rechten Winkel schneidende Wand in eine neue Scheitelzelle $\left(I^{n}+1\right)$ und in eine Gliederzelle $\left({ }_{n} I^{1}\right)$ theilt, nach der Formel $I^{11}=I^{n}+1+n I^{1}$. Diese Zellenbildung kann aber nur in cinzelnen seltenen Fällen wirklich gesehen werden, nämlich bei $L$. temuissima an den dünmern, spitzen Aesten und bei allen übrigen Arten bloss an ganz jungen Zweigen. Bei $L$. tenuissima endigen die Aeste theils spitz, theils stımpf; an jenen sieht man zu äusserst deullich die Scheitelzelle (lab. VIII, Fig. 4, a; ̋̈, a), und unterhalb derselben eine oder mehrese Gliederzellen (Fig. 4, b; 8, b, e); an den stumpfen Aesten kann nan die scheitełzelle unter den übrigen Zellen und unter den haarförmigen Blättern nicht erkennen, oder sie ist selbst in den vertieften Ende verborgen. Bei $L$. dasyphylla lassen sich die jungen Zweige, weil sie mil einer sehr schmalen Basis an der Mutterachse festsitzen, leieht trennen, die Figuren $15-16$ stellen solehe freie Zweige dar; die jïngrsten haben noch ganz das Ansehen einer Polysiphonia, nur dass der untere Theil im Verhältnisse zur Spitze verdickt ist (Fig. 15); das Wachsthum in die Dicke geht nun raseher von Statten als das Wachsthum in die Lünge (Fig. 14), so dass die Spitze (a) ringsum überwachsen wird (Fig. 13), und zuletzt in einer Vertiefung verborgen ist (Fig. 16), aus welcher bloss noch die haáförmigen Błätter hervorragen. In diesem Zustande bleibt nun fortwïhrend die Spitze an diesem Aste, so dass, mit Ausnahme von L. tenuissima, bei allen andern Laurenciaarten alle Aclssenenden, ausser den allerjüngsten Zweigen, ein vertieftes Punktum vegetationis besitzen (Fig. $2:$ im senkrechten Durchsehnitte). An ge]ungenen, senkrechten Durchsehnitten ist es zuweilen möglich, im Grunde der Vertiefung die Seheilelzelle zu erkennen. - Das Wachsthum der Slammachsen in die Länge ist unbegrenzt, wie hei Polysiphonia.

Das Wachsllıum in die Dicke heginnt in den Glielerzellen (II ${ }^{1}$ ). Diesc theilen sich durch eine senkrechte: excentrische Wand in eine kleinere äussere (,III) und in eine grössere Zclle $\left(I^{2}{ }^{2}\right.$ ). Die letztere theilt sich wieder durch eine excentrische, senkrechte Wand in eine kleinere äussere $\left({ }_{2} 111\right)$ und eine grössere Zelle $\left(11^{3}\right)$. In dieser wiederholt sieh die gleiche Zellenbildung bis die äusseren Zellen in einen vollständigen Kreis um eine Achsenzelle sich schliessen. Die Formel dieser Zeltenbildung ist die gleiche wie bei Polysiphonia:

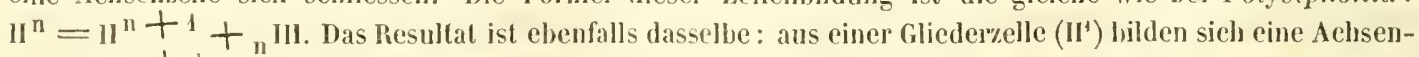
zelle $\left(\mathrm{II}^{\mathrm{P}}+{ }^{1}\right.$ ) und ein Kreis von gleichlangen tertiären Zellen ( III..... plII). In dem dritlobersten Gliede von Fig. 4 und dem viertobersten von Fig. 15 hat erst Eine Theilung in der Gliederzelle statt gefunden. Die untern Clieder in Fig. 4 und Fig. 15 haben siclı vollständig auf die angrgebene Weise getheilt, und sind in senkrechten Durchschnitte gezeichnet. - Mit dieser Zellenbildung ist das Wachsthum in die Dicke bei Polysiphonia fertig; bei Laurencia hat es erst begonmen. Von den bis jetzt gebildeten Zellen ist bloss die Achsenzelle $\left(\mathrm{II}^{\mathrm{P}}+\mathrm{I}^{1}\right.$ ) eine Dauerzelle (Fig. $4, \mathrm{~m}$ ); alle iibrigen (. III..... pIII) sind vutterzellen (Fig. 4, n, n). $\mathrm{AuI}$

(4) Zeitschifift f. w. Bot., Heft 5 und 4, pag. 207 und pag. 258. 
welche Weise aber cliese weitere Zellenbildung erfolge, habe ich bei Latrencia selbst nicht beobachtet. Ich kann tür diese Gattung bloss den fertigen Bau genau angeben.

Diejenigen Arten, deren Bau ich untersucht habe, nämlich L. temuissima Grev., L. dasyphylla Grev., L. ohtusa Lamour. und L. papillosı Grer. ergaben zwei rerschicdene Typen, wovon einer den ersten beiden Arten, der andere den beiden lelzlen angehört. Führt man einen senkrechten Schnitt dureh die Mitte eines jungen Asles von L. dasyphylla oder L. temuissima, so sieht man in der litte die Achsenzellen (Fig. 1, a); jedlerseits eine Zelle von gleicher Länge (Fi⿳⺈. 1, b. b); nach aussen von diesen zwei Zellen von halber länge übereinander (Fig. 1, e, c); auf dieselben folgt eine Reilıe doppelt kïrzerer Zellen (Fig. 1, d, d), und naclsher können noch eine oder zwei senkrechte Reihen von Zellen folgen, von denen jede Zelle bloss halb so hoch ist als die Zelle einer innern lieihe (Fig. 1, e, e). - Horizontale Durchschnitte zeigen im Centrum die Achsenrelle (Fig. 2, a); dieselbe ist umgelsen von 5 Zellen (Fig. 2, b, b); dann folgt eine concentrische Reihe von 10 Zellen (Fig. 2, c, c), dann eine solche ron 20 Zellen (Fig. 2, d, d). daraul auch wohl noch eine von (4). (Fig. 2, e, e) und ron 80 Zellen. - Fassen wir das Resultat dieser beiden Durcisclnitte zusammen, so ergiebt sich fïr den ersten Typus des Baues von Laurencia als Regel folgendes : Die Stämme bestchen aus lintereinander liegenden Gliedern. Jedes Glied hat in der Vilte eine Achsenzelle, von gleicher Länge wie das Glied (Fig. 1, 2 , a). Die Achsenzelle isł ungelsen von 3 im Kreise gestellten Zellen, von gleicher Länge wie das Glied (Fig. 1, 2, b). Jede dieser Zellen ist naclı ausen von 4 Zelien begrenzt, welche halb so lang als das Glied sind, und anı ganzen Glied eine Schicht ron 20 Zellen ausmacinen (Fig. 1, 2, e). An jede ron diesen Zellen slossen nach aussen wieder 4 Zelien an, welche $\%$ solang sind als das ganze Glied, und zusammen eine Schicht ron 80 Zellen darstellen (Fig. 1, 2, d). Yon diesen Zellen kann wieder jede nach aussen von 4 Zeilen bedecht sein, welehe de! 6ten Theil der Länge des ganzen Giedes haben, und zusammen eine Schicht von 520 Zellen ausmachen; u. s. f. - Dieser regelmäissige Bau ist anch sehr schön an Aesten von L. dasyphylla zu sehen, welche Sporen bilaen. Die gallertartige Intercellularsubstanz vermehrt sich hier ott so sehr, dass die Zellen, welche zugleich n radialer Richtung sich bedeutend ausdehnen, sejtlich in bełächtlichem Nasse von einander getrennt werden. n:an erkenni dann, sowohl auf rerticalen als namenliich auf horizonlalen Durchschnitten (Fig. 10), rermittelst Veränderungen des Focus leicht, dass je auf einer innern Zelle 4 äussere Zellen befestigt sind. So folgen au jede Zelle is deullich 4 Zellen $c$, auf jedes $\mathrm{c}$ nach aussen 4 Zellen d.

Taclidem ich den Bau, wie er als Regel festzuhalten ist, hetrachtet habe, muss ich auch noch von den Ausnahmen sprechen. Nicht inmer verhält sich die Sache auf senkrechten und lıorizontalen Durchschnitten so regrelmässig, als es eben geschildert wurde. Dic Aclısenzelle (a), die כ̆ glejchlangen sie umgebenden Zellen (b), sowie die 20 lsloss halbsolangen und hail, so breiten Zellen, welche daraul folgen (Fig. 1, 2, 5, 6, 9, 10, c) erkennt man zwar immer, wenn die Schnilte nicht schief geführt werden. Nach aussen scheint es aber oft, als ob dic Zahl der Zelien unregelmässig würde, und zwar als ob sie sich unregrelmässig vermehrte; unter die regelmåssige Zahl sah ich sie nicht fallen. So sieht man in Fig. 6 in der Reihe d-d statt 4 Zellen 3 , in der Reilse e-e 11 statt 8 , in der Reihe f-f $20 \%$ statt 16. Namentlich sind es die Epidermiszellen, welche, wenn auch alles andere ganz. regelmässig ist, eine Zunahme zeigen, so z. B. zühlte ich auf einem horizontalen Durclıschnitl, welcher nm die Achsenzelle 4 concentrische Zellenreihen hatte, 66 Epidermiszellen, ferner sielıt man in Fig. 5 an der äussern Fläche von 10 Zellen d 24 Zellen e. Ich glaube jedock, dass alle diese Ausnahmen nur sclıeinbar sind. Es ist sehr begreiflich, dass im senkrechten Burchschnitt, welcher besonders solche scheinbaren Ausnahmen zu Tage fördert, am äussern Rande einer Zelle zuveilen 5 , oder am äussern liande zweier Zellen zuweilen 5 , stat 2 und 4 Zellen, gesehen werden, weil ja in der That nach der Regrel an del Aussenfläche jeder Zelle 4 äussere Zellen stehen, und diese sowohl unter einander als mit den übrigen Zellen, die mit ihnen in einer concentrischen Schicht liegen, bei der Ausdehnung leicht etwas verschoben werden, und weil ja auch der Schnitt leicht etwas schief geführt łird. Das gleiche ist auch bei horizontalen burchschnilten möglich. Bei den EpiderIniszellen, welche meistens in einer grössern Zahl beobachtet werden, als es nach der Regel der Fall sein sollte, wirkt ausser der gleichen Ursache, wic bei den inneren Zellen, offenbar noch eine andere mit, um diese Unre- 
gelmässigkeit zı erzengren. Die Epidermiszellen gehören nämlich, wie man oft deutlich sieht, nicht alle der gleicheı concentrischen Schicht an, indem man darunter etwas grössere mehr naclı innerı und elwas kleinere melır nach anssen stehende Zellen unterscheidet, die aber alle an die Oberfläclie anslossen, und desswegen als Epiderniszellen betrachtet werden müssen (Fig. 10, e-e; 11, d-d). Es scheint mir daher, als ob die einen Zellen dersclben äussere Zellen erzeugten, während die anderen diess nicht thun, woher denn eine die Regel iibersteigende Zahl ron Epidermiszellen leicht erklärt wird. - Wir können also füglich annehmen, dass an der Aussenfl̈̈che einer Zelle (mit Ausnahıme der Aclısenzelle) inmer 4 Zellen, 2 üher und 2 neben einander stelıen, und diess um so mehr als überall da, wo eine genaue Untersuchung möglich ist, (nämlich an jungen Aelısen, iu denen die Zellen noch ihre ursprỉngliche Lage besilzen, und in sporenbildenden Aesten, deren Zellen ein: selır lockeres Gewebe bilden) die Regel sich bestätigt.

Um jede Achsenzelle stehen also 5 gleichlange Zeilen, und von da nach aussen folgen auf eine innere $\downarrow$ äussere Zellen. Die Lage aller Zellen eiıes Gliedes hängt demnach ganz von der Lage jener ๖ Zellen ab. Diese selbst alterniren in den successiven Gliedern, so dass sie in dem 1, 5, 5, 7ten Gliede einerseits, und in den 2, 4, 6, 8ten Gliede anderseits senkrecht über einander stehen; die Divergenz betrügt also ' durch einen sporenbildenden $\Lambda$ st dünne senkrechle Durehschnitte, so sieht man in Folge dieser Alternanz blos; je an der zweiten Achsenzelle eine der nächst begrenzenden Zellen, indem sie in den zwischenliegenden Gliedern durch den Schnitt weggefallen sind. In Fig. 11 bezeichnet a-a den Strang von Achsenzellen, b, b die unterbrochene Reihe der sie berïhrenden Zellen, $\mathrm{n}, \mathrm{n}$ die alternirenden, Jeeren (gallertartige Intercellularsubslan\%. entlıaltenden) Räume. - Da die 马̊ innersten Zellen alternirende Quirle bilden, und von ilınen die Stellung aller übrigen Zellen eines Gliedes bedingt wird, so alterniren auch alle ülırigen Zellen in den successiven Gliedern, während sie im gleichen Gliede, wenigstens im Anfange, senkrecht über einander stehen.

Der zweite Typus des Baues der Stammachsen, welcher bei L.obtusa und L. dasyphylla gefunden wird, ist schwieriger zu untersuchen, und verhält sich auch nicht so mathematisch regelmässig wie der erste. Die nitte des Gewebes ist auch hier von einer Reilıe von Achsenzellen durchzogen. Ein characteristischer Unterschied liegt aber darin, dass die Achsenzellen (Fig. 20, a) 2 bis 5 mal küzzel sind als die anliegenden Zellen. (b). Und zwar scheint es mir ziemlich Regel zu sein, dass je 5 Achsenzellen auf eine der letztern gelien (Fig. 17, a-a). Die Zelten nehmen auch hier auf senkrechten Durchschnilten nach dem Rande hin an Länge ab und an Zahl (in senkrechter Richtung) zu. Zuweilen ist ebenfalls die Zunahme regelmässig und zwar so, dass auf jede innere nach aussen zwei doppelt kürzere Zellen folgen (Fig. 17). Häufig ist aber die Zunahme langsamer, so dass auf eine innere Zelle bloss eine äussere, oder auf zwei bloss drei äussere Zellen folgen (Fig. 20). Auf horizontalen Durchschnitten war es mir zwar meist möglich, die Achsenzelle zu erkennen, nicht aber mit Sieherheit zu erfahren, von wie vielen Zellen sie zunächst umgeben ist, ebenso wenig ob sich in der Lage der übrigen Zellen eine bestimmte Regel kund gebe. Nur soviel ist deutlich, dass auch hier die Zelleñin concentrisclıen Reihen liegen, und dass sie nach dem Rande an Grösse ab und an Zahl zunelımen.

Der Untersehied des? ersten und des zweiten Typus offenbart sich also zunächst đarin, dass beim ersten die Achsenzellen mit den nächstanlieģenden Zellen gleiche Länge lraben, dass sie bein zweiten wenigstens 2 und vielleicht constant 5 mal kürzer sind. Doch begründet höchst wahrscheinlich diess nicht die einzige Verschiedenheit. Beim ersten Typus ist jede Achsenzelle bestinmt von $っ$ Zellen umgeben ; beim zweiten ist, wie ich vermuthe, jede Achsenzelle ursprünglich von 5 Zellen ungeben. Für diesen ternären Bau des zweiten Typus habe ich zwei Gründe. Das Punctum vegetationis is bei L. obtusa und $L$. papillosa beträchtlich vertieft. Betrachtet man eine Astspitze von L. papillosa von oben, so erseheint jenes dreilappig, indem von einer mittlern dreieckigen Vertiefung aus drei Furchen nach aussen und unten verlanfen, welche sich bald verlieren. Die ohersten Quersclinitte liefern immer drei getrennte Stücke, welche von einander fallen (Fig. 25); die folgrenden Durchschnitte zeigen in der Mitte eine dreieckige Höhlung, welche von Epidermiszellen begrenzt ist (Fig. 2/). Diese dreilappige Gestalt der Stanmspitzen scheint mir auf eine dreifache Theilung des Zellgewebes zu deuten, welche cinzig davon herrühren könnte, dass die Achsenzellen von drei Zellen umgehen wären, ob. 
gleich ich allerdings auf keinen Durchschnitlen eine Andeutung dieser dreifachen Theilung des Gewebes erkennen konnte. Uebrigens thut das der Annalıme keinen Eintrag, da auch bei $L$. dasyphylla und $L$. tenuissima nichts von einer fünffachen Theilung des Gewebes gesehen wird. - Fin zweiter Grund fïr die oben ausgesprochene Ansicht liegt darin, dass die Aeste sehr häufig zu 2 oder zu 5 verticillirt an den Stammachsen slehen, und dass, wie ich mehrmals beobachtete, sie im erstern Falle nicht opponirt, sondern durch einen grössern Bogen von circa $240^{\circ}$ und einen kleinern von circa $120^{\circ}$ getrennt sind, während sie im zweiten Falle einen regelmässigen lernär'en Quirl bilden.

Ist der Sehluss richtig und bestätigt sich die ausgesprochene Vermuthung, so beruht die Verschiedenheit der beiden Typen nicht bloss darin, dass beim erstern die Achsenzellen solang, beim zweilen bloss $\%$ - $\%$ \$olang sind als die anliegenden Zellen, sondern auch vorzüglich noch darin, dass beim erstern die Achsen-

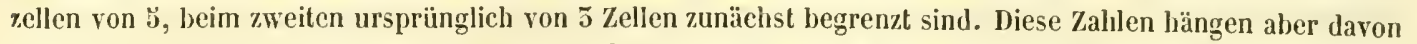
ab, in wie viele Zellen sich die Gliederzellen anfänglich theilten. In erstern Falle mussten sie eine Achsenzelle und 5 tertiäre Zellen, im zweiten Falle eine Achsenzelle und $\mathbf{3}$ tertiäre Zellen erzeugen. Im erstern Falle musste in der Formel II $\mathrm{n}=1 \mathrm{In}+{ }^{1}+{ }_{\mathrm{n}} \mathrm{III}$ das n nach einander die Werthe $1 \ldots .5$, im zweiten Falle bloss $1 \ldots 5$ annelımen. Es ist möglich, und mir auch wahrscheinlich, dass sich dic hauptsächlichste Differenz zwischen den beiden Typen auf diesen einfachen Ausdruck reducirt: In der Formel $\mathrm{II}^{\mathrm{n}}=\mathrm{II}^{\mathrm{n}}+^{1}+\mathrm{vllI}$, welche beiden gemeinsam ist, nimmt $n$ nach cinander die Werthe $1 \ldots p$ an; $p$ ist beim ersten Typus $=$ z̆, beim zweiten $=5$.

Die jungen Zellen der Stammspitze von Laurencia sind parenchymatisch, mit zarten Membranen. Der Inhalt ist homogener farbloser Schleim; in jeder Zelle sieht man in der Regel einen Kern, wenn die Zellen in einem grössern Gewebe beisammen liegen (in Fig. 26 sind die jüngsten Zellen der Stammspitze von L. papillosa aus dem Querschnitt dargestellt); der Kern ist dagegen undeutlich in den Zellen der dünnen Stammspitze von L. tenuissima (Fig. 4, כ̈). - Nit der Ausdehnung der Zellen wird der Inhalt heller und körnig; man erkennt deutlich die laterale Lage des Kernes (Fig. 27, aus dem Quersehnilt der Stammspitze von L. papillosa). - Mit der weitern Ausdehnung der Zellen tritt der feste Inhalt an die Wandung, das Lumen enthält bloss wasserlıelle Flüssigkeit. Zu gleicher Zeit fängt die Zellwandung an, sich zu verdicken. - An den entwickelten Theilen der Stammachsen haben sich überall zwischen den Zellen Intercellularrüume gebildet, welche mit dünner Gallerte gefüllt sind (Fig. 9, 17, 20). Besonders viel dieser gallertartigen Intercellularsubstanz findet man an den Theilen der Stammaclisen, welche Sporen bilden (Fig. 10, 11). Im Innern der entwickelten Stammachsen findet man grössere wasserhelle ungefïbte Zellen, mit einer homogenen Schleimschicht (PrimordialschIauch) und einem Nelz von zarten, meist feingekörnten Fäden an derselben, in wclchem hin und wieder homogene Schleimbläschen ( ${ }^{1}$ ) liegen (Fig. 5, 17). Der laterale Kern ist zuerst noch häufig sichlbar, 'später verschwindet er. Am längsten bemerkt man ihn iı den Achsenzellen (Fig. 17, a). - Nach aussen gegen die Oberfläehe hin melırt sich der wandständige feste Zelleninhalt, und färbt sich allmälig röthlich, dann roth; die äussersten Zellen sind lıäufig braunrolh. Ins Alter geht die Farbe wie bei vielen andern Florideen, mehr oder weniger volıstïndig in grün (Chlorophyll) über. In L. tenuissima und dasyphylla werden die Stämme ins Alter mehr gelbgr'in, in L. obtusa intensiver grün, und in $\boldsymbol{L}$. dasyphylla häufig schwarggrün. - Die äusserste Zcllschicht unterscheidet sich schon schr frïh von allen übrigen durch Geslalt, Farbe und Inhalt, und bildet eine das Gewebe umschliessende Epidermis. Zuerst zeichnen sich die Epidermiszellen dureh die Gestalt aus; Ihr radialer Durchmesser übertrifft die beiden tangentalen Durehmesser mehrmals, während in den nächsten Zellen kein wesentlicher Unterschied in den drei Dimensionen bemerkbar, und in den innern Zellen der radiale Durchmesser kürzer ist als der verticale. Nachher zeichnen sich die Epidermiszellen vor den innern Zellen auch durch die Farbe und den Inhalt aus, indem dieselben viel intenser gefärbt, und mit kürnigem Inhalt oft ganz gefiilit oder

(') Vgl. über diesen Ausdruck Zeitschrift f. w. Bot., Ileft 3 und 4, pag. 107. 
an der innern Fläche damit dieht ausgekleidet sind (Fig, 5, 17, e). Später wenn die innern Zellen sich abrunden und in den Intercellularräumen eine beträchlliche Masse von verdünnter Tallerte auftritt, so bleiben die Epidermiszellen fest mit einander verbunden (Fig. 5, 9, 10, 11, 17, 20), und sind nach aussen häufig von einer gelben Cutieula bedeckt, welche keilförmig zwisehen die Epidermiszellen lineindringt in Fig. 21 ist die Epidermis von L. papillosa im Querschnitt, in Fig. 22 von aussen dargestellt). - An den Epidermiszellen ist auch noch das Verhalten des Kernes merkwürdig. Derselbe fehlt bej L. obtusa und L. papillosa fast nie (Fig. 17, e); er liegt, sowoht wenn die Epidermiszellen von der Fläche (Fig. 19), als wenn dieselben im senkrechten radialen Durehschnitt betrachtet werden (Fig. 18), in der Mitte der untern Wand. Diese Lagerung des Kernes, welche bei den genannten Arten sich mir seir constant zeigte, ist nicht etwa Folge der Schwerkraft sondern irgend einer orgauischen Ursache, da sie von Anfang an dieselbe ist, obgleich die Epidermiszellen an der vertieften Stammspitze zuerst eine räumlich-umgekchrte Stellung besitzen. Man findet daher z. B. an den Epidermiszellen in a Fig. 25 den Kern an der äussern Wand, in b an der obern Wand.

Wenn die Zellen des Stammes von Laurencia sich ausgedehnt, ihren Inhalt umgebildet, ihre Wandungen verdickt und durch Intereellularsubstanz sich von einander getrennt haben, so trilt hæufig eine nachtrægliche. Zuellenbildung auf. Sie beginnt in der Mitte, und schreitet nach aussen hin fort. Sie besteht darin, dass die zellen mit ihrem untern seitlichen Ende in einen Fortsatz auswachsen, weleher sich als Astzelle abtheilt. Diese Astzelle verlangert sich nach unten, und wird zu einer einfachen oder spærlich veræstelten Zellenreihe. Die Zellenreihen zusammen bilden zwischen den eigentliclıen Gewebezellen ein intercellulares Geflecht, wie in Delesseria IIypoglossum ${ }^{4}$ ). Auf dem verticalen Durchsthnitt sieht man diese Zellfæden neben den übrig̨en Zellen (Fig. 6); auf dem horizontalen Durclsschnit erblickt man dieselben in den Intercellularræumen (Fig. 4).

Die blatter von Laurencia stimmen in allen wesentlichen herkmalen mit denen von Polysiphonia ïber(ein ${ }^{2}$ ). Man findet sie bloss an der Spitze der Stammachsen, wo sie in der Vertiefung (Fig. 25, b) stehen, und als ein Büschel ron Haaren aus derselben hervorragen (Fig. 16). Sie entwickeln sich sehr rasch und fallen balıl ab, so dass selten noclı ein Blatl an dem Unfange jener Vertiefung gesehen wird. Es sind veræstelte Zellenreihen, an denen jedes Glied mit Ausıahme der lelzten Zellen jeder Achse und der Basiszelle der Hauptachs' eine einzige Tochterachse trægt; die Divergenz der Verastchng ist " $\%$. Bei der Ausbildung nehmen sie ein. jseudo-dichotomische Gestalt an. In Fig. 7 und 8 sind zwei junge, noch durch Zellenbildung wachsende Blæetle. dargestellt. Die einzelnen Achsen verlangern sich dadureh, dass die Scheitelzelle sıch theilt, nach der Formel $I^{n}=I^{n}+^{1}+$ nII. Sie veræsteln sich dadurch, dass die Gliederzellen (II) seitlich auswachsen und eine Astzelle (I ${ }^{4}$ fül' eine Tochterachse) erzeugen. Das Wachsthum der Achsen, so wie die Wiederholung derselben ist begrenal. - Die eylindrisehen Blattzellen enthalten anfæenglich einen lomogenen farblosen Schleim. In denselben enistehen zuerst kleine hohle Raume, welche sich vermehren, und dem Inhalte ein schaumförmiges Ansehen geben. Wie die Zellen elwas grösser werden, so geht der Schaum in ein hełz über, welches noch dis gàze Lumen ausfüllt, und einem zarten Parenchym nicht unæhnlich ist. Zugleich wird ein kleiner an der Wandung liegender Kern sichtbar, welcher sich gewöhnlich in der Mitte der Cylinderflaeclıe befindet. Die Zellen dehnen sich betræechtlich in die Lenge, dabei verschwindet das Schleimnetz, und zwar zuerst in dem oberı und untern Theile einer Zelle, wæhrend es in der Milte derselben und in der Næhe des Kernes noch vorhanden ist. Zuletzt ist es auch hier verschwunden; das Lumen ist bloss mit wasserheller Flüssigkeit gefüllt ; an der Wandung liegt die Schleimschicht (Primordialsclılanch), an derselben ist zuweilen ein zarles peripherisches vełz von Schleimfxeden bemerkbar. - Die Ausdehnung der Blittzellen verbunden mit der Lmbildun $\underline{\underline{g}}$ des Inlıaltes beginnt an der Spitze des Blattes, und schreitet nach der Basis lin fort. Wenn die obersten Zellen sehw. atusgeljildet, cylindriseh und ohne Schleihnetz sind, so enthalten die untersten in noch ganz burzen Zellen erst

(4) igl. pag. 213

(2) Zeitscl,nift f. w. Bot., Ileft 5 und 4 pag. 210 
rinen undenflichen Schaum. - Die Zelle, aus welcher ein Blatt in seinem ersten Stadium besteht, oder dic prinære Zelle des ersten Grades seiner IIauptachse, bildet sich durch Auswachsen der ungetheilten Gliederzellen der Stammachsen (Fig. 4, c, d).

Alle Zellen von Laurencia, sowohl die der Stæmme als die der Blætter, besitzen Poren, und zwar findet sich, wie bei Polysiphonia zwisehen je zwei Zellen nur ein Porus, in der Milte der Scheidewand. So hat also jede Blattzelle, wo die Achsen sich veræsteln, drei Poren; jede Gliederzelle, wo die Achsen einfach sind, zwei Poren und jede Scheiteizelle einen Porus. Die Zellen des Stanmes haben ungleiche Poren, grössere und kleinere; die letztern sind oft undeutlich; ins Alter verschwinden sie hæufig, und die Zellen trennen sich von einander (in Fig. 21 sieht nan die Poren zwischen den Epidermiszellen). Die Zellen des intercellularen Genechtes besitzen bloss Poren nach den unter und über ihnen stehenden Fadenzellen (mit denen sie zu Zellenreihen verbunden sind) und einen Porus nach der Gewebezelle, aus welcher der Faden entsprungen ist; aber nit den anliegenden andern Gewebezellen, und mit den Zellen anderer Fæden sind sie durch keine Poren verbunden.

Die Sporenbildung findet im Gewebe der jungen Stammachsen statt. leh kenne sie bloss bei $L$. dasyphylla genauer. Hier liegen die Sporenmutterzellen dicht unter der Epidermis; die Mitte ihrer aussern Flæche ist unbedeckt, indem die Epidermiszellen daselbst aus einander treten und eine Oeffnung zwisehen sich lassen. In Fig. 11 sieht man an einem senkrechten Durchschnitte zwei Sporenmulterzellen, in Fig. 12 von der aussern Flache eine Sporenmutterzelle mit der Epidermis (welche sie theilweise bedeckt) und ihrem Intercellularraum in der Milte. - De Zelien der sporenbildenden Aeste erzeugen eine grosse Menge dünner gallertartiger lntercellularsubstanz. Dadurch werden dieselben von einander getrennt und das Gewebe xeusserst Iocker (Fig. 10, 11). Es erleichtert dieser Umsland die Untersuchung über die Stellung der Sporenmutterzellen. Dieselben stehen in der zweiten senkrechten Zellschicht von den Achsenzellen nach aussen. Sie sind an der æussern Flæche derjenigen Zellen befestigt, welche die Achsenzellen berühren (Fig. 11, b). Bei L. (lasyphylla ist jede Achsen zelle, wie ich oben gezeigt habe, von 5 Zellen umgeben; jede derselben hat an ihrer aussern Flache 4 Zellen wie mir scheint, ist es eine dieser 4 Zellen, welche zur Sporenmutterzelle wird. Die Sporen sind tetradrisch. Bei den übrigen Arten weicht die Stellung der Sporenmutterzellen ab, indem dieselben bei $L$. obtutsa und L. papillosa mehr peripherisch gelagert sind; bei L. temuissima dagegen scheint es mir, als ob die sporenmutterzellen unmittelbar die Achsenzellen berühren. Ist das letztere richtig, so müsste diese Art wohl von der Gattung getrennt werden, wie es bereits von Kützing ġeschehen ist.

Antheridien habe ich bloss an L. tenuissima gesehen, leider nur an trockenen Exemplaren, so dass eine genane Untersuchung nicht wohl möglich war. Sie sind, wie bei Polysiphoniı, an den Blattern befestigt.

Die Keimbehälter siizen seitlich an den Stammachsen (Tab. IX. Fig. 1). Sie bestehen aus einem fast kugeligen oder ovalen, oben stumpf-abgeschnittenen und geöffneten Sacke. In Grunde desselben liegt der Samenbolen, an denı die Keimhaare befestigt sind. Dieselben sind kurz und stark veræstelt; die Endzellen der Aestehen und Zweige entwickeln sich zu Keimzellen; und zwar scheinen es ziemlıch regelmassig die Scheitelzellen von zweigliedrigen Achsen zu sein, welche zu Keimzellen werden, indess die untere oder Gliederzelle das Vermögen besitzt, durch seitliches Auswachsen wieder eine Tochterachse zu erzeugen; so dass also die Keimzellenbildung an einem llaar sich beliebig lang fortsetzen kann. In Tab. IX. Fig. 1 ist ein Keimbehælter, in Fig. 2 cin junges, in Fig. 5 ein xlteres Keimhaar abgebildet. - Die Keimzellen sind birnförmig, und mit braunrothen körnigem Inhalte gefüllt.

Laurencia besitzt, wie Polysiphonia, zwei wesentliche Organe: Stamme und Blatter. Die Stammachsen wachsen unbegrenzt in die lange, und erzeugen hin und wieder ihnen gleiche, ebenfalls unbegrenzte Tochterachsen (Aeste); alle Stammachsen sind einander gleich. Kützing unterseheidet zwar obesondere Fruchfaste " (Carpoclonia); es sind alser nichts Anderes als kurze noch junge gewölunliche Aeste, welche einzelne zellen ж) Sporenmutterzellen umwandeln, nachher aber sich verlængern und unbegrenzt werden. - Die Blatter sind von den Stremmen ausser dem besondern Bau und der eigenthümlichen Veraestelung ferner durch das begrenzte Wachsthum, furch die von ohen nach unten hin fortschreilende Ausbildung der Zellen und durch den 
ITrsprung versehieden, indem die Blatter durch Auswachsen der ungetheilten Gliederzellen des Stammes (II') entstehen, die Stanmachsen dagegen, insofern sie nicht aus einer Sporen- oder Keimzelle hervorgehen, so vie? ich beolachten killn, im Innern des Stammgewebes entspringen. Ein physiologischer Unterschied zwiselreu Blatt und Stanm liegt ferner darin, dass ersteres die Antheridien, letzterer die Sporenmutterzellen erzeugt.

\section{RHODOMENIAGEAE.}

Die Hauptachsen sind Zellschichten oder Zellkürper, deren Scheitelzelle, wenigstens der reproductiven Achsen, sich durch schiefe Wünde theilt; Sporenmutterzellen im Gevebe.

Diese Ordnung unterscheidet sich von den Ceramiaceen in gleicher Weise wie die vorhergehende; nämlich die Hauptachsen sind niemals Zellenreihen, und die Sporenmutterzellen sind nie Scheitelzellen oder Gliederzellen, sondern immer im Gewebe eingeschlossen. - Von den Delesseriaceen unterscheidet sich die Ordnung der Rhodomeniaceen durch das Wachsthum, welches merkwürdiger Weise genau mil demjenigen der Moose übereinstimmt. Die Scheitelzelle oder primäre Zelle des ${ }_{n}^{\text {ten }}$ Grades $\left(I^{n}\right)$ theilt sich durch eine schiefe Wand in eine neue Scheitelzelle oder primäre Zelle des $n+4^{\text {ten }}$ Grades $\left(I^{n+1}\right)$ und in eine secundäre Zelle des ersten Grades ( $\mathrm{n} \mathrm{II}^{1}$ ), welche keine Gliederzelle ist. Ist die Achse eine Zellschicht oder ein flacher Zellkörper, so sind die Wände in den Scheitelzellen abwechselnd nach rechts und nach links geneigt, und die secundären Zellen des ersten Grades alterniren mit der Divergenz von $180^{\circ}$. Ist dagegen die Achse ein cylindrischer Zellkörper, so sind die Scheidewände in den Scheitelzellen abwechselnd nach drei oder mehr Seiten hin geneigl, und die secundären Zellen des ersten Grades alterniren mit der Divergenz von $180^{\circ}-\mathrm{x}$. Im ersteren Falle stimmt das Längenwachsthum mit demjenigen der Laubachsen von Echinomitrium und des Laubmoosblattes, im zweiten Falle mit demjenigen des Laub- und Lebermoosstammes überein. 1) - Das Wachsthum in die Breite und Dicke oder die Zellenbildung, welche in den secundären Zellen des ersten Grades beginnt, ist ebenfalls die gleiche wie bei den Moosen. - Es ist daher characteristisch für die Rhodomeniaceen, dass ihre Achsen immer, auch in den frühsten Stadien, unge-

1) vgl. Zeitschrift für wissenschaftl. Bot. Ileft 2. pag. $158 \pi$. 
gliedert sind, und dass dieselben im Innern keine Reihe besonderer Achsenzelien besitzen.

Bei den meisten Gattungen, welche zu dieser Ordnung gehören, entwickeln sich alle Achsen auf die eben angegebene Weise. Bei einigen wenigen findet zwischen vegetativen und reproductiven Achsen ein Unterschied statt : die ersteru besitzen gleiches Wachsthum und gleichen Bau wie die Delesseriaceen, indem sich die Scheitelzellen durch horizontale Wände theilen; die letztern, nämlich die Aeste, in denen sich die Sporen bilden, entwickeln sich in der den Rhodomeniaceen eigenthümlichen Art, indem die Scheitelzellen sich durch schiefe Wände theilen. Diese merkwürdige Combination der beiden Wachsthumsarten findet sich bei Plocamium Grev. und bei Thamnophora Ag.

Die Keimzellen sind zu Keimhäufchen vereinigt, welche im Gewebe entweder der Laubachsen oder besonderer Keimäste liegen.

\section{Procamieae.}

Flacher Zellkörper mit ungleichen Achsen, die vegetativen durch horizontale, die reproductiven durch schiefe Wünde in der Scheitelzelle in die Lünge wachsend.

Die vegetativen oder Laubachsen entwickeln sich auf gleiche Weise wie die Delesserieen. Die jeweilige Scheitelzelle $\left(\mathrm{I}^{\mathrm{n}}\right)$ theilt 'sich durch eine horizontale Wand in eine neue Scheitelzelle $\left(I^{n+1}\right)$ und in eine Gliederzelle $\left({ }_{n} I^{1}\right)$, wodurch das Wachsthum in die Länge vermiltelt wird. Aus der Gliederzelle bildet sich eine Zellschicht, wodurch das Laub in die Breite wächst. Die Zellschicht erzeugt durch Theilung der Zellen einen mehrschichtigen Zellkörper, wodurch das Wachsthum in die Dicke statt findet. - Die reproductiven Achsen oder die Sporenäste und Keimäste entwickeln sich auf gleiche Weise, wie das Laub der Lebermoose (z. B. von Echinomitrium). Sie wachsen dadurch in die Länge, dass sich die Scheitelzellen $\left(I^{n}\right)$ durch eine schiefe Wand in eine neue Scheitelzelle $\left(I^{n}+1\right)$ und eine secundäre Zelle des ersten Grades $\left({ }_{n} \mathrm{I}^{1}\right)$ theilen, indem die Wände abwechselnd nach rechts und nach links geneigt sind. Das Wachsthum in die Breite geschieht dadurch, dass aus den secundären Zellen des ersten Grades eine Zellschicht 


\title{
entsteht. Das Wachsthum in die Dicke verwandelt dieselbe in einen mehrschich- tigen Zellkörper.
}

Zu den Plocamieen gehört die Gattung Plocamium Grev. und Thammophora Ag.

\section{Plocaminm coccinernm Grev.}

\author{
TaB. X. Fig. $22-57$.
}

Plocamium hat ein zusammengedrücktes, astiges Laub. Die Achsen enden spilz, und man erkennt fast überalt teicht die Scheitelzelle, und die Zellenbildung, welche im Punctum regetaiionis statt findet. Dieselbe ist doppelter Art. Die Scheitelzelle theilt sich ersllich durch eine horizontale, die Achse der Zelle unter einem rechten Winkel schneidende Wand in eine neue Scheitelzelle (Fig. 54, 53, a) und in cine Giiederzelle (Fig. 54, $\left.5^{5}, \mathrm{~b}\right)$, nach der Formel $\mathrm{I}^{\mathrm{a}}=\mathrm{I}^{\mathrm{n}}+^{1}+{ }_{\mathrm{nII}}{ }^{1}$. Diegliederzelle theilt sieh durch eine excentrische, fast senkrechte Wand in eine kleinere und in eine grössere Zelle (Fig. 54, c; 55, c, d, e); diese letatere durch eine gleiche Wand in eine mittlere und eine seitliche Zelle (Fig. $55, \mathrm{f}, \mathrm{h}, \mathrm{k}$ ). Diese Zellenbildung geschieht immer so, dass die erste exeentrische Wand in den Gliederzellen der Zweige dem Mutlerzweig abgekehrt ist. Aus der filiederzelle entstehen demnath zunæchst eine innere und zwei seitliche oder Randzellen. Jede der beiden letztern theilt sich durch eine fast senkrechte und mit der innern Wand ziemlich parallele Wand in eine innere und eine aussere oder neue Randzelle (Fig. 35, 1; 54, d), wovon die letztere wieder aut die næmliche Weise 7.wei Zellen bildet (Fig. 54, e, f, g). Die Wande weichen von innen nach aussen melır von der senkrechten Stellung ab, und nelımen eine schiefe, oft der horizontalen Richtung sich nahernde Lage an. Aus dieser Zellenbildung geht eine einfache Zellschicht hervor, welche aus horizontalen gebogenen Reihen besteht (Fig. 54, f; 57, $\mathrm{h}-\mathrm{h}, \mathrm{i}-\mathrm{i}, \mathrm{n}-\mathrm{n})$, und deren Zellen einzig durch Theilung der Randzellen entstanden sind; die innerns Zellen hilden nie Zellen in dieser Richtung. Spæeter aber scheinen sich auch die innern Zellen der Schicht zu theilen, zuerst durch horizontale oder schiefe (Fig. 5/, g-g, h-h, i-i), dann auch durch senkrechte Wände (Fig. 5 $/, \mathrm{k}$ ). boch isŁ es leicht möglich, dass diese Wände erst mil dem Wachsthum in die Dicke auftreten, welches, auf eine mir nicht näher bekannte Art, die Zellschicht in einen zusammengedrückten Zellkörper verwandelt.

Die andere $\Delta \mathrm{rt}$ der Zellenbildung im Punctum vegetationis ist folgende. Die Scheitelzelle theilt sich durch eine schiefe, die Achse der Zelle unter einem spitzen Winkel schneidende, von unten und innen nach oben und aussen gerichtete Wand in eine neue Scheitelzelle oder primäre Zelle (Fig. 56, a; 57, a) und in eine secun-

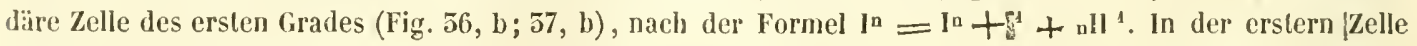
wiederholt sich fortwährend die gleiche Zellenbildung, nur divergiren die Sclıeidewände um einen Bogen von $180^{n}$, d. h. sie sind alternirend nach rechts und nach links geneigt. Die secundäre Zelle des ersten Grades theilt sich durch eine ihren radialen Längsdurchmesser unter einem rechten Winkel schneidende Wand in eine ${ }^{i}$ nnere oder tertiäre Zelle und in eine neue secundäre oder Kandzelle (Fig. $\left.57, \mathrm{c}, \mathbf{d}\right)$. In der letzlern wiederhoit sich die gleiche Zellenbildung (Fig. 57, e, f. g). Das Resultat derselben ist eine cintache Schicht von tertiären Zellen, begrenzt von einer Reihe von secundären oder Randzellen. Die Zellenbildung, welche das Wachsthum in die Dicke begleitet, ist mir auch hier nicht hinreichend bekannt; sie verwandelt ebenfalls die Zellschicht in riıen zusa mmengedrückten Zellkörper.

Die beiden elen besehriebenen Wachsthumsarten zeigen folgende Verhältnisse rücksichtlich des Umfanges, in welchem sic sich realisiren. Die vegetativen $\Lambda$ chsen wachsen zuerst durch horizontale Wände in der Scheitelжetle, und beendigen ilı Wachsthum meist Jurch schiefe Wände; zuweilen mangelt ihnen die lełztere Zellenhildung ganz. Die Sporenäste und Keimäste dagegen wachsen durch schiefe Wände in der Scheitelzelle. - Der 


\section{9
$-\quad 1$}

Vebergang der einen Zellenbildung in die andere findet einfaclı so statt, dass, nachdem die vorhergehende Scheitelzelle sich noch durch eine horizontale Wand theilte, die Wand in der folgenden Scheitelzelle dagegen schief liegt, und etwas seillich von der Mitte an die Grundnäche und an die Seitenfläche angesetzt ist (Fi乡ّ. 56). Die erste schiefe Wand liegt, nacli den Beobachtungen, die mir zu Gebote stehen, an einem Zweige immer dem sutterzweige zugekehrt, die zweite demselben abgekehrt u. s. w. In Fig. 57 sind zwei entstelıende Seitenzweige abgebildet; der Pfeil bezeichnet die Richtung der Mutterachse. In dem einen hat sich zucrst durch eine liorizontale Wand eine Glıederzelle ( $\mathbf{n}-\mathbf{n})$, in dem andern zwei Gliederzellen $\mathrm{i}-\mathrm{i}$ und $\mathrm{h}-\mathrm{h}$ gehildet, und dann sind dureh schiefe Wände in dem einen nach einander die secundären Zellen des ersten Grades m, d, c, b, in dem andern $g, f, e, d, c, b$ entstanden.

Die ausgebildeten Achsen bestehen aus einem parenchymatischen Gewebe, dessen innere Zellen sehr gross sind, indess die änssern rasch kleiner werden. Doch mangeln mir hinreichende und genatre Untersuehungen, um etwas Bestimmtes über die Stellungsverhältnisse der Zellen und über die Verschiedenheiten des Baues bei den beiden Wachsthumsarten sagen zu können. Auf Querschnitten konnte ich bloss das eine Mal die Centralzelle unterseheiden, wälırend sie das andere Mal zu fehlen schien; ebenso zeigte sich nir einige Mal deutlich eine in der Achsenfläclıe liegrende Zellschicht. Wenn die Zellenbildung in die Dicke bei Plocamium, woran nicht zu zweifeln, derjenigen anderer Florideen analog ist, so muss bei beiden Wachsthumsarten eine besondere, in der Achsenfläche liegende Zellschicht rorhanden sein, bei der erstern (durch horizontale Wände in der Endzelle) muss überdem in dieser Zellschicht eine besondere, in der Achsenlinie liegende Zellenreihe zu unterscheiden sein, bei der zweiten (durch schiefe Wände) dagegen muss diese Achsenzellenreihe mangeln.

Die Verästelung der Laubachsen ist elıaracteristisch. $\Lambda \mathrm{m}$ ausgebildeten Laub sind die Ilauptachsen leicht hin und her gebogen, und tragen abwechselnd rechts und links je 2, 5 oder 4 Seitenachsen, von denen inmer die unterste einfach und am kürzesten, die oberste am meisten verzweigt und am längsten ist (vgl. Fig. $50, a^{4}, c^{1}$, $\left.\mathrm{d}^{\prime}\right)$. Alle Achsen eines Laubes liegen in einer Ebene. Auf den ersten Blick glaubt man unbegrenzte Ilauptachsen vor sich zu haben, welche alternirend mehrere einseitswendige theils begrenzte theils unbegrenzte Tochterachsen erzeugen. Eine Untersuchung der obern Achsenenden, wo die Verästelung statt findet, zeigt jedoch, dass diese Annahme unrichtig ist, und dass alle Achsen der Pflanze begrenzt sind, und in eine dornige Spitze mit abortirtem punctum vegetationis endigen, und dass das scheinbare unbegrenzte Längenwachsthum der Achsen eine unbegrenzle Wiederholung begrenzter Achsen ist. Der Entwickelungsprocess ist folgender: Irgend eine Achse crzeugt auf der gleichen Seite 2, 5 oder 4 secundäre Achsen; von diesen wächst jede bis zu einer bestimmten Länge, und bildet auf der ihrer Mutterachse zugekehrten Seite einige terliäre Aclısen; diese wachsen wieder begrenzt, und bilden an der ihrer Mutterachse zugewendeten Seite einige quartäre $\Lambda$ chsen u. s. w. 1)ieser Process wiederholt sich, so lange das Laub wächst. Dabei ist zu bemerken, dass von den Tochterachsen einer Hutterachse immer die oberste sich rascher entwickelt, und dass sie liäulig mehr Tochterachsen erzeugt als die unterste. Da jede Achse für sich begrenzt ist, da jede Tochterachsen erzeugt, und die Wiederholung durch die successiven Generationen unbegrenzt fortdauert, so werden die Achsenenden immer seillich gerïckt, und erscheinen als dornige Seitenzweige. Da von den Schwesterachsen die oberste am schnellsten sicil entwickelt, und somil die stärkste ist, so trilt sie scheinbar als die Fortsetzung der llutterachse auf, und bildet mit ihr die Hauptachse; die übrigen Schwesterachsen aber erseheinen als Seitenachsen. Plocamium zeigi daher die gleiche Erscheinung, wie jede Pflanze nit begrenzten Achsen und unbegrenzter einseitiger Wiederholung derselben : die seheinbaren Iauptachsen sind nicht reine, sondern gemisclıte Achsen, und bestelıen aus Stücken der successiven Tochterachsen. - An dem in Fig. 50 grezeichneten Laube ist aa 'die unterste Achse, die ich die prinäre nennen will. Von den drei Tochterachsen oder secundären Achsen, welche sie erzeugte, ist $\mathbf{b b}^{1}$ die oberste. Dieselbe bildete ihrerseits als Tochterachsen die tertiären Achsen $\mathbf{c c}^{1}$, $\mathrm{dd}^{1}$ nnd $\mathrm{ec}^{4}$. Die Verzweigung von $\mathrm{ce}^{1}$, und von $\mathrm{dd}^{\prime}$ ist deutlich; jede trägt drei Tochterachsen, von denen die oberste amı

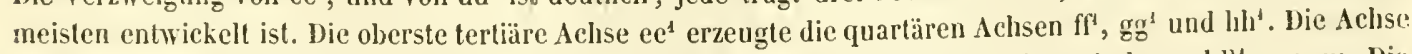
\{f $f^{1}$ billele zwei, gg drei Tochterachsen; die Achse $h h^{4}$ trägt drei quintäre Achsen i, $\mathrm{k}$, und $1 l^{4} \mathrm{u}$. S. W. Die 


\section{$-250$}

Ilauptachse a h besteht aus dem Stïck a b der primären Achse, b e der secundären Achse und $\mathrm{e} h$ der tertiärer Achse. Diese Ilauptachse endigt jetzt in $\mathrm{e}^{\mathrm{t}}$; aber in kurzer Zeit wird $\mathrm{e}^{t}$ seillich gerückl, und die sich ausbildende

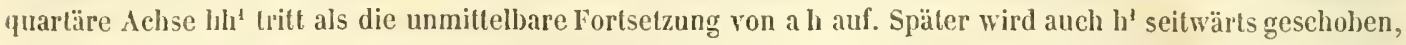
und die IIauptachse wird a $\mathrm{h}^{1} \mathrm{I}^{1}$ sein, noch später a h I $\mathrm{m} \mathrm{m}^{1}$ u. s. . . - Die gleiche Veränderung wird der seitenzweig dd ${ }^{1}$ erfahren. Seine prinæere $\Lambda$ chse $d d^{1}$ erscheint jetzt noch als Ilauptachse. Durch die Ausbildung der olsersten secundæren Achse $\mathrm{m} \mathrm{m}{ }^{1}$ wird $\mathrm{m} \mathrm{d}^{1}$ seillich gerückt, und als Hauplachse tritt dann $\mathrm{d}_{\mathrm{m}} \mathrm{m}^{1}$ auf. Vachher muss in gleicher Weise vor der sieh entwickelnden obersten tertiæren Achse das Ende der secundieren Achse $\mathrm{n} \mathrm{m}^{3}$ zur Seite weichen, und die Hauptachse geht nun von d durch $m$ und $\mathrm{n} z \mathrm{n} \mathrm{n}^{\mathrm{t}}$.

Die Astzelle oder primære Zelle des ersten Grades, woraus eine Tochterachse entsteht, ist bei den Achsentheilen, welche durch horizontale Wrende in der Endzelle wachsen, die zweite tertiere Zelle des ersten Grades (:III $\left.{ }^{\sharp}\right)$. Die Gliederzelle $\left(\mathrm{II}^{1}\right)$ namlich theilt sich durch eine excentrische Wand in eine der Mutterachse abgekehrte ${ }_{1} I^{\ell}$ und in $\mathrm{II}^{2}$ (Fig. 5.5, c, d, e); die letzlere theilt sich durch eine gleiche Wand in eine mittlere $\mathrm{II}^{3}$ und in eine der Mutterachse zugekehrte ${ }_{2} \mathrm{IH}^{\perp}$ (Fig. 5\%, f, g, $\mathrm{h}$ ). Die letztere Zelle besondert sich zuweilen, und wird zur Astzelle oder zur primeren Zelle les ersten Grades für eine neue Achse (Fig. 5̋, m, nı). An einer Achse besondern sich gewöhnlich 5 , doch auch von 1 bis 4 solcher Zellen; sie stehen je an dem zweiten Gliede, und zwwar in der Regel entweder auf dem $4^{\text {ten }}, 6^{\text {ten }}$ und $8^{\text {ten }}$, oder auf dem ğten, $^{\text {ten }}$ und 9ten Gliede einer $A$ ehse, von unten gez:alt. - Ausser der regelmassigen Veræstelung der regetativen Achsen durch Astzellen, welche durch Metamorphose der zweiten tertiaren Zelle des ersten Grades entstehen, giebt es zuweilen noch Prolification am Rande. Eine Randzelle besondert sich, und wird zur primæren Zelle des ersien Grades für eine entstehende neue Achse. - Die regelmassige Verastelung der Achsentheile, welche dur'ch schiefe Winde in der Scheitelzelle wachsen, ist mir unbekannt. Ich glaube, dass sie nur an den Sporenæesten und an den Kieimhaufchen auftritl, indem die Laubachsen sich Bloss an dem Theile, welcher durch horizontale Wænde in der Schejtelzelle entstanden ist, zu veræsteln scheinen.

Die Sporenbildung findet in den Sporenæsten statt; es sind diess metamorphosirte Laubachsen, welche entweder keine oder nur begrenzte Verzweigung hesitzen. Es ist diess der allgemeine Ausdruck, der genau die Bedingungen für den Umfang angiebt, in welchem die Sporenbildung an dem Laube auftreten kann. - Jede Achse kann sich in einen Sporenast verwantieln. Entweder sind es alle oder nur einzelne Tochterachsen einer Hutterachse, welche es wirklich thun; im Jetztern Falle trift die Vetamorphose jedoch immer die untern Schwesterachsen, indess die obern steril bleiben und als Laubeste sich cntwickeln. - Die Sporenæsle sind ferner immel' ganze Achsen, nie etwa bloss die obern Enden von vegetativen Achsen. Die dornæhulichen Seitenaste (Fig. 30, $a^{1}, b^{1}, e^{1}$ ) erzeugen daher nie Sporen, und wenn an einer llauptachse ein oder mehrere Sporenæste nach einer Seite hin stehen, so findet man unter ihnen auf der gleichen Seite immer entweder eine vegetative Hauptachse oder einen dornæhnlichen Seitenast. - Die Sporenæste sind einfach oder sie sind verzweigt; die Verzweigung ist aber immer begrenzt; ein Sporenast wird aus 1 bis 7, selten aus mehr einfachen Achsen gebildet (Fig. 32, a, b, c, d). Eine Achse, in welcher Sporenbildung aultritt, erzeugt immer nur wieder sporentragende, nie vegetative Achsen. - Die letztere Thatsache hat wahrscheinlich ihren Grund in dem doppelten Læengenwachsthum der Achsen. Die Sporenæste wachsen dureh schiefe Wrende in der Scheitelzelle; sie besitzen eine dieser Zellenbildung analoge Verzweigung, und können daher neue Sporenzweige erzeugen. Da aber das Wachsthumı durch schiefe Wande in der Seheitelzelle nicht in dasjenige durch horizontale Waende übergeht sondern nur der ungekehrte Uebergang statt findet, so kann auch aus einer Sporenachse keine vegetatire Achse lıervorgehen. - In Fig. $\mathbf{5 3}$ ist ein Theil von einem sporenbildenden Laube gezeichnet; die Sporenæste sind durch doppclte, die Laubachsen durch einfache Linien gegeben, aa ${ }^{1}$ ist die unterste Laubachse, welche einen Sprorenast und zwei Laubachsen $h_{1} h^{1}$ und $b^{1} b^{1}$ erzeugte. $b b^{1}$ bildete zwei Sporenæsle und die Laubachse $r c^{1} \cdot c^{1}$ bildete einen Sporenast und zwei Lanbachsen n und $\mathrm{dd}^{4}$. $\mathrm{dd}^{1}$ erzeugte einen Sporenast und zwei Laub

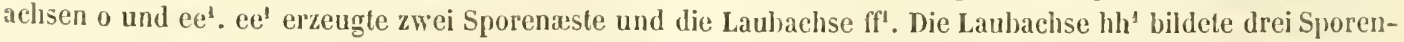
isste und die Laubachse $\mathrm{ii}^{1}$. $\mathrm{ii}^{1}$ bildete einen Sporenast und drei Laubachsen $\mathrm{p}$, q und $\mathrm{kk}^{1}$. $\mathrm{kk}^{-1}$ erzeugte einen Sporenast und zwei Laubachsen $\mathrm{r}$ und $\mathrm{II}^{1}$. $\mathrm{Il}^{4}$ erzeugte zwei Sporenæste und die Laubachse $\mathbf{m m}^{\prime}$. 


\section{- 251}

In jeder einfachen Achse eines Sporenastes bilden sich mehrere Zellen zu Sporenmutterzellen um. Diese Zahıl varirt nach meinen Beobachtungen von 1 bis 8. Sie liegen in der obern Halfte der Achse, haufiger in zwei Reihen, seltener in einer einfachen lieilıc, der Langsdurchmesser ist bald horizontal, bald vertical oder sehief gerichtet (Fig. 32). Ich lıabe die Sporenbildung bloss an getrockneten Exemplaren untersucht, und bin in Bezug auf die Frage, auf welche Weise die Sporen aus den llutterzellen entstehen, zu keinem sichern Resultate grclangt. Soviel ist gewiss, dass zuerst Hutterzellen auftreten, welche durch zonenartige Theilung in 4 Tochterzellen ïbergehen, und dass diese Tochterzellen sich auch noch weiter theilen. Es ist nun zweierlai möglich, entweder sind jene ursprüuglichen Mutterzelien wirklich die Sporenmutterzellen; dann theilt sich jede in mehr als 4 , nienlich in $\ddot{3}$ bis 8 und vielleicht noch mehr Sporen. Oder die 4 aus einer ursprünglichen Mutterzelie entstehenden, zonenartigen Zellen sind ersi die Mutlerzellen; dann müsste nachgewiesen werden, dass jede dieser letztern sich in 4 Sporen theilte, und auf welche Weise diess geschähe. Die erstere Annahme ist mir die walırseheinlichere, da auch bei den Phanerogamen der Fall vorkommt, dass aus einer Multerzelle 14 bis 8 Pollenkörner entstehen. - Das Resultat ist eine Gruppe yon Sporen, welche von einer Gallerlschicht umgeben ist. Solcher Gruppen finden sich in jeder Achse des Sporenastes 1 bis 8 (Fig. 52). - Wahrend Kültzing den Verlauf der Sporenbildung in der Zeichnung richtig andeulet, ist dagegen der Ausdruck "tetrachocarpia quadrijuga” nicht ganz passend.

Die Keimzellen sınd in Keimlıxufchen zusammengeballt, welche einzeln in kugeligen Keimbelıeltern liegen, von denen jeder für sich eine besondere Achse, ein Keimast ist. Die Keimæste haben eine bestimmte Stellung : sie stehen an vegetativen Aclisen, an deren unterm Ende und an dem der Veræstelungsseite gegenüberliegenden Rande. Am hreutigsten entspringt der Keimast aus der Basis der obersten Schwesterachse, und steht somit einem dornæhnlichen Seitenast gegenüber, nur etwas höher als dieser an der Hauptachse cingefügt. Seltener entspringt der Keimast aus der Basis der zweitobersten Schwesterachse, und liegt somit an der Basis

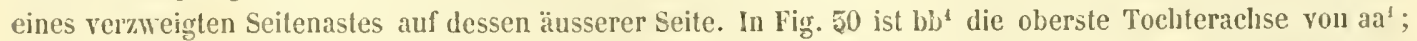
sie hat 5 vegetative Achsen $\mathrm{cc}^{4}$, $\mathrm{dd}^{4}$ und $\mathrm{ee}^{4}$ nach einer Seite hin, nach der gegenïberliegenden Seite und an der Basis dagegen den Keimast $n$ erzeugt. Yon den Schwesterachsen $c^{4}$, dd $^{1}$ und $e^{1}$ hat die zweitoberste dd $^{4}$ an ihrer Basis und auf dem den Tochteraclısen abgekehrten Rande den Keimast o gebildet. - Von der cben ausgesprochenen Fiegel finde ich in der Natur keine Abweichungen. Kützing giebt eine Abbildung ${ }^{1}$ ), welche nicht mit del Regel übereinstimmt; da abel dieselbe auch gegen die übrigen regelmässigen Stellungsverhältnisse der Achsen verstösst, so scheint der Verfasser weniger genau auf diesen Punct geachtet zu lıaben. Die Stellung der Sporenäste und der Keimäste ist absolut verschieden. Die Sporenäste sind metamorphosirte Laubäste, und nehmen diejenige Lage an einer Hauptachse ein, welche sonst die vegetativen Acste einnehmen würden. Die Keimäste dagegen sind neue Achsen, inden sie an einem Plalze stehen, wo sonst nie andere (Sporen- oder Laub-) Aeste gefunden werden. Jede Laubachse von Plocamium hat zwei morphologiselh-verschiedene Ränder, einen Verüstelungsrand und einen sterilen Rand; an dem erstern stehen dic vegetativen Tochterachsen und die Sporenäste, an dem letztern die Keimäste.

Ueber den Ursprung der Keimäste an den Laubachsen bin ich nicht ganz in's Klare gekommen. Wie es mir seheint, so isî es eine Zelle am Rande, welche sich besondert, und zur primären Zelle des ersten Grades für den entstehenden Keimast wird. Erweist sich diese Vermuthung als rıchtig, so wäre der Keimast einer durch Prolification sich bildenden Laubachse analog. Das früheste Stadiım des Kieimastes, das ich deutlich unterscheiden kann, zeigt an Rande des Laubes schon eine Gruppe von melıreren Zellen, welehe offenbar durch schiefe Wandbildung in der Scheitelzelle entstanden ist; sie zeigt schiefe Streifung von der Mittelliuic aus nach zwei Seiten, und ihre Basis wird ebenfalls durch zwei schiefe Linien gebildet (Fig. 24, a). Im Grunde dieses Winkels erkennt man eine oder zwei grössere Zellen. - Diese Gruppe von Zellgewebe wird stetigg grösser (Fig. 2y, a), indem sie an Scheitel wächst, und verwandelt sich in einen keulenförmigen Ast, welcher aus ho-

1) Phyc. general. Tab. 6ł. 1 . 
mogenem Zellgewebe besteht (Fig. 26). Die Zellen liegen in Reihen, welche von innen und unten nach oben und aussen divergiren, und dabei sich forlwährend theilen, \{so dass eine unten einfache Reilie sich nach oben in zwei, jede dieser dann wieder in zwei spaltet u. s. f. - Darauf unterscheidet man im Centrum einige grössere lockere Zellen; eine davon, mehr nach unten liegend, ist beträchtlicher, von länglicher Gestalt, und ganz mit kleinen körnchen erfüllt (Fig. 27, a), die andern, mehr nach oben betindlich, sind kleiner, eiförmig oder kugelig, mit homogenem Schleime und einem wasserhellen, ein Kernchen einschliessenden Kernbläschen (Fig. 27 , b). Ich vermuthe, dass die grössere längliche Zelle die erste Zelle ist, von welcher die Bildung des Keimlıäufchens ausgeht, und dass die kleinern melır rundlichen Zellen aus ihr entspringen. - Später hat sich der Keimast zu einem Keimbehälter umgebildet (Fig. 22, im horizontalen, Fig. $25 \mathrm{im}$ verticalen Durchschnitt), welcher aus einer Wandung besteht, eine ziemlich kugelige Höhlung enthält, und.an Scheitel eine kleine regelmässige Oeffnung besitzl. Die Wandung besteht aus radialen, sich nach aussen fortwälırend theilenden Reihen von tafelförmigen Zellen, so dass auf jede Zelle an der innern Fläche der Wandung auf dem Durchschnitte je $4-8$ Zellen, im Ganzen aber je 20 bis ら0 Zellen an der äussern Fläche der Wandung entsprechen (Fig. 28). Es stimmt dieser Bau der Wandung genau mit der Structur des jungen, noch soliden Keimastes überein. Betrachtet man die innere Fläche der Wandung, so sieht man von der Basis mehrere Zellenreihen ausstrahlen, welche nach ohen und aussen divergiren, und sich dichotomisch verzweigen (Fig. 29); dieselben bilden die innerste Schicht der Wandung. Auch diese Erscheinung ist eine natürliche Folge des ursprünglichen Baues des Keimbehälters; bei der Ausdehnung der Wandung konnten die innersten und altesten Zellen dieser Ausdehnung nicht in beiden Richtungen folgen; statt tafelförmig zu werden, wie die æussern Zellen, trennten sie sich seitlich von einander, blieben nur nach oben und unten mit einander in Berührung, und wurden langgestreckt. - In der Hölılung des Keimbehælters, von dessen Wandung dicht umschlossen, liegt ein Conglomerat von Zellen, welches in grössere und kleinere Lappen getheilt ist. Anfanglich, wenn das Conglomerat noch klein ist, bestelıt es ganz aus kleinen farblosen Zellen. Spæter sind die obern grösseren Lappen aus grossen rothen Keimzellen, die untern kleinern Lappen aus röthlichen, sich nicht mehr vermelırenden Zellen, die kleinsten Lappen aus ganz kleinen farblosen sich noch theilenden Zellen gebildet (Fig. 25). Die ganze Keimzellenmasse ruht auf einer ziemlich gl'ossen, længlichen, am obern Ende lappig-getheilten Basiszelle, und auf mehreren længlichen Zellen, welche einen kurzen lockern Strang bilden, der unten die Basiszelle berührt, und bis ungefahr in die Mitte der Keimzellenmasse reicht (Fig. 25). Diese Zellen sind dieselben, welclı man zuerst im jungen Keimaste untersclıeidet. Es ist wohl keinem Zweifel unterworfen, dass die Entwickelung folgendermassen geschieht: In der Mitte des Keimastes besondert sich eine Zelle (die Basiszelle), welche nach oben mehrere Astzellen bildet; jede derselben erzeugt wieder eine oder mehrere $\Lambda$ stzellen, so dass eine kurze astige Zellenreilse entsteht, von welcher jede Zelle (wahrscheinlich mit Ausnahme der untersten) einen Lappen der Keimzellenmasse erzeugt; da die Bildung von Astzellen immer fortdauert, so findet man an der Basis der Keimzellenmasse immer junge, noch in der Entwickelung begriffene Keimzellenlappen. - Die Keinzellenlappen sind wieder gelappt, sie bestehen aus einer IJauptachse und aus melıreren Seitenachsen; jede derselben ist ein Körper von Zellgewebe, welcher aus einer einfachen Zelle entsteht, durch Zellenbildung in der Scheitelzelle in die Længe, und durch Theilung der unter der Scheitelzelle liegenden Zellen in die Dicke wæchst. Die Scheiteizelle theilt sich durch schiefe Wiende, wie an dem Endheile der vegetativen Achsen und an den Sporen- und Keimæsten. In Fig. 5 t ist ein in der Entwickelung begriffener Keimzellenlappen dargestellt, dessen Hauptachse mit melıreren Seitenlappchen besetzt ist; das Længenwachsthum durch schiefe Wande in der Endzelle ist deutlich an den Seitenachsen, welche nach rechts und links liegen, zu sehen. Wenn die Zellenbildung an einem Lappen beendigt ist, so dehnen sich die Zellen aus, werden körnig, und farben sich roth. Wegen der gedrangten Lage besitzen sie auch in ausgebildeten Zustande noch eine eckige, parenchynatische Gestalt. - Kützing sagt, dass die Keimzellen an einem "Spermopodium centrale fibrosum» befestigt seien, und læsst dasselbe in der zeicl-nung ron ler Basis des Keimbehalters dureh das Keimlıaufchen hindurch bis zur obern Wand gehen, und jich an dieselbe festsetzen. Nach meinen Untersuchungen ist das Keimhxufchen bloss an der Basiszelle be- 
festigt und sonst am ganzen Umfange frei; der Treger oder der Strang ron Zellen, die sich nicht in Keimzellen verwandeln, reicht kaum bis zur Hitte des Hæufchens, und wenn man einen horizontajen Durchschnilt durch dic Nille oder etwas über derselben macht, so sieht man bloss Keimzellen, und nichts von einem centralen Träger. - Die unentwickelten Keinzellen nennt Kützing Nebensamen (paraspermatia). Er glaubt nicht, dass es unentwickelte Samen seien, weil sie in den kleinsten und grössten Früchlen vorkommen. Dennoch sind es nichts ander's als junge keimzellen, deren Entwickelung man sowolıl in jungen als in ältern Keimbehälterı beobachten kann; dass sie auch in den grössten KeimbelıäItern noch gefunden werden, hat darin seinen Grund, weil die Keimzellenbildung immer fortdauert. - Die Beschreibung der Keimzellenbildung in Endlicher's Gen. plant. suppl. III. "Coccidia sporas e fili articulati brevissimi arliculo exlremo pyriformi orlas includentia" is wenigstens sehr unpassend.

\section{Chondieae.}

Zellschicht mit mehrschichtigen Nervationen oder flacher Zellhörper, mit gleichem Längenwachsthum in allen Achsen; Wachsthum in die Breite und Dicke geschieden, ersteres in der Richtung der Achsenfï̈che eine Zellschicht erzeugend, letzleres senkrecht zu derselben die einfache Schicht in mehrere theilend.

Die Entwickelung aller Achsen ist die gleiche. Hierin unterscheidet sich diese Familie von der vorhergehenden. Das Längenwachsthum findet dadurch statt, dass in der Scheitelzelle $\left(\mathbb{I}^{\mathrm{n}}\right)$ durch eine schiefe Wand eine neue Scheitelzelle $\left(I^{n}+1\right)$ und eine secundiire Zelle des ersten Grades $\left({ }_{n} I^{1}\right)^{1}$ entstehen. Die Wände in den successiven Scheitelzellen sind abwechselnd nach rechts und nach links geneigt; die secundären Zellen des ersten Grades alterniren daher mit einer Divergenz von $180^{\circ}$, und sie bilden zusammen eine zweireihige Zellschicht. Das Wachsthum in die Breite beginnt in den secundären Zellen des ersten Grades, und geschieht dadurch, dass dieselben sowie die daraus hervorgehenden Zellen sich durch Wände theilen, weichc die Achsenfläche unter einem rechten Winkel schneiden. Diese Wände können senkrecht zum radialen Zellendurchmesser oder mit demselben parallel oder zwischen beiden Richtungen geneigt sein. Die Zellenbildung schreitet regelmässig von der Achsenlinie nach der Peripheric hin fort. Das Resultat derselben ist eine Zellschicht. - Das Wachsthum in die Dicke beginnt damit, dass die Zellen der Zellschicht durch excentrische Wände, welche mit der Achsenfläche parallel laufen, sich theilen, wodurch aus jeder Zelle zunächst eine kleinere äussere und eine grössere Zelle, und durch eine neue gleiche Theilung dieser letzteren drei Zellen, eine innere und zwei äussere Zellen 
hervorgehen. Die innere dieser drei Zellen ist eine Dauerzelle, und bildet mit allen übrigen gleichen Zellen cine die Achsćnfläche einnehmende Zellschicht. Die beiden seitlichen Zellen sind Mutterzellen, in denen das Wachsthum in die Dicke weiter fortschreitet, indem die Zellen abvechselnd durch Wände, welche mit der Achsenfläche paraliel laufen, und durch solche, welche rechiwinklig zu derselben sind, sich theilen.

Die Sporenmutterzellen liegen seitlich von den Zellen der Achsenfläche, bald an dieselben anstossend, bald von denselben entfernt in der Rinde. Diese Verschiedenheit, welche ohne Zweifel von gleicher Bedeutung wie bei den Delesserieen ist, mag einmal dazu dienen, die Familie in zwei natürliche Gruppen zu trennen.

Zu den Chondreen gehören Iridaea Bory, Chondrus Grev. (Maslocarpus Kütz.), Kallymenia I. Ağ. (Euhymenia Kütz.), Cryptonemia I. Ag., Grateloupia Ag., Gigartina Isamour. excl. spec. (Chondroclonium Kütz.), Rhodomenia Grev. (Callophyllis Kütz., Calliblepharis Külz.), Cryptopleura Kütz.

\section{Crypropleman Hacerata Kützing.}

(Delesseria I. Ag. $\Lambda$ glaoplıyllum I. Montagne. Nitophyllum I. Grev.)

$$
\text { TAB. IX. Fig. } 26-55 .
$$

Das bandarlige, diehotomisch-getheilte und an den Enden lappenförmig-eingeschnittene Laub besteht aus einer geaderten Zellschicht. Die Adern, welche meist zu 2 bis 4 in der ganzen Breite einer Laubachse getrennt ron cinander liegen, verzweigen sich; die Zweige enden frei, oder anastomosiren mil einander. Die Adern bestehen in der Breite aus 1, 2 oder 5 neben einander liegenden Zellenreihen, in der Dicke gewöhnlich aus je 5 Zellen. - Die Zellenbildung an der Spilze der Achsen ist sehr schwer zu beobachten. An einer Menge von Pflanzen, welche ich untersuchle, fand ich bloss drei ziemlich deutliche Zuslände, welche in Fig. 26, 27 und פ̊̊ gezeichnet sind, Zuäısserst liegt eine einfache Zelle, die Scheitelzelle (Fig. 26, 27, 28, a) welche sich, so lange die $\Lambda$ chse in die Länge wächst, durch eine schiefe, von unten und innen nach oben und aussen gerichtete Wand in cine neue Scheitelzelle oder prımäre Zelle des folgenden Grades (Fig. 26, a) und in eine secundäre Zelle des ersten Grades (Fig. 26, b) theilt. 1)ie Scheidewände in der Scheitelzelle liegen abweclsselnd nach rechts und nach links. - Die schualen, langgestreckten secundären Zellen des ersten Grades theilen sich durch (rine ilıren längendurchmesser unter einem rechten Winkel sehneidende Wand in eine innere, kleinere, tertiäre Zelle (Fig. 26, c; 28, b) und in eine äussere secundäre Zelte des zweiten Grades (Fig. 26, d; 28, c). Jede folgende secundäre Zelle kann sich auf gleiche Weise in cine tertiäre Zelle und in cine neue secundäre Zelle theilen (Fig. 26, fund $\mathrm{g}, \mathrm{i}$ und k, $\mathrm{n}$ und $\mathrm{o}$ elc.). Dic secundären Zellen theilen sich abwechselnd auch durch cine radiale, von der obern Seitenwand ausgehende, schief nach aussen gerichtete und sich ziemlich an die Nitte der äussern Wand anselzende Scheidewand in zwei neue ungleiche secundäre Zellen, eine kleinere obere (Fig. 


\section{$-253$}

28, e) und eine grössere untere (Fig. 28, f); in diesen beiden Zelleı trill dann wieder die erste Zellenbilduug auf. Solche radiale Wende hildeten sich in Fig. 26 zwischen 1 unıl $\mathrm{ik}$, zwischen $\mathrm{p}$ und $0 \mathrm{nq}$, und zwischen $q$ und $\mathrm{p}$; in Fig. 27 zwischen $\mathrm{fg}$ und $\mathrm{lkih}$, zwischen $\mathrm{f}$ und $\mathrm{g}$. awischen is und $\mathrm{ik}$, wischen e und $\mathrm{d}$, zwischen pq und nosr, zwischen p und q, und zwischen r und os. - Die heiden beschriebenen Zellenbildungen durih Wrende, welche mit dem Radius ziemlich parallel laufen, und dureh solehe, welche in der Richtungr der Secante liegen, vollfïhren hanj)(sxehlich das Wachsthum in die Breite. Das Resullat ist cine Schicht von tertiaren Zellen, welche am Rand durch eine Reihe von secundxeren Zellen lyegrenzt werden. - Die tertixen Zeller. wenigstens die in der Mille der Achse liegenden, theilen sich ehenfalls; so sind in Fig. 27 aus einer tertiarun Zelle 4 Zellen(m I- m), aus ciner andern ebenfalls 4 (n), und aus zweien je zwei Zcllen $(1,1)$ entstanden.

Wenn das Wachsthum in dic Breite vollendet ist, so besteht das Laub aus einer einfachen Schicht von gleicharligen Parenchymzellen. In dieser homogenen Schicht besondern sich einzelne, sich verzweigende und anastomosirende Strange von Zellen, dieselben sind 1, 2 oder כreihig, l. h. die Besonderung trifft 1, 2 oder 5 neben einander liegende Zellen, in welchen ein Wachsthum in die Dicke auftritt. Eine tertiære Zelle theilt sich gewöhnlich in 3 Zellen, eine nittlere und jederseits eine xussere, zuwcilen auch in כ̆ Zellen, eine mittlere und jederseits zwei reussere, wie man in Fig. $5 \overline{5}$, d und $f$ auf dem Querschnitte sicht. Im erstern Falle theilt sich die tertixre Zelle zuerst durch eine, mit der Achsenflæche des Laubes parallele, excentrische Wand in eine kleinere aussere und eine grössere Zclle (Fig. $35, \mathrm{c}$ ), dicse Jetztere dann durch cine gleicla Wand in eine inner und eine æussere Zelle (Fig. 55, d). Im zweiten Falle theilt sich die tertiære Zelle durch eine mit der Achsenf̊xche parallele, schiefe, die Aussenwand zicmlich in der Mitte berïhrende Scheidewand in eine kleinere mussere (Fig. 55, m) und eine grössere Zelle (Fig. 55, ne), djese letztere dann durch eine xhnliche, nach aussen convergirende Wand in eine zweile kleinere æussere (Fig. $55, n$ ) und eine grössere Zelle (Fig. 55 , e); die letzlere rerwandelt sich darauf durch gleiche doppelte Theilung in eine innere und zwei aussere Zcllen (Fig. $5 \bar{j}, \mathrm{f}$ ). Dicse Zellenbildung kann auf jeller Stufe stehen bleiben. - Kützing lasst in dem einschichtigen' Laub von Cryptopleura ảie Adern bloss aus længern Zellen besiehen, eine unrichtige Darstellung, welche ron dem Mangel eines Querschnilles herrülırt.

Wenn das Laub vollkommen entwichelt ist, und die Zellen siclı ansgedehnt haben, so bilden sic ein parenchymatisches Gewebe, in welchem von ihrer ursprünglichen, regelmxssigen Anordnung nichts mehr zu sehen ist. Ihr Inhalt ist eine wasserhclle Flüssigkcit und die wand̉stændige Schleimschichf, an welcher rothe Farbblæschen licgen. Die lełzleren sind zusammengedrückt, von der Flæche rundich oder længlich (Fig. 50), bald locker, bald dicht beisammen liegend und ein vollkommenes Parenclym bildend. Ins Alter werden die Farbblæschen bræunlich, dann schön grrïn und gleichen rolikommen den Chloroplyyllblæschen vieler Algen. - Die jümgsten Zellen enthalten einen homogenen fast farblosen Sclıleim, wolcher bald röthlich, feingekörnt und zartschaumig wird, und nachher an die Wandung als Schleimschicht umb als ein schönes Schleimnetz sich lagert, in welehem sich die Farlbbleschen bilden.

Das Laub ist durch Haftwurzeln auf der Unterlage befestigt. Dieselben entspringen nahe dem Rande bald aus der cinen', bald aus der andern Flache des Laubes. Sie sind kurzeylindrisch, oder etwas koniseh (Fi⿳亠. 29, a), und bestehen aus vielen neben cinander liegenden und durch Galierte in einen Körper vereinigten Wurzelıaaren. Sie bilden sich so, dass mehrere (etwa 10 - 1:j) Zcllen des Laubes auswachsen, unl jede ein Wurzelhaar erzeugen. Fig. 29, b zeigt eine Haftwurzel im Durchschnilt; man sicht die durchschnittenen Wurz.ellatare und die sie verbindencie Gallerte.

Die Sporenmutlerzellen liegen in kreisförmigen oder længlichen Anschwellungen des Laubes (Fig. 51). Die terliæren Zellen haben sich daselbst in mehrere Schichten getheilt. An dem Durchschnilte unterscheidet man cine miltlere Reihe von Zellen, welche für die ganze Anschwellung eine in der Achsenfleche liegende Schicht bilden. Die Sporenmutterzellen berühren diese Achsenzellen unmiltelbar, und liegen demnach auf Dur'ıschnit'en in zwei Reihen. Ursprünglich sind sie im Gewebe eingeschlossen, spater ist ilır Scheitel frei, indem er bloss ron Gallerte bedecht wird (Fig. 52). Nur selten sieht man die Achsenzelien so deutich, wie es gezeichnet ist; 


\section{- 256}

Jureh die Ausdehnnng der Sporenmutterzellen kommt das Gewebe haeufig in Unordnung, so dass man die Achsenzellen nur stellenweise erkennt, unil dass die Mutterzellen, wenn sie gegenüber liegen, einander zu berïhren scheinen. - Die Sporenbildung ist teträ̈drisch.

Die Keimzellen sind in Keimhehælter eingeschlossen, welche zerstreut in der Flæche des Laubes liegen, und denjenigen von Nitophyllum ziemlich nahe kommen. Die obere Wand besteht ans melıreren (etwa :3) Zellscliclıten, deren Zellen fast so breit und lang sind als die übrigen Zellen des Laubes; sie ist in der Mitte mit einer kleinen runden Oeffnung rerselıen, an deren Umfang die Zellen betraechtlich kleiner und dunkler gefaerht sind. Die untere Wand wird ebenfalls von melırern (fast doppelt so vielen als in der obern Wand) Zellschichton gebildet, deren Zellen, besonlers gegen die Mitte der Wand, nicht über halb so breit und lang sind als die Zellen der obern Wand. In beiden Wanden stehen fibrigens die Zellen genau in senkrechten, von der Mitte aus etwas divergirenden Reihen. Auf der Mitte der untern Wand, welche wenig verdickt ist, stehen eine Menge yon Keimharen, welche in einen lockern Knwnel zusammengedrængt sind. - Die Enlwickelungsgeschichte des Keimbchalters stimmt mit derjenigen bei Nitophyllum überein. Alle Laubzellen, welche an einer kreisförmigen Stelle beisammen liegen, theilen sich zuerst in eine Achsenzelle und zwei seitliche Zellen; die Theilung wiederholt sich in den lelztern. Das Zellgewebe trennt sich auf die Weise in zwei Lamellen, dass die Achsenzellschicht den Boden des Keimbehælters (die obere Schicht der untern Wand) darstellt. - Die Keimhaare sind veræstelt. Thre Zellen verwandeln sich von oben nach unten in Keimzellen, welche eiförmig oder fast kuyelig und mil braunrothem körnigem Inhalte erfüllt sind.

\section{Leptophyllium bifidume $N a ̈ g$.}

(Sphaerococcus b. Ag. Rhodomenia b. Grev.)

TAB. X. Fig. $1-7$.

Das dïnne, blattartige, nervenlose Laub ist zweitheilig oder dichotomisch veræstelt. Nan erkennt hæufig deutlich an der Spitze der Achsen die Scheitelzelle, welche sich, so lange das Wachsthum der Achse dauert, lurch eine schiefe Wand in eine nene Scheitelzelle oder primare Zelle rles folgenden Grades und in eine secundiere Zelle des ersten Grades theilt. Die secundxren ZelIen liegen alternirend nach rechts und nach links von der . Achsenlinie. In Fig. 1 ist das obere Ende eines Lappens des Laubes dargestellt, wo die dichotomische Theilung eben im Werden begriffen ist. Statt des einen Punctum vegetationis haben sich zwei neue gelsildet, welche, so weit ich die gesetzmæssige Stellung der Zellen erkennen konnte, gezeichnet sind. Nan sieht in a, a die beiden Scheitelzellen. In Fig. 2 ist ein durch Prolification am Rande des Laubes entstehendes Aestehen darøestellt; a bezeichnel die Scheitelzelle ( $\mathrm{n}$ ), b die secundere Zelle des ersten Grades, welche mil a aus einer Scheitelzelle entstanden ist. - In den secundwen Zellen des ersten Grades beginnt das Wachstlum in die Breite, und setzt sicl fort durch secundxre Zellen der folgenden Grade. Ls besteht darin, dass eine secundare Zclle (oder Pandzelle) entweder durch eine llen radialen Durchmesser unter einem rechten Winkel schneidende Wand in eine secundare und eine tertiære Zelle, oder durch eine schiefe, von oben und innen nach aussen gehende und mit dem radialen Durchmesser fast parallel laufende Wand in zwei secundære Zellen, eine kleinere vorlere und eine grössere hintere sich theilt. - In Fig. 1 werden die Zellgruppen, welche aus den successiven secundaren Zelten des ersten Grades entstanden sind, die oberste durch b, die zweitoberste durch c, die dritte durch d, die vierte durch efm, die fünfte durch ghion, die sechste durch $\mathrm{k}$, die achte durch I bezeichnet. In der obersten (b) hat sich eine Querwand, in der zweitobersten (c) zwei Querwxnde, in der ưritten (d) zwei Querwande dann eine seliefe Lengswand, in der vierten (efm links) vier Querwænde (mi) dann eine schiefe Langswand (ef) gebildet; in der fünften sindizuerst zwei Qnerwande und die Zellen n 


\section{$-\quad 257$}

entstanden, die Randzelle 0 -g theilte sich durch eine schiefe Langswand in die beiden Zellen $0-i$ und g-h, wovon die erstere mehrere Querwande, die letztere aber sogleich wieder eine schiefe Længswand und dadurch die Zellen g und lı erzeugte. - In Fig. 2 hat sich die oberste secundrere Zelle des ersten Grades (b) noch nicht getheilt; die zweit- und drittoberste (c und d) haben vermiltelst einer Querwand eine erste tertiaere Zelle und eine secundære Zelle des zweiten Grades gebildet; die vierte (e) hat sich zuerst dureh zwei Querwande in eine tertiare und eine neue seeundxere Zelle, dann durch eine schiefe Langswand in zwei secundxre Zellen getheilt; die fünfte $f \mathrm{~g} n \mathrm{~m}$ theilte sich in die tertixe Zelle $\mathrm{m}$ und die secundare Zelle $\mathrm{n} f \mathrm{~g}$, die letztere in zwei secundxre Zellen $f$ und $g \mathrm{n}$, die letztere in $\mathrm{n}$ und $\mathrm{g}$; die sechste hikpo theilte sich in III (o) und II (hik p), die letztere in II $(\mathrm{pk})$ und II (hi), davon die eine in III (p) und II $(\mathrm{k})$ und die andere in II (h) und II (i), von diesen beiden die letztere in 111 und II.

Diese gesetzmæssige Zellenbildung, welche von der Aclısenlinie ausgeht, und sich in den jedesmaligen Randzellen fortsetzt, bedingt das Wachsthum in die Breite, und erzeugt eine Zellschicht, welche aus tertixen Zellen besteht, und am Rande von einer Reilıe von secundxren Zellen abgeschlossen ist. Ob die tertiaren Zellen sich ebenfalls theilen, wie bei Cryptopleura lacerata, weiss ich nicht; man sicht in einer gewissen Entfermung unterhalb der Scheitelzelle Querwande auftreten (Fig. 1, n, links); ob aber dieselben eine Theilung der tertiaren in neben einander liegende Zellen andeuten, oder ols sie eine mit dem Wachsthum in die Dicke verbundene Erscheinung sind, ist mir noch zweifelhaft. - Das letztere trifft alte tertiæren Zellen, nicht aber die Randzellen. Jede der erstern theilt sich durch Wande, welche mit der Achsenflache parallel sind, in $\overline{3}, 4$ oder : hinter einander liegende Zellen. In der Achsenflæche liegt eine besondere Schicht von Achsenzellen; die ieussern Zellen haben mit denselben entweder gleiche oder auch bloss halbe Lange und Breite. Das Resultat dieser Zellenbildung ist ein aus 5, 4 oder ว̆ Schıchten bestehender flacher Zellkörper. In Fig. 5 ist ein lıorizontaler Querschnitt durch den Seitentheil des Laubes dargestellt; man sielıt in b eine Randzelle (secundære Zelle), in a die Achsenzellen; die aeussern Zellen sind gleich breit wie die Achsenzellen, nur die Zelten $\mathrm{c}$ sind halb so breit. Auf verticalen Querschnitten sieht man ganz dasselbe, næmlich eine Reihe von Achsenzellen und jederseits eine oder zwei gleichlange Zellen; zuweilen sind die äussern auch bloss halb solang. Die Achsenzellen sind nicht immer deutlich zu erkennen; es kommt viel darauf an, dass der Schnitt die rechte Richtung treffe, und dass das Laub in dem geeigneten Entwickelungsstadium sei. Später werden die Zellen durch ungleiche Ausdehnung verschoben.

Das Laub theilt sich dichotomisch, indem an dem Ende einer Achse stalt cines Punctum vegefationis sich deren zwei bilden, und zwei neue Tochterachsen erzeugen (Fig. 1). Alle Dichotomieen einer Pflanze liegen in der gleichen Ebene. Ausserdem bilden sich zuweilen am Rande neue Lappen durch Prolification, inden einc Randzelle sich besondert, und einen Zellenbildungsprocess einleitet, weleher denjenigen, der im Purctun vegetationis statt findet, vollkommen analog ist (Fig. 2).

Iie Sporenmutterzellen liegen zerstreut durch das Laub. Auf Durchschnitten sieht man sie im jungen Zuslande neben den Achsenzellen (Fig. 4, b); sie sind eiförmig, mit dem langen Durchmesser horizontal von innen nach aussen gerichtet. Sie dehnen sich vorzüglich in der Richtung des Längendurchmessers aus, verschielsen dabei die Achsenzellen, und nehmen nun nicht bloss die eine IIälfte des Laubes sondern auch noch einen Theil der andern Hälfte ein (Fig. 4, c). Bei der völligen Reife reichen sic oft von der einen Flïche bis fast zur gegenüherliegenden Fläche des Laubes. Schon ziemlich früh ist ihr Scheitel frei, und bloss von Gallerte bedeckt, ob er es von Anfang an ist, oder ob sie zuerst von Zellen (ron der Epidermis) bedeckt werden, weiss ich nicht. - Die Sporenbildung ist zonenartig, indem sich die Iutterzellen zuerst dureh eine den langen Durehmesser unter einem rechten Winkel schneidende Wand in zwei Zellen theilen, welche auf gleiche Weise durch parallele Wände je zwei Zellen erzeugen.

Die Keimzellen liegen in Keimhäufehen beisammen, und sind in einen Keimbehälter eingeschlossen (Fig. 7), welcher in der Laubfäche nahe anı Rande liegt. An der Stelle, wo sich ein keimbehälter bilden soll, vermehren sich die Zellen beiderseits von den Achsenzellen, vorzüglich auf der einen Seite, welehe dadureh warzen- 
förmig sich erheht. Fig. "ै stellt einen solchen Zustand im horizontalen Durehsehnitt dar; b ist der Rand des Laubes, a b die durchschnittene Achsenzellschicht; neben den Aclısenzellen liegen die Zellen in Reihen, welche auf der obern Seite strahlenförmig divergiren, und nach der Oberfläche hin durch Theilung sich vermehren. Der ganze Durchsehnitt zeigt ein continuirliches Gewebe. - Die warzenförmige Erhebung wırd bedeutender, in der Mitte bildet sich eine Höllung, worin ein Conglomerat von jungen Keimzellen dicht auf den Achsenzellen ruht; die Zellen desselben scheinen um einen Punct geordnet zu sein, von einem besondern Träger ist nichts z.ı sehen. Fıg. 6 zeigt diesen Zustand im horizontalen Durchschnitt. - Die Keimwarze wird fortwälırend grösser, die Höhlung weiter, und das Keimhäufehen in derselben unfangreieher. Einen solchen Keimhehälter sieht man in Fig. 7 im horizontalen Durchschnitt; die Keimzellen sind noch nicht ausgebildet, ilıre Farbe ist hellroth; sie bilden einen kugeligen und gelappten Körper; jeder Lappen besteht aus einer Menge von Keimzellen; an der Basis der ganzen Masse befinden sich einige kleinere farblose Läppchen (c), aus kleinen erst entstehenden keimzellen gebildet; - die Wand des Keimbehälters besteht (wic in Fig. ̋̆ und 6) aus strahlenförmig-geordneten, nach aussen fortwährend sich theilenden Zellenreihen; in Fig. 7, $\mathbf{d}$ ist ein Theil derselben stärker vergrössert ; auf eine innere Zelle folgen nach aussen häufiger zwei, seltener nur eine Zelle. — In älteren Keimbehältern liegt ein Conglomerat von rothen Keimzellen, welche aus einander fallen, und die in der vitte ein Klümpchen von farblosem kleinmaschigem Zellgewebe cinschliessen; es sind diess theils kleine noch unausgebildete Keimzellen, theils eine oder mehrere Basiszellen, dureh die das ganze Keimhäufehen an den Boden des Behälters befestigt ist. - Die Keimzellenbildung wird von $J$. Agardh ") für Rhodomenia, wohin er die vorliegende Pflanze stellt, unrichtig als Coceidia glomerulum sporarum obovatarum, in filis clavato-moniliformibus ex placenta basali egredientibus nidulantium, foventia beschrieben. Kützing, weleher Spharococeus bifidus mit Sph. confervoides in die gleiche Gattung vereinigt, beschreibt die Keimbehälter auf eine für die letztere Art richtige fir die erstere ganz unpassende Weise als Cystocarpia spermopodio centrali, compacto, parenchymatico; spermatia fasciculata sessilia oblonga. Von einer Placenta (Samenboden) oder einem Spermopodium (Samenträger) kann bei Leptophyllium bifidum nicht in der Art die Rede sein wie bei andern Florideen (Nitophyllum, Polysiphonia, Delesseria etc.) Allerdings schweben die Keimhäufehen nicht in der Luft, und sie sind an einem Puncte befestigt, nämlich an die Nitte des Bodens des Keimbehälters; aber so sind alle Keimhäufchen (die Favella und Favellidia der Autoren) an eine Zelle befestigt. Macht man nun, wie es gewöhnlich geschieht, den Unterschied, dass man bei den eigentlichen Keimhäufchen (Favelle, Favellidia), wo ein ganzer Knäuel von Keimzellen auf einer Zelle befestigt ist ${ }^{2}$ ), nicht von einer Placenta oder einem Träger spricht, und diesen nur da annimmt, wo von einer mehrzelligen Parenchymmasse viele Keimhare entspringen, so besitzt auch Leptophyllium bifidum keinen Träger oder Placenta. So viel ich nämlich sehe, ist es nur eine der Achsenzellen, von weleher die Bildung des Keimläufchens ansgeht, und auf welcher dasselbe dureh eine Basiszelle befestigt ist.

Diese neue Gattung unterscheidet sich von der Gattung Rhodomenia Grev. (Spherococcus II Rhodomenia, und Callophyllis Kütz.) vorzïglich durch die Sporenbildung, welche bei Leptophyllium zonenartio, bei Rhodomenia kugelquadrantisch ist; von Calliblepharis Kïl. (Rhodomeniae sp. Auct.), wo die Sporenmulterrellen sich ebenfalls zonenartig theilen, besonders durch die Lage der Sporenmutterzellen, welche bei Leptophyllium neben den Achsenzellen, bei Calliblepharis, von denselben entfernt, in der Rinde liegen, ferner durch die struclur und Stellung der Keimhäufchen, welehe bei ersterer Gattung einfach, und in der Laubfïche befindlieh, bei letzterer zusammengesetzt und in besonderen cilienartigen Keimästen gelegen sind.

1) Alga maris medit. et alriat. p. 155.

2) igt. oben bei Callithamnion und Plocamium, unfen bei Rhodomenia, Dunontia und Lomentaria. 


\section{$-\quad 259$}

Rhodomenia Iaciuiata Grev.

(Callophỵllis 1. Kütz.)

TAB. X. Fig. $8-12$.

Das Laub besteht aus grossen, fast farblosen Parenchymzellen, welche in 4 bis 5 Schichten neben einander liegen; die innern Zellen sind selır weit, die äusserı sind mehrmal kleiner. Zwischen diesen Parenchymzellen liegt ein Geflecht von dünnen, gegliederten, rothgefärbten Fäden, welche lıäufig so zahılreich sind, dass jede dersetben ganz damit umgeben ist. Nach aussen werden die Parenchymzellen jederseits von einer Lage kleiner rothgefäbler Zellen bedeckt, welehe an Grösse, Farbe und Gestalt den Zellen des innern Fadengeflechtes ähnlich sind, und auch in dieselben überzugehen scheinen. Da mir die Entwickelungsgeschichte des Gewebes noch unbekannt ist, so weiss ich nicht, ob die äussere kleinmaschige Zelllage eine wirkliche Rinde vorstellt, oder ob sie durch das innere Fadengeflecht erzeugt wird, welches olne $\mathbf{Z}$ weifel den gleichen Lirsprung hat, wie die analoge Erschelnung in Delesseria, Gelidium, Laurencia und andern Gattungen.

Die Sporenmutterzellen liegen in linienförmigen Gruppen längs dem Rande. Die Sporenbildung ist kugelquadrantisch. - Die Keimzellen befinden sich in kleinen, cilienartigen, randständigen keimästchen, von denen jedes einen Keimbehälter darstellt. - Die Wand desselben hat den gleichen Bau wie das Laub, und besteht aus den grossen fast farblosen Parenchymzellen, die 2 bis 5 Schichten bilden, aus den rothen, gegliederten, dieselben rings umgebenden Zelffiden;, und aus dem rothen kleinzelligen rindenartigen Gewebe. Das Innere des Behälters ist mit einem faserigen Gewebe ausgefültt, in welchem getrennt von einander eine zahllose Menge von kleinen besondern Keimhäufchen liegen. Jedes derselben besteht in der Regel aus nicht mehr als 6 bis 12 Keimzellen, welehe durch Gallerte verbunden sind. Jedes dieser besondern Keimhäufchen entsteht aus einer Zelle, welche an einer Zelle des faserigen Gewebes befestigt ist. Jie Zelle theilt sich in eine obere (Fig. $8, b)$ und in eine untere Zelle (Fig. 8, a); letztere ist die Basiszelle oder Trägerzelle des Keimhäufchens, sie theilt sich nicht weiter; aus ersterer geht durch Zellenbildung ein Klümpchen von Zellgewehe hervor, an welchen sich alle Zellen zu Keimzellen entwickeln. Diese Zellenbildung ist die gleiche, wie im Punctum regetationis des Laubes bei der rerwandten Gattung Leptophyllium. Jene obere Zelle nämlich (Fig. 8, b) theilt sich durch cine schiefe Wand in eine untere und in eine obere Zelle (Fig, 9, b und c) und diese Theilung wiederholt sich je in der obern Zelle (Fig. 10). Die Scheidewände sind abwechselnd nach verschiedenen Seiten geneigt, ob bloss nach rechts und nach links wie im Punctum vegetationis des Laubes, oder auch nach andern Seiten, war mir nicht deullich; das erstere ist mir wahrscheinlich. Das Längenwachsthum der Keimhäufchen ist somit das gleiche wie dasjenige des Laubes; es besteht darin, dass eine Scheitelzelle oder primäre Zelle sich in eine Scheitelzelte des folgenden Grades und in eine secundäre Zelle theilt. Ob und in weleher Weise die secundæren Zcllen sich theilen, konnte ich mit Sicherheit nicht entscheiden. Die Keimzellen sind zuerst mit homogenem schwach röthlich gefærbtem Schleime erfüllt, und liegen in einem dichten Parenchym beisammen. Sie werden etwas grösser, farben sich rollı und werden durch gallertartige Intercellularsubstanz von einander getrennt (Fig. 11, 12). - Alle diese zahlłosen besondern Keimhæufchen, von denen jedes aus einer Zelle entsteht, und jedes in einer Loge des faserigen Gewebes eingebettet ist, bilden mit dem sie umschliessenden faserigen Gewebe zusammen das zusammengesetzte kicimhæufchen. 


\section{Gracilarieat.}

Cylindrischer oder etwas zusammengedrückter Zellkürper, mit gleichem Lüngenwachsthum in allen Achsen; Wachsthum in die Breite und Dicke nicht geschieden, son der Achsenlinie nach allen Seiten gehend.

Diese Familie unterscheidet sich von den Plocamieen auf gleiche Weise wie die vorhergehende, indem nämlich das Längenwachsthum in den vegetativen und in den reproductiven Achsen das nämliche ist. In beiden theilen sich die Scheitelzellen $\left(I^{\mathrm{n}}\right)$ durch schiefe Wände in eine neue Scheitelzelle $\left(I^{\mathrm{n}}+1\right)$ und in eine secundäre Zelle des ersten Grades $\left({ }_{n} I^{1}{ }^{1}\right)$. Die Wände in den successiven Scheitelzellen sind abwechselnd nach verschiedenen Seiten geneigl; die secundären Zellen des ersten Grades alterniren mit einer Divergenz, die kleiner ist als $180^{\circ}$, und sie bilden zusammen einen cylindrischen, mehrreihigen Zellkörper. Das Wachsthum in die Dicke beginnt in den secundären Zellen des ersten Grades, und zwar in jeder in derjenigen Richtung, welche durch den Radius bezeichnet wird. Die Zellenbildung schreitet von innen nach der Peripherie hin fort, und geschieht abwechselnd durch Wände, welche radial (senkrecht oder wagrecht) tangental oder zwischen beiden Richtungen geneigt liegen.

Die Gracilarieen unterscheiden sich von den Chondreen dadurch, dass bei der ersten Familie das Wachsthum in die Breite und in die Dicke nicht geschieden ist, indem die Zellenbildung rings um die Achsenlinie ursprünglich gleichmässig vertheilt ist, und radienförmig von derselben aus nach allen Seiten hin geht, dass bei der zweiten Familie dagegen das Wachsthum in die Breite und in die Dicke scharf von einander gesondert ist, indem zuerst eine einfache Schicht, und dann erst aus dieser ein mehrschichtiger Zellkörper entsteht, indem also die Zellenbildung von der Achsenlinie aus zuerst nach zwei gregenüberstehenden Seiten in die Fläche, und darauf senkrecht auf diese Fläche in die Dicke sich bewegt. 'Der Unterschied zwischen Chondreen und Gracilarieen ist genau der nämliche, wie der zwischen Delesserieen und Rhodomeleen. Dem Begriffe nach ist er scharf und absolut. In der Anwendung zeigt sich die Schwierigkeit, dass das Wachsthum meist nicht deutlich erkannt wird, und man daher oft bloss auf den innern 
Bau oder auch wohl nur auf die äussere Gestalt angewiesen ist. Was den erstern betrifft, so zeichnen sich die Chondreen durch eine besondere Zellschicht in der Achsenfläche aus, welche den Gracilarieen mangelt ; - und was die letztere betrifft, so kann, wenn bei einer im Innern faserigen Structur die Achsenzellschicht unkenntlich ist, eine flächenförmige Form ziemlich sicher für das den Chondreen, sowie eine cylindrische Form sicher für das den Gracilarieen eigenthümliche Wachsthum entscheiden. Es bleiben somit bloss dicjenigen Arten zweifellaft, welche, bei ciner weder entschieden cylindrischen noch entschieden flächenförmigen Gestalt, weder das Wachsthum noch den innern Bau deutlich erkennen lassen.

Zu den Gracilarieen gehören Catenella Grev., Furcellaria Lamour., Polyides Ag., Dumontia Lamour., Halymenia Ag., Gracilaria Grev. (Plocaria Nees, Cystoclonium Kütz.), Hypnea Lamour. (? Hypnophycus Kütz.).

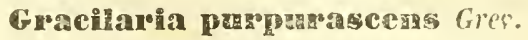

(Sphaerococeus p. Ag. Plocaria p. Endl. Cystocloninm p. Kütz.)

TAв. VII. Fig. $57-41$.

Die Pflanze ist ein cylindrisches ungegliedertes veriesteiles Lauli, an welchem alle Achsen einander gleich und unbegrenzt sind. An der Spitze jeder Achse befindet sich eine cinzige Zelle, dic Scheitelzelle ( In ${ }^{\mathrm{i}}$. Dieselbe theilt sich durch eine die Achse unter einem spitzen Winkel schneidende, von unten und innen nach oben und aussen gerichtete Wand, welche mit ihrem untern Rande an del obern Seite der næchst untern Zelle aufgesetzt ist, in eine untere $\left({ }_{n} I^{1}\right)$ und in eine obere Zelle $\left(\mathrm{I}^{\mathrm{n}}+^{1}\right)$. bie Wiende, Wodurch sich die Scheitelzellen theilen, sind abwechselnd nach versehiedenen Seiten gerichtet. An len Enden der dünnern spitzen Aeste unterscheidet man imıner die Scheitelzelle (Fig. 57, 58, a) und unter derselben eine oder mehrere secundxre Zellen des ersten Grades (Fig. 57, b, b). - Die Zellenbildung, welche in den secundieren Zellen beginnt, und das Wachsthum in die Breite bedingt, kann nicht deutlich verfolgt werden.

An ausgebitdeten Achsen unterscheidet man zwei Lagen des Gewebes. Im Innern liegt das Mark; es besteht aus Fasern (Reihen von langgestreckten oder cylindrischen Zellen), welche meist senkrecht, einige auch sehief verlauten, und in einer reichliehen Gallerte liegen. Fig. 11, a zeigt das Nark im Durchschnitt. Die Narkzellen sind ungleich gross; der Durchmesser betrægl von 0,006 bis $0,012^{\prime \prime \prime}$. Ihre Wandung ist betraechtlich verdickt. Das Mark nimmt gewöhnlich zwischen der Iłxlfte und einem Drillıeil des ganzen Durchmessers ein. - Die Rinde besteht aus mehrern $(5-7)$ concentrischen Schichten von Jarenchymzellen. Die Zellen werden von innen nach aussen kleiner und zahlreicher, zugleich auch mil mehr festem und gefachbtem Inhalte erfüllt. Dic xusserste Sehicht oder die Epidermis unterscheidet sich meist ziemlich deutlich von dem innern Gewebe; ihe 'Zellen sind bedeutend (sclbst 2 bis 5 mal) kleiner als die nxchst innern; sie zeigen eine intensere Farbe und ein Vorherrschen des radialen Durchmessers über den tangentalen (Fig. 41). - Kützing unterscheidet drei Lagen. 


\section{- 242}

les Gewebes, indem er das, was ich Rinde nannte, in zwei Theile trennt. Doch gehen dieselben allınælig in einander über; eine bestimmte Grense ist nicht vorhanden. Nan muss daher auch die ganze Rinde als Ein Gewebe betrachten. Am meisten zeiehnet sich in der Regel an demselben die xusserste Schicht als Epidermis aus. - Da mir die Entwickelungsgeschichte unbekannt ist, so weiss ich nicht, wie sich die beiden Gewebe zu einander verhalten, und ob die Benennung von Mark und Rinde eine richtige sei. An jungen Aesten finde ich das Nark an Ausdehnung relativ geringer und aus weniger Fasern bestehend als an æeltern Aesten. Der Durchschnitt durch die ersteren zeigi bloss $6-8$ Fasern, durch die letzteren dagegen $10-20-40$ und noch mehr. An jungen Aesten finde ich ferner die Markfasern bloss innerhalb der Parenchymzellen, an æltern dagegen nicht bloss innerhalb, sondern auch zwischen den Zellen der zwei oder drei innersten Parenchymschichten. lus der Zunahme der Fasern mit dem Aiter der Achsen und aus dem Umstande, dass sie theilweise auch deutlich in den Intercellularræumen sich finden, möchte ich fast schliessen, dass die spæter gebildeten auf aehnliche Weise entstehen, wie die Fxden bei Delesseria IIypoglossum und bei Lautencia, und dass daher dieselben auch hier als ein intereellulares Geflecht zu betrachten seien. Degegen ist es mir wahrscheinlich, dass die ursprünglich schon vorhandenen Fasern wirkliche Gewebezellen seien, und den innersten Theil des durch geseizmassige Zellenbildung entstandenen Gewebes darstełlen, namentlich aus dem Grunde, weil in dem Harke die Keimzellen entstehen.

Die Aestchen sind hreffig mil einfachen gegliederten oder ungeglieder(en, dünnen und farblosen Haaren besetzt. Es sind diess wirkliche Ilaare, denn sie entspringen aus den Epidermiszellen (Fig. 38, c). Sie unterseheiden sich durch diesen Ursprung von den haarörmigen Blattern der Gattungen Polysiphonia und Laurencia; die Jetztern entstehen seilich an den nngetheilten Gliederzellen. Die morphologische Verschiedenheit der beilen Organe ist somit klar. Ueber den pliyshologischen Unterschied lasst sich noch nichts bestimmtes sagen, va die Antheridien, welche bei den zwei genannten Gattungen an den Blattern stehen, bei Gracilavia noch nicht gefunden wurden.

Die Sporenbildung geschieht in den noch jungen Aesten. Die Sporenmutterzellen liegen in der Rinde (Fig. 11, wo ein Querschnitt gezeichnet isi). Sie sind ellipsoidisch, mit radial gestelliem langem Durchmesser, und berühren mit der Spitze die Cuticula, mit der Basis das Mark. Anfänglich zwar liegen die Sporenmutterzellen im Gewelle verborgen, und sind nach aussen wenigstens von der Epidermis bedeckt; später aber trennt sich Jas Gewebe von einander, so dass sie an ihrem peripherisehen Theile bless noch von Gallerte überzogen sind (Fig. 41). Dieser Zustand scheint demjenigen voraus zu gehen, wo sie ganz aus dem Gewebe heraustreten, und ausgestreut werden. - Die"Sporenbildung ist zonenartig, das heisst die Jfutterzelle theilt sich erst in zwei IHälften, worauf jede derselben sich durch eine mit der ersten Wand parallele Wand theilt. - Die Zweige, welche Sporen bilden, wachsen fortwährend an ihrer Spitze in die Länge, und sie werden nachher, wie alle ïbrigen Aeste, zu unbegrenzten Achsen. Der von Külzing gebrauchte Ausdruck "earpoclonia distincta, besonlere Fruchtäste" ist daher auch für diese Gattung, wie für Polysiphonia, Lantrencia, Gelidium unpassend.

bie Keimzellen sind zu Keimhäufchen vereinigl, welehe mitten in den Aesten liegen, und an diesen kugelige Anschwellungen verursachen. In Fig. 39 ist eine solche Anschwellung im Querschnilt, in Fig. 40 im Längsschnitt dargestellt. Die ganze Anhxufung von Keimzellen ist von einer Lage des faserigen Markes umgeben. Die Keimzellen liegen in einzelnen Partieen beisammen. Der letztern sind im Ganzen etwa 13 bis 20 ; sie werJen ron cinander durch faserige Scheidewende, die ron dem umgebenden Marke entspringen, getrennt. Das ganze Keimhxufchen ist dessnahen ein zusammengesetztes zu nennen, welches aus mehreren besondern Hæufchen gebildet wird. Ueber die Entstehungsweise der Keimzellen ist mir nichts bekannt. Sie sind ziemlich gross, parenchymatisch-vieleckig, und braunroth. - Der Character Endlicher's "Coceidia glomerulum sporarum wblongarum, e placenta centrali egredientium forentias passt auf die eine Art P. purpurascens durehaus nicht. 
Dumontia filiformis Gres.

\author{
TAB. IX. Fig. $4-8$.
}

Diese Pflanze ist ein cylindrisches, ungegliedertes und verxesteltes Laub. Das Wachsthum in die Lxnge geschieht du'ch cine Sclıeitelzelle, Welche man an dünnern spitzen Aesten deutliclı erkennt. An den stærkern und weniger spitzen Achsen dagegen kann man dieselbe neben den übrigen Zellen nicht unterscheiden. Itit Zellenbildung in der Scheitelzelle ist die gleiche wie in Gracilaria purpurascens. Man sieht unter derselben zwischen den Zcllen schiefe Waende, welche von der Achsenlinie nach versehiedenen Seiten ausstrahlen. Durch diese Anordnung der Zellen (Fig. 4) überzeugt ınan sich bald, dass auch hieı die Scheitelzellen sich fortwatırend durch schicte ron unten und innen nach oben und aussen gerichtete Wrende theilen, in eine neue Scheitelzelle $\left(\mathrm{I}^{\mathrm{a}}+^{1}\right)$ und in eine secundære Zelle des ersten Grades $\left(\mathrm{n} \mathrm{H}^{4}\right)$. Dieses Langenwachsthum ist unbegrenzt, es dauert in den einzelnen Achsen, so lange als die Pflanze lebt. - Das Wachsthum in die Breite, relches in den secundieren Zellen beginnt, ist nir durch Beobachtung nicht bekannt. - Im ausgebildeten Zustande untersclieidet man an den Aclisen zwei Lagen von Gewelsen, das Mark und die Rinde. Ersteres lestelit aus eines verdünnten Gallerte, in welcher, getrenut von einander, veræstelte Zellenreihen liegen. Die Ilauptreihen steigen senkrecht vou unten nach oben, und geben Aeste ab, welche meist schief nach oben und ausserı zur Rinde gehen, und sich stelig verzweigen. Einzelne Aeste könmen auch horizontal, einzelne Zweige sogar von innen und oben nach unten und aussen verlaufen. Die innern und mehr senkrechten Faeden liegen weiter von einander entferni; sie sind weniger veresteli, inden sie je auf dem zweiten Gliede, zuweilen auch bloss je auf dem vierten und füften Gliede eine Tochterachse tragen; ihre Zellen sind langgestreckt und uugefirtbr (Fig. f, a-a). Die æussern und mehr der horizontalen Lage sich nahernden Faden liegen dichter in einander; sie sind meh! verzweigt, indem lixufiger auf jedem Gliede Tochterachsen stehen, und durch eine gleiche Ausbildung wie die Vfutteracise dem ganzen lZweige ein dichotomisches Ansehen geben; ilire Zellen sind kur' cyliudrisch oder ellipsoidisch, und sehwach röthlich gefarbt (Fig. 6, b-b). - Die Rinde besteht aus kleinen. gefierbten, dichter in einander liegenden Zellen, welche eine, zwei oder drei Schichten bilden (Fig. $6, c-c)$. Doch kann man meist auch in der Rinde noch und zuweilen bis in die Epidernis eine zweigartige Anordnung der Zellen verfolgen, indem die zusammengehörigen Zellen immer durch schmalere Zwischenæume getrenni sind als die tibrigen; und wenn man die Epidernis ron aussen betrachtet, so sieht man læufig auch hiel, dass die Zellen in Gruppen von 2, 5 und 4 beisammen liegen, indem zwiselien diesen Zellen die Wande fast zu mangeln scheinen, wrelıend die Gruppen selbst weiter von einander abstehen (Fig. 3). Kützing unterscheidet drei Schichten, Hark, Zwischenschicht und Rinde, und læsst die Harkfasern unter einander anastomosiren. Was das letztere betrift, so möchte ich fast bezweifeln, dass es eine wahre Anastomose sei, was man z. B. bei Gefaessbündeln mit liechıt so nennt. Es scheint mir bloss eine einlache Veræstelung zu sein, welche aber danı den Schein der Anastomose annimmt, wenn die erste Tochterachse eines lorizontal abgehenden $\Lambda$ stes und die Fortsetzung desselben so selı von einander divergiren, dass sie einen fast geraden, scheinlar zusammengehörigen, mit der Ilauptachse mel̀r oder weniger parallel laufenden und mit ilır durch einen Querast verbundenen Faden lilden. Was die rerschiedeneu Lagen betrifft, aus denen das Gewebe besteht, so kann man wohl zuweilen Nark, Rinde und eine Zwisehensehichı unterseheiden; meist ist diess aber niclıt möglich, indem das Hark und die Zwischenschicht olıne Grenze sind. Selhst die Rinde sondert sich nicht immer deutlich von deu nnern rewelse, so dass es fast scheint als ol) selbst die Trennung in Mark und Rinde bloss eine künstliche sei. - Das Gewebe ist dichıt unter der Spitze einer Achse gleichı̈̈rmig und parenchymatisch. Nachher bilıtet sich im innern Theile die gallertartige Intercellularsubstanz; dadureh werden die Zellen seitlich von einander getrennt, und sıe nelımen, da sie bloss nock der Lange nach mit einander verbunden bleiben, dic: Gestalt von 
Zellenreihen an. Die letztern sind zuerst noch ziemlich regelmassig; mit der Zunalıme der Gallerte und der Ausdehnung des Achsentheiles, namentlich in die Breite, werden sie unregelmassig, und zeigen dann hin und wieder jene scheinbaren Anastomosen, von denen ich vorhin gesprochen habe. Wegen der grossen Menge der inuern Gallerte und ihrer grossen Verdünntheit, so wie wegen der geringen Menge von Zellenreihen, welche in derselben liegen, werden die Achsen von Dumontia hohl genannt, was sie aber nicht eigentlich sind.

Die Sporenmutterzellen liegen in der Rinde. Sie sind nach aussen von der Epidernis bedeckt, nachlıer frei. Mit ihrer Basis reichen sie in den æussersten Theil des Markes. Ihre Gestalt ist eiförmig, der lange Durchmessel' radial von innen nach aussen gerichtet. Sie theilen sich durch eine senkrechte, den langen Durchmesser unter einem rechten Winkel schneidende Wand in eine innere und eine æussere Halfte, dann jede derselben durch eine radial stehende (senkrechte oder horizontale) Wand in zwei kugelquadrantische Zellen. Wenn die reilen Sporen durclı Druck von einander getrennt werden, so behalten sie die Gestalt von Kugelquadranten. bie Keimzellen sind in Keimhæufchen vereinigt, welche einzeln in den Laubachsen liegen, und in denselben eine gleiche Lage haben, wie die Sporenmutterzellen, mur dass sie vielleicht etwas tiefer liegen. Die [Keimzellenhaufchen entstehen in dem æussern Theile des Markes unter der Rinde. Eine Zelle der horizontal liegenden veræstelten Zweige der Markfæden, welche schon eine Dicholomie trægt, bildet an ilırer æussern Flæche eine istzelle. Aus derselben wird durch Zellenbildung eine Gruppe von kleinen Zellen (Fig. 6, d, d). Indem sich die \%ellen weiter vermehren, nimmt das liæufchen eine kugelige Gestalt an. Es bildet sich um dasselbe cine Gallertschicht, welche Extracellularsubstanz ist, und mil Unrecht perisporium oder peridium genannt wurde (Fig. $7,8)$. Das Keimhæufchen durchbricht nach und nach die Rinde; seine xussere Flseche wird, indem die Epidermiszellen auseinander geschoben werden, frei (Fig. 8). Die die Epidermis überziehende Gallerte oder Cuticula wird daselbst in einen kleinen Höcker emporgehoben. Nachher werden die Keimzellen ausgestreut. sie sind braunroth und wegen ihrer ziemlich lockern Lagerung meist rundlich oder bloss mit slumpfen Ecken und Kanten rersehen.

\section{LOMEITTARIAGEAE.}

Die Hauptachsen, wenigstens die reproductiven, sind hohle Zellkürper; Sporenmutterzellen im Gewebe der Windung.

Diese Ordnung unterscheidet sich im Bau von allen übrigen Florideen. Entweder sind alle Hauptachsen (Laub) oder bloss die reproductiven Achsen (Fruchtäste) hohl. Die Entwickelungsgeschichte ist mir noch ziemlich unbekannt. Aus meinen Untersuchungen geht bloss soviel mit Sicherheit hervor, dass das Längenwachsihum in Einer Scheitelzelle statt findet, und mit Wahrscheinlichkeit, dass dieselbe sich wie bei den Rhodomeniaceen durch schiefe Wände theilt. - Die entwickelten Achsen sind gegliedert, indem die innere, mit Wasser gefüllte Höhlung durch Scheidewände unterbrochen ist. Die Wand besteht aus einer oder mehreren Parenchymschichten. An der innern Fläche derselben liegen getrennt von cinander einzelne der Länge nach verlaufende Reihen von dünnen cylindri- 
schen oder fast fadenförmigen Zellen; diese Reihen sind meist einfach, zuweilen etwas verästelt, in seltenen Fällen scheinbar anastomosirend; sie setzen sich an den Stellen, wo die Höhlung durch Scheidewände abgetheilt ist, zwischen diesen und der äussern Wand ununterbrochen fort. An den langen Zellen dieser Reihen oder Fäden sind ziemlich in der Mitte einzelne oder mehrere sehr kleine, meist birnförmige Zellen befestigt, welche der Höhlung zugekehrt sind.

Dieser eigenthümliche Bau unterscheidet die Lomentariaceen bestimmt und scharf von den beiden vorhergehenden Ordnungen. Es giebt zwar namentlich unter den Rhodomeniaceen einzelne Gattungen, deren Laub ebenfalls als hohl beschrieben wird, so z. B. Catenella, Dumontia, Halymenia ; ebenso selbst einige Delesseriaceen z. B. Bonnemaisonia. So lange diess geschieht, so ist dann allerdings der Begrriff des hohlen Zellkörpers für die Systematik unbrauchbar, weil es von den genannten Gattungen zu denen mit wirklich soliden Achsen keine Grenze sondern einen allmäligen Uebergang giebt. Ich glaube aber nicht, dass jene Gattungen hohl genannt werden dürfen. Im jungen Zustande sind ihre Achsen im eigentlichsten Sinne solid, und bestehen durch und durch aus einem parenchymatischen Gewebe. Dasselbe wird im Innern nach und nach sehr locker, indem eine grosse Menge von meist sehr verdünnter Intercellularsubstanz gebildet wird. Hohl aber wird es nicht, da der Raum immer noch wie anfänglich von den gleichen Zellen, die aber nun seitlich mehr oder weniger von einander getrennt sind, und als Zellenreihen auftreten, durchzogen wird; so in Catenella, Dumontia, Halymenia. In Bonnemaisonia, deren Wachsthum durchaus mit demjenigen der Delesserien übereinstimmt, wird auch an den entwickelten Achsen mitten in dem innern Raume noch die Reihe der Achsenzellen angetroffen. Bei den Rhodomeniaceen und bei den Delesseriaceen ist dessnahen die sogenannte Höhlung bloss scheinbar, bei den Lomentariaceen ist sie wirklich vorhanden. Dort ist die Wand nach innen durch einen eigenthümlichen Bau morphologisch abgeschlossen; sie besitzt inuen ebensowohl als aussen eine durch bestimmte Zellenbildung gegebene Oberfläche. Es beweist diess, dass die Höhlung nicht etwa bloss mechanisch durch Trennung oder Zerreissung entstanden ist, sondern dass ihre Bildung zum Begriffe des Wachsthums gehört.

Die Sporenmutterzellen liegen in der Wandung der hohlen Achse entweder Denkscbr, NGGI. 


\section{anstossend an die innern Reihen langgestreckter Zellen, oder von denselben durch eine Zellschicht getrennt. - Die Keimzellen sind zu Keimhäufchen vereinigt, wie bei den Rhodomeniaceen .

\author{
Zu den Lomentariaceen gehören Lomentaria Lyngb. (Gastroclonium Kütz., \\ Chondrothamnion Kütz) und Champia Ag.
}

\section{Lomentaria kallformis Gaill.}

(Chylocladia k. Grev.

TAB. X. FIG. $15-21$.

Das cylindrische Laub erscheint gegliedert; es ist quirlförmig verästelt, indem an jedem Gelenke gewöhnlich mehrere (bis zu :̈) Tochterachsen stehen. Die Glieder sind hohl, und werden durch Scheidewände von einander getrennt. - Dic Zellenbildung im Punctun vegetationis ist schr schwer zu studiren, theils weil die Achsenenden abgerundet sind, theils weil fast unmitteibar unter den Seheitel sehon die Höhlung sich zu bilden anfängt, und ein für die übrigen Florideen fremdes Moment zu den Erscheinungen hinzufügt. An der Spitze der Achsen steht eine Scheitelzelle, welehe sich, wie mir scheint, dureh schiefe Wände theilt. Unter der Scheitelzelle ist das Gewebe eine sehr kurze Strecke weit solid, dann treten Ilöhlungen im Innern auf, welche durch horizontal liegende, einfache Zellsehichten von einander getrennt sind. Die Wandung besieht aus zwer Zellschichten, welche ursprünglich das Verhältniss zu einander zeigen, dass auf je cine innere Zelle mit kurzem cine äussere Zelle mit mehrmals längerm radialem Durchmesser folgt. Die äussern Zellen theilen sich durch horizontale Wände in 5 oder mehr über einander liegende Zellen, indess die innern, sich nicht theilend, in senkrechter Richtung länger werden, do dass nun an verticalen Durchschnitten auf jeder innern Zelle mehrere ïussere Zellen stelen. Die innern Zellen trennen sich seillich von einander, werden cylindrisch, und bilden mit den über und unter ihnen stehenden Zellen senkrechte Reihen. Die äussern Zellen dehnen sich ebenfalls von unten nach oben aus, so dass ihr verticaler Durchmesser den horizontalen Durchmessern gleich wird, oder dieselben übertrifft; sie bleiben immer zu einem continuirhichen Geweje verbunden. - Am entwickelten Laub bestchen die Scheidewände aus einer Parenchymschicht ron Zellen mit ziemlich cubischer Gestalt (Fig. 15, a), dic Wandungen ebenfalls aus ciner Schicht von Parenchymzellen, deren drei Durchnesser gleich sind oder weniggstens keine sehr bedeutenden Differenzen zeigen (Fig. 13̈, 16, b-b). An der innern Fläche der einschichtigen Wandung steigen dieht anliegend senkrecite Reihen von schmalen cylindrischen Zcllen, welche 3 oder mehrmal länger sind als die Zellen der Wandung, empor (Fig. 15, 16, c). Diese Reihen sind gewölnlich einfach; selten theilt sich eine nach oben scheinbar dichotomisch in zwei Reihen. Im ganzen Umfang der WanJung tinde ich einigemal 15 solcher Peihen, indess die Zahl der,Wandzellen zwischen 58 und 45 beträgi. In den gleichen Fällen finde ich, dass durehschuittlich je zwei Zellen dieser Reihen auf die Länge eines Gliedes gehen. - An der äussern Fläche der einschichtigen Wandung liegen kleinere Zellen in den Intereellularwinkeln (Fig. 15, 16, d). Ursprïnglich mangein diese Zellen (Fig. 14, a), dann treten sie als ganz kleine hreise in den Ecken auf (Fig. 14, b), nachher auch an den hanten zwischen den Zellen. Entwickelt sind sie von unglei(ller Grösse, bald bloss aussen an den Zellen silzend, bald mehr oder weniger zwischen dieselben eindringend. Einzelne dieser Zellen wachsen aus, und erzeugen an ihrer æussern Seite cine længliehe Zelle, auf welcher zuweilen ausserst zarte, einfache oder sperlich verzweigte, gegliederte Fæeden stehen (Fig. 17, n). - Auf den eylindrischen Zellen der senkrechten Zellenreihen sind in der Regel an jeder in der Hitle der Lwenge eigen- 


\section{- 247}

thümliche, birnförmige oder kugelige, kleine Zellen befestigt (Fig. 15, 16, e). Dieselben stehen hæufiger einz.eln, seltener zu 2 oder 5 beisammen und einen lıalben Quirl bildend (Fig, 15). Sie scheinen durclı Auswachsen der langen Zellen zu entstehen. Hhre Bedeutung ist mir rathselhaft.

Der Inhalt der jüngsten Zellen ist farbloser homogener Schleim, welcher nachlher körnig wird. Die grossen Parenchymzellen del' Wandung enthalten spxter eine wasserhelle farblose Flüssigkeit und eine wandstændige Schleinschicht, an welcher körniger gefierbter Inhalt oder dentliche Farbblaschen liegen, die letztern sind zuerst klein und rundlich, dann verlengern sie sich in verschiedenen Richtungen, werden unregelmæssig, selbst faserartig und etwas verzweigt (Fig. 19). Sie liegen bald locker, bald sind sie dicht zusammengedrangt und parenchymatisch. Die kleinen Zellen, welche aussen an den Wandzellen liegen, sind intenser gefærbt als die letztern. Die Zellen der Scheidewænde zeigen sich im entwickelten Zustande fast farblos; ihre den IIöhlungen zugekehrten Wande sind betrachtlich verdickt. Die langen Zellen der an der Wandung liegenden Zellenreihen besilzen cinen bald reichlichen, bald spærlichen, feinkörnigen, farblosen Schleim (Fig. 15̈). Die kleinen an ihnen befestigten, birnförmigen Zellen enthalten ebenfalls farblosen Schleim, welcher zuerst homogen, dann feingekörnt, meist eine ziemlich breite, wandstændige Schicht bildet (Fig. 15). - Das ganze Laub ist von einer breiten gallertartigen Extracellularsubstanz (Cuticula) überzogen (Fig. 13, 14, 1).

Die Sporenmutterzellen liegen zerstreut in der Wandung der Glieder; sie entstehen durch Besonderung einzelner Wandzellen (Fig. 17). Dieselben werden grösser, indem sie sich vorzüglich in radialer Richtung nach innen ausdehnen. Der gefærbte, an der Membran liegende Inhalt wird aufgelöst; statt dessen tritt eine centrale farblose Schleinmasse aú, in welcher ein kugeliger kern liegt, und von welcher radienförnige Strömungsfæden auslaufen. Die letztern sind zuerst in geringer Menge, nachher in grösserer Zahl vorhanden. Dann verschwindet der centrale Kern, und die Zelie theilt sich tetraëdrisch in 4 Zellen, welche ich immer so angeordnet finde, dass eine nach anssen, die drei andern nach innen liegen.

Die Keimzellen sind in ein Keimhæufchen zusammengeballt, welches in der Nitte eines kugeligen keimbehaclters, von dessen Wandung dicht umschlossen ist. Die Keimbehælter stehen an der æussern Flæche des Laubes zerstreut, sowohl verticillirt an den Gelenken allein oder neben einigen Laubxsten, als zerstreul an der Seite der Glieder; sie sind jeder für sich eine besondere Achse, ein Keimast. Die Keimæste bestehen in jüngsten Zustande aus einem continuirlichen parenchymatischen Gewebe, in welchem die Zellen, xhnlich wie in jungen Keinæsten von Plocamium, von der Basis nach der Spitze in divergirenden und sich fortwæhrend tỉeilenden Reihen georlnet sind. In ảer Mitte dieses Gewebes bildet sich das lieimhæufchen, welches in ausgebildeten Zustande aus rothen Keimzellen, die ziemlich enge in einander gelagert und daher mehr oder weniger eckig sind, besteht. Fig. 18 zeigt einen Keimast im horizontalen, Fig. $20 \mathrm{im}$ verticalen Durchschnitt, wo h die Wandung, g die mitKeimzel!en erfüllte Höhlung bezeichnt. In dem untern Theile des Kcimhæufchens liegt cine grosse langgestreckte, fast farblose Zelle, die Basis- oder Trægerzelle, welche der gleichen Zelle bei Plocanium, Rhodomenia u. s. $\pi$. analog ist, und von der die Keimzellenbildung ausgieng (Fig. 20). Die Wandung des ausgebildeten Keimbehalters besteht etwa aus 7 Zellschichten, wie man in Fig. 21 an einem senklechten Durchschnilt sieht; die Zelten, zwischen 'denen, namentlich im innern Theile del Wand viel Gallerte liegt, sind sowohl inil den ausserhalb und innerhalb, als nit den neben ilnen liegenden Zellen dureh Poren verbunden. Betrachtet man die Wandung des Keimbehælters von der innern Flæche, so sieht man die Zellen, entsprechend der ursprünglichen Anordnung, in Reihen, 'welche yon unten nach oben und aussen strahlenförmig verlaufen und nach dem Lmfange hin an Zahıl bedeutend zunehmen. Die Höhlung des Keimbehælters ist von der llölılung des Laubgliedes durch eine Wand getrent; dieselbe besteht aus einer Schicht grösserer Parenclınmellen (Fig. 20, b), welche zur Wandung des Laubes gehört, und aus cinigen Schichten kleinerer Zelleiı, welche in Gestalt und Grösse mit dem Gewebe der Wandung des Keimbehrlters übereinstimmen, und in dasselbe sich fortsetzen. Der Keimbehælter ist von einer breiten Gallertschicht ïberzogen, wclehe in die des Laubes continuirlich übergeht (Fig. 18, 20, f). - J. Agardh sagt von del Keimzellenbildung " Keramidia sporas cuneatas simplici serie a placenta centrali radiantes, intra reticulum laxissimum filorum reclangulariser anostomosantium, forentia, " was für alle Arten, so weit sie mir bekannt sind, gleich unrichtig ist. 


\section{$-248$}

\section{PHYLLOPHORAGEAE.}

Die Ilauptachsen sind Zellkörper; Sporenmutterzellen ausserhalb, sitzend oder gestielt oder in Reihen.

Mit den drei vorhergehenden Ordnungen stimmt diese Ordnung darin überein, dass die Achsen (Laub) Zellkörper, möglicher Weise auch Zellschichten sind; dadurch unterscheidet sie sich von den Ceramiaceen, wo die Achsen entweder Zellenreihen oder auch bloss Zellen sind. Während indess bei den drei vorhergehenden Ordnungen das Wachsthum in die Länge durch eine einzige Scheitelzelle statt findet, so scheinen die Phyllophoraceen immer durch mehrere Zellen in die Länge zu wachsen, entweder durch viele Zellen am Rande oder durch mehrere Zellen an der Spitze; bei einigen Gattungen ist diess sicher, bei andern ist es wahrscheinlich.

Durch die Sporenbildung unterscheiden sich die Phyllophoraceen bestimmt von den Delesseriaceen, Rhodomeniaceen, und Lomentariaceen. Bei diesen Ordnungen liegen die Sporenmutterzellen im Gewebe. Bei den Phyllophoraceen stehen dieselben ausserhalb; sie sind einzeln sitzend (Scheitelzellen des ersten Grades) oder gestielt (Scheitelzellen eines folgenden Grades), oder sie liegen in Reihen beisammen (Gliederzellen). Die morphologische Bedeutung der Sporenmutterzellen ist daher hier die gleiche wie bei den Ceramiaceen.

Zu dieser Ordnung gehören Peyssonellia Decaisne, Hildenbrandtia Nardo, Phyllophora Grev. (Phyllotylus Kütz., Coccotylus Kütz., Acanthotylus Kütz.) und Tylocarpus Kütz.

\section{Peyssomellia scymamaria Decaisne,}

$$
\text { Tab. 1X. Fig. } 9-25 .
$$

Das I.aub, woraus diese Pflanze besteht, ist blattartig und fecherförmig, von der Basis aus radial-gestreift, am obern Rande hxufig gelappt; diese Lappen sind ebenfalls mehr oder weniger fxelıerförmig. An dem Laube sind drei lixnder, die beiden naclı der Basis convergirenden Seitenrænder und der vordere, gebogene Rand, wo das Wachsthum durch Zellenbildung statt findet, ferner zwei Flacchen, eine obere dem Lichte zugekehrte, und cine untere, welche auf der Unterlage wurzelt, zu unterseheilen. Der vordere Rand verhalt sich in allen 


\section{$-\quad 249$}

Theilen volkommen gleich; er wird durł eine heihe neben einander liegender gleichwerthiger Zellen begrenzt. Macht man einen verticalen Querschnilt durch das flache Laub, so findet man an dem Ende desselbeı immer eine einzige Zelle, eine Randzelle (Fig. 9, 10, 11, 12, a). Betrachtet man das Lauls von der Flache, so liegen die Randzellen in einer Reihe neben einander (Fig. 15, a-a). Dieselben theilen sich durch eine, die $A$ chse unter einem rechten Winkel schneidende Wand in eine vordere (Fig. 9, 12, a, 15, a) und in eine hintere Zelle (Fig. 9, 12, b, 15, b). Das erste Wachsthumsgeselz für Peyssonellia ist demnach folgendes: Die Randzellen theilen sich durch eine ihre Achse rechtwinkelig-schneidende Wand in eine nene Randzelle und in eine Flaxchenzelte; dadureh geschicht das Længenwachsthum des Laubes.

In den Randzellen trilt abwechselnd mit dieser Zellenbildung eine andere auf. An dem von der Flsecle betrachteten Laube sieht man einzelne Randzellen, welche elwas breiter sind als die übrigen, und die sich durch eine schiefe Wand in eine xussere kleinere und eine grössere Zelle getleilt haben (Fig. $15, m$ und $n$ ), und andere, wo auch diese grössere Zelle (n) durch eine whliche, ebenfalls schiefe, al)er nach der andern Seite geneigte Wand in eine æussere kleinere Zelle (Fig. 15,0) und in eine innere grössere Zelle (Fig. 15, p) getheilt hat. Durch diese doppelte Zellenbildung entstehen aus einer Randzelle zwei neue Randzellen (m und 0 ), welelı॰ sich weiterhin auch als solehe verhalten, und eine Flæchenzelle (p). Dadurch vermehren sich die Zellen, welche den Rand bilden; dieser wird breiter; - die fæcherförmige Gestalt des Laubes findet hierin ihren Erklærungsgrund. Das zweile Wachsthumsgesetz ist demnach folgendes: Aus einer Randzelle entstehen durch zweimalige Theilung vermiltelst schiefer, gegen einander geneigter, die Aclisenflache des Laubes unter einem rechten Winkel schneidender Wände zwei neben einander liegende neue Randzellen und eine Flächenzelle; dadureh geschieht das Breitenwachsthum des Laubes.

Diejenigen Zellen, welche unmiltelbar unter den Randzellen liegen, und mit ihnen je aus einer Nutterzelle entstanden sind (Fig. 9, 15, b) haben eine mehr oder weniger seheibenförnige Gestalt. Sie theilen sich durch eine, mit der Laubfäche parallele Wand in zwei neben einander liegende, ungleiche Zellen (Fig. 9, 10, 11, 12. $c$ und d), wovon die eine (c) der unteren, die andere (d) der obern Flache des Laubes entspricht. Die crstere theilt sich dann durch eine scliefe, von vorn und innen nach hinten und aussen gerichtete Wand in eine innere grössere Zelle (Fig. 9, 10, e) und in eine äussere (untere) kleinere Zelle (Fig. 9, 10, f). Die innere Zelle (e) bıldet mit allen übrigen ihr gleichen Zellen die Zellschicht der Achsenfäche, welche in Fig. 14, e-e im Durchschnilte gezeichnet ist. Die äussere (untere) Zelle (f) stellt mit allen ihr gleichen Zellen eine Schicht dar, welche die Achsensehiclıt an der unteren Seite bedeckl (Fig. 14, f-f). Beicles sind Dauerzellen; nur entwickelı sich einige der letztern späterhin zu Haaren. - Die zweite Zelle, welche aus der Flachenzelle entsteht (Fig. 9, 11. 12, d) theilt sich durch eine schief von rorn und innen nach aussen gerichtete Wand in zwei lange parallele Zellen, wovon die vordere kürzer ist als die hintere (Fig. 11, g und h). Beide theilen sich wiedlerholt durch Wände, welche den langen Durchmesser unter einem rechten Winkel schneiden; die innersten Winde entstehen zuerst, nach ihnen in regelmässiger Folge je die äusseren (Fig. 9, g, i; 10, g, h; 11, i, k, l, m; 14). Die Zellenbildung des Laubes ist damit beendigt.

Das Wachsthum in die Dicke umfasst demnach folgende geselznässige Zellenbildungen : Die Flächenzslle (Fig. 9, b) theilt sich durch eine nit der Achsenfäche des Laubes parallele Wand in eine obcre Seitenzelle (Fig. 11, d) und eine untere Zelle (c), die letztere durch eine gleiche, aber nach vorn mehr oder weniger convergirende Wand in eine innere odel Achsenzelle (Fig. 11, e) und eine untere Seitenzelle (f). Die obere Seitenz.elle (Fig. 11, d) theilt sich durch eine sehiefe Wand in eine vordere (g) und cine hintere 7elle (h); in jeder terselben entstelıen Querwände, die mit der Achsenfläche parallel laufen, ron innen naclı aussen. - Durchschneidet anan das ferlige Laub so, dass der Schnitt in der Riclıtung des Radius gefüh't ist (Fig. 14), so sieht man an der untern Fläche die untern Seitenzellen (am Durchschnill eine Reihe f-f, am ganzen Laub) eine Schiclıt bildend), über denselben die Zellen der Aclısenfläclıe (am Durchschnitl ebenfalls eine Reihe e-e, an ganzen Laube eine Schicht bildend), endlich auf jeder Achsenzelle zwei sehief-senkrechte Reilıen ron 6 bis 10 Zelleı. Einige Mal schien es mir, als ob auf einer Achsenzelle auch drei Reilıen stehen könnten; doch kann das auch

Denkscbr, N.EGELI. 


\section{- 250}

bloss ein durch die Mangelhaftigkeit des Durchschniltes (wenn derselbe nicht vollkommen radial gefiilırt wurde) erzeugter Schein sein. Stehen aber wirklich drei Zellreihen auf einer $\Lambda$ chsenzelle, so hat sich in der oberen Seitenzelle die Theilung durch eine ron vorn und innen nach aussen gerichtete Wand noch einmal wiederholt, und zwar ist es ohne Zweifel die vordere Zelle (Fig. 11, g), weiche sich noch einmal getheilt hat. Wïhrt man dagegen den Querschnilt durch das Laub in der Richtung der Secante, so liegen die Zellen in senkrechten Reihen (Fig. 15 und 16). Die unterste Zelle (f) ist eine unlere Seitenzelle, die zweitunterste (e) eine Achsenzelle, alle folgenden Zellen sind solche, welche aus len oberen Seitenzellen entslanden. Da die natürlichen Reihen dieser letztern Zellen im Laube schief verlanfen, wie man es in Fig. 14 an dem radialen Querschnilt sieht; so müssen, wenn der Schnilt der Richiung der Secante (n-f in Fig. 111) folgt, künslliche Reilıen sichtbar werden, in welchen bei etwas dickeren Schnitten die Zellen, besonders die innern und längern, sich theilweise decken (Fig. 13), bei dünnern Schnitten dagegen sich zwar nich lecken aber kürzer und zahıpeicher auftreten (Fig. 16). Aus dem Umstande, thass bei solchen Schnitien die Zellen in einfachen senkrechten lecihen liegen und die Epiderniszelien somit eben so breit sint als die Achsenzellen, ergiebt sich klar, dass wïhrend des ganzen Zellenbildungsprocesses, welcher in den Flächenzellen heginnt, und las Wachsthum in die Bicke ausdrückt, nie radiale (ron der Basis nach dem vorteren fanic gerichtele, und die Laubfäche unter (rinem rechten Winkel schncidende) Wände atiftreten, - dass demnach das ganze Wachsthum in dic Dicke durch Zellenbildung auf radialen Querschnilten gesehen werden kann, und in dem vorhin ausgesprochenen Geselze vollständig enthalten ist. - Der Querschnilt, welcher in der Riching der Secante durch einen der beiden Seitenrænder gefïhrt wird (Fig. 17, 18), zeigt zuxusse:st eine oder mehrere ungetheilte Flæchenzellen (b), dann ein oder zwei Glieder, wo sich die Flæchenzelle in zwei Zelien (c und d), dann ein oder mehrere frlieller, wo sie sich in drei" zellen (eine mitlere oder Achsenzelle e, eine untere Seitenzelle f und eine obere Seitenzelle d) getheilt hat; in den folgenden Gliedern nimmt die Zah! der Zellen durch Theilung der obern Seitenzellen allmxlig 7.u. Man sieht hier, da die Zellenbildung lange aufgehürt hat, an stehenbleibenden EntwickeInngsstufen den gleichen allmxligen Fortschritt des Wachsthums in die Dicke, wie ihn die radialen Durchschnille durch den wachsenden vorderen Rand von einer anderen Seite (Fig. 9, 11) zeigen.

Das Wachsthum von Peyssonelia hat in den übrigen Ordnungen der Forideen nichts Analoges; ebenso ist mir keine Algengattung bekanut, welche volikommen damil überein stimmt. - Das Wachsllum in die Laenge, nxmlich durch eine Reihe gleichwerthiger Randzelien, ist das gleiche wie bei Hyrionema, Coleochcele und Padina. - Das Wachsthum in die Breile beruht in Allgemeinen auf dem namlichen Princip wie bei diesen dyre rattungen; es geschieht durch Vermehrung der Randzellen. Aber die Art dieser Vermehrung ist verschieden. - Das Wachsthum in die Dicke stimmt mit demjenigen yon Padina darin überein, dass'aus einer Flächen-

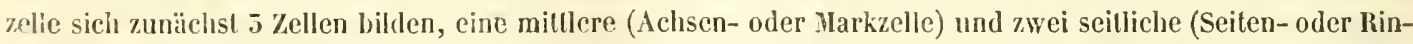
Jenzellen), idie unter einander selbst ungleich sind. Die weitere Zellenbildung aber verhält sich bei beiden ratimngen ganz verschieden, indem sie bei Peyssonelia ganz dem eigenthchen Fiorideentypus folgt, und grosse Achnlichkeit theils mit dem Wachsthum in die Breite theils mit demjenigen in die Dicke an andern Florideengatiungen mil flachem Laube zeigt.

Die untem Seitenzellen, welche an der untern Fläche des Laubes zusammen eine, die Achsenzellen bodeckende Schicht darstellen (Fig. 14, 1.), 16, f), können einzeln auswachsen , und durch Zellenbildung sich in eine Zellenreihe verwandeln (Fig. 11, 1/, 16, r), Diese gegliederten, gewöhnlich einfachen, seltener etwas verästelten Haare sind Wurzeln woslurch das Laub auf der Unterlage befesligt ist. Besonders viele solcher Wurzelhare bilden sich in der Milte des Laubes, wo sie oft eine scheinbare Mittelrippe erzeugen. Zuweilen überzichen sie die ganze untere Fläche als ein dichter Filz. An der Basis sind die Wurzelhaare in so grosser Menge rorhanden, dass sie oft einen besondern, 1 bis $1 \frac{1}{2}$, Linien dicken, verfilaten Fuss bilden, welcher über das eigentliche spitz enủigende Laul, hinausragt (Fig. 19); es kann selbst seitliclı von der Basis ein zweiter ähnliwer aus Wurzelfilz bestehender kleinerer Fuss auftrelen (Fig. 20).

Dic regrlmässige Gesial des Laubes ist die fïcherförmige, wo der vordere Rand in allen seinen Puncten eine 


\section{- 251}

gleiche Entfernung von der Basis zeigt. Es setzt diess voraus, dass die Zellenbildung in allen Randzellen gleichmässig fortschreite. Die Gestalt wird schief und ungleichförmig, wenn die Zellenbildung zwar in allen Randzellen, aber in den einen rascher von statten geht als in den andern. läufig geschieht es, dass einzelne Randzellen auftüren, sich zu theilen, und absterben, während die neben ilınen liegenden sich fortwährend theilen. Dann wird der Rand, weil er stellenweise zurïckbleibt, stellenweise fortwächst, zuerst luchtig und nachher gelappt (Fig. 21). Die Lappen sitzen mit einer sclımälern oder Jreitern Basis fest, sie werden selbst wieder fächerförmig und später gelappt. In Fig. 22 sieht man ein Stück von dem vorderen Rande, wo die einen Randzellen (b) abstarben, und durch die neben ilınen liegenden, lebenskräftigen und sich ausdelınenden Zellen (a) zusammengedrückt wurden, und deren Inhalt sich in eine Iräunlich-gelbe coagulirte Masse verwandelte.

Der Inhalt der Randzellen ist homogener, farbloser Schleim; gewölınlich jedoch zeigt sich derselbe im unter'u (hintern) Theil der Zelle feingekörnt (Fig. 22, a). In längern Randzcllen unterscheidet man zuweilen sogar an der Spitze einen homogenen, farblosen, schleimigen, - in der Mitle einen feinkörnigen, farblosen, schleimigen, und an der Basis einen körnigen, röthlich-gefärbten, zuweilen feingeschaumten Inhalt; - so dass also der Inhalt die gleichen Erscheinungen zeigt', wie an Zellen, 'die sich durch Spitzenwachsthum verlängern (Bryopsis, Caulerpa, Conferva, Dasycladus ete.), was ohne Zweifel auch hier beweist, lass die Randzellen besonderes Spitzenwachsthum besitzen. Die gleiche Versehiedenheit des Inhaltes findet man an den Scheitelzellen der wachsenden Haare. - In den ausgebildeten Zellen des Laubes liegt der feste Inhalt an der Wandung und zeigt eine schön rothe Farbe. Später wird er braunroth. Im Alter ballt sich der feste Inhalt häufig in eine kngelige Masse qusarimen, welche im Centrum der Zelle liegt und beim Durchschneiden des Gewebes leicht herausfaillt (Fig. 25). - Ursprünglich enthalten alle Zellen Kerne, welehe bald als belle grössere Bläschen mit einem Kernehen (Fig. 15, 22), bald als dichtere kleinere kugelige Massen, an denen man kein Kernchen unterseheidet, erscheinen (Fig. 12, 15, 22). Analog mit anderen Thatsachen scheint mir der erste Zustand der normale und unverảnderte, der zweite Zusland dagegen ein durch äussere Einflüsse veränderter zu sein. In den ältern Zellen wird der Kern zuweilen deutlich als parictaler wahrgenommen. - poren fand ich mit Sicherheit bloss in den Wurzelhaaren, und zwar je einen zwischen zwei Zellen. Wenn sich in Folge störender äusserer Einflüsse die Schleimschicht mit dem übrigen festen Inhalte von der Wandung zurückzieht, so bleibt sie durch einen dünnen Schleimstrang mit dem Porus in Verbindung (Fig. 24).

Die Fructification bildet warzenförmige Erhabenheiten auf der obern Fläche des Laubes, welche aus einfachen gegliederten Haaren und dazwischen liegenden gestielien Sporenmutterzellen bestehen (Fig. 25). Die Epidermiszellen wachsen aus, und erzeugen cine Astzelle, aus welcher entweder cine cinfache Zellenreihe aus 6 bis $\mathbf{9}$ Zellen oder eine solche aus zwei Zellen hervorgeht. Die erstere ist ein steriles, den Nebenfiden oder paraphysen der Padineen, Fuceen und Lichenaceen zu vergleichendes Ilaar; die zweite ist ein fruchtbares oder Sporenhaar. Die Sporenmutterzelle ist, wie bei einigen Ceramiaceen, eine Scheitelzelle des zweiten Grades. Vie Sporenbildung ist kugelquadrantisch, wobei die Sporen gewöhnlich tetraëdrisch, selten in einer Fläche liegen. - Antheridien und Keimzellen sind unbekannt. 


\section{$-252$}

\section{UEBERSICHT DER ORDNUNGEN UND FAMILIEN DER ALGEN UND FLORIDEEN.}

\section{A. ALGAE.}

Zelleninhalt theilweise aus Stärkekörnern und Farbbläschen bestehend; keine Urzeugung; Fortpflanzung geschlechıslos durch Keimzellen (Pag. 116).

I. Prlmellaceac. Zelle ohne Spitzenwachsthum, ohne Astbildung und ohne vegetative Zellenbildung; Fortpflanzung durch wands(ændige Zellenbildung (Theilung) in 2 oder 4 Zellen. (Pag. 123).

I. Nostochaceac. Durch vegetative Zellenbildung entsteht eine Zellenreihe; einzelne Zellen derselben werden unmittelbar zu Keimzellen. (Pag. 152).

III. Bangiacene. Durch regelative Zellenbildung entstelıt eine Zellenreihe oder eine Zellschicht; einzelne Zellen derselben erzeugen durch wandständige Zellenbildung (Theilung) melrere Keimzellen. (Pag. 136).

1. Lyigryeae. Zellenreihe. (Pag. 136).

2. Ulveae. Zellschicht. (Pag. 159).

IV. Mesogloeaceae. Durch vegetative Zellenbildung entsteht eine Zellenreihe, Zellschicht oder Zellkörper, welche kurze Seitenæestchen bilden, deren (sitzende oder gestielte) Scheitelzelle durch wandständige Zellenbildung (Theilung) melırere Keimzellen erzeugl. (Pag. 141.)

1. Ectocarpeas. Zellenreihe (veræstelt); die Keimmulterzellen sind Astzellen oder die Scheiteizellen kurzer Aeste, welche seillich aus den Gliederzellen entstehen. (Pag. 145).

2. MrronemeaE. Zellschicht; Keimmulterzellen an der Flæche derselben, sitzend oder gestielt. (Pag. 145).

3. Stılophoneat. Zellkörper (einfach oder veræstelt); Keimmutterzellen an der Oberflæche desselben, silzend oder gestielt, auf einfachen oder veræstelten, aus Zellenreihen bestebenden Stielen. (Pag. 146.)

1. Zyg gamaceae. Durch vegetative Zellenbildung entsteht eine Zellenreihe; in einzelnen oder in je zwei mit einander copulirten Zellen des gleichen Individuums oder verschiedener Individuen bildet der ganze sich zusammenballende Inhalt eine Keimzelle. (Pag. 149).

V. Protococeracene. Zelle olne Spitzenwaclssthum, ohne Astbildung und ohne vegetalive Zellenbitdung; sie pflanzt sich curch freie Zellenbildung in mehrere einzellige Individuen fort. (Pag. 155).

VI. Valomlaceac. Zelle mit Astbildung und Spitzenwachsthum in den Aesten, ohne regetative Zellenbildung; sie erzeugt durch freie Zellenbildung melırere Keimzellen. (Pag. 19\%.)

III. Confer vaceae. Durch vegelative Zellenbildung entsteht eine mehrzellige Pflanze (neist eine Zellenreihe oder Zellschicht), deren Zellen durch freie Zellenbildung mehrere Keinzellen erzeugen. (Pag. 158.)

1. Comferveae. Zellenreihe; die Keimzellen entstehen in den Gliederzellen. (Pag. 158.)

2. Acetabllarieat. Einzelliges Laub oder Stamm, mit vielzelligen Haaren oder Blallern. (Pag. 158.) 


\section{$-235$}

5. Coleochatete. Zellschicht (durch Vereinigung von veræstelten Zeltenreihen entstanden); die heimzellen entstehen in einzelnen Iandzellen (d. h. Scheilelzellen jener Zellenreihen). (Pag. 166.)

I. L. Lehenaceac. Durch vegetative Zellenbildung entsteht ein Zellkörper; an der Oberflæche einzeluer Partien desselben sitzen die Ilulterzellen, welche durch freie Zellenbildung mehrere Keimzellen (in bestimmler Zahl) erzeugen. (Pag. 168.)

X. Exccecaceac. Zelle ohue Spitzenwachsthum, ohne vegelative $A$ stbildung und ohne regetative $\mathcal{L}=\mathrm{l}-$ lenbildung; die neuen Individuen entstehen durch wandstændige Zellenbildung je eines in einem kurzen $\Lambda$ sle. (Pag. 169.)

i. Fameheriaceac. Zelle mit vegetativer Astbildung und Spitzenwachsthum in den Aesten; die Keimzellen entstehen durch wandstandige Zellenbildung je eine aus einem kurzen Aste, oder aus dem Endıheile eines langern Asles. (Pag. 170.)

1. Brvopsideat. Die Veriestelungen der Zelle sind frei. (Pag. 171.)

2. Codıea. Die Veræestelungen der Zelle legen sich in ein Gewebe zusammen, und bilden scheinbar einen Zelikörper. (Pag. 177.)

\1. Zomarasaceac. Durch vegetative Zellenbildung entsteht eine Zellenreihe (Zellschicht), oder ein Zellkörper; die keimzellen entstehen durch wandstiendige Zellenbildung, je eine aus dem auswachsenden Thei!e der Gliederzellen oder der Rindenzellen. (Pag. 179.)

1. Chastravieat. Die Achsen sind Zellenreihen. (Pag. 179.)

2. P.dorsede. Flacher Zellkörper, welcher durch viele Zellen am Rande (nicht durch Eine Scheitelzelle) in die Længe wachst. (Pag. 180.)

э. FucedE. Zellkörper, dessen Achsen durch Eine Scheilełzelle in die Læenge wachsen. (Pag. 18j.)

\section{B. FIORIDEAE.}

Zelleninhatt theilweise aus Stxrkekörnern und Farbbleschen bestehend; keine Urzeugung; Fortpflanzung geschlechlich; mamnliche Geschlechlsorgane nit Samenblaschen (Samenzellehen), welche nichl in einen zelligen Sack eingeschlossen sind; weibliche Geschlechtsorgane ohne besondere Hülle (calyptra), mit Sporenmutterzellen, in denen 4 Specialmutterzellen, in jeder derselben eine Spore entstehen; Vermehrung (geschlechtsIns) durch Keimzellen. (Pag. 187.)

1. Geramatateac. Mehrzellig; jede Achse besteht aus einer Zellenreihe, seltener aus einer Zelle; Sporenmutterzellen seitlich, sitzend oder gestielt. (Pag. 196).

II. Delesseriaceac. Die Hauptachsen sind Zellschichten oder Zellkörper, deren Scheitelzelle sich dureh horizontale Wrende theill; Sporenmutterzellen im Gewebe. (Pag. 208.)

1. Nitopinzleat. Zellschicht; die Sporenmutterzellen liegen in der Achsenflæche. (Pag. 209.)

2. Delesseriete. Zollschicht mit mehrschichtigen Nervalionen, oder flather Zellkörper (mit einer Reihe von Achsenzellen, deren jede zunæehst ron nicht mehr als 4 Zellen umgeben ist); Wachsthum in die Breite und Dicke geschieden, ersteres in der Richtung der Achsenflieche eine Zellschicht el'zeıgend, letzteres senkrecht zu dersellon die einfache Schicht in mehrere theilend; die Sporenmulterzellen liegen nach aussen von den Zellen der Achsenflache. (Pag. 212.) 


\section{- 254}

5. Rnopoyeleat, Cylindrischer, selten zusammengedrückter Zellkörper (mit einer Reihe von Achsenzellen, vor denen jede zunæchst meist von Wachsthum in die Breite und Dicke nicht geschieden, von der Achsenlinie nach allen Seiten gehend. (Pag. 218.)

III. Bhodomeniaceae, Die Hauptachsen sind Zellschichten oder Zellkörper, deren Scheitelzelle, wenigstens der reproductiven Achsen, sich durch schiefe Wænde theilt; Sporenmutterzellen im Gewebe. (Pag. 226.)

1. Procamieae. Flacher Zellkörper mil ungleichen Achsen, die vegetativen durch horizontale, die reproductiven durch schiefe Wande in der Scheitelzelle in die Lange wachsend. (Pag. 227.)

2. Choxneae. Zellschicht mit mehrschichtigen Nervationen oder flacher Zellkörper, mit gleichem Længenwachsthum in allen Achsen; Wachsthum in die Breite und Dicke geschieden, ersteres in der Richtung der Achsenfleche eine Zellschicht erzeugend, letzteres senkrecht zu derselben die einfache Schicht in mehrere theilend. (Pag. 255.)

5. GRacılarieaE. Cylindrischer oder etwas zusammengedrückter Zcllkörper, mit gleichem Laengenwachsthum in allen Achsen; Wachsthum in die Breite und Dicke nicht geschieden. von der $\Lambda$ chsenlinie nach allen Seiten gehend. (Pag. 2h0.)

IV. Lomentariaceae. Die Hauptachsen, wenigstens die reproductiven, sind hohle Zellkörper; Sporenmutterzellen in Gewele der Wandung. (244.)

V. Phyllophoraceae. Die Hauptachsen sind Zellkörper; Sporenmutterzellen ausserhalb, silzend oder grstielt oder in Reihen. (Pag. 2/8.) 


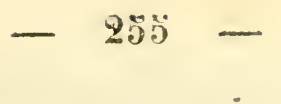

\section{ERHL ERUNG DER ABBILDUNGEN.}

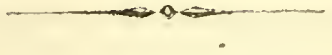

Talb. 策.

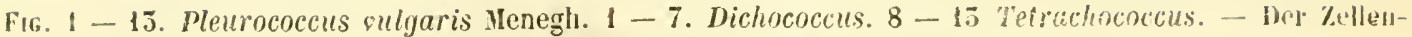
durchnesser varirt von $0,002-0,004 \prime \prime \prime$.

1. Ein freies Individuum; D. II. $=0,00 \%$ '"'.

2. Ein freies Individuum, das sich eben in 2 Tochterindividuen getheilt hat.

5. Fanilie von 4 Individuen; I und II verschiedene Ansicht, durch eine Aclısendrelıung um einen Winkel von $90^{\circ}$ erzeugt.

4. Familie von 8 Individuen; I und II Aclsendrehung nm $90^{\circ}$.

ว. Familie von 16 Individuen; I und II Achsendrehung un $90^{\circ}$; die einzelnen Individuen haben $11,00 \bar{s}^{\prime \prime \prime}$ im D. II.

6. Familie von 4 Individuen; I und II Achsendrehung um $90^{\circ}$; die Zellenbildung der letzten Geueration hat in verschiedener Richtung stattgefunden, so dass je die beiden Schwesterzellen a, a und b, b eine" ungleiche Lage haben.

7. Familie von 16 Individuen, ron denen man bloss die 8 zugekehrten sieht; die lefate Zellenbildnng in a a und b fand in verschiedener Richtung statt.

8. Ein freies Individuum; D. H. $=0,004^{\prime \prime \prime}$.

9. Ein solehes, das eben 4 Tochterindividuen erzeugt hal.

10, 11. Familie von 4 Individuen, in verschiedener Lage.

12. Jedes der 4 Individuen hat sich in 4 neue getheilt.

15. Familie von 16 Individuen; D. II. eines einzelnen $=0,0023^{\prime \prime \prime}$.

FIg. 14 - 29. Palmella. I Ditoce. Fig. 23 - 29. Palmella, Il Tetratoce.

14 Ein freies Individuum (D. H. $\left.=0,002^{\prime \prime \prime}\right)$, mit einer Schicht von gallertartiger Extracellularsubstanz (D. M. $\left.=0,005^{\prime \prime \prime}\right)$.

15. Ein solches, mit ciner doppelten Schicht von Gallerte (D. N. $==_{3} 0,007^{\prime \prime \prime}$ ).

16. Ein solches, nit כ deutlichen Gallertschichten (a, D. M. $=0,010^{\prime \prime \prime}$ ).

17. Ein freies Individuun, das sich eben in 2 neue getheilt hat, mit deutlich geschichtetes (iallerte ungreben (a, D. M. $\left.=0,011^{\prime \prime \prime}\right)$.

18. Familie von 2 jungen Individuen, welche selbst noch keine Gallerte ausgeschieden haben, ${ }_{2}^{\text {von }}$ der ungeschichteten Extracellularsubstanz des Vutterindividuum's umgeben.

19, 20. Familie von 2 Individuen; b Gallerte der Tochterindividuen; a Gallerte des Mutterindividuums.

刃1. Fanilie von 4 jungen Individuen, die noch keine Gallerte ausscheiden; b,b Gallerte, welehe ron den beiden Iutterindividuen, a Ciallerte, welche von dem gemeinsamen Grossmulterindividuum ausgeschieden wurde. 
22. Familie ron 4 Individuen; $\mathbf{c}, \mathbf{c}$ die von ihnen secernirte Gallerte; b, b die von den beiden IJutterzelien. a die von der Grossmutlerzelle abgesonderte Gallerte.

25. Ein freies Individuum mil einem Kern, ohne Extracellularsubstanz; D. M. $=0,003^{\prime \prime \prime}$.

2/. Ein solches mil Extracellularsulstanz; D. M. der letzleren $=0,012^{\prime \prime \prime}$.

9.:. Ein freies Individumm, das sich eben fortpflanzen will, urd zu diesem Behufe 4 Kerne erzeugl lıat. D. M. der Zelle $=0,007^{\prime \prime \prime} ;$ D. M. der Exlracellularsubstanz $=0,017^{\prime \prime \prime}$.

26. Ein freies Individuum, das sich eben in 4 neue getheilt hat.

$\exists 7$. Familie von 4 jungen Individuen, welche noch keine Gallerle ausgeschieden haben; a Gallerte des Yutterindividuums.

2s. Familie von 4 Individuen; b, b, die von denselben abgesonderte Gallerte; a Gallerte der Multerzelle.

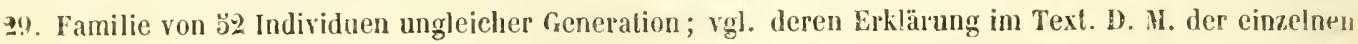
Zellen $=0,005-0,005^{\prime \prime \prime}$.

Fig. $50-56$. Nostoc commune Vauch.

31). Eine Keimzelle.

31. Dieselbe hat sich verlängert, und in 2 Tochterzellen getheilt.

52. Jede der beiden Tochterzellen hat sich noch einmai getheilt.

5.5. line Zellenreihe; a Zellen, die sich eben getheilt haben; b, b junge Zellen, die sich ausdehnen und abrunden; c, c etwas ältere Zellen; d, d noch ältere Zellen, die sich bald wieder theilen wollen; g Keintzelle. Quer-D. I. der Zellen $=0,002^{\prime \prime \prime}$; Quer-D. M. der Keimzelle $=0,00 \mathbf{3}^{\prime \prime \prime}$.

34. a Slïck von einer Zellenreihe; gg Keimzelie, diè sich in 2 Tochterzellen getheilt hat.

3i. a a Stück von einer Zellen reihe; g Keimzelle mit verdichler Wandung; jederseits ist ein zapfenartiger Vorsprung sichthar.

76. a Slïck von einer Zellenreihe; g Keiuzolle, mit 2 Kernen für die beiden zu bildenden Tochterzelten.

$$
\text { F1G. } 57 \text { - 146. Bryopsis. }
$$

37. Oherer Theil einer Pflanze; ab Stamm; er ist ron a bis c mil Blättern (t), ron c bis b mit den Narben von alıģefallenen Blättern beselzt. rr, rr $2 \Lambda$ este; der eine ist ganz mil Blättern, der andere bloss ron a bis r mit Blättern und von d bis e mil Yarben bedeckt.

38. Spitze einer stammachse; von a bis b mil farblosem Schleim, unterhalb mil chlorophyll und Schleim erfüllt. $f^{t}, f, f, f$, junge Blätter'.

79. Spitze eines ausgewachsenen Blattes; in a ist die Wandung am dicksten. An der innern Flache der Wandung liegt die Schleimschicht (m), daran die Chlorophyllblæschen (p).

'1). Schıleimschicht von der Flæche angesehen; mit Chlorophyllblæschen. a Netz von Schleimfæden (Strömungsfieden); b die Schleimschicht ist staeker, das Schleinnetz mangelt oder ist nicht sichtbar.

11. Chlorophyllblaschen; a - e von der Flache, mil 1, seltener 2 oder 3 Amylumkernchen; $f$ - h von der scile, $f$ in der unverletaten Zelle, $g$, h frei im Wasser, und durch die Einwirkung des letzlern concar geworden. Laenge $=0,005-0,015^{\prime \prime r}$; Breite $0,005-0,004$ '1'.

12. Junge Chloroplıllibeschen, welche sich theilen: a mit i Amylumkernchen, b, c mil a Anylumkernchen, d mil einer leichten Einschnürung in der Milte, e mit eincr Scheidewand.

15. Stiick von der Wandung im Durelischnitt; $m \mathrm{~m}$ Schleimsehicht, welche sich nach oben, in Folge der' Endosmose von süssem Wasser, von der Wandung abgeiöst hat. a Zellmemiran, b gallertarligge ExIraccllulatsubstanz; c ausserste reranderic Schicht dieser Gallerte. p Chlorophyllblasehen. Der Zwi-

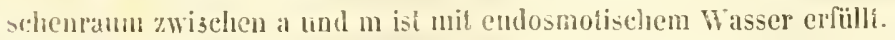

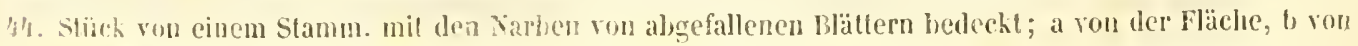
Jer scite. 


\section{- 237}

45. Durchschnitt durch die Seitenwandung eines Stammes, wo er eine Blallnarbe trägt. a b-ab Wandung des Stammes; a-a Zellmembran; b-b Extracellularsubstanz; c Ueberrest des abgefallenen Blattes; d Scheidewand, welche das Lumen des Stammes abschliesst.

16. Zwei krankhaft veründerte Chlorophỵllbläschen; sie sind kugelig geworden; das Amylumkernchen und das Chlorophyll haben sich aufgelöst, und sind in eine ungefä:bte, etwas dunkle körnige Masse übergegangen.

\section{FIG. 47 - 5九. Ulothrix zonata Kütz.}

47. Keimzellen, nachdem sie einige Zeit frei im Wasser gelegen haben; a mit einem kleinern, b mit einem grỏssern inhaltsleeren Raum; jede mit einem rothen Punct an der Wandung.

48. Eine Keimzelle mit einer schmalen Schicht grünen Inhaltes, welche nur einen kleinen Theil der innern Oberfläche überzieht, und mit zwei dicht neben einander liegenden rothen Puncten an der Wandung. I und II verschiedene Ansichten, durch eine Drehung um einen Winkel von $45^{\circ}$ herrorgebracht.

49. Keimzelle, welche nach unten in die Wurzel auswächst.

วั0. Junge Pflanze, welche aus 2 Zellen besteht.

ăt. Junge Pflanze, welche aus 5 Zellen besteht.

52. Der untere Theil einer ältern Pflanze; a Wurzel.

ว5. Stück eines Fadens, in welchem die Fructification begonnen hat. a noch unveränderte Zellen. b Zellen, welche ellipsoidisch werden. $\mathrm{c}$ die Zelle hat sich in zwei neben einander liegende Zellen getheilt. $\mathrm{d}, \mathrm{e}$ die Theilung ist weiter fortgeschritten ; jedes der Glieder e bestelıt aus 8 Zellen.

3̆. Stïck eines Fadens, in welchem die Fructification fast vollendet ist. a Gliederzellen, welche noch die Keimzellen, in der Zahl von 8 bis 20 enthalten. b Gliederzellen, welehe die Keimzellen entleert haben.

\section{FIG. 5马 - 58. Enteromorpha compressa Grev.;}

55. Ende eines haarförmigen Aestchens. a Scheitelzelle. b Gliederzellen. d, e, f beginnende Theilung der Glieder.

36. Horizontaler Durchschnitt durch das Ende eines Aestchens in der Höle von e und $f$ in Fiğ. 5 כ̆.

37. Horizontaler Durchschnitt etwas tiefer; die Zellen trennen sich im Centrum von einander.

58. Horizontaler Durchschnitt noch tiefer geführt. Jede der 4 Zellen von Fig. 57 hat sich noch einmal getheilt; das Aestchen ist röhrig geworden.

$$
\text { Fig. } 59 \text { - 62. Porphyra oulgaris Ag. }
$$

๖9. Durchschnitt durch die noch unveränderte Frons.

60. Durchschnitt durch die Frons in dem Momente, ehe die Theilung zum Behuf der Fruchtbildung beginnt. Die Zellen sind durch Ausscheidung von Gallerte ellipsoidisch geworden; einige sind herausgefallen (a).

61. Durchschnitt durch den Theil einer Frons, wo die Fructification begonnen hat. a ungetheilte Glieder. b, c, d, e Glieder, welche sich bereits mehr oder weniger getheilt haben, und welche bei dieser Ansicht 2, 3, 4 und 10 Zellen zeigen.

62. Wie Fig. 61. a ein ungetheiltes Glied. b ein solches wo die Theilung begonnen hat. c ein solches, wo die Theilung sich mehrfach wiederholt hat, und das bei dieser Flächenansicht aus 18, in seinem körperlichen Inhalte somit etwa aus 90 Zellen besteht. 


\section{$-258$}

Tab. 目.

Fıc. 1 - 6. Ectocarpus Lyngb.

1. E. siliculosus Lyngh. Zwei Zellen eines Astes. Die Schleimschicht, an welcher Chlorophyllbläschen liegen, hat sich an den Kanten von der Wandung losgelöst. Von dem centralen Kern gehen radienförmige Schleimfieden aus.

‥ 5. E. minimus Nïg.

2. Junge Pflanze; a Keimzelle, D. I. $=0,00$ : $^{\prime \prime \prime \prime}$.

5. Aellere Pflanze. a entleerte Keimmutterzellen, D. MI. $=0,008-0,010^{\prime \prime \prime}$, Længe $=0,015-0,0 \mathrm{f5}^{\prime \prime \prime}$. b, e Mutterzellen, welche die Keimzellen noch einsehlie ssen.

4. E. tomentosus Lyngb. a entleerte Keimmutterzellen. b, c Ifutterzellen, in denen die Theilung vor sich gelit.

‥ 6. E. littoralis Lyngh.

รั. Einzelne Gliederzellen schwellen zu Mutterzellen an, füllen sich mit Inhait, und theilen sich.

6. 'Einzelne Glieder' (a, b, c) besonders dargestell, um die fortschreitende Theilung zu zeigen.

Fig. 7 - 24. Valonia utricularis $\mathrm{Ag}$. $(7-14$ wenig vergrössert $)$.

7. Einzelnes Individuun. g Keimzellenbrut.

8. Einzelnes Individuum. g Keimzelle; $r$ Wurzeln.

9. Einzelnes Individuum. 1, 1 Aeste oder Lappen; g Keimzellenbrut.

10. Einzelnes Individuum. I Ast oder Lappen; g Keimzellenbrut. m junges Tochterindividuum.

11. Familie von $\mathbf{3}$ Individuen. a Mutterpflanze. g Keimzellenbrut. r Wurzeln. m Tochterpflanzen.

12. Familic von 6 Intividuen. a Mutterzelíe; m Tochterzellen.

15. Familic von 5 individuen. a Mutterzelle; m Tochterzellen.

14. Familie von 9 Individuen. a Mutlerpflanze; $m, m$ erste Generalion von Tochterpflanzen; $n$, $n$ zweite Generation. g Keimzellen.

15. Keimzellen von der Fläche, rund und parenchymatisch.

16. Keimzellen von der Seite (g), an der inneren Fläche der Wandung liegend.

17. Keimzelle, welche anfängt sich zu entwickeln, und bereits die Wandung der Mutterzeile durchbrochen hat; a, a innere, b, b äussere Flache der Zellwandung.

18. Durchschnill durch die Wandungen, da wo eine Tochterzelle der lifutterzelle aufsitzt. ab c-ab c Wand der IIulterzelle; a reussere, b innere Schicht der Extracellularsubstanz, c Zellmembran, c neugebildetes Stück der Zellmembran; d-d Wand der Tochterzelle.

19. Strömungsnetz von zarten Schleimfieden aus einer Keimzelle; darin liegen winzige Schleimkörnchen. kleine Chlorophyllbläschen und grössere Amylumkïgelchen.

20. Netzförmig an der Wand gelagerte Clılorophyllblaschen, aus der untern IIselfte einer Zelle.

21. Entstehung der Amylumkïgclchen, aus einer Keimzelle. a, a ChlorophyllbJeschen, in denen kein Kernchen sichtbar ist; b, b mit einem Amylumkernchen; c, $c$ mit einem grössern Amylumkernchen; d, l das Amylumkügelehen füllt das Bläschen fast oder ganz aus, das Chlorophyll ist verschwunden; e, e Ireie Anylumk ügelcheı, das Blaschen ist resorlyirt worden.

29. Clıloroplyyllblaschen aus der obejn IIxlfte einer Zelle, mil klcinen Amylumkernchen; cinige langge.streckle Jlæsehen besilzen kein deulliches Kernchen. 
25. 7wei Chlorophyllblxschen (a und b), mit I Stærkekernchen. I von der Flache; II von der Seite.

느. Entstehung der Keimzellen, a, a, a scheinen lomogene, farblose Schleintröpfelien zu sein (D. N. = $\left.0,001 \mathrm{~g}-0,005^{\prime \prime \prime}\right) ; \mathrm{b}, \mathrm{b}, \mathrm{b}$ sie sind etwas körnig gewor(len; c, c Zellen mit körnigem, grünlichen Inhalt; d, d deutliche Zellen, mil Chlorophyltblieschen nnd Sehleim.

\section{Fig. 23 - 50. Udotea cyalliformis Decaisne.}

2.. Senkrechter Querdurchschnill. m m eine Markrölıre; c, c Rinde.

⒍ a a und ec 2 Markrölırenachsen, die aus der Achse I durelı Dichotomie in m entstanden sind. b, b Rindenæstchen; d, d gelappte Zweige der Rindenæstchen.

27. $\mathrm{a}, \mathrm{b}, \mathrm{b}, \mathrm{c}, \mathrm{c}, \mathrm{c}, \mathrm{c}$ Markröhrenachsen; $\mathrm{m}, \mathrm{n}, \mathrm{n}$ die Stellen, wo sie sich dichotomisch getheilt haben. d cin junges, e, f, g etwas allere Rindenaestchen.

23. Rinde von aussen.

29. Ein regelmassig gebauter Zweig eines Rindenæstchens von aussen.

30. Eine Frons in natïrlicher Grösse. a eine junge Frons, welche durch Prolification aus der Flache, h, b, b eben solche, welche durch Prolification aus den Rande entstanden sind.

\section{Fig. 51 - 54. Myrionema. 51, 55, 5\%. M. strangmans Grev. 52. M. Rhodomeniae Näg.}

วł. Durchschnill durch Enteromorpha und durch das auf dersclben parasilische Myrionema; der Schnitt hat das letzlere tangental getroffen. a-a Enteromorpha. b-b Myrionema, D. 11. der Zellen $=0,0023^{\prime \prime \prime}$.

32. Ein Stiick les Randes, von der Flæclıe angeselıen.

55. Radialer Querdurchschnitt. a-a Enteromorpha. b-1) Frons von Iyrionema, Lange der Zellen $=$ $0,006^{\prime \prime}$; Breite $=0,005^{\prime \prime \prime}$. c langes fadenförmiges Ilaar, dessen oberste Zellen abgefallen sind. d, ll kurze keulenförnige Haare, Længe $=0,015-0,020^{\prime \prime \prime}$. e, f Keimmutterzellen, Længe $=0,012^{\prime \prime}$, D. M. $=0,009^{\prime \prime \prime}$,

74. Die Fruchtschicht yon der Flaeche angesehen; neben den kleinern keulenförmigen IIaaren (D. M.:= $0,00 \iota^{\prime \prime \prime}$ ) sieht man mehrere ungetheilte und in Theilung begriffene Keimmutterzellen (D. M. $=0,008$ $\left.-0,010^{\prime \prime \prime}\right)$.

\section{Tab. HBL.}

\section{Fig. I - 12. Acelabularia medilerranea Lamour.}

1. Die eine Ilalfte des durch cinen senkrechten Schnitt in der Mitte durchschnittenen Schirmes mil dem obersten Theile des Stieles, ron der Schnittfaeche angesehen. a Stiel. b-b Durchschnill des Schirmes (b, b zwei geöfnete Strahlen). s Strahlen des Schirmes von der obern Flxche. c, e xussere Wülste des unteren Ringes; e, e innere Wülste des unteren Ringes. f Wülste des obern Ringes. I cin Ilaar, das auf einem Wulst des obern Ringes steht.

2. Senkrechter Durchschnilt durch die Mitte des Schirmes, stærker vergrössert. a Slicl. b, b Strahılen des Sehirmes e, c xussere, e, e innere Wülste des unteren Ringes; d, d Einfaltung der Membran zwischen den inneren und aeusseren Wülsten des unteren Ringes. f, f Wülste des obern Ringes; g, g Warzehen auf diesen Wülsten; h cin Haar, das aus einem Welzchen hervorgegangen ist; $h^{1}$ ein Wixzehen, das in ein Ilaar auswechst. n Nabel. m Wandung des Sticles.

5. Ein Wulst des obern hinges besonders dargestell, mil den Wierzchen, die er tragt (g, g).

'. Senkrechter Durchschnitt durch deu Schirm, als Secante gefülıst. Die schıeinbaren Zellen (b, b) entsprechen den Strahlen des Schirmes (Fig. 1, 2, b, b) 


\section{- 260}

Э. Ein Theil der durchschnittenen Wandung aus Figg. 4 starker vergrössert. Verdünnte Sæure lıat den Kalk aufgelöst, und die Wandung etwas aufyelockert. a, a Zellmenbran. b, b innere Lage der ExtracelIularsubstanz; $c$, $c$ aussere Lage derselben. In der Scheidewand scheint jetzt die Extracellularsubstanz ganz zu mangeln, weil der daselbst befindliche Kalk aufgelöst worden ist.

6. Rand des Schirmes von der Flæche, nach Behandlung mit verdünnter Saure. a Zellnembran. b innere gestreifte Lage der Extracellularsubstanz, verschmælert sich nach innen (nach $b^{1}$ hin); c aussere, ungestreifte Lage der Extracellularsubstanz.

7. Unterster Theil des Stieles, nach Behandlung mit verdünnter Sxure; ganzer Durchmesser $=0,090^{\prime \prime \prime}$; Wandung 0,025'"'. An der Membran liegen Amylumkörnchen; dieselben in b staerker vergrössert. $\mathbf{r}, \mathrm{r}^{\prime}$ Wurzeln.

8. Stïck der Wandung von einem Querschnitt durch den Stiel, stark vergrössert. a Zellmembran. b innere, gestreifte, kalklose Extracellularsubstanz. c æussere Lage der Extracellularsubstanz mit kleinen Kalkkörnchen.

9. Stück von einem Stiel, aus dessen oberer Hælfte, nach Anwendung von Sæure. An der Membran liegen grössere, einfache und zusammengesetzte Stærkekörner; die einfachen betragen 0,008 "' - 0,012 "' im Durchmesser. Die Starkekörner sind in B besonders dargestellt.

10. Oberer Ring (zwischen dem Schirm und dem Nabel) von oben angesehen. $1, f$ die Wülste. g, g die Wærzchen. b, b die Strahlen des Schirmes. (vgl. die gleichen Benennungen in Fig. 1, 2, 5).

11. Die beiden untern Ringe (zwischen dem Schirm und dem Stiel) von unten angesehen. b, b die Strahlen des Schirmes; c, c die Wülste des aussern Ringes, e, e die des inneren Ringes; d-d die Einfaltung der Membran zwischen den Wülsten des æusseren und denen des inneren Ringes. (vgl. die næmlichen Benennungen in Fig. 1 und 2).

12. Ein junges Haar; a die Basiszelle oder der ersten Ordnung; b die Zellen der zweiten, c die Zellen der dritten, d die Zellen der vierten, e die Zellen der fünften Ordnung. Die letztern sind eben erst entstanden und noch ganz klein.

Fig. 15 - 20. Myriotrichia Harv.

13. Stück von enner jungen Pflanze; die Gliederzellen theilen sich durch horizontale Wænde; Breite del' Zellen - 0,010 $/ \prime \prime$; llöhe $-0,005-0,006^{\prime \prime \prime}$.

14. Oberes Ende einer etwas weiter entwickelten Pflanze, D. M. $=0,012 / \prime \prime$; die Gliederzellen theilen sich durch verticale Wænde. a haarförmige Spitze, deren Zellen von oben nach unten abfallen, D. M. $=$ $0,006^{\prime \prime \prime}$. b junges Aestchen. c etwas alteres haarförmiges Aestchen, die Zellenausdehnung geht von der Spitze nach der Basis hin.

13. Querschnitt durch den Theil einer Pflanze, welcher in seiner Entwickelung dem untern Ende von Fig. 14 entspricht; D. M. $=0,012^{\prime \prime \prime}$.

16. Stück yon einer Pflanze, wo die Fructification begonnen lat. a junge Keimmutterzelle. b, c mit Keimzellen gefüllte Mutterzellen. d entleerte Mutterzelle. e junges Aestchen. Durchmesser der Mutterzellen $=0,020-0,050^{\prime \prime \prime}$.

17. Stück von einer Pflanze, wo alle Zellen gleichzeitig anfangen, Aestchen zu bilden.

18. Alle Zellen einzelner Glieder haben angefangen, $\Lambda$ estchen zu bilden.

19. Einzelne Zellen verschiedener Glieder fangen an, Aestelien zu erzeugen.

20. Stïck von einer Pflanze, wo aul viclen Epidermiszellen Aestchen stehen, dazwischen einige Keimmutterzellen. 
FIg. 21 - 25. Spirogyra quimina Link. (21, 29. Sp. longata Kütz. 25 - 25ั. Zygnema alternatum Hassall.)

21. Junge Zelle, in welcher das Chlorophyll noch die ganze Cylinderflache überzieht; Lange $=0,023^{\prime \prime \prime}$. Breite $=0,010^{\prime \prime \prime}$.

22. Etwas aeltere Zelle, in welcher die Chlorophyllschicht sich in ein spiraliges Band getrennt hat; Læenge: $=0,0: 0^{\prime \prime \prime} ;$ Breite $=0,010^{\prime \prime \prime}$. Die grünen und die farblosen Streifen sind gleich breit.

23. Stück von einer Pflanze, wo die Gliederzellen sich unter einander copulirt haben. Einige Zellen (a) sind mit der Mitte ihıer Cylinderflæche ausgewachsen, um sich auf gewölınliche Art zu copuliren.

24. Zwci Zellen in Copulation, bevor idas zwischen den Fortsætzen liegende Membranstück resorhirt ist.

2ั. Wie Fig. 2't, nach der Resorption.

\section{Ta. 18.}

Fig. 1 - 20. Dasycladus clasceformis Ag.

1. a-a Stamm.-f, f Blætter; die übrigen Blætter des Verticills sind nielı gezeichnet.

z, 3. Verschiedene Blætter.

4. a Stammspitze. $f$, f zwei Blattrerticille. p, p Poren zwischen der Stammzelle und den Basiszellen der Blætter.

3. Oberer Theil einer wachsenden Blattzelle; a homogener Schleim; b körniger Schleim; c körniger, gl'üngefærbter Inhalt.

6, 7, 8, 9. Blattzellen, welche oben auswachsen in 2 (Fig. 6, 8) odel 5 (Fig. 7, 9) Fortsælze, gleichzeitig (Fig. 6,7 ) oder ungleichzeilig (Fig. 8, 9), um neue Zellen zu bilden. a homogener farbloser Schleim; b kölniger farbloser Schleim; c körniger grüner Inhalt.

10. Eine untere Blattzelle mil 2 obern jungen Blattzellen an ilırer Spitze. a homogener Schleim ; b körniger Schlein ; c körniger, grünlicher Inlıalt.

11. Basis einer untersten Blatizelle; p Porus nach der Stammzelle.

12. 3 junge Blattzellen an der Berührungsstelle. $m$ Schleimschielıt, welche in Folge der Endosmose von süssem Wasser sich ron der Membran zurückgezogen hat. p, p Poren.

15. Scheidewand zwischen 2 Blattzellen $(f, f)$, mit dem Porus.

14. Spitze der Endzelle eines Blattes.

15. Wandung yom obern Theile del Stammzelle, im Durehschnitt. c Zellmembran; e Extracellularsubstanz, am æussern Rande gekerbt.

16. Wandung yom untern Theile der Stammzelle, von der Flæche angeselıen mit einem doppelten Netze (b-b). a, a 2 Poren von abgefallenen Blættern; sie sind umgeben von einem breiten, strahlenförmicrgestreiften Rande.

17, 18. Wandung der Stammzelle im senkrechten Durchschnitt, mit den Poren nach den Blættern. a Membran der Stammzelle; $m$ innere, melır verdünnte, gestreifte Lage, $n$ aussere, diethere, von Kalkniederschlægen körnige Lage der Extracellularsubstanz der Stammzelle. b, b, b Membran der Blattzellen; 0, o, o Extracellularsubstanz der Blattzellen.

19. Oberer Theil einer Stammzelle; die Schleimschicht hat sich durch Endosmose von Wasser theilweise von der Zellmembran losgelöst, so dass sie nur noch mit einzelnen Fortsatzen, welche die Gestalt der Linien eines Netzes haben, an derselben befestigt ist. a, eingedrungenes Wasser.

20. Körner, die aus mehreren Chlorophyllblæschen zusammengeselat sind; mit einem hohlen Raum in Centrum. 


\section{- $262-$}

Fig. 21, 22. Iuucheria spssilis Lyngb.

21. Keimastchen (a) und Hakenastchen (b) vor ler Copulation.

22. Nach der Copulalion. a, c Keimastchen, in denen sich eine Keimzelle dureh Copulation mit den Hakenrestchen b und a gebildet hat. e ein Keimæstchen, in welchen sich eine Keimzelle ohne Copulation bildele, inden das Hakenestchen $f$ sein Ziel verfehlte, und seinen Inlalt nicht entleeren konnte. B ein Keimæstchen stæerker vergrössert; g Narbe, wo das Ilakenæstehen mit denselben vereinigt war.

F1G. 25 - 57. Acrocladus mediterraneus Näg.

25. Ganze Pflanze, doppelt so gross als in der Natur. c Stamm. r Wurzeln. f Blatter.

21. Unterer Theil des Stammes mit den Wurzeln, stærker vergrössert.

25. Das Ende einer Wurzelachse noch melır vergrössert.

26. r Stïck einer Wurzel, in der sich eine Wand gebildet hat. Der betreffende Theil ist daneben starker vergrössert. a Hembran der Wurzel. e Extracellularsubstanz. m, m die nen gebildeten Menbranstücke (vgl. den Text).

27. c Oberes Ende des Stammes; f, 110 Blælter.

28. c Oberes gelapptes Ende des Stammes. Von den 12 Blættern sind Inur die 6 zugekehrten (f) dargestellt

29. e Oberes Ende des Slammes; mit 12 Blæltern, von denen 6 gezcichnet sind (f). a Ast, mit 5 jungen (noch einzelligen) Blættern ( $\left.\mathbf{f}^{\mathrm{t}}\right)$.

$\bar{\jmath} 0$ - Ј̆. Ausgewachsene Blælter besonders dargestellt.

36. Ein waehsendes Blatt; die untere der beiden Zellen ist in einen Fortsatz (a) ausgewachsen, um einen Ast zu erzeugen.

57. Chlorophyllbliesehen, jedes mil einem Amylumkernchen. b von der Seite angesehen.

Fig. 58, 59. Cystoseira.

78. Durchschnitt durch einen jungen Sorus (Conceptaculum). a-a Epiderniszellen.

59. Ein Stück aus dem Grunde eines etwas æeltern durchschnitlenen Sorus. a-i Epidermiszellen. b junge Keimzelle. c junge Nebenfæden.

\section{Talb. V.}

Fig. 1 - 9. Padina Paconia Lamour.

1. Senkrechter Durelischnitt durch den obern eingerollten Rand der Frons. a Randzelle. b Flachenzelie. c Flæchenzelle mit 2 Kernen. d Secundære Flachenzelle. e priniere Rindenzelle. f, h secundære Flachenzellen oder prinære Markzellen. g primære Rindenzelle mit 2 Kernen. i, k, l, m, n, o, p Rindenz.ellen.

2. Senkrechter Durehschnitt durch den obern eingerollten Rand der Frons. a secundære Flæchenzellen oder primare Markzellen. e Rindenzellen. p durchschnittener, junger Nebenfædengürtel.

3. Senkrechter J)urchschnitt durch einen jungen Nebenfiedengürtel (Fig. 2, p stærker vergrössert). a-a ${ }^{4}$ secundxre llachenzellen oder primære Markzellen, e- $\mathrm{e}^{1}$ Rindenzellen. r, r lindenzellen; welche einen Nebenfaden tragen. c-c Culicula. g Gallerte, die von den Nebenfaden ausgeschieden wurde. - In a und e ist der Zelleninhalt dargestellt, wenn die Focalebene den Mittelpunct der Zelle trifft; der Kern 


\section{$-265$}

ist in einem IIaufen ron Schleimkörnchen und Chlorophyllblæschen verborgen; er sendet Strömungsfaden vach der Wandung; an der Membran liegen Chlorophyllblaschen. In at und $\mathrm{e}^{t}$ ist der Zelleninlialt dargestellt, wenn die Focalebene die Wandung der Zelle trifft. Man erblickt die Chlorohpyllblaeschen, welche in einem peripherischen Strömungsnetz liegen.

4. Senkrechter Durelısehnitt durch die Frons. a-a secundiere Flachenzellen oder primere IIarkzellen. e-e Rindenzellen. r, r Rindenzellen, die einen Nebenfaden erzeugt haben. Auf den 2 aussern ist er noch rorhanden; auf den 2 mittlern ist er abgefallen.

3. Verticaler Durchschnitt durch die Frons, a-a mittlere Markzellen. b-b vordere Iarkzellen. e-e Rindernzellen; r, r solche, welche einen Nebenfaden getıagen haben.

6. Verticaler Durehschnitt durch die Frons. b-b vordere Markzellen, $\mathbf{c}-\mathrm{c}$ und d-d mittlere Markzellen. e-e Rindenzellen. Zelleninhalt wie in Fig. 5, a und e.

7. Verticaler Durchschnitt. e Rindenzellen; f solche, die auswachsen, nm eine Keimzelle zu erzeugen. : Rindenzelle, welche eine junge Keimzelle ( $\mathrm{k}$ ) trægt. g Gallerte, welehe von den auswachsenden Rindenzellen und den jungen Keimzellen ausgeschieden wird. c Cuticula.

8. Verticaler Durchsehnitt. b-b vordere Markzellen; c, d mittlere Markzellen. e Rindenzellen; r solche. die Keimzellen $(k, k)$ tragen. Ganzer Durchmesser $(e-b)=0,060^{\prime \prime \prime} ;$ Længe der Warkzellen $=0,050^{\prime \prime \prime}$ $-0,050$ "l'.

9. Aufgerollter und flach gelegter Rand der Frons. a-a Randzellen; $m, m$ solche, die fsich eben durch di: Wand $I$ in eine neue Randzelle und in eine Flechenzelle getheilt haben. 0 , o senkrechte Wand iı den Randzellen, welche dieselben in 2 neben einander liegende, neue Randzellen $(n, n)$ trennt.

\section{Fig. 10-2I. Dictyota dichotoma Lamour.}

10. Senkrechter Durchschnitt durch die Frons (D. M. $\left.=0,05 \mathrm{~g} /{ }^{\prime \prime \prime}\right)$. In-m Markzellen, Dickendurchmesser $=$ $0,02{ }^{\prime \prime \prime}$; die Länge beträgt durehschnittlich 0,050 "' . e-e Rindenzellen; Dickendurchmesser $=$ $0,003^{\prime \prime \prime}$.

11. Horizontaler Durchschnitt dureh den untern Theil der Frons; D. M. $=0,060^{\prime \prime}$. m-m Markzellen; Dicken - D. M. $=0,044^{\prime \prime \prime}$; Breiten-D. M. $=0,050^{\prime \prime \prime}-0,050^{\prime \prime \prime}$. e - e Rindenzellen; Dicken - D. M. $=0,008^{\prime \prime \prime}$.

12. Spitze einer Achse. a Scheitelzelle. b ungetheilte Gliederzelle. c-c Glied, das sich in 2 Zellen getheilt hat. d-d, e-e, f-f, g-g, Glieder, die sich in 4, 8, 16, 52 Zellen getheilt haben.

15. Die Scheitelzelle hat sich durch eine senkrechte Wand in 2 neue Scheitelzellen getheilt $(a, a)$. b ungetheilte Gliederzelle. c Glied, das aus 2 Zellen besteht.

14. e-e, d-d, e-c 5 Glieder, die der Mutterachse angehören; b, a und b, a je 2 Zellen, die den . Infang zweier Tochterachsen bilden. a, a Scheitelzellen; b, b ungelheille Gliederzellen. c-c Glied, das aus $/ 1$ Zellen besteht; d-d Glied, das aus 8 Zellen, e-e Glied, das aus 16 Zellen besteht.

15. $f-f, e-e, d-d 5$ Glieder, die der Iutterachse angehören. $c$, b, a je 5 Zellen, welche die beiden Tochterachisen bilden; a, a Scheitelzellen; b, c ungetheilte Gliederzellen. d-d Glıed, das aus 4 Zellen besteht; e-e, f-f Glieder, die aus 8 und $\mathbf{1 6}$ Zellen gebildet sind.

16. y-gr das oberste Glied der Mutterachse. f, e, d, e, b je $\ddot{3}$ Glieder, die den beiden Tochterachsen angehören. a, a Scheitelzellen derselben; b ungetheilte Gliederzellen; e, d, e-e, f-f, Glieder, die aus 2, 1, 8, 16 Zellen gebildet sind.

17. Uarkzellen von der Fläche. e, e, e Zellen, welche ringsum eine beträchtliche Menge von Gallerte gebildet haben. c eine Zelle, die nur nach der einen Seite hin ihre Wandung verdickle. b, l, Zellen olme bedeutende Verdickungen der Wandung.

18. Dic Scheidewände zwisehen den Markzellen aus Fig. 10, slüker vergrössert, um die Poren zu zeiggen. 


\section{- 264}

19. Horizontaler Durchsclınitt durch den obern Theil der Frons, da wo ein Büschel ron jungen Nebenfäden auf derselben stelıt; D. M. der Frons $=0,018^{\prime \prime}, \mathrm{m}-\mathrm{m}$ Ilarkzellen. e-e Rindenzellen. c Cuticula. g Gallerte, die von den Nebenfäden ausgeschieden wurde.

20. e-e Rindenzellen; 2 daron sind ausgewachsen, um Keimzellen zu bilden.

21. e-e Rindenzellen; die Zelle r trägt eine Kicinzelle.

Fıg. 22 - 31. Coleochate scutata Bréb. $28-51$ Var. soluta.

22. Kreisförmiges Laub mit gelapptem Rande und einer concentrischen Reilıe von Keimmutterzellen.

25. Ein Stiick des Randes, c, c Keimmutterzellen.

'24. Ein Stïck des Randes. a, a Randzellen, die sich durch eine radiale Wand in zwei neue Randzellen theilten. b, b Randzellen, die sich durch eine tangentale Wand in eine neue Randzelle und eine Flächenzelle getheilt haben. $c$, c Keimmulterzellen. $d, d$ Borsten.

2..). Ein Faden von der gelösten Form, dessen Scheitelzelle (c) sich zur Keimmutterzelle umbildet, und dessen oberste Gliederzelle (d) eine Astzelle erzeugte.

घ6. b, c Keimmutterzellen, von einen Zellenring umgeben, welcher durch Astzellenbildung aus den obersten Gliederzellen (d) entstanden ist.

¿̄̄. b heimmulterzelle, mit cinem Aestchen umhïllt, das einen unvollständigen Ring bildet. c Keimmutterzelle mit einem vollständigen Ring. d, d oberste Gliederzellen.

28. Keimmutterzelle, welche mit cinem vollständigen Ring umgeben, und deren obcre Fläche theilweise durch Zellen bedeckt ist.

99. Eine vollständige kleine Pflanze der gelösten Form. Dic Keimmutterzelle (a) ist an der freien (nicht angewachsenen) Fläche mit einer Zellschicht bedeckt. b, b Borsten.

50. Querdurchschnitt durch eine Keimmutterzelle, wie sie in Fig. 29 abgebildet ist. a die der Unterlage anhaftende Fläche.

51. Keimmutterzelle mit einigen Keimzellen.

\section{Tab. 但。}

Fıg. 1 - 6. Antithamnion cruciatum (Callithamnion c. Ag.)

1. c-d Stück ron einem Stamm; auf dem Gliede c stelıt das Blatt a-b; das diesem gegenüberliegende Blatt ist nicht sichtbar; auf dem Gliede d stehen die beiden Blătler $f, f$. a, a unterste secundäre Zelle der Blätter, welche keine Tochterachse bildet, s, s abortirte Sporenmutterzellen.

․ Spitze eines Stammes. a primäre Zelle (Scheitelzelle). b oberste secundäre Zelle. c secundäre Zelle, welche auswächst, um ein Blatt zu erzeugen. $d, e$, g ganz junge Blätter, welche noch erst aus einer oder aus zwei Zellen bestehen.

J. Junges, in der Entwickelung begriffenes Blatt. a primäre Zelle (Scheitelzelle). b, c, d secundäre Zellen : die letztere (d) wächst aus, un cine Astzelle zu erzeugen. e, $f, g, h, i, k$ junge Tochterachsen des Blattes, worunter e er'st ein Zellast und f eine einfache Zelle ist; 1 unterste secundäre Zelle, welche keine rochterachse bildet.

4. c secundïre Stammzelle, mit einem Blatt. r Wurzel, welche aus der untersten secundären Zelle des Blattes entspringt. s, s abortirte Sporénmutterzellen.

ॐ. Zellen eines ältern Blattes mit den Poren. m Zellmembran; a innere, b äussere Lage der Extracellularsubstanz.

¡. Porus zwischen 2 ältern Stammzellen. m Zellmembran; a innere, b äussere Lage der Extracellularsubstanz. 
Fig. 7 - 28. Poccilothammion versicolor (Callithamnion v. Ag.) 29. Poecilothamnion corymbosum (Callithamnion c. Ag.)

7. a-d gemischte Achse; r, r', r'/ Seitenäste mit Sporenmutterzellen ('grl. den Text).

8. f Laubzelle. a Ausgewachsener Theil der Laubzelle, in welchem sich noch keine Sporenmutlerzelle gebildet hat. b Sporenmutlerzelle mit einem centralen seeundären Kiernbläschen. c Specialmutter'ellen mit ihren kernen.

9, 10. Laubzellen mil Sporenmutterzellen, a noch ungetheilt, b in 4 Specialnutlerzellen getheill.

11. a, a gemischte Aclise. r Seitenast mit Antheridien.

12-19. Entwickelungsgesehichte der Antheridien.

20. Samenzellehen, a ein jüngeres, das feinkörnigen Schleim enthält. l), c, d ältere mit waisserhellem Inhalt und einem wandständigen Puncle, von welchem eine sich allı̈älig verlierende Linie (Samenfaden ?) ausgeht.

21. a-a gemischte unbegrenzle Achse; r, r, Seitenäste. Die Keimzellenhänfehen sind paarweise gegenüberstehend; die Paare alterniren mil einander.

코-26. Entwichelungsgeschichte der Keimhäufehen.

27. Keimhäufehen, lappenförmig abgetheill. a Basiszelle.

28. a-a gemischte Achse; g, g Keimhäufchen, mit verdünnlel Säure zerllückt. Der contrahirte Inhalt der

Keimzellen längt durch Poren zusammen. Die Zellenwände sınd aufgelöst.

99. An einem Laubgliede stehen 4 Keimhäufehen, die beiden obern sind ansgebildel, roth-gefärbl, und mil Extracellularsubstanz umgeben. Die beiden untern entwickelı sich eben, sind fast farblos und noch ohne Extracellularsubstanz.

\section{F1g. 30 - 57. Callithamion.}

50. C. seminudum Ag. Ende eines Asles. a Scheilelzelle (primäre Zelle des $n^{\text {ten }}$ Grades, In ). b oberste Gliederzelle $(n-1 I)$. c Gliederzelle $\left(n-{ }_{2} I I\right)$, welche auswächst. d Astzelle (primäre Zelle des ersten Grades, $\left.\mathrm{I}^{1}\right)$. e, $\mathrm{f}$, g Tochterachsen.

31. C. roseum Ag. Ende eines Astes mit Keimhäufchen. B cines derselben stürker vergrössert; g Extracellularsubstanz; in derselben ist an der Basis des Iläufehens ein Porus befindlich.

52. C. tetricum Ag. Ende eines Astes mit Sporenmutterzellen. r eine secundäre Zelle, welehe auswäehst, um eine Astzelle zu bilden. a eine secundäre Zelle, welehe auswselıst, um eine Sporennullerzelle zu erzeugen. b, b, b junge Sporenmutterzellen.

55. C. scopulorum Ag. Seheidewand mil einem Porus. m Zellmembran. e Exlracellularsubstanz.

54 - 57. Sehematisehe Zeichnungen mil Angahe der Werthe für die einzelnen Zellen. 5't Ende einss Astes. 3:-57. Keimende Pllanzen.

\section{Fıg. 58 - 42. Ptilota plumosa var. tenuissima Ag.}

58. a-b primære IJauptachse. Auf jeder Gliederzelle stehen zwei primare Tochterachsen, eine nach rechts und eine nach links. Von denselhen ist bloss das unterste Glied gezeichnet: c, c, d, d, e, f, g, g, h, h. Nur zwei dieser primaren Tochterachsen sind fertig gezeichnel: $\mathrm{i}-\mathrm{t}$ (welche gegenübersteht) und $\mathrm{u}$ (welche $\mathbf{f}$ opponirt ist). - $\imath$ Scheitelzelle $\left(\mathbf{I}^{11}\right)$. s oberste orler zehnte Gliederzelle ( $\left.\mathrm{III}\right)$. Die zweitoberste oder neunte Gliederzelle (.II) hal erst eine Astzelle erzengl: r. Dic achte Gliederzelle (.II) trægt links eine $\Lambda$ stzelle, rechts einen zweigliedrigen $Z w$ eig (primære Toclıterachse), q-q. Die sie- 


\section{- 266}

bente bis zweite Gliederzelle (,II . . ., II) tragl jederseits einen mehrgliedrigen Zweig ( $p-p, 0-0$, $\mathrm{n}-\mathrm{n}, \mathrm{m}-\mathrm{m}, \mathrm{I}-\mathrm{I}, \mathrm{k}$ ). An der ersten oder untersten Gliederzelle (.II) ist rechts ein zweigliedriger Zweig (i) belestigt. Die 2-5̈le Gliederzelle tragt auf der obern (zugekehrten) Seite (die abgekehrte Seite ist nicht sichtbar) je eine Astzelle (secundiere Tochterachse), welche an den fünften Gliede (zwischen n-n) noch unverandert ist, an dem vierten und dritten Gliede (zwischen m-m und I-I) nach unten eine Istzelle, und an dem zweiten Gliede (bei k) nach unten zwei Astzellen erzeugt lat, woraus Wurzelfaden hervorgehen. Die unterste Gliederzelle des Zweiges $m$ (rechts) hat eine Astzelle fïr eine primære Tochterachse, die des Zweiges l eine (obere) Astzelle für eine primære Tochterachse und eine solche (unten) tür ein Wurzelhar, die des Zweiges $\mathrm{k}$ und i bloss je eine Astzelle für ein Wurzelhaar gebildet. - Die Gliederzellen der Iíauptachse a-b lıaben ausser den zwei Reihen von primären Tochterachsen zwei Reihen von secundären einzelligen Tochterachsen erzeugt, von denen die eine zugekehrte sichtbar ist. Jede Gliederzelle trägt an ihrem obern Seitentheile eine solche Zelle. Von denselben hat die des obersten Gliedes (zwisehen h-h) nach unten zwei Aslzellen, die des zweitobersten Gliedes (zwischen $g-g)$ unten zwei und nach oben liuks eine Astzelle, die des drilten (bei f) und del ührigen untern Glieder (bei e, zwischen d-d und e-c) unlen 2 und oben 2 Astzellen erzeugt, welehe in den drei untern Gliedern theilweise anfangen, in Wurzelfäden auszuwachsen. - Die untersten Gliederzellen der primären Seitenachsen (c, d, e, f, g, h) tragen alle nach unten und innen entweder eine Astzelle für ein Wurzelhaar, oder cin kurzes zweigliedriges Wurzelhaar. Nach oben uind aussen tragen bloss zwei eine Astzelle für eine primäre Tochterachse (h) oder eine kurze primäre Tochterachse (i). Ausserdem haben von $f$ abwarts alle auf ihrer obern zugekehrten Seitenflæche eine Zelle erzeugt, welche ohne Zweifel den secundaren Laubachsen analog ist, und welche in d, d nach unten und innen eine Astzelle, in $\mathrm{e}$, $\mathrm{c}$ aber sowohl nach unten als nach oben eine Astzelle erzeugt hat, welche sich zu einem Wurzelfaden entwickeln wird.

59. ว̌ Gliederzellen einer primæren Laubachse mil den secundæren (einzelligen) Laubachsen an der zugekehrten Flæche. Von den letztern ist a unveraendert; b hat I (nach unten), c 2 (nach unten), d 5 ( 2 unten, 1 oben), e 4 ( 2 unten, 2 oben) Astzellen für Wurzelfaden gebildet.

40. a eine fliederzelle aus einer primæren Laubachse. b, b unterste Gliederzellen der beiden primæreı Tochterachsen. $\mathrm{c}$ zugekehrte secundare Tochterachse. d, e, g Astzellen an der Zelle c, aus welchen Wurzelfaden entstehen; f ein junger, zweigliedriger' Wurzelfaden an der Zelle c. h Astzelle an der Zelle b, aus welcher ein Wurzelfaden hervorgeht; i junger zweigliedriger Wurzelfaden.

11. a eine secundære (eiozellige) Laubachse, mil den 4 Wurzelfæden, welche an ihr befestigl sind, b, c. $d, e . b$ und $d$ sind noch einfach; $c$ und e fangen an sich zu verzweigen.

14. Wie Fig. 41. Alle vier Wurzelfeden haben angefangen, sich zu verzweigen.

\section{Tab. Vu.}

Vig. 1 - 15. Nitophllum punclatum Grev.

1. Ein Stiick von dem Rande des Laubes. In a werden die Zellen nach aussen von einer Reilıe, in b ron жwei Reihen doppelt kleinerer Zellen begrenzt.

ע. Quersehnitt durch ein sporenhildendes Laub. a, a ungetheilte Laulzellen. b, b die Laubzellen haben sich in je 5 Zellen gelleilt. e Sporenmutterzelle mit den eingesehlossenen 4 Sporen.

5. Wie Fig. 2. a, a ungetheilte Laubzellen. b die Laubzelle hat sich in 2 ungleiche Zellen getheilt. $\mathrm{c}$, $\mathrm{c}$ die I aubzellen haben sich in 5 Zellen getheilt. $d$, d Sporenmutter\%ellen. 


\section{- 267}

4. Stück yon cinem sporenbildenden Laub, von der Flæche, mit 5 Sporenmutterzellen, welche in der Witte unbedeckl sind.

ว. Sporenmulterzellen, a mit einer breiten Schicht farblosen Sclıleimes an der Wand, b mil cinem centralen Kern und radialen Schleimfieden, e mit zwei Kernen, d in zwei Specialmulterzellen getheilt.

6. Querschnitt durch ein Antheridium.

7. Querschnilt durch ein Antheridiun, starker vergrössert. a ungetheilte Lanbzelle. b Centralzellen des gretheilten Laubes. c, c Samenzeflchen.

8. Stück ron einem Antheridium, von der Flæche. a ungetheilte Laubzellen.

9. Junge Samenzellchen, parenchymatisch, mit homogenem Schleim und einem lateralen Kernchen.

10. Ausgebildete Samenzellchen, kugelig, mit wasserhellem Inlıal, und cinem lateralen Kernchen. a zwei freie Samenzellchen, welche einen Samenfaden einzuschliessen sclıeinen.

11. Querschnitt durch einen keimbehelter. a, a ungetheilte Laubschicht. b das Laub hat sich in 5 Sehichten getheilt. c Boden des Keimbchælters. d Samentræger. e, e Deche des Keimbehælters. f warzenförmige Oeffnung.

12. Keimhaar': die oberste Zelle bildet sich zu einer heimzelle aus.

15. Veræsteltes Keimlaar; die beiden obersten Zellen bilden sich zu Keimzellen aus.

14. Keimzelle, mit einem centralen Kernbleschen.

1\%. Querschnitt durch einen Theil eines jungen Keimbehælters. a ungetheilte Laubzelle. b die Laubzelle: hat sich in zwei ungleiche Zellen getheilt. $\mathrm{c}$ dic Laubzelle hat sich in 5 Zellen, eine Achsenzelle und zwei Seitenzellen getheilt. d-d Decke des Keimbehælters; die Seitenzellen haben sich jede in zwei Zellen getheilt. c Boden des Keimbehælters; die Seitenzellen haben sich in je 2 bis 5 Zelten getheilt. f unveranderte Achsenzellen. g eine Achsenzelle, welche sich ausdehnt, um Zellen zu bilden. h die Achsenzellen rerwandeln sich in Zellenreihen (Keimlıare).

FIg. 16 - 25. Delesseria IIypoglossum Lamour. (Iypoglossum Hooduardi Kütz.)

16. Querschnitt durch den Stiel des Laubes; Breitendurchmesser $=0,060^{\prime \prime \prime}$; Dickendurchmesser $=$ $0,053^{\prime \prime \prime}$. a-a Zellmasse, welche aus der secundæren Zelle des drillen Grades (II $\left.{ }^{5}\right)$ entstanden ist. b-b. b-b je $\mathbf{\jmath}$ Zellen, welche aus einer ersten quintæren Zelle $(V)$ hervorgiengen. $c$ - $c$ eine zweite quintiere Zelle hat sich bloss in 2 Zellen getheilt. d ungetheilte quintære Zelle. e, e tertiære (III) oder quartære (IV) Zellen des letzten Grades.

17. Querschnitt durch einen Mittelnerv (Bezeichnung wie in Fig. I6) a-a entspricht der II $^{5}$, b-b einer V. d ungetheilte $\mathrm{V}$. Der ganze Mittelnerv ist also aus einer $I^{3}$ und aus vier $\mathrm{V}$ entstanden; seine Breite betrægt $0,040^{\prime \prime \prime}$, scine Dicke $0,050^{\prime \prime \prime}$.

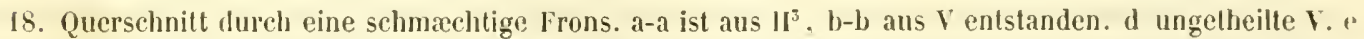
III oder IV des letzten Grades. - D. II. a-a $=0,056^{\prime \prime \prime} ; \mathrm{b}-\mathrm{b}=0,150^{\prime \prime \prime}$.

19. Querschnitt durcl den Miltelnelv einer altern Frons. Zwischen den Zellen und ausserhalb der Lejıen desselben liegen durclischnittene Zellfæden (b), ebenso an der xussern Flæche der quintæren Zellen (a). Grösste Dicke des viittelnerven $=0,20^{\prime \prime \prime}$.

20. Querschnitt dureh ein sporenbildendes Laub. Die sterile Stelle a-a entspricht der secundaren Zelle des dritten Grades und den innersten quintaren Zellen. Die Sporenmutterzellen liegen neben der Achsenzellschicht.

21. Senkrechter Durchschnitt durch ein Glied in der Richtung a-a von Fig. 17.

22. Senkrechter Durchschnitt dureh ein Glied in der Riclstung b-b von Fig. 17.

25. Senkrechter Durchschnith in der Richtung b-b von Fig. 19. Zwischen und ausserhalb der fiewebezellen liegen Zellfaden, welche aus dem untern Seitenende der Zellen entspringen, nach unten wachsen. und sowohl ein intercellulares als ein peripherisches Geflecht bilden. 
Fıg. 2/4 - 56. Gelidium corneum Lamour.

24. Spitze eines Aestchens der Varietat capillaceum. a Scheitelzelle ( $\left.\mathrm{I}^{\mathrm{a}}\right)$. b Gliederzelle $\left(\mathrm{n}-\mathrm{III}^{\mathbf{A}}\right)$. c dic Gliederzelle lat sich in eine grössere und eine kleinere Zelle getheilt. d die Gliederzelle hat sich durch doppelte Zellenbildung in 5 Zellen getheilt.

9.8. Ende eines dünnen Aestchens der gewöhnlichen Form. a Scheitelzelle $\left(I^{n}\right)$. b Gliederzelle $\left(\mathrm{n}-{ }_{-1} I^{1}\right)$. c die Gliederzelle lıat sich in 7 Zellen getheilt.

26. Wie Fig. 25. a Scheitelzelle $\left(\mathrm{I}^{\mathrm{n}}\right)$. b Gliederzelle $\left(\mathrm{n}-\mathrm{III}^{1}\right)$. Die Gliederzellen $\mathrm{c}$ und d haben sich in 5 und 7 Zellen getheilt.

$27,28,29$. Enden von dickeren Aestchen; in Fig. 27 erkennt man noch die Scheitelzelle und die oberste Gliederzelle, in Fig. 28 bloss die Scheilelzelle; in Fig. 29 ist das Punctum vegetationis vertieft und nicht siclitbar.

7). Sporeumulterzelle, die sich in zwei primare Specialmutterzellen 'getheilt hat.

51. Sporenmutterzelle, die sich vollstæendig in 4 kugelquadrantische (secundære) Specialmutterzellen getheilt hat. I und II Ansichten von oben und von der Seite.

32. Sporenmutterzelle, welche sich vollstæendig in 4 (secundære) Specialmullerzellen getheilt hat; dieselben liegen in Einer Flieche. I und II Ansichten von oben und von der Seite.

5.j. Horizontaler Durchschnitl durch einen Ast mit Keimbehaltern. a Mündungen. b Rinde. c Mark.

57. Verticaler Durchschnilt durch einen Ast mit Keimbehseltern. a Mündungen. b Rinde. c Mark.

5.). Ein Theil des horizontalen Durchschnittes, stierker vergrössert. a Mark, Welches den Samenboden bildet; D. M. der Fasern 0,0025"/, l, Keimhaare mit den Keimzellen. c innere aus Mark bestehende Lage der æussern Wandung. d horizontale Fasern zwischen dem Samenboden und der æussern Wandung; D. $\mathbf{\text { I. }}=0,004-0,00 \mathrm{马}^{\prime \prime \prime}$. c Rinde ; innere Zellen $=0,005-0,006 / 1 /$; Epidermiszellen kaun $0,0027 \prime \prime$.

56. Ein Keimhaar besonders dargestellt. Keimzellen $=0,020^{\prime \prime \prime}$ lang und $0,007^{\prime \prime \prime}$ breit.

Frg. 37 - 41. Gracilaria purpurascens Grev.

37. Enden zweier dünner und spitzer Aeste. a Scheitelzelle $\left(I_{n}\right)$. b, b secundære Zellen des ersten Gra$\operatorname{des}\left(11^{1}\right)$.

58. Wie Fig. 57. c, c zwei ungegliederte, aus den Epidermiszellen entsprungene Haare.

79. Querschnitl durch die Asschwellung eines Astes, in welcher ein Keimhæufelıen liegt. Man sieht 7 besondere Ilacufchen von Keimzellen, welche durch Scheidewande von llarkgewebe von einander getrennt und aussen yon einer Harklage umgeben werden, auf welche nach aussen die gefarbte Rinde folgt.

10. Senkrechter Durchschnilt durch die Anschwellung eines Astes, in welcher ein Keimheufchen liegt. a-a Mark. b-l, Rinde. Nan sieht 6 besondere Ilwfelıen von Keimzellen im Markgewebe eingebettet.

11. Querschıitt durch ein sporenbildendes Aestchen. a Mark; in der Gallerte liegen bloss 8 durchschnittene Fasern. b Rinde. Ganzer Durchmesser $=0,160 \%$.

\section{Tab. VIx.}

Fig. 1 - 97. Laurencia. lig. 1 - 7 L. tenuissima Grev. - Fig. 8 - 16. L. dasyphylla Grev. lig. 17 - 20. L. obtusa Lamour. - Fig. 21 - 27. L. papillosa Grer.

1. Senkrechter Durchschnitt durch einen jungen Ast (ron L. tenuissima), zwei Glieder darstellend. a-a Aclisenzollen. b-l) erste, c-c zweite, d-d dritte, e-e vierte concentrische Zellschicht (oder Epidermiszellen). 


\section{- 269}

2. IIorizontaler Durchschnilt durch einen jungen Ast. Bezeiclınung wie in Fig. 1.

5. Horizontaler Durchschnitt durch einen seltern Ast, (D. M. =0,300 ${ }^{\prime \prime \prime}$ ); Bezeichnung wie in Fig. 1 und und 2. Die Zellen b, c, und d enthalten ein wandständiges Schleimnetz, und sind wenigg gefärbt; die Fpidermiszellen (e) sind mit gefärbtem körnigem Inhalte gefüllt. Zwischen den innerı Zellen ( $a, b$ und c) sieht man die durehschnittenen Fäden des intercellularen Geflechtes.

4. Ende eines spitzen $\Lambda$ stes. a Scheitelzelle ( $\mathrm{In}^{\mathrm{n}}$ ). b oberste Gliederzelle $\left(\mathrm{n}-\mathrm{III}^{\mathbf{}}\right)$. Dic zweitoberste Gliederzelle $\left(n-{ }_{2} I^{1}\right)$ hat eine Astzelle, die erste Zelle eines Blattes (c) erzeugt. Die drittoberste Gliederzelle $\left(u-3 I^{s}\right)$ hat eisenfalls eine Astzelle (d) gebildet, aus welcher sich ein Blatt entwickeln wird, und sich dain in zwei Zellen ( $\mathbf{H}^{2}$ und $\left.\mathbf{I I I}\right)$ getheilt. Alle folgenden Glieder laben sich vollständigg getheill; sie sind im senkrechten Durchschnitt dargestellt; $m$ Achsenzellen, $n, n$ tertiäre Zellen; e, f, g junge Plätter.

3. Ende eines etwas weniger spitzen Astes als Fig. 4. a Scheilelzelie ( $\left.\mathrm{I}^{\mathrm{n}}\right)$. b, c Gliederzellen $\left(\mathrm{n}-\mathrm{II}^{\mathrm{i}}\right.$, $\left.n-{ }_{2} 1^{4}\right)$. f junges Blatt. Nach unten von $\mathrm{c}$ ist die Zellenbildung in die Dicke so beträchtlich, dass man die einzelnen Zellen nicht deutlich unterscheidet.

6. Senkrechter Durehsehnitt durch den ältern Theil eines $\Lambda$ stes, wie Fig. 5 ihn im Querschnitt darstellt; man sieht etwas über die Hälfte eines Gliedes. a die Achsenzelle (Länge $=0, \overline{500}{ }^{\prime \prime \prime}$ ); b), b zwei grleielılange Zellen wie a; c-c z.weite, d-d dritte, e-e vierte, f-f fünfte concentrische Zellschicht (oder Epiderıniszellen). Auf den innern Zellen liegen Fäden des intercellularen Gellechtes.

7. Junges, durch Zellenbildung wachsendes Blatt; der Zelleninhalt ist homogener farbloser Schleim. a, a Scheitelzellen ( In ); b, b Astzellen oder Scheitelzellen des ersten Grades (I'); c, c Gliederzellen, welche auswachsen, um eine Astzelle zu erzeugen. d unterste Gliederzelle (.II), welche keine Tochterachs: træogt.

૨. Junges, durch Zellenbildung wachsendes Blatt (ron L. dasyphylla) etwas xlter als Fig. 8. Bezeichnun! wie in Fig. 8 .

9. Horizontaler Durchschnitt durch einen $\mathbf{A s t}$; die Zellen sind durch gallertartige Intercellularstibstanz von einander getrennt. Bezeichnung wie in Fig. 1, 2, 5 und 6. Ganzer Durchmesser $=0,530{ }^{\prime \prime}$.

10. Horizontaler Durchschnitl durch den untersten Theil eines Astes, wo früher Sporenbildung statt fand; die Zellen sind durch dünne gallertarlige Intercellularsubstanz von einander getrennt. a Achsenzelle; b Zellen der ersten, c der zweiten, d, d der dritten, e, e Zellen der vierten und fünften concentrischen schicht, welche die Epidermis bilden. Ganzer Durchmesser $=0,500 \mathrm{\prime \prime \prime}$.

11. Senkrechter Durchschnitt durch den untern sporenbildenden Theil eines Aestchens; bloss die eiıt Hælfte ist gezeichnet; Ganzer Durchmesser $=0,220^{\prime \prime \prime}$. a-a Achsenzellen. b, b Zellen der ersteu coucentrischen Schicht (vgl. b in Fig. 1, 2, 9 und 10); sie haben sich in radialer Richtung betraechtlich verlængert; seitlich sind sie durch gallertartige dünne Intercellularsubstanz von cinander greschieden; wegen der Alternanz dieser Zellen in den successiven Gliedern sieht man an dem dünnen Schnitte jederseits bloss je an der zweiten Aclısenzelle eine derselben $(b, b)$, und weben den übrigen Achsen zellen die leeren gelatinosen Intercellularræume $(n, n)$. c, c zweite concentrische Schicht, in welcher die Sporenmutterzellen liegen. d, d Zellen der dritten und vierten concentrischen Schicht, welelıe zusammen die Epidermis bilden.

12. Epidermiszellen mit einer Sporenmutterzelle unter denselben, von aussen, von einem Aestchen wie Fig. 11. Mitten auf der Sporenmutterzelle liegt eine Oeffnung zwischen den Epidermiszellen.

15. Junger Zweig, 0,030 "' lang, von der Mutterachse losgetrennt. $\Lambda$ n der Spitze (a) sieht man die Scheitekelle ( In ); dann folgen 5 ungetheilte Gliederzellen $\left(I^{4}\right)$. Die riertoberste Gliederzelle hat sich iu $z$ wei Zellen ( $\mathrm{H}^{2}$ und,$\left.I I I\right)$ getheilt. Alle folgenden Gliederzellen haben sich voltstandig in eine Achseryelle und in umgebende tertiare Zellen getheilt; die Glieder sind in Durchschnitte gezeichnet. Dis 


\section{$-\quad 270$}

unterste Gliederzelle ist ungetheilt geblieben. f, f junge Blatter. - Alle Zellen enthalten erst einen homogenen farblosen Schleim.

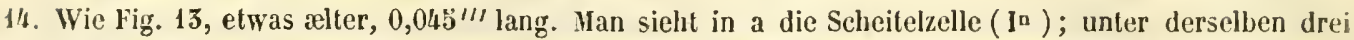
ungetheilte Gliederzellen $\left(11^{1}\right)$; dann ein Glied, welches aus einer Achsenzelle und einer Schicht von tertiæren Zellen besteht, im Durchschnitt gezeichnet. Unterhalb desselben haben sich die Zellen in die Dicke so sehr vermehrt, dass man sie nicht mehr deutlich erkennt (b)). An der Basis bemerkt man eine ungetheilte Gliederzelle, und über derselben ein Glied, das aus einer Aclısenzelle und aus tertiæren Zellen besteht, im Durchschnitt gezeichnet. f, f junge Blætler. - Die Zellen des obern Theiles sind mit farblosem Schlein gefülit, der untere Theil (b) erscheint schwach pöthlich.

15. Wie Fig. 14, etwas æelter, $0,070^{\prime \prime \prime}$ lang. Man sieht in a die Sclseitelzelle, und darunter zwei Gliederzellen. Der untere Theil des Zweiges (b) ist betræchtlich in die Dicke gewachsen. f junge Blætter, welche mit der Stammspitze (a) in einer Vertiefung von b stehen. - Die obersten Zellen sind farblos; der ïbrige Theil (b) ist röthlich gefærlt.

16. Wie Fig. 15. Das Wachstlum in die Dicke ist so rasch fortgeschritten, dass es die Stammspitze überholt hat, welche nun, in einer Vertiefung eingesenkt, nicht melır sichtbar ist. Bloss die obern 'Theile einiger Blætter ragen liervor. - Der Zweig ist roth gefærbt.

17. Senkrechter Durchschnitt durch einen Ast (von L. obtusa). a-a Achsenzellen. b-b erste, c-c zweite, d-d dritte, e-e vierte concentrische Zellschicht (oder Epidermiszellen).

18. Epidermiszellen aus einem Ast wie Fig. 17, besonders dargestellt, im radialen senkreclıten Durchschnilt; der Kern liegt in der Nitte des untern Randes.

19. Epidermiszellen wie in Fig. 18, aber von der æussern Flæclıe geselıen. Der Kern liegl auch hier in der Mitte des untern Randes.

20. Senkrechter Durchschnitt durch einen Ast. a-a Achsenzellen. b-b erste, c-c zwejte, d-d dritte, e-e vierte, f-f fünfte, g-g sechste Zellschicht (Epidermiszellen).

21. Epidermiszellen von einem xltern Aste (von L. papillosa) im horizontalen Durchschnitt, von einer gelben derben Cuticula bedeck», welche keilförmige Fortsatze zwischen die Epidermiszellen hinein sendet. In der Mitte jeder Zelle sielıt man einen (wandstændigen) Kern. An der Wandung liegen Farhblæschen. Zwischen je zwci Epidermiszelten befindet sich ein Porus.

22. Epidermis, wie in Fig. 21, von der æussern Flæche angesehen.

25. Horizontaler Durchsclınitt durch die Spitze einer Stammachse, derselbe liefert 5 getrennte Stücke; welche rings von einer Epidermis ungeben, nach aussen rölhlich, nach innen farblos sind.

24. Ilorizontaler Durchschnitt, wie Fig. 25 , aber etwas tiefer geführt. In der Mitte befindet sich eine dreieckige Oeffnung. Am russeren Rande so wie am Rande der dreieckigen Oeffnung unterscheidet man eine Epidermis. Das Gewebe ist nach aussen röthlich, nach innen farblos.

2\%. Senkrechter Durchschnitt durelı eine Stammspitze. Das plunclum vegetationis liegt in einer Vertiefung (b). Nan kann die Epidermis von dem reussem Rande über den Sclıcitel (a) in die Vertiefung hinein verfolgen.

26. Zellgewebe aus der Stammspitze, von einem horizontalen Durclıselınitt, mit Kernen und farblosem homogenem Schleim.

27. Wie Fig. 26; die Zellen sind etwas alter, mil hernen und farblosem, körnigem Inhalte.

\section{Tab. IX.}

FIG. 1 - 3. Laurencia obtusa Lamour.

1. Ein Stück von ciner Stammachse, mit einem Keimbehælter, schwach vergrössert.

2. Ein junges Keimhaar; alle Zellen enthalten farblosen homogenen Schlcim. a-b primare Achse, deren 
abere Zelle b zur Keimzelie wird, and deren untere Zelle a die seeundære Aclıse e-d trægt, alz welcher ebenfalls die obere Zelle d zu einer Keimzelle bestimnt ist, die untere Zclle c aber die tertiære Achse e erzeugt.

3. Aelteres Keimhaar. a-b primare, e-d secundære, e-f terliære, g-h quartare, i quintare Achse. Je dic obern Zellen b, d, f und h werden zu Keimzellen. b entwickelte Keimzelle, 0,080" 'lang, mit braunrothem körnigen Inhalt; d röthlich und schwachkörnig; die Zellen e, f, g, h, i entlıalten farblosen hiumogenen Schleim; i ist $0,00 \bar{j} / \prime$, $h$ ist $0,00:$ "' lang.

\section{FIG.. 4-8. Dumontia filiform is Grev.}

4. Ende einer dünnen und spitzen Aehse, an welchem man deutlich die Scheitelzelle, durch deren Thejlung das Lxngenwachsthum statt findet, erkennt.

ॐ. Epidermis des jüngern Theiles eines Astes von aussen. Die Zellen liegen in Gruppen von 2, 3, th näher beisammen.

6. Senkrechter Durchschnitt durch einen Ast. a-a senkreehte Markfeden; b-b Zweige derselben, welche fast horizontal zur Rinde gelıen; c-c Rinde. d, d junge Keimlæufchen.

7. Reifes Keimheufchen unter der Rinde, von einer Gallertschicht umgeben.

8. Reifes Keimhæufchen, welches mit seinem æussern Theile die Epidermis durehbricht, und die gallertartige Cuticula zu einem kleinen Höcker erbebt.

Fig. 9 - 2:3. Peyssonellia squamaria Decaisne.

9. Radialer Quersehnitt durch den vorderen Rand. a Randzelle. b Flæchenzelle. Die Zellengruppen e-d, ferner g-e f und i-ef entsprechen drei Flæchenzellen wie b. d obere Seitenzelle. e Achsenzellen. f untere Seitenzellen.

10. Wie Fig. 9. - a Randzelle. d und e Zellen, die dureh Theilung einer Flæchenzelle entstanderı. I-gh Zellgewebe, das ebenfalis einer Flæchenzelle entspricht. e Aclisenzelle. f untere Seitenzelle.

11. Wie Fig. 9. - a Randzelle. d obere Seitenzelle. e Achsenzellen. f untere Seitenzellen. $r$ untere Seitenzelle, welche sich zu einem Wurzellraar zu entwickeln beginnt. - Die Zellengruppen $\mathrm{ed}$, ef-gh, $\mathrm{f}-\mathrm{i} k$, und $1 \mathrm{~m}-\mathrm{e}$ sind aus $₫$ Flachenzellen entstanden.

12. Wie Fig. 9. - a Randzelle. b Flæchenzelle. Die zweite Flæchenzelle hat sich in zw\&i Zellen $c$ und $d$ getheilt. - Der Zelleninhalt ist Schleim, mit einem Kerne.

15. Vorderer Rand von der Flæche angesehen. a Randzellen. b Flæchenzellen. Eine Randzelle hat sich iu zwei neue Randzellen in und $\mathrm{n}$, die letztere an einer andern Stelle in eine neue Randzelle o und eine Flæchenzelle p getheilt. - Zelleninhalt nach vorn homogener, nach hinten feinkörniger Schleim. Die Kerne sind in zwei Zellen wasserhelle Blæschen mit einem Kernchen; in den übrigen Zellen sind sie verendert, und ersehemen als dichte Schleimmassen.

14. Radialer Quersehnitt dureh den obern Theil des Laubes. Die Pfeile bezeichnen die Richtung nach dem vorderen Rande. e-e Aclisenzellen. f untere Seitenzellen. $r$ junge Wurzelhaare. Auf jeder Achsenzelle stehen zwei schief-senkreelıte Reihen von Zellen, welche je aus einer obern Seitenzelle entstande॥ sind.

15. Querschnitt durch das Laub in der Richtung der Secante ( $\mathrm{n}-\mathrm{f}$ von Fig. 1/4) geführt. e Achsenzellen. f untere Seitenzellen. Auf jeder Aclisenzelle steht eine einfache senkrechte Zellenreihe, deren untere Zellen sich wechselsweise decken.

16. Wie Fig. 13. Der Schnilt ist nur dünner, so dass die Zellen sich nieht decken, sondern bloss nebeneinander liegen. $\mathrm{r}$ junges Wurzelhar. 


\section{- 272}

7. 18. Querschnitt durch den Seitenrand, in der Richtung der Secante geführt. b Flachenzellen. d obere Srytenzellen. e Aclısenzellen. f untere Seitenzellen. c Zellen, welche sich in e und flieilen sollten.

19. Basis eines Laubes (f), schwach vergrösser! ; von cinem dichten Filz aus Wurzelhaaren umgeben, welcher einen Fuss bildet ( $r$ ).

ㄴ). Wie Fig. 19. Aus dem Seitenrande entspringt ein zweiter kleinerer, aus Wurzelfiz bestehender Fuss $\left(\mathrm{r}^{1}\right)$.

ㄴ. Laub, welches am vorderen Rande gelappt ist, indem bloss einzelne Stellen dieses Randes weiter grwachsen, die übrigen aber zurückgeblieben sind.

ㅃ). Vorderer Rand, von der lilache angesehen. a lebenskræftige Randzellen, rorn mit homogenem, nach hinten mit kürnigem Schleime erfïllt. Der Kern ist ein wasserlelles Blæschen mit einem Kernchen; er verændert sich leicht in eine dichte Schleimmasse. b abgestorbene Randzellen, zusammengedrücht, mit braungelbem Inhalte dicht erfüllt.

93. Einige æeltere Parenchymzellen, wo sich der feste Inhalt von der Wandung losgelüst, und in eine k\|lgelige freie Hasse zusammengeballt hat, welche durch den Schnitt leicht herausfält.

Ðొ1. Ein jüngeres Wurzelhaar. Durch störende aussere Einwirkung hat sich die Schleimschicht mit dem ïbrigen festen Inhalte von der Wand losgelüst und zusammengezogen; sie bleibt durch dünne Schleimstrange nit den Poren in Berührung.

„2.). Ein Stück von dem Durchschnitte durch eine Fruchtwarze. a-a Parenchym des Laubes, dem oberu Theile des Durchschniltes in Fig. 14 analog. b sterile Ihaare, Paraphysen. c-d Sporenhar. c untere oder Gliederelle. d Sporenmutterzelle (Scheitelzelle des zweiten Grades).

\section{Fig. 26 - 55. Cryptopleura lacerata Küitzing (Delesseria 1. Ag.)}

26. Ende einer wachsenden Achse. - a Scheilelzelle oder primære Zelle des 1 $^{\text {ten }}$ Grades (In ). b secunlare Zelle des ersten Grades (III). c tertiære Zelle (.III); d secundære Zelle des zweiten Grades (II²). $e=$ III. $\mathrm{f}={ }_{2} I I I . \mathrm{g}=\mathrm{Il}^{5}$. - Die oberste $\mathrm{II}^{4}(\mathrm{~b})$ ist ungetheilt; die zweitoberste hat sich in $c \mathrm{~d}$, die dritte in $\mathrm{efg}$, die vierte in hikl, die fünfte in m nop q getheilt. In der vierten secundaren zelle des ersten Grades hat sich zuerst eine Querwand, dann eine schiefe Lingswand, und in jeder der dadurch entstandenen secundæren Zellen eine Querwand gebildet. Die fünfte secundære Zelle des erstenjGrades hat sich zuerst durch eine Querwand, dann durch eine schiefe Lengswand in zwei secundere Zellen getheilt, wovon die untere bloss Querwande, die obere zunæchst wieder eine Langswand erzeugle.

27. Wie Fig. 26. - a Schcitelzelle ( $\left.I^{\mathrm{a}}\right)$. Die Zellen b entsprechen der obersten, c der zweitobersten, de del driltobersten, fghikll der vierten, und p qrsonm der fünten secundæren Zelle des ersten Grilies. Die tertixeren Zellen 1,1 haben sich jede in $z w e i, m-m$ und $n$ jede in vier Zellen getheilt.

포. Wie Fig. 26. - a Scheitelzelle ( $\mathrm{I}^{\mathrm{a}}$ ). Die oberste secundære Zelle des ersten Grades ( $\mathrm{II}^{1}$ ) hat sich in . III (b) und $\mathrm{II}^{2}$ (c); die zweitoberste $\mathrm{II}^{1}$ ebenfalls in .III (d) und $\mathrm{II}^{2}$ (e-f), die letztere in zwei secundiere Zellen e und $f$ getheilt.

„2). Haftwurzel, welche aus dem Laube nahe an dessen Rande entspringt; a schwecher, In staerker vergrössert, und im Durchsehnitle gesehen.

3). Rothe Farbblieschen, an der Zellwandung liegend, von der Flæche.

31. Seitlicher Lappen des Laubes, mit einer kreisförmigen Anschwellung, in welcher die Sporenmulterzellen liegen.

3ஷ. Querschnitt durch ein sporenbildendes Laub.

55. Querschnitt durch ein steriles Laub. a Randzellen (secundare Zelian). b Flachenzellen (tertixre Zellen). $\mathrm{cd}$, ef, fd und d vier durchscbnittene Adern. 


\section{$-\quad 273$
Tab. $\mathrm{x}$.}

FIG. 1 - 7. Leptophylium bifidum (Sphærococcus b $\mathrm{Ag}$.)

1. Ende eines Laubastes, welcher anfengt, sich dichotomisch in zwei Zweige zu theilen. Statt des einen centralen Punctum vegetationis sieht man nun zwei seitliche. a Scheitelzellen. Die Zellengruppen, welche aus den successiven secundæren Zellen des ersten Grades entstanden sind, werden die oberste durch b die zwcitoberste durch $c$, die dritte durch $d$, die vierte durch $\mathrm{ef} m$, die fünfte durch ghi on, die sechste durch $k$, die achte durch I bezeichnet.

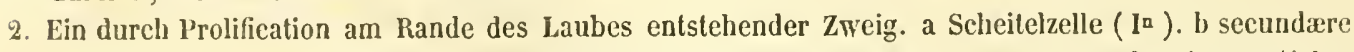
Zelle des ersten Grades $\left(\mathrm{n}-\mathbf{i} \mathbf{I}^{3}\right)$. Die zweitoberste secundære Zelle des ersten Grades $\left(\mathrm{n}-\mathbf{2 I I}^{4}\right)$ hat sich in eine tertiære Zelle (III) und in eine secundære Zelle $\left(\mathrm{II}^{2}\right)$ getheilt (c), obenso die drittoberste (d) ; die Zellengruppen, welche aus der vierten, fünften und sechsten entstanden, sind durch e, fg nu und hik po bezeichnet. - r-r Rand des Laubes.

5. Ilorizontaler Durchschnitt durch den Rand des Laubes. b Randzelle oder secundære Zelle des $\mathrm{n}^{\text {ten }}$ Grades. a Achsenzellen. Die seitlichen Zellen haben gleiche Breite mit den Achsenzellen; die Zellen c sind halb so breit.

4. Morizontaler Durchschnitt durch ein sporenbildendes Laub. a-a Achsenzellen. b Sporenmutterzelle, welche sich erst in zwei Specialmutterzellen getheilt hat. e Sporenmutterzelle, welche vollstændig getheilt ist.

3. Horizontaler Durchschnitt durch den Rand eines Laubes, wo sich ein Keimbehælter bildet. b Rand. a Achsenzellen. Die warzenförmige Erhebung ist noch solid.

6. Horizontaler Durchschnitt durch einen ganz jungen Keimbehälter. b Rand des Laubes. a Achsenzellen. Die kleine Höhlung ist mit einer kleinmaschigen, farblosen Zellmasse ausgefüllt.

7. Horizontaler Durchschnitt durch einen Keimbehälter, in welchem die Keimzellen noch nicht ganz ausgebildet sind. b Rand des Laubes. a Achsenzellen. Die llöhlung wird von der gelappten Keimzellenmasse ausgefüllt, an deren Grunde ein farbloses Klümpchen von Basiszellen und erst noch entstehenden Keimzellen (c) liegt. $-d$ Wand des Keimbehælters stæerker vergrössert.

Fig. 8 - 12. Rhodomenia laciniata Grev. Besondere Keimbäufchen; 8 - 10 noch in Zellenbildung begriffen; 11, 12 in ausgebildeten Zustande.

8. a Basiszelle. b die primære Zelle des ersten Grades $\left(\mathrm{I}^{\prime}\right)$ für das entstehende Keimbæufchen.

9. a Basiszelle. $\mathrm{b}$ erste secundære Zelle $\left(\mathrm{II} \mathrm{I}^{1}\right) ; \mathrm{c}=\mathrm{I}^{2}$.

10. a. Basiszelle. $b=i I^{1} ; c=: I^{4} ; d=3 I^{4} ; e=d I^{1} ; f=I^{5}$.

11. 12. Keimhæufchen mit ausgebildeten, rothgefærbten Keimzellen. a Basiszelle.

\section{Fig. 15 - 21. Lomentaria kaliformis Gaill.}

15. Senkrechter Durchschnitt durch das Laub. a-a Scheidewand, die Zellen hahen an deu beiden freien Flæchen verdichte Wænde. b-b Seitenwand. $\mathrm{c}$ gegliederte Zellfæden, welche an der insern Flæche der Seitenwand liegen. d kleine Zcllen an der æussern Flæche der Seitenwand. e kleine birntörmige Zellen an den Zellfieden, welche frei in die Höhlungen der Glieder hineinragen. f gallertartige Extracellularsubstanz. 


\section{$-\quad 274$}

14. Seitenwand ron aussen angesehen. a in einem ganz jungen Stadium, ehe die xussern kjeinen Zellen sich zu bilden anfangen. b elwas alter; an den Intercellularwinkeln treten kleine Zellen auf.

1:3. Die birnförmigen Zellen an den innern Zelifæden besonders dargestelit, a einzeln, b zu zweien an der cylindrischen Zelle befestigt. Die letztere enthæit farblosen körnigen oder homogenen farhlosen Schleim.

16. Von einem horizontalen Durehsehnitt dureh das Laub. Bezeichnung wie in Fig. 15.

17. Von einem senkrechten Durehsehnitt durch ein sporenbildendes Laub. b-b Seitenwand; eine Zelte in derselben hat sich vergrössert, und zur Vutterzelle umgebildet; sie enthælt ein centrales Kernblæschen, um welches der Schleim angelagert, und in radienförmigen Strömungsfaclen durch das ıumen der Zelle vertheilt ist. d kleine Zellen an der æussern Flæche der Seitenwand. f gallertartige Extracellularsubstanz. n langgestreckte Zellen, welche aus den Zellen d entspringen, und an ilırer Spitze kirze, selır zarte, gegliederte und spærlich verxstelte Freden tragen.

18. Horizontaler Durchsehnitt dureh eimen Keimast (Keimbehælter), schwach vergrössert. f Extracellularsubstanz. g Keimbæufchen, welches die IÏ̈hlung ausfülıt. h Wandıng.

19. Rothe Farbblaschen an der Oberflache der Zellen von der Seitenwand des Laubes, stark vergrössert.

20. Senkrechter Durehsehnitt dureh einen Keimast. b Seitenwand des Laubes. f Extracellularsubstanz. g

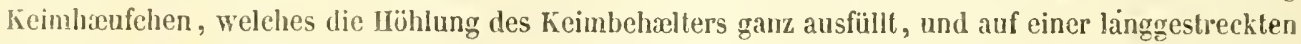
Basiszelle ruht. h Wandung.

21. Ein Stück der Wand des Keimbehxlters von Fig. 20, starker vergrössert. f Extracellularsubstanz. g Ifölılung des heimbehælters. - Die Zellen sind durch Gallerte getrennt, und durch Poren mit einanler verbunden.

\section{Fig. 22 - 37. Plocamium coccinelim Grev.}

229. IIorizontaler Durchschnitt dureh einen Keimbehælter (Keimast), wenig üher der Hitte. D. I. = $0,500 "$ 'l'; Wand $=0,050^{\prime \prime \prime} ;$ Keimzellen $=0,020-0,02 \mathrm{a}^{\prime \prime \prime}$.

25. Vertiealer Durchschnitt dureh einen Keimbeheiter (Keimast); derselhe hat nicht genau die Mittellinie getroffen, so dass die Oeffnung am Seheitel niehı sichtbar ist. Im cirunde der IIöhlung. sieht man die grosse gelappte Basiszelte, und über derselben einige længliche Zellen; die obern Lappen des Keimhxufchens bestehen aus rothgefierbten grössern, die untern aus röthliehen und farblosen, kleinen und noch unentwickelten Keimzellen.

2\%. Stïek von einer Laubachse; a Ursprung des Keimastes.

2:. IVie Fig. 2ht, etwas spater.

26. Junger keulenförmiger Keimast, im verticalen Durchischnit; es hat sich noch keine Höhlung in demselben gehildet. Dic Zellen liegen in senkrechten, divergirenden, wach oben und aussen sich vermehrenden Reihen.

97. Zellen aus der Nitte des jungen Keimastes, der in Fig. 20 dargestellt ist. a langliche Zelle mit körni. gem Inhalte, wird spæeter zur Basiszele des Keimhxufehens. b eine der über der Basiszelle stehenden Zellen (vgl. Fig. 23) mit homogenem Schleime und einem Kernblæsehen, welches ein Kernchen einsehliesst. e die gleiche Zelle wie b, nachdem sie einige Zeit im Wasser gilegen; der Inhalt des Kernblaschens und der 7elle hat sich zusammengezogen, und ist dichter geworden; in Umfange des Kernes hat sich ein hohler, mit Wasser gefüllter Raum gebildet.

28. Ein Stïck von der Wandung des in Fig. 22 dargestellten Keimbehälters, stærker vergrössert. Die Zellen liegen in radialen, von innen nach aussen sieh vermehrenden Reihen.

*9. Verticaler Durchsehnitt durch einen Keimbehalter; das Keimhaufehen ist herausgenommen. Man sieht an der innern Flæche lieihen von langgestreckten Zellen, weleho ron dem Grunde aizgehen, nach oben dirergiren, und sich dichotomisch verzweigen. 
30. Ast von einem keimzellenbildenden Laube, schwach vergrössert. $\mathbf{t}$, o heimbehälter. vgl. über die Verzweigung den Text, pag. 229.

31. dunger Lappen des Keimhäufchens (Fgl. Fig. 23, im Grunde des Keinbelälters); derselbe ist mit Seitenläppchen beselzt, welche durch schiefe Wände in der Scheitelzelle wachsen (rgl. Fig. 57 ).

52. a, b, c, d Sporenäste.

35. Ast ron einen sporenbildenden Laube; die Sporenäste sind dureh doppelte, die vegetativen Achsen durch einfache Linien dargestellt. Vgl. über die Verzweigung den Text, pag. 250.

34. Ende ciner Laubachse. a Scheitelzelle. b Gliederzelle oder secundäre Zelle des ersten Grades. Die 7.weitoberste Gliederzelle hat sich in eine tertiäre Zelie und eine grössere Zelle (c) getheilt. Das dritte rlied (d) lıat sich in eine mittlere und zwei tertiäre Zellen, von diesen hat sich die links liegende durch eine verticale Wand getheilt. In dem rierten und finften Gliede (e und f) ist die Zellenbildung in den Randzellen weiter fortgeschritten. In den folgenden Gliedern (g-g, h-b und $\mathrm{i}-\mathrm{i}$ ) werden auch horizontale und später wieder verticale (k) IVände sichtbar, welche aber wahrscheinlich erst eine Folge der mit ciem Waclisthum in die Dicke verbundenen Zellenbildung sind. - 1 cine mittlere senkrechte Zellenreihe, aus welcher sich heim Wachsthum in die Dicke die Achsenzellenreilıe bildet.

5). o p Laubachse, welche die $\Lambda$ chse $\mathrm{n}$-a als Tochterachse erzeugt hat. a Scheiteizelle ( $\mathrm{I}^{\mathrm{a}}$ ). b Gliedertelle $\left(I^{1}\right)$. c, d, e die Gliederzelle lat sich in ${ }^{\prime} I^{1}$ und $I^{2}$ getheilt. $f, g, h, i, k, I$ die Gliederzelle hat

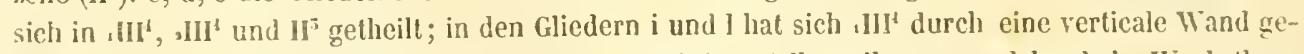
theilt. m, m Astzellen, aus 'III' cntstanden. $n$ eine miltlere Zellenreihe, aus welcher beim Wachsthum in die Dicke die Achsenzellenreihe entsteht.

56. Ende einer Laubackse, wo das Längenwachsthum durch horizontale Wände in dasjenige durch schiefe wände ăbergeht. a Scheitelzelle ( $\mathbf{I n}^{\mathbf{n}}$ ). c Gliederzelle oder secundäre Zelle des ersten Grades des ersten Wachsthums. b secundäre Zelle des erzlen Grades des zweiten Wachsthums. - In der ursprünglichen Zelle a b c $\left(\left[\left[^{n-3}\right)\right.\right.$ ist $e\left(n-2 I^{1}\right)$ und ab $\left(I^{n}-1\right)$, in der letztern ist $b\left(n-{ }_{1} I^{1}\right)$ und a ( In ) entstanden.

37. Zwei junge Achsen, in welchen zuerst das erste, danı das zweite Längenwachsthum stattgefunden hat. Der Pfeil bezeichnet die Richtung der Mutterachse. a Scheitelzelle. b secundäre Zelle des ersten Grades. Die Zellengruppen c, d, e, f, g und $m$ entsprechen den secundären Zellen ides ersten Grades, welche durch das zweite Längenwachsthum (vermittelst schiefer Wände in der Scheitelzelle) entstau_ den sind. Die Zellengruppen $\mathrm{h}-\mathrm{h}, \mathrm{i}-\mathrm{i}$ and $\mathrm{n}-\mathrm{n}$ entsprechen den secundären Zellen des ersten Grades, welche sich durch das erste Längenwachsthum (vermiltelst horizonlaler scheidewände in der Scheitelzelle) gebildet haben. 

j)

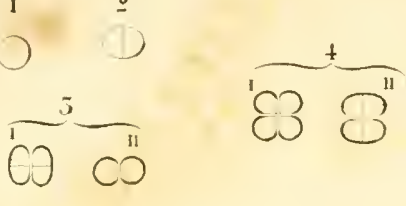

E3 23

.

3

‥

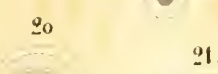

$\int_{\infty}^{\infty}: \cdots$

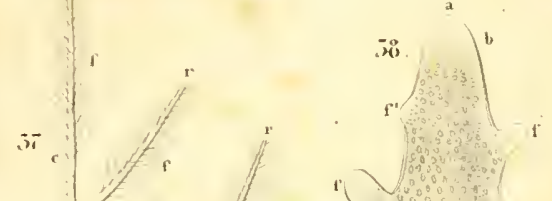

if if

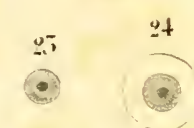<smiles>C1=[Si]CCC1</smiles>

39

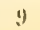 \\ (5)}

10

अ

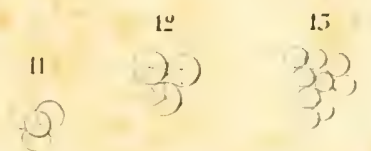

26

$(5)$

요
(3)

(0) (2)

$\left.18 \quad \frac{6}{6}\right)_{a}^{b}$

27

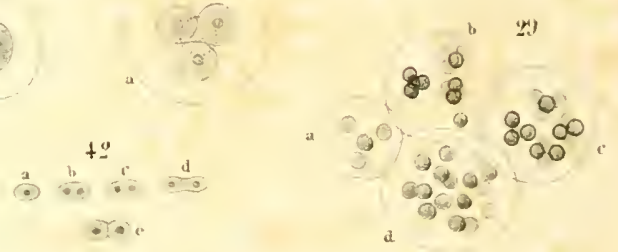

$\frac{19}{3}$

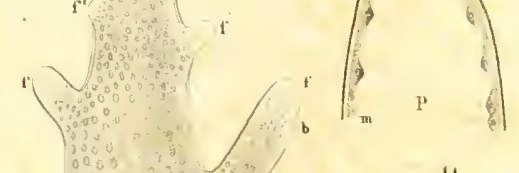

$+5$

ba m

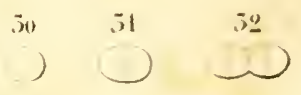

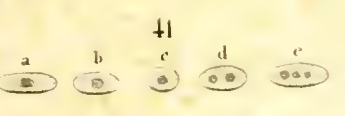

to a $\quad 04$

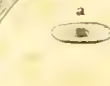

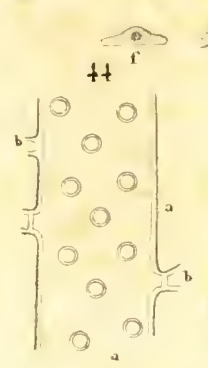

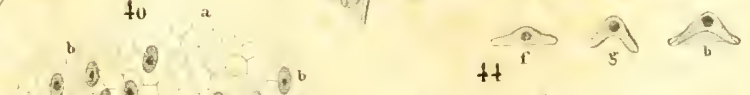

$\left(a+8 e^{8} e^{3}\right.$

${ }^{\circ}{ }^{2}$ ह के शे

b.

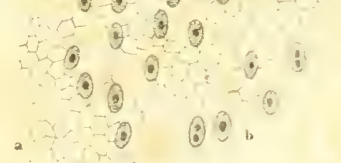

.5.

3

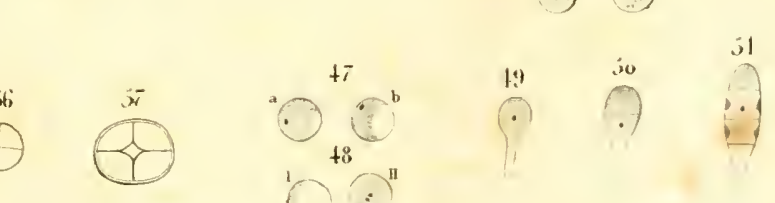

$\rightarrow b$

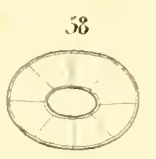

i9
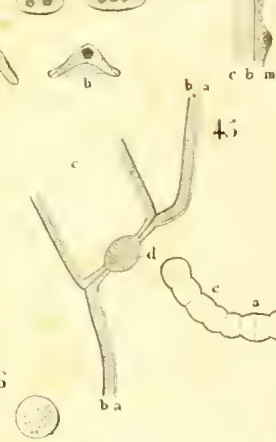

ti
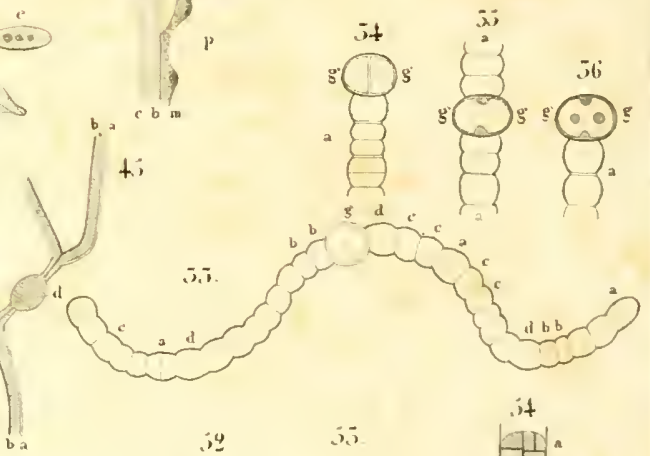

*0*0*
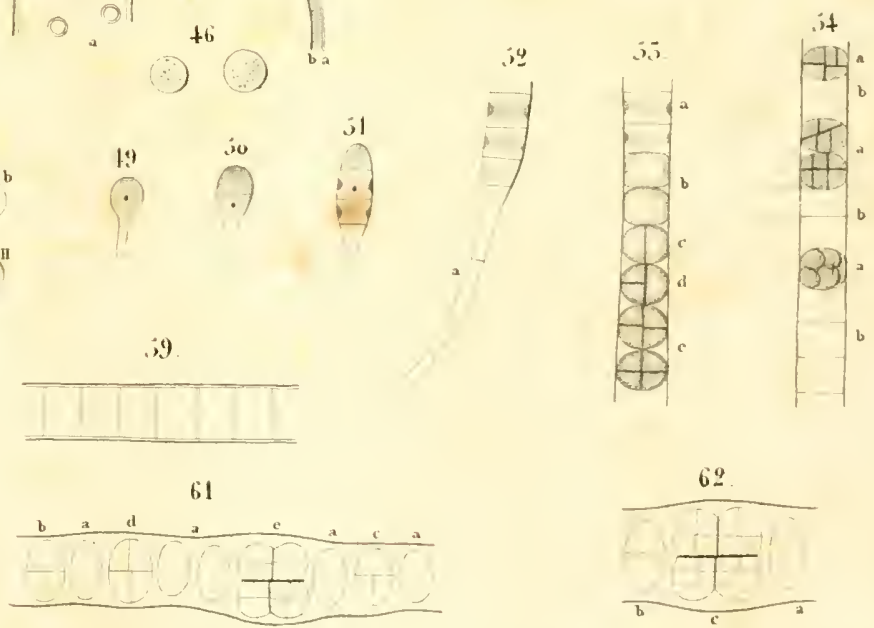



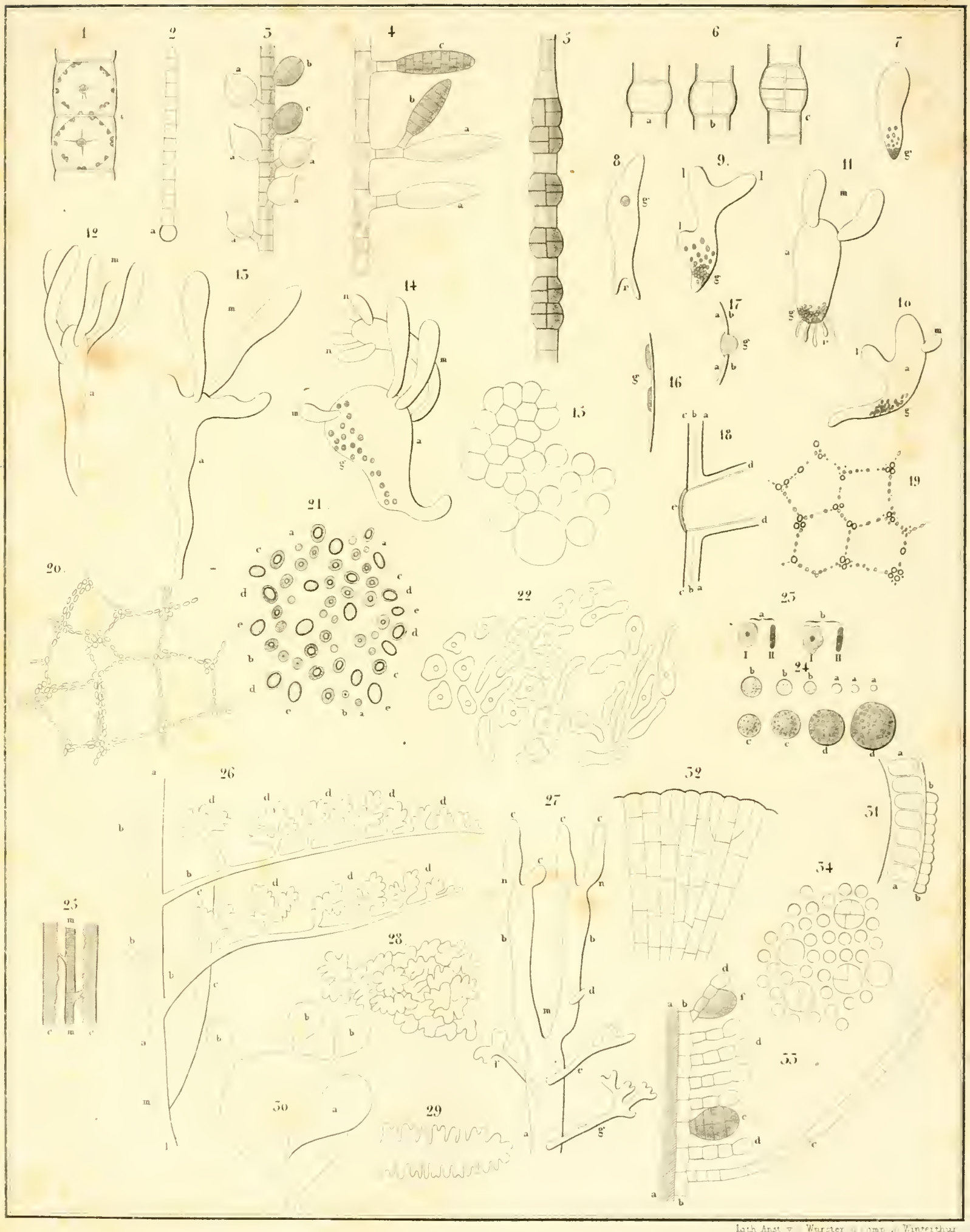





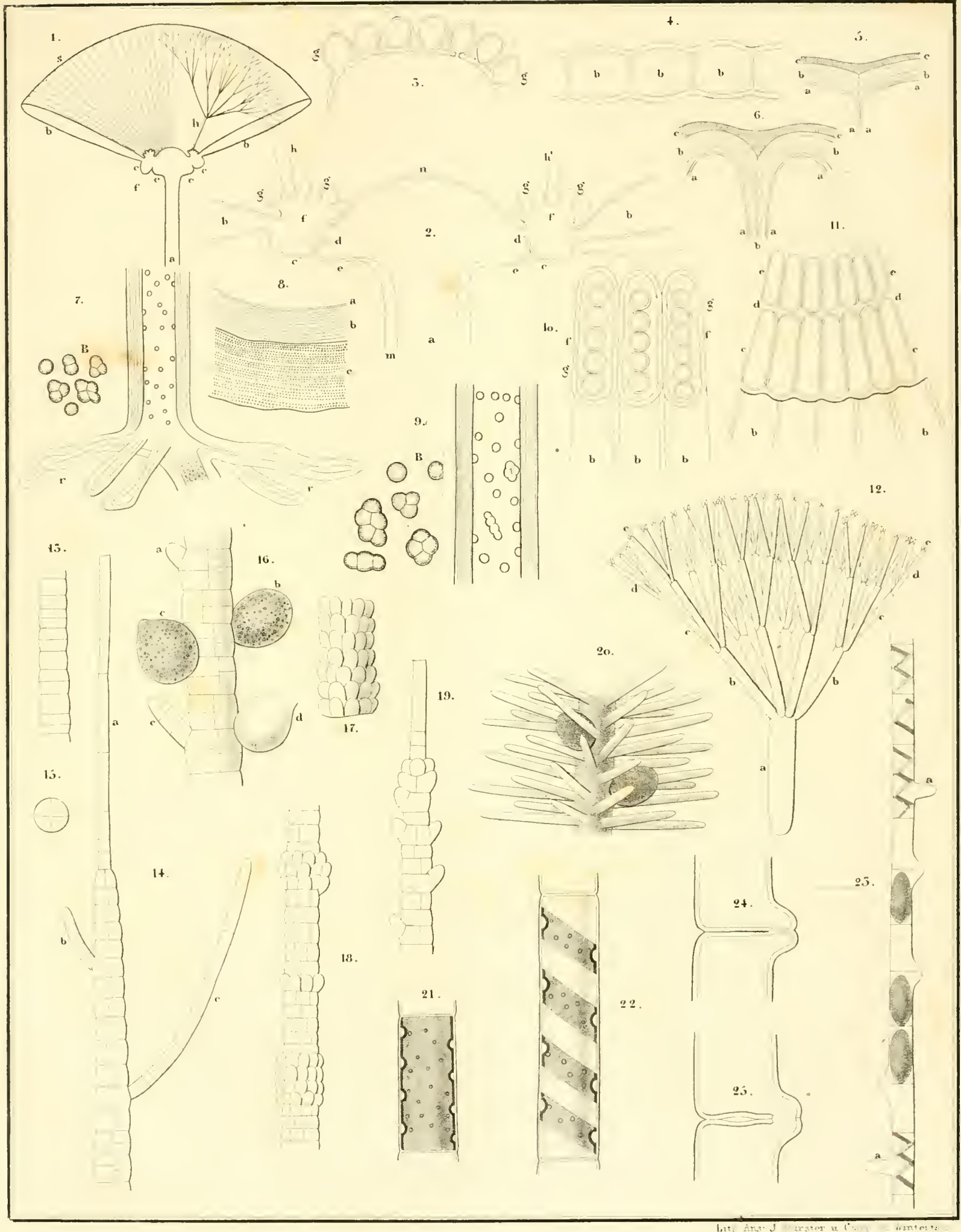



Tab. II.

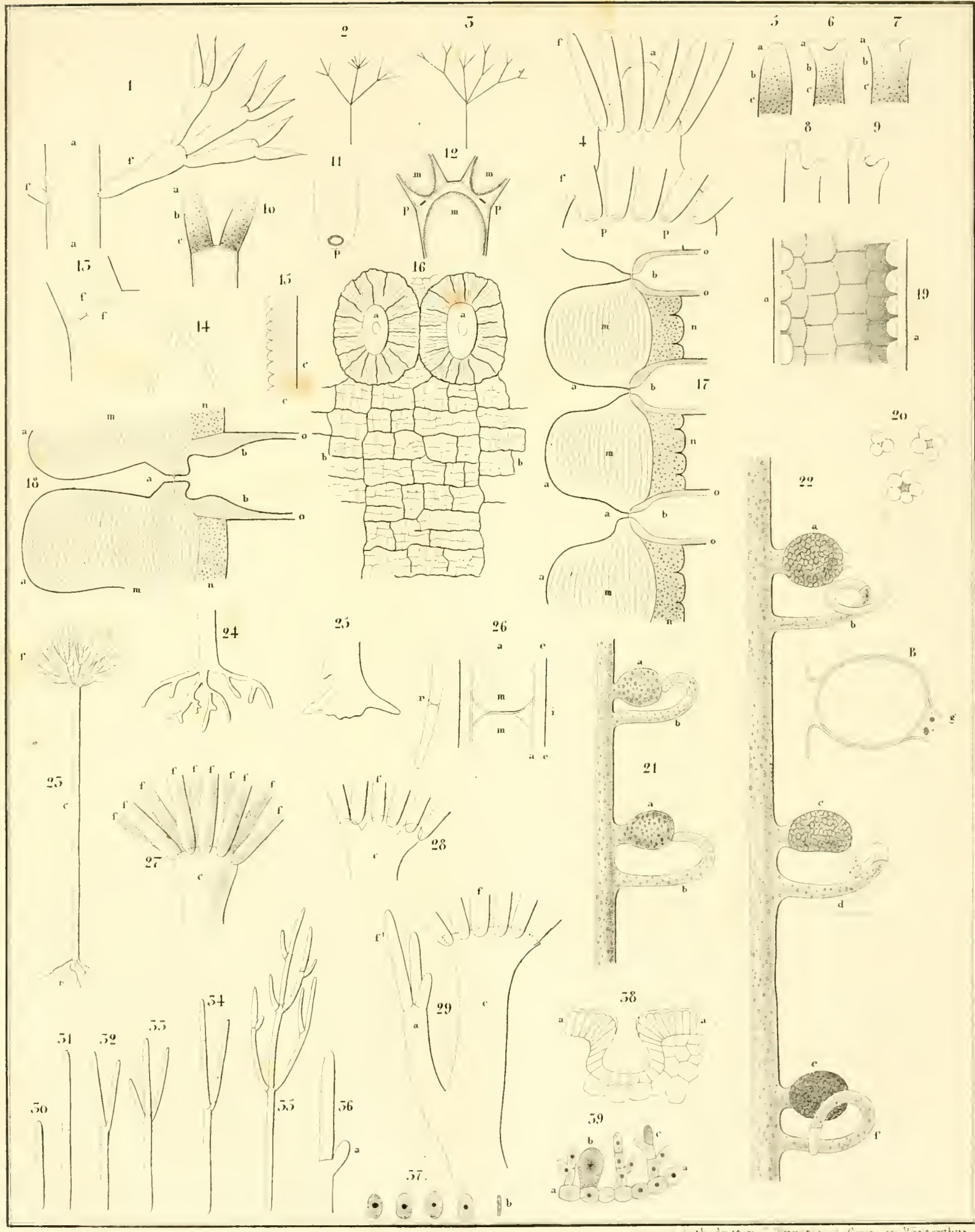




$$
\text { - }
$$




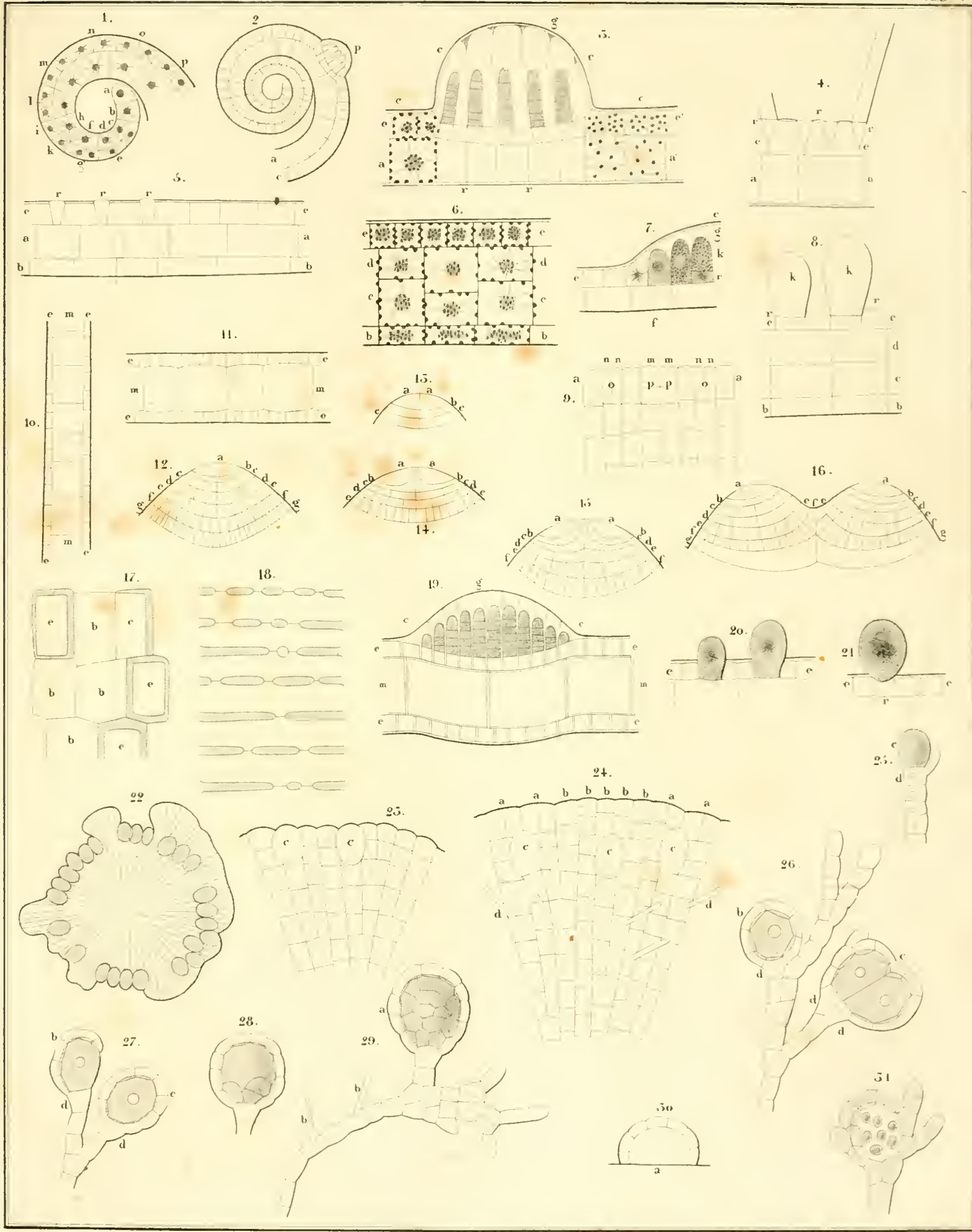



Tab. 11.

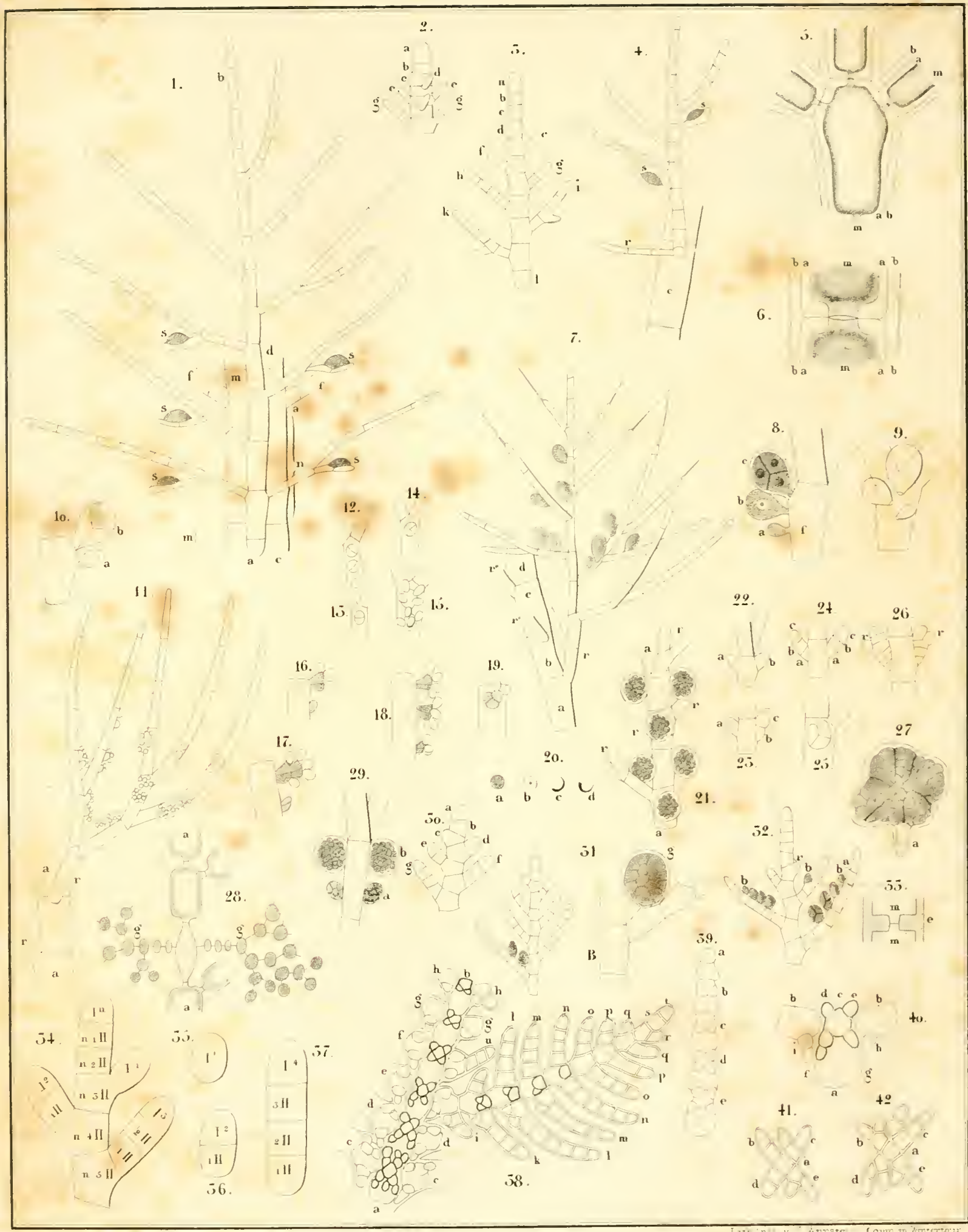




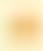

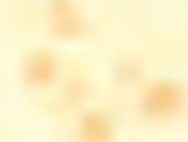

.

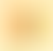

(2)

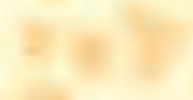

.

.

(n)

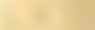


Tab. 111.

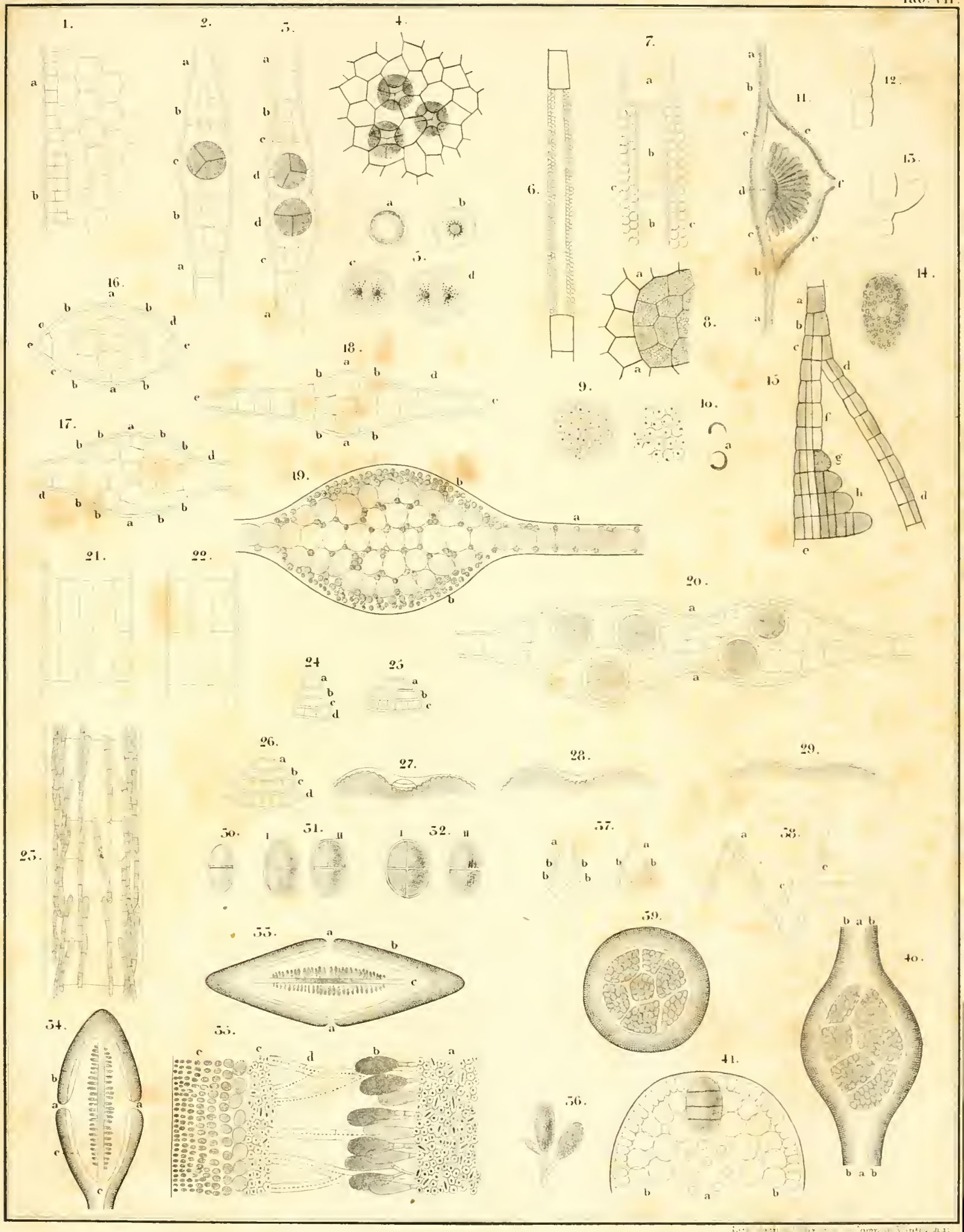


- 

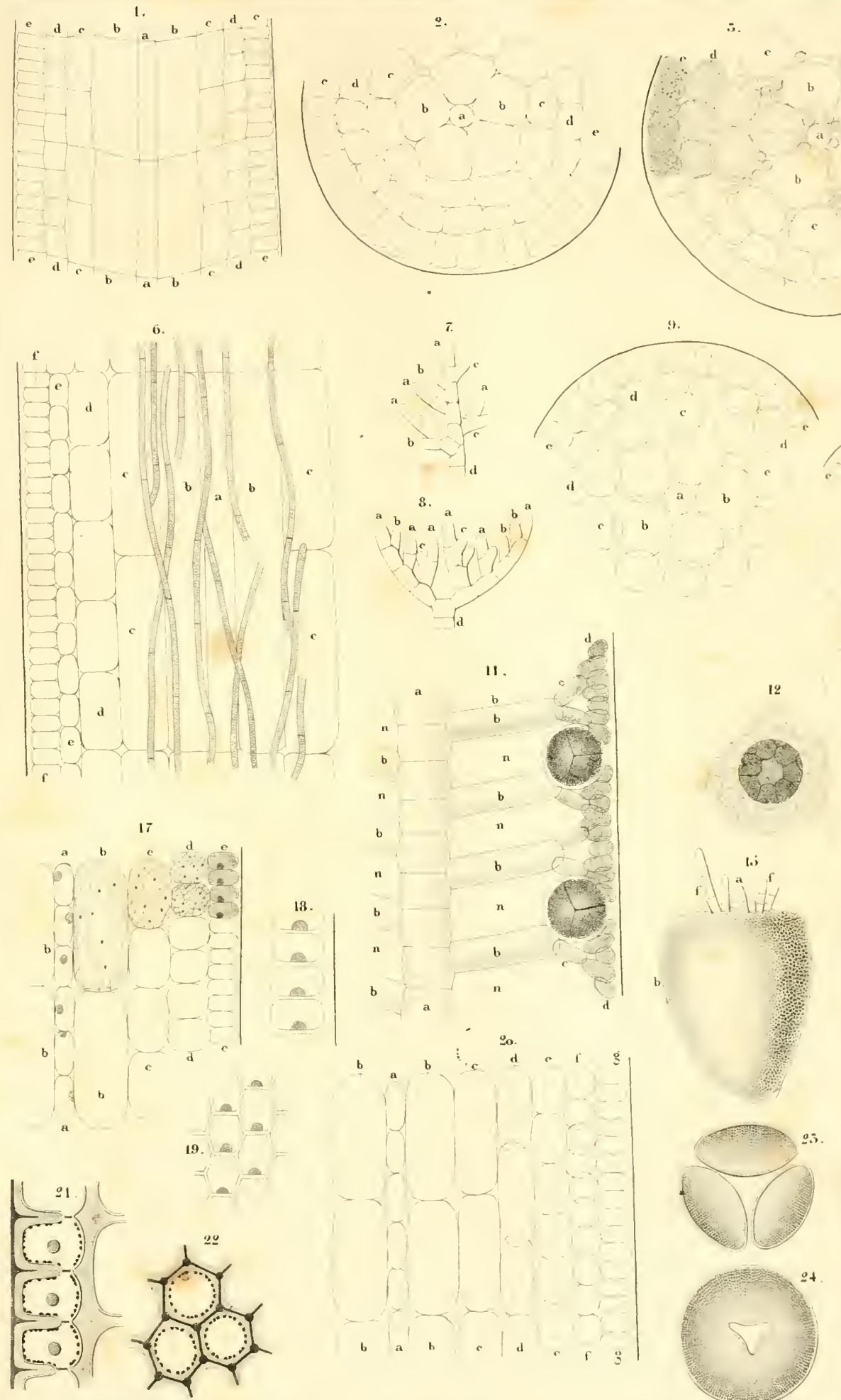

lab. II.

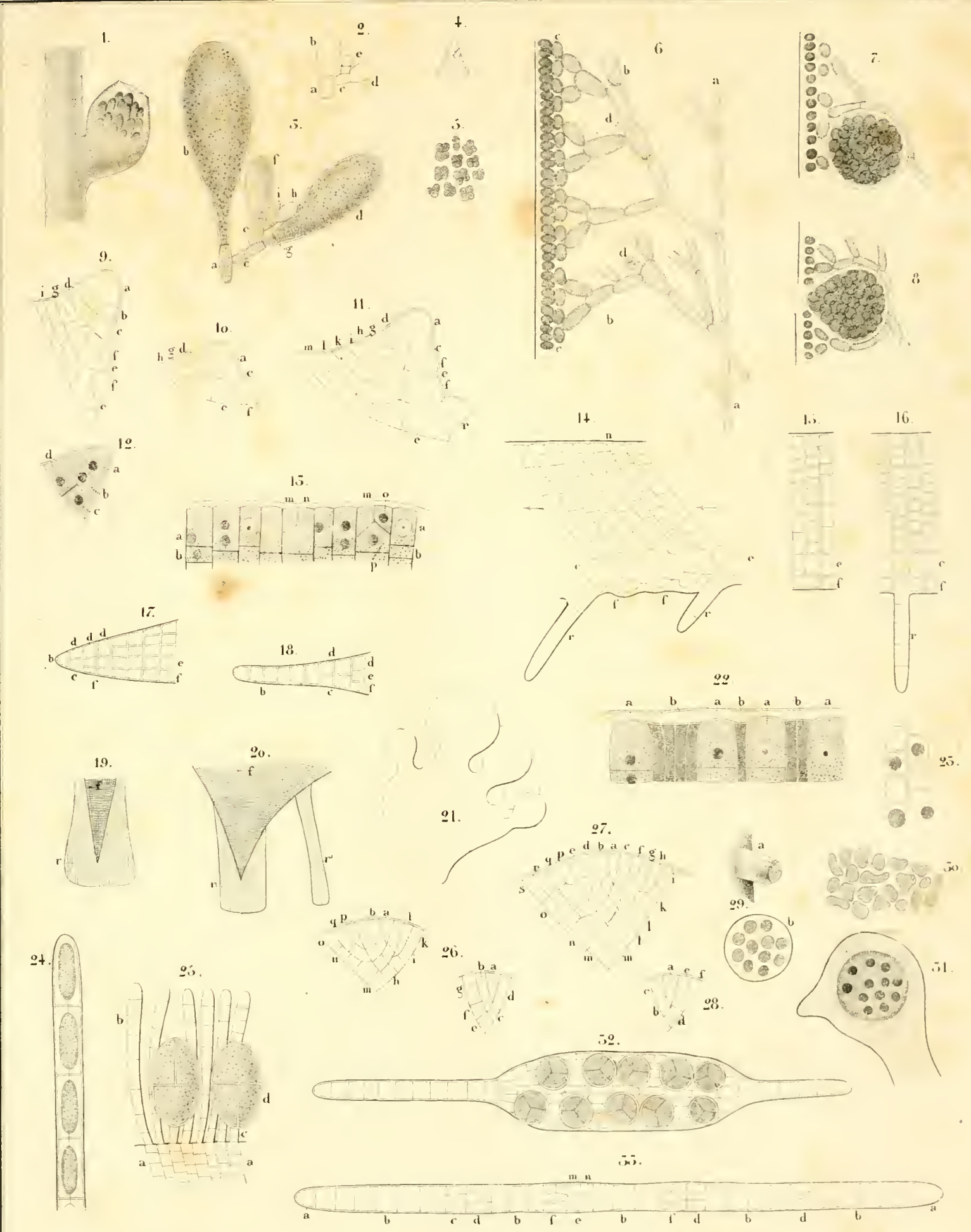



Tab I.

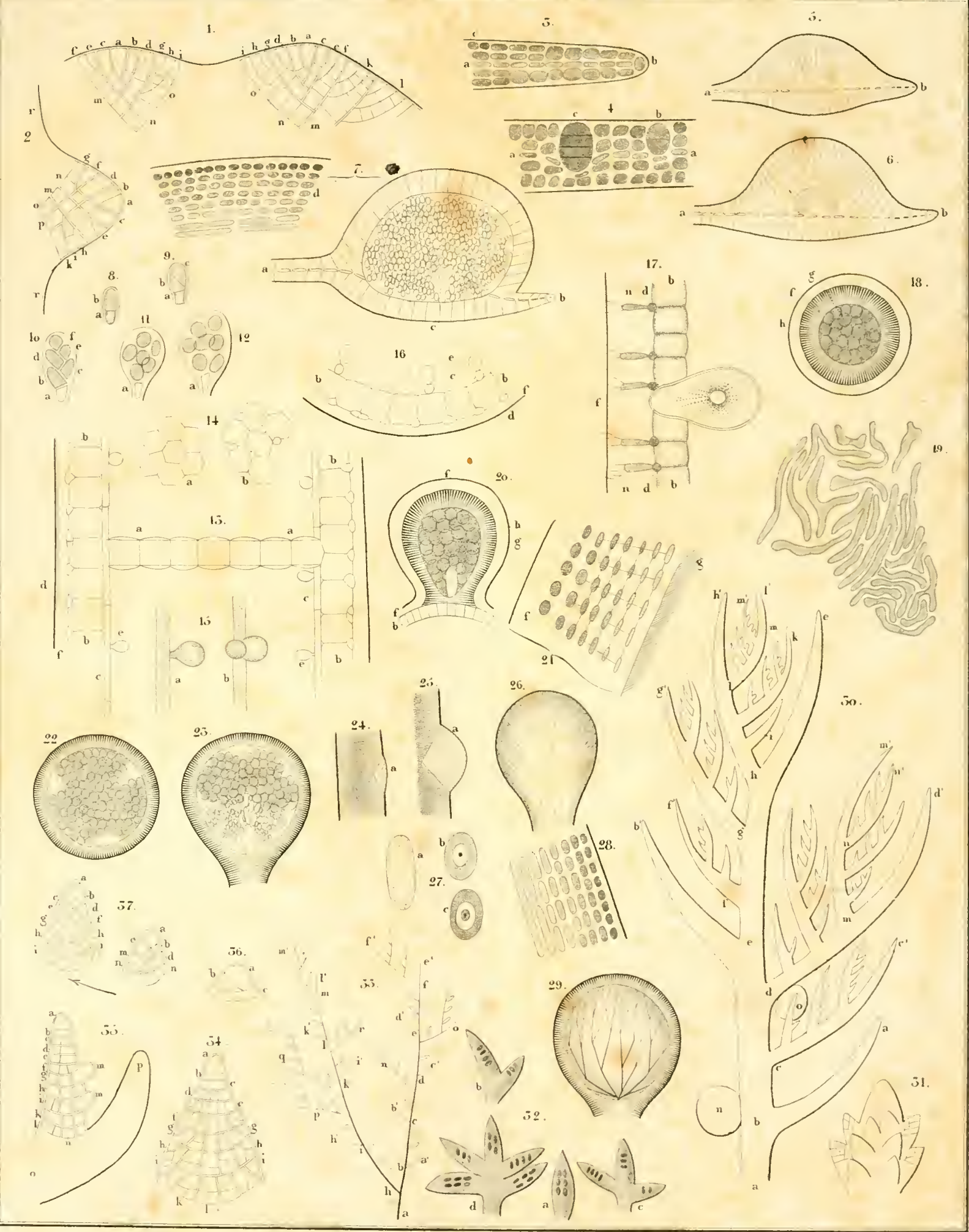






$6^{2}-1.5 .9$

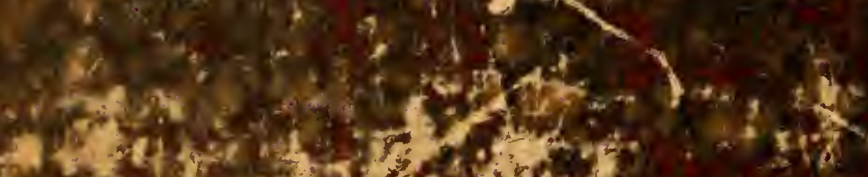
1.

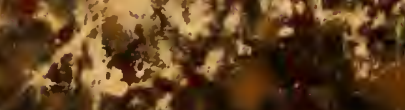

- +25

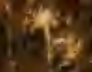

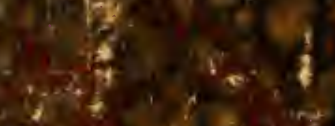

$$
\begin{aligned}
& \therefore x^{2}
\end{aligned}
$$

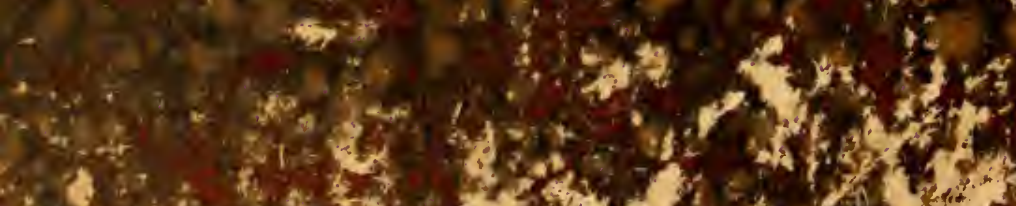

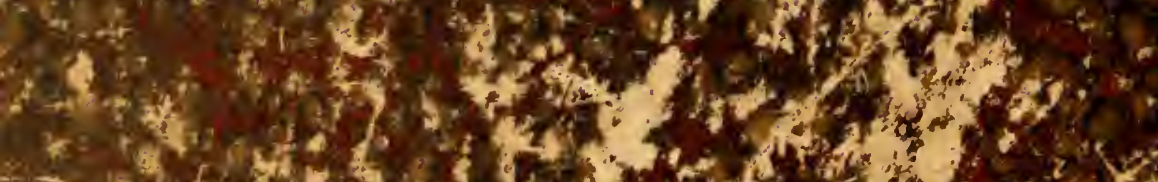
$25+4 x^{2}-30$

$$
\begin{aligned}
& -1+2 \\
& 4 \\
& \text { ? }
\end{aligned}
$$

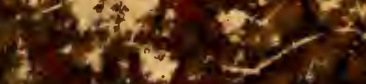

$$
\begin{aligned}
& 5 .+3 . \\
& \text { a. } 6 \text {. } \\
& 48
\end{aligned}
$$

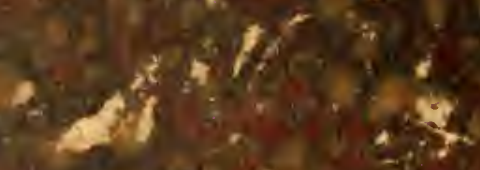

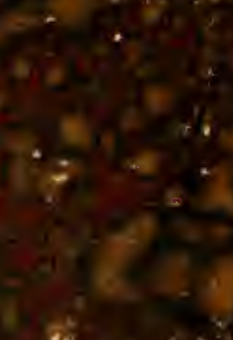

